\title{
القاضي في القانون الدولي والأوروبي
}

\author{
shel \\ د. / عبــد اللّه محمــد الهـواري \\ الأستاذ المساعد بقسم القانون الدولي العام \\ كليتالحقوقـ جامعت المنصورة
}




\section{المقدهة}

تُشَكَّلُ وظيفة القاضس، في الحقيقة، واحدةً من بين الموضوعات أو المسائل

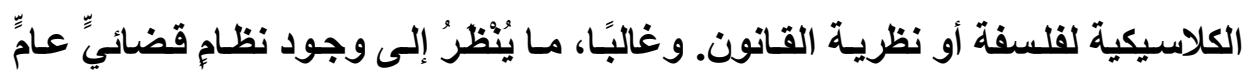
وإلزاميّ كعنصر أساس في أيِّ نظاج قانونيّ.

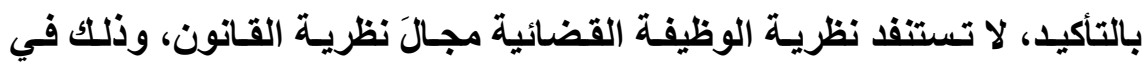

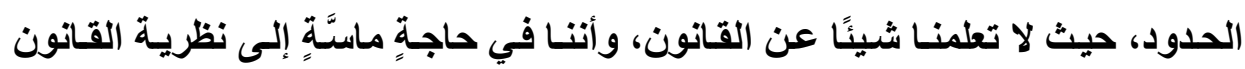
لتحديد ما هو هذا الأخير، ومن ثُّ توجيه القضاة في أدائهم لوظائفهم. ومع ذلك، ينبني

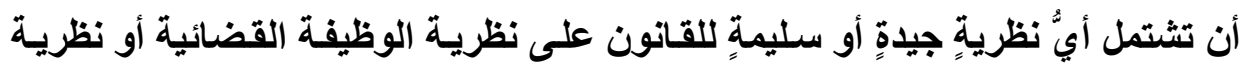

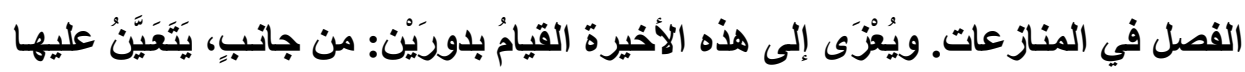

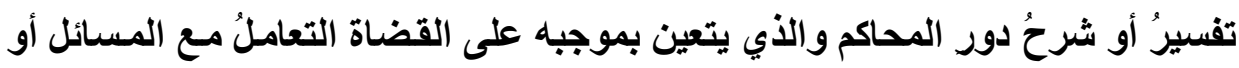

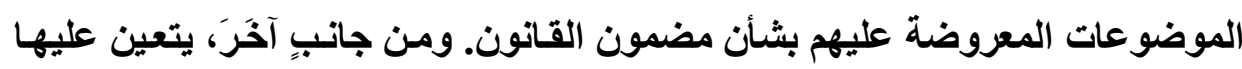

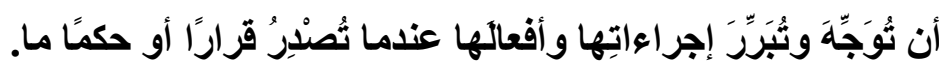

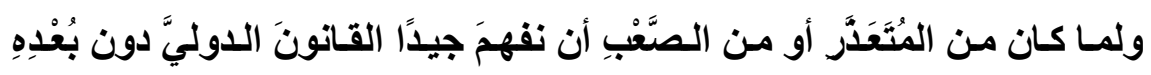

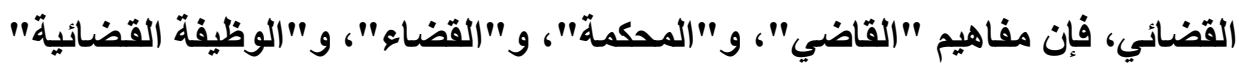

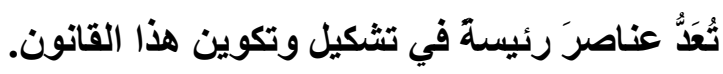

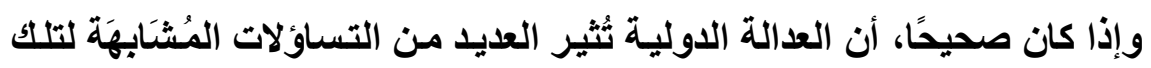

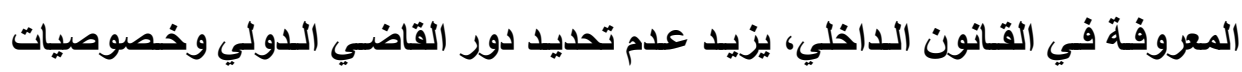

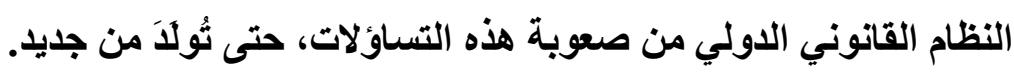

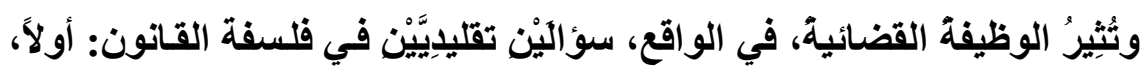

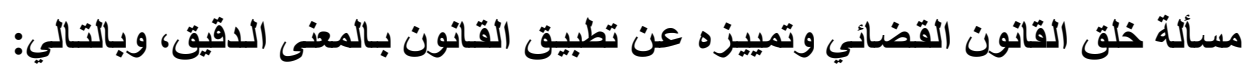


التمييز بين القانون القضائي والسياسة الديمقراطية، وثثانيًا، مسألة التقدير القضائي وتمييزها عن الفهم السليم للقانون، وبالتالي: التمييز بين القانون والأخلاق.

وتَرْجِعُ أهميةُ القاضي الدولي، التي تفوق بكثير أهميـة القاضسي الداخلي، أولاً، إلى الطبيعة المحدودة لمصادر القانون الدولي، وبالتالي: فإن الثغراتِ المحتملَ وجودُها في القانون الدولي أكثرُ منها في القانون الداخلي. ثانيًا، إلى الطبيعة غير المحدودة

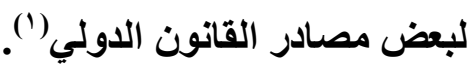

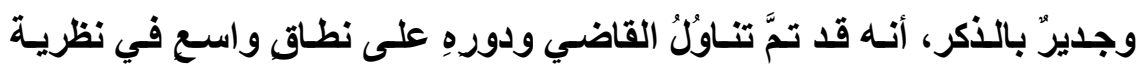
القانون، ولكن تقريبًا من زاويـة القانون والقاضسي اللداخِليَّيْن. ونحن نفكر، هكذا، في مسائل العَلاقاتِ بين العدالة والسياسة أو الديمقراطية، أو في الدور الإبداعي أو الخَلَّاَّ

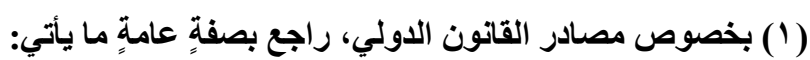

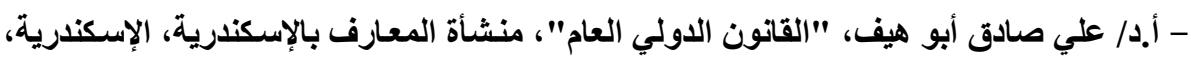

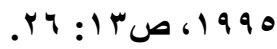

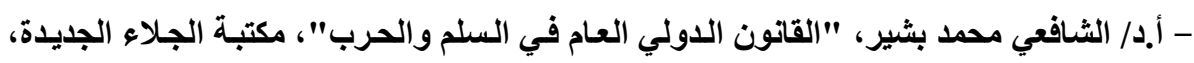

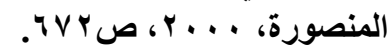

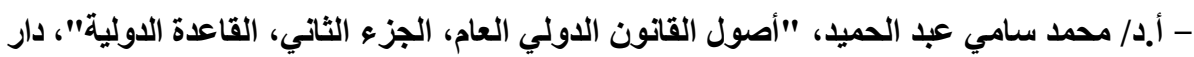

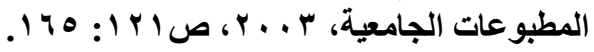

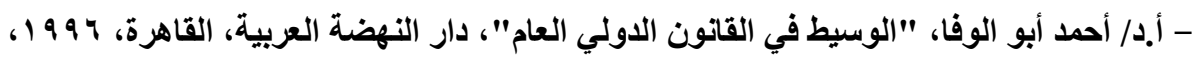

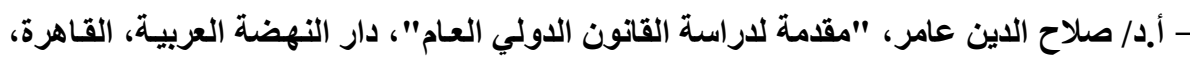

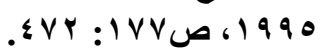
- أ.د/ عبد العزيز محمد سرحان، "القانون الدولي العام"، دار النهضة العربية، القاهرة، 199 19،

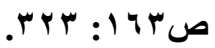
- أ.د/ مصطفى أحمد فؤاد، "المدخل للقانون الدولي العام"، القاعدة الدولية، مكتبة جامعة طنطا،

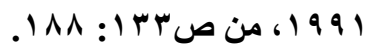
- أ.د/ حسازم محمد عهد عهلم، "الـوجيز في القـانون الدولي العـام"، دار النهضة العربيـة، القـاهرة،

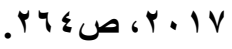


للقاضي في حالة وجودِ ثُغراتٍٍ قانونية، وكذا في حالة مشروعية القانون الحاكم. لذلك،

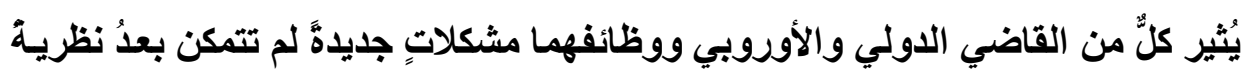
القانون من تقديم إجاباتٍٍ بصددها.

وتتعلق الصعوباتُ التي ثثيرها الوظيفة القضائية الاولية والأوروبية، ليس فقط

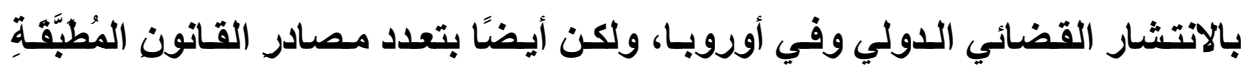

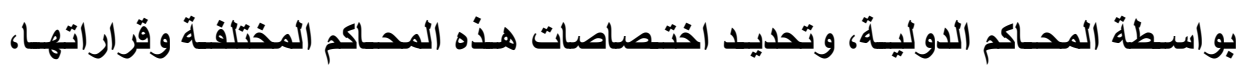
وبمسائل ترابط اللدعاوى، وحجيـة الشيء المحكوم فيسه، وحجيـة الشيء المفسر، وبالسوابق القضائية أو الترابطو التماسك.

ومن الأهمية بمكان، أن نتعاملَ أو نعالجَ بعُمْقَ المشكلاتِ أو المسائلَ النظريـة

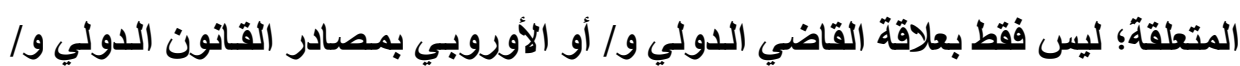

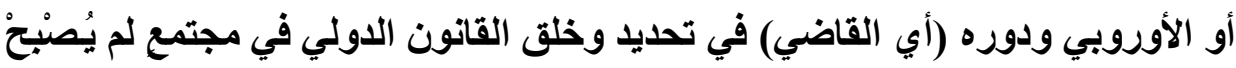

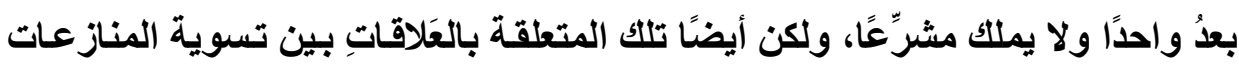

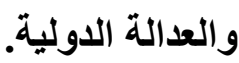
وبناءً عليه، سوف تنقسم دراستنا لهذا الموضوع على النحو الآتي: مبحث تمهيدي: بعض الاعتبارات الفلسفية حول العدالة الاولية أو كيف نتجاوز الحب المستحيل بين القانون الدولي و العدالة الدولية.

$$
\text { القصل الأول: القاضي في القانون الدولي. }
$$

المبحث الأول: الحكم القضائي متعدد المستويات في القانون الاقتصادي الأوروبي

$$
\text { والاولي. }
$$


المبحث الثاني: محكمة العدل الدولية في مواجهة تقرير المصير: دروس مستفادة عن دور المحكمة. المبحث الثالث: كلمات كلمات كلمات...أين القيم: تقييم القاضـي الدولي والقواعد

$$
\text { الآمرة. }
$$

$$
\text { المبحث الرابع: القاضي الاولي والضرورات العسكرية. }
$$

المبحث الخـامس: القضاة في مواجهـة تحدِّي قاعـات المحسكم الجنائيـة الدوليـة متعددة اللغات.

المبحث السادس: صناعة القانون القضائي الدولي ونظريـة المصادر: مشروعية القانون القضائي محلًً للجدل.

$$
\text { الفصل الثاني: القاضي في القانون الأوروبي. }
$$

المبحث الأول: المشاركة في الاتّّحاد الأوروبي والتسوية القضائية للمنازعات.

$$
\text { المبحث الثاني: الترابط أو التماسك في منطق القاضي الأوروبي. }
$$

المبحث الرابع: بين التعددية القانونية الأوروبية واستخدام السابقة عبر الوطنية في الفصل في مناز عات القانون الخاص الأوروبي.

المبحث الخامس: تأثير القانون الأوروبي بشأن الشروط التعسفية في القاضي

$$
\text { الوطني. }
$$




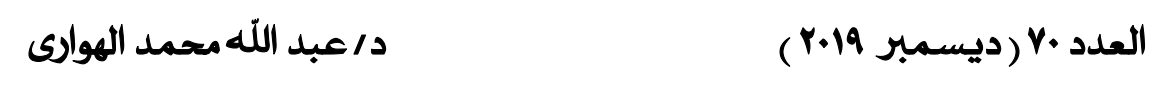

\section{هبمش تمهميدي \\ بعض الاعتبارات الفلسفية حول العدالة الدولية \\ أو \\ كيف نتخلب على الهب المستميل بين القانون الدولي \\ والندالة الدوليبة}

تُعَدُّ وظيفةُ الفصل في المنازعات أو الوظيفة القضائية، سواء تعلَّقَ الأمرُ بـدور

أو وظيفة القاضي في تطبيق القانون على ما يُعرض عليه من منازعات، واحدةَ من بين

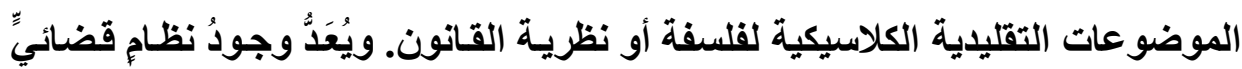
ذي ولايةٍ عامةِ و إلزاميةٍ عنصرًا أساسًا لأيٍ نظاجِ قانوني (').

بالتأكيد، لا تستتفد نظرية الوظيفة القضائية مجالَ نظرية القانون من حيث إنها لا تُعْلِمُنَا شيئًا مطلقَا حول القانون، مع أنتا بحاجةٍ إلى نظرية القانون لتحديد ماهية هذا

(1)Karen ALTER, Cesare ROMANO et Yuval SHANY, "Legal philosophical issues of international adjudication- Getting over the amour impossible between international law and adjudication", Oxford Hand book of international adjudication, Oxford university press, 2017, p. 31. Voir aussi Ronald DWORKIN, "Law's Empire", Fontana press, 1996; Joseph RAZ, "The Authority of Law", Oxford University Press, 1999, Joseph RAZ, "On the Nature of Law", Archive fur Rechts- and sozialphilosophie, Vol. 89, 1999, p. 1, H.L.A HART, "The concept of Law", $2^{\text {ème }}$ éd., Clarendon Press, 2013, p. 213- 216. 
الأخير، ومن ثم تحديد سلطة توجيه القضاة في تأدية وظائفهم (') ومـع ذلك، يجب أن تتضمن كلُ نظريةٍ جيدةٍ للقانون نظرية وظيفةِ الفصل في المنازعات أو نظريـة وظيفة

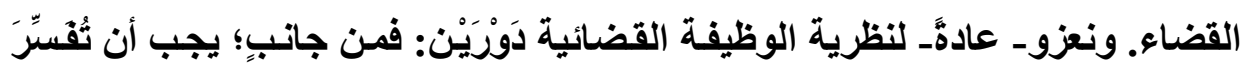

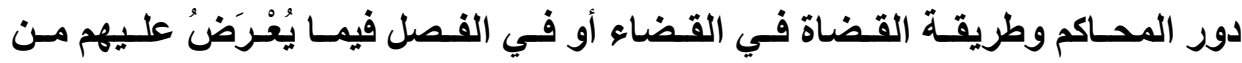
منازعات، ويجب أنْ تُعَالِجَ المسائلَ أو تفصلَ في القضايا المعروضة على القضاة بشأن

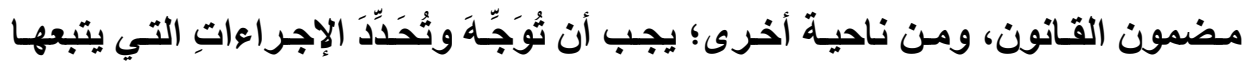
القضاهُ عند اتِّخاذ القرار(`)

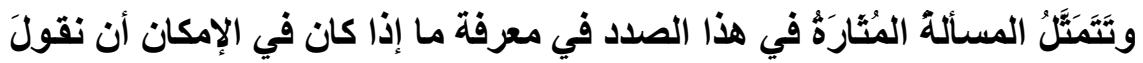
نفس الثيع عن العدالة الدولية، وكذا عن الوظيفة القضائية الدولية. وكمـا هو الحسال بالنسبة للجوانب الأخرى للقـانون الـدولي، تُثِيرُ العدالـة الدوليـة، مـن الآن فصاعدًا،

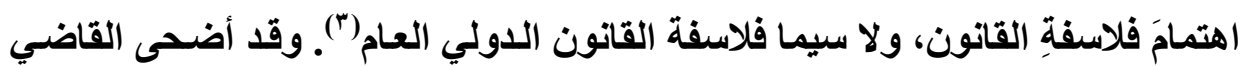

(1) Voir Julie DICKSON, "Interpretation and Coherence in Legal Reasoning", the Stanford Encyclopedia of philosophy, 2014, p. 29, Joseph RAZ, "The Authority of Law", Ibid; RAZ, "On the Nature of Law", Ibid; HART, "The concept of Law", Ibid; Contra: DWORKIN, Ibid.

(2) Voir, Julie DICKSON, "Interpretation and Coherence in legal Reasoning", Ibid.

(3) Emmanuelle JOUANNET, "La notion de jurisprudence internationale en question", in Société Française pour le droit international, dir., "La Juridictionnalisation du droit international", Pedone, 2013 ; Hervé ASCENSIO, "La notion de juridiction internationale en question", in Société Française pour le droit international, dir., Ibid ; Julie ALLARD, Antoine GARAPON, "Les Juges dans la mondialisation", Le seuil, 2012 ; Andreas PAULUS, "International Adjudication", in Samantha BESSON, John TASIOULAS, dir., "The philosophy of International $=$ 
الدولي والعدالة التي يحكم بمقتضاها تدريجيًّا أحدَ المميزاتِ الأسساسيةِ والمقبولةِِ عمومًا

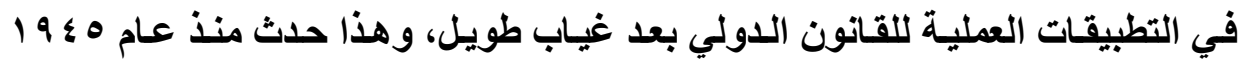

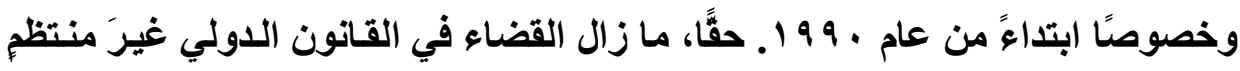

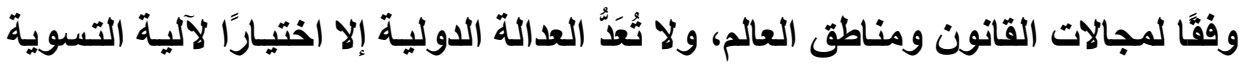
القضائية من بين الآليات المختلفة لتسوية المنازعات الدولية'(') ولا يمكنتا، بالتالي، فهُم القانون الدولي بدون إدراك بُعْدِهِ القضائي. وبدون مفاجآت، قد اكتثفنا منذ ذاك، أن

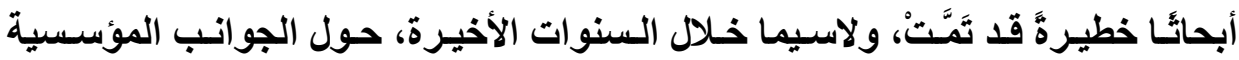
والقانونيـة للعدالـة الدوليـة(؟). وبـدأت مـع ذلـك، تـدعى أو ثُطرح الجوانـب القلسفية بصعوبةٍٍ، لاسيما الجوانب المعياريـة للعدالة الدولية؛؛ وذلك لبيـان مـا إذا كانت مفـاهيم مثل: القاضـي، المحكمة، التقاضـي، الوظيفـة القضائية، الاسـتلال القضائي، الحكم

Law", Oxford University Press, 2011; Donald H. REGAN, "International Adjudication : A Response to Paulus- Courts, Custom, Treaties, Regimes and The WTO", in Samantha BESSON, John TASIOULAS, dir., Ibid.; Benedict KINGSBURY, "International Courts : Uneven Judicialization in Global Order", in James CRAWFORD, Marti KOSKENNIEMI, dir, "The Cambridge Companion to International Law", Cambridge University Press, 2016, p. 65.

(1) Voir, KINGSBURY, Ibid.; Alain PELLET, "Judicial Settlement of international Disputes", in Rudiger WOLFRUM, dir., "Maz-PlanckEncyclpedia of public international law", Oxford University Press, 2016, p. 41.

(2) Alan BOYLE, Christine CHINKIN, "Law Making by international courts and tribunals", in "The Making of International Law", Oxford University Press, 2015; Chester BROWN, "A Common law of International A adjudication", Oxford University Press, 2014, p. 63. 
القضائي، القضاء، والسوابق(')، قد بََتَّ واضحةَ في القانون الدولي من عدمه. والحالة

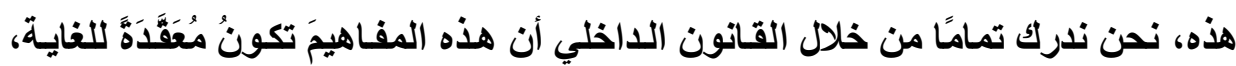
هذا فضلًا عن أنها، منذ زمن بعيدٍ، موضعُ نقاشِ حادِّ وشَرس.

ويمكنتا تفسيرُ الطريقة الأولى لعدم الاهتمسام بهذا الموضوع من خلال الصِّة التـي أقامهـا الفقهـاءُ الـدوليون بـين العدالـة الدوليـة والمسـألة المثيـرة للجدل بشأن مشروعية القانون الدولي. وربما يُوجَدُ قلقُ أو اهتمامٌ من جاتب البـاحثين وغيرهم من جرَّاء تحفظات الفقيه (ديسي) الشهيرة حول الطبيعة القانونيـة للقانون الدولي، تلك التحفظات التي كانت قد أزيلت بواسطة العَلاقةٍة التي أقيمت منذ القرن التاسـع عشر بين وجود القانون و/ أو النظام القانوني من جهة، ونظام قضائيِّ ذي ولايسةٍ عامـةٍ وإلزاميـةٍ

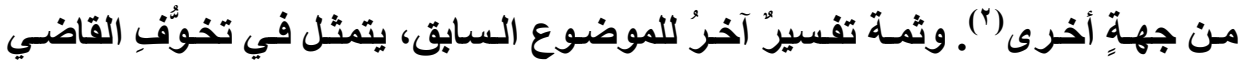
الـدولي مـن أن يلجـأ إلى اختصام العلاقـة بين مبدأ سـيادة القـانون ووظيفـة القضاء

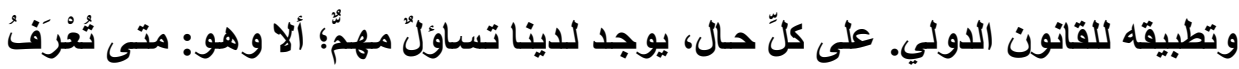
أهمية الرقابة القضائية بُعيَة العمل على احترام مبدأ سيادة القانون أو دولة القـانون في القانون الاخلي؟ فضلًا عن أن التساؤل حول وجود وشرعية العدالة الدولية يمكنُ أنْ

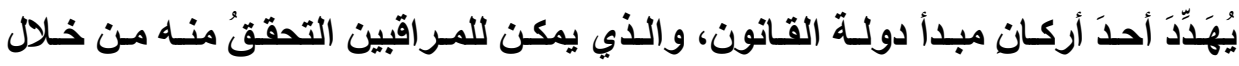

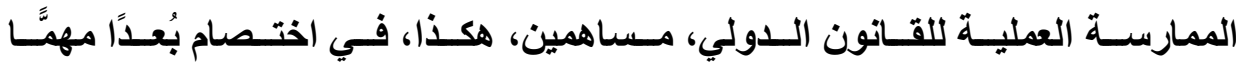
لمشروعيته(") - (r)

(1) Voir, JOUANNET, "La notion de Jurisprudence internationale en question", op.cit., p. 356-357.

(2) Voir, KINGSBURY, "International Courts: Uneven Judicialization in global order", op.cit., Voir, JOUANNET, "La notion de Jurisprudence internationale en question", op.cit., p. 344- 345.

(3) André NOLLKAEMPER, "The Internationalized Rule of Law", Hague $=$ 
وتَكْمنُ الصعوبةُ في حقيقة أن مفهوم العدالة الدولية، شأنه في ذلك شـأنُ العدالـة

الوطنيـة، لا يمكن إدراكُهُ إلا بـالرجوع إلى الطبيعة القانونيـة للقانون اللدولي، والذي بدوره لا يمكنُ التعامـلُ معه دون الرجوع إلى القاضـي الدولي. لقد حـان الوقتهُ لإزالة أوُجُهِ الغموض التي تحيط بمفهوم العدالة الدولية، وتحليل ما وصفه الفقيه (أسنسيو) بحَّر - بالحبِّ المستحيل بين القانون الدولي والعدالة الدوليةة('). بدون ذلك ينتظرنـا

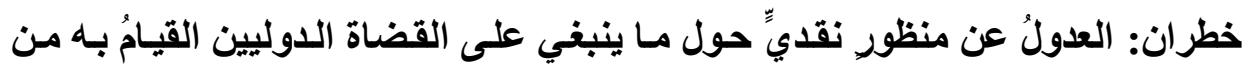

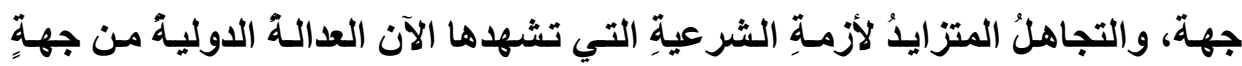

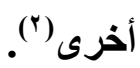

وبعيدًا عنا، قد أهْلِتْنْ تمامًا فكرةُ اقتراح مفهوم للعدالة الدولية من جانب فلاسفة القـانون. وفي المرات النـادرة التي نُوقشت فيها تلكك المسألة، كانت مفـاهيمُ التطوير

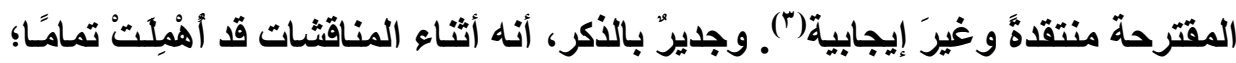

Journal on the Rule of law, Vol. 1, 2014, p. 73; Voir également Jeremy WALDRON, "Are Sovereigns Entitled to the Benefit of the International Rule of Law?", European Journal of International Law, no 2, Vol. 22, 2013, p. 332 et Samantha BESSON, "Sovereignty, International law and Democracy", European Journal of International Law, no. 2, Vol. 22, 2013, p. 373.

(1) Voir, ASCENSIO, "La notion de Juridiction internationale en question", op.cit., p. 202.

(2) Voir PAULUS, "International Adjudication", op.cit., p. 223 ; KINGSBURY, "International Courts : Uneven Judicialization in Global Order", op.cit., Conclusion.

(3) Martti KOSKENNIEMI, "The Ideology of international Adjudication and the 1907 Hague conference", in Yves DAUDET, "Topicality of the 1907 Hague conference", the second peace conference, Brill Academic publishes, 2008, p. 119. 
ليس فقط المسائلُ التقليدية التي تثير وظيفة القضاء في القانون الوطني، ولكن أيضًا المناقشاتُ القلسفيةٌ للقانون بشأن هذه الموضوعات (')

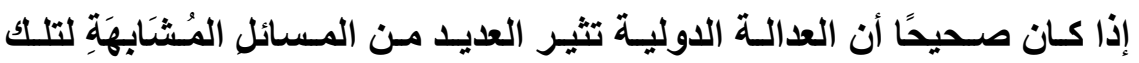
المعروفة في القانون الوطني، يَزيد عدمُ تحديد دور القاضي الدولي وخصائص النظام

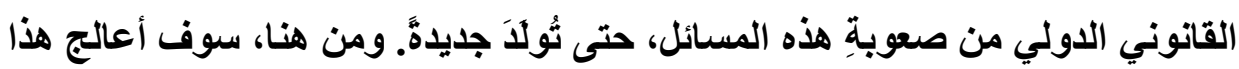
الموضوع على ثُلاثِ مراحِلَ، في البدايـة أعالجُ مفهومَ العدالـة الدولية. وفي المرحلة الثانية أتصدَّى لبيان الفلسفة العامة للعدالة الدولية. وفي المرحلة الثالثة أتولَّى دراسـة القلسفة الخاصة بالعدالة الدولية.

| - ا - هفهوم العدالة الدولية:

يُمْكِنُ تعريفُ الوظيفةِة القضائيةِ بأنها دورُ أو وظيفةُ أو مهمةُ القضاة (باعتبارهم

محكمة) الـائمين والمستقلين في تحديد وتطبيق القـانون؛ بغرَض تسويةِ المُنازَعَاتِ المعروضةِ عليهم أو المَطروحةِ أمامهم، وإصدار أحكاجِ وقراراتٍ مُلزمَةِة، بغرض احترام

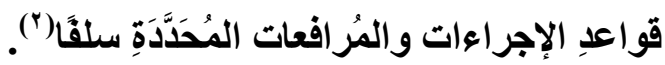

وترتبط الوظيفةُ القضائيةٌ رسميَّا بمؤسسة، بمعنى محكمة، اختصاص أو سلطة،

ليس ذلـك فقط ولكن أيضًا بـدعوى أو قضية ونتيجتها، بمعنى القرارات القضائية

(1) George LETSAS, "Strasbourg's interpretive Ethic: Lessons for the international lawyer", European Journal of international law, no. 3, Vol. 21, 2012, p. 409.

(2) Christian TOMUSCHAT, "International courts and tribunals", in, "Max-planck-Ecyclopedia of public international law", Oxford University Press, 2012, p. 227. 


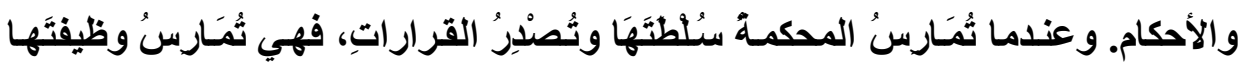
القضائية، ويُطلقُ على هذه الوظيفة في مجموعها مصطلحُ "العدالة")(')

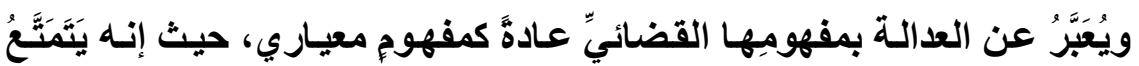
بقيمةٍ معينة، بمعنى أنه يطبق القانون على نزاع أو منازعة معينة، ويتضمن تطبيقه

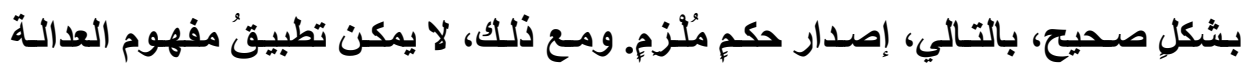

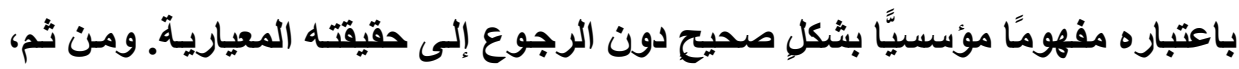

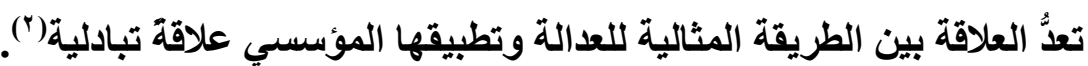
ويتميزُ القضاء الدولي عن القضاء الداخلي من حيث عدم تخصص المحاكم

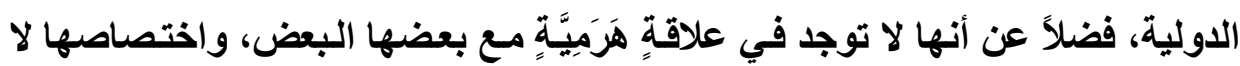

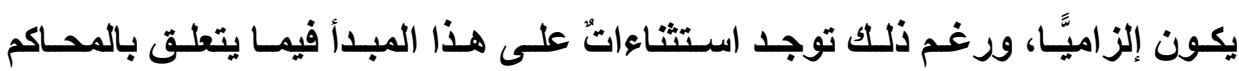
المتخصصة والإقليمية"(")، وتتعلق القرارات بالأطراف، ولكن لا لتتمتعُ بالضرورة بالقوة

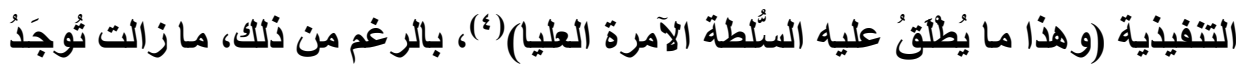
استثناءاتُّ بثأن المحاكم المتخصصة والإقليمية. ويَنْنتِّدُ الاعتراض الأول على مفهوم القضاء الدولي إلى إمكانيةِ تحويل المفهوم

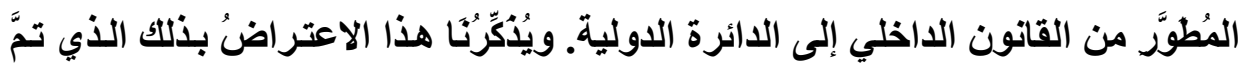

(1) Voir ASCENSIO, "La notion de Juridiction internationale en question", op.cit., p. 205.

(2) Voir KINGSBURY, "International Courts: Uneven Judicialization in Global order", op.cit., p. 73.

(3) Voir PELLET, "Judicial Settlement", op.cit., p. 11 et s.

(4) Voir ASCENSIO, "La notion de Juridiction internationale en question", op.cit., p. 177 et s. 
عمله إزاءَ مشروعية القانون الدولي بالرجوع إلى مفهوم القانون المُطوَّر في وللقانون الداخلي، وإلى تطبيق فلسفة القانون المطور في القانون الداخلي إلى القانون الدولي. و إذا لاحظنـا الممارسـة الدقيقة للوظيفة القضائية، سـواء في القـانون الـاخلي أو في القـانون الـدولي، يتأكد لنـا سـريعًا أن العدالـة الدولية تقترب مـن العدالـة الداخليـة'(').

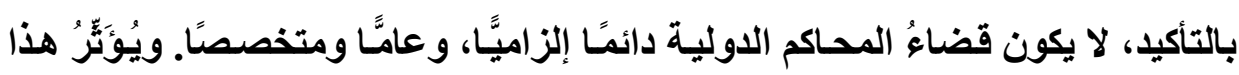
الظرف فقط على الوظـائف الأخرى المُعََْرَفِ بها للعدالـة الدوليـة في النظام القانوني الدولي، ولكن لا أثرَ لله على وظيفة القضاء (الفصل في المنازعـات المعروضـة أمسام المحاكم الدولية).

وفي كلِّ الأحوال، فإن إدماج القانون الدولي في النُّمُ القانونية الوطنيـة يعني

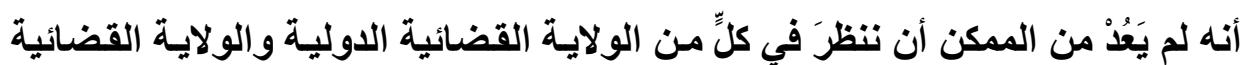

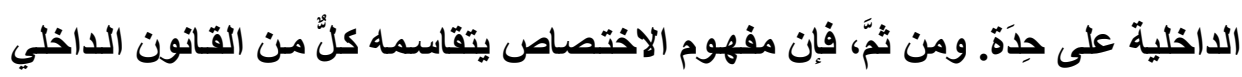

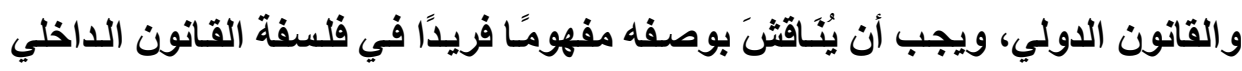

$$
\text { وفي فلسفة القانون الدولي (العام والخاص). }
$$

ويتعلق التساؤل التـالي، بطبيعة الحسال، بالـضوابط الدقيقة لعالميـة القضاء أو الولاية القضائية الدولية، وذلك على العكس من البُعْدِ الداخلي للقضاء الداخلي. ولا شكَّ أنه يمكن للمحاكم الأخلية أن تنتهيَ إلى تطبيق القانون الدولي، ومن ثم فهي تُسنهُهُ في تنفيـذه. وهذا يمكن أن يُسنْهُ، أحيانَا، في وظيفة الرقابـة القضائية

(1) Voir REGAN, "International Adjudication", op.cit., p. 227;

TOMUSCHAT, "International courts and tribunals", op.cit., p. 35. 
د/عبد الله محمد الهوارى

العدد •r (ديسمبر r.19)

الاولية. وعندما يحدث ذلك، يمكنتا القول، من جهة أخرى: إن المحاكم الداخلية تُمَرسُ

وظيفة القاضي الاولي (')

لمزياٍٍ من الوضوح، ومـع ذلك، وبالإشـارة إلى العناصر المحددة سلقًا، يمكنتـا

القول: إنَّ وظيفة القضاء تُعَدُّ دولية حال قيام القانون الدولي بتأسيس وتنظيم المحكمة،

واختـصاصها وإجر اءاتهـا المختلفـة(؟). بـالمعنى الـدقيق للكلمـة، لا تمـارس المحساكم

الاخلية باعتبار هـا مؤسساتِ وظيفة القضاء الدولي، وذلك إذا مـا رجعــا إلى نظامها

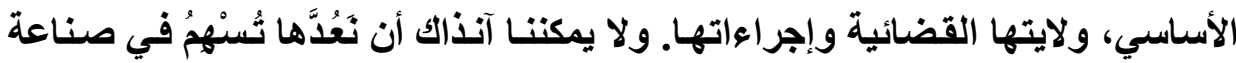

القانون القضائي الدولي، إلا بطريقةٍة غير مباشرة (r): على سبيل المثال، عن طريث

تدعيم التفسيرات متعددة القوميات، وكذا المبادئ العامـة للقـانون الدولي التي ظهرت جليَّا فيما بعدُ بواسطة القضَّاةِ الدوليين، كما هو الحال في سياق حقوق الإنسان بصفةٍ خاصنَّة(؛) (ن)

(1) Antonios TZANAKOPOULOS, "Domestic Courts in International law: The International Judicial Function of National Courts", Loyola of los Angeles International and Comparative law Review, Vol. 34, 2011, p. 101.

(2) Voir ASCENSIO, op.cit., p. 163- 167.

(3) Alain PELLET, "Article 38", in Andreas ZIMMERMANN, Christian TOMUSCHAT, Karim OELLERS-FRAHM, "The statute of the international court of Justice: A Commentary", Oxford University Press, 2006, p. 312.

(4) Samantha BESSON, "General Principales in International Law-whose principales?", in Samantha BESSON, "Les principes en droit européen principales in Européen Law", Schulthess, 2011, p. 93. 
وكان من بين الموضوعات المتكررة في مناقشات الوظيفة القضائية الدولية

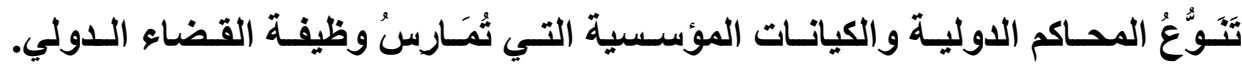
والسؤال الذي يطرح نفسه هو: كيف يَنَكَسُِ هذا التنوٌُعُ من الجهود النظرية والمذهبية

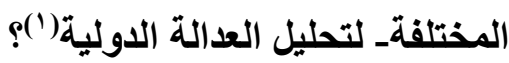

وتهذف هذه المساهمة، في الواقع، إلى تحديد ومناقشة مفهوم أسـاس للعدالة

الدولية المشتركة بين مختلف الممارسـات المؤسسية. وبـالنظر لأن القضاء الدولي لا لا لهاء

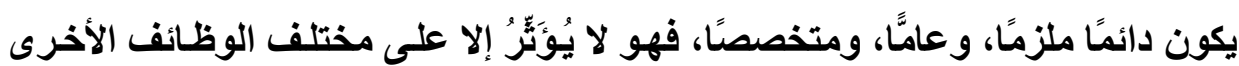
التي يُكَّلَُّ بها عن طريق القانون الدولي، ولا أثرَ لهله على وظيفة الفصل في المنازعات باعتبارها كذلك: ومن هنا، تبقى هذه الوظيفةُ هي بذاتها ـ بغضِّ النظر عن المحكمةِ

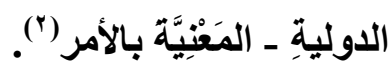

بطبيعة الحال، تُعَدُ وظيفة القضاء وظيفة مؤسسية، وبالتـالي، هنـاك علاقةة ببين العدالة الدولية بوصفها نموذجًا فريدًا من نوعه و الممارسـة المؤسسية المتعددة. لأجل

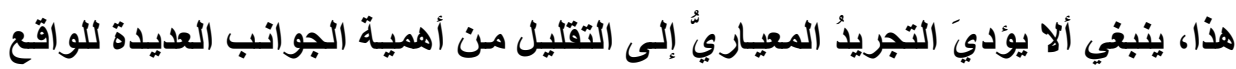

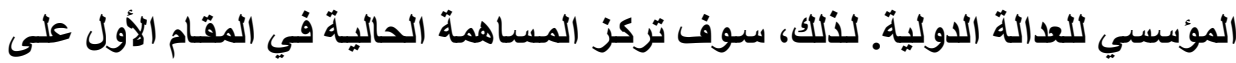

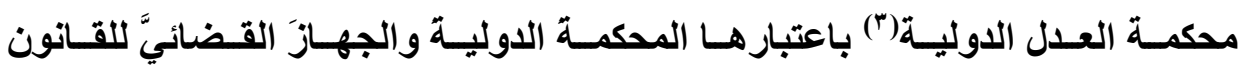

(1) Jonathan CHARNEY, "Is International Law threatened by Multiple International Tribunals?", Recueil des cours, Vol. 271, 1998, p. 101, 373.

(2) Armin VON BOGDANDY, Ingo VENZKE, "Beyond Dispute: International Judicial Institutions as law makers", German Law Journal, Vol. 12, 2011, p. 979.

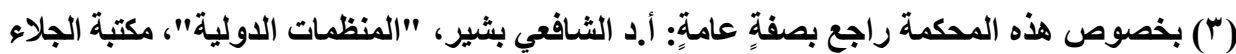

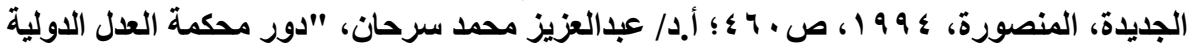

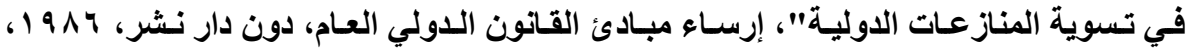
$=$ 
الاولي (')، إلا أن ذلك لن يَمْنَعَّا مـن الإثـارة في عددٍ من المناسبات إلى محسكَ دوليـةٍ أخرى لها صلاحياتُ قضائية محددة، مثل المحكمة الأوروبية لحقوق الإنسان كمكمـةٍ إقليميةٍ ومتخصصة.

r- الفلسفة العاهمة للعدالة الدولية:

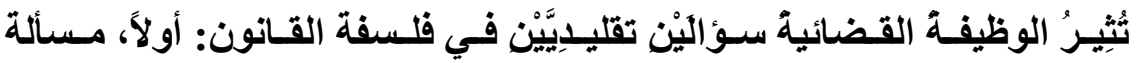

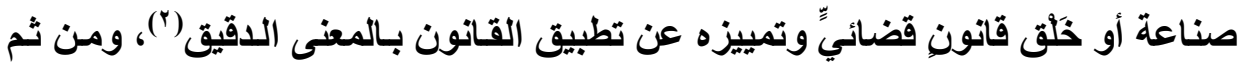
التعارض بين القانون القضائي والسياسة الديمقراطية، ثانيًا، مسألة السلطة التقديريـة

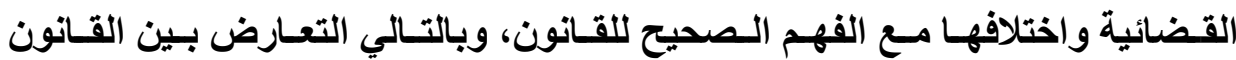
والأخلاق.

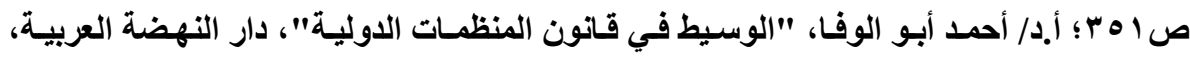

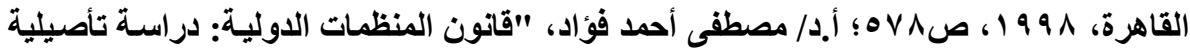

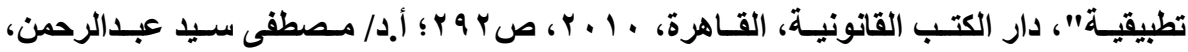

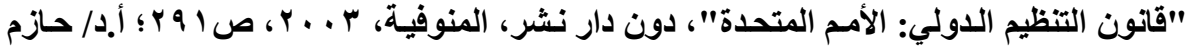

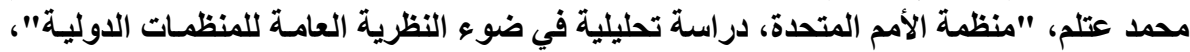

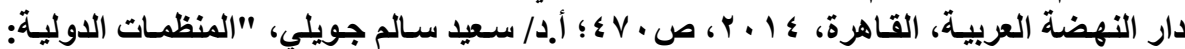

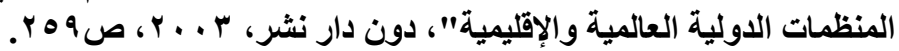

(1) CIJ, 9 avril 1949, Détroit de Corfou (Royaume-Uni de GrandeBretagne et d'Irlande du nord C. Albanie), arrêt, C.I.J. Recueil 1948, p. 4, Para. 35.

(2) Samantha BESSON, "International Judges Function between disputeSettlement and Law- Enforcement- From International law without courts to International courts without law. A Reply to Anna Spain", Loyola of los Angeles International and Comparative law Review, Vol. 34, 2012 , p. 101. 


\section{أ - قانون القضاء الدولي}

خلاقا للطرق غير القضائية لتسوية المنازعات الدولية، تستند العدالـة الدولية

والقراراتُ القضائية على القانون: فهي تهـف إلى تسوية المنازعات القانونية بين الأطراف في قضيةٍ معينةٍ من خلال تطبيق نصوص القانون. وبغرض تسوية النزاع بين

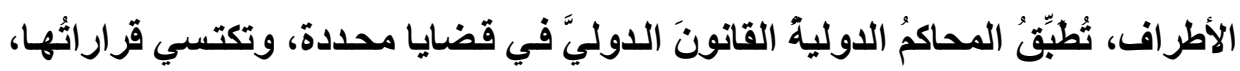
في هذا الصدد، بحجية الثيء المقضيّ فيه تجاه الأطراف المعنية. بيد أن القرارات أو الو

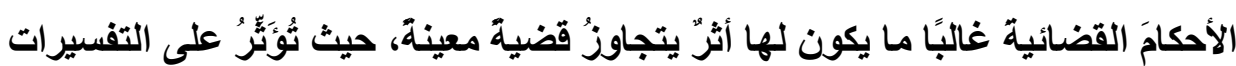
والتطبيقات اللاحقة للقانون. وهذا ما يُسنَّى بحجية الثيء المُفسِّ للقرارات القضائية.

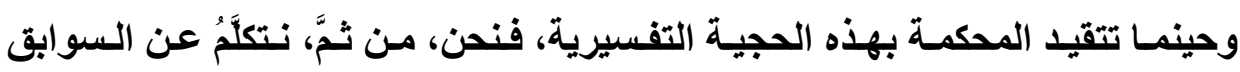

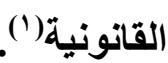

ونظرًا لأنَّ تنفيذ القانون ينطوي مُنْبَّا على تحديده، ثُ تفسيره في حالةٍِة معينةٍ

من جانب، ونظرًا لأن القراراتِ القضائية التي تُطبِّقُ القانونَ يمكن أن يكون لها سلطة تفسيرية تتجاوز القضية المَعْنِيَّة من جانبِ آخر؛ تتضمن الوظيفة القضائية أيضًا وظيفة

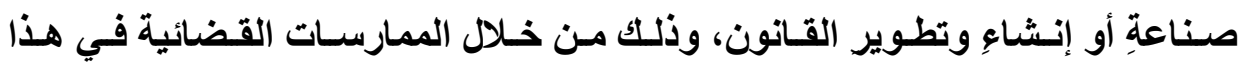
الخصوص. ونحن في هذا الصدد نتكلم عن تحديد وصناعة القانون القضائي.

(1) Samantha BESSON, "The Erga Ommes Effect of the European Court of Human Rights Judgments", in Samantha BESSON, "La Cour européenne des droits de l'homme après le protocole 14- premier bilan et perspectives", SCHULTHESS, 2011, P. 193 ; Robert JENNINGS, "The Judiciary, International and National, and the Development of International law", International and Comparative law Quarterly, Vol. 45, 1996, p. 1. 
وبطبيعة الحال، لا يُعَدُ التفسير القضائي ضروريًا دائمَا لتطبيق القانون؛ وذلك

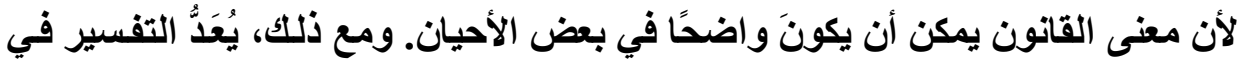

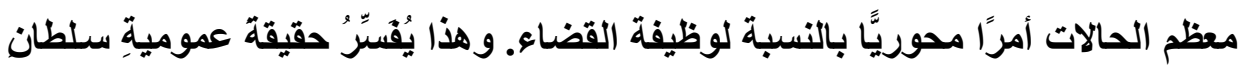
ونفوذِ القانون، وتستتذ هذه الحقيقة على اتِّصال أولئك الذين يملكون هذه السلطة بأولئك الذين يخضعون لها، والذين يجب أن يكون لهم الحقُّ في فهم و إدراك معنى

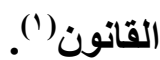

وتُقو دُنا عملية الصناعة القضائية للقانون أو التحديد القضائي للمبادئ القانونية

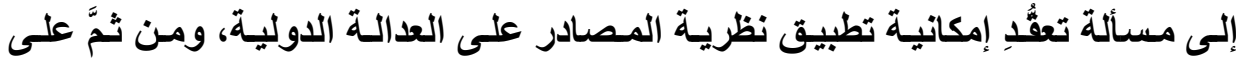

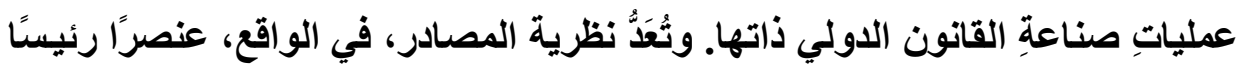

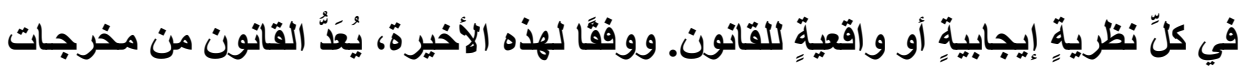

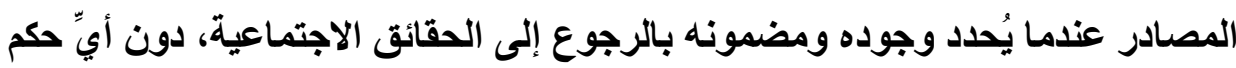

يوجد، في الحقيقة، العديُُ من الإجابات الممكنة في هذا الخصوص("). قبلَ كلّّ

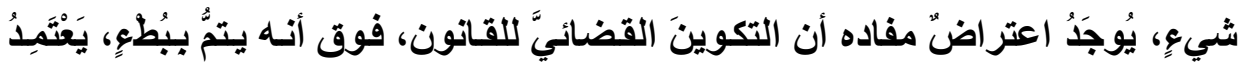

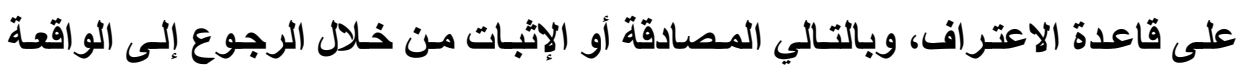

(1) Voir RAZ, "Authority", op.cit., p. 79; RAZ, "On the Nature of Law", op.cit., p. 113.

(2) Voir DWORKIN, op.cit., p. 111. en droit international, Voir, LETSAS, op.cit., p. 65 ; PAULUS, op.cit., p. 57.

(3) Roberto GUASTINI, "Les principes de droit en tant que source de perplexité théorique", in Sylvie CAUDAI, "les Principes en droit", Economica, 2012, p. 248. 
الاجتماعية المعنية. وليس هنـاك مـا يدعو للقلق من إقرار القيم الأخلاقيـة أو المبادئ الأخلاقية بواسطة أحكام القضاء.

وجدير" بالذكر، أنه يتمُّ تحديدُ مبادئ القانون من خلال الاستدلال القانونيّ، بمعنى

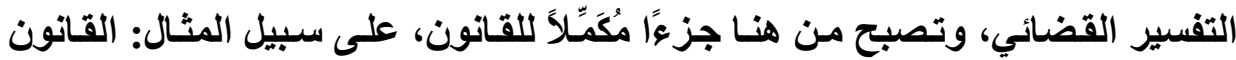
العرفي ذو الأصل القضائي. ويمكن تعزيز التشابه بين القـانون القضائي والقانون

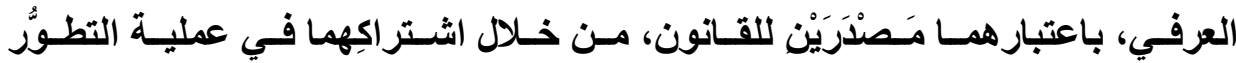

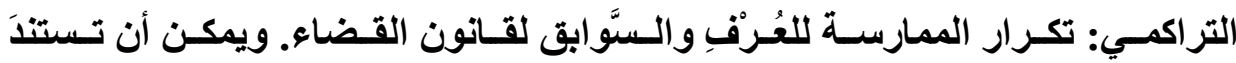
إجابة محتملة أخرى إلى وجود ثغراتٍ في القانون. وحتى لو تمّ اعتبار مبادئ القانون

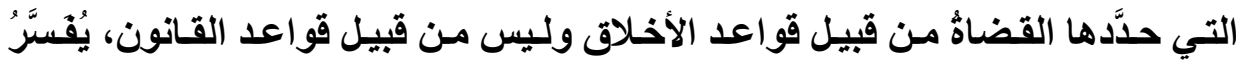

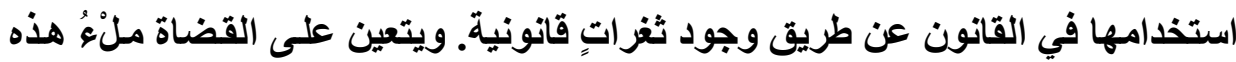

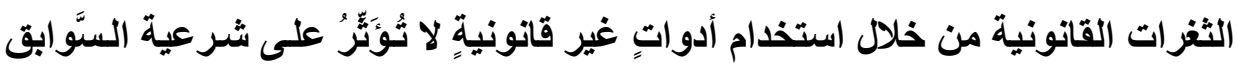

القضائية.

وترجع الصعوبة الرئيسة في التكوين القضائي للقانون، مع ذلك، إلى عنصر

آخر: وهو التمييز بين القانون البريتوري والقانون التشريعي، ومن ثم التمييز بين القانون والسياسة. ومن الخطأ أن نرى في التكوين القضائي للقانون نمونجًا أصليًّا

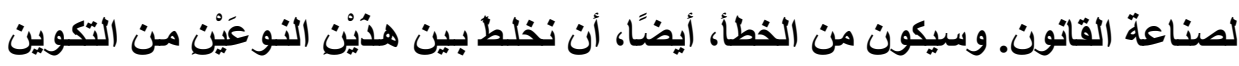

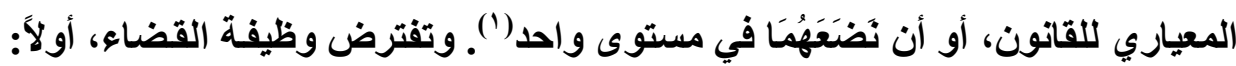
أسبقية القانون من حيث تتفيذه، وتطبيقه، وتفسيره، مع الأخذ في الاعتبار أن القانون

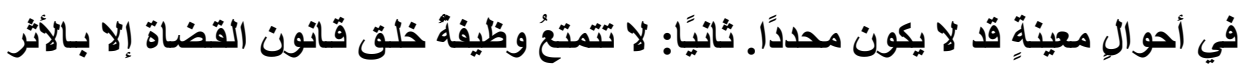

(1) Voir, DICKSON, op.cit.; RAZ, "Authority", op.cit.; RAZ, "On the Nature of Law", op.cit., p. 102. 
النسبي في مواجهة الأطراف، ولكن هذا لا يَنْزَعُ عنها تَمَتُعَهَا بحجية الشيء المقضيِّ

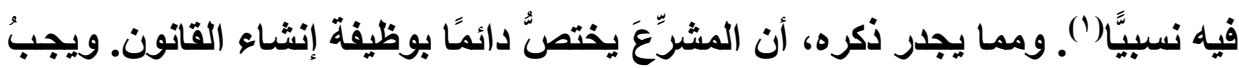
أن يمتثلَ القضاهُ دائمًا لسلطة المشرِّع الديمقراطي. ولنا أن نضيف، على سبيل المثنال، أنَّ ندرة مبادئ القانون التي استخلصها القضاة، من خلال مباثرة الوظيفة القضائية، هي خيرُ دليلٍ على احترام القاضي للستُطة التشريعية'(؟).

ويمُجرَّدِ نقّل هذا الاستدلال إلى القانون الدولي، فِإن السؤالَ المطروحَ هو مـا إذا

كان يمكن اعتبارُ العدالة الدولية وسيلة لإرساء قواعد القانون الدولي؟ وبـالنظر إلى أن

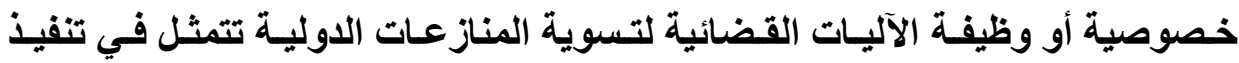
القانون الدولي، وأن هذه الأخيرةٌ تتضمن، أيضًا، تحديدَه وتفسيرَه في قضيةٍ محددةٍ،

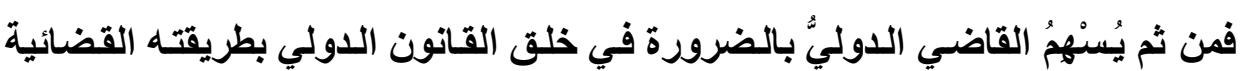

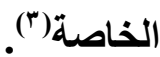

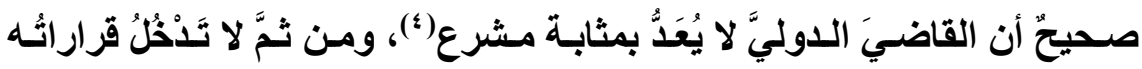

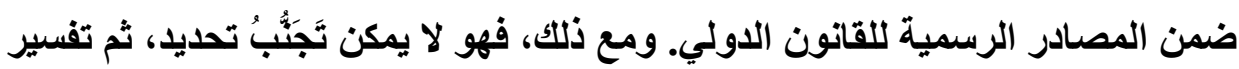

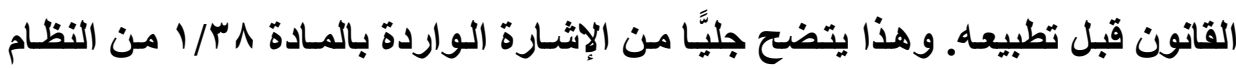

(1) Voir, DICKSON, Ibid.; JOUANNET, "Jurisprudence internationale", op.cit., p. 386.

(2) Pierre BRUNET, "Les Principes Généreux du droit et la hiérarchie des normes", in Denys de BÉCHILLON, Pierre BRUNET et Eric MILLARD, "L'architecture du droit", Mélanges en l'honneur de Michel TROPES, Economica, 2015, p. 222.

(3) Marc JACOB, "Precedents: Lawmaking through international adjudication", German Law Journal, no. 6, Vol. 16, 2014, p. 1005.

(4) Voir, CIJ, 8 juillet 1996, Licéité de la menace ou de l'emploi d'armes nucléaires, avis consultatif, G.I.J. Recueil 1996, p. 226, 237, Para. 18. 
الأسـاسـي لمحكسة العدل الدوليـة على القـرارات القضائية الدوليـة باعتبارهـا وسـيلة مساعدةَ لتحديد قواعد القـانون؛ لأنها مُسنْتَدََّةُ من المصادر الرسمية للقانون الدولي. ويُدْكَرُ أن للتفسير القضائي نتائجَ مهمهة بخصوص الاستدلال اللاحق للقضاة الدوليين (وهذا ما يُسََّّى بمبدأ السابقة أو واجب المحكمة في احترام السوابق القانونية)، هذا من جاتبٍ، والقهم العام للقانون بعيدًا عن المحاكم (وهذا ما يُطلقُ عليه سُططة أو حجية الشيء المفسر)، من جاتبٍ آخر.

صحيحٌ أن جانبًا من الفقه قد أنكر كلَّ حجيةٍ تفسيريةٍ للقرارات القضائية الدولية، وخصوصًا لقرارات محكمة العدل الدولية، مُسنتِّدِينَ في ذلك على المـادة وه من النظام

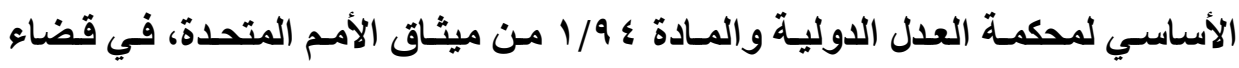
محكمة العدل الدوليـة، ولا سيما أن المحكمة ذاتها قـ أكلدت على الالتزام بـالترابط أو

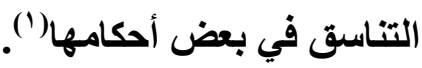

تُعَدُُّ مهام تحديد وصناعة القـانون الممنوحة للقضاة الدوليين أكثرَ أهميـة في

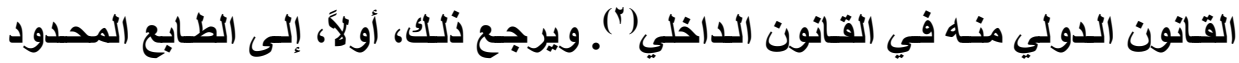
لمسادر القـانون الدولي: فثخرات القـانون الدولي أكثرُ مـن تلكت الموجـودة بالقـانون الوطني. ولِسَدِّ هذه الثغرات ووفقَا لتطبيق مبدأ عدم وجود قانونِ يحكم الموضوع في القانون الدولي(")، يَقعُ على عاتق القضاة الدوليين مهامُ تحديد وتفسير القانون الواجب

(1) Voir, CIJ, 11 Juin 1998, Frontière terrestre et maritime entre le Cameroun et le Nigéria, G.I.J. Recueil 1998, C.I.J. p. 275, 292, Para. 28.

(2) Rosalyn HIGGINS, "Problems and process: International law and How we Use it", Oxford University Press, 2014, p. 302; Hersch LAUTERPACHT, "The Development of International law by the International Court", Cambridge University Press, 2013, p. 55 et s.

(3) BOYLE et CHINKIN, op.cit., p. 289- 290. 
التطبيق بشكلِ أكثرَ أهميةَ من القضاة المحليين. وهذا يَصْدُقُ بوجـهِ خـاصٍ في مجالاتٍ جديدةٍ نسبيَّا للقانون الدولي، مثل القانون الدولي الجنائي والقانون الدولي للبيئة. ثانيًا، بسبب الطابع غير المحدد لبعض مصادر القانون الدولي لاسيما القانون

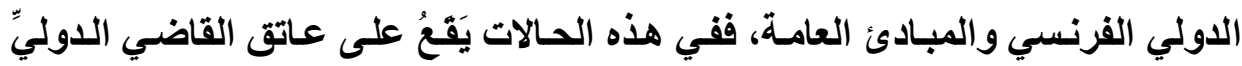
التزامُ بأن يَلَبََ دورًا محوريَّا في تحديد قواعد القانون الواجب التطبيق ('). ويتمثل التبرير الثالث لأهمية وظيفة خَّق قانون القضاء الدولي في تعدُّدِ فروع

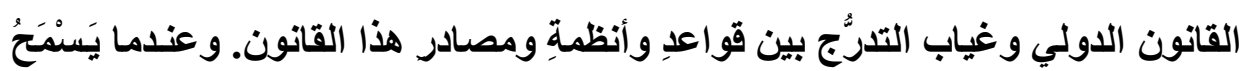
اختصاصه بذلكلك، يُدعى القاضي الدولي لأنْ يُحَدِّدَ كل القواعد و الأنظمة والمصادر وثيقةِِ

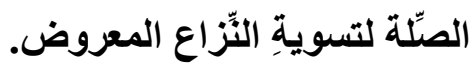

رابعًا، تقتضي بعضُ مسائل القانون الدولي، كتلك التي تتعلق بالقانون الدولي لحقوق الإنسان، ضرورة تجسيد الحقوق المضمونة في سياق محدد(؟)، وبالتالي تحديد

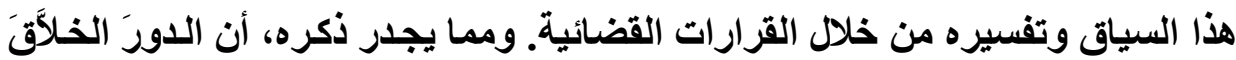
للقاضي الدولي ما زال أكثرَ محورية في القانون الدولي لحقوق الإنسان منه في الفروع

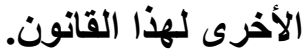
وتقتضي حماية حقوق الإنسان على المستوى الدولي تصديقًا متبـادلاً للقواعد

الاخلية والدولية عن طريق القضاة الدوليين والوطنيين(").

(1) BOYLE et CHINKIN, op.cit., p. 278- 285.

(2) Voir, Cour EDH, 25 avril 1978, Tyrer C. Royaume-Uni, req. No. 5856/72, Séries A, no. 26, Para. 15- 16.

(3) Samantha BESSON, "Human Rights and Democracy in a Global Context- Decoupling and Recoupling", Ethics and Global Politics, no. 1, Vol. 4, 2011, p. 19. 
يُضَافُ إلى ذلك، أنه لا يجبُ أن نُعُدَّ قانون القضاء الدولي عاملاً محوريَّا في خلق القانون الدولي. ويجب أن ثُوجََ، في كلِّ الأحوال، إمكانيةٌ تمييزه عن غيره. ويُعَدُّ إنكار

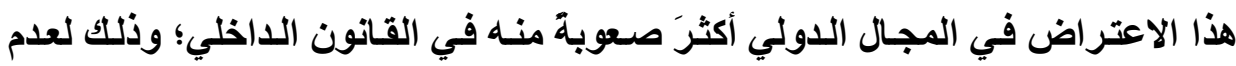
وجود مُشَرِّع دوليِّ وحيدٍ ومتخصص. وتبقى الدول فقط هي التي تنكر الاختصاص بصناعة أو خَلق القانون الدولي، على الرغم من أن تلكَ الصلاحية ثُقََّّضُ فيها، أحيانَا، المنظماتُ الدولية، أو أنها تشترك مع غيرها من أشخاص القانون الدوليِّ الأخرى في هذا الخصوص(') - 2 (') السؤال الذي يطرح نفسه في هذا الصدد، هو: كيف يمكن للقضاء الـدولي

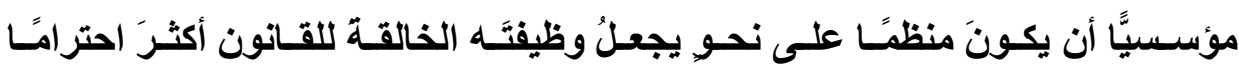
لصلاحياتِ الدول بوصفها السلطة التشريعية للقانون الدولي. وبالنظر إلى كون الدول أشخاصًا للقانون الدولي، فهي تخضعُ للعدالة الدولية،

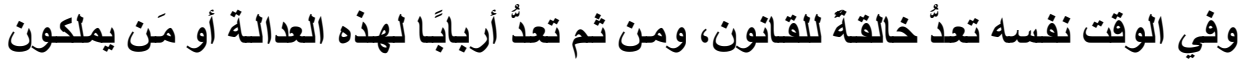

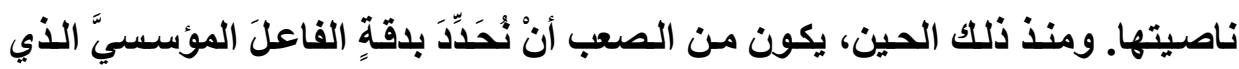
يختلف عن القاضي، ويعدُّ في الوقت نفسه شريكًا لهذا الأخير، ممـا يُتِيحُ إمكانيـة تمييز القانون الدولي القضائي عن القانون الدولي غير القضائي(؟) وقد تمَّ حلٌّ هذه المسألكة عن طريـق فصل السلطات وتوزيعها بين السلطات التشريعية والتنفيذية والقضائية. وبعيدًا عن المنظمـات الدولية، ونظرًا لغيـاب سُلطةٍ

(1) Voir, JOUANNET, "Jurisprudence internationale", op.cit., p. 389 et s.

(2) Voir, JACOB, "Precedents: Lawmaking through international adjudication", op.cit., p. 1007. 


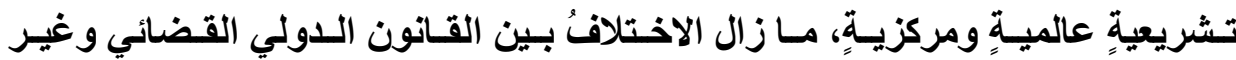
القضائي قائمًا من الناحية الواقعية.

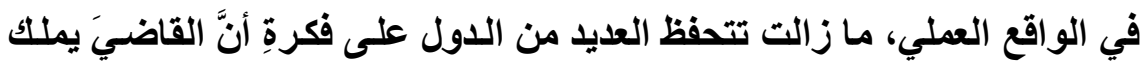

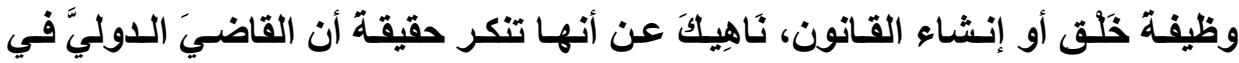

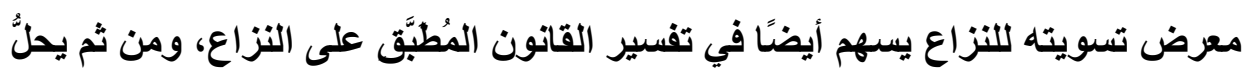

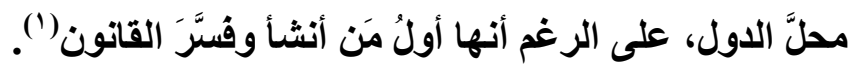

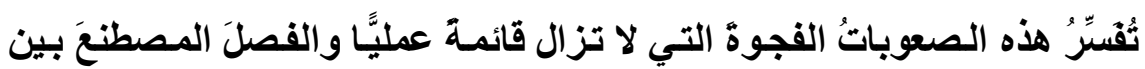
وظيفةٍ تسوية المنازعات من قِبل المحاكم الاولية من جاتب، ووظيفةِ تطبيق وتحديد

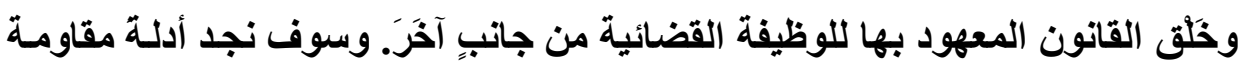
الوظيفة الإبداعية أو الخلاًّة للقاضي الدولي لا سيما في طبيعة اختصاصاته، وبالتالي ولاية المحاكم الدولية، حيث إنها لا تزال غيرَ إلزاميةٍ وغيرَ حصرية.

وتتطلب، في الواقـع، هاتـان الخصيـصتان للولايسة القـضائية الدوليـة بعضن الإيضاحات، حيث تظل العدالة الدولية إحدى الطرق العديدة لتسوية المنازعات الدولية،

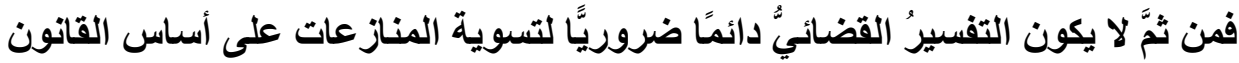
الدولي: ويمكن تسوية هذه المنازعات بآلياتٍ غير قضائيةٍ لا تلجأ إلى القانون للقيام

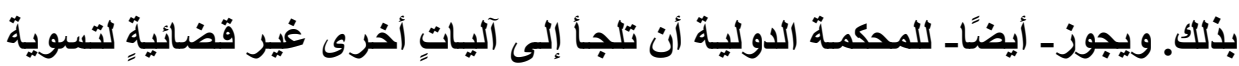
المنازعات، مثل المفاوضات، وذلك دون أن ثُطبَِّّ القانون ودون تفسيره أو تطويره. كلُّ هذا يساعد في تفسير لمـاذا ثُمثل العلاقات بين بُعد تسوية منازعات العدالة الدولية ووظيفة هذه الأخيرة في خلق القانون الدولي إثكالية في المجالات التي تتقلدم

(1) Elihu LAUTERPACHT, "Aspects of the administration of international Justice", Cambridge University Press, 2013, p. 32- 36. 
وتتطور فيها قواعد القانون الدولي غير الرضائية. ونحن نفكر، على سبيل المثال، في القضايا التي طبَّقتْ فيها محكمة العدل الدولية القانونَ الدوليَّ لحقوق الإنسان. وطالمـا

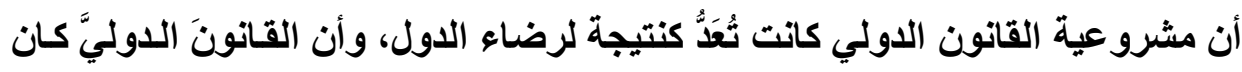

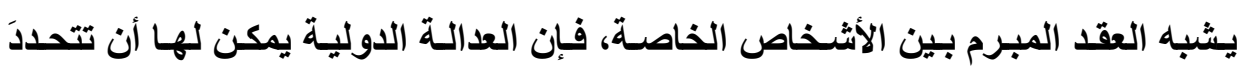

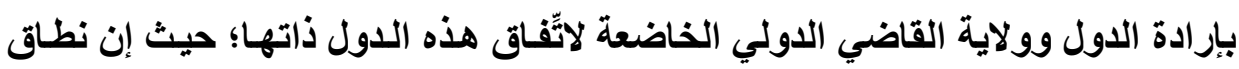

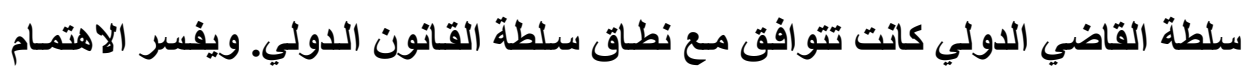

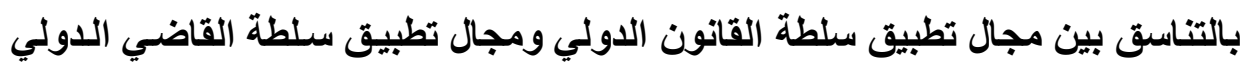

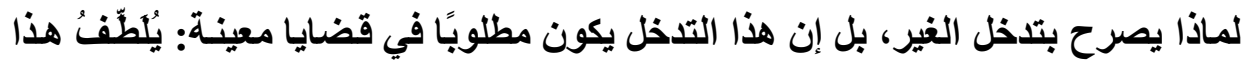

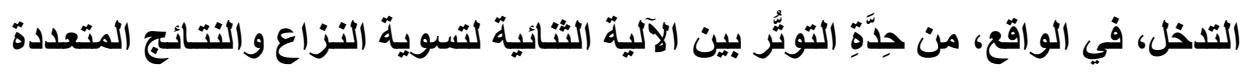

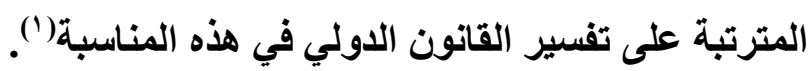

بطبيعة الحال، تختفي أحيائًا حدة التوتر بين الطابع الموضوعي للقواعد الجديدة

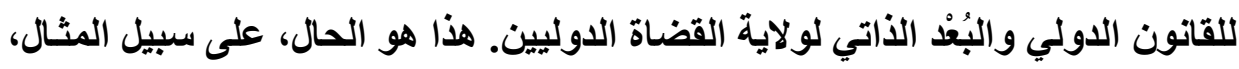

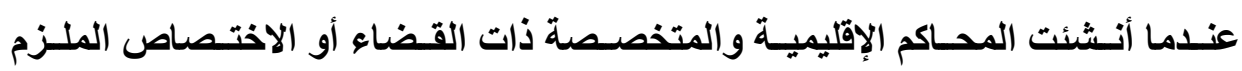

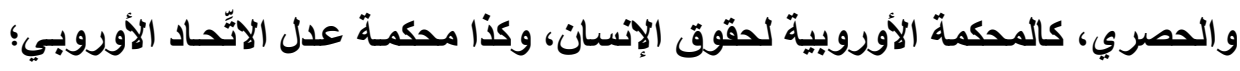

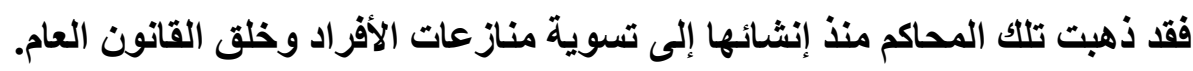

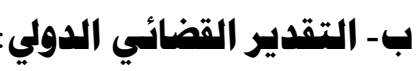

يتضح من العرض السابق أن القانونَ لا يكونُ محددًا بشكلِ كاملِ، وأن وظيفة

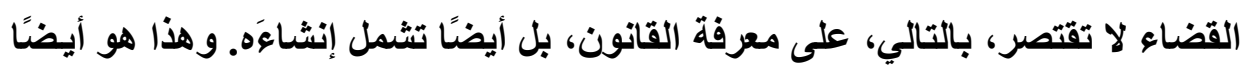

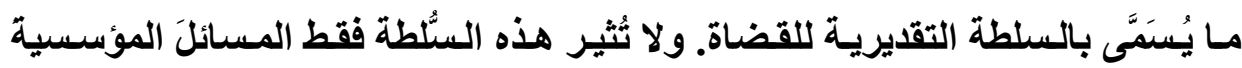

(1) Voir, BOYLE et CHINKIN, op.cit., p. 395. 


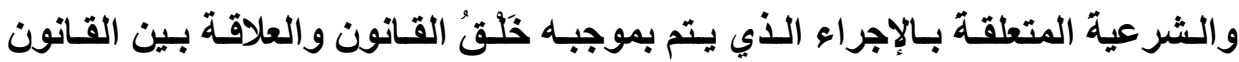
القضائي والسياسة، ولكن تشملُ أيضًا المسائلَ الماديـة المتعلقة بمضمون إجراعات صناعة القانون، وكذا العلاقات بين قانون القضاء والأخلاق. وفَّا للاعتراض التقليديٍ الثاني لقلسفة القانون العام، يتطلب قـانون القضاء إدماجَ القِيَّ ومبادئ الأخلاق في القانون، مما يشير إلى صعوبةِ شرح قانون القضاء في إطار واقعيٍٍ ودون اللجوء إلى نظريـات القانون الطبيعي. مرة أخرى، إجابـات مختلفة فئة تكون ممكنة. وقبل الدخول في تفاصيلها، يُذكر أن التمييز بين القانون والأخلاق عـادةً

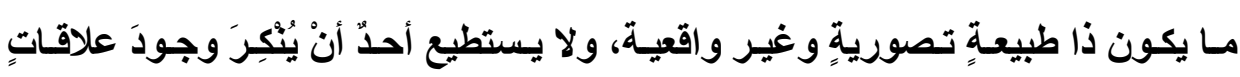
واقعيةٍ أو حلثيةٍ بين القانون والأخلاق (')

في المقام الأول، لا يمكن أن يقتصر القانون على دمج المبادئ والقيم الأخلاقيـة؛ وذلك لأنه يُعَدُ أحد عناصر الأخلاق، ويُطبَّقُ هذه الأخيرة بوضوح على الجميع دونمسا

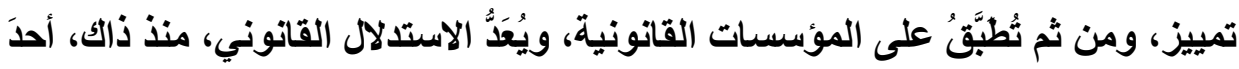
أشـكال هذا الاستـلال الأخلاقِي. وفـي هذه الظروف، لا يمكن للقـانون إلا أن يُعَدِّلَ أو

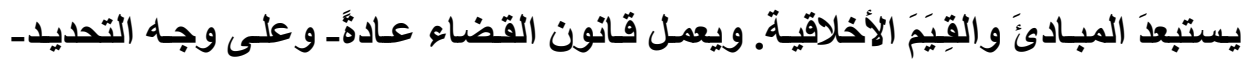

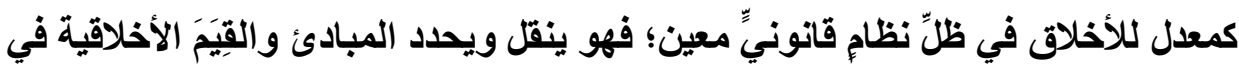

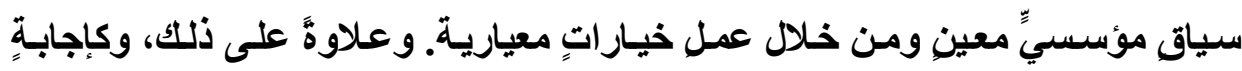
ثانيةٍة على النقد الوارد أعلاه، فحتى لو كان يُنظر إلى مبادئ القانون وغيرها من معايير

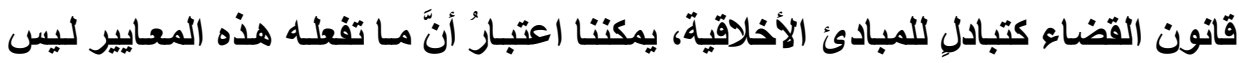
تحويلاً للأخلاق إلى قانون، بـل إعطاء آثـار قانونية كمعايير أخلاقية محددة في إطـار

(1) Joseph RAZ, "Incorporation by Law", Legal Theory, Vol. 15, 2013, p. 3; GUASTINI, ibid. 
نظام قانونيٍ معين. ويمكن مقارنة ذلك بالحالات التي يعطي فيها القاضي الداخليٌّ آثارًا قانونية للقانون الأجنبي دون اعتبار هذا الأخير قانونًا محليَّا.

وإذا ما انتقلنا إلى العدالة الدولية، ماز الت سلطة القاضي التقديرية مسألة أكثر حساسية. وما زال التحدِّي أكثرَ عِظمًا مما هو عليه في القانون الداخلي ('). وتوجد، في الحقيقة، قواعدُ قانونية أقلُّ من أن تحدد؛ وذلك بسبب ندرة مصادر القانون الدولي، وكذا تنوعها وتقسيماتها، وذلك على النحو الذي أوضحناه سلقًا. علاوةً على ذلك، تُعَدُّ القيم الأخلاقية التي يحميها القانون الدولي بالفعل عالمية، ومن ثَُّّ كثيرًا ما يُنظر' إلى الأصل الأخلاقي لهذه القواعد والمبررات الأخلاقية لسلطتها على أنها أكثرُ

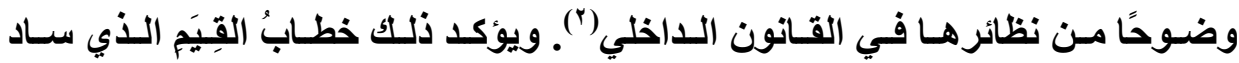
المناقشاتِ التي دارت حول القاضي الدولي ووظائفه("). وفي الواقع، يرى بعض القضاة اللدوليين والبـاحثين القيمَ الأخلاقيـة كنجم قطبيٍِ حقيقيٍ أو كنقطة استـلال للتسوية القضائية للمنازعات المعروضة عليهم(؛).

(1) LETSAS, op.cit.; PAULUS, op.cit., p. 117 et s.

(2) Samantha BESSON, "The Authority of International law- Lifting the State Veil", Sydney Law Review, no. 6, Vol. 34, 2012, p. 345.

(3) Armin Von BOGDANDY, Ingo VENZKE, "On The Functions of International Courts: An Appraisal in Light of Their Burgeoning Public Authority", ACIL, 2012, p. 88 et s.

(4) CIJ, 8 Juillet 1996, Licéité de la menace ou de l'emploi d'armes nucléaires, Opinion dissidente de Mme Higgins, note 37, p. 370, Para. 41. 
لا جَرَمَ، قد تتعارضُ نفس الردود في القانون الدولي كمـا هو الحسال في القـانون

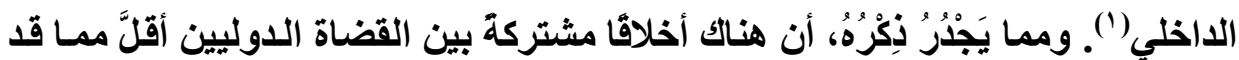
يعتقده المرع للوهلة الأولى. ويرجع ذلكك بصفةٍ خاصـةٍ إلى عدم وجود مجتمع دوليٍٍ يتقاسم قِيَمًا مشتركة ومحددةً بوضوح. ونتيجةَ لذلك، قد يكون تحديد وتنفيذ هذه القيم الأخلاقية العالمية غيرَ واضح للقضاة الدوليين أنفسهم.

تُوجــ على الأقـل صـعوبتان تتعلقــان بمكـان ودور الأخـلاق في عمـل القضاة

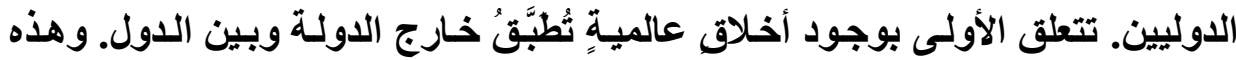
مسألة واسـعة تتجـاوز غايـة هذه الدراسـة. ويجب أن نؤكد، مـع ذلك، أنـه لا يكفي أن ندحض الحجج المؤيدة لنهج العلاقات الدولية التي تقوم على حالـة الفطرة، ولكن يجب

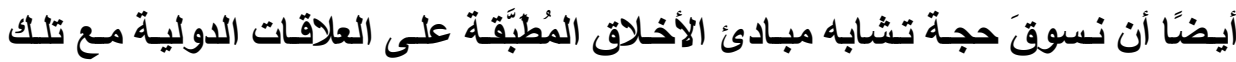

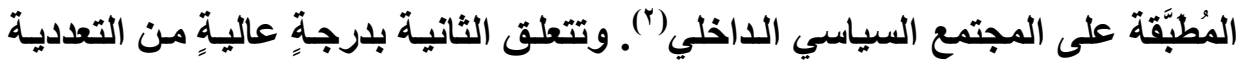
الأخلاقية العالميـة، حيث تؤديّي المنازعـات الأخلاقيـة إلى جعل التسلسل الهرمي للقيم

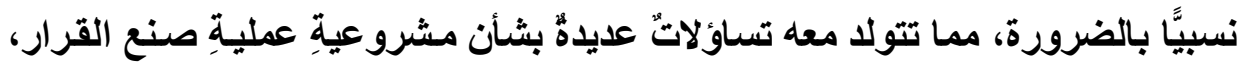
وبالتالي الأولويات القضائية التي تُعطى لواحدٍ أو لآخَرَ من هذه القيم. ويجب أن نحدد، مـع ذلك، بعض الدروس في المعرفة الاجتماعية والتنظيم المؤسسي والتي يمكن أن تساعدَ في تطوير مؤسساتٍ وإجراعاتٍ أكثر شورى ونقاثثًا بغية التعامل مـع هذا النوع من المنازعات، ووضع بعض القيود على السئلطة التقديريـة للقاضـي الدولي، ومن ثم تعزيز مشروعية قراراتـه. وقد تمَّ إنشاء مؤسساتٍ وطنيةٍٍ لتقدير السلطات القضائية الوطنيـة أو توافق الآراء من جانب المحكمة الأوروبيـة لحقوق الإنسان في تعليلاتها

(1) CIJ, Sud- Ouest africain, deuxième phase, arrêt, C.I.J. Recueil 1966, p. 47, Para. 49- 50.

(2) Voir, REGAN, op.cit., p. 23 et s. 
القضائية، وهي أمثلة على حدود السُّطة التقديرية للقاضي الدولي في سياق الرقابة القضائية الاولية على احترام حقوق الإنسان ('). r- الفلسفة الخاصة للعدالة الدولية:

إضافة إلى تقاسم نفس صعوبات العدالة الداخلية، ثثير العدالة الدولية أيضًا

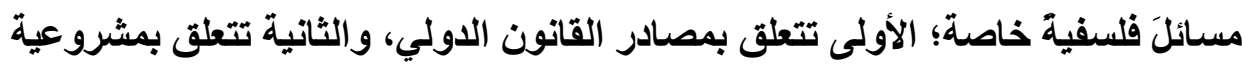

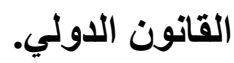

\section{أ - العدالة الدولية وهصادر القانون الدولي:}

يُشيريرُ مكان قانون القضاء بين مصادر القانون الدولي تساؤلاتٍ إضافية تتعلق

بذاتية النظام القانوني الدولي وطبيعة مصادره. ويُطلب من القضاة الدوليين القيامُ بأكثرَ

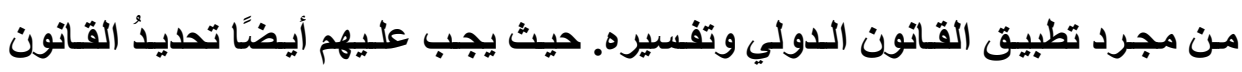

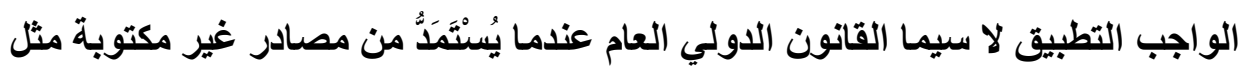
القانون الاولي العرفي أو المبادئ العامة.

ويتجاوز دورُ القضاة الدوليين في تحديد القانون الدولي دورَ القضاة الوطنيين

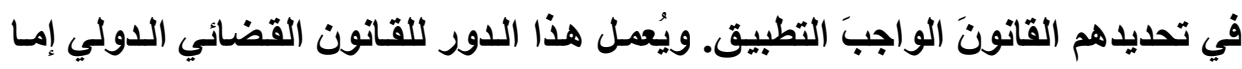
عند تحويل قاعدة القانون الدولي الوليدة إلى قاعدةٍ قائمةٍ بالفعل وذلكت من خلال مراقبة

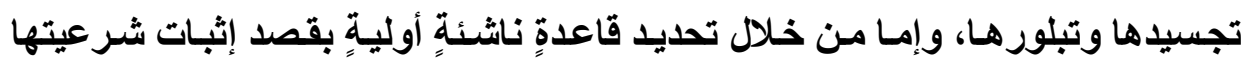
القضائية لاحقًا (†).

(1) Samantha BESSON, "The Erga Omnes Effect of the European Court of Human Rights Judgments", op. cit., p. 197 et s.

(2) Antonio CASSESE, Joseph WEILER, "Change and Stability in International Law- Making", Gruyter, 2010, p. 13. 
ويدون التصديق القضائي لا يكون للقواعد المستمدة من بعض مصادر القانون

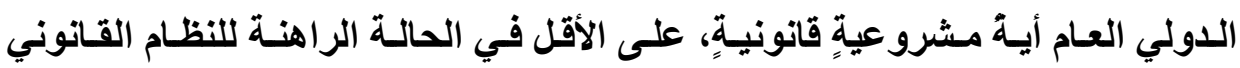
الدولي. ولا توجد، في الواقع، مؤسساتُّ عالميةٌ أخرى بخلاف المحاكم الدولية يمكن أن

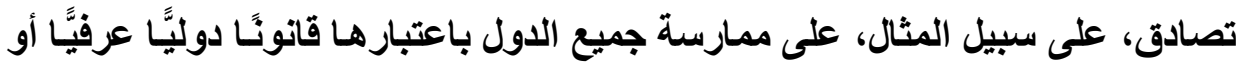
مبادئَ عامة معينة. وأحد الاحتمالات أن تتولى الجمعية العامة للأمم المتحدة ذلك، ولكن غياب القوة الملزمة لتوصياتها يُشَكِّلُ عقبة أسـاسية.

وتُثِثيرُ وظيفة تحديد قانون القضاة الدوليين مسائلَ فلسفية مُعَقَّهُ تتجاوز ضرورة التوفيق بـين قـانون القضاء ونظريـة المـصادر الواقعيـة أو الوضسعية وتحديـ قاعدة الاعتراف أو الإثبات في قانون القضاء الدولي. وتكمن المشكلة هنـا، في أن قـانون القضاء الدولي سوف يصبح مفيدًا للمصادر الأخرى للقانون الدولي العام أو أنه سَيُيَّةً كأداةٍ من جانب تلكك المصادر. وبالنظر إلى كون الدول أشخاصـًا للقواعد المستمدة من

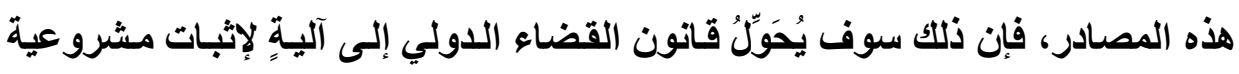
القانون، ومن ثم إلى مصدر مساعدٍ للقانون اللدولي، لا سيما القانون الدولي العرفي.

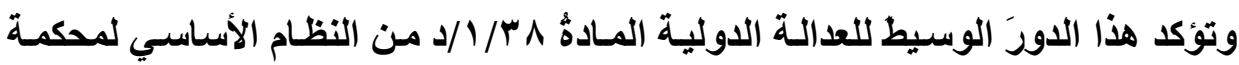

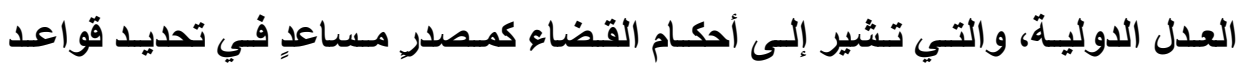

فالصعوبة القلسفية ذات شِقَيْن: فهي عمليـة ونظريـة في آن واحد. أولاًَ: يُمَتِلُ منح القضاة الدوليين وظيفة التصديق أو الإثبات إشكالية ليس فقط من وجهة نظر وظيفـة القضاء، ولكن أيضضًا مـن وجهـة نظر تنظيم النظـام القـانوني الدولي نفسه. فالقاضي الدولي يُنتخب عـادةً من جانب الدول، واختصاصه بالقضاء يكون ذاتيَّا أو

(1) Voir, BESSON, "General Principles", op.cit., p. 267.

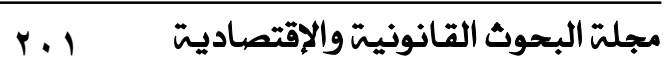


شخصيَّا؛ لأنـه يؤسس على رضـاء الدول('). والتفـاوت بين القضاء الذاتي والوظيفة الخلاَّقة للقانون الموضوعي المحدد سلقًا سـوف يصبح أكثرَ إزعاجِّا ومضايقة، حيث يبدو أن الطريقة التي يتمُ بها تنظيمُ وظيفة القاضي الدولي هي التي تمنعه من ممارسـة وظيفة التصديق على القواعد أو التحقق من صحتها؟(").

ثانيًا، سوف يصبح أمرًا صعبًا الحفـاظ على التمييز بين قانون القضاء بوصفه أحدَ أشكال القانون الدولي العرفي والقانون القضائي بوصفه مصدرًا مساعدًا للقانون الدولي العام. وبغضِّ النظر عمـا نفكر فيه من التشابه بين قانون القضاء والقـانون العرفي وتقاربهما، تُشَكِّلُ وظيفة تصديق القاضي الدولي عقبة كؤودًا أمام تطبيق نظرية

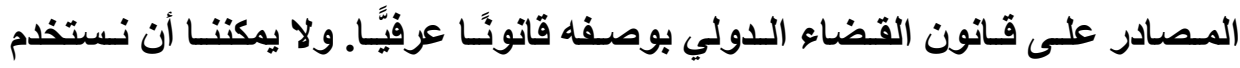
المصادر المعاونة للقانون الاولي والواردة بالمادة (^^) من النظام الأساسي لمحكمة العدل الدولية لتبرير مشروعية أو صلاحية قانون القضاء الدولي نفسه. ومن هنا، فإنـه يتعين أن نحدد قاعدة الاعتراف المتضمنة في النظام القـانوني الدولي. وتزداد المشكلة تفاقمًا، في الواقع، من خلال عمل المحاكم الدولية، وقد أسـهمت محكمة العدل الدولية، على وجـه الخصوص، في تطوير نظريـة مصـادر القـانون الدولي وقاعدة الاعتراف نفسها، موضحة، هكذا، عملَ أو وظيفة مصادر القانون الدولي. فعلى سبيل المثال،

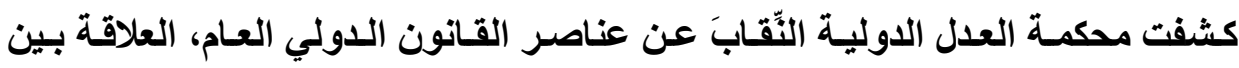
القـانون الـدولي العرفي وقـانون المعاهدات، ودور القـانون النـاعم (غير الملزم) في القـانون الـدولي، دور لجنـة القـانون الـدولي في تقنين قواعد القـانون الـدولي العـام،

(1) Voir, BOYLE et CHINKIN, Ibid., p 290 et s.

(2) CASSESE, WEILER, "Change and stability in International LawMaking", op.cit., p. 17 et s. 
وشروط تعيين وتحليد القواعد الدولية الآمرة(') كل هذا يؤكد دور القاضي الدولي في

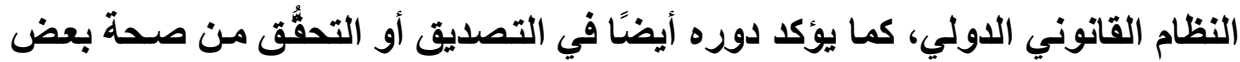

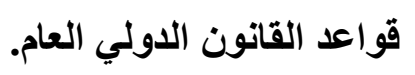
ب- العدالة الدولية ومشروعية القانون الدولي: يُيْيرُ دورُ قـانون القضاء الدولي في تبريـر سلطة أو سلطان القـانون اللدولي تساؤلاتٍ تتعلق بالمشروعية التي تختلف عن تلكت التي قد تكون معروفة في القانون

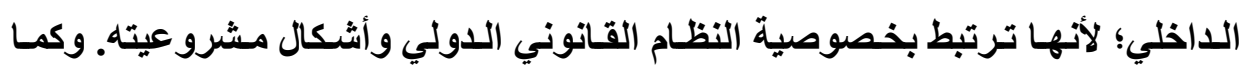
رأينا، يُدعى القاضي الدولي إلى تحديد وتفسير القانون الدولي، ومن ثم التحقق من

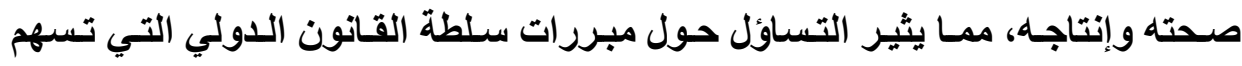
تحديدًا في التحقق من صِحََّّها وإنتاجها. يضاف إلى ذلكَ، أنها يُطلب من القضاة الدوليين

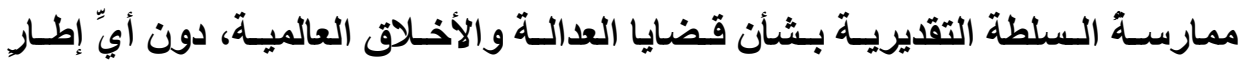
مؤسسيّ يؤخذ في الاعتبار عند إصدار قراراتهر.

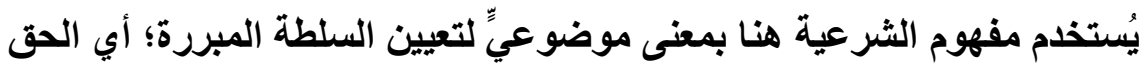
في خلق التزامات، وبشكلٍ أدقَّ: الحق في فرض واجباتٍ أخلاقيةٍة للعمل بطبيعةٍ حصرية. وهذا هو السبب في أنتا نستخدم أحياًًا المشروعية والتبرير بالتبادل. ويمكن أن تشير التير

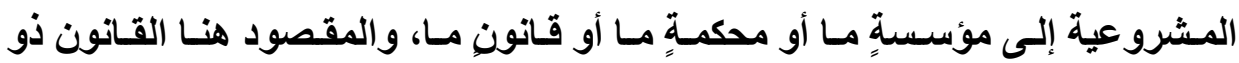
الطبيعة القضائية. ويرتبط الاستخدامان عادةً بالقدر الذي تعتمد فيه شرعية القانون

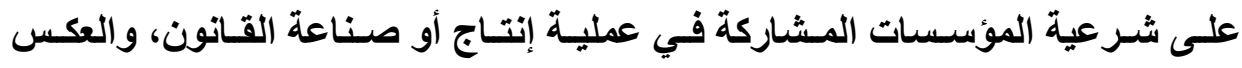

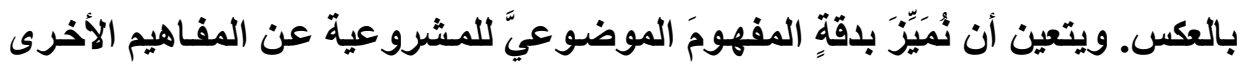

(1) Voir, BESSON, "General Principles", op.cit., p. 270 et s.

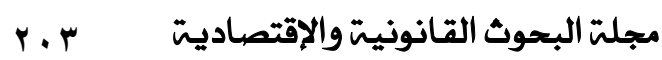


التي كثيرًا ما شُتخدم، لا سيما المشروعية الذاتية. وبطيعة الحسال، تسير المشروعية

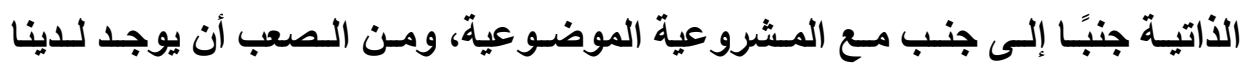

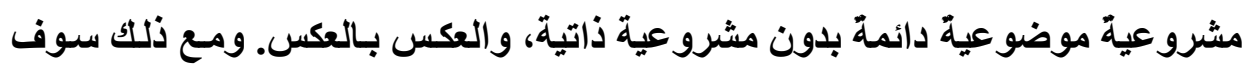
نركز هنا على المشروعية الموضوعية')

ثُعَدُ مسألة مشروعية القانون الدولي، ومن ثم المؤسسات الدولية مثل المحاكم

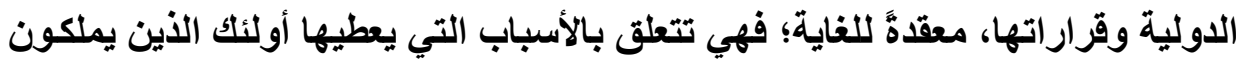
السلطة لأولئك الذين يخضعون للقانون الدولي، وفي معظم الأحوال، من دول إلى دول

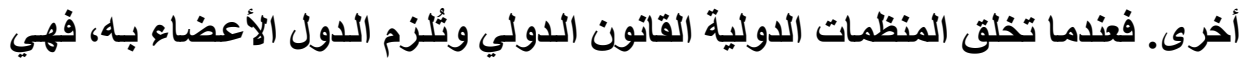
تباشر دورَوسيطِ السلطة، وهذا يسمح لنا أن نميز بوضوح بين الدول بوضعها ممثلة في المنظمة الدولية وبين الدول بوصفها خاضعة لقانون المنظمة الاولية. وعندما نهتم بالمبررات المختلفة لسلطة قانون القضاء الدولي، فمن الأهمية

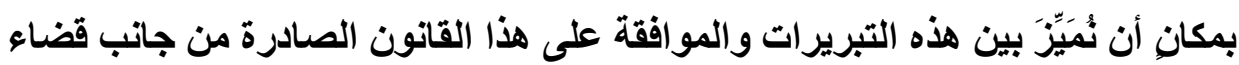

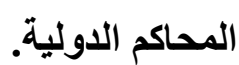

ويعزز هذا الرضاء، بالتاكيد، السلطة الثرعية للقانون الدولي من خلال تسليط

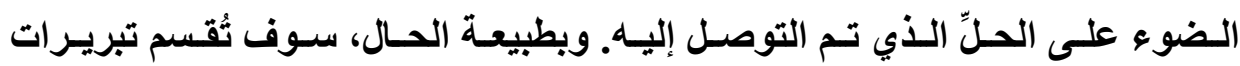
مشروعية قانون القضاء الدولي على خلفية تبريرات القانون الاولي في مجمله.

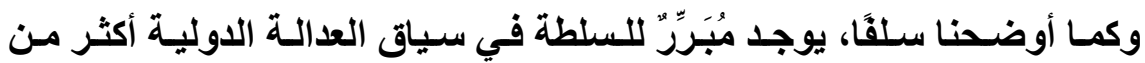

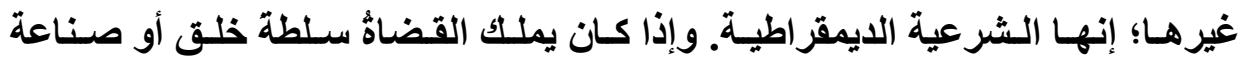

(1) John TASIOULAS, "The Legitimacy of International Law", in, Samantha BESSON, John TASIOULAS, "The philosphie of international law", Oxford University Press, 2011, p. 206. 
القانون، فيجب أن يُسألوا عن تصرفاتهم أمام هيئةٍ تثريعِةٍ منتخبةٍ ديمقراطيًا. ويتعين

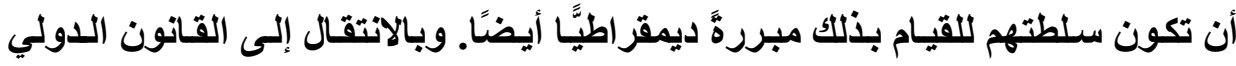

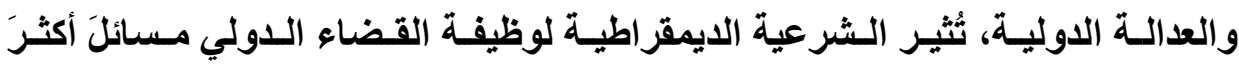

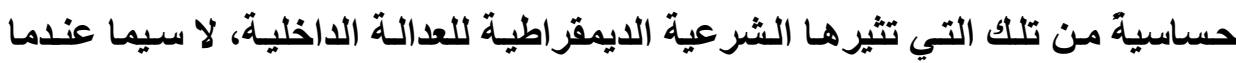
تتعارض مع تبريرات القـانون القضائي الدولي من خلال الرجوع إلى القيم الأخلاقية

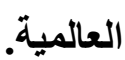
ويُعَدُ عدم النضج المؤسسي والديمقراطي للقانون الدولي والعدالة الدولية أحد التبريرات التي سيقت لتفسير وتبرير تحفظظ الدول تجاه قانون القضاء الدولي، لا سيما تجاه السلطة التقديريـة للقضاة الدوليين بخصوص القضايا الأخلاقية المثيرة للجدل.

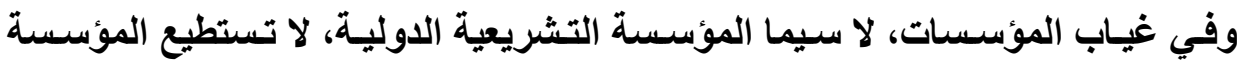
القضائية أن تؤديَ وظيفتها التفسيرية أو إنتاجَها المعيساري. والحالـة هذهاه، لا يمكن

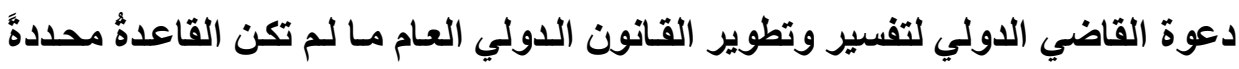

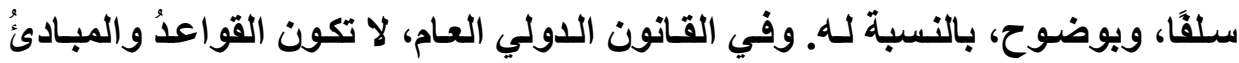
القانونية محدةً بوضوح للمحاكم الدولية، ولكن يتعين على هذه الأخيرة أن تستخلصها

بذاتها.

ومن الأهمية بمكان، استكشاف طرق مختلفةٍ بغرض تطوير النظام المؤسسي الدولي خارج المحاكم الدولية. على سبيل المثال، يمكن تعزيزُ الطابع المؤسسي لصور

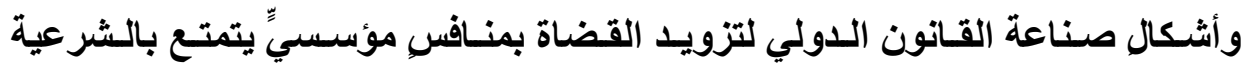

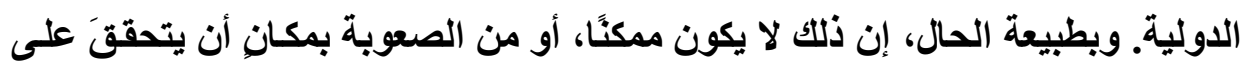

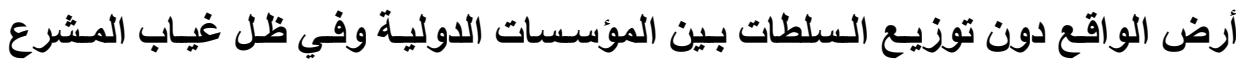
الدولي الممثل للجماعة الدولية. 


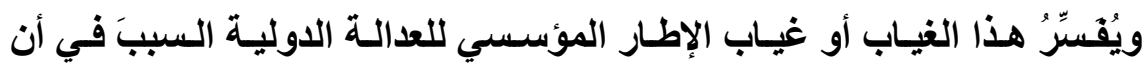

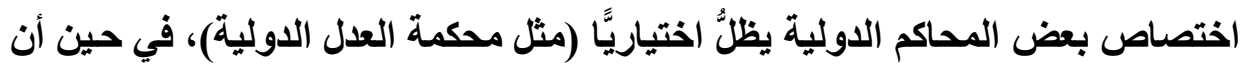

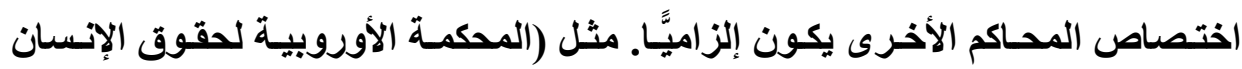
ومحكمة عدل الآتّاد الأوروبي)(')

(1) Armin Von BOGDANDY, Ingo-VENZKE, "In Whose Name? An Investigation of International Courts Public Authority and its Democratic Justification", European Journal of International Law, no 1, Vol. 23, 2012, p. 7. 


\section{الفصل الأول \\ القاضي في القانون الدولي}

\section{المبحث الأول \\ المكم القضائي متعدد المدتويات في القانون}

الاقتصادي الأوروبي والدولي

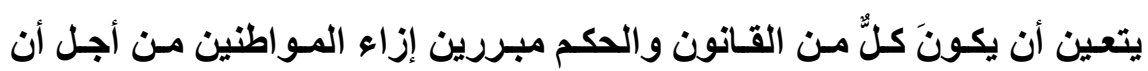

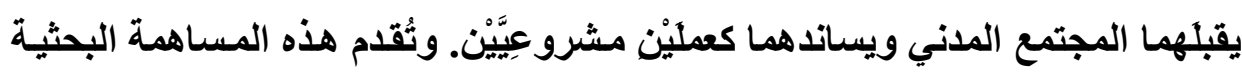

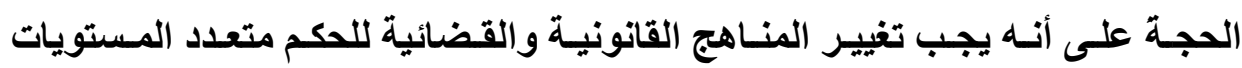
الخاص بالمصالح العامة الدولية من أجل حماية الاحتياجات الأساسية وحقوق الإنسان

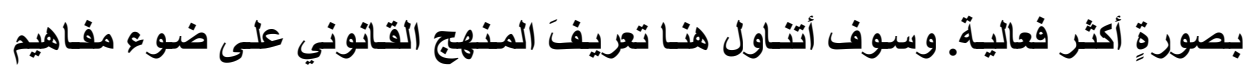

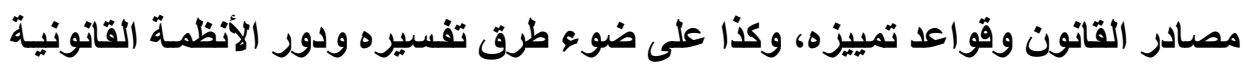

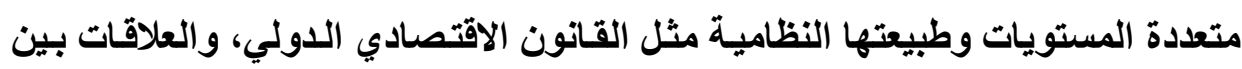

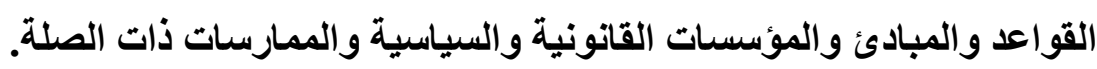

ويتناول الجزء الأول التطور التاريخي من الحكم الرشيد أو الصحيح إلى القضاء

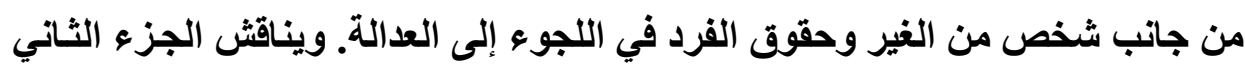

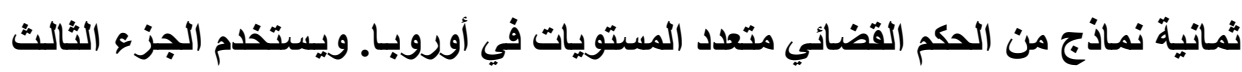

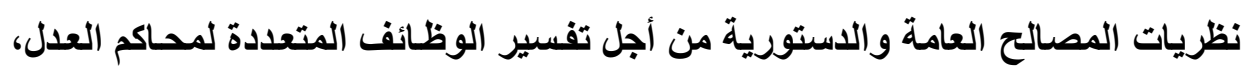


وعرض الأهيـة المتزايدة للتعـاون القضائي من أجل حمايـة القاعدة عبر الوطنيـة للقانون أو الحكم القضائي عبر الوطني في القانون الاقتصادي الأوروبي و الدولي. ويُقدِّمُ الجزء الرابع الحجة على أن المناهج الاستورية المتنوعة التي تطبقها كلّ" من محكمة عدل الاتّحاد الأوروبي ومحكمة منطقة التجارة الحرة الأوروبيـة والمحكمة التحة

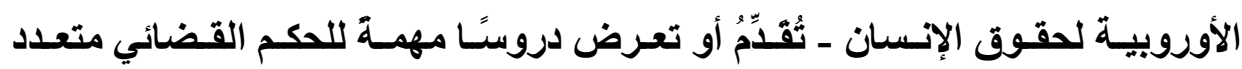
المستويات في القانون الاقتصادي الدولي خارج أوروبا. وفي الجزء الخامس يتم التأكيد على الدور القضائي في إدارة العدالة في القانون الاقتصادي الدولي، والحاجة إلى تحجيم الانقسام الفقهي و القانوني الحالي من خلال

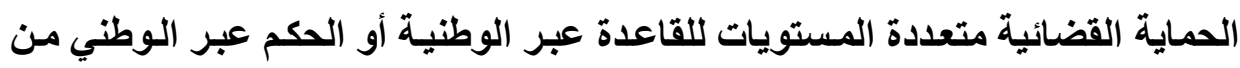

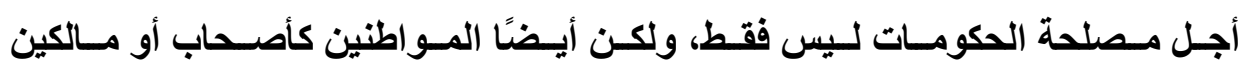
ديمقراطيين للقانون الاقتصادي الدولي. ا- هن المكم الرشيد إلى المكم القضائي:

لقد أدركت معظم الحضارات، منذ العصور القديمة، مدى الحاجة إلى الأخلاق

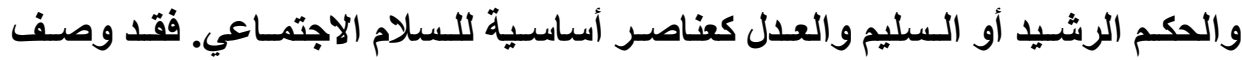
أفلاطون وأرسطو وشيشرون، على سبيل المثال، الفضائل الأساسية الأربع: الاعتدال، الاعيا،

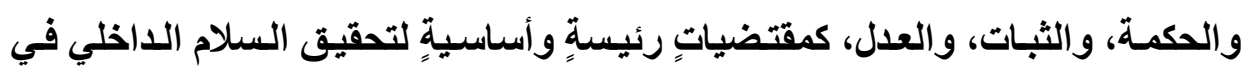

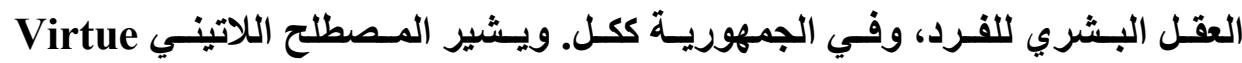
(الفضيلة) إلى قوة وسلطة الإنسان في أن يتحكمَ في مشاعره ورغباته، وأن يستخدمَ

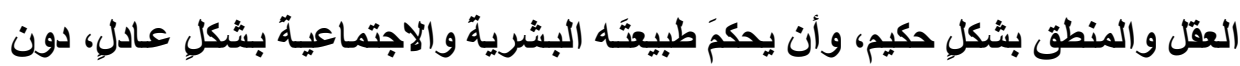

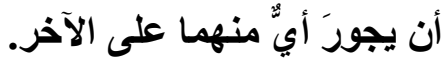


ويستخذم المسططلح اللاتينسي "Cardinal" صـورة المفـصلات أو العوامسل الحاسمة التي يتأرجح أعلاها باب الحياة الأخلاقية. وتبين لنا التراجيديا الإغريقية مثل

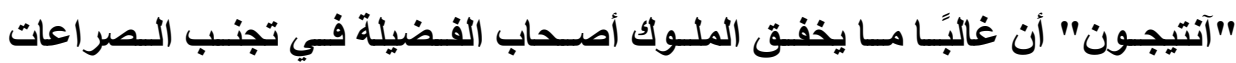

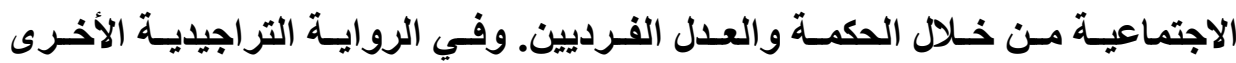
"أوريست" لم تتوقف دائرة الثأر الثخصي وحمامات الام المأسـاوية إلا بتدخل الآلهة

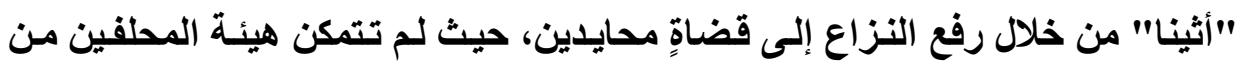

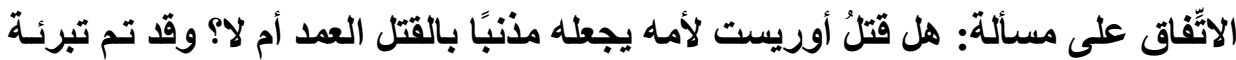

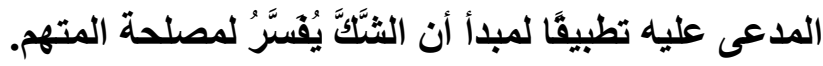
ويؤكد الإقرار العـالمي لمزيدٍٍ من مواثيق وآليات الحقوق الدستورية وحقوق الإنسان، إضافة إلى المزيد من مجالات القانون الاقتصادي الدولي وحقوق الفرد في اللجوء إلى العدالة، على الحكمة القديمة التي مفادها ضرورة وضع الضادئ الضمير الإنساني

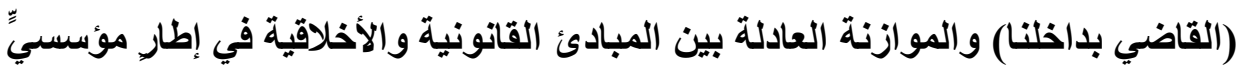
منظم حتى يتسنى لنـا تسوية الصراعات الحتمية بين الرغبات الإنسانية في التحكم و السيطرة وبين النزاعات الأخرى التي تنثأ بين المستبِّيّن محدودي المنطق. ومـا زال يصوغ القضاء الوطني والدولي (محسكم العدل)، بنـاءً على مقارنـات أرسطو وتفرقته بين عدالة التوزيع و عدالة التبادل والعدالة التصحيحية والمساواة،

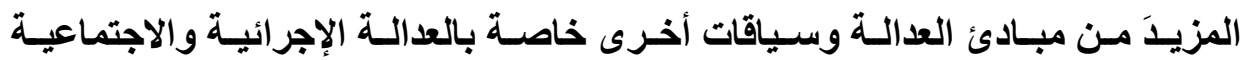

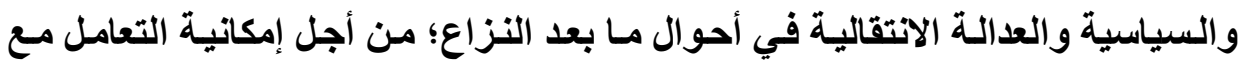

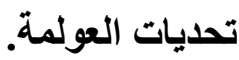

وتتطلب القواعد القانونية العرفية الخاصة بتفسير المعاهدات والتي تم تقنينها

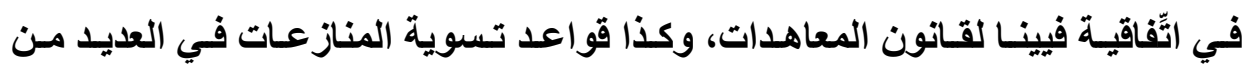


المنظمـات، تفسير المعاهدات وتسوية المنازعات ذات الصِّةً؛؛ ليس فقط استنادًا إلى

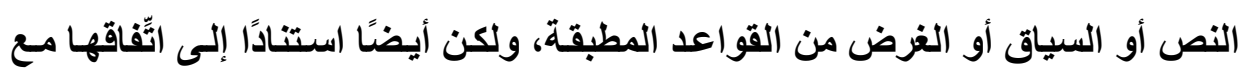

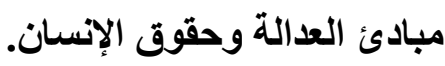

وتأخذ محكمة العدل الدولية والعديد من المحسكم الدولية الأخرى مـا يأتي كأمر

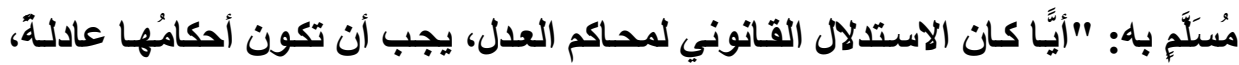

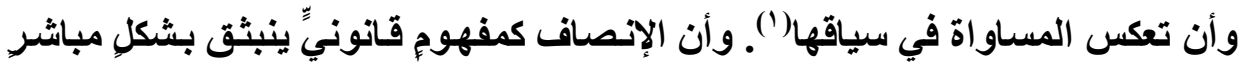
عن فكرة العدالة. ويتعين على المحاكم، والتي تكون بطبيعتها مسئولة عن إدارة مرفق الأقي

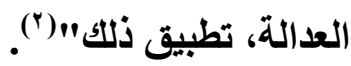

وحيث إن الحاجة للعمل من أجل الحصول على الموارد الضرورية لبقاء الإنسان

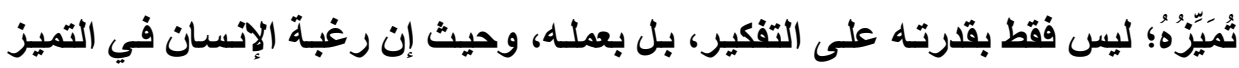

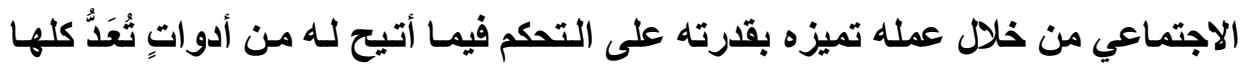

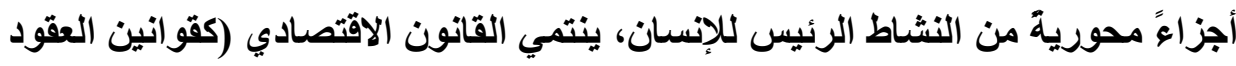

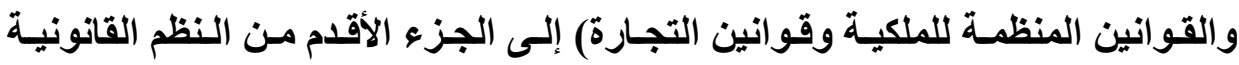

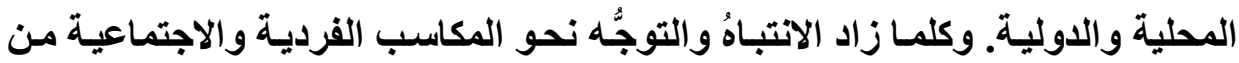
مجالات التجارة الدولية ومن قطاع العمل الدولي؛ زادت محساولات التجار والمنتجين و المستثمرين والمستهلكين والحكومات نحو تقليل تكاليف المعاملات المالية الدولية من

(1) ICJ, 20 February 1969, North Sea Continental Shelf, Judgment, I.C.J. Reports 1969, -. 48- 49, Para. 88.

(2) ICJ, 24 February 1982, Continental Shelf (Tunisia v. Libyan Arab Jamahiriya), Judgment, I.C.J. Reports 1982, p. 60, Para. 71.

r مجلت البحوث القانونيت والإقتصاديت 
خلال التظيم القانوني متعدد المستويات للتعاون الاقتصادي الدولي والمنازعات ذات

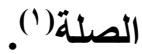

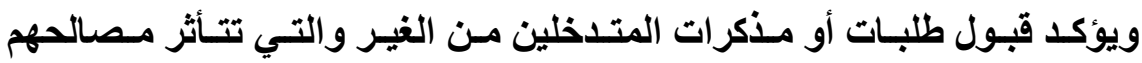
بالمنازعات الاقتصادية على التوازن القضائي بين الالتزامات القانونية الخاصـة بـخول

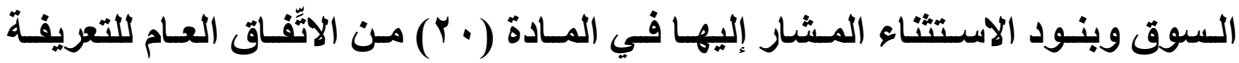
الجمركية والتجـارة (والتـي تتعلق بحمايـة القيم غير الاقتصادية والتفسير القضائي للنصوص الاقتصادية في ضوء أحكام المعاهدات الدولية الأخرى التي تحمي المصالح العامة)، مما يعكس دور القضاء في تسوية المنازعات بما يتفق ومبادئ العدالة. وكلما زاد التفاعل بين القوانين الاقتصادية الاخلية والدولية العامـة والخاصـة؛ أصبحت الحاجة مُلِحَّة للتعاون بين جهات تسوية المنازعات متعددة المستويات (التكامل القضائي) مـن أجـل حمايـة القواعد القانونيـة عبـر الوطنيـة وفقَـا لمتطلبـات التفسير المتناغم الخاصة بالأنظمة القانونية الوطنية والدولية(؟).

\section{r- النهاذج التنافسية للمكم القضائي متعدد المستويات في أوروبا:}

تُقَّرُ النظريات الدستورية الحديثة للعدالة سببَ الالتزام الدولي بحماية حقوق

الإنسـان وحرياتـهـ الأسـاسية وضـرورة صـياغة الاسـتـلال أو السبب العـام في إطـار

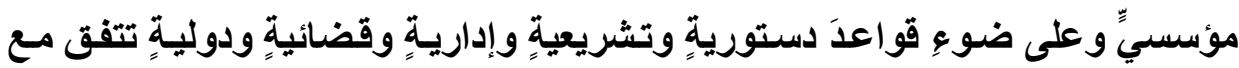

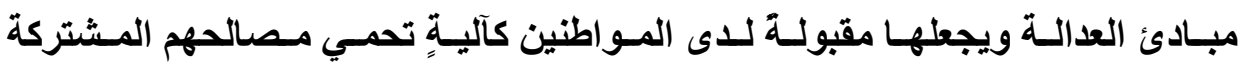
والمعقولة.

(1) H. ARENDT, "The Human Condition", Chicago, University of Chicago Press, 1998, p. 101 et s.

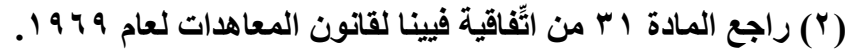

مجلت البحوث القانونيت والإقتصاديت 11 
وكلمـا زاد تحويل العولمـة للمصالح والمنـافع العامـة الكلية من مصالحَ ومنـافعَ

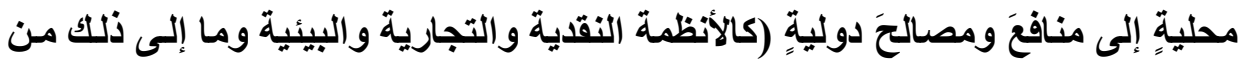

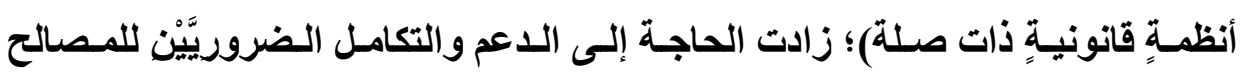

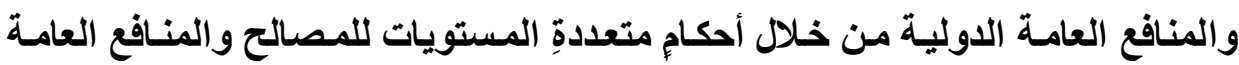

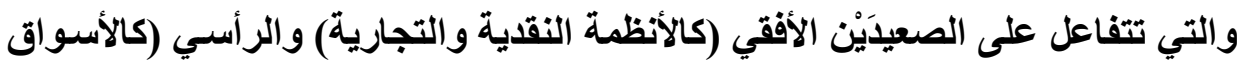

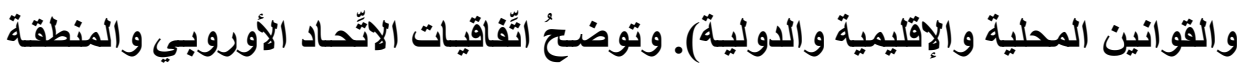

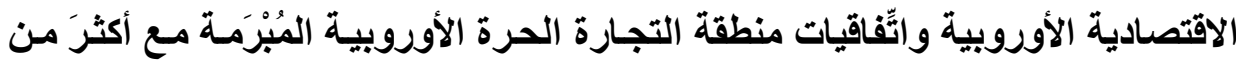

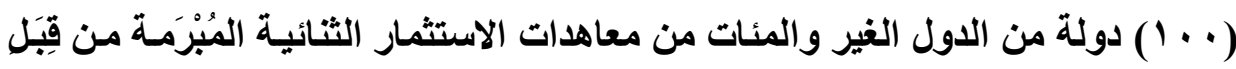

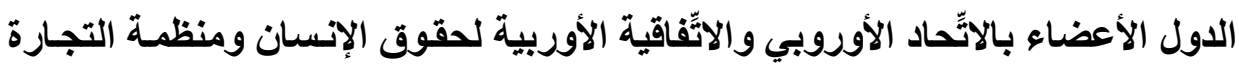

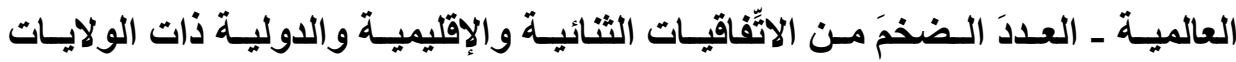

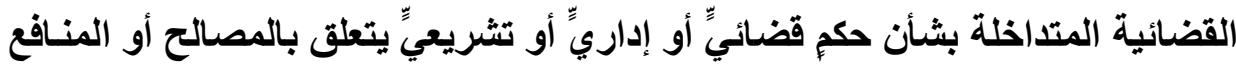

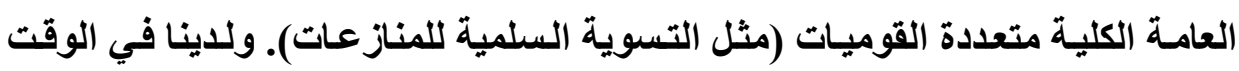

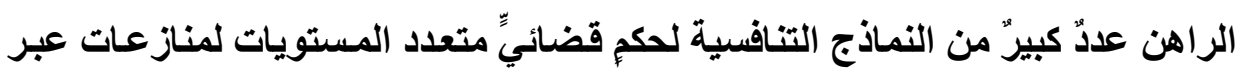

$$
\text { وطنية في أوروبا") }
$$

وتستمر محكمة العدل الدولية كجهاز قضائيّ رئيس للأمم المتحدة في تسوية

المنازعات الدولية المهمة بين الدول الأوروبية، وذلك كما هو واضحِ في حكمها الصادر

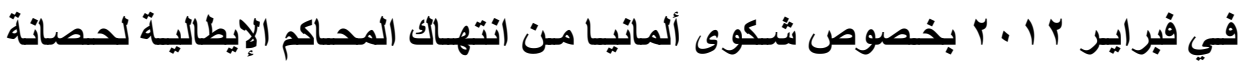

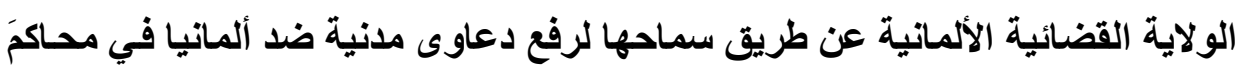
إيطاليةٍة بخصوص جرائم حرب ارتكبت خلال الحرب العالميـة الثانيـة واتِّنـاذ إيطاليـا

(1) E.U. PETERSMANN, "International Economic Law in the $21^{\text {st }}$ Century. Constitutional pluralism and Multilevel Governance of Interdependent public Goods", Oxford, Hart, 2016, Chapters II, III, VI. 
لإجراءاتٍ تقييديةٍ تجاه ممتلكاتٍ ألمانية في إيطاليا تستخدها الأولى لأغراض السياسة

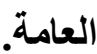

وتستمرُ أيضًا المحكمة الدولية لقانون البحار، وكذا مجالس تسوية المنازعات

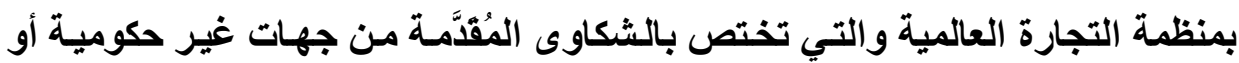

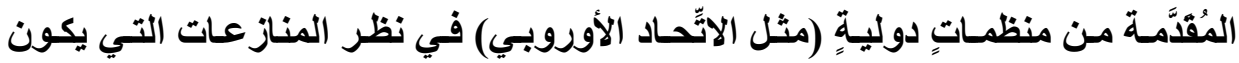

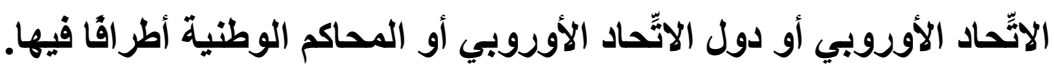
وللمحكمة الجنائية الدولية المؤقتة ليوغسلافيا السابقة، وكذا المحكمة الجنائية الاولية والمحاكم الوطنية، ولاية قضائية متزامنة ومتكاملة على الأفراد بشأن الجرائم المشار إليها في أنظمتها الأساسية. فيمكن للمحكمة الجنائية الدولية، على سبيل المثال،

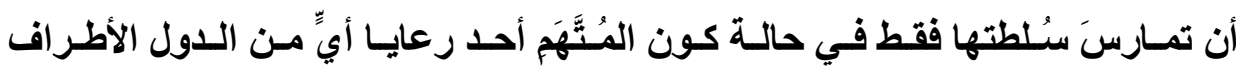
بالآثّاقية ووقَقَت الجريمة المزعومة في نطاق هذه الدولة، وكانت المحاكم الوطنية غيرَ

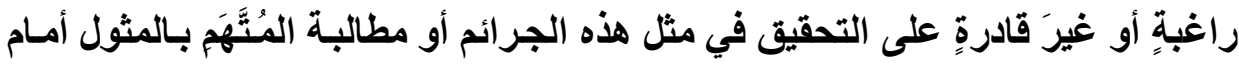

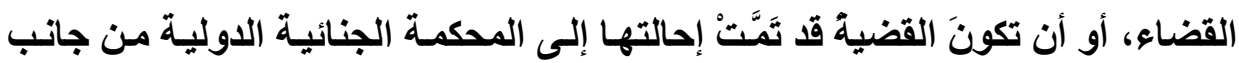

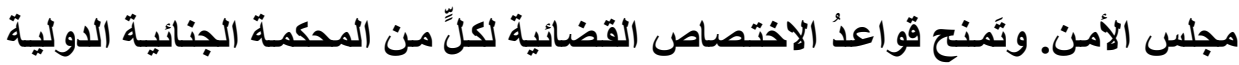
و المحكمة الجنائية الدولية ليوغسلافيا السابقة سُلطة تأجيل القضايا المنظورة أمسام المحاكم الوطنية لصالح المحاكم الدولية، والتي يجوز لها أن تحكمَ فيما بعد (بعد توجيه

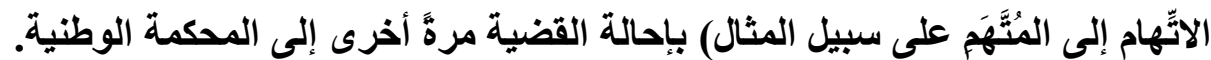

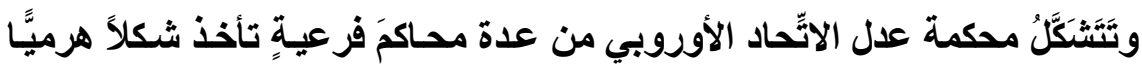

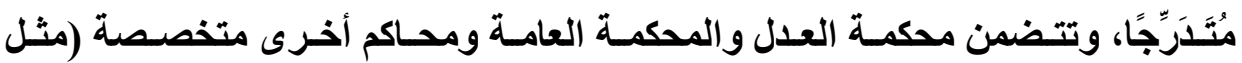

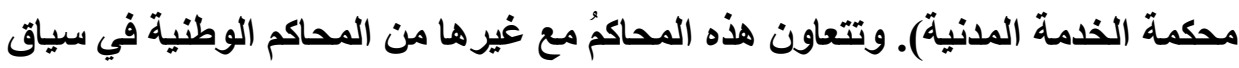


إجراعات إصـدار الأحكـام الابتدائيـة(')، حتى يتسنى التأكُدَ مـن أنَّ القـانون كـان نـصب

$$
\text { الأعين حال تفسير وتطبيق المعاهدات الأوروبية(؟). }
$$

ويتم تنفيذ قانون الاتِّحاد الأوروبي عبرَ مزيج من الآليـات القانونيـة والقضائية على المستويات الوطنية، وعلى مستوى الاتِّاد الأوروبي بنـاءً على التعاون القانوني والقضائي متعدد المستويات.

ويشير قانون الاتِّــاد الأوروبـي إلسى الإجراعات، وكذا إلى الدعاوى المباشـرة وغير المباشرة، التي قد ترفعها مؤسسات الاتِّحاد الأوروبـي وأعضاء أجهزة الاتِّـاد الأوروبـي والأفراد الطبيعيون والاعتبـاريون والدول الأعضاء والمحساكم الوطنيـة أمسام محكمـة عدل الاتِّــاد الأوروبـي، إضـافة إلـى الأسـانيد القانونيـة التـي قد تُستخدم أمسام المحاكم الوطنية (المادة rVV من معاهدة الاتِّحاد الأوروبي: الدفع بعدم المشروعية، واجبات التفسير المتناغم، طلب الأحكام الابتدائية من محكمة العدل الأوروبية) وأمسام محكمة عدل الاتِّحاد الأوروبي (مثل أولوية قانون الاتِّـاد الأوروبي في التطبيق وأثره

$$
\text { (المباشر). }
$$

وفي حالة غياب قواعدَ محدةٍٍ من قواعد الاتِّــاد الأوروبي، يكون حينها للنظام

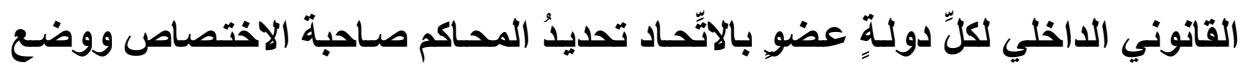
القواعد التنفيذية التي تحكم الدعاوى والإجراءات اللازمة لحماية الحقوق التي يستمدها الأفراد من قـانون الاتِّحـاد الأوروبـي، شريطة ألا تقلَّ هذه القواعدُ في أفضليتها عن القواعد التي تحكُمُ الإجراءراتِ المحليـة المشـابهة (مبدأ التكـافؤ)، وألا تجعلَ ممارسـة 
الحقـوق التــي يكفلهـا قـانون الآتّــاد الأوروبـي مستحيلة أو بالغــة الـصعوبة (مبـدأ

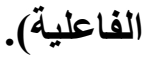

ويُذكر، أنه قد تم تأسيس محكمة منطقة أو رابطة التجارة الحرة الأوروبيـة في

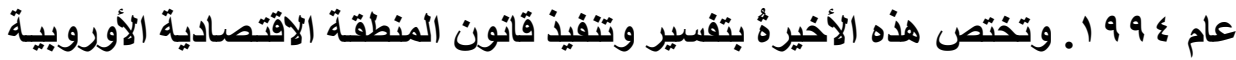
في دول منطقة أو رابطة التجارة الحرة الأوروبية الثلاث: آيسلتدا، وإمارة ليختنشتاين، و النرويج. ويستند النظام الأساسي لهذه الححكمة، وكذا قو اعدها الإجرائية، إلى مثيلاتها

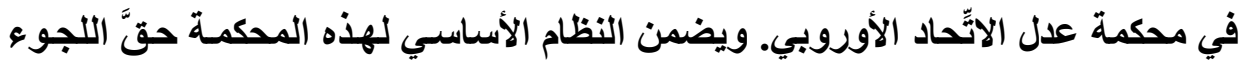

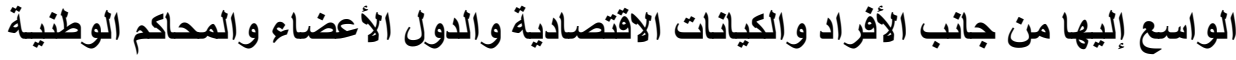

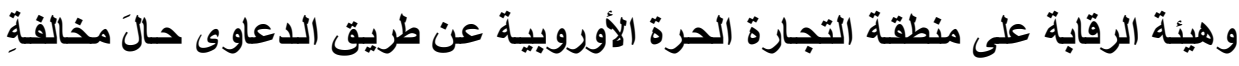
تنفيذ التزاماتٍ منصوص عليها، أو أيّ منازعات قد تثور بين دول منطقة التجارة الحرة الأوروبية وتتعلق بتفسير أو تطبيق قانون المنطقة الاقتصادية الأوروبية أو الدعاوى الخاصة بإبطال قرارات، أو عدم التصرف.

وللمحكمة حقُّ إصدار آراعِ استشاريةٍٍ بشأن تفسير اثَّفقيَة المنطقة الاقتصادية الأوروبية،، ويكون ذلك بناءً على طلب محكمةِ وطنيةٍ لإحدى دول المنطقة الاقتصادية الأوروبية أو منطقة التجارة الحرة الأوروبية. بالرغم من ذلك، فطبقًا للنظام الأساسي لمحكمة منطقة التجارة الحرة الأوروبية، لا يتضمن قانون المنطقة الاقتصادية الأوروبية مبادئَ أولوية التطبيق القانوني والأثر

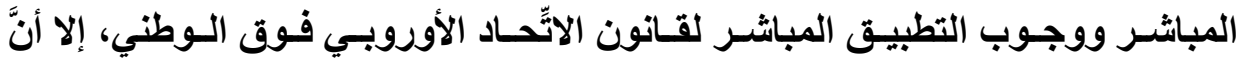

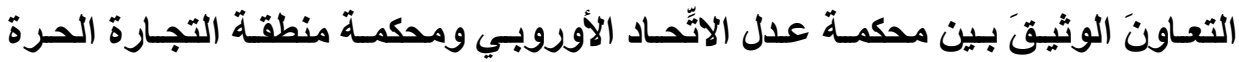
الأوروبية قد حافظ حتى الآن على فرص متكافئةٍ للأفر اد و الكيانات الاقتصادية من خلال

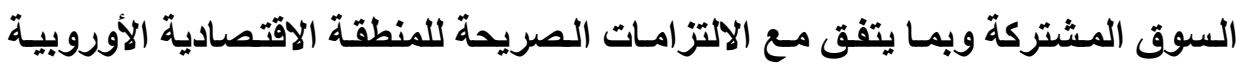


بُعْيَة الحفـاظ على التجـانس القـانوني في تطبيـق قواعد السوق المسشتركة للمنطقة الاقتصادية الأوروبية.

وتتعاون المحكمة الأوروبية لحقوق الإنسان مع المحاكم الوطنية في كافة الدول الأعضاء بالاثّفاقيـة الأوروبيـة لحقـوق الإنسـان في تفسير وحمايـة حقـوق الإنسـان وحرياته الأسناسية.

ونظرًا لتلقِي المحكمة المذكورة لأكثرَ من . . . . . ه ب شكوى منذ عـام 1909

إلى الآن، وصدور أكثر من . 10 حكم موضوعي سنويًًا، ففي عـام 991 19 تمَّ تحويل اختصاصها القضائي من اختياريٍ إلى إلزاميٍّ، الأمر الذي أدَّى إلى توفير حمايةٍ قضائيةٍ أكثرَ فعالية للحقوق المنصوص عليها في الاتِّفاقية الأوروبية لحقوق الإنسان. وكما هو الحال في محكمة عدل الاتِّحاد الأوروبي ومحكمة منطقة التجـارة الحرة الأوروبيـة، درجت المحكمة الأوروبيـة لحقوق الإنسان على استخدام طرق ديناميكيـةٍ ومتطورةٍ في تفسير وحماية الحقوق الأساسية للإنسان. وقد سـاعدت الأعدادُ الضخمة للثكاوى الفردية المحاكمَ الثلاثَ سالفة الذكر في تفسير وتطوير آليات المعاهدات ذات الصِّة كإحدى صور الآليات الاستورية الحية التي توفر حماية فعالة للحقوق الأساسية للمواطنين.

وعلى عكس الوضـع بمحكمة عدل الاتِّــاد الأوروبـي ومحكمـة منطقة التجـارة الحرة الأوروبيـة، يتطلب لجـوء الفرد للمكمـة الأوروبيـة لحقوق الإنسان استنفاده المسبق لطرق الطعن المحلية. ونُشَدَّدُ المحكمة ذاتها على أهمية مبدأ التبعية في تفسير الإس

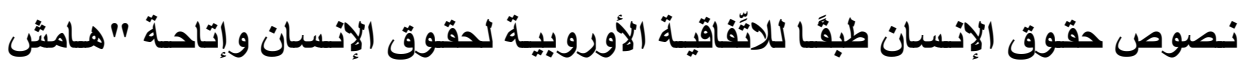
تقدير" للسلطات المحلية في هذا الخصوص. 


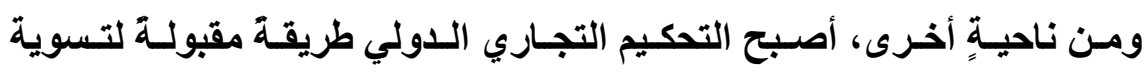
المنازعات التجاريـة الدولية في أوروبـا. وقد أسـهم تحديث التشريع المحلي المنظم

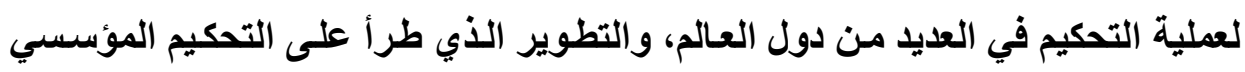
(والذي يخضع لإثراف غرفة التجارة الدوليـة، ومحاكم التحكيم بلندن واستكهولم،

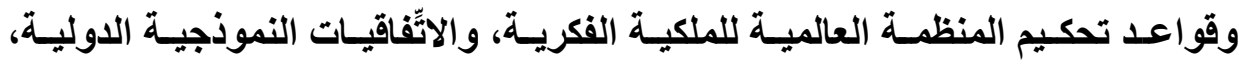
ونموذج شروط التحكيم، مثل قواعد اليونسترال للتحكيم)، وانضمام عدد كبير من الدول لمثل هذه الآثّاقيات الدولية ـ في تبنّي هيئات التحكيم التجاري الآلاف من أحكام التحكيم

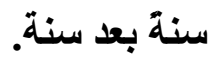

وغالبًا ما تتضمن هذه الهيئات أربعة نظظم قانونيةٍٍ مختلفة: (1) القانون المنظم لإقرار وتنفيذ اتَّاق التحكير. (r) ( القانون المنظم لإجراءات التدكيم. (T) القو اعد المُطبَّقة على النزاع من جانب هيئة التحكير. (؛) القانون المنظم لإقرار وتنفيذ حكم هيئة التحكيم. وغالبًا مـا تختلف المحاكم فيما إذا كـان يجب اعتبار التحكيم الدولي جزءًا من

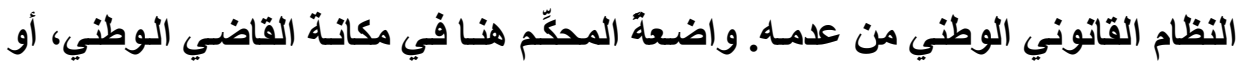

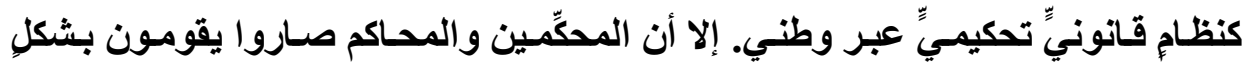
متزايدٍ بتفسير سلطتهم في القضاء وفي القواعد و الإجراءات واجبة التطبيق، مع كامل

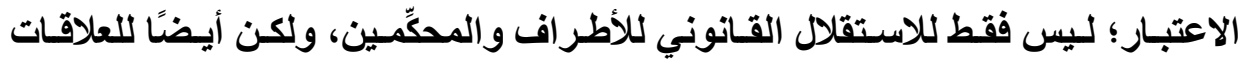

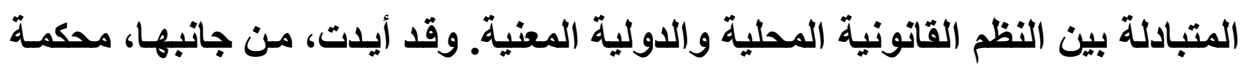

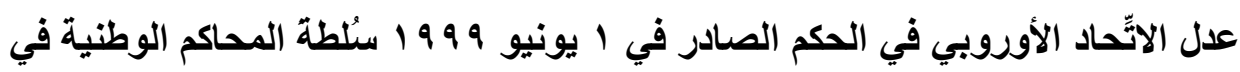


د/عبد الله محمد الهوارى

العدد •r (ديسمبر r.19)

إلغاء أحكام التحكيم التي لم تلتزم بـالمحظورات التي ينصٌٌ عليها القـانون الأوروبي

والتي تُشَكِّلُ جزعًا من القواعد الوطنية للسياسة العامةُ (').

وتستمر المحكمة الدائمة للتحكيم كآليةٍ اختياريةٍ لتسوية المنازعات في دورها في

تسوية المنازعات التي تثور بين الدول بمـا في ذلك دول الاتِّحـاد الأوروبي. كمـا أنها

تساعد في التحكيم بين الدول والمستثمرين وقضايا التحكيم الاولية الأخرى().

r- الحماية القضائية هتعددة المستويات للقانون عبر الوطني في القانون الاقتصادي

الدولي: - n

رغم أن معاهدة لشبونة للاتِّحـاد الأوروبـي قد تَمَّتْْ صياغتُها وتفعيلُها بشكلِ

واضح وصريح على سيادة القانون واحترام أحكام القانون الدولي، تستمرٌّ محكمة عدل

الاتِّحاد الأوروبي في التعاون مع عددٍ قليلٍ فقط من المحاكم الدولية الأخرى مثل محكمـة

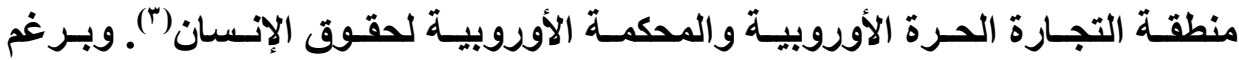

الإحـالات القليلـة لمحكمـة العـلـل الدوليـة ومنظمـة التجـارة العالميـة مـن أجلـ تبريـر

التفسيرات القضائية، ترفض محكمة عدل الاتِّحـاد الأوروبي تطبيقَ القواعد الخاصـة

بتسوية المنازعـات والتـي تـم إقرارهـا وتطبيقهـا مـن جانب منظمـة التجـارة العالميـة

والمحكمة الدولية لقانون البحار ضد الاتِّاد الأوروبي والدول الأعضاء(؛).

(1) ECJ, 1 June 1999, Eco Swiss China Time Ltd v. Benetton, C-126/97, Rec. 1999, p. 1-03055.

(2) A. REINISCH, "The Decisions on Jurisdiction in the Eastern Sugar and Eureko Investment Arbitrations", in Legal Issues of European Integration, Vol. 45, 2017, p. 175- 193.

(3) E.U. PETERSMANN, op.cit., chapter v.

(4) E.U. PETERSMANN, "Can the EU's Disregard for Strict observance of International Law", (Article 3 TEU) be Constitutionally Justified?", in $=$ 
ويتطلب أثرُ التظظيم الاقتصادي متعدد المستويات بشأن المشكلات الاقتصادية إخضاع متز ايد للمناز عات الاقتصادية لمحسكمَ قضائيةٍ دوليـةٍ متخصصةٍ مثل المحسكم الاقتصادية الإقليمية وإجراعات تسوية المنازعات بمنظمة التجارة العالمية. وفي أنظمـة المعاهـات الاقتصـادية ذات الولايـة القضائية الإلزاميـة مثل منظمـة التجـارة العالميـة واتِّاقية التجارة الحرة لاول أمريكا الثمالية والاتِّحاد الأوروبي، تصرٌّ الدول المتعاقدة

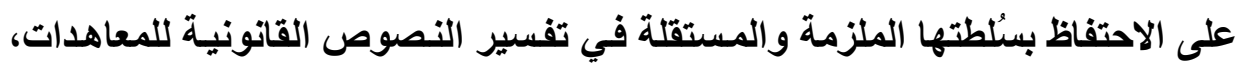
وتعديل التفسيرات القضائية من خلال تعديل المعاهدات وعدم الالتزام بالأحكام الدولية. وبعيدًا عن القانون الاقتصادي الدولي تقاومُ معظمُ الحكومات الصبّبْغة القضائية للعلاقات الدولية من خلال المعاهدات والمحاكم الدولية العالمية.

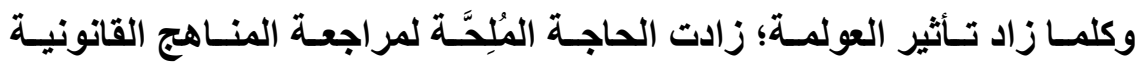
وإصلاح السياسات الاقتصادية والقانونية لمؤسسات الحكم متعدد المستويات. وكلمـا انخفضت سـيطرة البرلمانـات الوطنيـة على عمليـة صـنـاعة القـانون في المؤسسسات الاقتصادية الدولية؛ زادت أهمية الحماية القضائية متعددة المستويات للحقوق الدولية عبر الوطنية وقواعد القانون عبر الوطني (')

وحيث ترتكز المعاملات الاقتصادية الدولية بثكل أساس على التصرفات الفردية

للمنتجين والتجـار والمستثمرين والمستهلكين، يصبح التعـاون بـين المحساكم الدوليـة

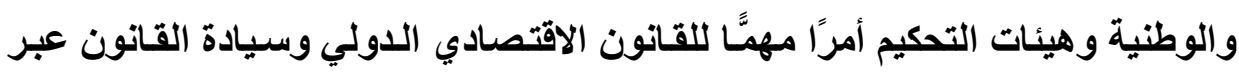

M. BRONCKERS, V. HAUSPIEL, R. QUIK, eds., Liber Amicorum for J. Bourgeois, Cheltenham, Elgar, 2014, p. 214- 225.

(1) N. LAVRANOS, "Jurisdictional Competition. Selected cases in International and European Law", Groning, European Law, 2014, p. 201. 
الـوطني. وسـهولة لجوء الفرد إلـى محكمـة عدل الآتّحساد الأورويـي ومحكمـة اتثّاقيـة

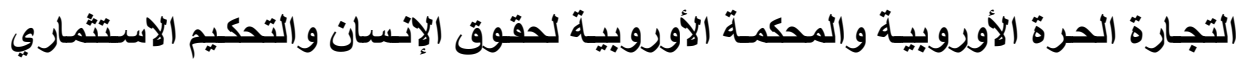

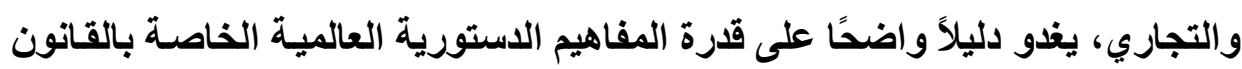
الدولي الاقتصادي على حماية الاحتياجات والحقوق الأساسية للمواطنين. ويبقى الخلاف سيدًا للموقف بثأن روئية الحكومـات والمحاكم الوطنية والدولية والهيئات الممثلة للقطاع الخاص حول أيّ المفاهيم الفقهية وأيّ المفاهيم المثالية ينبغي

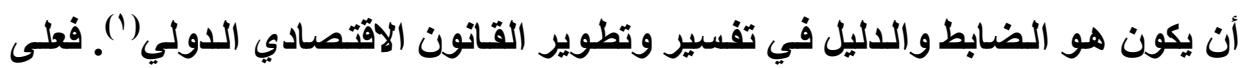

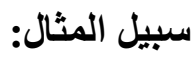

(1) تَعُدُ معظمُ الحكومات القانونَ الاقتصاديَّ الدوليَّ جزءًا من القانون الدولي العامَ، ويلعب دورًا مههًًا في تنظيم الاقتصاد الدولي على أسساس مفاهيم ويستيفال،

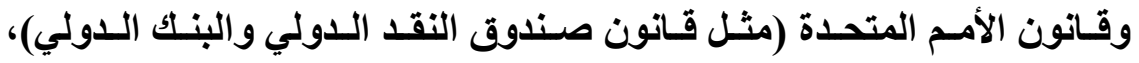

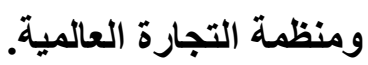

غالبًا ما يتم قصر القانون الاقتصادي الدولي الإقليمي متعدد المستويات على

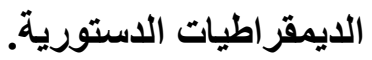

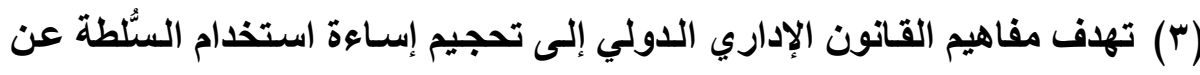
طريق إبراز أهمية مبادئ القانون الإداري متعدد المستويات والذي يمثل ركيزة

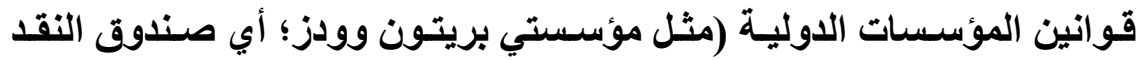
الاولي والبنك الاولي ومنظمة التجارة العالمية).

(1) H.L.A. HART, "The Concept of Law", Oxford, Oxford University Press, 2009, Chapter V. 


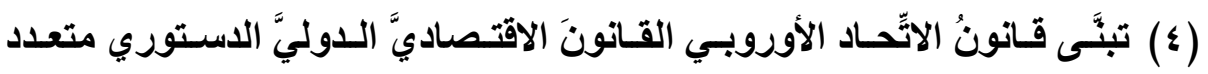

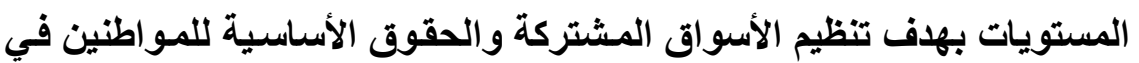
هذا الثأن.

(0) يؤكد كلُّ مـن القـانون والتحكيم عبر الـوطني للتجـارة والاستثمار على أهميـة التعددية القانونية، وأهمية التنسيق بين الاختصاصات القضائية المتعارضة عبر

$$
\text { مبادئ وطرق تنازع القوانين. }
$$

وتتطلب القواعد العرفيـة لتفسير الاتِّفاقيـات الدوليـة وقواعد الاعتراف الواردة بقانون الأمم المتحدة ضرورة التوفيق بين مفـاهيم القانون الاقتصادي الدولي الخمسة

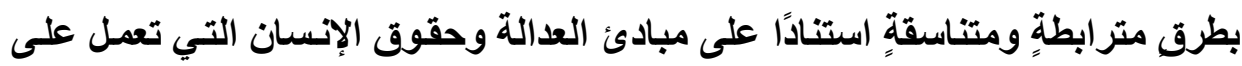

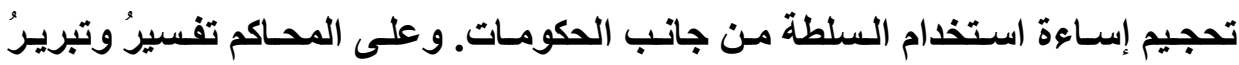

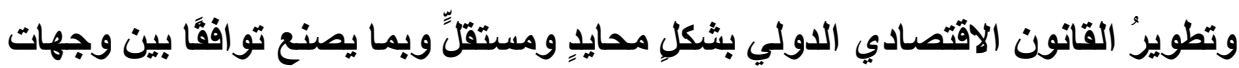

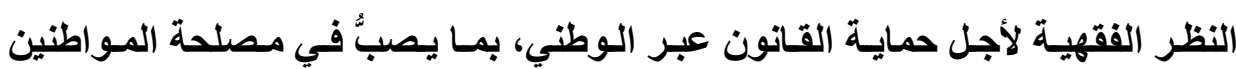

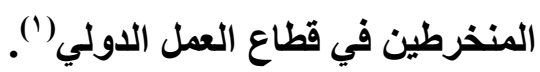
ويمكن أن يساعد التعـاون بين المحاكم الدوليـة والوطنيـة ومتطلبـات التفسير المتطابق للنظم القانونية الوطنية والدولية في الالتزام بمتطلبات القانون العرفي لتفسير

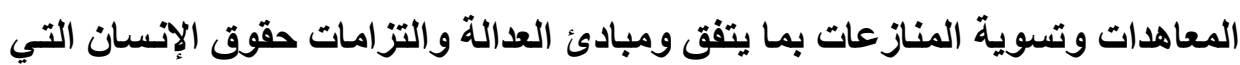

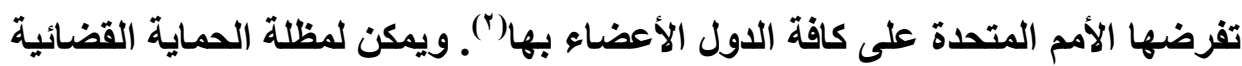

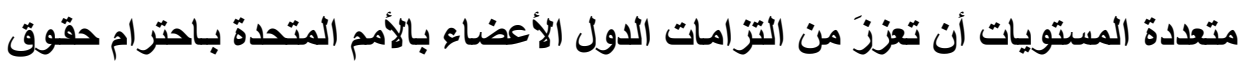

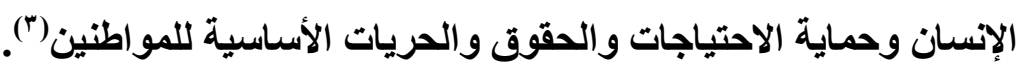

(1) J. RAZ, "Incorporation by Law", Legal Theory, op.cit., p. 72.

(2) R. JENNINGS, "The Judiciary, International and National, and the development of International law", op.cit., p. 67 et s.

(3) E.U. PETERSMANN, "International Economic Law in the $21^{\text {st }}$ century. $=$ 


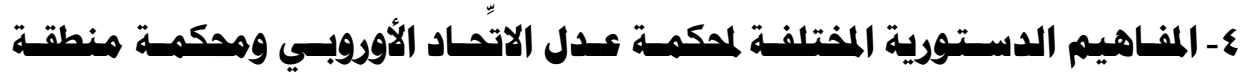
التجارة الحرة الأوروبية والمكمة الأوروبية لهقوق الإنسان.

غالبًا مـا تختلف الطرق القانونيـة والقضائية في وضع مفـاهيمَ أو رسم تصوُّر للمصادر القاتونية، وقواعد الاعتراف أو الإقرار، وطرق التفسير في دوائر الاختصاص

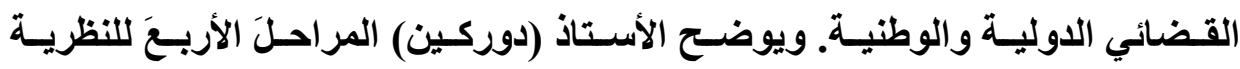
القانونيـة، وكيف تعتمــ المفـاهيم الفقهية للقـانون على التفسيرات القضائية لمبـادئ

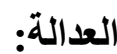

(1) في مرحلـة الـلالات اللفظيـة: تَمِيلُ المصطلحاتُ القانونيـةُ (كالعدالـة والصريـة والمساواة والايمقراطية وسيادة القانون) إلى كونها مفاهيمَ تفسيرية يتداولها الناس حتى وإن اختلفوا حول المعايير التي من شأنها تحديدُ ماهية الظلم. وحنى يتسنى تطبيقُ مثل هذه المفـاهيم التفسيرية، يجب أن تكون نظريـة المفهوم التفسيري تفسيرًا في حدّ ذاتها، وهو الأمر الذي غالبًا سيكون محلَّ خلافٍ في التطبيق الذي يحمل في طياته هذا المفهوم('). (Y) في المرحلة الفقهية: يتوجب على المفسر القانوني أن يبحثَ عن القِيَمَ التي تقدِّم أفضل تفسير للقِيَم التي تطح للوصول إليها من خلال المفاهيم القانونية كسيادة

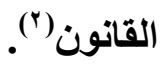

Constitutional pluralism and Multilevel Governance of Interdependent public Goods", op.cit., p. 117.

(1) R. DWORKIN, "Justice in Robe", Cambridge, Harvard University Press, 2013, p. 21.

(2) Ibid., p. 22. 
(r) في مرحلة وضع المبادئ: يجب تفسير حقيقة مدلولات القانون على ضوء القِيَم

التي تم تحديدها في المرحلة الفقهية؛ وذلك حنى تتناسبَ المبرراتُ القانونيةٌ مع

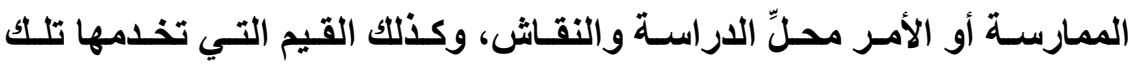

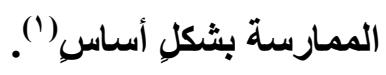

(ع) في المرحلة القضائية: يجب على محاكم العدل أن تقومَ بمراجعة ما إذا كان تنفيدُ القانون في قضايا محددةٍ من جاتب مسئولين سياسيين هو أمرًا مُبرَّرًا قانويًَا من

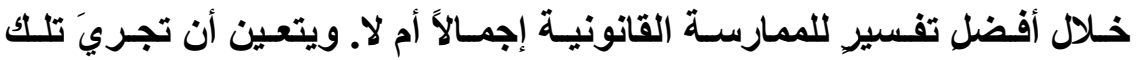

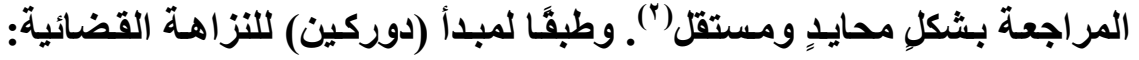
يتعين على القضاة تفسيرُ القـانون استتـادًا إلى أهدافـه والمبـادئ الدستورية الأساسية للعدالة، حيث يطالب القانون القضاة_ من قبيل النزاهـــ أن يفترضوا قارَ الإمكان أنه قد تَمَّتْْ صياغة القانون ويناؤه على أساس مجموعةٍ من مبادئ العدالـة والعدل والأصـول القانونيـة. ويطـالبهم كذلك بتطبيق ذلك في القضايا الجديدة المطروحة أمامهم، بحيث تتحقق العدالة والعدل لكلّ شخص طبقَّا لنفس (المعاييز (َ)

إن تقنين القواعد العرفيـة لتفسير المعاهدات في معاهدة فيينـا يمنحنـا تفسيرًا مستندًا إلى النص والسياق والهـدف والغرض(؛)، بمـا يتماثـى مـع مبـادئ العدالـة

(1) On the Two tests of fit and value as different aspects of a single overall Judgment of political morality and best Justification of legal practices, See ibid., p. 24- 26.

(2) Ibid., p. 28- 32, R. DWORKIN, "Law"s Empire", Cambridge, MA, Harvard University Press, 1996, p. 225- 243.

(3) R. DWORKIN, "Law"ss Empire", op.cit., p. 224.

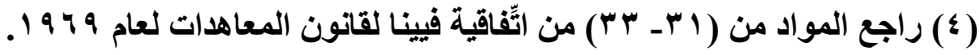


والقانون الدولي، بما في ذلك حقوق الإنسان والحريات الأساسية للجميع (') وعلى خلاف طرق التفسير المُتَبَعة في العديد من المحاكم القضائية الوطنية، وفي ظلّلّ انعدام

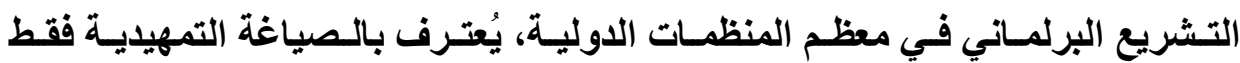

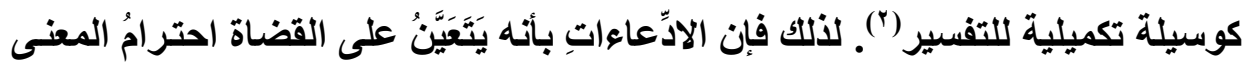

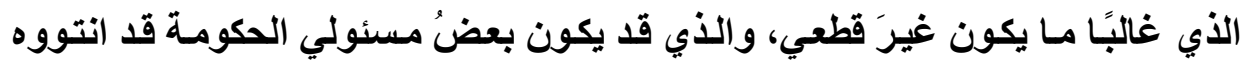
لنصوص المعاهدة وليس بغرض اكتشاف أكثر التفسيرات اتُّاقا والتي من شـأنها أن تصبَّ في مصلحة الدواطنين- تظلُّ محلَّ خلافٍ ونقـاش، ويظهر هذا جليَّا في حالـة المعاهدات التشريعية متعددة الأطراف والتي اشترك في التفاوض بشأنها في البداية

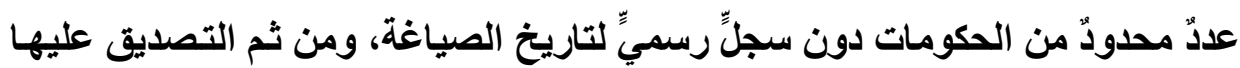

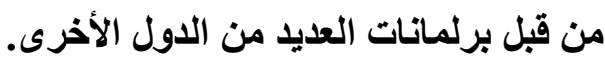

وحيث تتطلب التزامـات الدول الأعضاء بـالأمم المتحدة احترامَ حقوق الإنسان

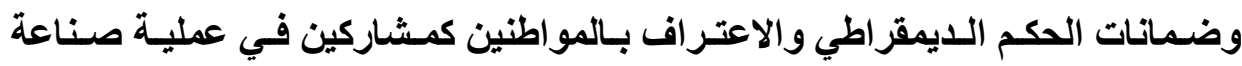
القانون بالإنابة، قد تبرر طبيعة التعاون الاقتصادي الدولي والتي ترتكز إلى المواطن

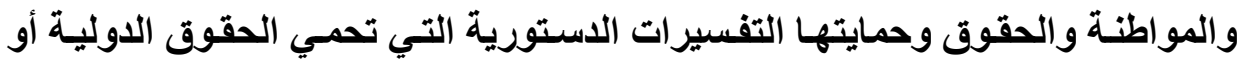

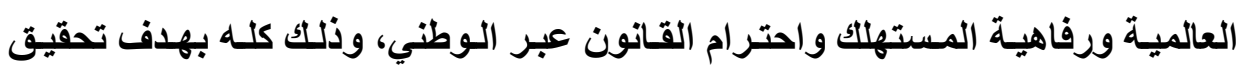

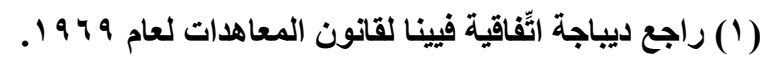

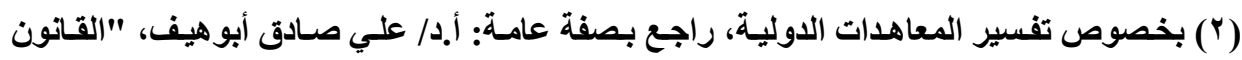

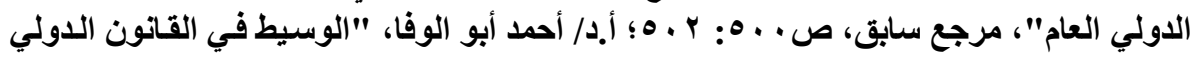

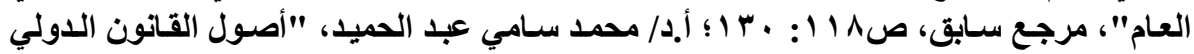

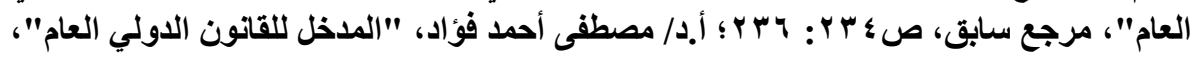

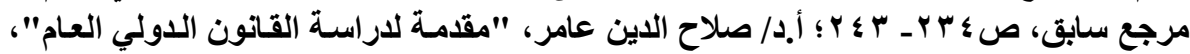

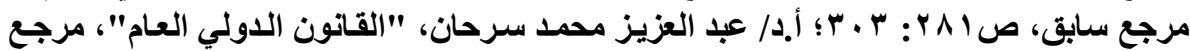

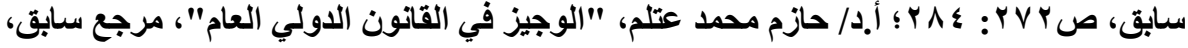


مصلحة المواطنين وليس المصالح الخاصـة لمسئولي الحكومـة أو للجماعـات الساعية

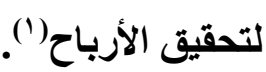

ومن ناحيةٍ أخرى، يوضح قانون الاتِّحاد الأوروبي وقانون المنطقة الاقتصادية

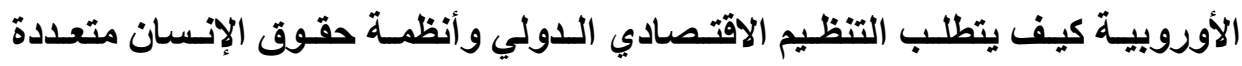

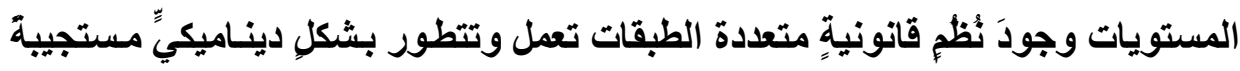
للوظيفة القضائية (الفصل في المنازعات) والحوار الديمقراطي. فعلى سبيل المثال،

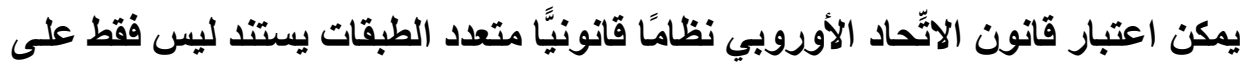

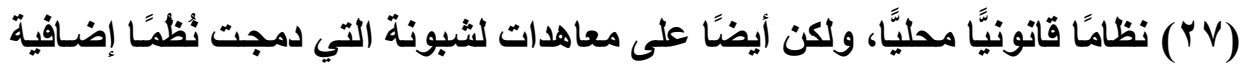

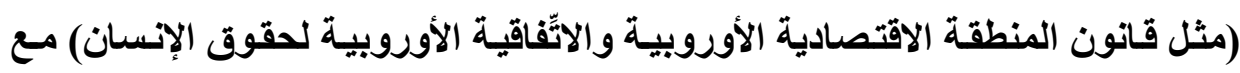

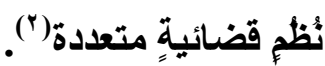

و إذا تمَّ النظر من جاتب منظماتٍ دوليةٍ كالاتِّحاد الأوروبي إلى الطُرُق أو المناهج

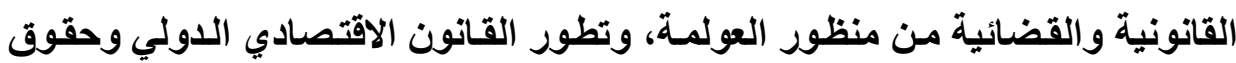

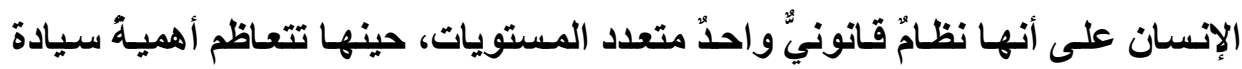

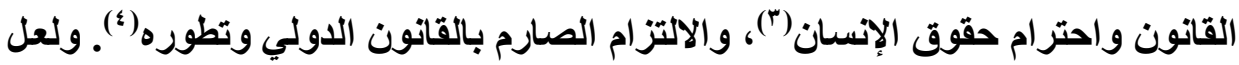

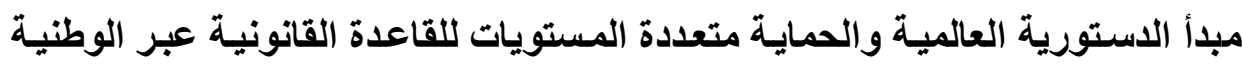

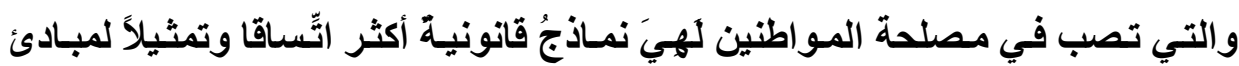
العدالة المدافعة عن المصالح العامة للمواطنين في القانون الاقتصادي الدولي أكثر من فئن فئن

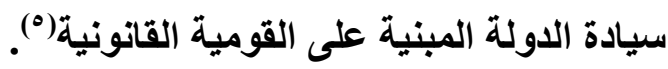

(1) N. LAVRANOS, "Jurisdictional Competition", op.cit., p. 209 et s.

(2) R. DWORKIN, "Law's Empire", op.cit., p. 250.

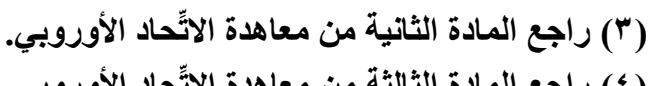
( ) راجع المادة الثالثة من معاهدة الاتِّاد الأوروبي.

(5) E.-U. PETERSAMANN, "Can the EU, Disregard for "Strict observance of International Law", op.cit., p. 230. 


\section{أ - المناهج القضائية التي تُطبقِقُها همكمة عدل الاتِّاد الأوروبي:}

لقد بَرَّرَت المبادئ الاستورية لقانون الاتِّحاد الأوروبي استخدامَ معاهدة الاتِّاد

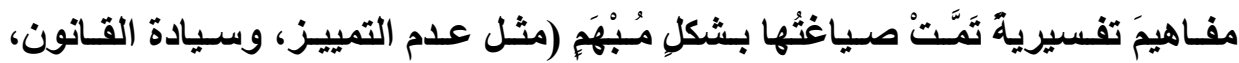

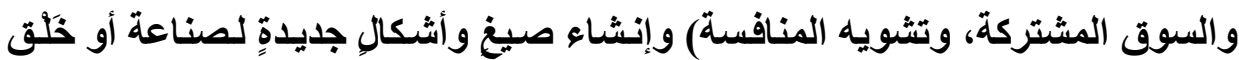

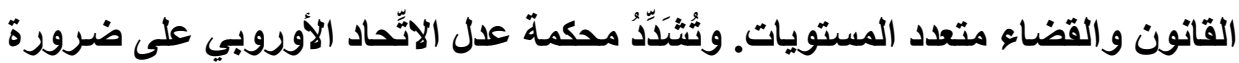
خَلق توازُنْ بين الحقوق الاقتصادية والحقوق الأساسية الأخرى دون إعطاء أفضليةٍ لإحداها على الأخرى، وذلك استنادًا إلى التفسيرات التي تستثد إلى غايسةٍ محددةٍ (مثل

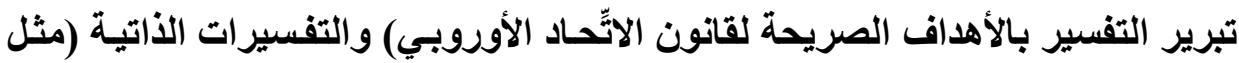

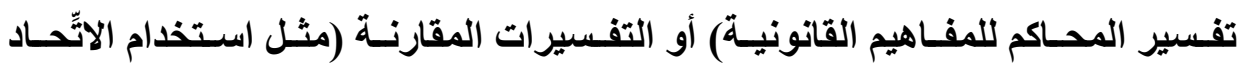

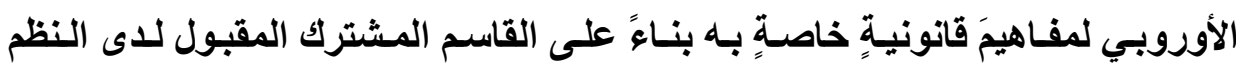

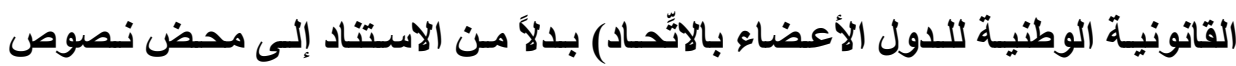

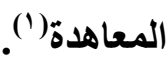

وفي كلّّ الأحوال، يجب أن تكون القيودُ الحكومية على الحقوق الأساسية قابلة

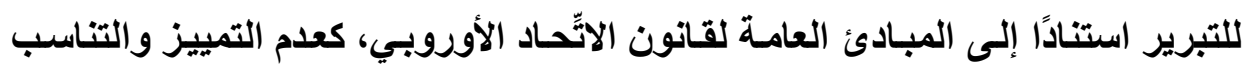

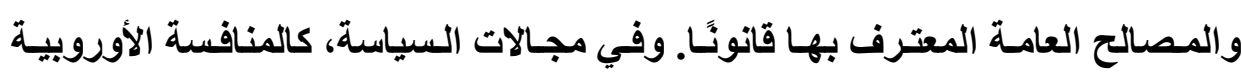

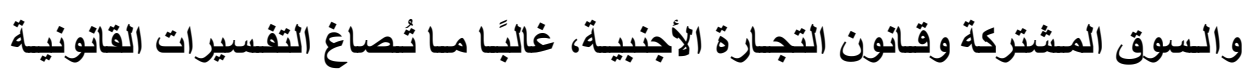

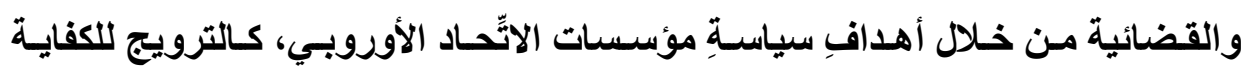

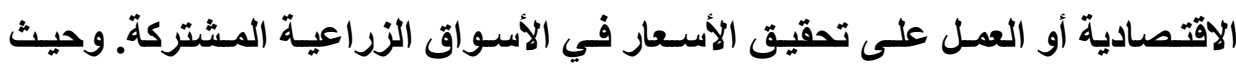

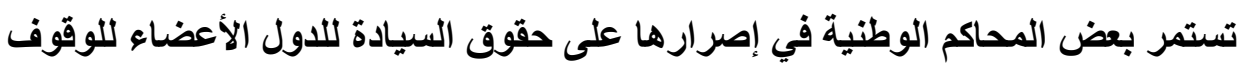

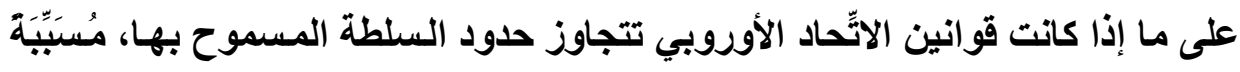

(1) J. GERARDS, "Judicial Argumentation in Fundamental Rights Casesthe EU Court's Challenge", in U.NEERGARD, R. NIELSEN, eds., "European Legal Method in a Multilevel EU legal order", Copenhagen, DJOF Publishing, 2012, p. 27 et s. 


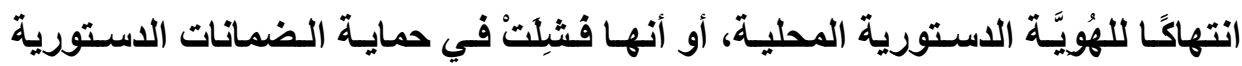

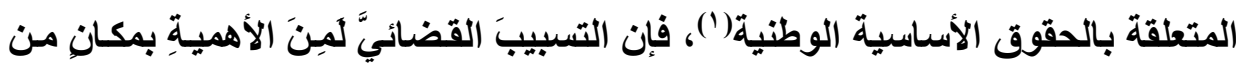

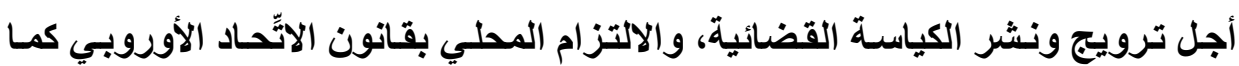

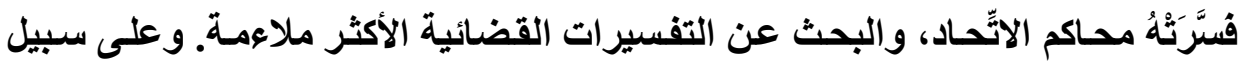

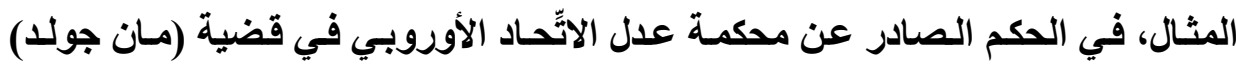

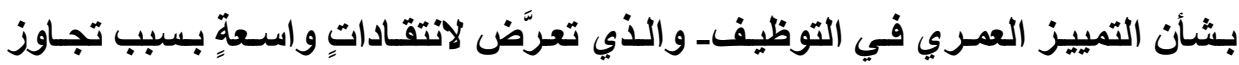

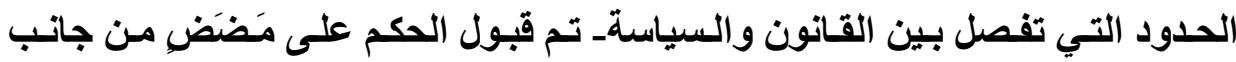

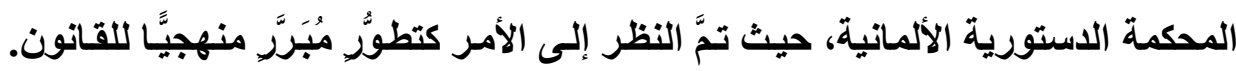

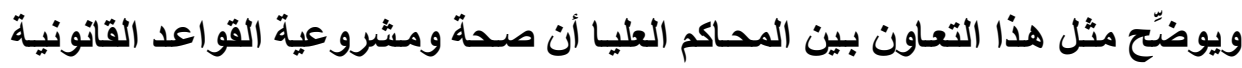

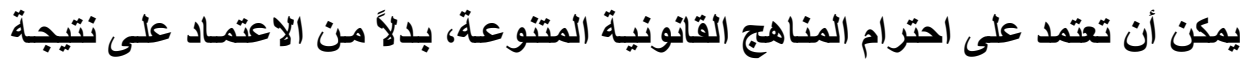

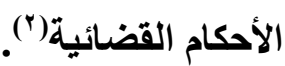

وقد يتبين للسلطات الوطنيـة أو المحلية عن طريق ربط التفسيرات الجديدة

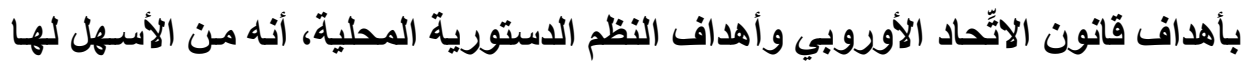

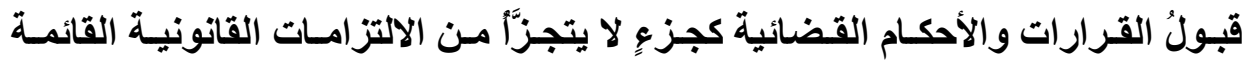

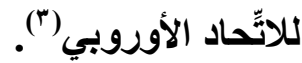

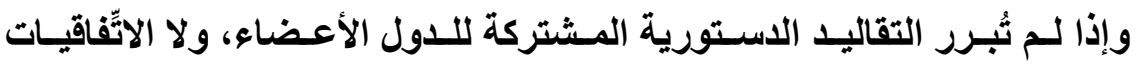

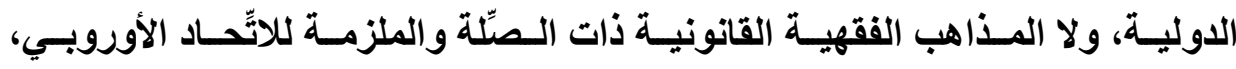

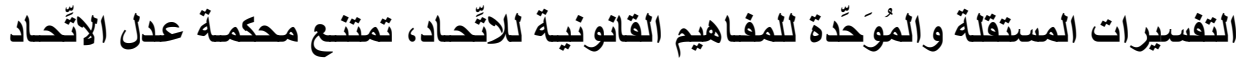

(1) The Lisbon Judgment of the German Bundesf assungericht of 30 June 2009, BV erf GE/23, 267.

(2) ECJ, 22 November 2005, Mangold, C-144/04, ECR 2005, p. I- 9981; BV erf GE, 2 Bv R 2661/06 of 6 July 2010.

(3) ECJ, 27 February 2003, Truly, C-373/00, ECR 2003, p. I- 1932, Para. 35. 
الأوروبي عمدًا عن تفسير المصطلحات القانونيـة الخاصـة بالاتِّـاد الأوروبي (مثل فئل

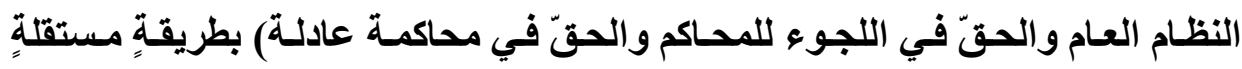

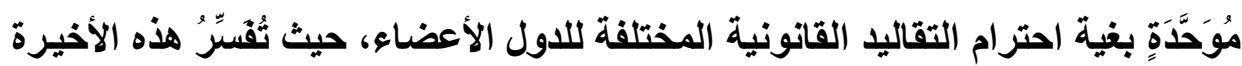

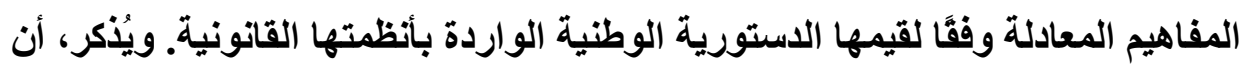

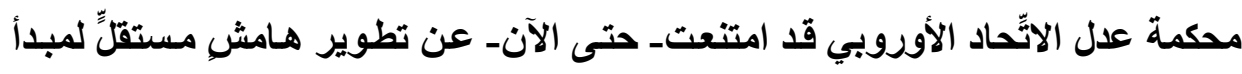

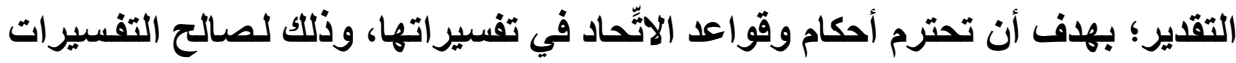

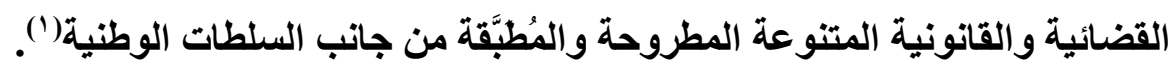

ب- المناهج القضائية التي تُطَبِّها همكمة هنطقة التجارة الحرة الأوروبية: تنصُ ديباجة اتقاقية المنطقة الاقتصادية الأوروبية على أنه: "في احترام كامل

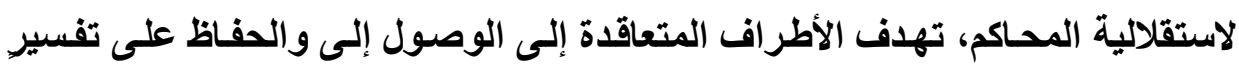

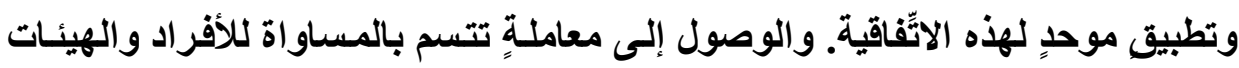

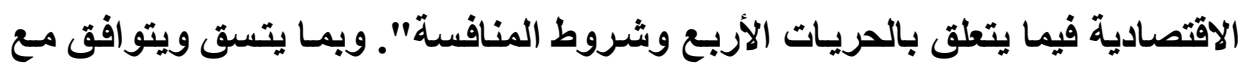

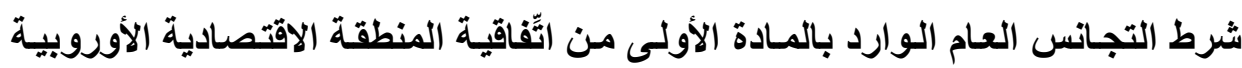

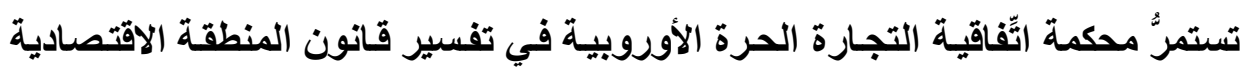

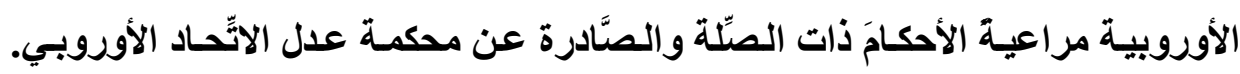

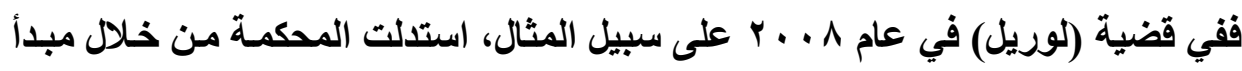

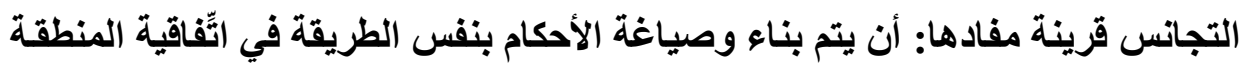

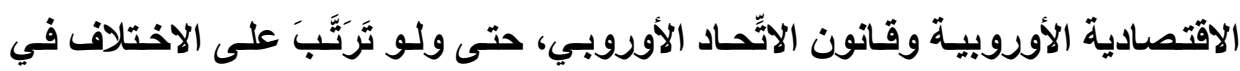

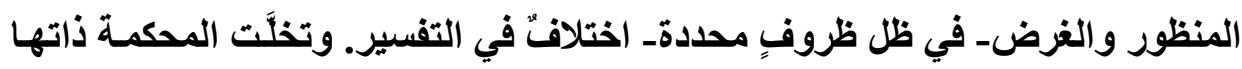
عن تفسيرها السابق في قضية (ماجلايت)، واتبعت التفسير السابق المستخلص من فن فئرئ

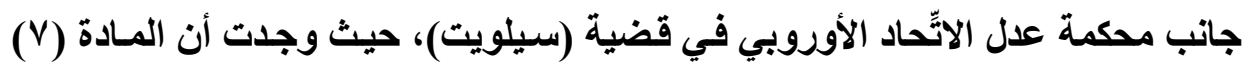

(1) J. GERARDS, "Judicial Argumentation in Fundamental Rights Casesthe EU Court's Challenge", op.cit., p. 47. 
مـن التوجيـه الخـاص بالعلامــات التجاريـة قـــ منعـت أيضضًا الـدول الأعضاء بالمنطقـة الاقتصادية الأوروبية في علاقاتهم مع الدول الغير من تطبيق مبدأ الاستنفاد الدولي ('). وعلى الـرغم مـن أن محكمـة عدل الاتِّــاد الأوروبـي تُــــم التجـانس القـانوني

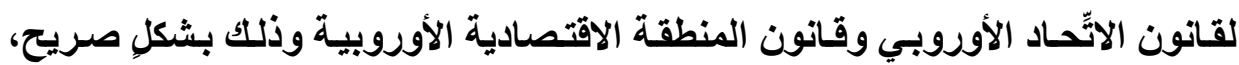

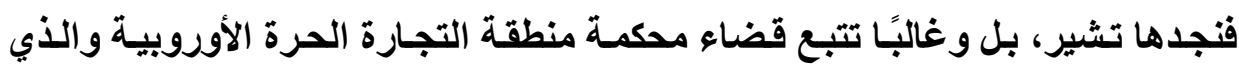

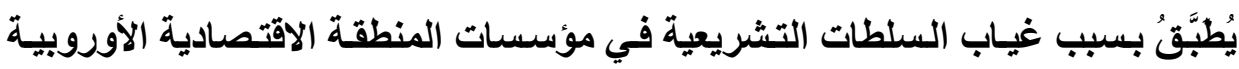

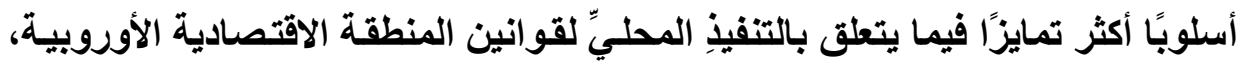

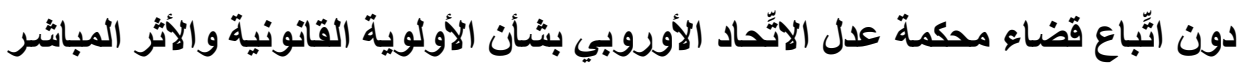

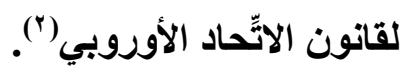
ج - المناهج القضائية التي تُطَبِقُها المكمبة الأوروبية لهقوق الإنسان: تُشدد المحكمة الأوروبية لحقوق الإنسان على دورهـا فيمـا يتعلق بالمسئولية

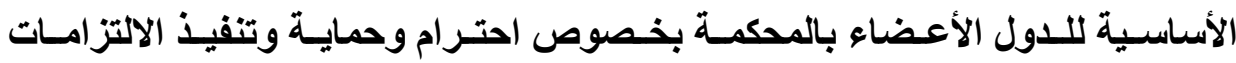
والحقوق المنصوص عليها في الاتّفاقية. وتؤكد المحكمة، مرارًا وتكرارًا، على أهمية

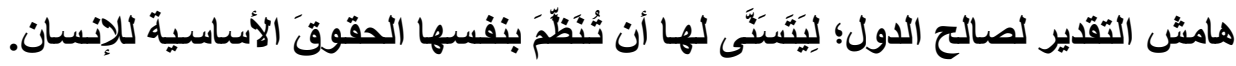
وحيث توجد السلطات المحلية في موضع أفضلَ من المحكمة الأوروبية لحقوق الإنسان يُمَكَُّها من تقييم احترام المصالح الاجتماعية، تميل المحكمة الأوروبيـة لحقوق الإنسان

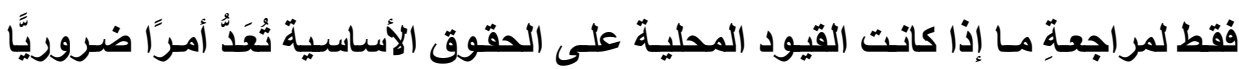

(1) EFTA Court, 8 July 2008, L'Oréal, E-10/07, EFTA CT Reports 2008, 258.

(2) O.I. HANNESSON "Giving Effect to EEA Law- Examining and Rethinking the Role and Relationship between the EFTA Court and the Icelandic National Courts in the EEA Legal Order", Florence, EUI, 2017, p. 199. 
لتحقيق المصالح العامة، أم أنها غير معقولة بشكل كبيز، أم أنها لا تضع في الاعتبار بدائلَ أكثرَ معقولية('). وتؤكد المحكمة ذاتها على أن الحمايـة الفعالـة والعملية للحقوق الواردة بالاتِّاقية تتطلب تفسيرًا ديناميكيَّا للاتِّقاقية الأوروبية لحقوق الإنسان في ضوء

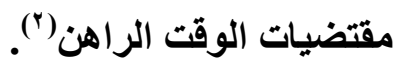

ودائمًا ما ثُثْار القيم الأساسية التي تضمنتها ديباجـة الاتِّقاقية المذكورة بهدف تبرير التفسير المتقدم والحماية الفعالـة للحقوق الأساسية. في حين أنـه أحيانَا مـا يتهُ توجيه الانتقادات للمراجعة القضائية الهامشية فقط؛ بسبب عدم وضْنِعَا نسبية الحقوق الأسساسية في الاعتبار (r). ويعتمدُ التركيز المتغير للمراجعة القضائية؛ ليس فقط على أهمية الحق الذي يتأثر بالعناصر السابقة، ولكن أيضًا على التقييم المقارن للتقاليد الاستورية الوطنيـة المتنوعة. ففي قضية (فو) الخاصة بالجدل حول الوقت الذي يبدأ فيهه الاعتراف بالطفل الذي لم يُولْْ بعدُ شخصنًا يتمتع بالحماية تحت مظلـة الحق في الحيـاة، أشسارت المحكمة الأوروبية لحقوق الإنسان إلى تباين الآراء في هذا الأمر في النُّطم القانونيـة الوطنية،

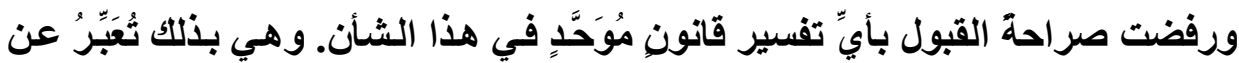

(1) J. CHRISTOFFersen, "Fair Balance: Proportionality, Subsidiarity and Primarity in the European Convention on Human Rights", Leiden, Nijhoff, 2016, p. 333.

(2) ECtHR, 25 April 1978, Tyrev. United Kingdom, Judgment, appl. No. 5856/72, Series A, Vol. 26, Para. 31.

(3) M. BOSSUYT, "Should the Strasbourg Court exercise more-selfrestraint? On the extension of the Jurisdiction of the European Court of Human Rights to Social security regulations", Human Rights Law Journal, Vol. 32, 2011, p. 321- 332. 
احترامها الثديد لتوجُّه الدول الأعضاء لتقرير ذلك بأنفسهم، عمـا إذا كـان الأشخاص يصبحون تحت مظلة الحمايـة القانونية منذ لحظة الميلاد أم يصبحون كذلك وهم في طور الحَلْ بهم كأجنَّة (').

\section{د- ههمة القضاء في إدارة هرفق العدالة:}

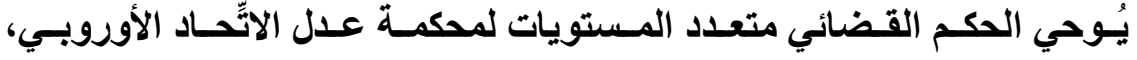
ومحكمة منطقة التجارة الحرة الأوروبية والمحكمة الأوروبية لحقوق الإنسان والمحاكم الداخلية بـأنَّ محور اهتمـامهم وتركيزهم المشترك ينصبٌٌ على التفسيرات ذات الغايـة

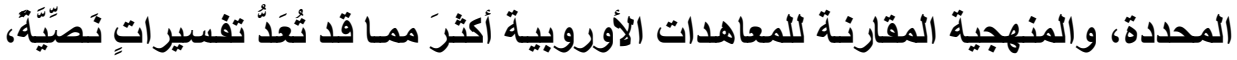
ليصبح بذلك متوافقَاــ بشكلِ كبير- مـع الأنظمة أو المنـاهج العرفية لتفسير المعاهدات الدوليـة أكثرَ ممـا هو عليهه مـع الأنظمـة أو المنـاهج القضائية التي تعمل بهـا المحساكم الوطنية)(؟)

وعلى عكس العديد من المحاكم القضائية في العـالم، تُوَكَّدُ المحسكم الأوروبيـة الثلاث على طبيعتها الدستورية والتزامها بحماية حقوق الإنسان وغيرها من المبادئ الاسـتورية المسشتركة للـدول الأعضاء. ولــم تمنـع مثـل هـذه القيـود الاسـتورية دور السلطات القضائية النَّشِطِ في تحجيم إساءة استعمال السلطة وحماية الحقوق الأساسية لمواطني الاتِّاد الأوروبي، وتعزيز أشكال جديدةٍ من التكامل من خلال القانون، وجعل

(1) ECtHR, 8 July 2004, Vo v. France, Judgment, no 53924/00, Reports 2004- VIII.

(2) ECJ, 6 October 1982, CILFIT, 283/81, ECR 1982, p. 3415, Para. 20. 
المكم متعدد المستوياتـ بشكلٍ تـدريجيٍِ أمـرًا دستوريَّا مـع كامـل الاحتـرام للتنـوع

الاستوري الاخلي والذي يُعَدُّ قيمة أوروبية إيجابيةة (').

وقد نُقل عن الفقيه الألماني (يرينج)- منذ ما يقرب من قرن- قوله: إنـه غالبَّا مـا

تعتمد حياة القانون على مواطنين يناضلون من أجل حقوقهم، ومثل هذا النضال من أجل حقوق المواطن قد يكون واجبًا على الشخص الذي تم انتهاك حقوقه، كمـا هو واجب على المجتمع.

ولم تمنع حقيقة أن العديد من أحكام المعاهدة تخاطب رسميَّا الدول الأعضاء،

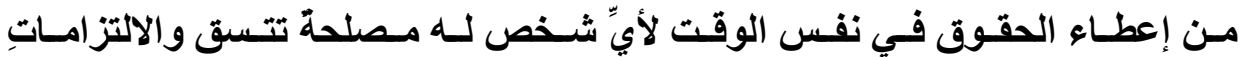
المنصوصَ عليها في هذا الثُأن. ويجب أن يكون مثلُ هذا الاعتبار واجبَ التطبيق على

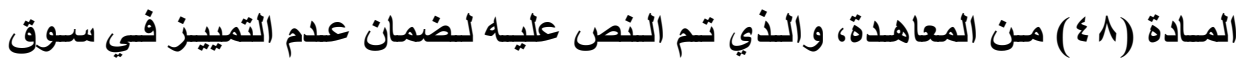

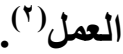

(1) R. JHERING, "The Struggle for Law", Chicago, Callaghan, 1915, Chapters II To IV; D.M. BEATTY, "The ultimate Rule of law", Oxford, Oxford University Press, 2012, p. 99.

(2) ECJ, 5 February 1963, Van Gend en Loos, 26/62, ECR 1963, p. 1; ECJ, 6 June 2000, Angonese, C-281/98, ECR 2000, p. I- 4139. 


\section{المبحث الثاني \\ همكمة العدل الدولية في هواجهة تقرير المير: \\ دروس" هستفادة" هن دور المكمة هولية}

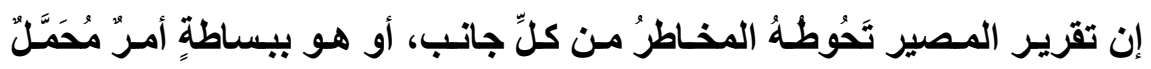

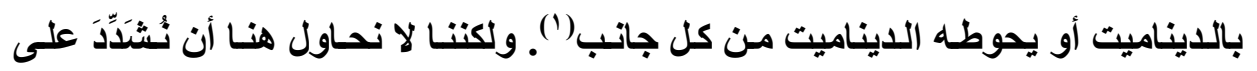

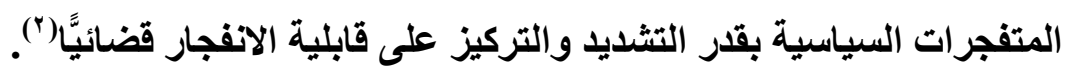

ا - تعاهل همكمة العدل الدولية هع تقرير الصير

في ضوء المكانة البارزة لتقرير المصير في القانون الدولي، غالبًا ما يثير الجالُ لئر

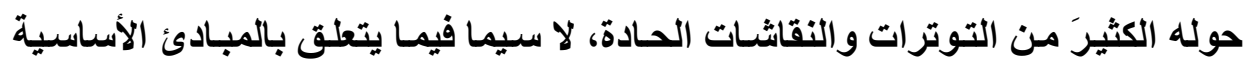

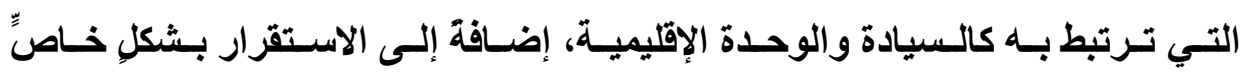

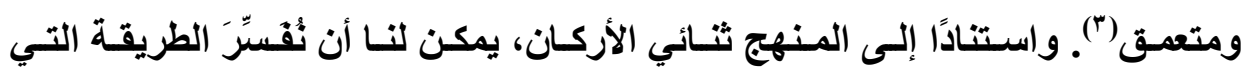

(1) R. McCORQUODALE, "Self-Determination: A Human Rights Approach". International and Comparative Law Quarterly, no4, vol.43, 1994, p.857-885.

(2) Jan KLABBERS, "The Right to be Taken Seriously: SelfDetermination in International Law". Human Rights Quarterly, no1, vol. 28, 2006, p. 186-206.

(3) ICJ, 21 June 1971, Legal Consequences for States of the Continued Presence of South Africa in Namibia notwithstanding Security Council Resolution 276, Advisory Opinion, I.C.J. Reports 1971, p. 16; Karim OELLERS-FRAHM, "Lawmaking through Advisory Opinions?", German Law Journal, Vol. 14, 2013, p. 1033-1056. 
استخدمتها محكمة العدل الدوليـة في الرأي الإفتائي بالصحراء الغربية ووصولاً إلى

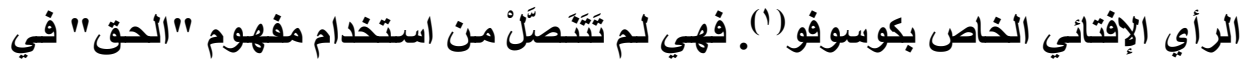

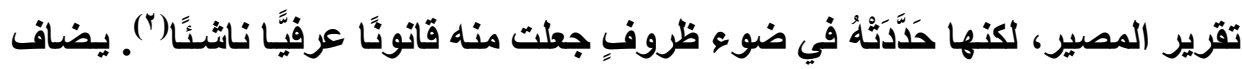

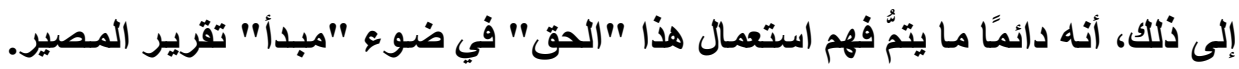
وإنتا لنجد مثالاً نموذجيَّا لهذا النهج في الصيغة المستخدمة من جانب المحكمة ذاتها في

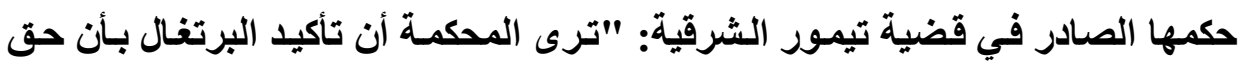

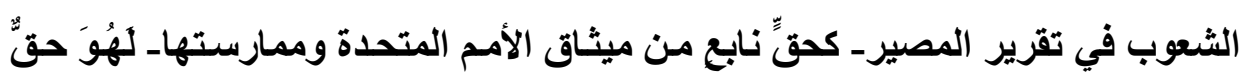
ذو حجيةٍ مطلقةٍ لا تشوبه شائبة"(").

وجديرٌ بالذكر، أنه قد تمَّ إقرار حق الثعوب في تقرير المصير في ميثاق الأمـ

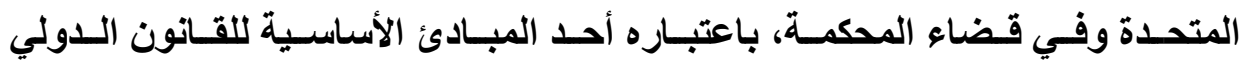

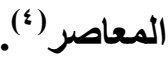

\section{أ- المنهمية ثنائية الأركان:}

لقد عرفت محكمة العدل الدولية، (1) أثنـاء ممارستها لوظيفتها الإفتائية بشأن قضية الصحراء الغربية، "مبدأ" تقرير المصير على أنه: "الحاجة إلى احترام التعبير

(1) ICJ, 16 October 1975, Western Sahara, Advisory Opinion, I.C.J. Reports 1975, p.12.

(2) Martti KOSKENNIEMI, "National Self-Determination Today : Problems of legal Theory and Practice", International and Comparative Law Quarterly, no2, vol., 43,, 1994, p. 24.

(3) Pierre D'ARGENT, "Les principes généraux a la Cour Internationale de Justice", Schulthess, 2011, p.107.

(4) JCJ, 30 June 1995, East Timer (Portugal v. Australia), I.C.J. Reports 1995 , p.89. 
الحر والأصيل لرغبة الشعوب المعنية"(؟). ووفقَا للأستاذ (كاسيس) فبإن لُبَّ تقرير المصير هو ضرورة احترامه من جانب المجتمعات السياسية (الدول بشكلٍ رئيس) التي تتخذ قراراتٍ من شأنها التأثيرُ على مصير الشعوب(").

ويجب ألا يخفيَ التركيز على "مبدأ" تقرير المصير، والذَي يمكن أن نُعَرِقهُهُ

أيضًا بأنـه الحاجـة إلى الالتفـات والاهتمـام بـالتعبير عن إرادة الشعب، حقيقة اعتراف المحكمة بخصوصية بعض الظروف والحسالات المحددة وتـاعياتها على الصلاحيات

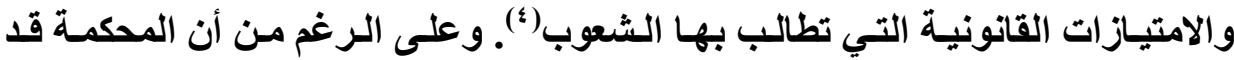
حََََّتْ قواعدَ عرفية معينـة تتعلق بتقرير المصير وتحظى بـالقبول الواسع في أوسـاط

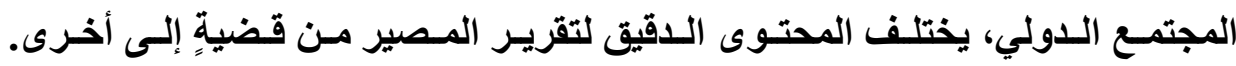

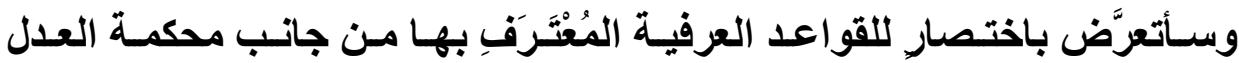

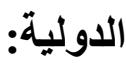

أولاً: يتم منـح الحق في تقريـر المصير الخـارجي للشعوب المستعمرة، وقد يكون تقرير المصير الاستعماري في الحقيقة هو أشهر وأقرب نموذج لتحديد وتقرير

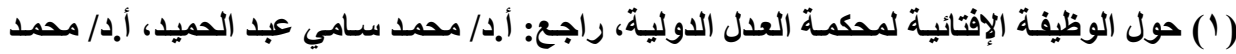

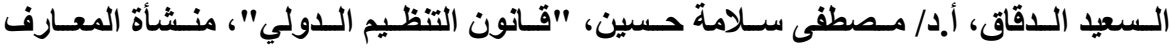

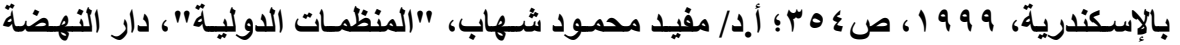

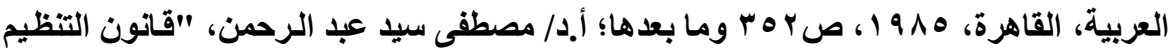

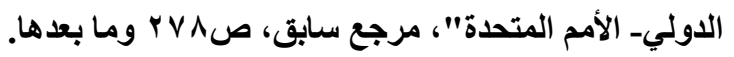

(2) James CRAWFORDM, "Book Review Self- Determination of Peoples", The American Journal of International Law, no.5, vol. 93, 2003, p.331.

(3) A. CASSESE, "Self- Determination of Peoples: a legal Reappraisal". Cambridge, Cambridge University Press 1995, P.317-320.

(4) Daniel THURER and T.BURRI, "Self- Determination", Max Planck Encyclopedia of Public International Law, 2015, p.226. 


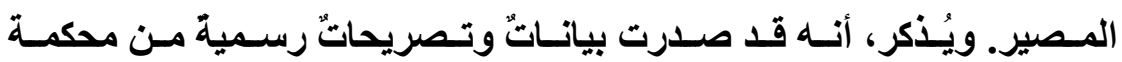
العـدل الدوليـة في مسسألة تقريـر مسير الـشعوب المستعمرة فـي رأيسين استشاريين، يُعََّّان من أوائل الفتاوى التي صدرت في هذا الصدد، بخصوص

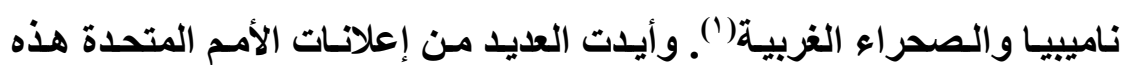

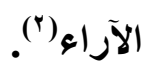

وتُخاطب القاعدة العرفية الثانية الثعوبَ التي تحيا تحت نيِّّر الاحتلال العسكري الأجنبي. وفي تفرقة بين الحالة الاستعمارية وهذه الحالة، نلاحظ أنَّ التركيز في هذه

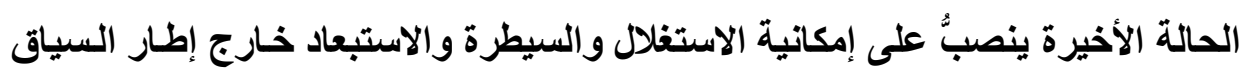
الاستعماري. على الرغم من ذلك، لا تشمل هذه الحالة الاستغلالَ الاقتصاديَّ أو الهيمنـة

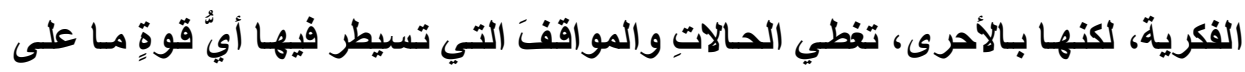
شعب إقليم أجنبي عبر اللجوء إلى القوة("). وفي رأيها الاستشاري بشأن كوسوفو، أكدت محكمة العدل الدولية على أنه "أثناء النصف الثاني من القرن العشرين، تطوَّر القانون الدولي لتقرير المصير بشكلِ من شأنه الاعتراف بـالحقّ في الاستقلال لشعوب الأقاليم غير المتمتعة بالحكم الأتي، والثعوب التي تعيش تحت وطأة استبعاد واستغلال

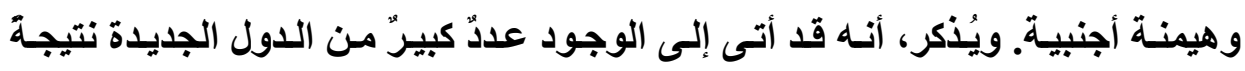

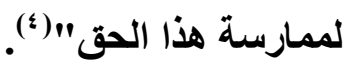

(1) Namibia Opinion, P.52-53, Western Sahara opinion, p.162.

(2) GA-Resolution 1514 (XV), 1960, UN Doc-A/4684.

(3) Original emphasis, A. CASSESE, op. cit., P.99.

(4) GA Resolution 2626, 1970, UN Doc. A/8028 (1971), voir aussi, ICJ, 9 July 2004, Legal consequences of the Construction of Wall in The occupied Palestinian territory, Advisory Opinion, I.C.J. Reports 2004, p.136. 
من ناحية أخرى، يرى العديد من الفقهاء أنهه يجب إقرارُ قاعدةٍ عرفيةٍة ثالثةٍ

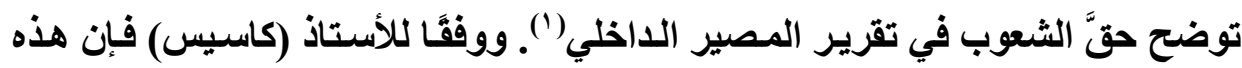

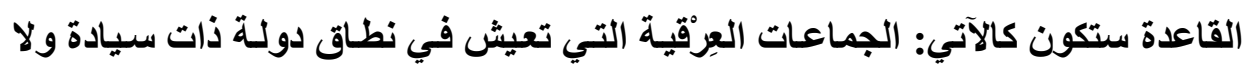

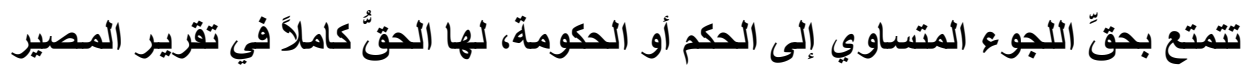

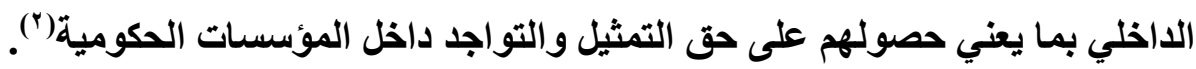

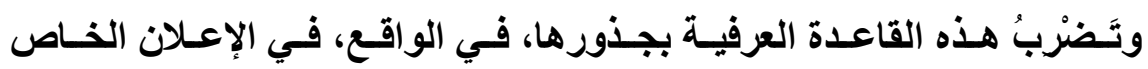

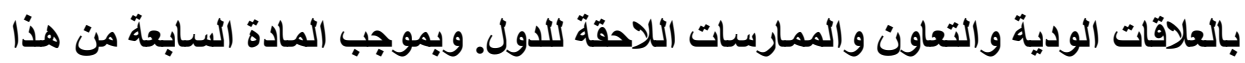

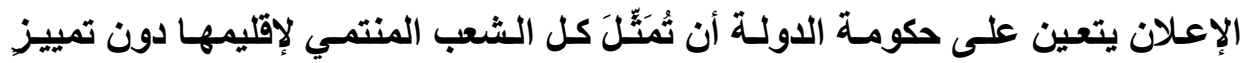

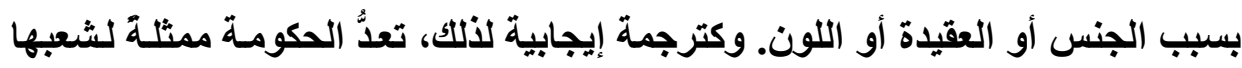

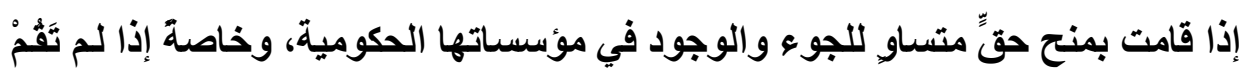

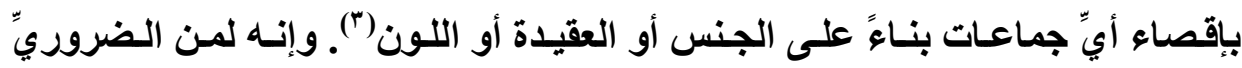

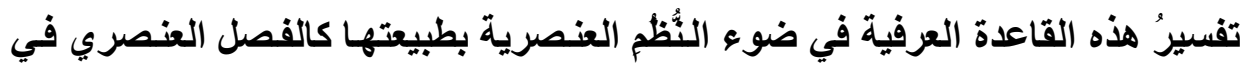
جنوب أفريقيا على سبيل المثال.

ومن ناحية أخرى، وكما أوضحت الأستاذة (أنايا)، يُعَدُ السكان الأصليون ممثلين

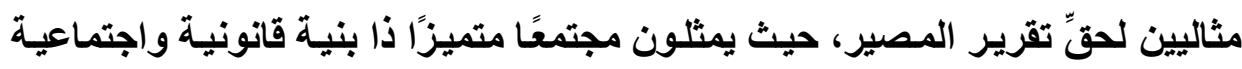
أكبر (") وقد يأخذ هذا الحقُّ صورة الاستقلال الداخلي أو الحصول على صدلاحيات

(1) For complete references, A. CASSES, op. cit., p.100.

(2) Ibid., p. 108-126.

(3) David RAIC, "State-hood and the Law of Self-Determination", The Hague, Kluwer Law International, 2013, p.320.

(4) S. James ANAYA, "Indigenous Peoples in International Law", Oxford, Oxford University Press, 2013, p.76. 
المشاركة في عملية صنع القرار. ولقد أكدت الجمعية العامـة للأمم المتحدة على حسن النية السياسية تجاه السكان الأصليين من الثعوب، حينما عَبَرَتَّْ عن رغبتها وإرادتها واستعدادها أن تهتم بالشعوب الأصلية بشكلِ أكبرَ مـن خـلال: "إعلان الشعوب مـن السكان الأصليين أو ما يسمى بالإعلان القائم على الشعوب الأصلية (V . . . ץ)"(').

\section{ب- هنهج هتطور}

من أجل تحقيق منهجية للاراسة القصيرة التي قمنْـا بعرضهـا سـلقًا، سـأحاول أن أضع في الاعتبار القواعدَ العرفية وتطوراتها المحتملة في سياق المبدأ العـام لتقرير المصير. كما رأينا، يقع جوهر تقرير المصير في نطاق مبدأ إجرائسيِ يُحَتُِّ وضـع إرادة

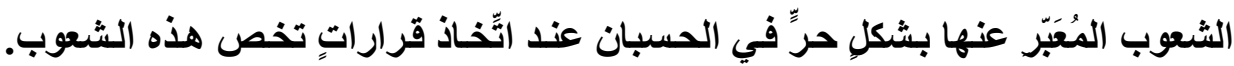
ولقد تحققت خصوصية وأدلـة ثبوت هذا المبدأ بالقواعد العرفية التي تغطي ظروفـا محددةً يتطور فيها الإجمـاع السياسي ليخلق حلولاً مُستسِقِة لمواقفَ محددةٍ يكون فيها

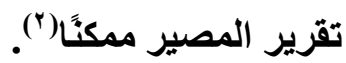

وتستحق منا ثلاثة عناصر تحليلية المزيـــ من الانتباه. أولاً: أنها من الضروريٍ

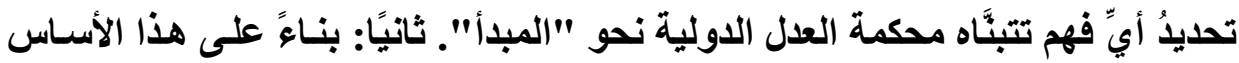
سـأتولَّى شرح كيف قامـت المحكمـة بتـأمين أو ضـمان هـامش مهم وضروري لنفسها بغرض التعامل مـع التطورات المتعلقة بتقرير المصير. ولقد استخدمت المحكمة هذا الهامش في دمج أنواع مختلفة من التطورات. ثالثًا: أنه من المهم أن نضع إستراتيجية

(1) GA Resolution 61/295, 2007, UN Doc. A/Res 61/295.

(2) A. CASSESE, "Self-Determination of peoples: a legal Reappraisal", op. cit., p.321. 
المحكمة في إطار مؤسسيِّ أوسع، ولأجل هذا، يجب أن نضع دور الجمعية العامـة للأمم

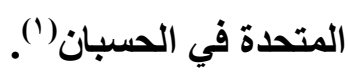

ومسن الجـوهريٍ أن نفهـم إسـتراتيجية المحكمـة في التعامـل مـع تقريـر المـصير بثكل يتوافق مع آلية "المبدأ". ويفسر الأستاذ (دارجنت) الأمر، بأن المحكمة تستخدم

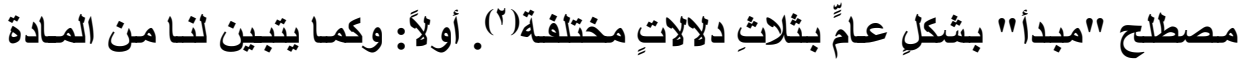
^//1 من النظام الأساس للمحكمة، فقد تثشير هذه الأخيرة إلى وجود "المبـادئ العامـة للقانون"، وهي عمليةة تفترض مسبقًا وجودَ منهجيـةٍ مقارنةٍة لقواعدَ قانونيةٍة محلية. وتُعَدُّ فتوى ناميبيا إحدى القضايا المعدودة التي أقرَّت فيها المحكمة مثل هذا "المبدأ". ثانيًَا: أثـارت المحكمـة إلى "المبـادئ العامـة" كالمبـدأ العـام للحيـازة الجاريـة. ثالثـا: أشارت المحكمة ذاتها إلى تعبير "مبدأ" في الرأي الاستشاري الخاص بكوسوفو ("). ويشير الأستاذ (دارجنت) إلسى أن استخدام "مبدأ" بالدلالتين الأخيرتين لَهُوَ

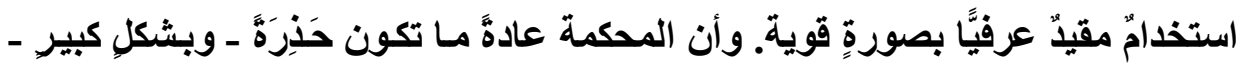

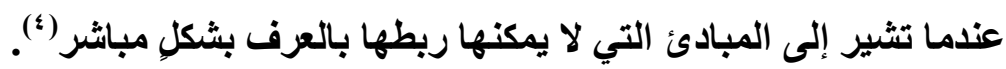

(1) James CRAWFORD, "The General Assembly, the International Court and Self- Determination", in V. LOWE, ed., "Fifty Years of the International Court of Justice-Essays in Honour of Sir Robert Jennings", Cambridge, Cambridge University Press, 1996, p. 586.

(2) P. D'ARGENT, "Les principes généraux à la Cour Internationale de Justice", op.cit., p. 108 et s.

(3) T. BURRI, "The Kosovo Opinion and Secession: The sounds of Silence and Missing Links", German Law Journal, Vol. 11, 2010, p.881.

(4) P. D'ARGENT, "Les Principes généraux à la Cour Internationale de Justice" op. cit., p.110. 
وفي حالة تقرير المصير، يبدو أن المحكمة تستخلم "المبدأ" كنوع محدد من القواعد القانونية، وتعديدًا كقاعدةٍ قانونيةٍٍ عامـةِ وتأسيسية، (') تتعارض مـع القاعدة القانونية الخاصة. وباعتبارها كذلك، تنص وتعبر عن القيم السياسية والأخلاقية. بهذا المعنى، يمكن أن يُعََّ مبدأ تقرير المصير قاعدةًَ قانونيةَ تتضمن مضمونًَا قياسيَّا يمكن

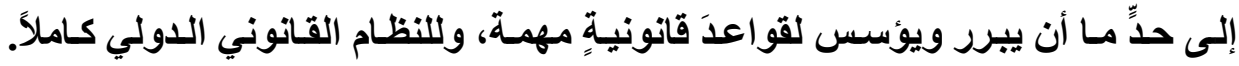
باختصار، يبدو أن المحكمة تفسر مفهوم "المبدأ" كقاعدةٍ قانونيةٍ ذات إمكانية معيارية مهمة في التلاقي مع القواعد العرفية والمثل العليا السياسية والأخلاقية(؟).

ومن وجهة نظر القضاء الدولي، يتطلب هذا التكييف "للمبدأ" مجهودًا كبيرًا في التفسير. حيث يتعين على القضاة تعريف وتحديد وتخصيص فهمهم للمضمون الدقيق ولدلالـة مبدأ تقريز المصير، وذلك على ضوء الواقع القـانوني والسياسي والأخلاقي

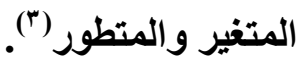

واتِّاعًا لتحليل الأستاذ (دارجنت)، فقد لا يكون مدهشًا أن نجد أن المحكمة قد واجهت هذا التحدِّيَ بربط تفسيرها بما قـ يتطلبه هذا المبدأ من تحدياٍ للقواعد القانونية العرفية الناشئة أو الوليدة. وعلينا الرجوع إلى الأحكام القضائية الدولية وإلى منهـج المحكمة وطريقة عملهـا، على سبيل المثال لا الحصر؛ لوضـع تفسير محدد لتقريـر

(1) Riccardo GUASTINI, "Les principes de droit en tant que source de perplexité théorique", in, S. SIZARET, "Les principes en droit", Paris, Economica, 2008, p. 113.

(2) Samantha BESSON, "General principles in International Law- Whose Principles?", in Samantha NBESSON, "Les principes en droit européen- principles in European Law", Schulthess, 2011, p.65.

(3) David RAIC, "State-hood and the low of self-Determination", op. cit., p.325. 
المصبر.ومن المهمِّ في الوقت الراهن، أن نقرَّ بأن "مبدأ" تقرير المصير هو نوعٌ

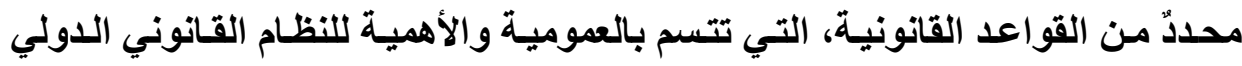
و وعلاقته بالقيم السياسية والأخلاقية)' (1)

إن التمعن في "مبأ" تقرير المصير يساعد في تفسير كيف تعاملت وتفاعلت

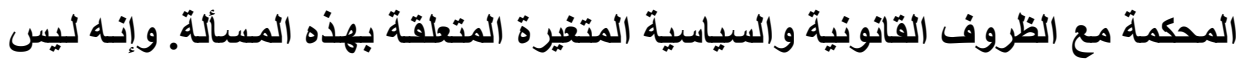

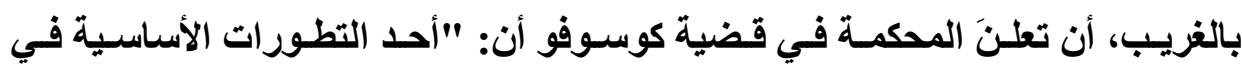
القانون الدولي أثناء النصف الثاني من القرن العشرين يتمثل في التطور الأي طرأ على

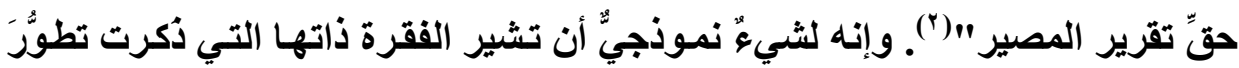

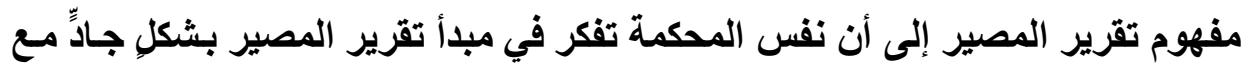

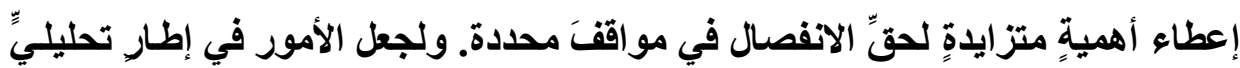

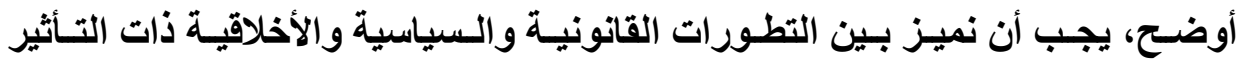
المتبادل على مسائل تقرير المصير (").

في بُعد أول للمسألة، تعاملت المحكمة أو تفاعلت مع التطورات القانونية ذات الصلة. وقد يكون المثال الأوضح على ذلك هو إبراز أو تقديم قواعدَ قَانونيةٍ جديدةٍ ذات التهات

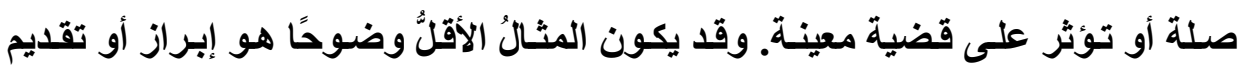
قاعدةٍ جديدةٍ من قواعد القانون النـاعم أو غير الملزم قانونَّا، كقرارات أو توصيات

(1) Pierre D'ARGENT, "Les principes généraux à la Cour Internationale de Justice", op.cit., p. 111.

(2) ICJ, 16 October 1975, Western Sahara, Advisory Opinion, I.C.J., Reports 1975.

(3) J.KLABBERS, "The Right to be taken Seriously: Self-Determination in International Law", op. cit., p. 197. 
الجمعيـة العامـة، وكمـا نـرى، ينتج عن الحالـة الأخيرة في المقابـل أسئلة أو تساؤلاتُّ

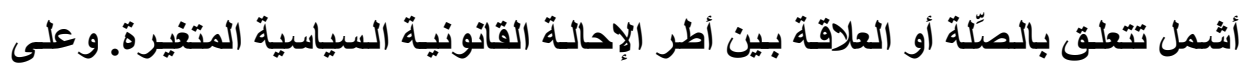

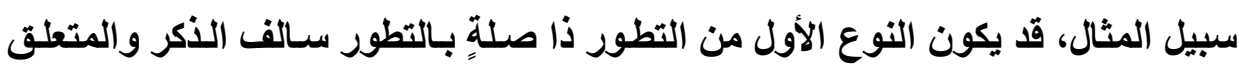
بالثعوب الأصلية، وهو مجالٌ تتثارب فيه حقوق الإنسان وحماية الأقليات وحق تقرير

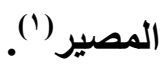

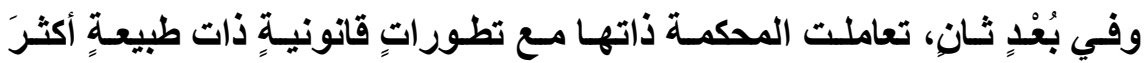
هيكلية. وفي ذهابها إلى ما هو أبعدُ من جوهر القانون الدولي، كان باستطاعة المحكمة

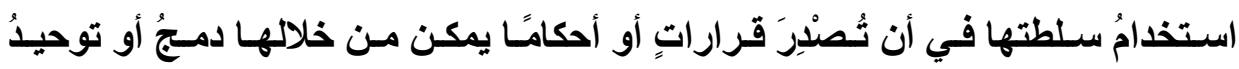
تظورات القانون الدولي ذاته كنظام قانوني عام(؟)

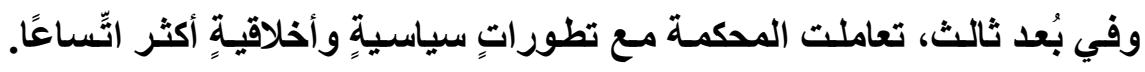
ويجب أن نفهم هذا البعد الثالث جديَّا كـأمر مرتبط بـالنوعين الآخرين. ويُعَدُ هذا البعد بـد الثالث بالفعل دمجًا لهما طبقَا للعديد من وجهات النظر. وكأحد أكثر الأمثلة وضوحًا، يمكن التفكير في عملية إنهاء الاستعمار بصورةٍٍ كليةٍ والوقوف على جذورها، وذلك من خـلال التغيـرات العالميـة القانونيـة والسياسية والثقافيـة في مفهـوم التقبـل الأخلاقي والمعنوي للاستعمار (")

(1) Daniel THURER and T.BURRI, "self-Determination", op. cit., p.230 ET S.

(2) Allen BUCHANAN, "Justice, Legitimacy and self-Determination: Moral Foundations for International Law", Oxford, Oxford University Press, 2014, p.311.

(3) P. D'ARGENT, "Les principes généraux à la Cour Internationale de Justice", op.cit., p. 115. 
ومن المثير للاهتمام، وجوب التأكيد على أن المحكمة لا تنفرد بأمرهـا. بـل على النقيض، وضعت المحكمة قراراتِها وأحكامَها في إطار مؤسسيِّ أشـمل، وسجلت تفـاعلاً

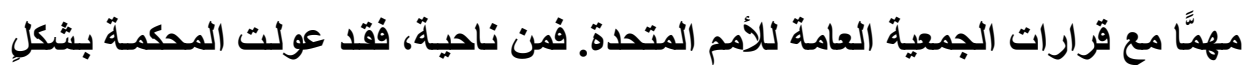
كبيز على نوع ما من تقسيم العل، والذي أكلت من خلاله على محدودية دورها. ويؤثر ذلك، في الحقيقة، بشكلٍ واضح على العلاقة المؤسسية والسياسية للعناصر القانونية والحلول التي يمكن أن توفرها. ومن ناحيةٍ أخرى، فقد عولت المحكمة بثكلٍ كبيز على التظورات التي لحقت بنظام الأمم المتحدة فيما يتعلق بآليات التّخـاذ القرارات بها. وفي سياق عملية إنهاء الاستعمار، حاولت المحكمةُ أن توفق بين قراراتها وبين التطورات السياسية التي تلدعمها الجمعية العامـة للأمم المتحدة في هذا الشأن. ويقول الأستاذ (كراوفورد): إن المحكمة قد حاولت قدر الإمكان التوفيقَ بين أحكام القـانون الطبيعي وسياسات وممارسات الجمعية العامة في هذا الصدد (').

ويتضح لنا من التحليل السابق، أن السِّمَة الأسساسية لمنهجية المحكمة تنعكس في خصوصية مبدأ تقرير المصير من خلال القواعد العرفية السائدة في ظروفٍ وأحوال قانونيةٍ معينة. ولقد برزت أهميةٌ الاعتماد على العرف في تحديد الملامح الدقيقة لتقرير المصير عن طريـق التعامل أو التفاعل بـين المحكمـة والجمعيـة العامـة للأمسم المتحدة كهيئة منظمة ديمقر اطيَّا تعكس ممارسات الدول وقبولها لتطوراتٍ معينة. r- الدروس المستفادة هن دور المكمة: إن الهـف من الاراسة الحالية هو إعـادة بنـاء منهجية المحكمة لتقرير المصير في إطار أشمل عن دورها وطرق القضاء بها. ولذلك تعدُّ هذه الدراسـة بمثابة الخطوة

(1) James CRAWFORD, "The General Assembly, The international Court and self-Determination", op. cit., p. 587 et s. 
الثانية في رحلتنا المنهجية بشأن إعادة بناء منهج المحكمة وبيـان الكيفية التي يتعين عليها العمل والتصرف بمقتضاها. أ- سنَُّ القانون القضائي وتصدياته:

لقد خلصت الأستاذة (بيسون) إلى وجود مسألتَيْن تتعلقان بتأسيس نظريـةٍ عامـةٍ

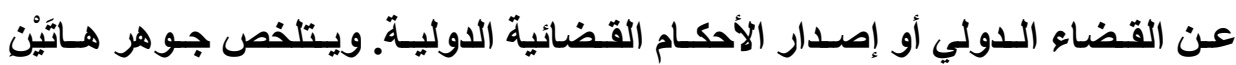

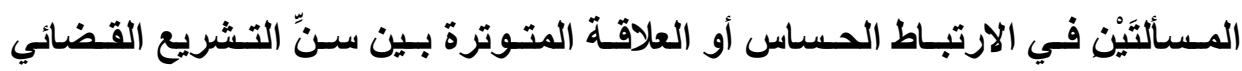
والسياسة من ناحيةٍة، وسن التشريع القضائي والأخلاق من ناحيةٍٍ أخرى. وبـالتركيز

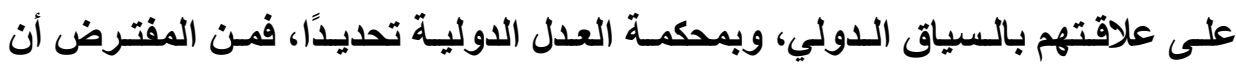

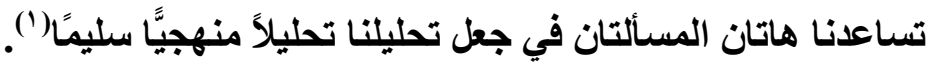

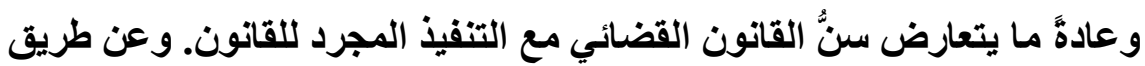
تحديد وتفسير قاعدةٍ قانونيةٍ بطريقةٍ معينةٍة، يصدر عن المحكمة ما يتعلق بكيفية تفسير القاعدة القانونية على ضوء كلِّ من القضية المحددة وفي المستقبل (وهذا هو المُتَّبع مع مبدأ السوابث). أما فيما يخص مسألة مَن يجب أن يكون مُخَوَّلَا سُلطة إصدار الأحكام والقرارات استنادًا للقانون. يستوجب سن القانون القضائي تقسيم العمل بين المشرعين وهؤلاء ممن يجب عليهم أن يكونـوا مسئولين عن تطبيق وتنفيذ قانون قائم بالفعل. وعلى الرغم من ذلك، قد يكون من الخطأ مساواة سن القانون القضائي بسنِّ القانون التقليدي. وإذا كان سنُّ القانون العادي السياسي سابقًا على سنٍ القانون القضائي بشكلٍ واضح؛ يُستخدم القانون القضائي لفهم وإدراك النتائج الإبداعية التي لا يملك القضاة

(1) Samantha BESSON, "Legal Philosophical Issues of International Adjudication- A bout the Amour impossible Between International Law and Adjudication", op. cit. p.311. 
خيار تجاهلها، بمعنى أنهم لا يملكون إلا القيام بها من خلال تحديد وتطبيق القواعد القانونية في ظروفٍ محددة (')

وتُعَدُّ إثكالية سن القانون القضائي إثُكالية متعاظمـة في نطاق النظام القانوني الدولي؛ ويرجع ذلك لسببين: الأول هو وجود ثغرات في القانون الدولي أكثر ممـا يمكن أن نجد في القـانون الـوطني. ويعنـي ذلك، أنـهـ يتعين على المحسكم الدوليـة أن تبـل مجهودًا أكبر في تفسير القواعد القانونية (القليلة) والتي توجد تحت تصرفها بهدف إصدار قرار أو حكم في القضية المعروضة أمامها. وممـا يؤكد هذه الصعوبة، التعدديـة

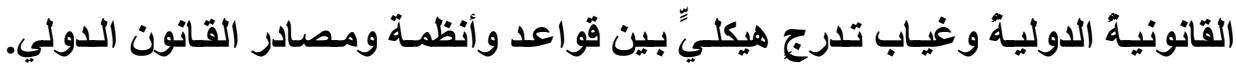
والسبب الثاني هو أن القانون الدولي يعطي المحاكم الدولية، بناءً على مصادره، وظيفة

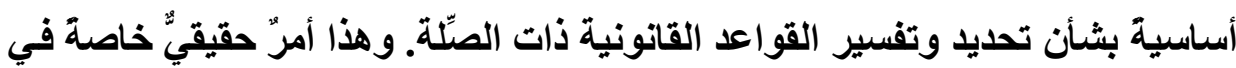
القانون الدولي العرفي الذي يتم في إطاره طلب تدخل المحكمة لتحديد ممارسـة دولـةٍ أو دولٍ معينة. ويزيد هذه الصعوبة، غيابُ منتدى ديمقراطي واضـ يقرر فيه المشرعون

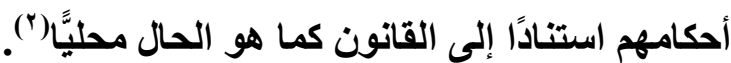

هذه الحساسيات بين سـن القـانون القضائي والسياسة تعكسها إثكالية ثانيةة تتعلق بالقضاء الدولي أو إصدار الأحكام القضائية الدولية، وتتمثل في العلاقة ببين القانون والأخلاق. فبشكل عامًٍ، ومما لا شكَّ فيه، يرتبط القانون بالأخلاق ارتباطَا وثيقًا. والتركيز هنـا، يكون على الروابط الفقهية الخاصـة بالمفـاهيم ذات الصتّلة بين الاثنين

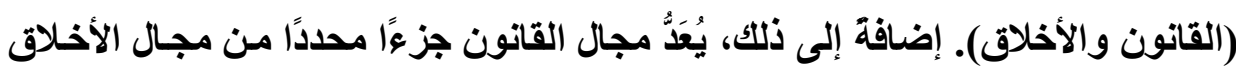

(1) Donald H. REGAN, "International Adjudication: A Response to Paulus- Courts, Custom, Treaties, Regimes and The WTO", op.cit., p. 226.

(2) Andreas PAULUS, "International Adjudication", op.cit., P.223. 
الشامل والمتسع. والقضية التي توجد على المحك هنا، هي بـالأحرى قضية كيف يُعدل

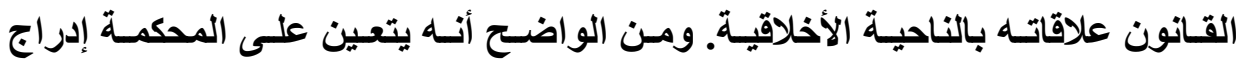
محتوى أخلاقي في القـانون، أي محتوى معيـاري لا تتضمنه مـصادر القـانون بشكل

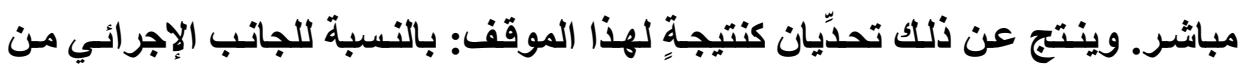
المسألة، يجب أن يكون من الواضـح أنـه يتعين على المحكمة أن تُــل في قراراتها

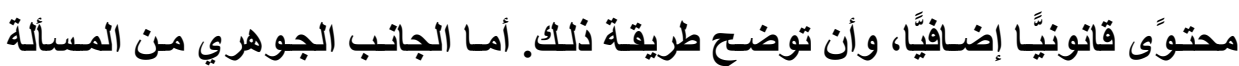
فيجب توضيح أي محتوى محدد يجب أن تدرجه المحكمة في قراراتها وأحكامها('). ب- بين السياسة والأخلاق: البحث عن طريق لتقرير الصير لأجل النقاش الحالي، أقترح أن نضع في اعتبارنـا هذيْنْ السؤالَيْن التقليدِيَّنْن عن القضاء في القضايا الدوليـة جنبًا إلى جنب مـع بُعدين اثنين: يتعلق الأول بـالإجراء،

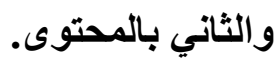
أولاً: يتعلق البُعد الإجرائي بالتحديات المتعلقة بالسياسة والأخلاق وبمـا هو ذو صلة مـع سن القـانون القضائي. آخذين في الاعتبـار السوابق القضائية بشأن تقرير المصير، كيف يمكنتا فهم أحكام المحكمة على ضوء هذا التحدِّي الإجرائس؟ ثاتيًا: بُعد محتوى القرار الذي تُصدره المحكمة في قضايا تقرير المصير. إن هذا الأمر يثير بشكلٍ مباشرٍ التساؤلَ حول بعض العناصر التي قد تسترشد بها المحكمة في حكمها في قضيةٍ ما من قضايا تقرير المصير، وفي اتِّاذها موقةًا معينًا من المبادئ المتعارضة.

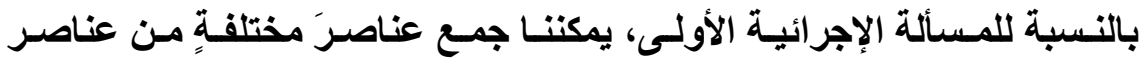
التحليل المـذكورة بالقعل. ويمكن، أيضًا، إعـادة صـياغة الارتبـاط بـين سـن القـانون

(1) Leslie GREEN, "Legal Positivism, Stanford Encyclopedia of Philosophy", 2013, p.273. 
القضائي والسياسة الديمقراطية على النحو المذكور، وذلك في السؤال الآتي: عنــ تفسير مبـدأ تقريـر المصير، كيف تراعي المحكمة الإرادة السياسية التي يُعبر عنهـا المشرعون الدوليون، أي الدول فيمـا يصدر عنهـا من أعمـال قانونيـة؟ إن إعـادة بنائنـا

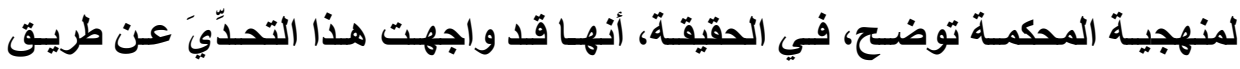
محاولاتهـا المتكـررة للتوفيـق بـين منهجيتهـا وبـين المواقـف التـي تتخــها الـدول

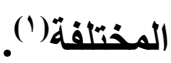

أولاً: لقد تم توضيح أن المحكمة قد قامت بفصل جوهر تقرير المصير في صيغة اختبـار إجرائسي، اعتمـادًا على العرف في تحديـ هذا المبـأ في ظل ظروفٍِ متغيرةٍ ومتطورة. وإذا اعْتُبرَ لبُّ تقرير المصير منفصلًا عن الواقع المتغير، فِإن مواصفاتِهِ تتظور على ضوء تحولاتٍ قانونيةٍ وسياسيةٍٍ وأخلاقيةٍ معينـة. ويمكن فهم هذا الاعتمـاد

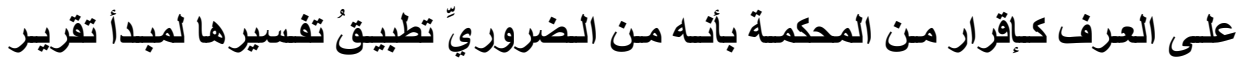
المصير في أفضل الصور الممكنة المتسقة مع الإرادة التي ثُعَبِرُ عنها أغلبية الدول. وقد

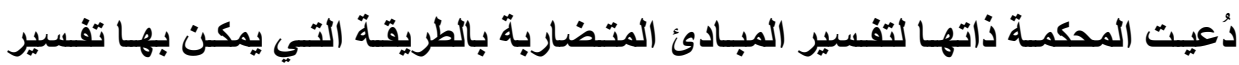

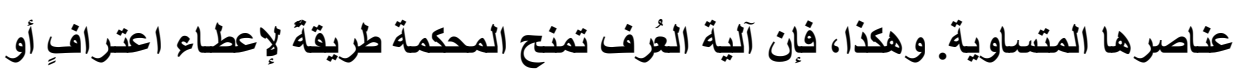

$$
\text { إقرار قضائيٍٍ (مباع بالضرورة) للتطورات ذات الصلةة(؟). }
$$

ثانيًا: كما أوضـحنا سـلقًا فيمـا يخص الجمعيـة العامـة للأمم المتحدة، فقد بحثت المحكمة عن طرق لامج تفسير ها لمبدأ تقرير المصير في إطار مؤسسيٍ أوسعَ وأعظم. وكمـا عرضـنا سـلقًا، قد أعطت تفسيرات لمهمتهـا القضائية، وتفسير تقرير المـصير

(1) Pierre D'ARgENT, "Les principes généraux à la Cour Internationale de Justice", op.cit., p. 112..

(2) Allern BUCHANAN, "Justice, legitimacy and self-Determination: Moral Foundations for International Law", op. cit., p.315. 
مرتبط أو من القرب بمكان للمواقف التي تتخذها الدول التي توجد تحت مظلة الجمعية

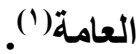

ومن ناحيةٍ أخرى، يمكن صياغة حالـة الحساسية أو العلاقة المتوترة بين سن

القانون القضائي والأخلاق في التساؤل الآتي: كيف يمكن إيجاد توافق بين منهجية المحكمة في دمـج محتوى قانوني إضـافي متجدد لمبدأ تقرير المصير وبين الموقف الوضعي؟ يمكنتا القول: إن العناصر المهمة للإجابة عن هذا التساؤل تعتمد على التحديد الاقيق لمبدأ تقرير المصير واستخدامه في القضاء الدولي أو الفصل في المنازعات الاوليـة. باختصار، يسمح التفسير (إعـادة التفسير) القضائي للمبدأ بعملية انـماج تدريجية وبطيئة لمحتوى متجدد لمبدأ تقرير المصير (†).

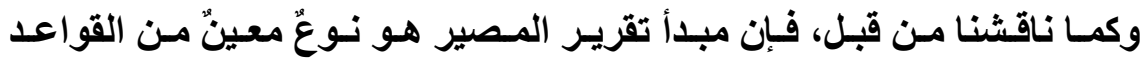

القانونيـة التـي تتسم؛ ليس فقط بالعموميـة والأصـولية، ولكن أيضًا تتسم بعلاقاتهـا

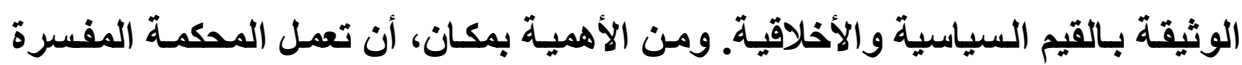
لهـا المبدأ كمـوازن بيلن القيم السياسية والأخلاقيـة والقواعد القانونيـة ذات الصلة. وتقوم المحكمة بصياغة القيم السياسية والأخلاقيـة في نصوص قانونيـةٍة، وذلكك عن طريق تفسير ما يرقى إليه مبدأ تقرير المصير تفسيرًا يتسم بالتجديد أو الجدة. ويساعد هذا التركيز على القـانون القضائي في تفسير الطريقـة التي يمكن بهـا تحويل القيم

(1) Pierre D'ARGENT, "Les principes généraux à la Cour Internationale de Justice", op.cit., p. 113..

(2) Johan ROCHEL, Alain ZYSSET, "Between Authority and Morality : Identifying Two Legitimatory Roles of Legal Principles", in Samantha BESSON, Pascal ICHONNAZ, eds., "Principes En droit européen Principles in European Law", Schulthess, 2014, p.105 et s. 


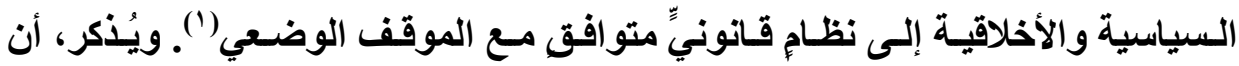
محكمة العدل نفسها ثُدعم وجهة النظر هذه وتدافع عنها. فكما أعلنت في حكمها الصادر

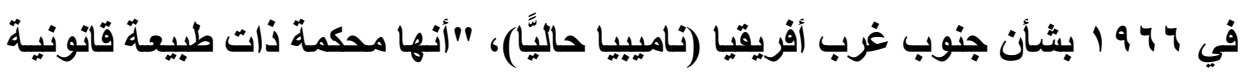
وتختص بالمسائل القانونية. ويمكن أن تضع في حسبانها المبادئ الأخلاقيـة إذا مـا تم التعبير عنها بشكلٍ كـافٍ في صورةٍ قانونية. وكمـا هو معروف، فِإن القانون موجودٌ لخدمة حاجة اجتماعية، ولهذا وعلى وجه التحديد، يمكنه القيام بهذه الوظيفة فقط من خلال وفي نطاق حدود نظامـه الخـاص. وإلا فلا يكون الأمر الذي نـن بصدده خدمـة

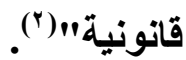

وتتلخص انعكاساتنا عن الجاتب الإجرائي للتساؤلات التقليدية المذكورة سلقًا،

مـن خـلال القـول بـأن إعـادة بنـاء منهجيـة المحكمة لهـو أمـرّ متوافق مــع المنهجيـة الوضعية. إلا أنه لا يجب فهم هذه الاحتمالية النظرية على أنها ادِّعاء بأنه قد تم التظلب على الصعوبات القضائية العملية أو حلها، وأن مسألة تقرير المصير وكونها ذات صلة

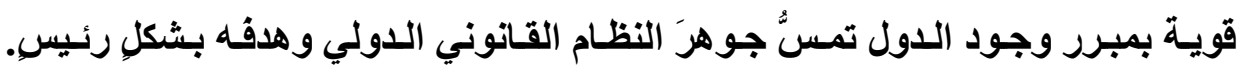
ويُذكر، أن محكمة العدل الدولية ذاتها في موقفٍٍ صعبٍ في تفسيرها لذلك، ومن هنا فِان

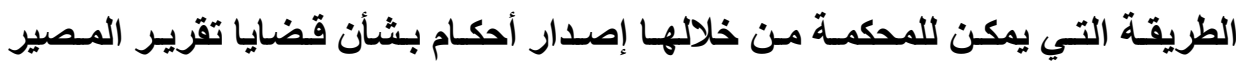
كمسألة محتوى (وليس كمسألة إجراء) لهي إذا مسألة ذات أهمية قصوى(").

(1) Ibid., p.108.

(2) ICJ, 18 July 1966, South West Africa, Second phase, Judgment, I.C.J. Reports 1966, p.6, Para. 49.

(3) Robert JENNINGS, "The Judiciary, International and National, and the Development of International Law", op. cit., p.196. 


\section{جـ- أي تقرير هصير؟ حذِس بخصوص القيم الفردية}

إذا كان من الممكن إعادةُ بناء أو إعادة تنظيم منهجية محكمة العدل الدولية في

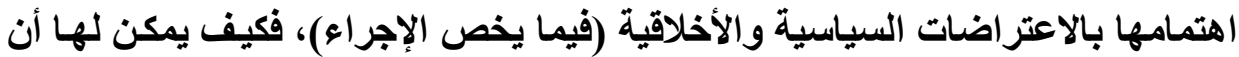

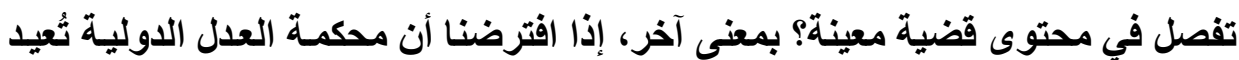

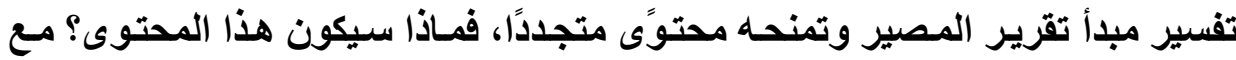

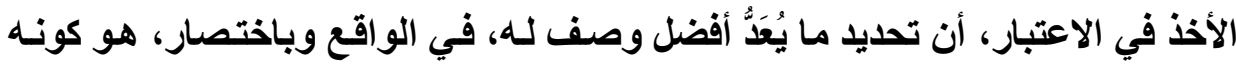

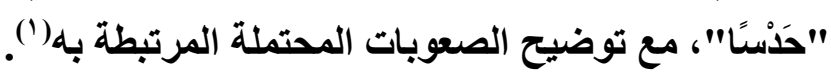

سأستهل الأمر بتحذير مهم. ليس الهدف من هذا الجزء الحالي من الدراسـة هو

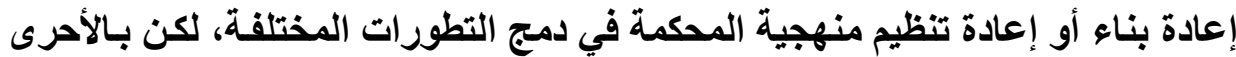
طرح تساؤل، من وجهة نظر المحكمة التي تنظر إحدى قضايا تقرير المصير، عن كيفية إصدار حكمها في القضية المعروضة عليها. أولا، يفسر هذا التركيز السبب وراء أهمية أهية تناول هذه المسألة من خلال سلطات وصلاحيات محكمة العدل الدولية والسياق الدولي المحدد والذي يتعين عليها فيها أن ثُصدر قرارًا في القضايا المعروضـة عليها. ثانيًا، يحول هذا التركيز دون اعتبار المحكمة الجهة الوحيدة المسئولة عن علاج كافة أوجهـ

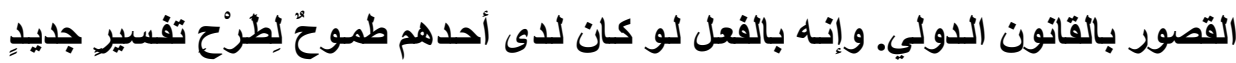

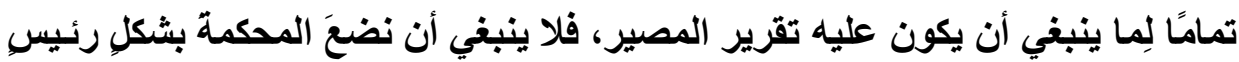

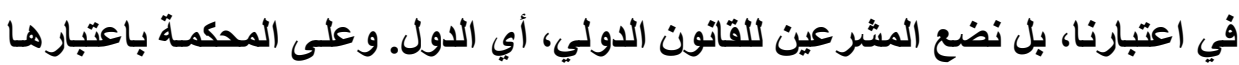

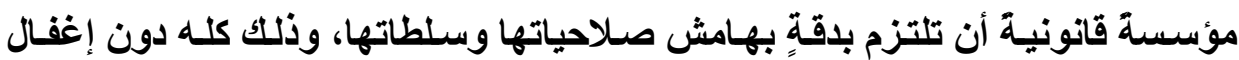

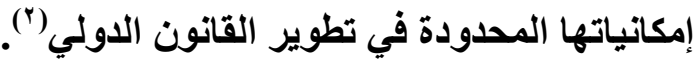

(1) Leslie GREEN, "Legal Positivism, Stanford Encyclopedia of Philosophy", op. cit., p.275.

(2) Allen BUCHANAN, "Justice, Legitimacy and self-Determination: Moral Foundations for International Law", op. cit., p.317.

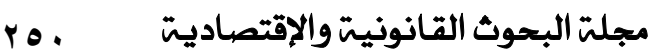




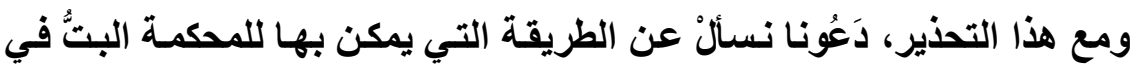

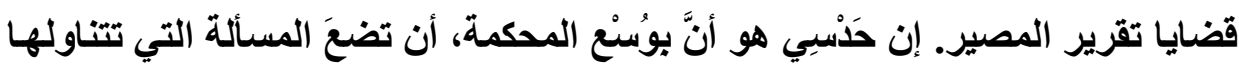

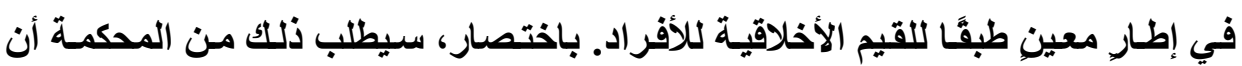

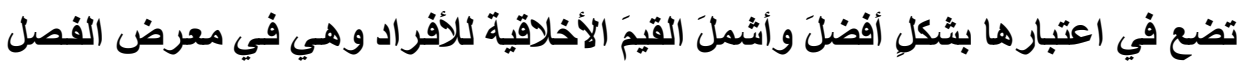
في قضايا تقرير المصير.

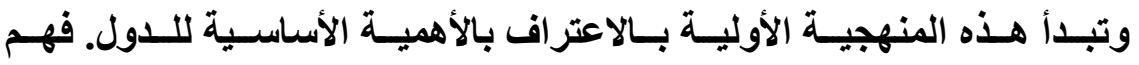

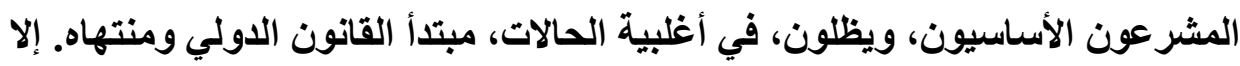

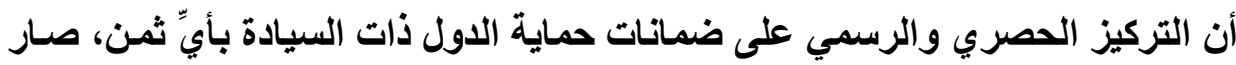

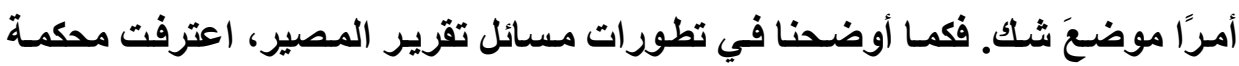

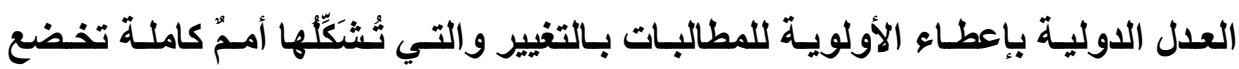

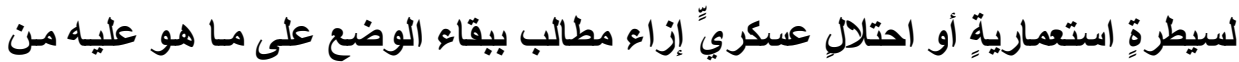

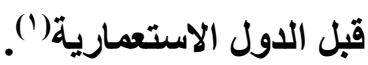

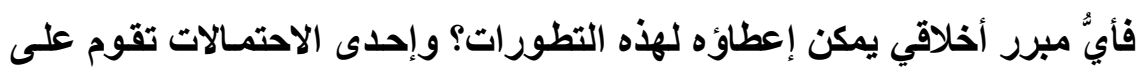

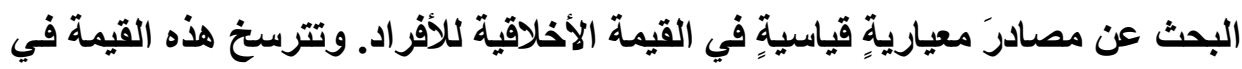

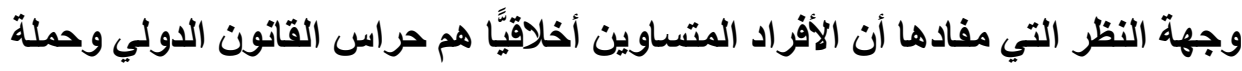

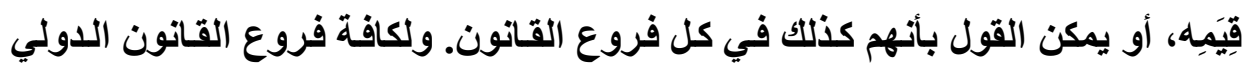
الأخرى قيمة محدة فقط فيما يخص هؤلاء الأفراد (†) .

(1) Emmanuelle JOUANNET, "Le juge international face aux problèmes d'incohérence et d'instabilité du droit international: quelques réflexions a propos de l'arrêt CIJ du 6 novembre 2003, Affaire des plates,- Formes pétrolières". Revue générale de droit international public, no4, Vol. 108, 2004, p.917.

(2) Jeremy WALDRON, "The Concept and the Rule of Law", Georgia Law Review, no1, Vol. 48, 2013, p.351. 
وترتبط القيم الأخلاقيـة للأفراد بشكلِ قويٍ بالصور الجماعية لتقرير المصير.

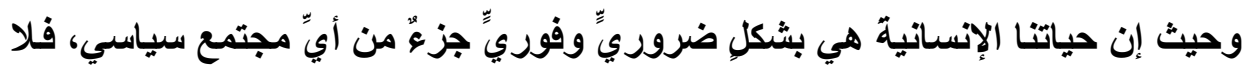

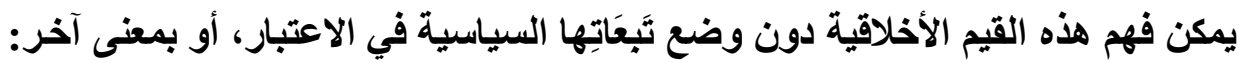

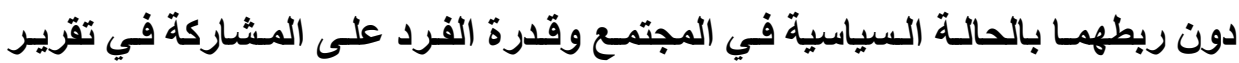
ظروف وجوده في مجتمعه. ومن هذا المنطلق، يرتبط تقرير المصير السياسي بصورةٍ وثيقةٍ بالقيم الأخلاقية للأفراد.

وتثير وجهة النظر هذه، إلى أنه من الخطأ أن نعتقد وجودَ تعارض بين القيم

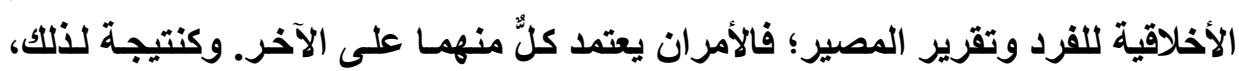
نجد ارتباطا وثيقًا بين المجتمعات السياسية التي تتسم بعدم الديمقراطية وبين المطالبات

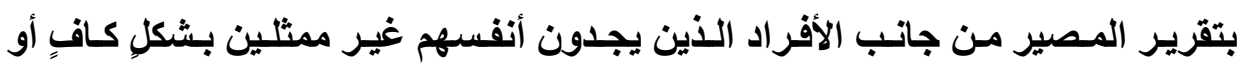

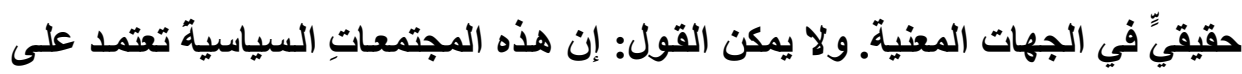

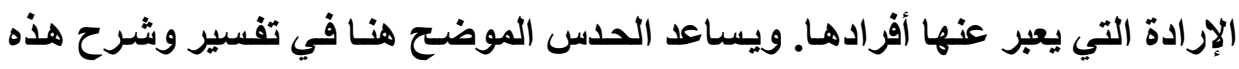

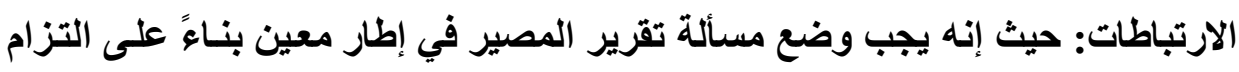
بالقيم الأخلاقية الأسناسيةـ غير الحصرية_ للأفراد (1) بالطبع، ليس مقدرًا لوجهة النظر هذه الإلمـام أو الإحاطة بواقع تجريبيٍّ حاليٍّ

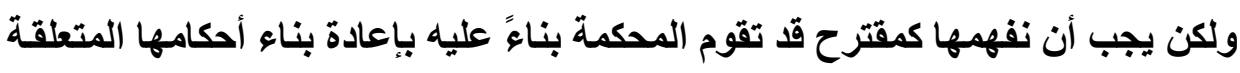

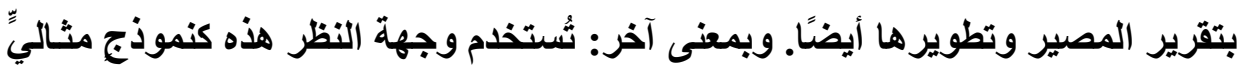

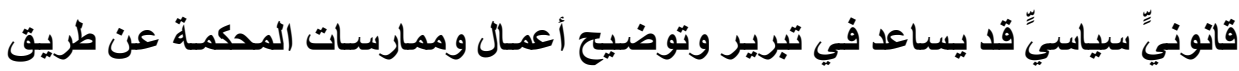

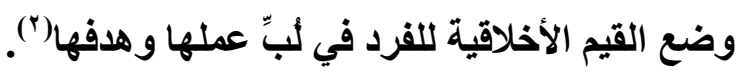

(1) Daniel THURRER and T. BURRI, "Self- Determination", op. cit., p.229.

(2) Samantha BESSON, "Legal philosophical Issues of international Adjudication-About the Amour Impossible Between international Law and Adjudication", op. cit., p.319. 
فهل يمكن لهذا الحسل أن يُقرِيّنَا من تحديد الطريقة التي قد ثُصدر بها المحكمة

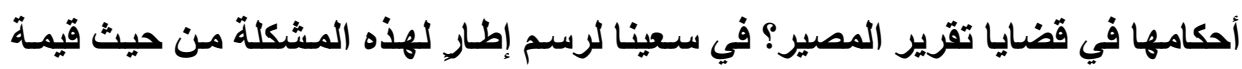

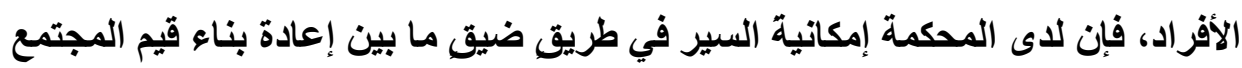

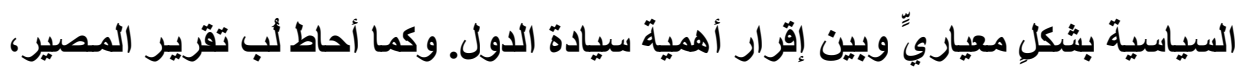

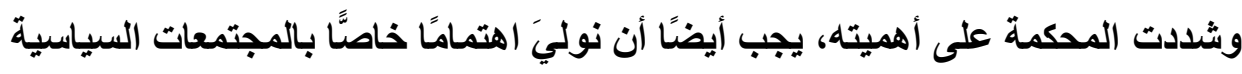
باعتبار أنها تعبر عن إرادة أفرادها(')

ولا يدعو هذا الحسل، الذي يعتمد على قيمة الأفراد، إلى تغيير كامل في طريقة

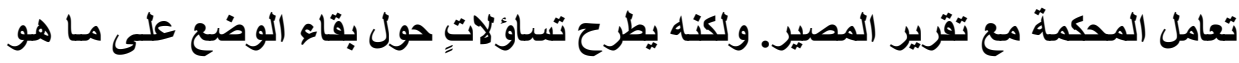

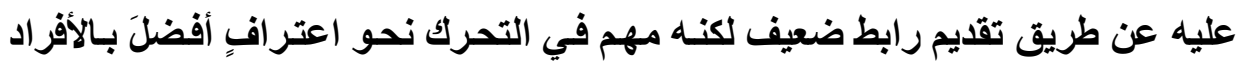

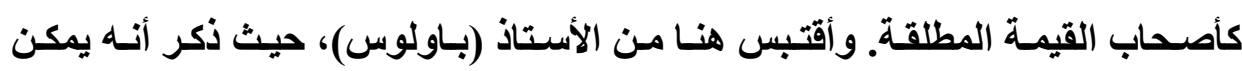

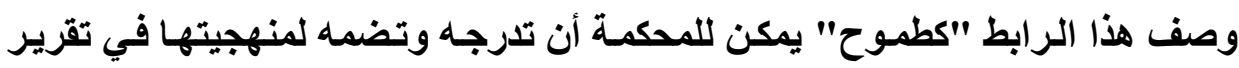

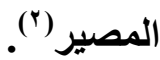

وبالنسبة للمحكمة، فإن مفهوم "الطموح" نفسه يشداد على دور هـا المحدود.

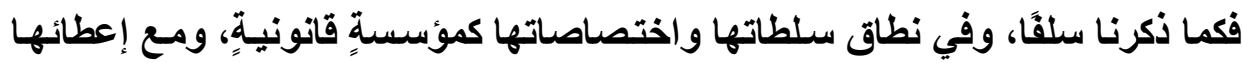

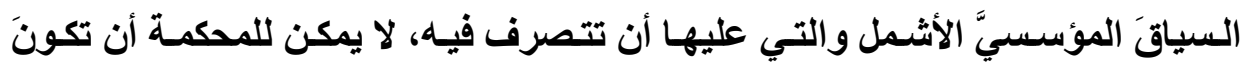
مسئولة عن تطوير وتعزيز شرعية القانون الدولي. ولكن عليها بالفعل، أن تلعب دورَها

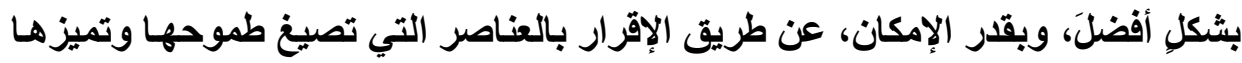
في قراراتها (كما في قضايا تقرير المصير)(").

(1) Allen PUCHANAN, "The legitimacy of International Law", in, Samantha BESSON, John TASIOULAS, eds., "The Philosophy of International Law". Oxford, Oxford University Press, 2010, p.79-80.

(2) A. PAULUS, op. cit., p.229.

(3) Andreas PAULUS, "International Adjudication", op. cit., p.224. 


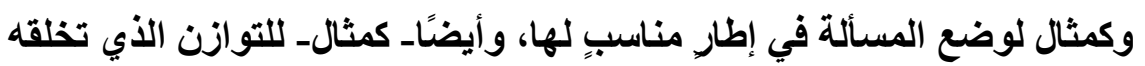

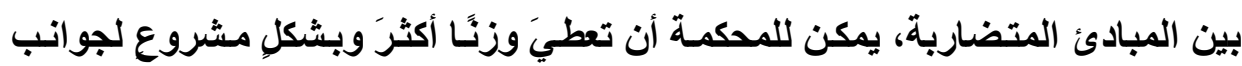

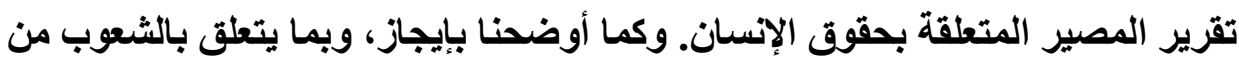

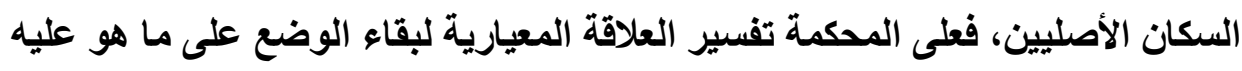

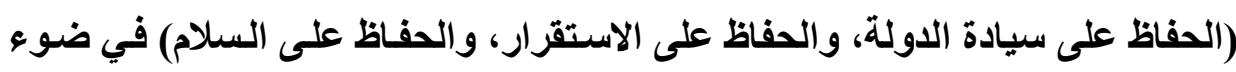

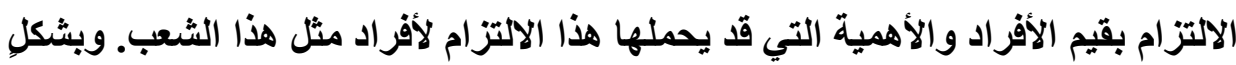

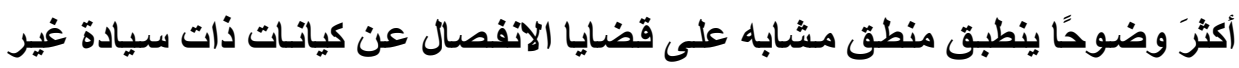

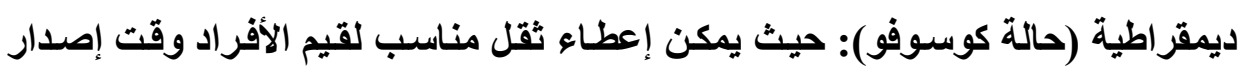

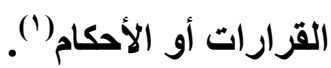

وتلخيصًا للحدس الذي تم توضيحه، فقد أوضحت أنـه يمكن لمحكمة العدل

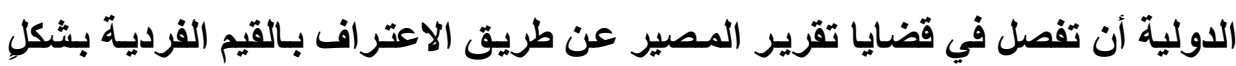

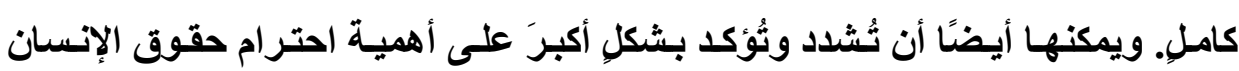

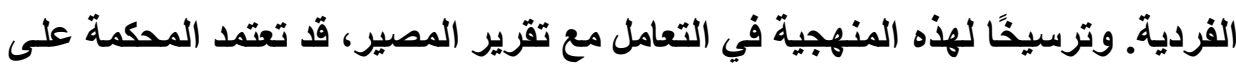

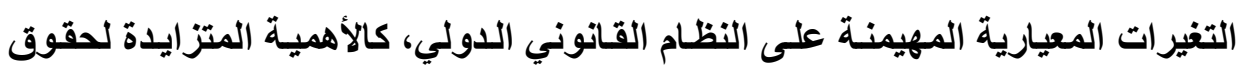

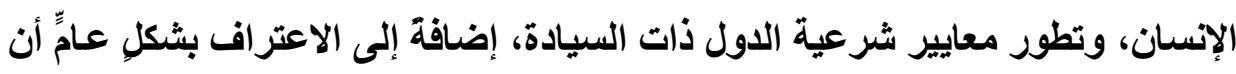
القانونَ الدوليَّ لا يفوت مسألة التمحيص الأخلاقي.

(1) Emmanuelle JOUANNET, "Le Juge International Face Aux Problèmes d'instabilité du droit international : Quelques réflexions à propos de l'arrêt CIJ du 6 novembre 2003, Affaire des plates- formes pétrolières". op. cit., p.918. 


\section{المبحث الثالث

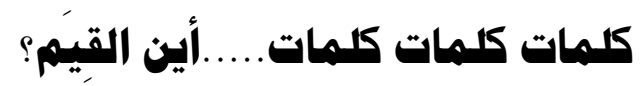 \\ تقييم القاضي الدولي والقواعد الآهرة}

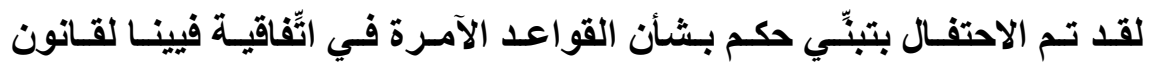

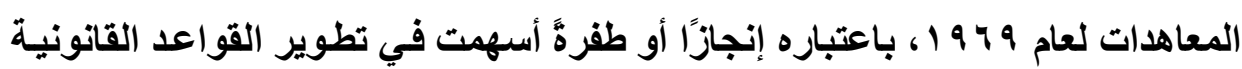
الاولية؛ فقد اعترفت للمرة الأولى وثيقة دوليةّة بوجود قواعدَ قانونيـة دوليةٍة عليـا أو أعلى ذات طابع لا يمكن التحلل منه. فقي وقت إعداد المـادة (به ) من الآتّفاقية سـالفة الأكر والتي تتص من منطلق عامٍ على أن تكون المعاهدةٌ باطلة إذا تعارضت مـع قاعدةٍ آمرةٍ من قواعد القانون الدولي العام، توقعت لجنة القانون الدولي (ILC) أن المحتوى الكامل لهذه القاعدة سوف ينجح؛ ليس فقط في ممارسات الدول، ولكن أيضًا في قضاء

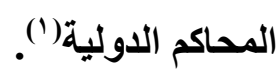

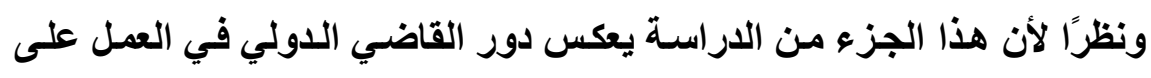
نجـاح المقصود بالقواعد الآمرة، سـوف أتنـاول بالتحليل الأجزاء ذات الصيّلة بقضية فئية الحصانـات القضائية للاولـة، والتـي تـم الفصل فيهـا في الثالث مـن فبرايـر مـن عـام

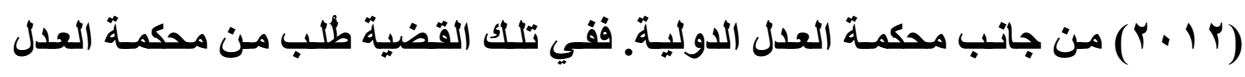
الدولية أن تتناول من بين مسائلَ أخرى العلاقةة بين القواعد الآمرة وحصانة الدولة'(؟).

(1) ILC, Draft Articles on the Law of Treaties with commentaries, YBILC, 1966, Vol, II, p.248.

(2) ICJ, 3 February 2012, Jurisdictional Immunities of the state (Germany/Italy, Greece intervening), Judgment, General list No. 143. 


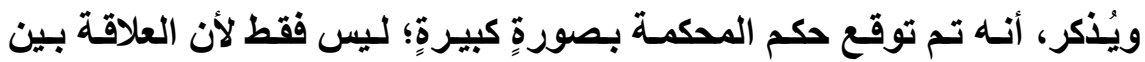

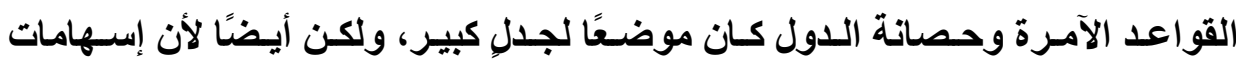
محكمة العدل الدولية في تفسير القواعد الآمرة حتى ذلك الوقت كانت محدودةًَ للغايـة. وكان الاستخدام الأول للقواعد الآمرة من جانب المحكمة في عام (؟ . . Y ) في حكمها الصادر بخصوص الأنشطة المسلحة، حيث قضت بأن الطابع الآمر للقاعدة لا ينهض

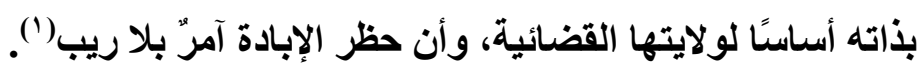
ويُذكر، أن المحكمة لم تقدم أنـه تفسيراتُ إضـافية تبين لنـا كيف اكتسبت تلكت القاعدة هذا الطابع الآمر.

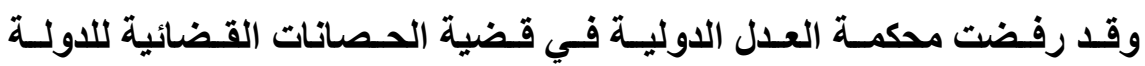
الادِّعاء بأن القاعدة التي ثُعطي دولة ما الحصانة أمام محاكم دولةٍ أخرى يجب أن نُطبق

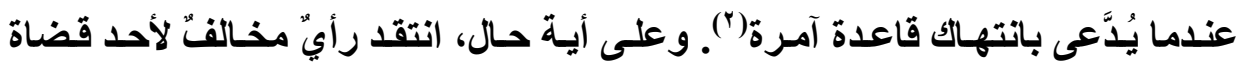
المحكمة منهجَها في هذا الشـأن؛ نظرًا لأنسه أدى إلى تقويض أسـاس مفهوم القواعد

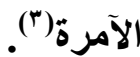

وفـي وجهـة نظـر القاضــي المخــالف (كانسـادو ترينــداد)، أن المـــهج الـــي

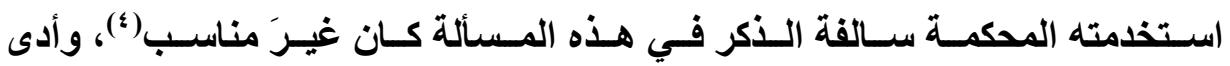
إلى جعل القانون الدولي شيئًا باليًا، بـل أفصح عن تخلفهـ المتواصل أكثرَ من تطوُّره

(1) ICJ, 3 February 2006, Armede Activities on the territory of the Congo (New Application: 2002) (Democratic Republic of the Congo/Rwanda), I.C.J. Reports 2006, p.32, Para, 64.

(2) ICJ, Jurisdictional Immunities of the State, Para. 92-97.

(3) Ibid., Dissenting Opinion of Judge Cancado Trindade, Para. 296.

(4) Ibid., Para. 294. 


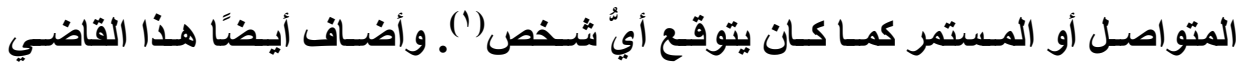
المخـالف ســالف الإثـارة إليـه، أن مـنهج المحكمـة في هـا الشأن قد أعطى مفـاهيمَ

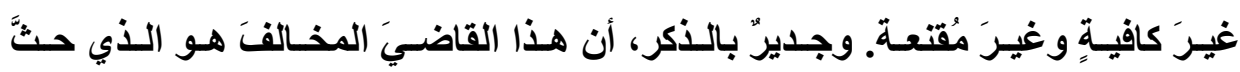

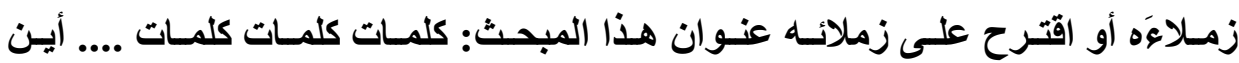

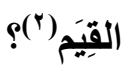

ويثير اختلاف القاضي سالف الأكر، في الواقع، تساؤلاتٍ عدةَ حول الدور الذي يلعبه القاضي الدولي، أو الذي يتعين أن يلعبَه في الفصل في القضايا المعروضـة عليه، والتي تتضمن قواعدَ آمرة. وبصورةٍ أكثرَ أهمية، فإنهـ قد طرح ابتداءً التساؤل الآتي:

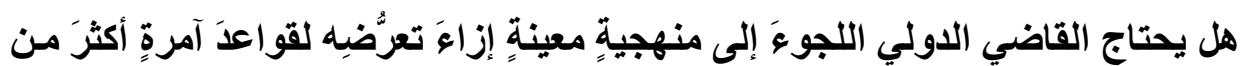
القواعد الدولية الأخرى العادية. ويسوق بعض الفقهاء الحجة على سبيل المثال، بـأن القاضسيَ الذي يُطلب منـه التعريفـُ بالقاعدة الآمـرة أو تطبيقها يتعين عليها أن يصبح

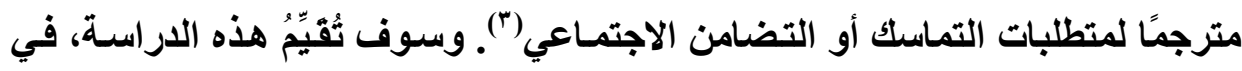

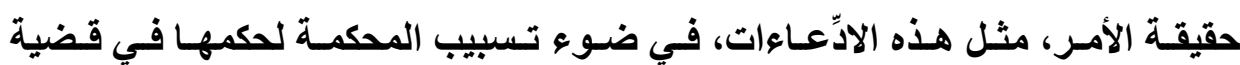

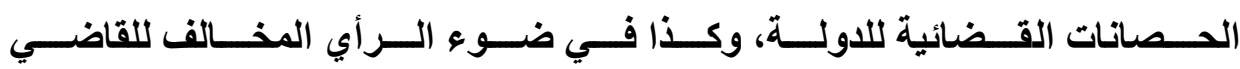

(1) Ibid.

(2) Ibid.

(3) Pierre-Marie DUPUY, "Le Juge et la Règle Générale". Revue générale de droit international Public, vol. 93, 1989, p. 597, Voir aussi, Catherine MAIA, "Le Juge international au Cœur du dévoilement du droit impératif : entre nécessite et prudence", Revue de droit international de sciences diplomatiques et politique, Vol. 83, 2005, p. 136. 


\section{ا - القواعد الآهرة ومكمية العدل الدولية:}

القواعد الآمـرة "Jus Cogens" هي، في الواقع، قواعدُ قانونيـة دوليـة لا

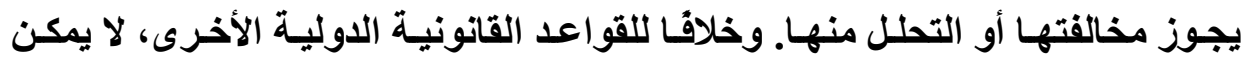

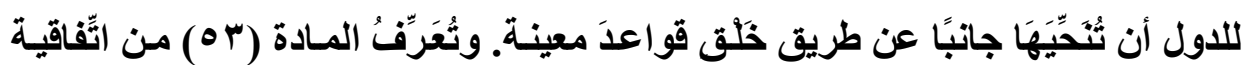

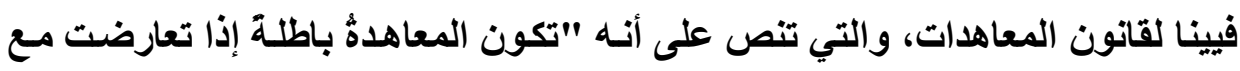
قاعدةً آمرةٍ من قواعد القانون الدولي العام"، مثلَ هذه القاعدة على أنها قاعدةٌ مقبولنة

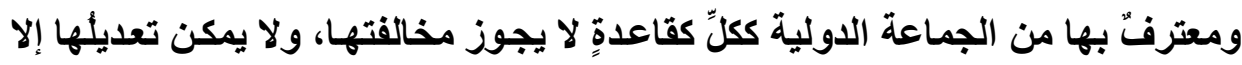

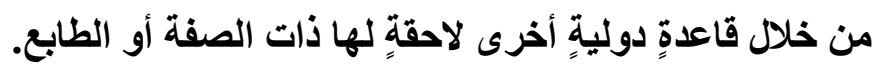

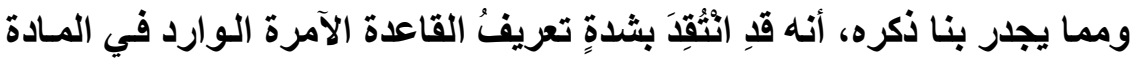

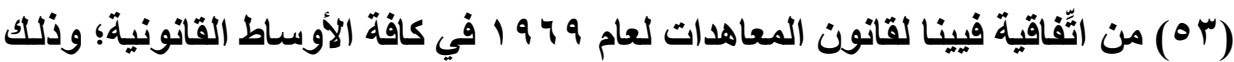
نظرًا لصياغته غير المكتملة، وكذا طابعه الغامض وغير الضروري (') .

وصرَََّتْ، من جانبها، لجنة القانون الاولي بأن صياغة المادة المذكورة سلقًا لا

تخلو من الصعوبات؛ نظرًا لعدم وجود معيار بسيط يمكن من خلاله التعريفُ بقاعدة عامة للقانون الدولي على أنها ذات طابع آمر (").

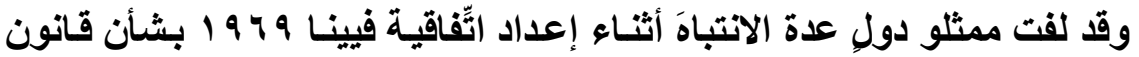

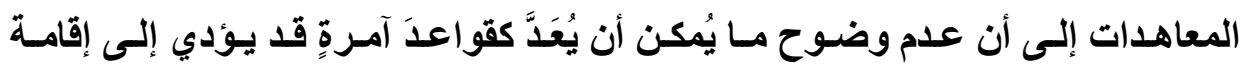

(1) Christos L. ROZAKIS, "The Concept of Jus Cogens in the law of treaties". Amsterdam, North-Holland Publishing, 1996, p.45; Bruno SIMMA, "From Bilaterism to Community Interest in International Law", Recuiel des cours, Vol. 250, 1994, p.217-318, 286-287.

(2) ILC, Draft Articles on the Law of Treaties with commentaries, note 1, p.247-248. 
د/عبد الله محمد الهوارى

ادِّعـاعات تحكميـة، بـل قد يُضْعِفُ كليـة استثرارَ قـانون المعاهدات أو العلاقِات الدوليـة

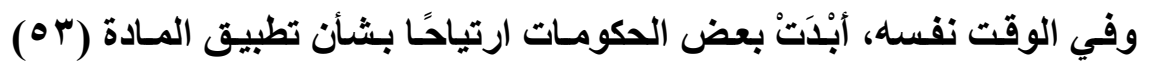

سالفة الذكر، ما لم يصاحب ذلك نظامًا مستقلاً للفصل في المنازعات المتعلقة بالتحديد الرسمي للقواعد التي تكون آمرةَّ(ّ). ويُنكر، أن العديد منهم كان مترددًا في قبول طريقةٍ

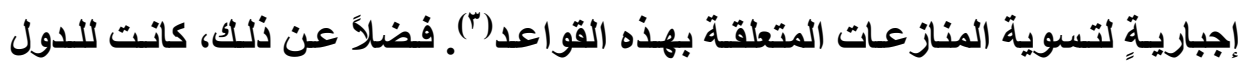
وجهاتُ نظر مختلفةٍ بشأن الآليات الممكنة لتسوية هذه المنازعـات؛ ففي حين أيدت العديا من الدول محكمة العدل الدوليـة؛ بسبب مركزهـا القانوني كجهاز قضائي رئيس

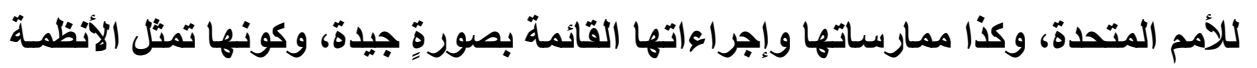
القانونية الرئيسة والنماذج المختلفة للحضارة في العالم(؛)، نجد أن عددًا من بينهم عَبَّرَ

(1) UNCLOT, Summary records of the plenary meetings and of the meetings of the committee of the whole, First Session, Vienna 26 March- 24 May 1968, UN Doc. A/CONF. 39/11, p.312 (New Zealand); 324 (Monaco); UNCLOT), Summary records of the plenary meetings and of the meetings of the committee of the whole, Second Session, Vienna, 9 April- 22 May 1969, UN-Doc. R/CONF. 39/Add. 1,p. 93-95 (France); 95-96 (Germany).

(2) ILC, Draft Articles on the Law of Treaties with commentaries, note 1, p. 247-248.

(3) UNCLOT, First Session, note 12, p.310 (Israel); 314 (Trinidad and Tobago).

(4) UNCLOT, Second Session note 12, p.107 (Japan); 138-140 (India, insisting, at the same time, on States freedom to choose, whichever means of settlement they wished); 160 (Switzerland); 199 (Nepal). 
عن عدم ثقته في المحكمة؛ بسبب عدم رضـائه عن بعض أحكامها السابقة المثيرة

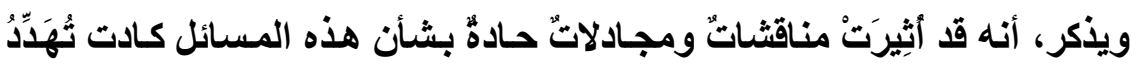

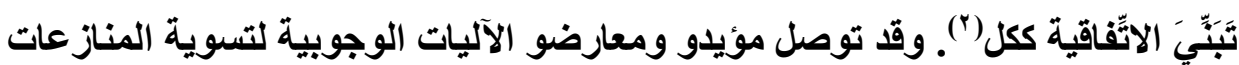

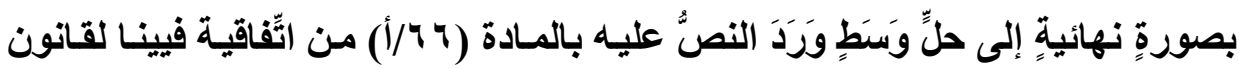

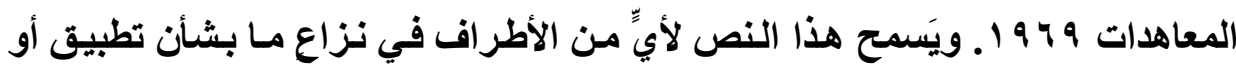

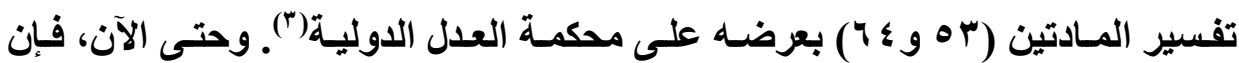

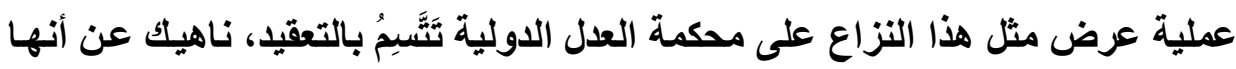

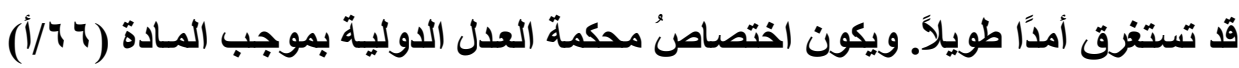

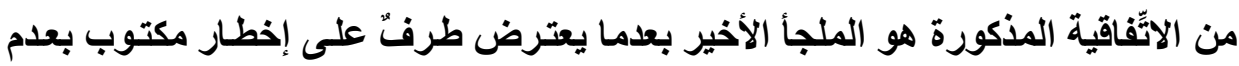

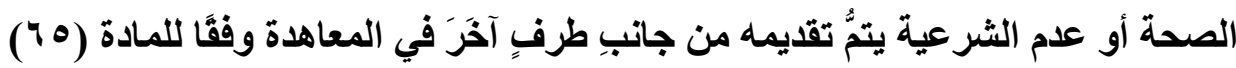

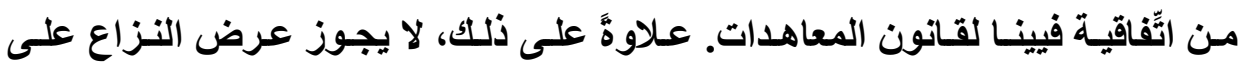

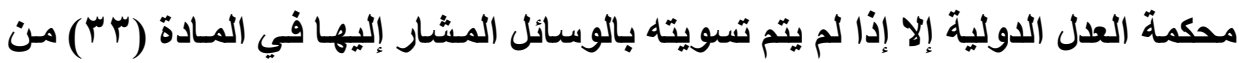

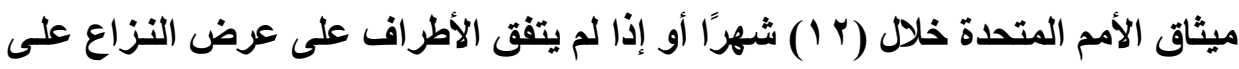

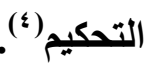

(1) UNCLOT, First Session, note p. 241 (Senegal); 300 (Sierra Leone); UNCLOT, Second Session p.288 (Democratic Republic of the Congo).

(2) Hélène Ruiz FABRI, "Article 66", in Olivier CORTEN, Pierre KLEIN, eds., "The Vienna Convention on the law of Treaties: A commentary", Oxford, Oxford University Press, 2013, p. 1513- 1536, 1519- 1525.

(3) Article 64 of the VCLT provides that if a new peremptory norm of general international law emerges, any existing treaty which is in conflict with that norm becomes void and terminates.

(4) See VCLT, Articles 65 and 66.

مجلت البحوث القانونيت والإقتصاديت 


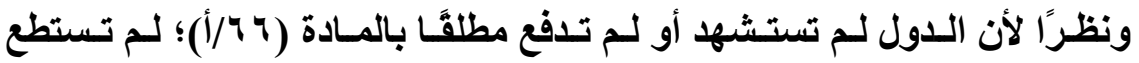

محكمة العلا الدولية أن تمارسَ اختصاصنها بموجب هذا النص. وفي أثناء الفصل في

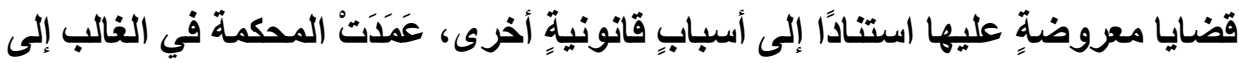
عمل إشاراتٍ غير مباشرةٍ للقواعد الآمرة"(') وفي القضايا التي كان يمكن فيها تناول المسألة، تجنبت محكمة العدل الدولية مواجهة الأمر؛ ممـا دفع بعض الفقهاء للتساؤل

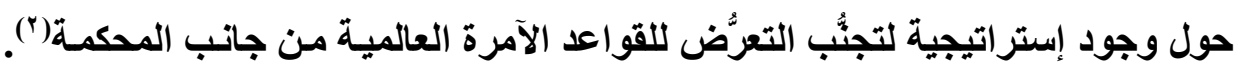
فعلى سبيل المثال، في قضية الجرف القارِيِّ لبحر الثمال لاحظت محكمـة العدل الدوليـة أنه يمكن عدم تطبيق القواعد الدولية في حالاتٍٍ معينةٍٍ دون محاولـة الدخول ابتداءً في مسألة القواعد الآمرة("). وفي القضية الخاصة بأعضاء السلك الدبلوماسي والقنصلي الأمريكي في طهران، أشسارت محكمة العـلـل الدوليـة إلـى الطـابع الآمـر للالتزامسات

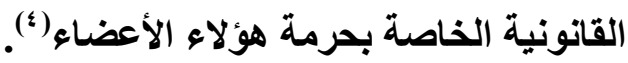

(1) Vera GOWLLAND - DEBBAS, "Judicial Insights int Fundamental Values and Interests of the International Community", in Alexander S. MULLER, eds., "The International Court of Justice: Its Future Role after Fifty Years", The Hague, Martinus Nijhoff, 2011, p. 327 et s.

(2) Catherine MAIA, "Le Juge international au Coeur du dévoilement du droit impératif", op.cit., p. 17 ; Andrea BIANCHI, "Human Rights and the Magic of Jus Cogens", European Journal of International Law, Vol. 22, 2013, p. 491.

(3) ICJ, 20 February 1969, North Sea Continental shelf (Federal Republic of Germany/ Danemark; Federal Republic of Germany/ Netherlands), Judgment, I.C.J. Reports 1969, p. 42, Para. 72.

(4) ICJ, 24 May 1980, Case Concerning United States Diplomatic and consular staff in Tehran (United States of America/ Iran), Judgment, I.C.J. Reports 1980, p. 41, Para. 88. 
وفـي القضية الخاصـة بالأنسطة العسكرية ومـا وراء العسكرية فـي/وضــ

نيكاراجوا، استشهدت المحكمة المذكورة بتصريح للجنةِ القانون الدولي يفيدا بأن حظر

استخدام القوة الوارد في ميثاق الأمم المتحدة يتعلق بالقواعد الآمرة، ولاحظت تأييد أطر اف النزاع لذلك التكييف، ولكنها لم تتخذ أيَّ موقفٍ بشأن هذه المسألة ('). وفي رأيها الاستشاري بشأن شرعية التهديد أو اسـتخدام الأسـلحة النوويـة، أشارت المحكمة إلى مبادئَ معينةٍ للقانون الدولي العرفي لا يمكن مخالقتها أو تجاوزها،

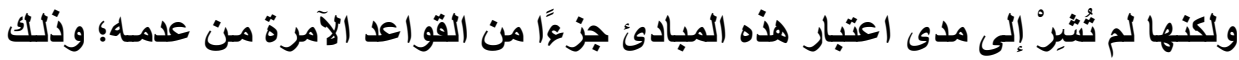
لعدم إثارة الأطراف مسألة الطابع القانوني للقانون الإنساني الأي سنيُطبَّقُ على استخدام الأسلحة النوويةة(').

ومسن اللافت للنظر بصورةٍ كبيرةٍة أن محكمـة العدل الدوليـة قد أشـارت في

رأيها الاستشاري الصادر بثأن بناء حائط في الإقليم القلسطينيِ المحتلٍّ إلى العواقب أو النتائج الوخيمة التي تترتب على الانتهاك الجسيم للقواعد الآمرة، وذلكك وفقَا للمـادة (1 ) الفقرة الأولى والثانية من مشروع قانون لجنـة القانون الدولي بشأن مسئولية الاول، وإن كاتت قد امتنعت عن الاعتراف صراحة بالطابع الآمر للقواعد المنتهكة(").

(1) ICJ, 27 June 1986, Military and Paramilitary Activities in and against Nicaragua (Nicaragua/ United States of America), Judgment, I.C.J. Reports 1986, p. 100, Para. 190.

(2) ICJ, 8 July 1996, Legality of the Threat or Use of Nuclear Weapons, Advisory Opinion, I.C.J. Reports 1996, p. 257, Para. 70; p. 258, Para. 83.

(3) ICJ, 9 July 2004, Legal consequences of the Construction of a wall in the Occupied Palestinian Territory, Advisory opinion, I.C.J. Reports 2004, p. 200, Para. 159. 


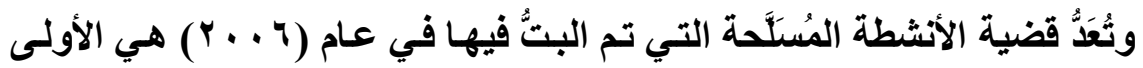

التي أثـارت المحكمة بشأنها إلى بعض اللدلالات القانونيـة للقواعد الآمـرة الدوليـة.

وقضت بـأن مجرد الادِّعاء بـأن النزاع يتعلق بـالالتزام بقاعدةٍ آمرةٍة، لا ينهض بذاتـهـ أسـاستًا لاختصاص المحكمـة بنظر النزاع('). وعلى وجـه الخصوص، أعلنت المحكمة

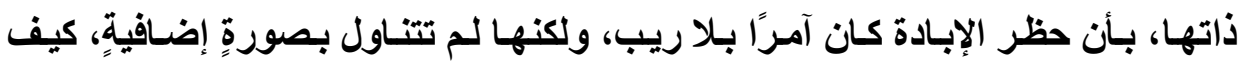

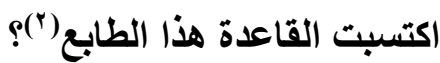

وفي قضية الأنشطة العسكرية، صرحت المحكمة بأن القاعدة التي تحظر الإبـادة

تنتمي إلى القواعد الآمرة الخاصـة بتطبيق اتِّاقيـة منـع وعقاب جريمـة إبـادة الجنس

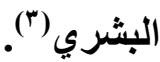

\section{r - القاضي الدولي والقواعد الآهرة: تقيسيم أ - هل القاضي الدولي ضرورة للقواعد الآهرة ؟}

أخفق هَجْرُ استخدام المـادة (7 7) من جانب محكمة العدل الدولية، وكذا تردُّدُهـا في أن تعلن عن موقفها إزاء القواعد الآمرة، توقعاتِ العديد من القائمين على صياغة

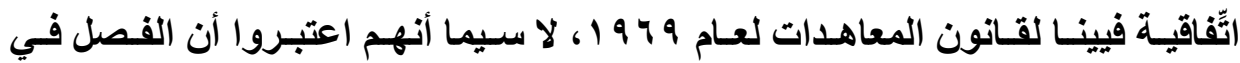
المنازعات الدولية يُعَدُّ جوهريًّا لتحديد مفهوم القواعد الآمرة.

(1) ICJ, 3 February 2006, Armed Activities on the territory of the Congo (New Application: 2002), (Democratic Republic of the Congo/Rwanda), I.C.J., Reports 2006, p. 32, Para. 64

(2) Ibid.

(3) ICJ, 26 February 2007, Application of The Convention on the Prevention and Punishment of the Crime of Genocide (Bosnia and Herzegovina/ Serbia and Montenegro), Judgment, I.C.J. Reports 2007, p. 111, Para. 161. 
وصرَّح العديد من الفقهاء بضرورة القضاة الدوليين بالنسبة للقواعد الآمرة،

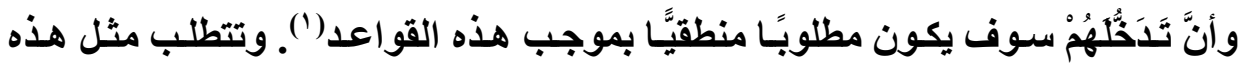

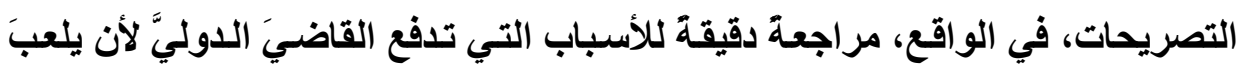
مثثل هذا الدور الحيويٍ إزاء القواعد الآمرة. ويبدو أن الفصل أو القضاء في المنازعات الدولية بات أمرًا ضروريَّا بـادئ ذي بَدْعِ للتعريف بالقواعد الآمرة. فعلى خلاف الأنظمـة القانونية الوطنية، لا يعتمد النظام القانوني الدولي على سُططةٍ تشريعيةٍ مركزيـةٍ في خلق قواعده، سواء أكانت آمرةًَ أم

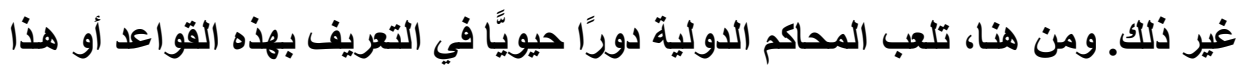
النظام القانوني. ويُعَدِّدُ المادة (؟^) من النظام الأساسي لمحكمة العدل الدولية المصادرَ الرسمية للقانون الدولي، وهي: المعاهدات الدولية والعُرْف الدولي والمبادئ العامـة للقانون. وباستثناع المعاهدات الدولية، لا نُشْئُ المصادر الرسمية للقانون الدولي قواعدَ يمكن تحديدها أو التعريف بها. ومن هنا، يلعب القضاة الدوليون دورًا جوهريًّا للوصول إلى مثل هذا التعريف أو التحديد، وذلك عن طريق الكشف عن وجود ممارساتٍ مستقرةٍ للـدول، أو مـن خـلال إجراء تحليـلِ مقـارنِ للأنظمـة القانونيـة لـدولٍ مختلفـة مـن أجلـ استخلاص المبادئ المشتركة بين هذه الأنظمـة ونقلها إلى القانون الدولي. وكمـا ذكر

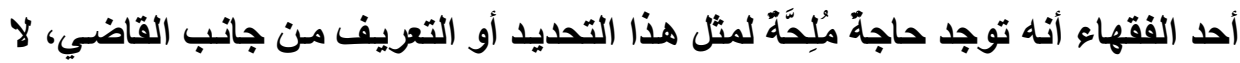

(1) Pierre- Marie Dupuy, "Le Juge et la règle générale", op.cit., p. 594 ; Voir aussi, Antonio CASSES, "For an Enchanced Role of Jus Cogens", in Antonio CASSES, ed., "Realizing Utopia: The Future of International Law", Oxford, Oxford University Press, 2016, p. 158- 171, 169. 
سيما في حالة التطبيق العالمي لأيِّ قانونِ وضعي(') وفي أثناء الفصل في القضايا، سويف يُعَرِّف القضاة الدوليون القواعدَ التي تُعَدُّ آمرة.

وجدير بالذكر، أن القواعد الآمرة تؤسس نظامًَا هرميَّا بين القواعد الدوليـة:

فعلى خلاف القواعد العادية، تعجز قدراتُ الدول على سنّ أو صناعة القوانين الخاصـة بحماية القِيَمَ أو المصالح التي تحميها تلكك القواعد(؟). وحال تحديد أو تعريف القضاة للقواعد الآمرة، يتولون- فيما بعد- توضيح أيّ القواعد الأعلى التي ثُطبق أو تعمل في النظام القانوني الدولي، وهكذا، فإنهم يسهمون في الحفاظ على ترابطها المعياري. وعلى ضـوء التعريـف الـوارد بالمـادة (به)، سـوف يتـولى القضاة الـدوليون التعريف بالقوانين في مرحلتَّنْ مختلفتَيْن من التحليل: أولاً: التعريف بمسألة: هل إحدى عمليات سنَِّ القوانين الخاصة بالقانون الدولي قد أقامت قواعد للقانون الدولي العام أم لا؟ ثانيًا: التعريف بمسألة: هل تمخض عن إحدى هذه العمليات قبولُ واعترافـُ المجتمع الدولي بعدم مخالفة هذه القواعد؟

(1) Donald H. REGAN, "International Adjudication: A Response to Paulus- Courts, Custom, Treaties, Regimes, and the WTO", op.cit., p. 241.

(2) As explained by the ILC, A rule of international law may be superior to other rules on account of the importance of its content as well as the Universal acceptance of its superiority. This is the case of peremptory norms of international law (Jus Cogens, article 53 VCLT), That is, norms accepted and recognized by the international Community of States as a whole from which no derogation is permitted, ILC, Report on the work of its fifty- eighth Session (2006), A/61/10, "Conclusions of the work of the Study Group on the Fragmentation of International law: Difficulties arising from the diversification and expansion of International Law", Para. 32. 
ويشير دورهم في التعريف بالقواعد الآمرة مسألة: هل يجوز للقضاة الدوليين التعريفُ فقط بالقواعد الآمرة أم يجوز لهم أيضًا العمل على تطوير أو حتى خلق قواعد آمرة جديدةٌ فطبقًا للمادة (r^) من النظام الأساسي لمحكمة العدل الدولية، فإن الإجابة سوف تكون سلبية؛ أولاً: لعدم الاعتداد بأحكام القضاء كأحد المصادر الرسمية للقانون الدولي، ولكنها شُستخدم فقط كمصادرَ مُعاونةٍة تُساعد في تحديد القواعد القانونية. ثُاتيًا: أن المحاكمَ تؤتمن فقط على تطبيق القواعد التي تقيمها الدول، والتي ستظل (أي الدول)

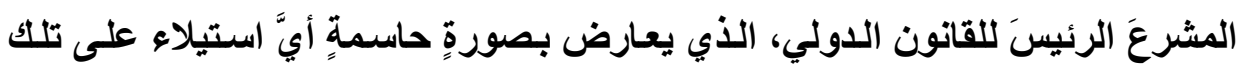
السلطة التشريعية من جاتب القاضي الدولي (') وقد أكَّد ذلك أحدُ ممثّلي الدول، حينما صرح أنه أثناء إعداد اتِّفاقية فيينـا لقانون

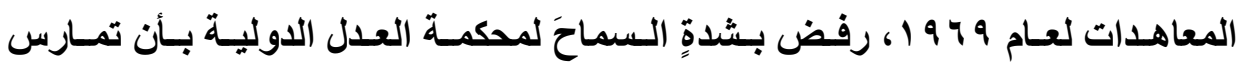
اختصاصًا وجوبيَّا بشأن المنازعات المتعلقة بالقواعد الآمرة؛ وذلك خشية أن تصبح

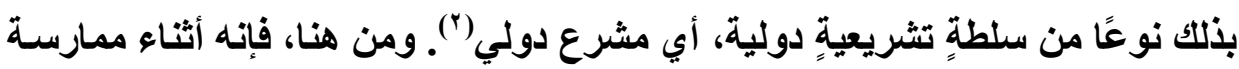
وظيفتها القضائية، تتحقق فقط المحساكم الدولية مـن وجود القواعد الآمرة، ولكن لا تُنْشِيُُ مثْلَ هذه القواعد. وتكتسي هذه الأخيرة بالطـابع الآمر من خلال قبول واعتراف

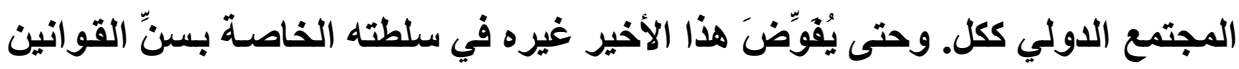

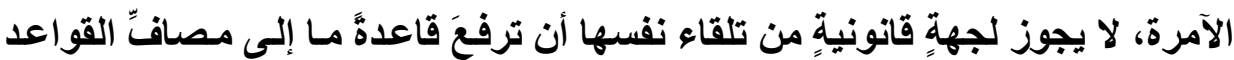

(1) Pierre- Marie DUPUY, "Le Juge et la règle Générale", op.cit., p. 596.

(2) UNCLOT, Second Session, Vienna, 9 April 22 May 1969, UN Doc. A/ CONF. 39/ 11/Add. 1, p. 93- 95 (France); 95- 96 (Germany). 
وبينما تقتصر وظيفة المحاكم الدولية على تسوية المنازعات الدولية بموجب

قواعد القانون الدولي، يشهر الواقع العملي بغير بـلك؛؛ إذ تتطلب التسوية القضائية

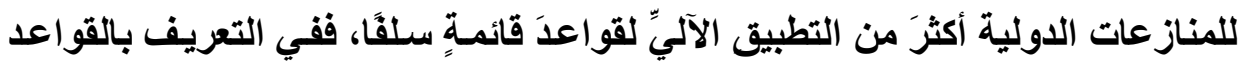
القانونية وتفسيرها، يُسنْهُ القاضي الدوليُّ بصورةٍ حتميةٍ في تطور القانون ('). وكما بَيَّنَ أحد الفقهاء، فحتى لو وجب علينا أن نرى محكمـة العدل الدولية على أنها تَنْهَرْ على تطبيق القواعد القانونية القائمة المعترف بها أو مبادئ القانون، فإنها

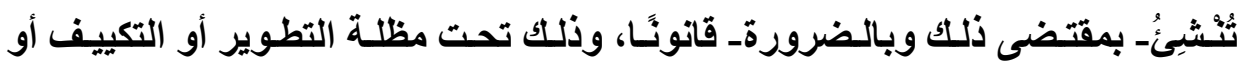

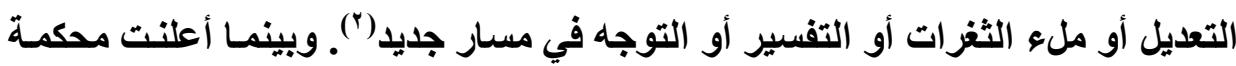
العدل الدولية أنها ليست جهة تثريعية(")، يستدل على البعد الخاص بسنِّ القوانين من خلال وظيفتها الإفتائية، لا سيما رأيها الاستشاري الصادر بشأن مشروعية التهديد أو استخدام الأسلحة النووية(؛)، فبينما تعرض محكمة العدل الدولية أن وظيفتها القضائية

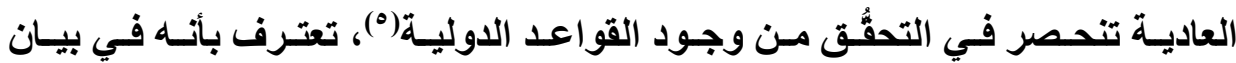

(1) Armin Von BOGDANDY and Ingo VENZKE, "On the Democratic Legitimation of International Judicial Lawmaking", German Law Journal, Vol. 12, 2011, p. 1341- 1370; Emmanuelle JOUANNET, "La notion de Jurisprudence internationale en Question", op.cit., p. 343.

(2) Robert. Y. JENNINGS, "The Judicial Function and the Rule of Law in International Relations", in International law at the time of its Codification, Essays in Honor of Roberto Ago, Milano, Dott. A. Giuffré Editore, 1987, p. 139- 151.

(3) ICJ, 13 July 1966, South West Africa (Ethiopia/South Africa; Liberia/South Africa), Judgment, I.C.J. Reports 1966, p. 43, Para. 80.

(4) ICJ, Legality of the Threat or Use of Nuclear Weapons, p. 237, Para. 13.

(5) ICJ, Military and Paramilitary Activities in and against Nicaragua, p. 106- 107, Para. 202. 
د/عبد الله محمد الهوارى

العدد •r (ديسمبر r.19)

وتطبيق القانون، يتعين على المحكمة بالضرورة أن تُحَدَِّ نطاقه، وأحياتًَا تلاحظ اتِّجاهـه

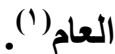

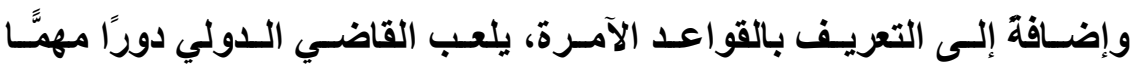

بخصوص تنفيذ تلك القواعد. فلمواجهة الانحر افـات، يُقْدِمُ القاضسي الدولي على تنفيذ الأثر المُبطِل للقواعد الآمرة، وذلك من خلال إعلان القواعد المخالفة بأنها باطلة. وهذه المسئولية، في الواقع، تكون مهمة للغاية(؟). وعندما يقوم القضاة بتنفيذ الأثر المُبطِل للقواعد الآمرة، تسهم بـلكك المحاكم الدولية في بنـاء الوضع الهرمي الأعلى للقواعد

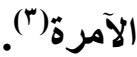

ب- القاضي الدولي كمترجم لمتطلبات التسماسك أو التضاهن الاجتهاءي:

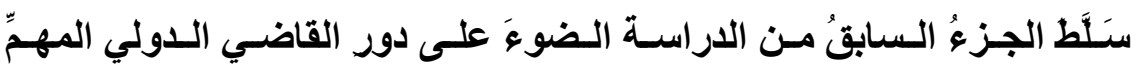
بخصوص القواعد الآمرة. آخذين في الاعتبار الوضعَ الخاصَّ لهذه القواعد، فقد أعلن أحل الفقهاء، أنـه عندما يحكم القاضـي الدولي بنـاءً على القواعد الآمرة، فِإنه يصبح مترجمًا لمتطلبات التضامن أو التماسك الاجتماعي. ويُعَدُ رأي محكمة العدل الدوليـة في

(1) ICJ, 12 October 1984, Delimitation of the Maritime Boundary in the Gulf of Maine Area (Canada/ United States of America), Judgment, I.C.J. Reports 1984, p. 288- 290, Para. 70.

(2) Armin Von BOGDANDY; Marc JACOB, "The Judge as Law- Maker: Thoughts on Bruno Simma's Declaration in the Kosovo Opinion", in Ulrich FASTENRATH, eds., "From Bilateralism to Community Interest", Essays in Honour of B. SIMMA, Oxford, Oxford University Press, 2011, p. 809- 824, 810.

(3) Tom GINSBURG, "Bounded Discretion in International Judicial LawMaking", Virginia Journal of International Law, Vol. 44, 2005, p. 666. 
قضية الحصانات القضائية للاولـة مـع نقد القاضـي (ترينداد) لمنهج الأغلبيـة أساستًا واضحًا يعكس ذلك(')

ففي القضية سالفة الذكر، طِبَ من محكمـة العدل الدولية تحديدُ مـا إذا كانت إيطاليـا قد تقاعست عن احترام الحصانة القضائية لألمانيـا من عدمـه، وذلكك عندما سمحت برفع الدعاوى المدنيةـ التي تطلب جبر الأضرار التي أحلثتها انتهاكاتُ القانون

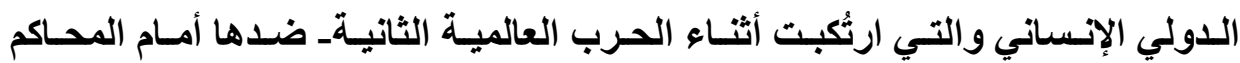
الإيطالية؛ فتلك هي المرة الأولى التي كانت فيها القواعد الآمرة هي إحدى المسائل الأساسية في النزاع أمام محكمة العدل الدولية(؟)، وقد دفعت إيطاليا بأن القواعد التي انتهنتها ألمانيا كاتت ذات طابع آمر. ونظرًا لأن القواعد الآمرة تُرَجَّحُ على كافة قواعد

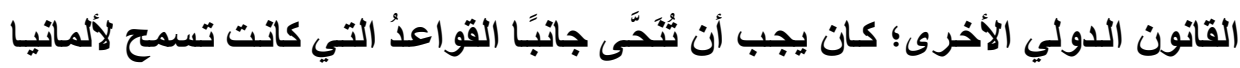
بالافع بالحصانة القضائية("). وممـا يجدر بنـا ذكره، أن محكمة العدل الدولية كانت قد رفضت كل الأسـانيا والحجج القانونية لإيطاليا في القضية، بمـا في ذلك الادِّعاء المتعلق بالقواعد الآمرة؛ فبافتراض أن القواعد القانونية للنزاع المُستَّح التي تحظر القتل العمدي للمدانيين في الإقليم المحتل، وترحيل السكان المدنيين إلى عمل العبيد، وترحيل سجناء الحرب إلى عمل العبيد، هي قواعد آمرة، فإنـه لا يوجد تعـارضٌ بين هذه القواعد وتلكك المتعلقة

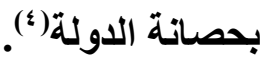

(1) Pierre- Marie Dupuy, "Le Juge et la règle Générale", op.cit., p. 594.

(2) ICJ, Jurisdictional Immunities of the State, Para. 92.

(3) Ibid., Para. 93.

(4) Ibid. 


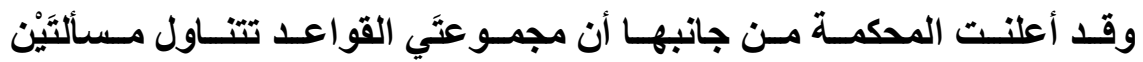

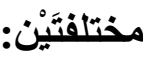

تلك القواعد الخاصة بحصانة الدولة، وهي إجرائية في طابعها، ومقصورةٌ على لئى تقرير هل يجوز لمحاكم دوليةٍ مـا أن تمـارس الاختصاص بخصوص دولئة أخرى أم لا، ولكنها لا تتناول مسألة: هل السلوك الذي رُفعت الإجراءات بشأنه كـان مشروعًا أو لاج وتدعيمًا لحكمها، لاحظت محكمة العدل الدولية أن أحكام المحاكم الإيطالية التي باثرت الأدرات

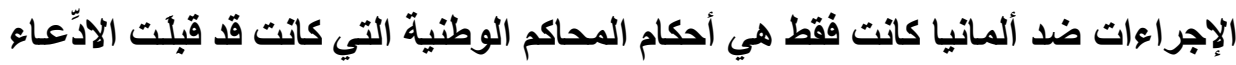
بأن للقواعد الآمرة أثرًا في إزاحة حصانة الدولة الأجنبية، وأن التشريع المحلي بشأن التهان

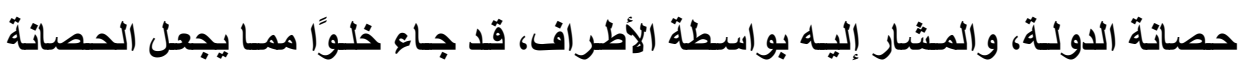
محدودةً في الحالات التي يُحتج فيها بانتهاك القواعد الآمرة. 


\section{المبحث الرابع \\ القاضي الدولي والضرورات العسكرية}

الـضرورة العسكرية هـي مفهومٌ متعدد المعـاني، الأمسر الذي يثير العديـ مـن

التساؤلات، لاسيما فيما يتعلق بتطبيقه من جانب القاضي الدولي. والفكرة التي مفادها

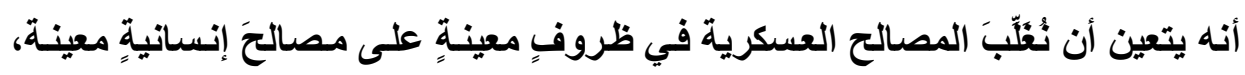

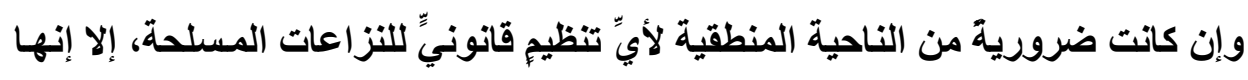
تثير صعوباتٍ جمة، فيما يتعلق بشرعية القاضي الدولي، وكذا شرعية النظام المعيـاري لإي

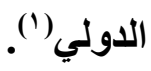

وتهدف هذه الاراسة إلى فحص هذه التساؤلات، واقتراح بعض الطرق للحدِّ من

خطر نزع الشرعية. وبعد إبداء بعض الملاحظات على مبدأ الضرورة العسكرية في القـانون الـدولي الإنسـاني، سـوف نتعـرض لـدور القاضــي الـدولي في تطبيقـه، ومــا سيواجهه من صعوباتٍ في هذا الثأن. ا - هفهوم الضرورة العسكرية في القانون الدولي الإنساني:

يُمْكِنُ تلخيص مبدأ الضرورة العسكرية في الحدِّ الأقصى الذي لا تَسمح فيهـ تلكك

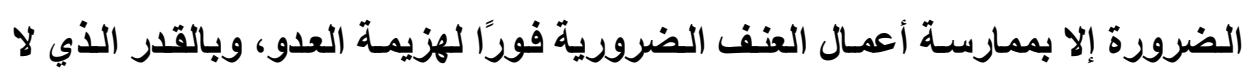

(1) Mohamed SHAHABUDDEEN, "The International Criminal Tribunal for the former Yugoslavia: The third Wang Tieya Lecture", Chinese Journal of International Law, Vol. 11, 2016, p. 27. 
يكون محظورًا بموجب قواعد القانون الدولي الأخرى واجبة التطبيق. ووفقَا لمدونـة

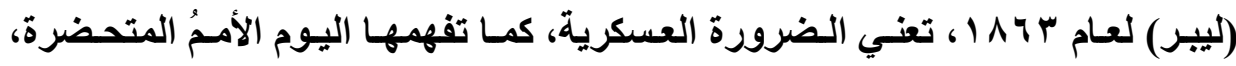

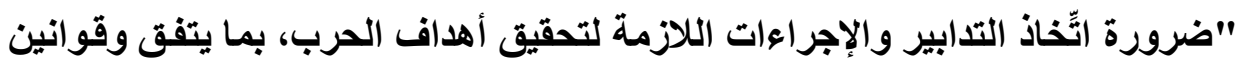

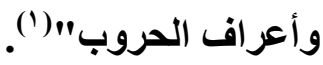

ويتضضمن هـا المبـدأ العسام للقـانون اللـولي الإنساني، وظيفـة "إراديسة" أو

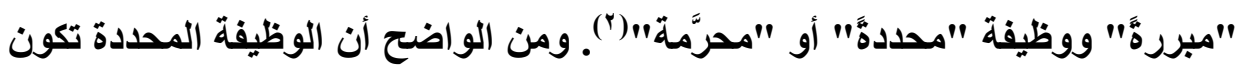

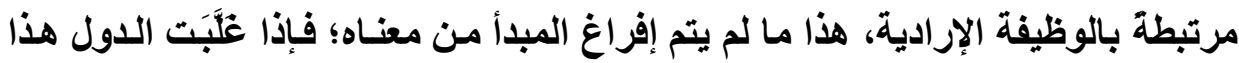

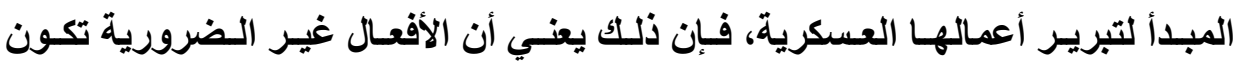

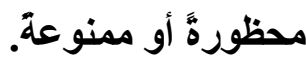

وفي ظل عدم وجود تعريفٍ محددٍ لهذا المبدأ، وقد تم تجسيد المبدأ أثناء عملية تقتين قواعد القانون الدولي الإنساني، يتساعل ـ بل يشكك ـ البصل اليوم في وجود

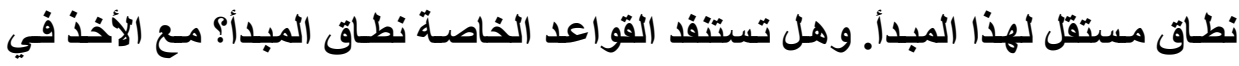

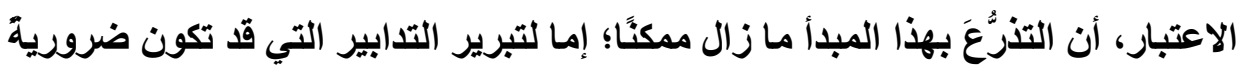
على الرغم من تحريمها (نظريـات كريجسريزون) (")، و إمـا لتحريم التدابير التي تكون

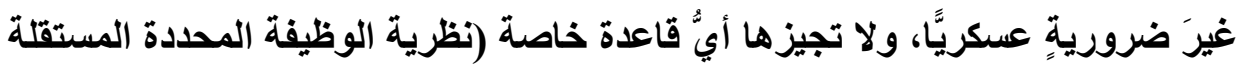

(1) D. SCHINDLER, "Droit des conflits armés : Recueil des conventions, résolutions et autres documents", Genève, CICR/Institut HenriDunant, 1996, p. 6.

(2) Alberico GENTILI, "The classics of International Law", Oxford/Londres, Clarendon, 1997, p. 142.

(3) William V. O' BRIEN, "The Meaning of Military Necessity in International Law", World Polity, Vol. 41, 1997, p. 128. 


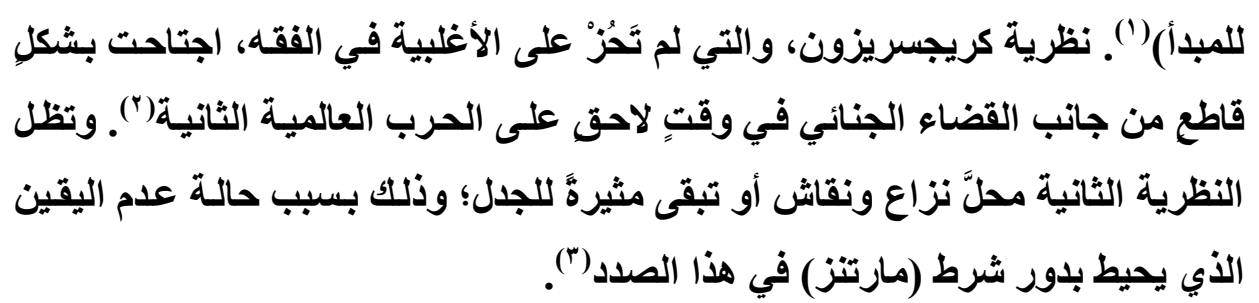

على أيَّةِ حال، استمر مبدأ الضرورة العسكرية، فضلاً عن مبدأ دستورية القانون

الاولي الإنساني ومبدأ الإنسانية"() في أن يلعب دورًا مهمَّا باعتباره يمثل روح القانون

أو الحق، ويُعبر عن قواعدَ أكثرَ واقعية(ْ). وفي كل الأحوال، يجب أخذ هذا المبدأ في

الحسبان عند تفسير وتطبيق القواعد التي ياخل فيها أو يمتزج بها.

(1) Robert KOLB, "La nécessité militaire dans le droit des conflits armésEssai de clarification conceptuelle", in SFDI, dir., "La nécessité en droit international", colloque de Grenoble, Paris, Pedone, 2009, p. 157.

(2) Voir, Trail of Wilhelm List and Others, Nuremberg, 8 July 1947 to 19 February, 1948 (The Hostages Trial), Vol. VIII, p. 67.

(3) Marco SASSOLI, "Geneva Conventions: A Commentary", Oxford, Oxford University Press, 1993, p. 16.

(4) Robert KOLB, "La nécessité dans le droit des conflits armés- Essai de clarification conceptuelle", art. préci., p. 158.

(5) Gabriella VENTURINI, "Necessity in the law of armed conflict and in international law", Netherlands Yearbook of International Law, Vol. 44, 2013, p. 49. 
وفي إطار قواعد القانون الدولي الإنساني(')، يتجلى المبدأ على سبيل المثال من

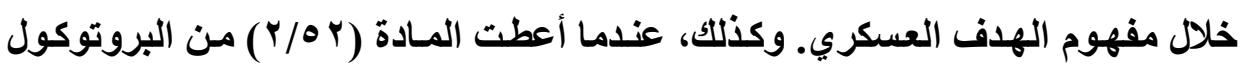

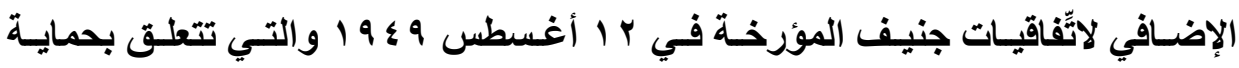

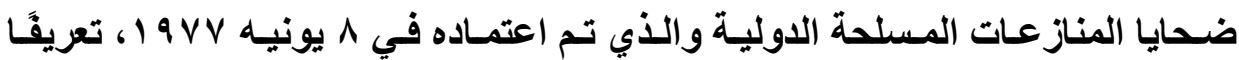

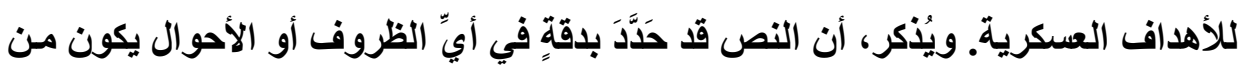

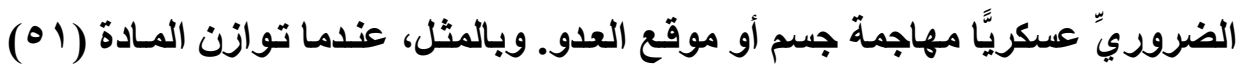
من البروتوكول الأول الإضافي حماية الممتكات والمدنيين مع الميزة أو الغنتم العكري

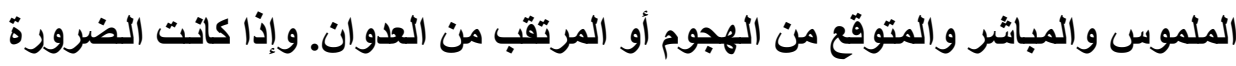

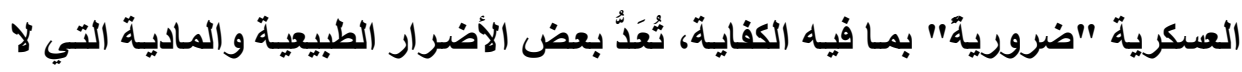

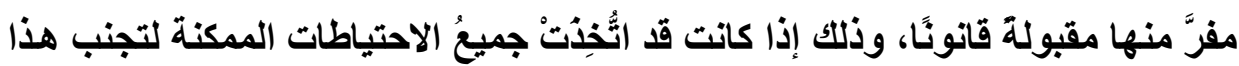

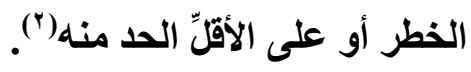

من هذا المنظور، يمكن اعتبار الضرورة العسكرية ومفهوم الميزة العسكرية أو

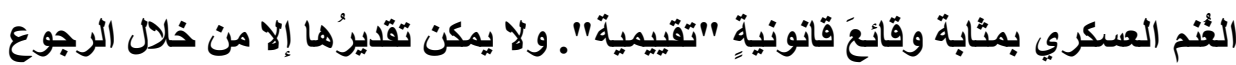

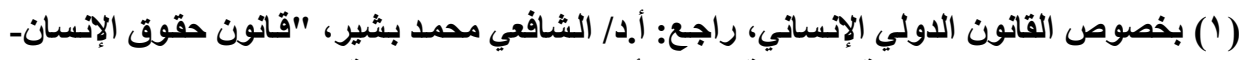

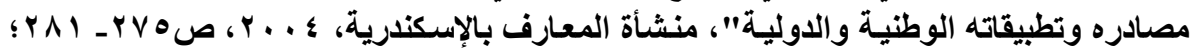

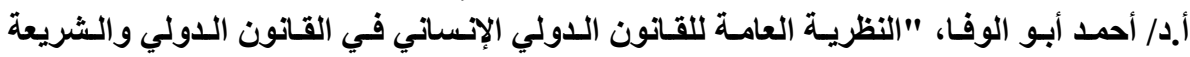

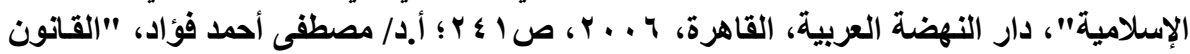

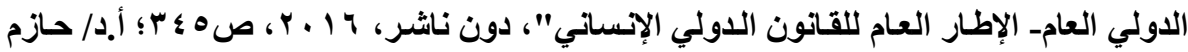

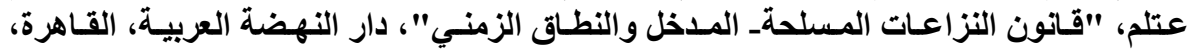

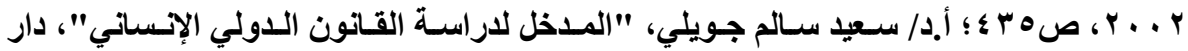

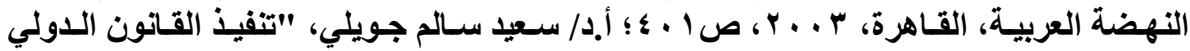

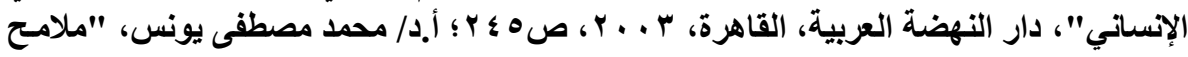

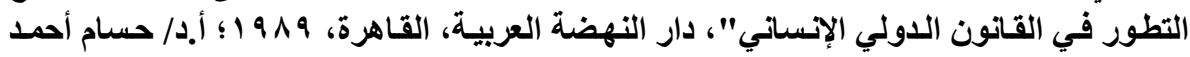

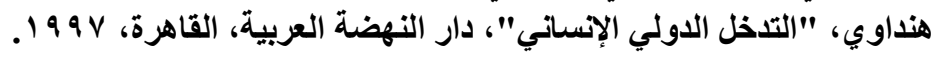
(2) Voir, Article 57, p. A.I. 
إلـى اعتبـاراتٍ خـارج القـانون، مثـل "العـــم" أو "الفـن العسكري" أو "الاعتبـارات

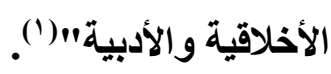

ويضاف إلى ذلك، أنه يتم استخدام هذا المصطلح لوصف الحقيقة القانونية التي

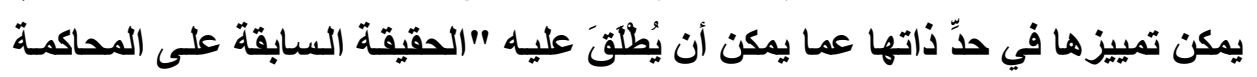

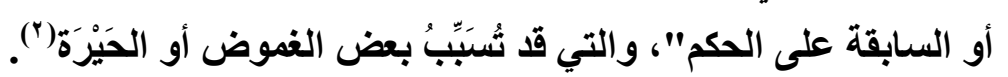

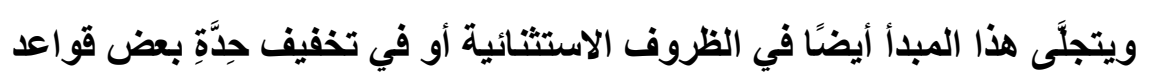

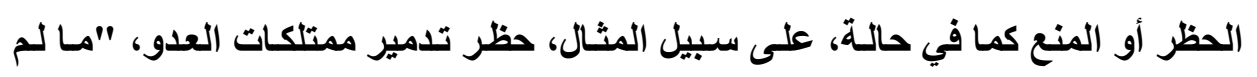

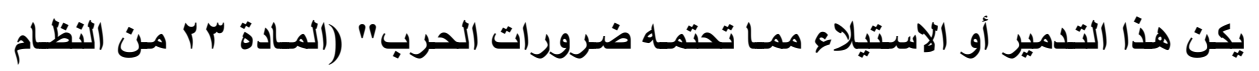

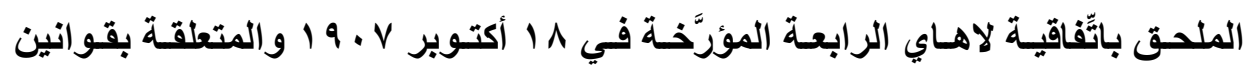

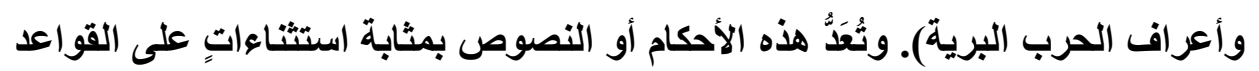

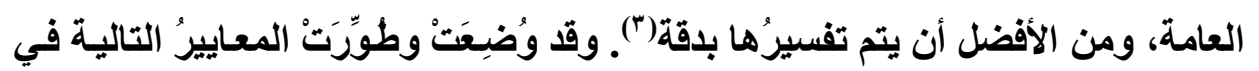

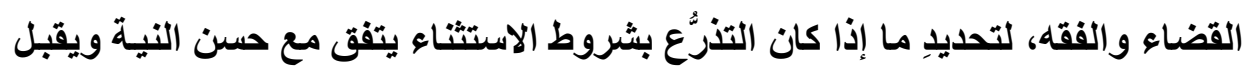

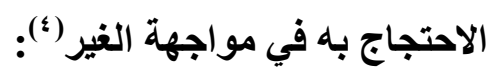

(1) Jean SALMON, "Le fait dans l'application du droit international", Recueil des Cours, Vol. 175, 1982, p. 274 ; Sarah CASELLA, "La nécessité en droit international : De l'état de nécessité aux situations de nécessité", Leiden/ Boston, Martinus NiJhoff, 2011, p. 93.

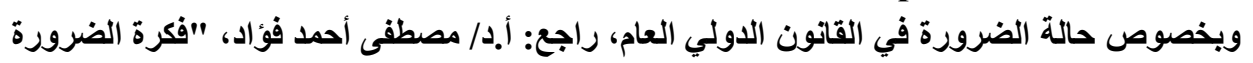

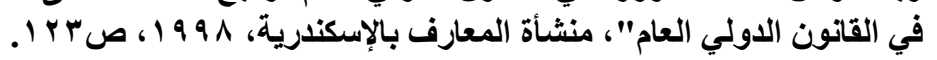

(2) Robert KOLB, "La nécessité militaire dans le droit des conflits armésEssai de clarification conceptuelle", art. préci., p. 155.

(3) Affaire des biens Britanniques au Maroc espagnol (Espagne c. Royaume-(uni), $1^{\text {er }}$ mai 1925, R.S.A., Vol. II, p. 632.

(4) Nobuo-HAYASHI, "Requirements of military necessity in international Humanitarian law and international criminal law", Boston University International Law Journal, Vol. 30, 2012, p. 67. 
(1) وجـود حالـة الـضرورة: وهـو مـا يمكن أن ينطـويَ على فكرة السرعة أو

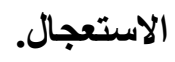

(Y) قدرة التدبير على الوصول إلى الهدف و إقامة عَلاقةةٍ موضوعيةٍ أو معقولةٍ بين

$$
\text { التدبير والهدف المنشود. }
$$

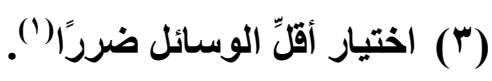

$$
\begin{aligned}
& \text { (4) التناسب بين الضرر الناجم والميزة العكرية المقصودة(؟) } \\
& \text { تطابق الأهداف المُنَوَخَّاة مع قواعد القانون الدولي الإنساني. }
\end{aligned}
$$

وفقَا لذلك، لا بدَّ من الاعتراف بأن المبدأ، إذا كـان يهدف إلى حظر العنف غير

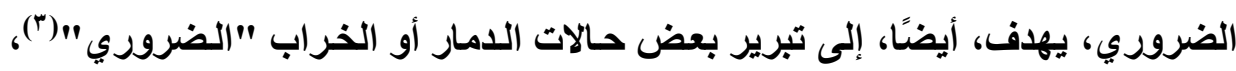

والرعب أو الهلع الذي ينتج عن الأعمال العدائية المشروعة لاى المدنيين(؛). وتتضمن بـن

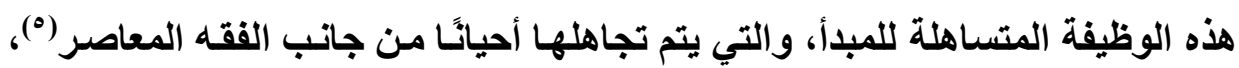

جوانبَ متناقضة وغريبة أو غيرَ معقولة، وذلتك في الحسات التي تتعارض فيها مـع

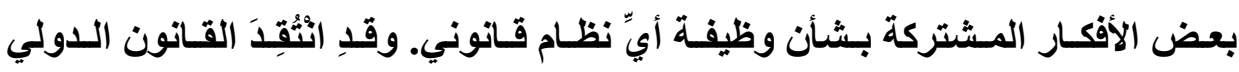

(1) Robert KOLB, "Note sur l'émergence d'une maxime de l'utilisation du moyen le moins fort en droit international public", Revue belge de droit international, no. 4, 2008, p. 605.

(2) Voir, TPIY, 29 Juillet 2004, le procureur c. Tihomir Blaskic, Jugement, Chambre d'appel, IT- 95- 14- A, Para. 109.

(3) Voir, In Re Esau, ILR, Vol. 16, p. 483.

(4) Voir, TPIY, 30 novembre 2006, le procureur C. Stanislav-Galic, arrêt, Chambre d'Appel, IT- 98-29- A, Para. 103.

(5) Nobuo HAYASHI, "Requirements", art préci., p. 42 et pp. 55- 57. 


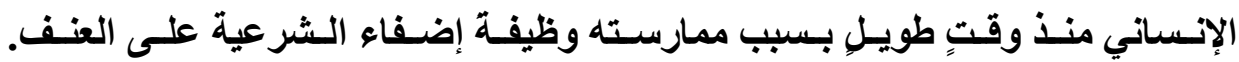
وباختصار، ووفقًا لما ذكره هؤلاء النقاد، سيكون القانون الدولي الإنساني أكثرَ ضررًا إذا كان مـا يخول القيـام بـه أكثرَ ممـا يحرمـه('). وقد هـاجم النقـادُ بشكل خـاصِّ مفـاهيم الضرورة العسكرية والأضرار الجانبية، والتي وصفها الأستاذ (بروتونس) بأنها "قناع

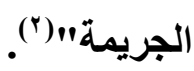

وإذا كاتت هذه الانتقاداتُ مفرطة، وتؤدِّي في بعض الأحوال إلى رفض جذريٍ وخطير للقانون الدولي الإنساني، فلا ينبغي أن نرفضَها على وجه السرعة باعتبارهـا لا أسناسَ لها من الصحة.

خلاصة القول، أن هؤلاء النقاد يتجاهلون أحيانًا أن شرعيةٌ العنف ستظلُّ تعتمدُ على عواملَ أخرى، يـأتي على رأسِِها ضرورةُ احترام قاعدة "القانون ضـد الحرب". وعلى المستوى القـانوني البحت، يجب رفض النظريـة التي مسن شـأنها أن تضفيَ الشرعية على استخدام العنف. ولكن بـالنظر إلى ضعف تنفيذ قاعدة "القـانون ضــ الحرب"، فمن الصنَّب إنكارُ وجود الحالة الفعلية لهذه الوظيفة الثرعية للمبدأ. والحالة هـذه، يمكن أن يقودَ القاضـي، حتى على الـرغم مـن نفسـه، إلسى الإسـهام فـي هـذه الممارسات بسبب القيود المفروضة على اختصاصاته القضائية.

(1) Roger NORMAND, "The Legitimation of Violence: A Critical History of the laws of war", Harvard International Law Journal, Vol. 45, 2004, p. 95.

(2) Antonio REMIRO BROTONS, "Article analysis of the Gulf War", Harvard International Law Journal, Vol. 50, 2009, p. 416. 


\section{r- r - غياب القاضي: الأسباب الذاتية للمبدأ:}

تظلُ الإشارة إلى مبدأ الضرورة العسكرية في أحكام القضاء الأخيرة قليلة، وذلك

إذا ما تم استثناء المجال الجنائي، والذي ساعد، مع ذلك، في الماضي، في توضيح عددٍ كبيز من المسائل أو الموضوعات(') غير أن القضاءَ الجنائيَّ لم يُطوِّر، بما فيه الكفاية،

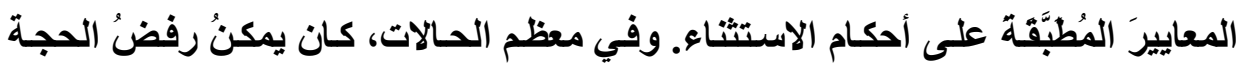
بسهولةٍ دون الاخول في تفاصيل تطبيق النصوص ذات الصلة. يضاف إلى ذلك، في الرأي الاستشاري حول الجدار الفاصل، اجتاحت محكمة العدل الدوليـة حجـة الضرورة

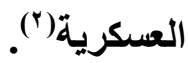

ومع ذلك، كانت الإشـارات إلى المبدأ أكثرَ تواترًا في قضاء التحكيم في القرنين

التاسع عشر والنصف الأول من القرن العشرين، وذلك كما يتضح من عددٍ من قرارات لجـان التحكيم المختلطـة المسئولة عن الفصل في قضايا التعويضات لصالح بعض الرعايا الأجانب، لا سيما في أعقاب حرب الانفصال، والتدخل الفرنسي في المكسيك

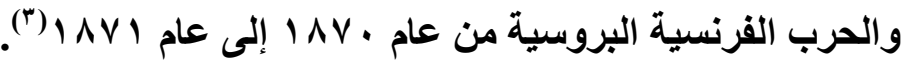

(1) Karine BANNELIIR, "L'argument de la nécessité dans les procès ayant suivi la seconde Guerre mondiale", in SFDI, dir., "La nécessité en droit international", art. Préci., p. 311- 323.

(2) CIJ, 9 July 2004, Conséquences Juridiques de l'édification d'un mur dans le territoire palestinien occupé, avis Consultatif, C.I.J. Recueil 2004, p. 193, Para. 137.

(3) Voir, notamment les cas de destruction de propriété privée in Bassett MOORE, "History and digest of the international Arbitrations to which the United States has been a party, Vol. IV, Chapter LXV, Washington D.C., Government Printing office, 1998, p. 3677 et s. 
وفي مواجهة مطالبات بعض الدول بإقامـة قضاعٍ خـاصٍ بضروراتها العسكرية،

اتخذ المحكمون في كثير من الأحيان موققَا مؤمنَّا، رافضين ممارسـة الرقابة القضائية على القرارات التي اتخذها القادة العسكريون، كمـا كـان الحسال في الماضـي، في قضية

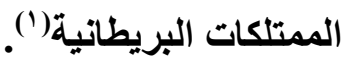

غير أن محاكم التحكيم لم تَقْبَلْ هذه الادِّعاعاتِ على نحوِ سلبٍِّ وكثيرًا ما أعلنت عن موقفها تجاه الظروف التي تجعل تدمير أو حجز أو مصادرة الممتلكات الخاصة من قبيل الضرورات العكريةة(؟) وفي بعض القضايا، لم تتردد المحاكم أو بعض أعضائها في الحكم بأن الأضرار التي حَدَثَتْ لم تكن مُبَرَّرَةَ، على الأقَل عندما يبدو بوضوح أن التدميرَ تعسفيٌّ"). هذه المحاكم المعنية لم تدرس فقط مجرد قدرة التدبير على تحقيق الغرض المنشود منها، ولكن أيضًا أعلنت عن موقفها بخصوص التناسبية أو الغرض من التدبير. وبعد التأكد من أن المبرِّرَ الوحيدَ الممكن لإقدام فنزويلا على تدمير ممتلكات القتصل تثـارلز هيرمـان دي ليموس كان لضرورةٍ عسكرية(")، لم يتردد أحد أعضاء المحكمة في التشكيك؛ ليس فقط في الضرورة، ولكن أيضًا في فائدة وفعالية الهجوم(ْ). في حالة أخرى، على العكس من ذلك، فبعد تقدير الوقائع وتحليل العديد من السوابق والآراء الفقهية، رفض الإمبراطور منح تعويض للسيد بمبليستا عن الأضرار التـي لحقـت بـه في منزلـهـ، نتيجـة مهاجمـة القـوات الحكوميـة لمديــة بويرتوكـابيلو

(1) Affaire des biens britanniques au Maroc espagnol (Espagne c. Royaume- Uni), ${ }^{\text {er }}$ mai 1925, R.S.A., Vol. 2, p. 682.

(2) Voir, The claims of orr and Laubenheimer and the Post-Glover Electric-Company (Nicaragua, United States), RSA, Vol. XV P.39.

(3) Heirs of Jules Bran, 31 July 1905, RSA, vol. X, P. 40.

(4) De Lemos Case, 1903, RSA, Vol. 9, p. 370.

(5) Ibid., PP. 371-373. 
المحصنة. وقد ارتأى هذا الحكم أنه نظرًا لأن منزل صاحب الشكوى كان يقع بالقرب من

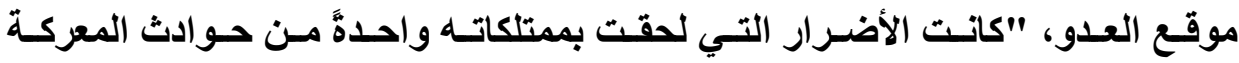
العادية"('). وبالتالي، فِان تدميرها من جانب القوات الحكومية كـان بسبب الضرورة

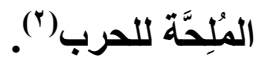

وجدير" بالملاحظة، أنـه قد تمَّ صسياغة عددٍ مـن الحجج على نحو يعوق نظر

القاضي في الضرورة العسكرية للتدابير التي يتخذها المتحساربون. وبالتالي، فقد قيل أحيائَا: إن هذا المفهوم يشير إلى بقايـا سيادة الدولـة التـي تركتهـا القواعد الحاليـة للقانون الدولي الإنساني سليمة(").

والإشـارة إلى الضرورة العسكرية ومر ادفاتها المختلفة على أنها تكون بمثابـة

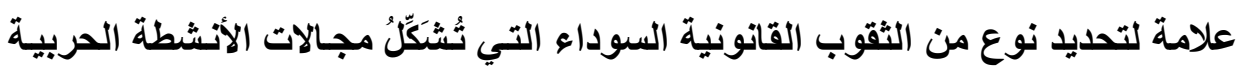
يؤدِّي إلى منع أيِّ أثر مفيد، ومن ثم أيّ نطاق معياري للمبدأ (مبدأ الضرورة العكرية)

ولقــ كـان مـن المؤكـد، كلاسـيكيًّ، أن أحكـام الاسـتثنـاء، لا سـيمـا بـالنظر إلى

الصياغة العامة والمجردة وطابعها الظرفي، تتضمن سئطة تقديرية للقائد العسكري(ْ). ووفقَا للأستاذ (باركس)، على سبيل المثال، "إذا كـان العدو قد حدَّد الأنشطة المدنية

(1) Bembelista Case, 1903, RSA, Vol. 10, p.718.

(2) The Great Venezuelan Railroad Case, 1903, RSA, Vol. X, P.475.

(3) Bin CHENG, "General Principles of law as Applied by International Courts and Tribunals", Cambridge, Cambridge University Press, 2006, P. 43.

(4) CPJI, 7 Septembre 1927, Affaire du Lotus, serie A, no 10, P.18.

(5) ICSID, 27 June 1990, Asian Agricultural Products Limited (AAP) v. Republic of Sri Lanka, Arbitration Tribunal, ILR, vol. 106, p.496. 
ليشكل جـزعًا مباشـرًا للأعمـال العدائيـة"، يتخلى المــني عن حصانته إزاء الهجـوم المباشر (') وإذا كـان مثل هذا التأكيد يتوافق مع أنمـاط الممارسـة العملية، فهو غيرُ دقيق على المسنوى المعياري. ومن الناحية القانونية، يفقد المدنيون حصاناتِهم ضد

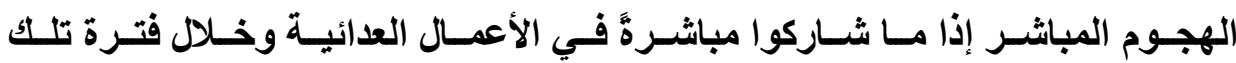

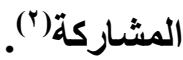

وتنطوي الطبيعـة غير المحددة نسبيَّا للمبـادئ العامـة على حريـةٍ معينةٍة في التفسير("). ويتعلق الموضوع هنا، في الواقع، بالفصل بين هامش التقدير الذي يجب تركهـ للمتــاربين، وذلك الذي يجب أن يـخل في سـلطة القاضـي في المراجعة. فـي النظام الدولي اللامركزي المجرد من الطابع القضائي الإلزامي، يُشَكِّلُ عدم اليقين بشَّئن هذه المسألة مصدرًا لصعوبةٍ كبيرة"(؛). والقول بأنه يجب أن يكون هـامش التقدير كـاملاً سيكون استثناءً، وسوف يَدٌُّ من دور القاضي في الرقابة على القرارات التي يتخذها

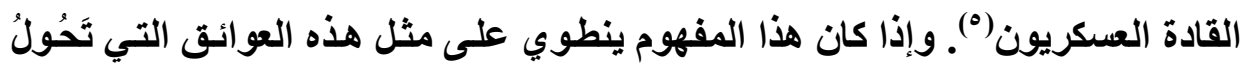
دون النظر في تصرفات المتحاربين، فسوف تتقلص سُّطة القاضسي الدولي في التقدير

(1) William Hays PARKS, "Port ix of the ICRC Direct Participation in Hostilities Study: No Mandate, No Expertise, and Legally Incorrect", New York University Journal of International Law and Politics, Vol. 42, 2010, p.779.

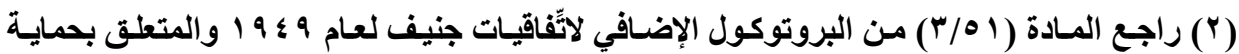
ضحايا النزاعات المسلحة الاولية.

(3) Voir, In Re Flick and Others Nuremberg, Germany, United States Military Tribunal, December 22, 1947, ILR, Vol. 14, P. 270.

(4) Voir, Sarah CASELLA, "La nécessité en droit international : De l'état de nécessité aux situations de nécessité", op. cit., p.195 et s.

(5) Yuval SHANY, "Toward a General Margin of Appreciation Doctrine in International Law",. Vol. 16, 2006, p.907-940. 


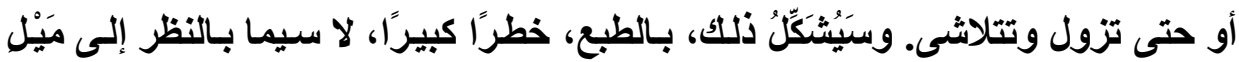
المتحاربين إلى الاستفادة من ضرورة تبرير جميع أنواع الفظائع المرتكبة. إلا أن تحليل

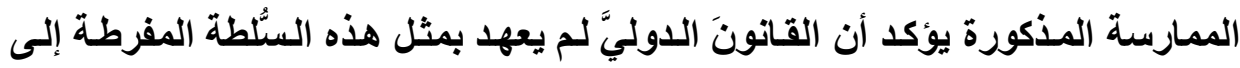

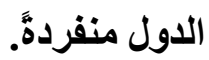

وقد أكلد القضاء الجنائي، من ناحيته، على أنسه يجب تقدير مبدأ الضرورة العسكرية من جاتب القاضي على ضوء الظروف التي اتخذ فيها القرار، و المعلومـات

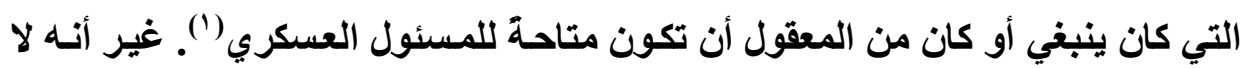

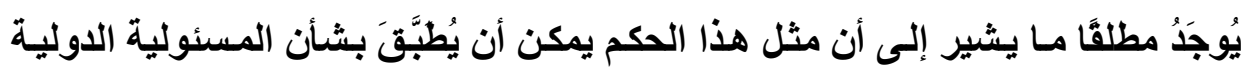

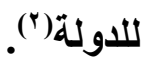

وفي النهايـة، تطرح نظرية السئطة التقيريـة للقائد العسكري، وكذا تلك التي

تتعلق بهامش التقدير الوطني، فرضية انتمساء شروط الضرورة العسكرية إلى فئة:

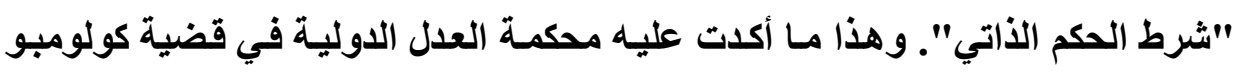

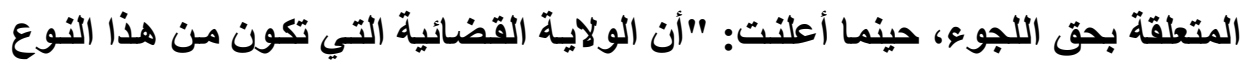

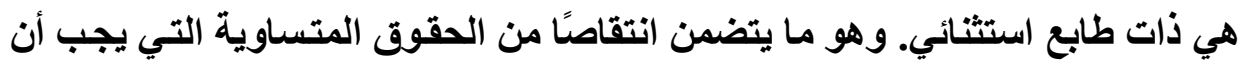

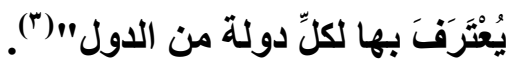

(1) In Re List and Others (Hostages Trial), February 19, 1948, ILR, Vol. 15, P. 648-649.

(2) Gabriella VENTURINI, "Necessity in the Law of Armed conflict and International Law", art. Preci., P. 66.

(3) CIJ, 20 novembre 1950, Affaire Colombo relative au droit d'asile, arrêt, C.I.J. Recueil 1950，p. 275 ; CIJ, 6 novembre 2003, plates-formes pétrolières (République Islamique d'Iran C. États-Unis d'Amérique), arrêt, C.I.J. Recueil 2003, p. 196, Para. 73. 


\section{r- إثبات الوقائع وشرعية أو صلاحية القاضي الدولي:}

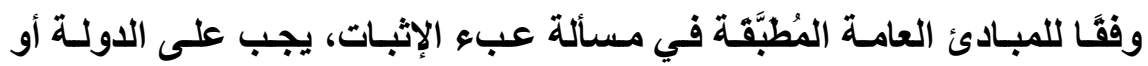

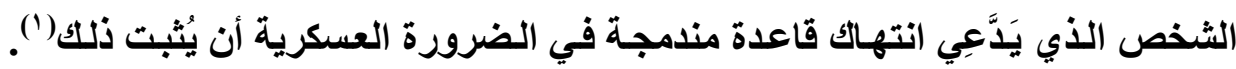

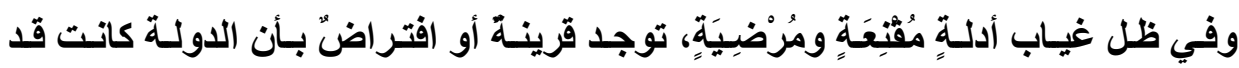

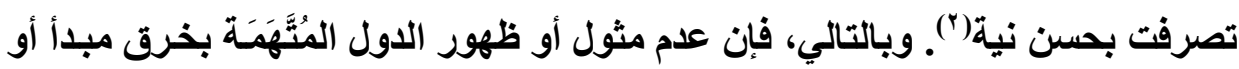

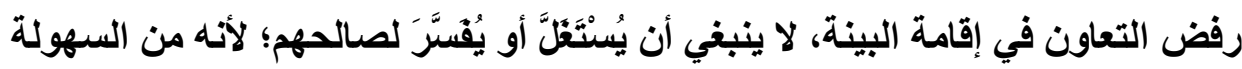
بمكان في هذه الحالات قلبُ الافتراض أو الذهاب إلى عكسه.

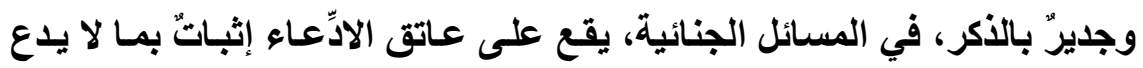

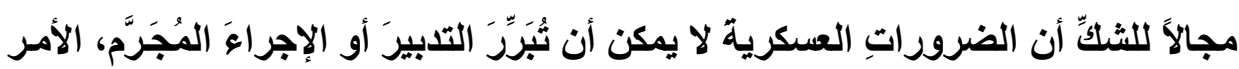
الذي قد يستفيد منه المتهمون في بعض الحاتلات.

وتُثير الطبيعة الواقعية للقو اعد التي تتضمن الضرورة العكرية(") مسائلَ أخرى

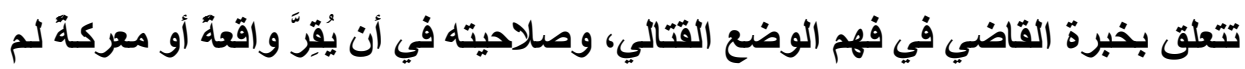

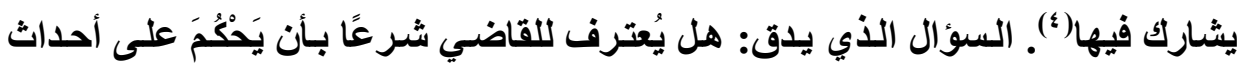

(1) Voir, par exemple, ICSID, 27 June 9190, Asian Agricultural Product Limited (AAP) v. Republic of Sri lanka, Arbitration Tribunal, Desseuting Opinion of Samuel K.B. A sante, ILR, Vol. 106, p. 496.

(2) Ibid., pp. 450- 451, Para. 63. Voir aussi, The Buena Tierra Mining Company (Ltd.) (Great Britain) V. United Mexican States, 3 August, 1931, RSA, Vol. V, p. 251.

(3) Théo Boutruche, "Credible Fact- Finding and Allegation of International Humanitarian Law Violations : Challenges in Theory and Practice", Journal of conflict, Security law, Vol. 16, 2015, p. 123.

(4) R. MAISON, "Le Juge combattant", in Abdelwahab BIAD, P. TAVERNIER, "Le droit international humanitaire face aux défits du xxi ${ }^{\mathrm{e}}$ siècle", Bruxelles, Bruylant, 2016, p. 115- 132. 


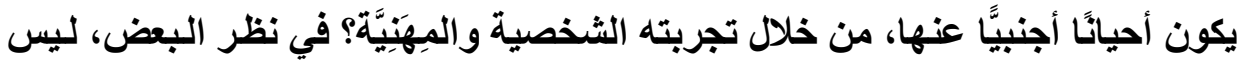

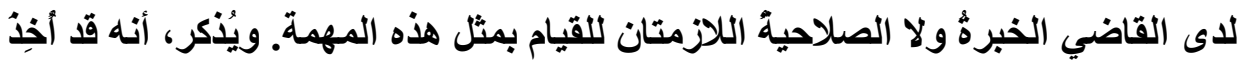

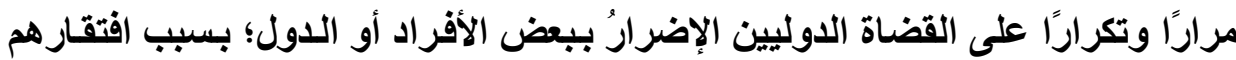

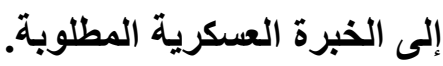

ومحكمة العدل الدولية، على سبيل المثال، وفقًا للبعض، ليست هي المحفلَ أو الجهازَ المناسبَ للحكم على تطبيق القانون الاولي الإنساني" (1).

ويَفترض جوهرُ المبدأ الأساسي مسبقًا، معرفة القاضسي للوقائع التي تَسمح

بتحديد قدرة التدبير العسكري على تحقيق هدفٍٍ معين. وبعيدًا عن مسائل الإثبات والأدلة، يتطلب تقديرُ الضرورة العسكرية أن يعلنَ القاضي عن موقفه بثأن شرعية

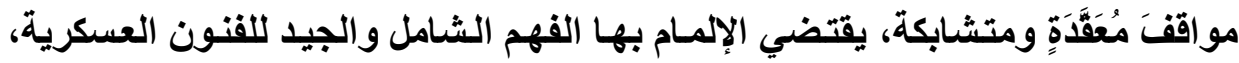
والمعرفة العلمية والفنية للمقذوفات على سبيل المثال. ويتجاوز الإدراكُ الثامل لهذهاه

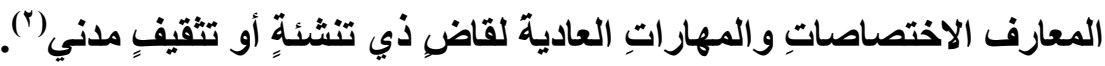

لأجل ذلك، ثُشَكَكُلُ لجان التحقيق(")، التي تتولى التحقيق في الانتهاكـات المحتملة

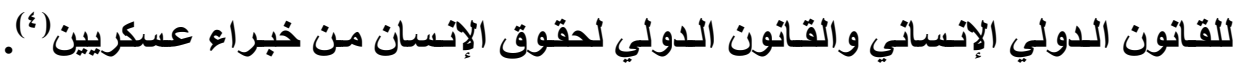

(1) W.V. O'BRIEN, "The Meaning of Military Necessity in International Law", art. Préc., p. 155.

(2) Gary P. CORN, "The Law of Operational Targeting: Viewing the LOAC Through an Operational lens", Texas International Law Journal, Vol. 51, 2015, p. 37.

(r) أ.د/ محمود شريف بسيوني، "المحكمة الجنائية الدوليةـ نشأتها مع دراسة لتاريخ لجان بان التحقيق

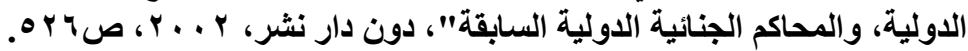

(4) Théo BOUTRUCHE, "Credible Fact-Finding and Allegations of International Humanitarian law violations : Challenges in Theory and Practice" art. Préci., p. 107. 
السؤال الذي يلقق: هل ينبني أن نعتمد نفس الحل بالنسبة للقضاة؟ مـع الأخذ في

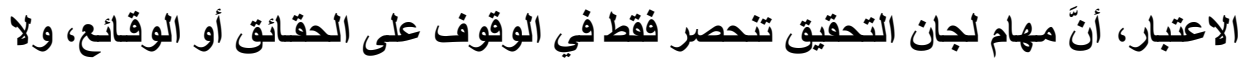

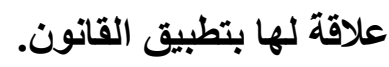
ومـن الضروريٍّ بـالطبع، تحديدُ الإطـار القَانوني المناسب أو الملانم لاختيـار

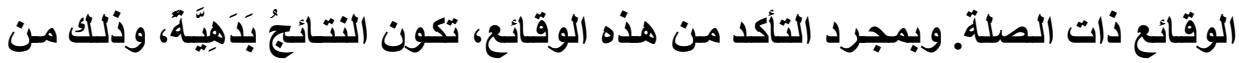

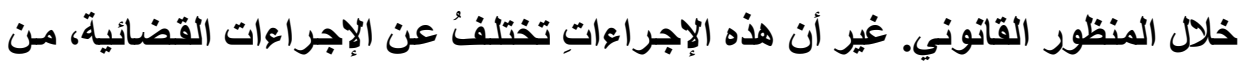

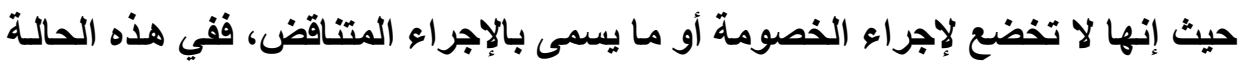

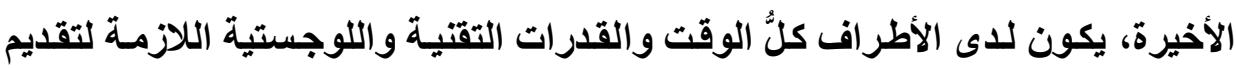

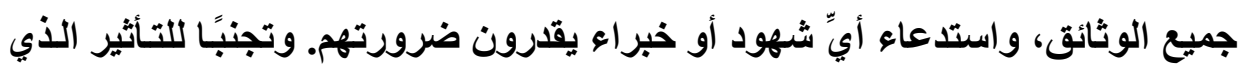

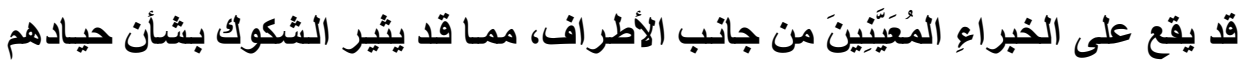

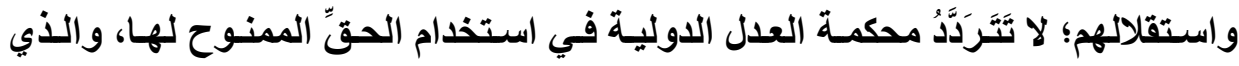

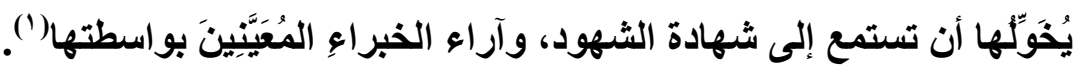

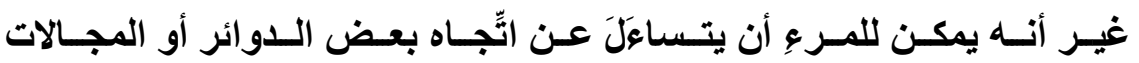

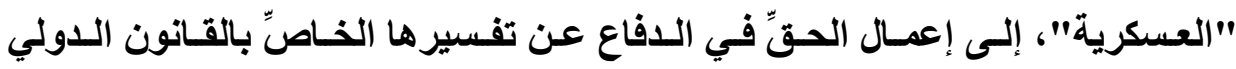

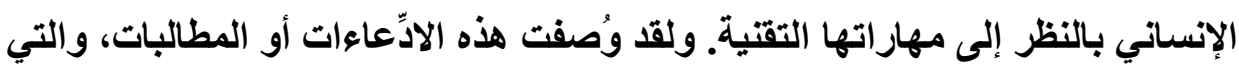

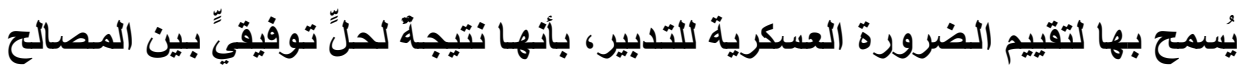

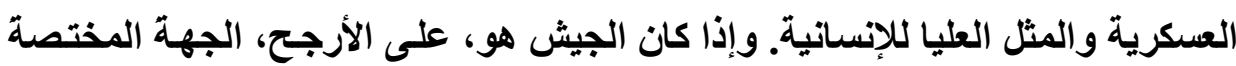

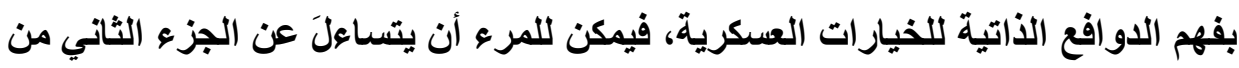

(1) CIJ, 20 Avril 2010, Usines de pâte à papier sur le fleuve Uruguay (Argentine C. Uruguay), arrêt, C.I.J. Recueil 2010, p. 109- 117, Para. 217. 
المعادلة؛ وهو العنصر البشري، هل القاضي العسكري أكثرُ كفـاعةً مـن القاضسي العـادي في تقييم قيمة الممتلكـات الثقافية وتقدير الحياة البشرية؟ مـع الأخذ في الاعتبار، أن القانون الدولي الإنساني يرمي إلى إقامة التوازن بين الجوانب العسكرية البحتة وقيمة الحياة البشرية أو التراث الثقافي للشعوب. من هنا، فلا يوجد، في رأينـا الخـاص، سببُ الإن وجيهُ لتعيين قضاةِ مهنيين عسكريين في الدوائر القضائية الدولية.

§- الضرورة العسكرية وحقوق الإنسان: هخاطر نهو صلاحية القاضي الدولي: في مجتمع يتـألف بشكلٍ حصريٍٍ تقريبًا مـن الدول(')، تثير مسألة مشروعية قواعد القانون الدولي، وهيئات القضاء الدولي، بعبارة بسيطة: إن المشروعية تعادل في هذا النموذج الشرعية. ولكن من الممكن أن تكون مشروعية قرار أو حكمٍ قضائيٍ

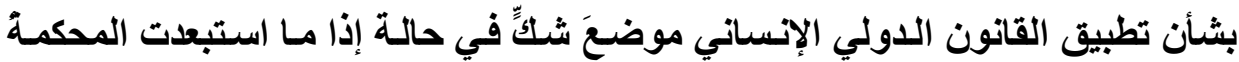
المسائلَ المتعلقة بمفهوم القانون ضد الحرب. وفي كل الأحوال، يتعين أن يتمَّ التحقُق من تطابق الوقائع التي تسببت في حدوث أضرار معينةٍة، مثل قتل المدنيين "كأضرار جانبية أو إضـافية" أو موت المحاربين في سـاحة المعركة مـع قواعد القـانون الدولي معي

$$
\text { على مستوى كلٍّ من القانون ضد الحرب والحق في الحرب(؟). }
$$

ويمكن على ضوء القانون الدولي الإنساني، تبريرُ الأضرار الإضافية أو الجانبية

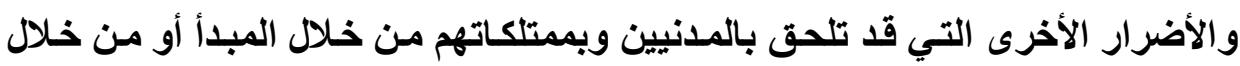
القواعد التي تحدده. ولتجنب مسئولية الدولة التي يُعْزى إليها ارتكابُ تلكك الأفعال، يجب

(1) Georges ABI- SAAB, "Cours général de droit international public", Recueil des cours, Vol. 207, 1987, p. 62.

(2) CIJ, 8 Juillet 1996, Licéité de la menace ou de l'emploi d'armes nucléaire, avis consultatif, C.I.J. Recueil 1996, p. 244, Para. 39. 
أن تكون هذه الأخيرةُ قد تَمَّتْن بالتطابق مـع قاعدة أو مفهوم القانون ضد الحرب('). والمسألة هنا ليست مسألة التثكيك في مبدأ المساواة بين المتحاربين، بل، بـالأحرى،

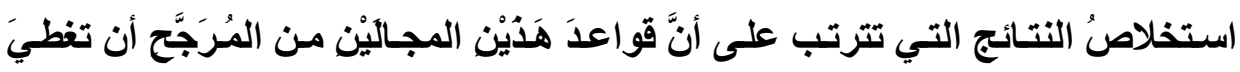
نفس الوقائع. وأن تطبيقها بثكل تراكميٍ قد يؤدي إلى إنشاء أو استبعاد وجود الالتزام بالإصلاح. وهكذا، يمكن أن تتطابقَ أعمالُ العدوان مع مفهوم القانون ضد الحرب، وكذا

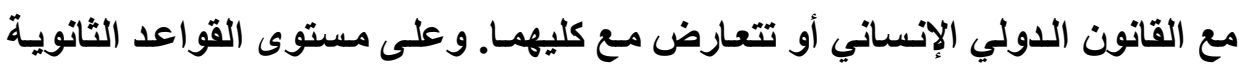

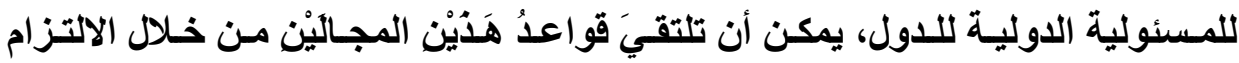
بإصـلاح الأضرار الناتجـة عن مخالفـة قواعد القـانون الـدولي. في هذه الحالـة، تعمل

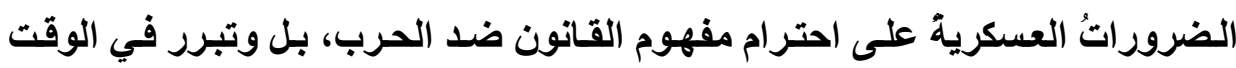
نفسه الأضرارَ التي لحقت بالأفر اد.

وفي معظم الأحوال، يُعَدُّ أخذ مفهوم القـانون ضـ الحرب في الاعتبار، على

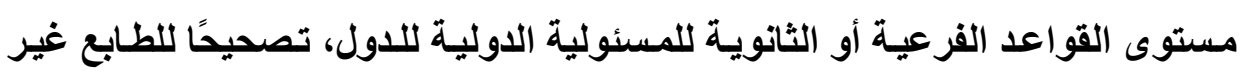
الكامل للقانون الدولي الإنساني(). وهكذا، يمكن أن ثُعزى الأضرار التي لحقت بـالأفراد إما إلى الدولة التي انتهكت مفهوم القانون ضد الحرب، أو الدولة التي انتهكت قواعد

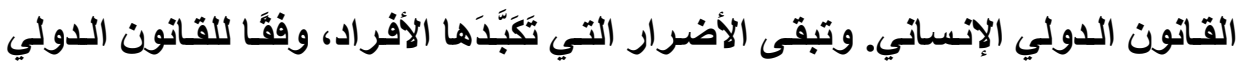

(1) CIJ, 19 décembre 2005, Activités armées sur le territoire du Congo (République démocratique du Congo C. Ouganda), arrêt, recueil 2005, p. 359- 360, Para. 5 ; Pierre D'ARGENT, "Les réparations de guerre en droit international public: La responsabilité internationale des Etats à l'épreuve de la guerre", Bruxelles/Paris, Bruylant, L.G.D.J., 2002, p. 119.

(2) Final Award, Ethiopia's Damages claims (Eritrea-Ethiopia), 17 August 2009, RSA, vol. XXVI, p. 731, Para. 321-323. 
الإنساني، بواسطة مواطني الدولة المعتدية، مُبَرَّرَةَ بالضرورات العسكرية. وبالتالي لا يُستحق بموجبها أيُّ تعويض، اللهم إذا أجاز القانون اللاخلي ذلك. ويمكن للمرء أن

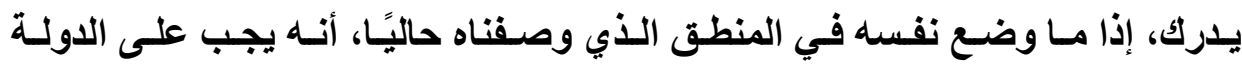
المعتديـة، باعتبار هـا شخصًا واحدًا غير قابلِ للتجزئسة، أن تتحملَ عبعَ خطئهـا. وفي القانون الوطني، لا يمكن أن يحصل المعتدي على تعويض عن الأضرار التي لحقت بـه من جرَّاء حالة الدفاع الثرعي للضحية"(') ومع ذلك، يمكن للمرء أن يلاحظ في تطور العدالة الجنائية الدولية، والتي تقتصر حاليًَا فقط على الجرائم الناجمـة عن انتهاكـات القـانون اللدولي الإنساني أو حقوق الإنسان، وفـي تصوُر المجتمـع المـنـي الدولي أو

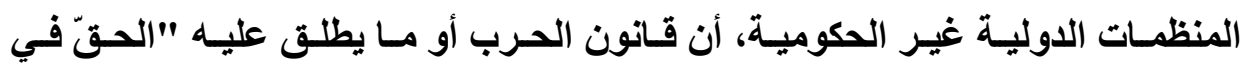
الحرب" لا يلعب إلا دورًا هامشيَّا.

و إذا كـان مبـدأ الاختـصاص الرضــائي للمحساكم الدوليـة، يجيـز، أو يجعـل مـن الممكن، تقسيم منازعات الجواتب القانونية للموقف أو الحالة، بغرض فتح آفـق اتِّـاذ قرار أو حكم قضائي بالنسبة لبعضها دون البعض الآخر، فسوف يشجع هذا الاحتمـال الدولَ على وضع إستراتيجيات قضائية تسمح بمثول أعدائها أمام المحاكم الدولية حينما يقدرون أو يرغبون في ذلك، مع تجنُب القيام بهذا الأمر في النزاع بأكمله(؟).

(1) Gilbert GUILLAUME, "Terrorism and International Law", International and Comparative Law Quarterly, vol. 53, 2004, p. 547.

(2) William SCHABAS, "Unimaginable Atrocities, Justice, politics, and Rights at the War Crimes Tribunals", Oxford, Oxford University Press, 2014, p.58 et s. 
ويصف مفهوم (نيبن كريغشوبلاتز) هذا الخطر بشكلٍ معقولِ ومفيدٍٍ للغاية(').

فبقدر ما يسمح به القانون أو النظام، من الطبيعي أن تلجأ إليه الدول أو الأفراد، لا سيما

من أجل كسب "حرب الآراء"("). وفي هذا الشأن، يبدو مفهوم القانون، الذي تتبَّنَاه

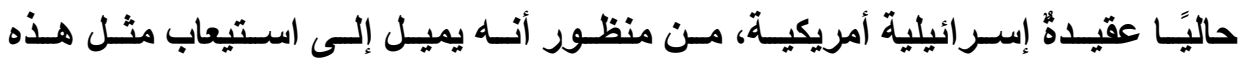
الإستراتيجيات القضائية (أو التدليل القانوني بالمعنى الواسع) مـع السلوكيات المخالفة بثكلٍ واضح للقانون الدولي الإنساني، أمرًا عبثيَّا.

من هنا، تبقى الحقيقة، أنـه يمكن أن تكون للإشـارة إلى قواعد القـانون الدولي الإنساني، في سياق استخدام القوة بثكل يتعارض مع قاعدة القانون ضد الحرب، إذا ما أدت إلى عدم وجـود انتهاكـات، بحكم الواقع وليس بحكم القـانون، وظيفـة الإقرار أو التصديق القانوني (إضفاء المشروعية)("). في ظل هذه الظروف، يمكن لنا أن نفهمَ قرَ

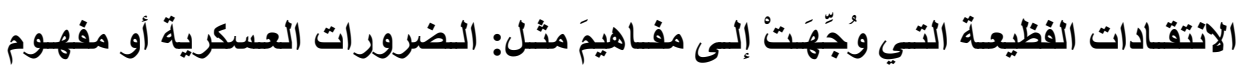
الأضرار الجانبيـة. من هنـا، يمكنتـا استتتاج أنـه لا يمكن ربط القانون الدولي بمخـاطر التلاعب التي يستتبعها ذلك، وإلا أضير في مصداقيته ومشروعيته.

(1) Bruno SIMMA, "Mainstreaning Human Rights: The Contribution of the International Court of Justice", Journal of International Dispute Settlement, vol.5, 2015, p.16 et 22.

(2) Thomas FRANCK, "Fairness in the International Legal and Institutional System: General Course on public International Law", Recueil des Cours, vol. 240, 1993-III, P. 320; Pierre BUHLER, "La Puissance aux $\mathrm{XXI}^{\text {ème }}$ Siècle: Les nouvelles définitions du monde", Paris, CNRS Editions, 2012, p.135-141.

(3) CIJ, 2 Juin 1999, Licéité de l'emploi de la force (Yougoslavie C. Royaume-Uni). Mesures Conservatoires, Ordonnance, Opinion dissidente de M. Kreca, C.I.J. Recueil 1999, P. 914, Para. 17. 
ويقع على عاتق جهات القضاء الدولي، في الحدود التي تمنحها الدول اختصاصًا في هذا الصدد، مسئولية عمل تمييز بين الأمور فيمـا يتعلق بالدعايـة ومحاولـة التحفيز

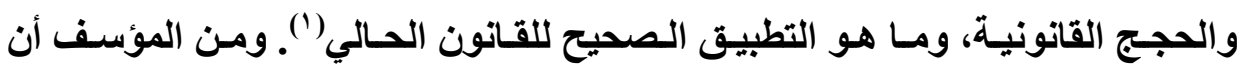
المتحمسين لمفهوم "القانون" لا يكرسون طاقتهم للاعوة إلى توسيع نطاق التسوية القضائية الإلزامية. ولا تتمثل الطريقة الوحيدة الفعالة لمكافـة إسـاعة استخدام الحجج أو الأدلة المترتبة على تفسيرات المؤيدين للقانون الدولي الإنساني في رفض القضاء القضاء

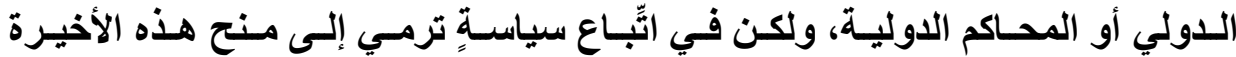
اختصاصًا موسعًا. ويترتب على ذلك، إعطاء الدول صساحبة الإجراء المشروع أسبابًا لإقرار أو إضفاء الشرعية على جهات القضاء الدولي.

و إذا مـا نظرنـا إلى الأفراد، على المستوى اللدولي، كأصـحاب حقوق أسـاسيةٍ تُقَرِّهـا قواعد القـانون، فـن الصعب قبول مقولـة: إن الحرب، المعروفة بأنها مسألة دولية، يجب أن يدعمها الأفراد كقَر محتوم("). وينعكس ذلك في الواقع، بشكلِ متز ايدٍا، في الرأي العـام الدولي. وإذا كـان تطور العقليات يسمح بـالتنبؤ بإمكانيـة وجود نظاج

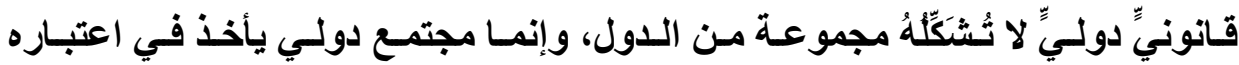
الاحتياجات ويخلم مصالح الأفراد(")، فستظهر مسألة الشرعية بمعان أخرى. في هذا

(1) Roy W.GUTMAN, "Spotlight on violations of International Humanitarian Law: The Role of The Media", International Review of the Red Cross, vol. 38, 1998, p. 619.

(2) Christian TOMUSCHAT, "Human Rights and International Humanitarian Law", European Journal of International Law, Vol. 23, 2012, p.17.

(3) Antonio A-TRINDADE, "International Law for Humankind Towards a New Jus gentium: General Course on Public International Law", Recueil des Cours, vol. 317, 2005, pp.9-312, Michael BYERS, "War $=$ 
النموذج، ستبقى الحجج التي طرحناها سـارية، ولكن ستفقد بعض الأهمية إلى الحدِّ الذي لا يمكن بأيّ حال من الأحوال اعتبار أغلبية الأفراد مسئولين قانونَّا عن أفعال دولتهم المخالفة لمفهوم القانون ضد الحرب، باستثناء الذين ارتكبوا جريمة العدوان. ومن هذا المنظور، يبدو أن عدم وجود التزام بإصلاح الضرر في حالـة "الأضرار الجانبية أو الإضافية" سوف يكون أمرًا مشكوكًا فيه للغاية من وجهة نظر العدائة العالة. بعد كل ذلكك، هناك تساؤلّ" يطرح نفسه: ما علاقة العدالة بفرع من فروع القانون يستوعب الإرهاب والدمار كموتٍٍ محتوم؟ ومن الواضح أن القانون الدولي الإنساني، الذي يكون فلسفيًا أقرب إلى الخيرية من العدالة، سوف يتحرك يومًا ما في هذا الآجّاه (اتجّاه العدالة)، ولكن من الواضح أيضًا أن هذا اليوم ما زال بعيداً.

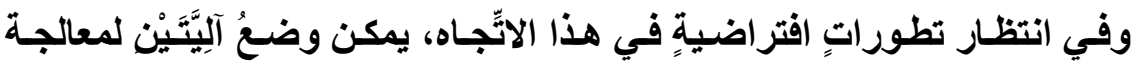
الوضع الراهن؛ أولاً: يمكن للقاضي الدولي، عندما يكون مختصنًا، أن يعتبر أن الدولئة

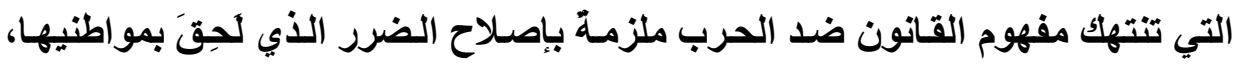
ويمكن أن نصل إلى هذه النتيجة في مجال حقوق الإنسان من خلال إعادة تفسير مفهوم

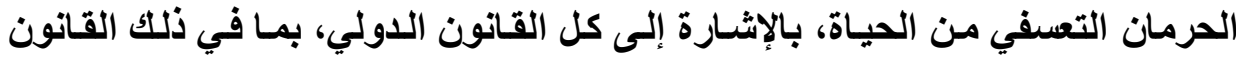

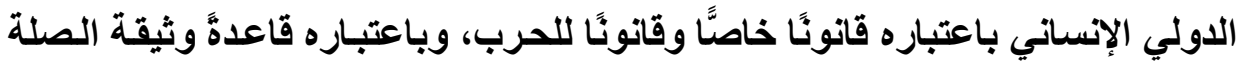

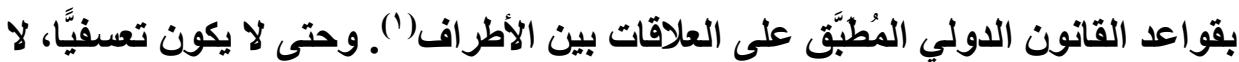

Law: International Law and Armed Conflict", Londres, Atlantic Books, 2005, p. 126.

(1) William SCHABAS, "Lex Specialis? Belt and Suspenders? The Parallel Operation of Human Rights Law and The Law of Armed Conflict, and the Conundrum of Jus ad Bellum", International Review of The Red Cross, Vol. 42, 2007, p.592. 
يجب أن ينـتج الحرمـان مـن الحيـاة عـن أفعـال مرتكبـةٍ بالمخالفـة لقـانون الحـرب أو بالمخالفة للقانون الدولي الإنساني. ومحساكم حقوق الإنسان بالخيار: إمـا أن تعلن عن موقفها بشأن الحقِّ في الحياة تطبيقَا لهذا التفسير، وفي هذه الحالة سوف تمـارس سُلطة تتجـاوز فيها اختصاصاتها، وبالتالي تعلن عدم اختصاصها بالفصل في قضية الحرمان من الحياة الناتج عن حالات النزاع المسلح، وإمـا أن تعتمـد هذا التفسير مـع مراعاة مفهوم القانون ضد الحرب في تقدير ما يرقى إلى الحرمـان التعسفي من الحيـاة

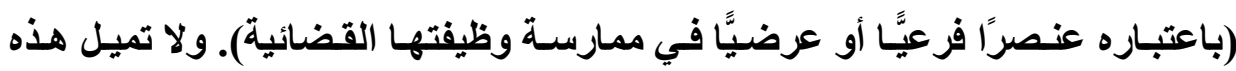

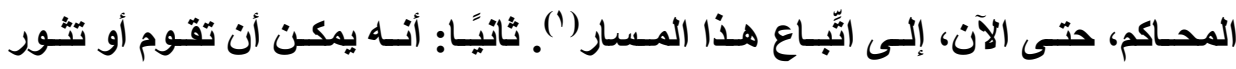
المسئولية الموضوعية عن الأضرار الجسدية والمادية التي يعاني منها المدنيون نتيجة لأيِّ عمل عدائي، سواء كان هذا العمل مشروعًا أو غيرَ مشروع. وتميل بعض الدول إلى تعويض ضحايا هذه الأفعال مع اعتبار ها متو افقة تمامًا مع القانون الدولي الإنساني

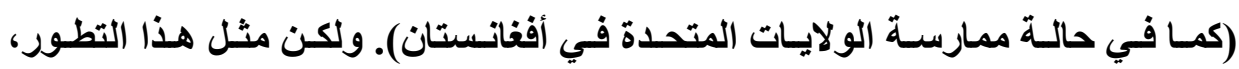
المرغوب فيه، قد يعتمد فقط على القواعد الاثّفاقية الجديدة أو القواعد العرفيـة وليس على العمل الإبداعي للقاضي (ץ).

(1) Cour EDH, $1^{\text {er }}$ Mars 2010, Demopoulos et autres C-Turquie, Grand Chambre, Décision sur la recevabilité, req. n 45113/99, Para . 115.

(2) William Hardman (Great Britain) V. United States, 19 June 1913, RSA, Vol. VI, P.26. 


\section{المبحث الخاهس \\ القضاة في هواجهة تهديّي قاعات المحاكم الجنائية \\ الدولية متعددة اللغات}

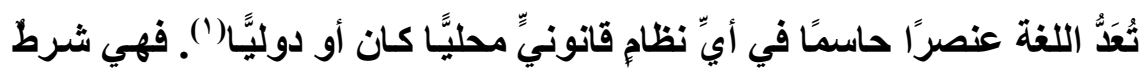

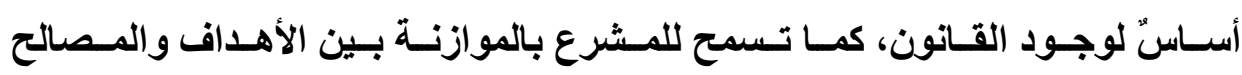

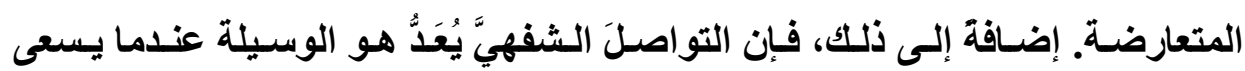

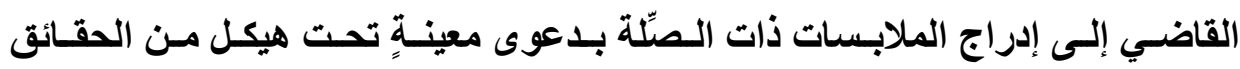
المجرَّدة المتضمنة في إحدى القواعد القاتونية. وفي الوقت نفسه، تبرز اللغة حدود القانون، وعدم الدقة المتأصِّة فيه، وغموضه، مما يعطي سبيًا للتوترات في المحادثة القانونية.

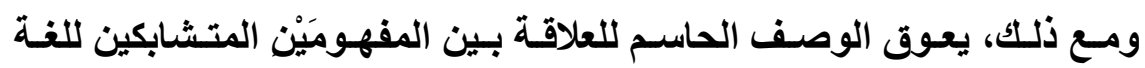

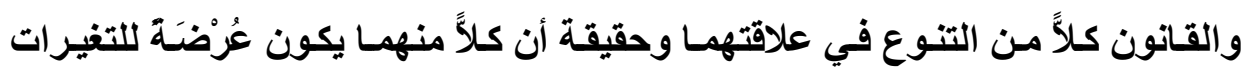

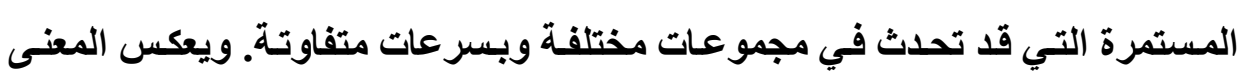

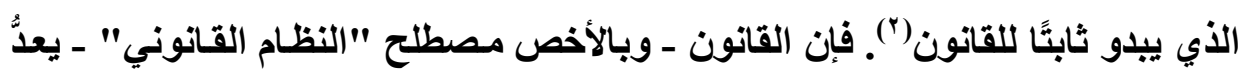

(1) Brian BIX, "Law, Language and Legal Determinacy", Oxford, Clarendon, 2007, p.1.

(2) Anne KJAER, "A Common Legal Language in Europe?", Oxford, Portland, 2007, p. 377; Richard POSNER, "The Problems of Jurisprudence", Harvard, Harvard University Press, 1993, p.51.

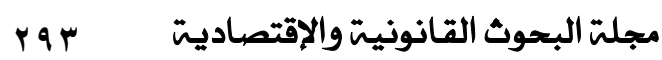




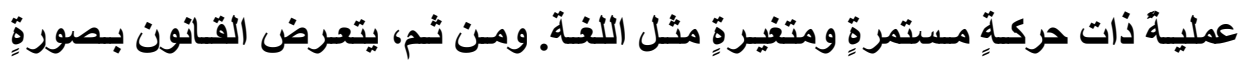
مستمرةٍ لتحدياتٍ بنائيةٍ وتأويليةٍة وذات علاقة بدلالات الألفاظ (').

وكما سيتضح لاحقًا، فِإن التحدِّيَ الأي يواجه المحامين والقضاة الدوليين على المستوى الدولي أكبر بكثير، حيث إنهم لا يتعاملون فقط مع نصوص قانونيةٍ تمَّ وضعُها بلفـاتٍٍ متعددة، ولكنهم أيضنًا فـي معظم الأحيـان يعملـون في بيئساتٍ متعددة اللغـات،

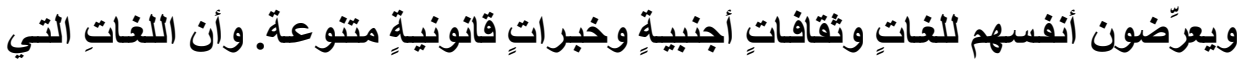
يتعاملون بها لا تقدِّم تحدِّاً لغويَّا فحسب، ولكنها أيضًا تعكس الفروقَ الدقيقة في العديد من الثقافـات القانونية، وإن وجود المترجمين الفوريين في قاعة المحكمةــ وإن كـان ضروريَّا ومفيدًا ــ غالبًا ما يصنع بعض المشكلات. ا - مكان عمل القاضي الدولي:

يأتي قضاة المحاكم الدوليـة من كافة أرجاء العـالم. فهم يمثلون خبراتٍ مهنيـة متنوعة، وقد تم تدريبهم في بيئاتٍ قانونيةٍٍ متفاوتة. إضافة إلى ذلك، فإنهم يأتون بلغتهم

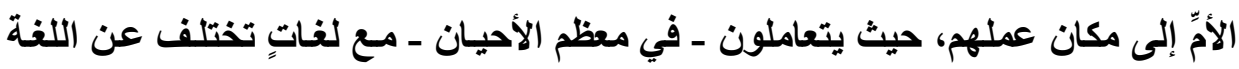
التي نشأوا عليها وتدرَّبوا في بيئتها.

(1) Peter TIERSMA, "The Oxford Handbook of Language and Law", Oxford, Oxford University Press, 2012; Andrei MARMOR, Scott SOAMES, "Language in the Law", Oxford, Oxford University Press, 2011; Chris HUTTON, "Language, Meaning and the Law", Edinburgh, Edinburgh University Press, 2009; Muller OLIVIER, "Avant dire droit, le texte, la norme et le travail du droit, la question de linguistique dans la théorie Structurante du droit", Laval, 2009; Peter TIERSMA, "Legal language", Chicago, Chicago University Press, 2000; Brian BIX, "Law, Language and Legal Determinacy", op. cit., p. 3. 
وللتغلب على العوائق اللغوية ـ بالطبعـ يمكن التعامل مـع المترجمين واستخدام

وسائل الاتِّصال والتواصل المُعََّّة لغرض الترجمة داخل قاعات المحكمة، وقواعد بيانات

المصطلحات المتخصصة متعددة اللغـات، والتدريب اللغوي لهيئة المحكمـة والعـاملين

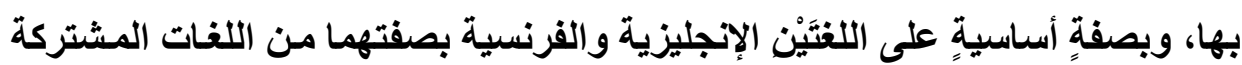

في العَلاقات الدولية والقاتون والمحاكم. وعلى الرغم من كلِّ هذه الوسائل التي ثُصاحب

عمل القاضي الدولي وثُيَسِّرُهُ، يُعَدُّ التعدد اللغوي على المستوى الدولي سمة خاصنة

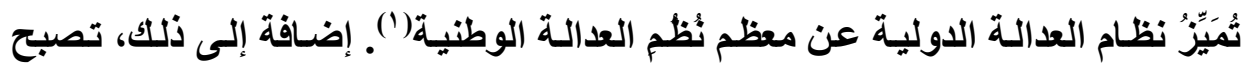
المسألة اللغوية أكثرَ حسمًا بكثيرِ عندما تمارس المحكمة الدولية اختصاصنها القضائيَّ

الشخصيَّ على أفرادٍ مُتُهَمِينَ بفئات من الجرائم المنصوص عليها في النظم الأساسية

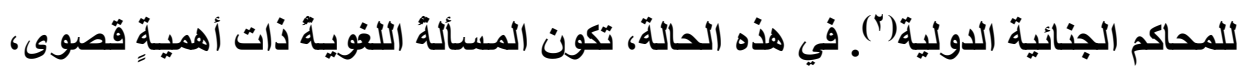

حيث ينبغي أن تكون الحقوقُ اللغويةُ الخاصةُ بجميع الأطراف المعنية المتنوعة قد تَمَّت

الموازنة بينها وبين تكلفة الحفاظ على التعدُّ اللغوي في قاعة المحكمة ل(").

(1) See, Eight Annual Report of the international Criminal Tribunal for the prosecution of persons Responsible for Genocide and Other Serious Violations of International humanitarian law committed in the territory of Rwanda and Citizens Responsible for Genocide and Other Such Violations Committed in the Territory of Neighboring States between 1 January and 31 December 1994, of 11 July 2003, UN Doc. A/58/140s/2003/707, Para. 4.

(2) For The Purpose of this article the terms (international criminal) Court (s) and (international criminal) tribunal (s) are used interchangeably and refer to any of the international criminal courts or tribunals.

(3) Joshua KARTON, "Lost in Translation: International Criminal Courts and the Legal Implications of Interpreted Testimony", Vanderbilt Journal of Transnational Law, no. 1, Vol. 41, 2008, p. 10. 
وحتى إذا كاتت التكلفة عنصرًا حاسمًا، يبدو أنه من الأمور المثيرة للجدل مـا إذا

كان ينبغي اتبّاع رأي المحكمة الجنائية الدولية ليوغسلافيا السابقة والتي اعتبرت أن اعتراف المتهم بالذنب "يسهم في المصلحة العامـة"، عن طريق القيام بتوفير كبيز للموارد، ومن بينها الترجمة والترجمة الفورية إلى اللفات المختلفة'(')

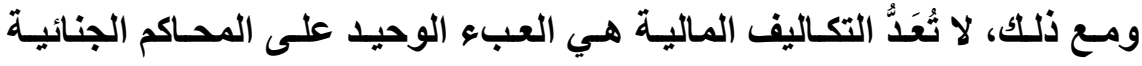

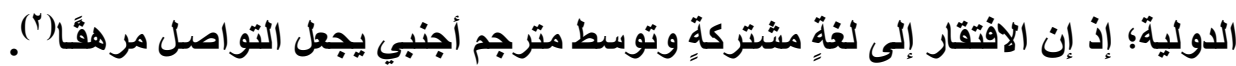

ومن ثم، يجب أن يكون للى القضاة وعيّ بالجوانب المتنوعة للتعدُّد اللغوي وخاصـة الترجمة في قاعة المحكمة، ويجب أن يلعب القضاة دورًا فعالاً فيمـا يتعلق باستخدام

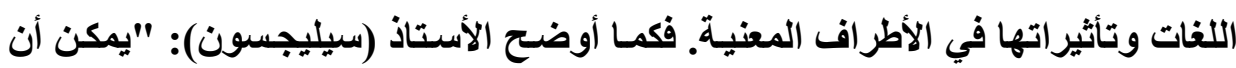

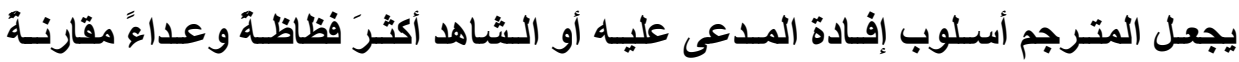
بالأسلوب الأصلي الذي تلقَّظ بـه، وعلى العكس يمكنهـه أن يجعل تأثيراتِهـه أكثرَ اعتدالاً

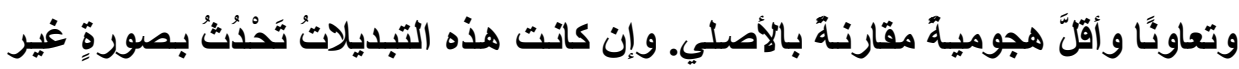
واعية، إلا أنه لا يمكن أن نقلل من تأثيراتها على القضاة"(").

(1) ICTY, 31 July 2001, Prosecutor V. Stevan Todorovic, IT-95-9/1-s, Sentencing Judgment, Para. 80.

(2) ICTY, 15 July 1999, Prosecutor V. Tadic, IT-94-1-T, Transcript of the Hearing of 7 May 1996, Para. 47.

(3) Berk SELIGSON, "The Bilingual Courtroom: Court Interpreters in the Judicial Process", Chicago, Chicago University Press, 2002, p. 2. 


\section{أ - الشروط القانونية المنظمة للمسألة اللغوية:}

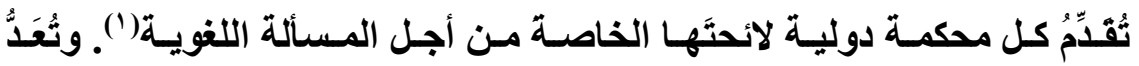

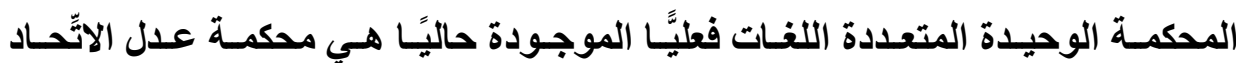

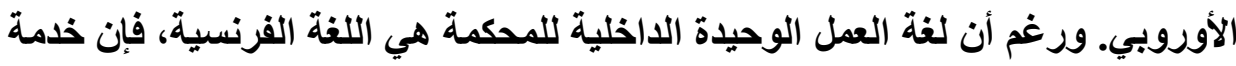

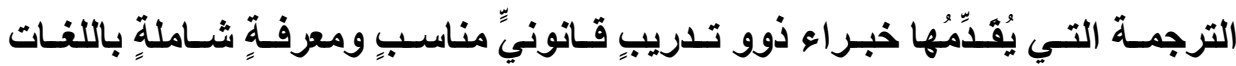

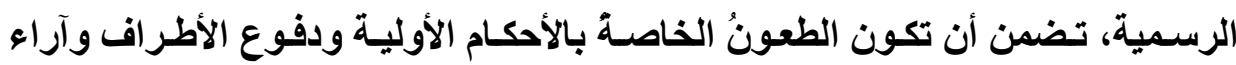

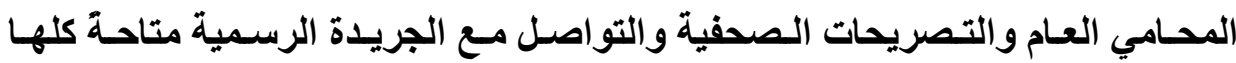

بجميع اللغات الرسمية للاتّحاد الأوروبي (†).

ومع ذلك، فخارج أسوار أوروبا، قرَّرت المحاكم والمنظمات الدولية تمثيلَ جميع

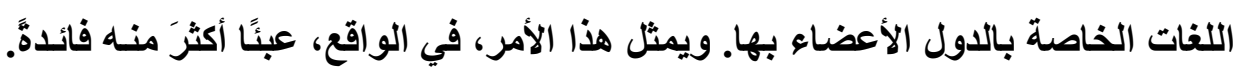

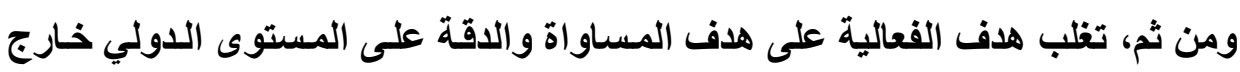

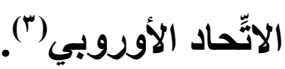

(1) Philippe SANDS, "The Manual on International Courts and Tribunals", Oxford, Oxford University Press, 2010, p. 13.

(2) Karen MAULIFFE, "Language and Law in the EU: The Multilingual Jurisprudence of the ECJ", Oxford, Oxford University Press, 2012, p. 200; Inigo URRITIA, "Approach of the European Court of Justice on the Accommodation of the European Language Diversity in the Internal Market: Overcoming Language Barriers or Fostering Linguistic Diversity", Columbia Journal of European Law, Vol. 18, 2012, p. 243; Claude TRUCHOT, "Languages and Supranationality in Europe: The Linguistic Influence of the European Union", Cambridge, Cambridge University Press, 2003, p. 99.

(3) M. SOLAN, "The Interpretation of Multilingual Statutes by the European Court of Justice", Brooklyn Journal of International Law, no. 2, Vol. 34, 2009, p. 279. 
وسوف نشير إلى عدد من الأمثثلة في هذا الشأن: طبقَّا للمـادة (q ب) من النظام

الأسـاسي لمحكمة العدل الدولية، اللغنات الرسمية للمحكـة هي الإنجليزيـة والفرنسية.

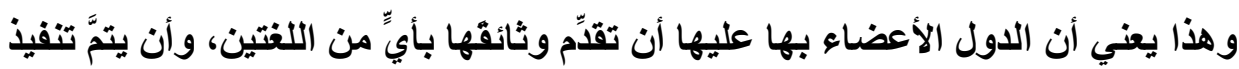
الإجراءات وإصدار الأحكام بالإنجليزية أو الفرنسية، ما لم يتم الحصول على ترخيص باستخدام لغةٍ أخرى.

وقد أقرَّت المحكمة الدوليـة لقـانون البحـار (')، وكذا المحكمة الأوروبية لحقوق

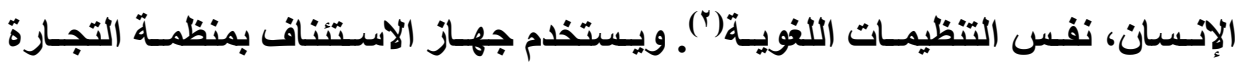

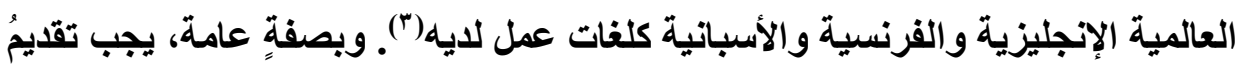

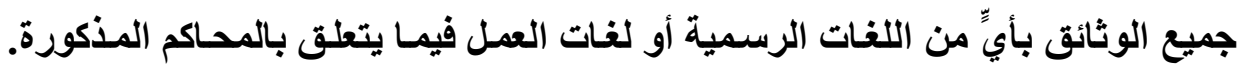

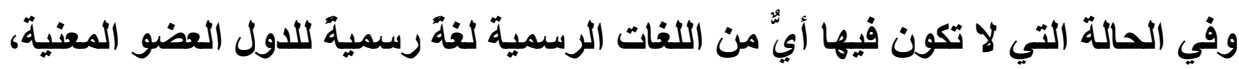

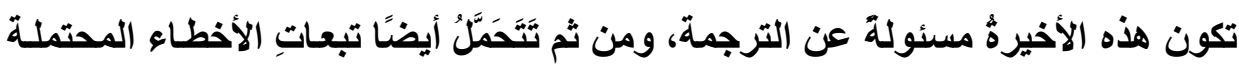

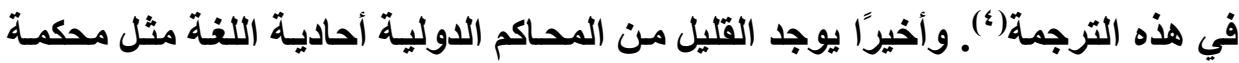
الرابطة الأوروبية للتجارة الحرة ومحكمة مجموعة دول الإنديز، وقد تسمح المحكمتان

$$
\text { بوجود استثناعات على هذه القاعدة( (ه). }
$$

(1) Art. 43 of the Rules of the International Tribunal for the Law of the Sea, as amended on 17 March 2009.

(2) Art. 34 of the Rules of the European Court of Human Rights.

(3) Art. 2 (c) (i) of the Marrakesh Agreement Establishing the World Trade Organization.

(4) Art 51 of the Rules of the International Court of Justice, See e.g. ICJ, 16 October 1975, Western, Sahara, Advisory Opinion, I.C.J. Reports 1975, p. 12.

(5) Art 25 of the Rules of Procedure of the EFTA Court, William SCHABAS, "The International Criminal Court: A commentary on the Rome Statute", Oxford, Oxford University Press, 2010, p. 634. 


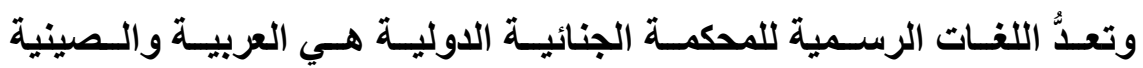

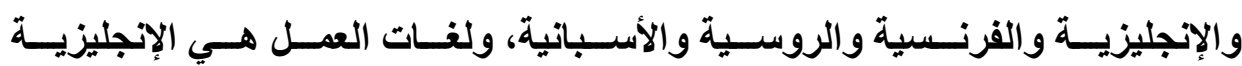

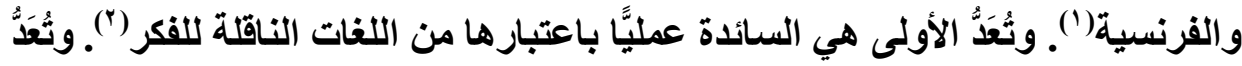
اللغـات الرسمية ولغـات العمل لكلِّ مـن المحكمة الجنائيـة الدولية ليوغسلافيا السابقة والمحكمة الجنائية الدولية لرواندا هي الإنجليزية والفرنسية("). ويحتاج جميع العاملين والقضاة إلى التحدُّثِ بلغةٍِ واحدةٍ على الأقَل من هاتين اللفتين. وعمليَّا، عـادةً مـا يكون

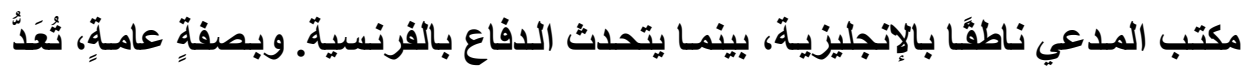

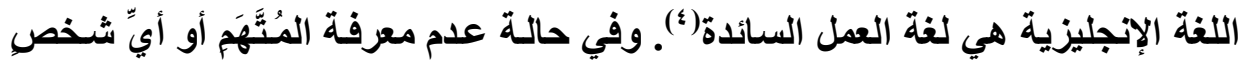

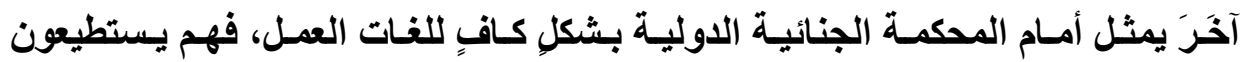
استخدام لغتهم الأصلية، وتتحمل المحكمة أعباء الترجمة.

ويوجد فرقّ مهمٌٌ بين سياسات الترجمة الخاصـة بالمحكمة الجنائية الدوليـة من

جانب، وكـلِّ مـن المحكمـة الجنائبـة الدوليـة ليوغسلافيا السـابقة والمحكــة الجنائيـة الدولية لرواندا من جانبٍ آخر. ففي هاتين الأخيرتين، لا توجد حدودٌ لكمية الوثائق التي

(1) William SCHABAS, "The International Criminal Court: A Commentary on the Rome Statute", op.cit., p. 635.

(2) Philippe SANDS, "The Manual on International Courts and Tribunals", op.cit., p. 15.

(3) Rule 3 of Rules of Procedure and Evidence of the ICTY, amended on 19 November 2012, IT/32/Rev. 43.

(4) Ludnila STERN, "Interpreting Legal Language at the International Criminal Tribunal for The former Yugoslavia: overcoming the lack of lexical equivalents", the Journal of specialized translation, no. 2, July 2004, p. 63. 


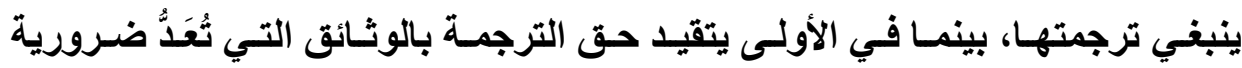

وبينمــا تحــد الأنظمـة الأسـاسـية وقواعـــ الإجـراعات ســالفة الــكر اللغــات

الرسمية ولغات العمل، تركت محاكم جنائية قليلة تحديد لغات العمل لتقدير القاضي ().

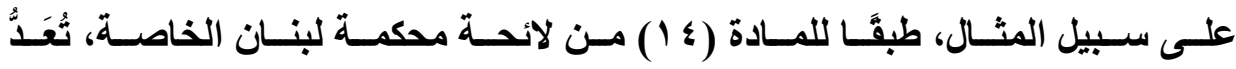
العربية والإنجليزية والفرنسية هي اللغات الرسمية للمحكمة. وقد يقرر القاضس- بعد

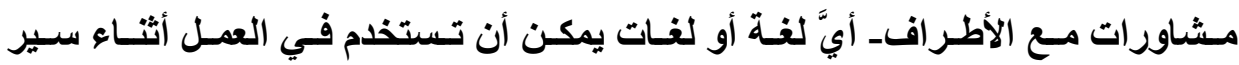

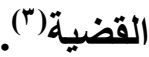

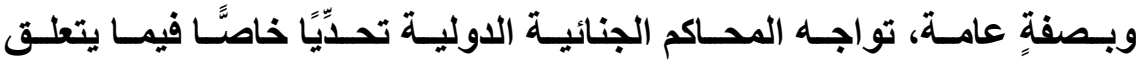
باللغات مقارنة بالمحاكم الأخرى؛ فقي الوقت الأي ثُلقي فيه محاكم دوليةــ مثل محكمة العدل الدولية أو المحكمة الدولية لقانون البحار- عبء الترجمة على الأطراف، وعليها أن تـدرس الوثائق والمر افعـات بلغاتها الرسـية فحسب، يكون على قضاة المحساكم الجنائية الدولية التعاملُ مع عدد أكبر بكثير من اللغات، حيث قد يأتي كلّ مـن المتهمين والثهود والضحايا الذين يَمْتُلونَ أمام هذه المحاكم من مجموعة متنوعة من الأمساكن

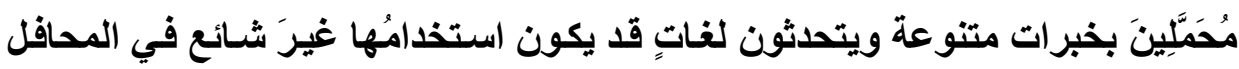

(1) Berk SELIGSON, "The Bilingual Courtroom: Court Interpreters in the Judicial Process", op.cit., p. 6 et s.

(2) Rule 10 of the Rules of Procedure and Evidence of the SLT, adopted on 20 March 2009, as amended on 20 February 2013.

(3) E.G. STL, 16 September 2011, decision on languages in the Case of Ayyash et al., STL-11-01/1/PT. 
باختصار، تعتمد التحديات المتعلقة بالتعدد اللفوي على نوع المحاكم الدولية، وبصفةٍ خاصةٍ الفاعلون المتضمنون. ويتم استقطاب الفوارق بين محاكم دوليـة تَمْتُلُ

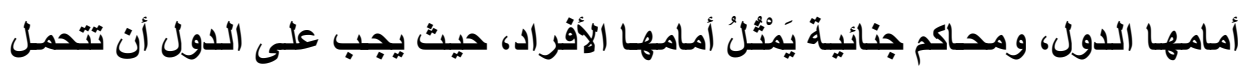
الأعبـاء بنفسها، ويسمح للأفراد باستخدام لغـاتهم الخاصـة، كمـا تُقدِّمُ لهم مسـاعداتٍ لغوية) (1) (1)

\section{ب- التعدد اللغوي في قاعات المحاكم الجنائية الدولية:}

نشأت المحاكم الجنائية الدولية في صورتها الحديثة في أعقاب الحرب العالمية

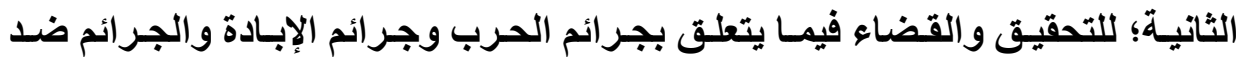

الإنسانية. وقد تَجَسَّدَ ذلك بصورةٍ كبيرةٍ في المحكمة العسكرية الدولية في نورمبرج التي أنثأتها القوى المنتصرة في الحرب العالمية الثانية. وجديرٌ بالذكر، أن المحاكم

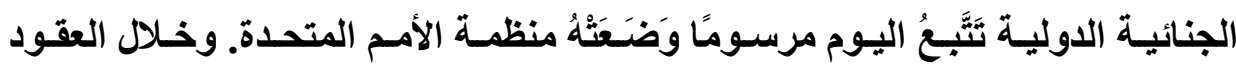

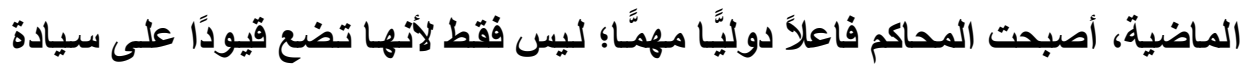
الاولة، ولكن أيضًا لأنها تتعرض للأفراد الواقعين خـارج مظلة المحاكم الوطنيـة. وهذا الأمر على درجةٍ كبيرةٍ من الأهمية، بصفةٍ خاصةٍ عند مواجهة المتهم بهيكلِ معقدٍ من

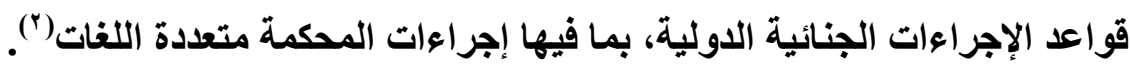

(1) For example, Art. 14 (3) (F) of the international covenant on civil and political rights, art. 6 (3) (e) of the European Convention for the protection of Human Rights and Fundamental Freedoms.

(2) Christin B. COAN, "Rethinking the Spoils of War: Prosecuting Rape as a War Crime in the International Criminal Tribunal for the former Yugoslavia", North Carolina Journal of International Law and Commercial Regulation, Vol. 26, 2000, p. 183.

مجلتّ البحوث القانونيتّ والإقتصاديت 
ولقد تطورت الإجراعات القضائية للمحاكم الجنائية الدولية بصورةٍ كبيرةٍ منذ بدايتها في عام 0 ؛ 9 1، وخاصة فيمـا يتعلق بأهمية شـهادة الشهود. ففي الوقت الذي

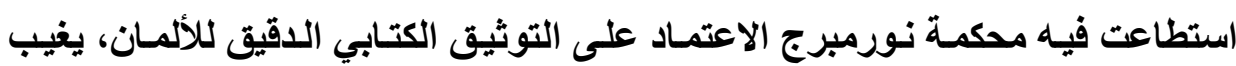
الـليل الكتـابي بشكلٍ كبيزٍ هذه الأيسام، وتعتمـد المحساكم بصورةٍ ضـمةٍٍ على الـليل الشفهي، والذي يحتاج بدوره إلى ترجمةٍ فوريةٍة متزايدة" (1).

زبدة القول، لا تقتصر مهمـة القاضسي على تعيين مترجم، ولا يُعَدُّ توسط هذا

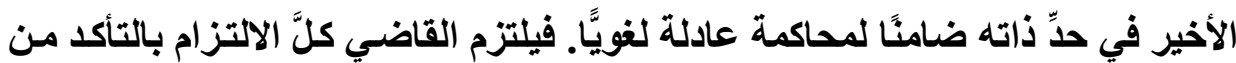
أن جميع الفاعلين في قاعة المحكمة على وعي وفهم بتعقد وتحديات مهمـة المترجم، وأن يكون هذا الأخير ذاته على وعي بمهمته ودوره. r- دور القاضي فيما يتعلق بترجمة قاعة المكمة: يتعين على مترجمي المحكمة أن يقوموا بترجمـة المـادة مـن المصدر الأصلـي دون تعديل أو تلخيص أو حذف أو إضـافة، مـع الحفـاظ على مستوى اللغـة ونمطها وأسلوبها ونية المتحدث(")

إذا توقف الأمر عند هذا الحد، فلن يتعدَّى دورُ القاضـي أن يكون مُنْصِتَّا يَقِظّا أثناء جلسات المحكمة. ومع ذلك، يضيف التوسط من خلال الترجمة طبقة إضـافية من التعقيد، ويكون دور القاضـي أقربَّ إلى المحقق، عليه أحيانَّا الاسـتفادة مـن بطاقتيه الصفراء والحمراء للإثـارة للأطراف باثِّاع القواعد. ونظرًا لأن الترجمـة هي نشاط

(1) Michael SCHARF, "An Insider's Guide to the International Tribunal for the former Yugoslavia", New York, Transnational publishers, 1995, p. 242.

(2) Holly-MIKKELSON, "Fundamentals of Court interpretation: Theory, Policy and Practice", Durham, Carolina Academic Press, 1991, p. 16. 
مقيدّ ثقافيًا، ولا يحتاج المترجم إلى إجـادة لغتي المصدر والهدف فحسب، ولكن عليه

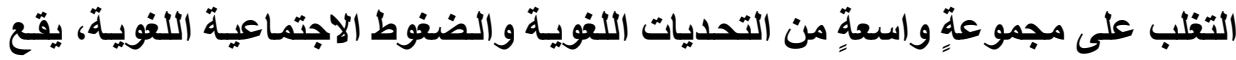

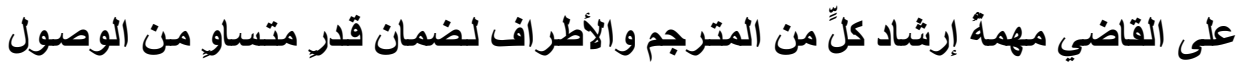

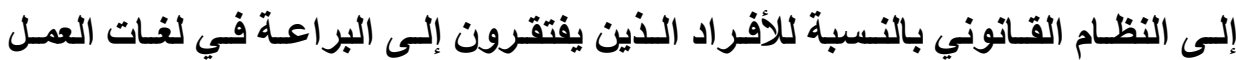
بالمحكمة.

ووفقَا لقو انين وقو اعد الإجراءات في معظم المحسكم الدولية، فـإن القاضسيَ

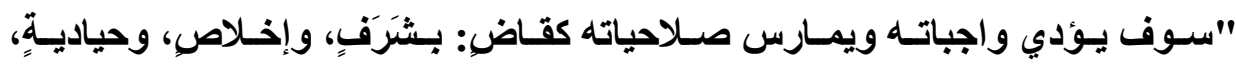

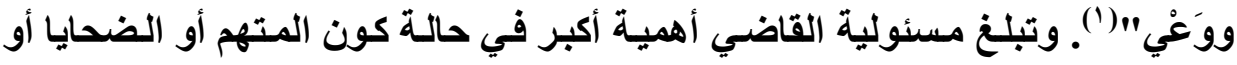

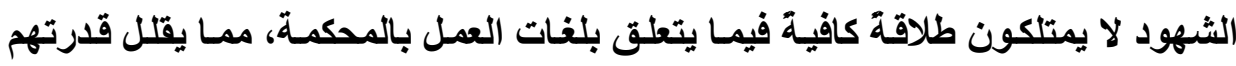

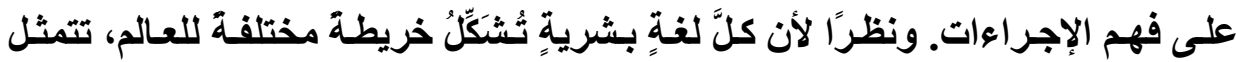

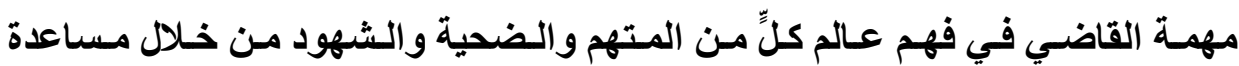

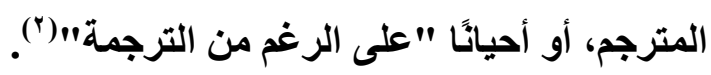

بعبارةٍ أخرى، يجب أن يتمتع القاضسي الذي يعمل في محكمةٍة جنائيسة دوليـةٍ بمستؤى عال من الحساسية والوعي العابر للثقافات؛ وذلك لما للاختلافات الثقافية من

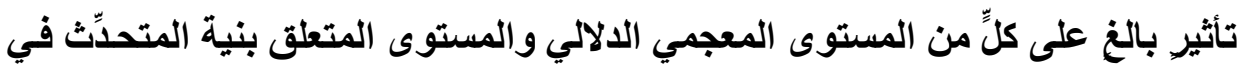

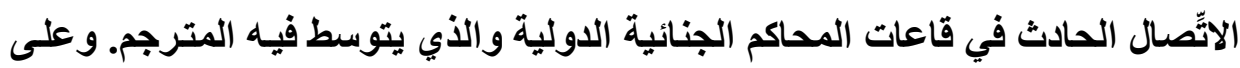

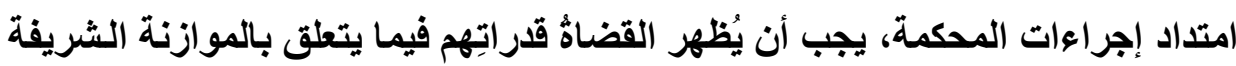

(1) Rule 4 of the ICJ Rules of Procedure; Rule 5 of the Rules of Procedure and Evidence of the ICC; Rule 14 of the ICTY Rules of Procedure.

(2) George STEINER, "After Babel", Oxford, Oxford University Press, 1992, p. XII. 
المخلصة الحياديـة الواعية بالكلمـات الأصلية للأطر اف وترجمتها إلى لغة العمل في المحكمة، أي اللغات التي يجيدها القضاة أنفسهم(') أ - القاضي كماَمٍ الهقوق اللغوية: رغم أن قوانين المحاكم الجنائية الدولية وقواعد إجراءاتها قد عمدت إلى تنظيم المسألة اللغوية، يخلق تطبيقها صعوباتٍ جمة على المستوى العملي. على سبيل المثال، تنص المادة (Y/V \) من قواعد إجراعات المحكمة الجنائية الدولية على أنه: "يجب أن

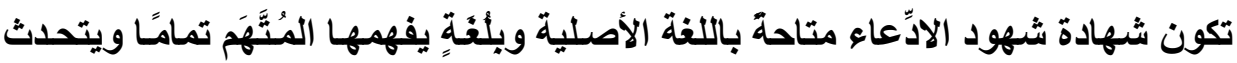
بها". وفي حالة المدعي عبد الله باندا أباكير نورين والمدعي صـالح محمد جيربو (")، كـان يجب على قضاة المحكمـة الجنائيـة الدوليـة التعامـل مـع مجموعـة متنوعـة مـن المسائل المعقدة، تتنوع بين ترجمة البند المتعلق بمستوى معرفة المشتبه بـه بلغـات العمل في المحكمة وبين مشكلاتٍ عمليةٍ تتعلق بترجمة الوثائق إلى لغة الزغاوة، وهي اللغة الأصلية للمدعى عليه("). وفي النهاية، اتخذ القضاة قرارًا لصالح الحقوق اللغويـة للمدعى عليه ولحقّه في محاكمة عادلنة. وقد ركز هذا القرار على مبدأ تكافؤ وسـائل

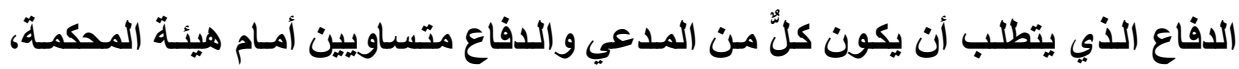

(1) ICTR, 1 June 2001, Prosecutor V. Clément Kayishema and Obed Ruzindana, ICTR- 95-1-A, Judgment, Para. 206.

(2) ICC, Prosecutor V. Abdallah Banda Abakaer and Saleh Mohammed Jerbo Jamus, Situation in Darfur, Sudan, ICC-02/05-03/09/Reasans for the Order on translation of witness statements and additional instruction on translation, 21 September 2011.

(3) Ibid., p. 5.

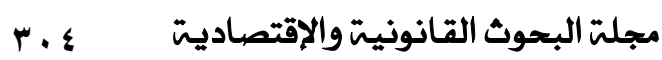


وعلى التزام الهيئة القضائية بضمان ألا يقع أيٌّ من الأطراف في وضع غير مناسبٍ عند

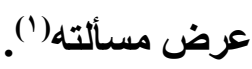

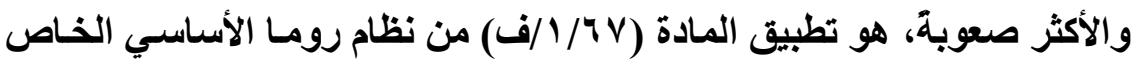

بالمحكمة الجنائية الدولية، والتي تنص على أنها: "يجب أن يتمتع المُتَّهَم- بدون أيِّ

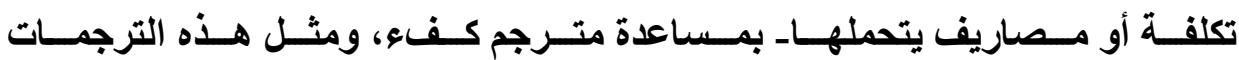
تكون ضرورية لتلبية متطلبات العدالة، وفي حالة كون أيٍّ من الإجراعات أو الوثائق

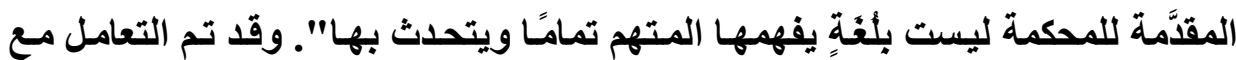
مسألة معنى مصطلح "متطلبـات العدالة" في قضية لوبانغـا(؟) وقد هدفت القاضية المسئولة بقرارهـا ـ في إثـارة إلى القرار الذي اتخذتـه المحكمة الأوروبيـة لحقوق

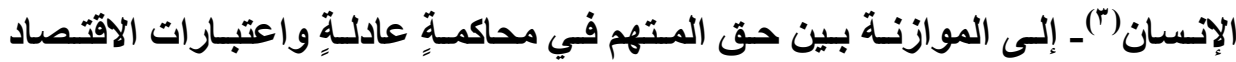

$$
\text { القضائي والملاعمة الإجرائية. }
$$

ولقد أصدرت كلّ مـن المحكـة الجنائية الدولية ليوغسلافيا السـابقة والمحكمة

الجنائية الدوليـة لروانـا أحكامًا متنوعـة تتعلق بحقِّ المتهم في ترجمـة الوثـائق ذات

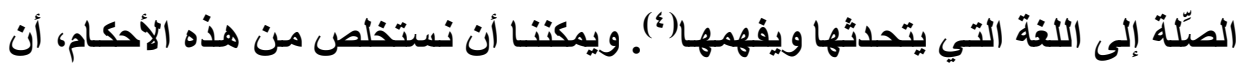

(1) ICTY, 15 July 1999, Prosecutor V. Tadic, IT-94-1-T, Judgment, Para. 48- 50.

(2) ICC, 14 March 2012, The Proscutor V. Thomas Lubanga Dyilo, ICC01/04-01/06, Decision on the Requests of the Defence of 3 and 4 July 2006.

(3) ECTHR, 19 December 1939, Kamasinski V. Austria, application no. 9783, Judgment, Para. 74.

(4) ICTY, Proscutor V. Zejnil Delalic et al., IT- 96-21, decision on defence application for forwarding the documents in the language of the accused, 25 September 1996. 
القضاة يهافون إلى الوصول إلى تفاهم مشتركٍ وتو افق حول ترجمة التنظيمات اللغويـة

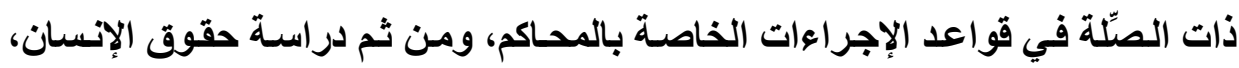
وخاصة كما يتضح في الآتّفاقية الأوروبية لحقوق الإنسان.

وعلى الجانب الآخر، استغرقت المناقثات الخاصة بالمسألة اللغوية في القضايا

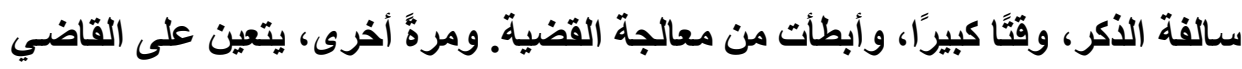

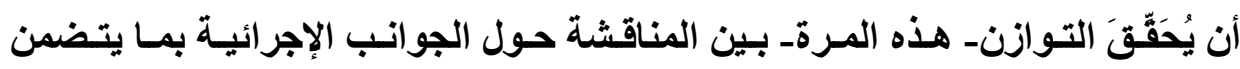

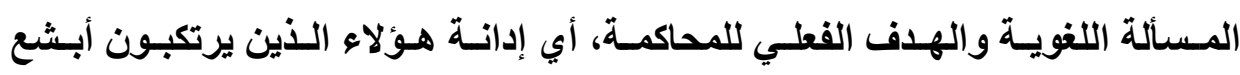

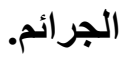

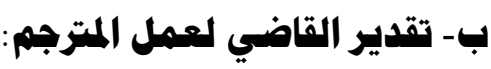

كان يتم اعتبار المترجمين حتى عهد قريبـ لا سيما على المستوى الوطني-

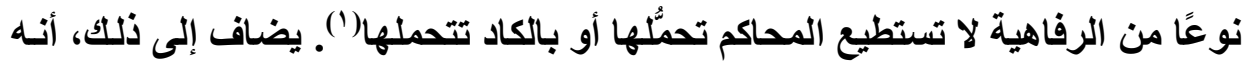

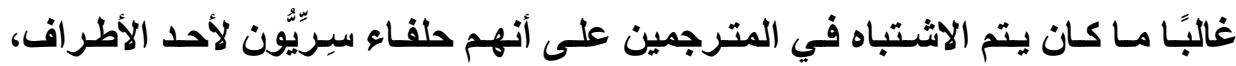

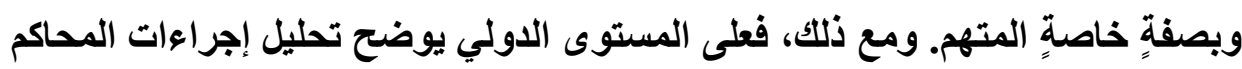
الجنائية الدولية مساهمة القضاة بصورةٍ ضخمةٍ في فهم أفضلَ وتقدير لعمل المترجم. على سبيل المثال، يُعَبرّر القاضسي (فولفورد) الذي يترأس إحدى غرف المحكمة

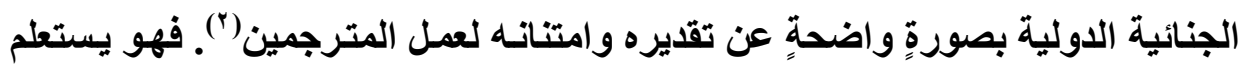

(1) Daniel PROCACCINI, "What we have here is a Failure to Communicate: An Approach for Evaluation Credibility in America's Multilingual Courtrooms", Boston College third World Law Journal, no. 1, Vol. 31, 2011, p. 163- 164.

(2) ICC, 14 March 2012, Prosecutor V. Thomas Lubanga Dyilo, ICC-01/0401/06, transcript of the hearing of 26 August 2011, p. 49.

مجلتّ البحوث القانونيت والإقتصاديت 
من المترجم في نهاية جلسة استماع مرهقة عما إذا كان يستطيع أن يستمر لعشر دقائق

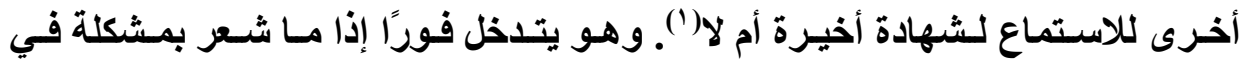

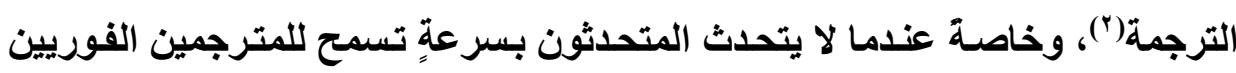

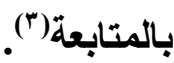

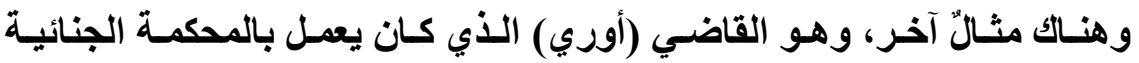
الدولية ليوغسلافيا السابقة، حيث كـان يذكر الأطر افت الذين يعطون الانطباع بـأنهم يضعون قررات المترجمين موضع التساؤل: "بأن الطريقة المثلى لمساعدة المترجمين، هي التحدث بالسرعة التي تجعلهم قادرين على أداء مهمتهم بالجودة التي يؤدونها بها لهانيا

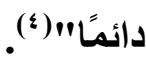

و الواقع، أنه في بعض الأحيان تكون محاولاتُ القضاة لتوجيه الإجراءات غيرَ

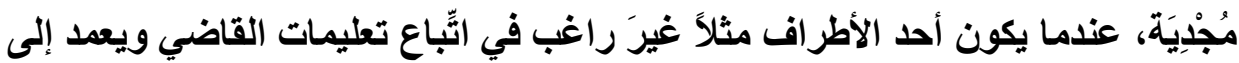
تخريب الإجراءات مثل ميلوسوفيتش الذي اعتاد التحدُّث بسرعةٍ لا يستطيع المترجمون

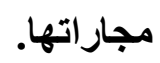

\section{ج - أساليب إجراء المقابلات:}

يكتسب فن توجيه الأسئلة للنتهم أو الضحايا أو الثهود في قاعة المحكمة التي

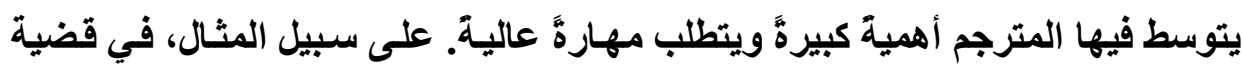

(1) Ibid., transcript of the hearing of 25 August 2011, p. 36.

(2) Ibid., transcript of the hearing of 18 April 2011.

(3) See the Transcript of the hearing ICC-01/04-01/06-T-360-Red2-ENGCT-WT-13-06-2012, 2/70 PVT.

(4) ICTY, The Prosecutor V. Jovica Stanisic and Franko Simatovic, IT-0369-T, Transcript of the hearing of 7 March 2012, p. 18056. 
ميلوسوفيتش السابق الإثارة إليها، سـأل القاضي (روينسون) الشاهد السؤال الآتي:

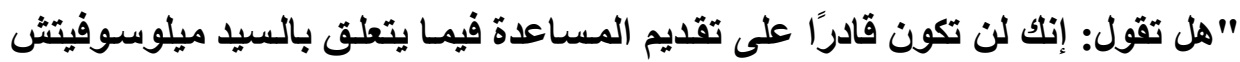

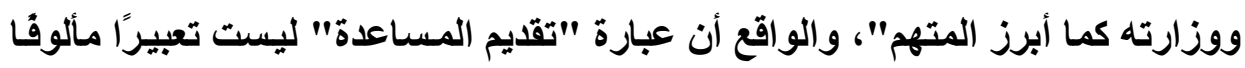

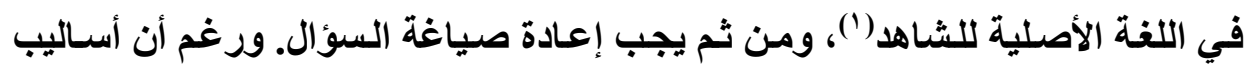

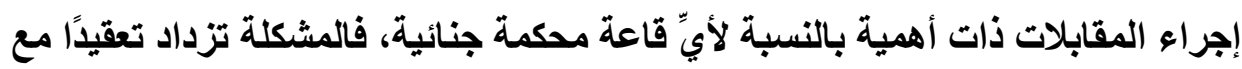

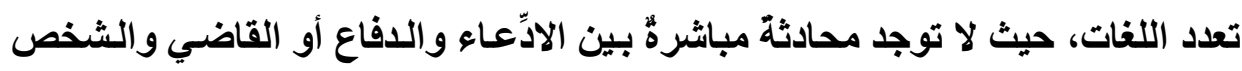

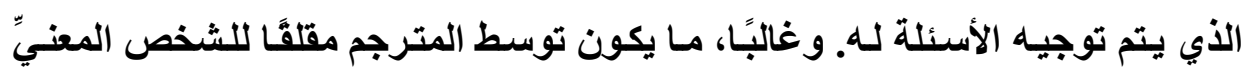

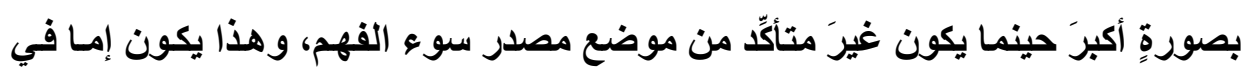
الصياغة الأصلية للسؤال أو في ترجمة المترجم.

\section{د- الجوانب البرجماتية في ترجمة قاعة المكمية:}

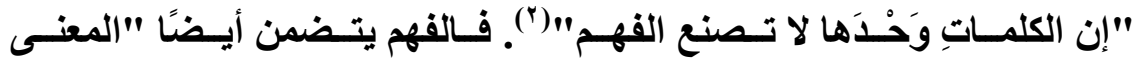

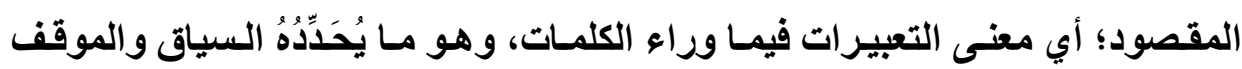

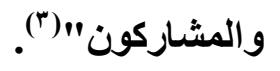

كما أوضحنا من قبل، يتمثل دور المترجم في قاعة المحكمة الدولية في السماح

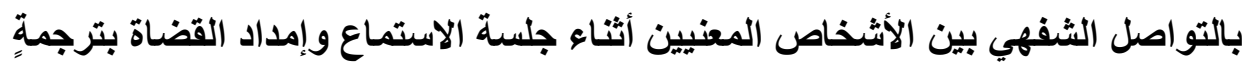
لحقائق القضية إلى اللغات الرسمية، بحيث يدرسونها بحرص ويستخدمونها في إصدار

(1) ICTY, Prosecutor V. Slobondan Milosevic, IT-02-54, Transcript of the hearing of 28 February 2006, p. 49002, line 8- 11.

(2) Ahmed MUNEER, "Interpreting Communities: Lawyering Across Language Difference", UCLA Law Review, Vol. 54, 2007, p. 1032-1033.

(3) Sandra HALE, "Themes and methodological issues in Court Interpreting research", Linguistica Antverpiehsia, Vol. 15, 2013, p. 205.

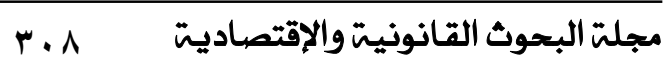


الحكم. لتحقيق هذا الهلف، ليس مطلويًا من المترجم أن يقدّم ترجمة حرفية فحسب، ولكن نحتاج أيضًا إلى تحقيق التكافؤ في نية المتحدث بين الألفاظ الأصلية وترجمته.

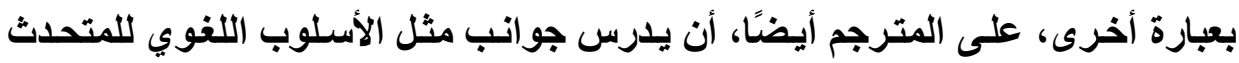
و الفروق الدقيقة والتوقفات والكلمـات والأصوات المخففة للمعنى و التصحيح الذاتي التي

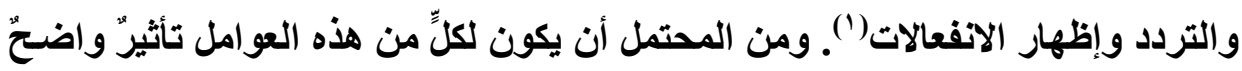

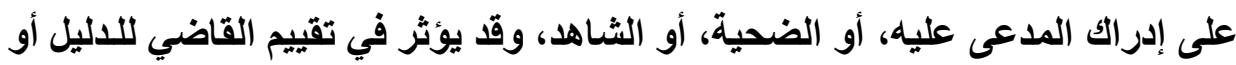
حتى قد يسهم في إدانةٍ خاطئةٍ لو تم تجاهلهة (†). وبالتالي، يجب على القاضي أن يركز اهتمامه بصورةٍ دقيقةٍ على لغة الجسد أو

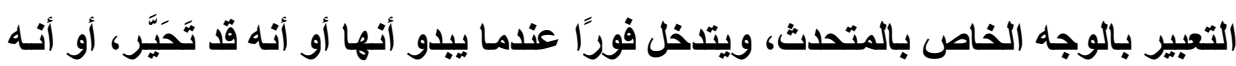

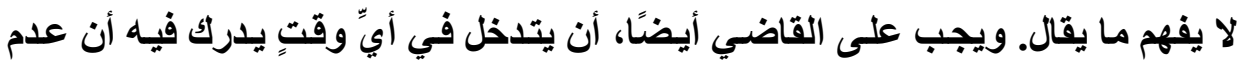

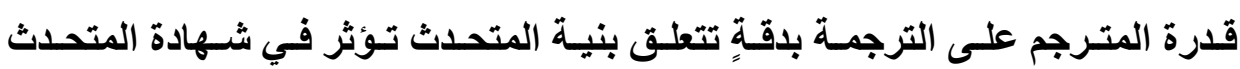
ومصداقيته. ويمكن للمترجم أن يخفف أو يُطظم من إمكانية لوم المدعى عليها أو يجعل ضحية أو شاهذا مـا يبدو غيرَ ممكن التعويل عليه، أو غيرَ جدير بالثقة أو غيرَ قابل للتصديق(")

و وأثناء المداولة اللاحقة، يعتمد القضاة بصورةٍ متكررةٍ على ترجمة المترجم

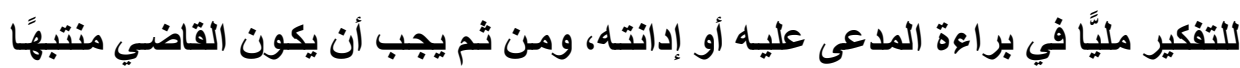

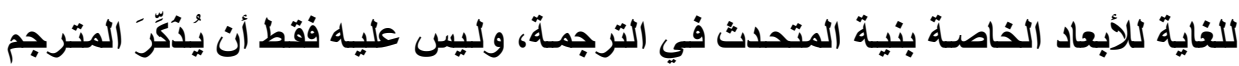

(1) Joshua KARTON, "Lost in Translation", op.cit., p. 24.

(2) Franklyn P. SALIMBENE, "Court Interpreters: Standards of Practice and Standards for Training", Cornell Journal of Law and Public Policy, no. 3, Vol. 6, 1997, p. 645.

(3) Ibid., p. 646 et $s$.

مجلتّ البحوث القانونيت والإقتصاديت 
بواجباته ومسئولياته، ولكن أيضًا أن يكون هو نفسه على وعي تامٍ بمعنى التعبيرات فيما وراء الكلمات، التي تتحدد بناءً على السياق والموقف والمشاركين.

هـ التعدد اللغوي في قاعة المداولة بالمكمة:

للحفاظ على سِرِيَّةِ المداولـة، يغيب المترجمون عن قاعة المداولنة. وللتعويض

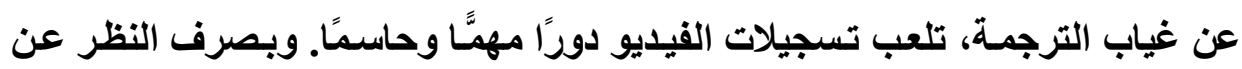
مدى الكفاعة في الترجمة، تظل تسجيلات الفيديو هي الوسيلة الوحيدة للوصول إلى الاليل الأصلي أثناء المداولات.

وتُعَدُّ إمكانيـة الوصـول للشهادات الأصلية ذات أهميـة كبيرة، حيث قد استمع القضاة لترجمات لغوية مختلفة لتلك الثهادات بناءً على اختيار هم للِفةِة العمل بالمحكمة. كما اتضح، ينقل كل مترجم الفوارق الدقيقة والنيـة بصورة مختلفة، ومن ثم يستخدم القضاة ترجماتٍ مختلفة في تقييم سلوك ومصداقية كلٍّ من المتهم والضحايا أو الشهود.

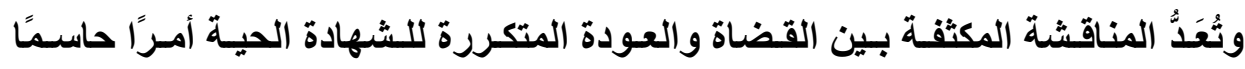
للتعويض عن الترجمات المختلفة لنفس الإفادة أو التصريح' (').

(1) William SCHABAS, "The International Criminal Court: A Commentary on the Rome Statute", op.cit., p. 637.

مجلت البحوث القانونيت والإقتصاديت 


\section{المبحث السادس \\ سنَُّ القانون القضائي الدولي ونظرية الصادر: \\ صحة القانون القضائي هل جدل}

طبقًا لرأي الأستاذ (جوزيف راز) فإن "النظريـة القانونية تكون مقبولنة فحسب

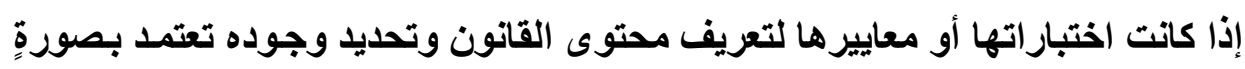
حصريةٍ على حقائق السلوك الإنساني التي يمكن وصفها في إطار حيادي"، وتطبيقها

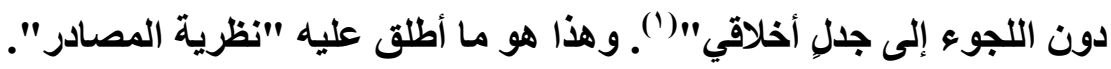

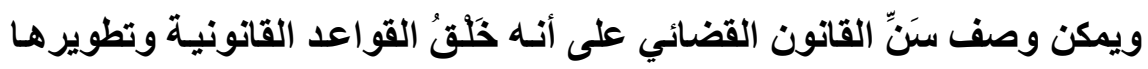

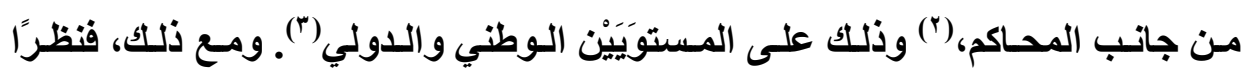

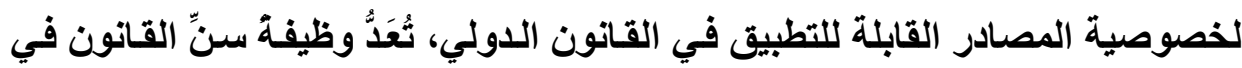

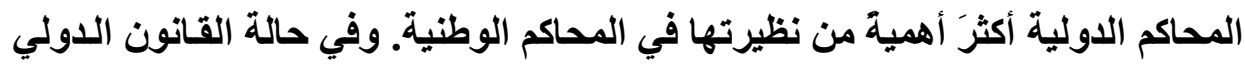

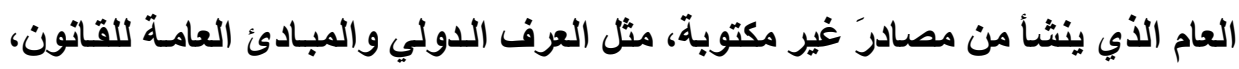

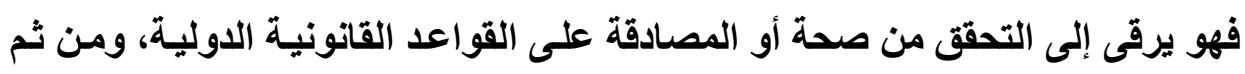

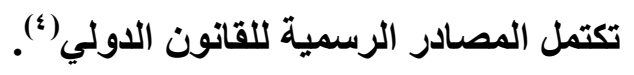

(1) Joseph RAZ, "Legal Positivism and the Sources of Law", Joseph RAZ, ed., "The Authority of Law", op. cit., p.37.

(2) Ibid., p.37.

(3) Ibid., p.37.

(4) Ibid., p.p.37. 
وفي سياق سنِّ القانون القضائي، كان تطبيق نظرية المصادر محلًً للجدل، وكان الأستاذ (دور كين) هو أشهر مَن ناقشها، حيث اعتقدَ أنها في الحسالات التي يجب فيها على القضاة دراسة المتطلبات الأخلاقية لتقرير ما يتطلبه القانون، لا يتم تحديد الالتزام بالقانون بناءً على الممارسة الاجتماعية فحسب، ولكن أيضًا بنـاءً على الأخلاقيـات ('). وكان رد الأستاذ (راز) المتعلق بالوضعية القانونية على هذه الفكرة، هو التأكيد على أن الأحكام القضائية تصل إلى وجود "عرف قضائي"، ومن ثم ثُشَكِّلُ حقيقة اجتماعية ملائمة، وأن الالتزامَ القضائيَّ بوضع الأخلاقيات في الاعتبار لا يتضمن كنتيجةٍة مباشرةٍ

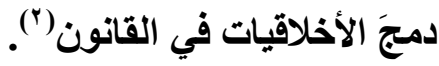

ومع ذلك، ففي سياق سنّ القانون القضائي الدولي، يتضح أن الافاع عن نظريـة المصادر الوضعية القانونية يكون أعقدَ بكثير. ويعود هذا إلى خصوصية المصادر القابلة للتطبيق في القانون الدولي ووظيفة إثبات صحة القانون في المحاكم الدولية. وفي الواقع، ووفقًا للمادة (^//// اد) من النظام الأساسي لمحكمة العدل الدولية، لا تمثل الأحكام القضائية مصدرًا رسميَّا للقانون الدولي، ولكنها تُمثل "وسـائل مساعدة لتحديد المبـادئ القانونيـة". ومـع ذلك، وفي الوقت نفسه، تكمـل الأحكـام القضائية المـصادر الرسمية في حالة الأعراف الدولية والمبادئ العامـة للقانون؛ نظرًا لأثرهـا في إثبات

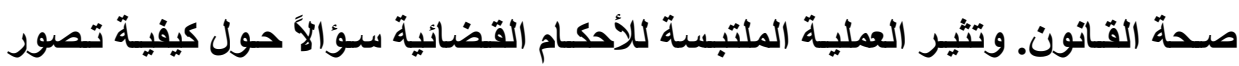
التحقق من صحة القانون القضائي الدولي في إطار الوضعية القانونية(").

(1) Ronald M. DWORKIN, "The Model of Rules I", in Ronald M. DWORKIN, ed., "Taking Rights Seriously", London, Duck Worth, 1999, P.22.

(2) Joseph RAZ, "Legal Positivism and the Sources of Law", op. cit., p.P.38.

(3) Ibid., P.39. 
وقد تـم تقسيم هذه الدراسـة إلى ثلاثـة أجزاء. يصف الجزءء الأول المعتقداتِ

الأساسية لنظرية المصادر. ثم يتم تناول ظاهرة سن القانون القضائي في سياق القضاء أو الأحكام القضائية الدولية والوطنية في الجزء الثاني. أما الجزء الثالث فيتناول هديْن الفرعَيْن معًا، ويشرح الصعوباتِ النظريـة الرئيسة التي تتعلق بقابلية تطبيق نظريـة المصادر على القانون الدولي الأي يسنه القاضي بالإضافة إلى الحلول الممكنة.

ا - نظرية المسادر الوضعية القانهنية: أ- الوضعية القانونية.

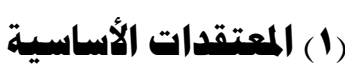

يُنظر إلى الوضسعية القانونيـة الحديثة على أنها تصديقُ على افتراض مميز

واحد، وهو الاعتقاد بأنه في أيِّ نظام قانوني، يكون إثباتثُ صحة قاعدةٍ معينةٍٍ معتمدًا على مصادرها وليس على مميزاتها أو جدارتهاب"). ويتضمن هذا الافتتراض ادِّعـاعَيْن

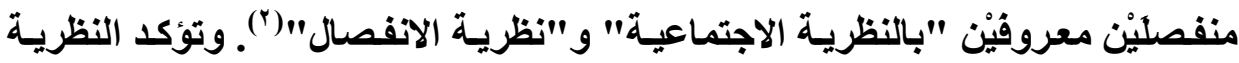

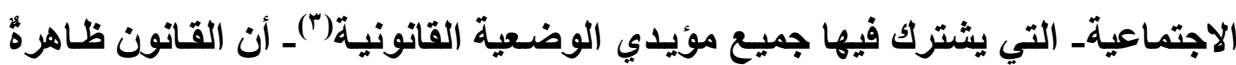

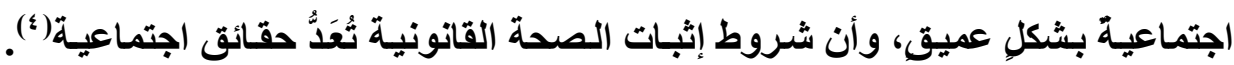

(1) John GARDNER, "Legal Positivism", The American Journal of Jurisprudence, $n^{\circ} 46,2009$, p.149.

(2) Andra MARMOR, "The Nature of Law", in Edward N. ZALTA, ed., "The Stanford Encyclopedia of Philosophy", Oxford, Oxford University Press, 2011, P.88.

(3) Joseph RAZ, "Legal Positivism and the Sources of Law", op. cit., p.P.38 et $\mathrm{s}$.

(4) See Andrei MARMOR, "The Nature of Law", op. cit., p.89 et s. 
ويعتقد الوضعيون القانونيون المحدثين أن القواعد الاجتمـاعيـة تُشَكِّلُ أساستًا للقانون. وهم يعتقدون بصفةٍ عامـةٍ أن هنـاك معاييرَ تقليديـة للتمييز؛ أي الأعراف الاجتماعيـة

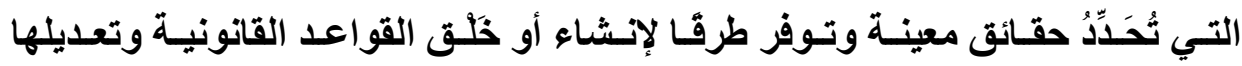

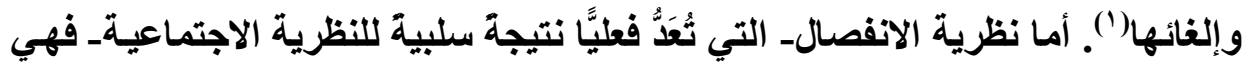
تؤكد أنَّ هناك انفصالاً مفاهيميَّا بين القانون والأخلاق. ومن ثم، لا تعتمد شرعية قاعدةٍ مـا إطلاقَا على محتواهـا الأخلاقي (). ومـع ذلك، فمن الجدير بالملاحظة أن الوضعية

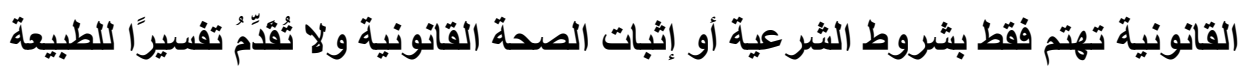

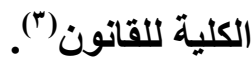

(ץ) الشاهل في همابل الهصري. بينمـا يوافق الوضسيون القـانونيون المعاصـرون بـصورةٍ كبيرةٍ على تفسير النظرية الاجتماعية، إلا أن الأمر ليس كذلك فيما يتعلق بنظرية الانفصال(؛). كنتيجة لنقا

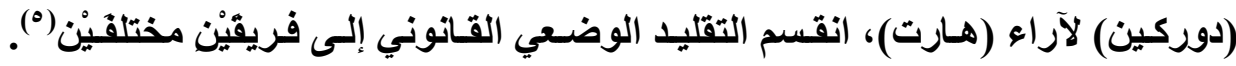

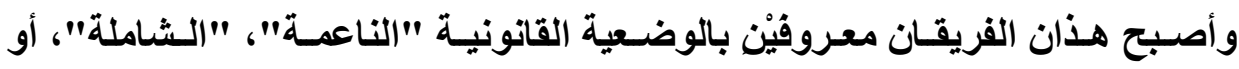
"الامجة"، والوضعية القانونيـة "(الملزمـة"(")، "الحصرية" أو "غير الدامجة"(1").

(1) See Ibid.

(2) See Ibid.

(3) John GARDNER, "Legal Positivism", art. Préci., p. 222.

(4) Wilfrid WALUCHOW, "legal Positivism, Inclusive Versus Exclusive", in Edward CRAIG, ed., "The Rutledge Encyclopedia of Philosophy", Landers, Atlantic Books, 20123, P.44.

(5) See Wildrid WALUCHOW "legal Positivism" op. cit., p.45.

(6) H.L.A. HART, "The Concept of Law", op. cit., p. 250, Philip E. SOPER, "Legal Theory and The Obligation of a Judger: The Hart/Dworkih Dispute", Michigam Law Review, no95, 1997, p.473; 
باختصار، بينما تسمح الوضعية القانونية المَرنَّة في بعض النظم القانونية، بـأن تكون

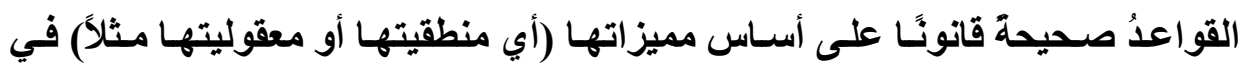
الظروف التـي تثبـت فيهـا القواعد الـصحيحة قانونَّا أن تلـك المزايـا تتصل بالـصحة القانونية، تنكر الوضعية القانونية الملزمة هذا الخلاف. وتؤكد هذه الأخيرة أن القاعدة التي تفترض أن جميع القواعد المعقوللة فقط يجب أن تكون صحيحة لا نُثبت قانونَّا صحة أو شرعية قواعدَ أخرى. بدلاً من ذلك، يتم تفويض وظيفة أو مهمـة التحقق من صحة المعايير أو القواعد الأخرى لمسئول رسمي يعلن معقوليتها. ومن ثم، لا تكون هذه الأخيرة صحيحة من منطلق معقوليتها (مميزاتها)، ولكن بفضل حقيقةٍ أن ممثنلاً أو وكيلاً ذا صلة قد أعلن معقوليتها (مصدرها) (r).

David LYONS, "Principles, Positivism, and Legal Theory", Yale Law Journal, no 87, 1977, p.415; Jules COLEMAN, "Negative and Positive Positivism", Journal of Legal Studies, no21, 1992, p.139; Wilfrid WALUCHOW, "Inclusive Legal Positivism", Oxford, Clarendon Press, 1994; Matthew H. KRAMER, "Where Law and Morality Meet", Oxford, Oxford University Press, 2008, p.93.

(1) Hans KELSEN, "The General Theory of Law and the State", Cambridge, Harvard University Press, 1995; Andrei MARMOR, "Positive Law and Objective values", Oxford, Oxford University Press, 2010; Brian LEITER, "Legal Realism, Hard Positivism and the Limits of Conceptual Analysis", Oxford, Oxford University Press, 2007, p.63 et $\mathbf{s}$.

(2) John GARDNER, "Legal Positivism", art. Préci., p.201. 


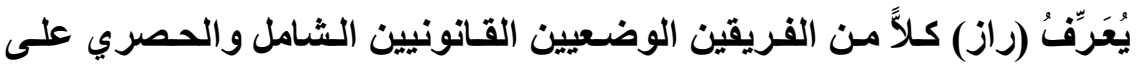

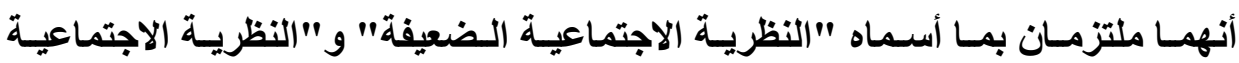

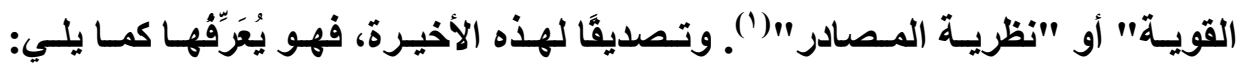

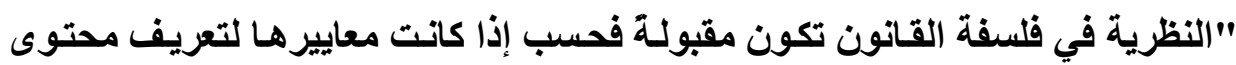

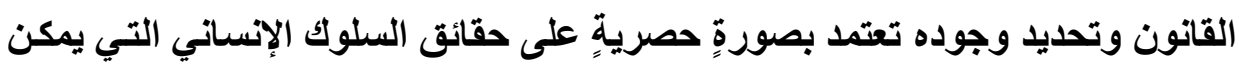

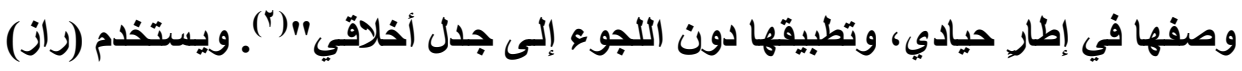

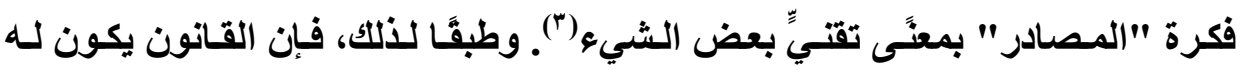

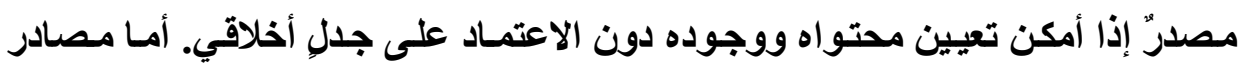

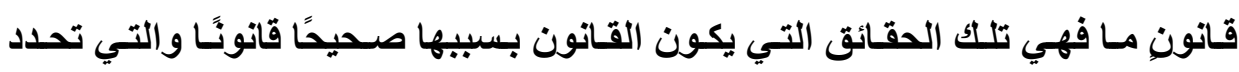

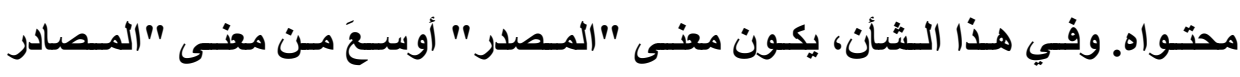

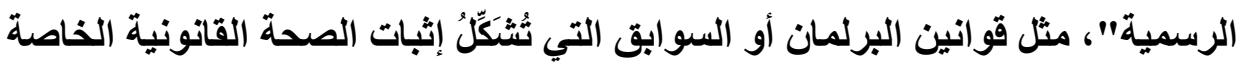

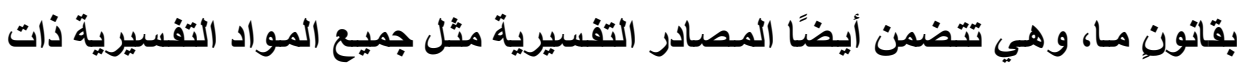

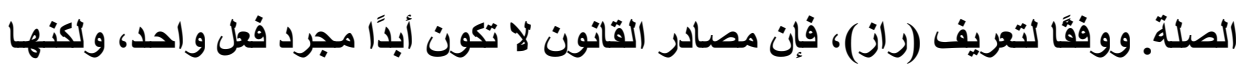

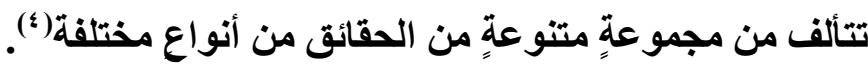

(1) Joseph RAZ, "The Concept of a legal system, An introduction to the theory of legal system", Oxford, Clarendon Press, 1997, p.210, Joseph RAZ, "Postema on Law's Autonomy and public practical Reasons: A Critical Comment", Legal Theory, no8, 2006, p.20; Joseph RAZ, "Incorporation by Law", Legal Theory, no14, 2008, p. 39-40.

(2) Joseph RAZ, "Legal Positivism and the Sources of Law", op. cit., p.P. 39.

(3) See. Ibid., P.47.

(4) See, Ibid., p.48. 


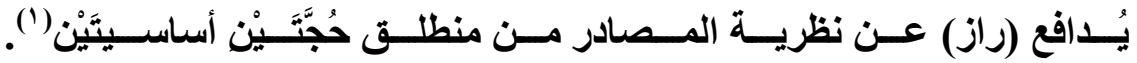

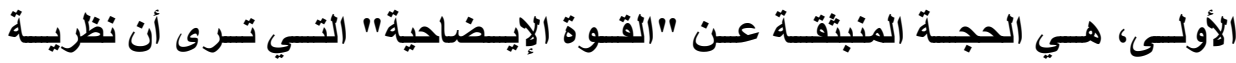

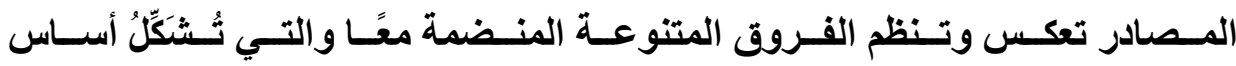
مفهوم الناس للقانون(). والثانية مفادها، أنـه مـن المفترض أن نظريـة المصادر نُحدد

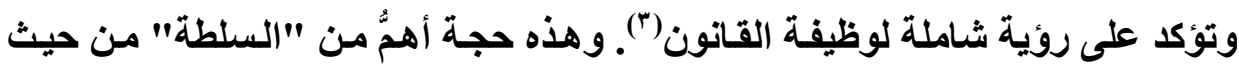

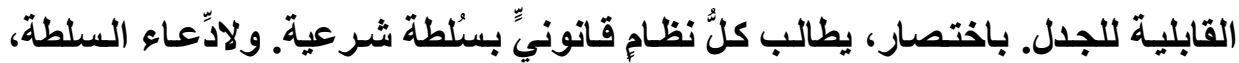
يجب أن يكون المُوَجِّهُ القـانوني قـادرًا على القيـام بذلك. ولكي يكون الموجهـ القانوني

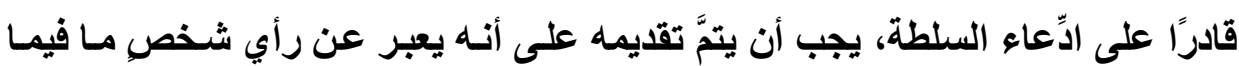
ينبغي على الرعايـا عَلَّه، ويجب أن يكون قابلاً للتحديد بطرق تستبّعد الاحتكامَ إلى أسبابٍ تابعةٍ (مفهوم الخدمة الخاص بالسلطة)(؛). ووفَّا لر أي الأستاذ (راز)، تتطابق

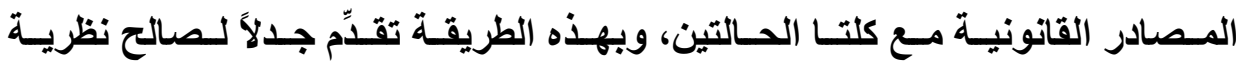
المصادر('). وعلى العكس، تتعارض الوضعية القانونية الشاملة مع الطبيعة المؤكدة

(1) See, Ibid., p.48.

(2) See, Ibid., p.48-50.

(3) Joseph RAZ, "Legal Positivism and the Sources of Law", op. cit., p.50.

(4) Joseph RAZ, "Authority, Law, and Morality", Oxford, Clarendon Press, 1995, p.50.

(5) Joseph RAZ, "Legal Positivism and the Sources of Law", op. cit., p.52.

(6) Wilfrid WALUCHOW, "Legal Positivism, Inclusive Versus Exclusive", op. cit., p.47. 


\section{r- سَنُّْالقانون القضانُي الدولي أ- سنَُّ القانون القضائي (1) القضاة كمشرِِِِنَ للانقون}

تُعَدُ الوظيفة الأساسية للمحاكم بصفةٍ عامةٍ هي تطبيق القانون من خلال تسوية المنازعات وفقَا لمجموعةٍة محدةٍٍ سلقًا من القواعد والإجراعات عن طريق إصدار أحكاج

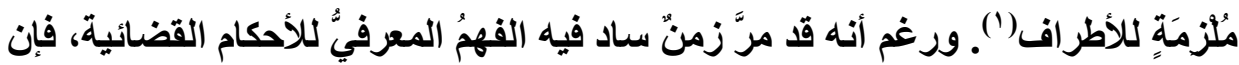
اليوم يوجد القليلون الذين لا يزالون يؤكدون هذا الأمر() ويبدو أن حقيقة كون القضاة هم الذين يصنعون القانون قد تم قبولها(")، وقد أصبح التساؤل حول كيفية أدائهم لهذه المهمـة مـع الاسـتمرار فـي تعزيـز شـكل الفـصل بـين القـانون والسياسة واحـدًا مـن الموضوعات الأساسية التي تثغل البحث القانوني (؛).

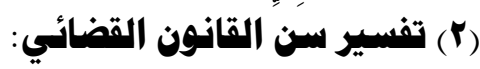

يمكن تعريف سن القانون القضائي على أنه إنشاء القواعد القانونيـة وتطويرهـا من جاتب المحاكم(ه). وهذا يحدثـ عادةَّـ في سياق حالات ملموسـة('). وتقوم الأحكام

(1) Benedict KINGESBURY, "International Courts: Uneven Judicialization in Global Order", op. cit., p. 227.

(2) Armin Von BOGDANDY, Ingo VENZKE, "Beyond Dispute: International Judicial Institutions as law-Makers", op. cit., p. 986.

(3) Samantha BESSON, "Legal Philosophical Issues of International Adjudication-Getting over the amour impossible between international Law and Adjudication", op. cit., p. 330.

(4) Lord REID, "The Judge as Law Maker", Journal of the Society of Public teachers of Law, no22, 1982-1983, p.22-29.

(5) See, BESSON, "Issues", op. cit., 227. 
القضائية بتسوية منـازعـاتٍ معينةٍة بـين الأطر اف المعنيـة مـن خـلال تطبيـق القواعد القانونية على مجموعةٍ محددةٍ من الحقائق("). وبعيدًا عن هذه التحديدات التي تسمح

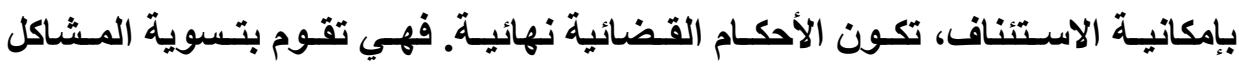
القانونية المتنازع عليها بين الأطراف المعنية بشكلٍ محددٍ (مبدأ الحكم الباتِّ أو السلطة ذات صـلاحية إصدار الأحكـام)("). ومـع ذلك، وفي الوقت نفسه لا يمكن فهم الأحكـام القضائية إذا تم عزلها بشكلٍ كامل؛ نظرًا لأنها قد تصل إلى أبعدَ من القضية التي يتم

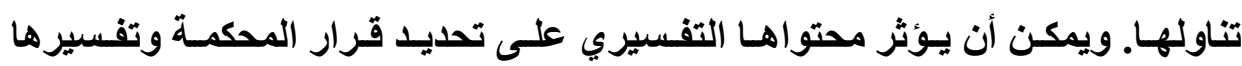
وتطبقها للقانون محلِّ النقاش، وللقانون بشكل أكثرَ عمومية في المنازعات اللاحقة (التفسير القاطع أو السلطة المخول لها التفسير)(؛).

\section{ب- سنَ القانون القضائي الدولي (1) الماكم الدولية كمشرعِ للاقوانين}

على المستوى الدولي، يبقى السؤال حول ما إذا كان الدورُ الأسساسُ للمحاكم يظل كما هو على المستوى الوطني، ومن ثم مـا إذا كان الحكم الدولي يتطلب أيضًا خلق

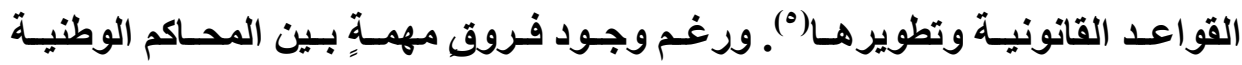
والدولية، فإنه يتفق العديد من الباحثين الدوليين على أن الوظيفة الأساسية للمحاكم(")،

(1) See, VON BOGDANDY, VENZKE, Ibid.

(2) See, BESSON, "Issues", op. cit., 228.

(3) See, BESSON, "Issues", Ibid.

(4) See, BESSON, "Issues", Ibid; BOGDANDY, Ibid.

(5) See, BESSON, "Issues", Ibid.

(6) See, KINGSBURY, op. cit., p.215-222. 
تظل كما هي على المستوى الدولي (') حيث تقوم المحاكم الدولية ـ شأنها في ذلك شـأن المحاكم الوطنية ــ بإقرار القانون وتطبيقه في تسوية المنازعات. ومن ثم، تقوم بخَّق القواعد القانونية وتطويرها عن طريق الحكم وتفسير القانون الدولي عند تطبيقه على حالات ملموسة ومحددة"(r)

ونظرًا لأن المهمـة الأسـاسية للمحاكم الدوليـة هـي تطبيقُ القـانون في تسوية

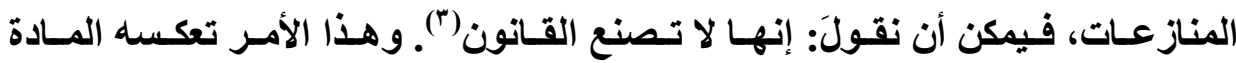
من النظام الأسـاسي لمحكمة العدل الدولية، والتي تحدد الأحكام القضائية على أنها فقط "وسائل مساعدة لتحديد أحكام القانون" وليست مصادر للقانون الدولي

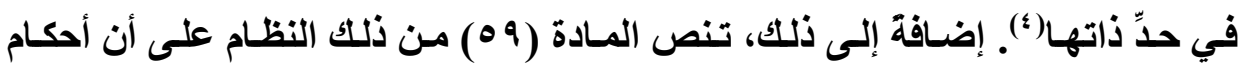
المحكمة ليس لها قوةٌ ملزمة إلا بين الأطر اف وفي حدود القضية المحدةة(0). وقد قررت

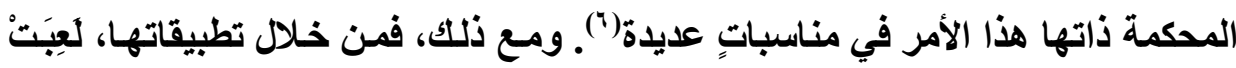

(1) See, G.ABI-SAAB, "The Normalization of International Adjudication: Convergence and Divergence", New York University Journal of International Law and Politics, no43, 2010, p.14.

(2) Alain PELLET, "Article 38", in Andreas ZIMMERMANN, art preci, p.677.

(3) Trullio TREVES, "Judicial Lawmaking in an Era of Proliferation of International Courts and Tribunals: Development or Fragmentation of International Law", vol. 177, Berlin, Springer, 2005, p.587; Gennady M. DANILENKO, "Law-Making in the International Community", Dordrect, Martimus, Nijhoff Publishers, 1999, p. 253.

(4) See, PELlET, "Article 38", op. cit., p.587.

(5) Chester BROWN, "Article 59", in Andreas ZIMMERMANN, "The statute of the International Court of Justice: A commentary", Oxford, Oxford University Press, 2012, p.1416.

(6) ICJ, 25 July 1974, Fisheries Jurisdiction (United Kingdom of Great $=$

مجلت البحوث القانونيت والإقتصاديت 
محكمة العدل الدولية دورًا مهمَّا في التكوين العام للقانون الدولي وإعادة تشكيله('). وقد اعترفت المحكمة ذاتها بذلك، وإن كانت قد اتخذت احتياطاتها المعتادة(؟). (َ) ضرورة سنَّ القانون القضائي الدولي:

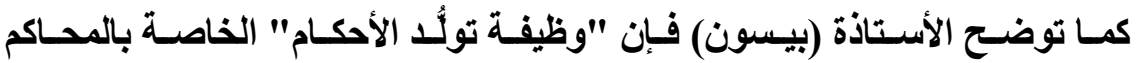

الدولية تُعَدُّ أكثر أهمية من نظيرتها في المحاكم الوطنيةة(").ويعتمد هذا على خصوصية مصادر القانون الاولي(؛).

أولاً: يمكن للمحسكم الدوليـة أن تعتمـد فقط على عـد محسدود مـن مـصادر

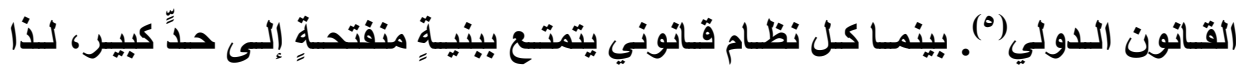

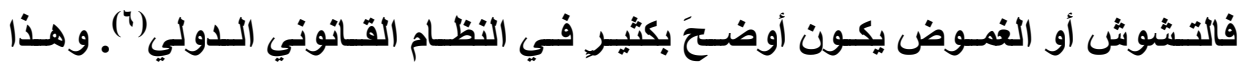
هـو السبب في حدوث ثفرةٍ قانونيـةٍة بـصورةٍ أكثرَ تكرارًا علـى المستوى الـدولي

Britain and Northern Ireland/Iceland), Judgment, I.C.J. Reports 1974, P.3, Para p.53; ICJ, 8 July 1996, Legality of the Threat or use of Nuclear Weapons, Advisory Opinion, I.C.J. Reports 1996, P.226, Para. 18.

(1) See, PELLET, "Article 38", op. cit., p.322.

(2) ICJ, 8 July 1996, Legality of the Treat or use of Nuclear Weapons, Advisory opinion, I.C.J. Reports 1996, p.226, Para. P.18.

(3) BESSON, "International Judge as Dispute- Settlers and LawEnforcers: From International law Without Courts to International Courts Without Law- A reply to Anna Spain", op.cit., p. 43.

(4) Donald REGAN, "International Adjudication", op.cit., p. 227.

(5) See Article 38.1 of the Statute.

(6) P. WEIL, "The Court Cannot Conclude Definitely", Colombia Journal of International Law, no. 36, 1998, p. 119. 
مقارنة بالسياق الوطني. ومن ثم، فنظرًا لوجود مبدأ عدم الوضوح؛ لعدم وجود قانون واضـح يمكن تطبيقه على المستوى الـدولي (')، يجعل مـن الضروري على المحسكم الدوليـة أن تمـلأ الثغرات بتحديد القـانون الواجب التطبيق وتفسيره بدرجةٍٍ أعلى مـن

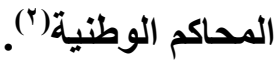

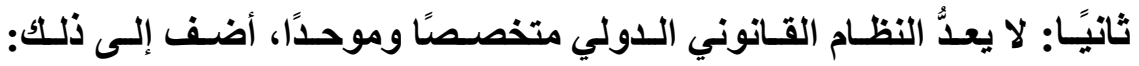

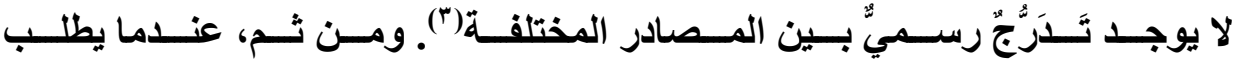

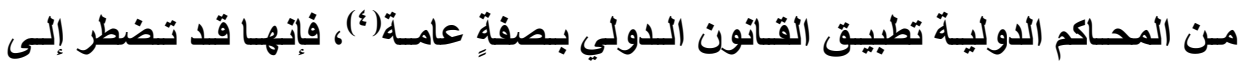
تحديـد جميـع القواعـد القانونيـة ذات الـصِّة وتفسير ها بـصورةٍ تنسجم مـع بعضها البعض(0).

ثالثًا: ليست جميع مصادر القانون الدولي سهلة التعريف. ففيمـا يتعلق بـالعرف

الدولي والمبادئ العامة للقانون، يلعب القضاة الدوليون دورًا مهمتًا في تحديد القانون الذي يتم تطبيقه، وهذا يختلف تمامًا عن دور القاضي المعتاد في النظم الوطنية، حيث لـيث تكون مصادر القاتون واضحة بشكلٍ طبيعي(")

(1) Alain PELLET, "Article 38", op.cit., p. 90.

(2) Samantha BESSON, "Issues", op.cit., p. 241.

(3) See Alain PELLET, "Article 38", op.cit., p. 92.

(4) Alan BOYLE, "The Making of International Law", Oxford, Oxford University Press, 2007, p. 272.

(5) Samantha BESSON, "Issues", op.cit., p. 241.

(6) Donald H. REGAN, "International Adjudication", op.cit., p. 229.

مجلة البحوث القانونيت والإقتصاديت 


\section{r- سنَ القانون القضائي الدولي ونظرية المصادر:}

أ - سَنْ القانون القضائي ونظرية المصادر:

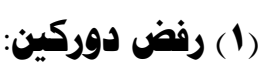

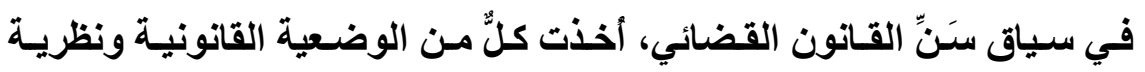
المصادر محلّ الجدل في الحسبان. وكان أشهر مَن فعل ذلك هو الأستاذ (دوركين) الذي الذي

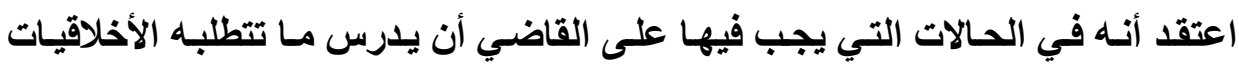

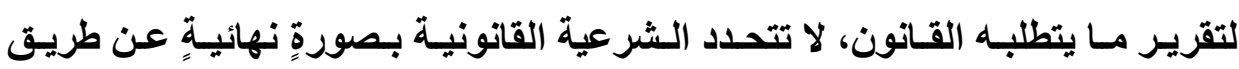
الحقائق الاجتماعية فحسب، ولكن أيضًا عن طريق الأخلاقيات(')

وقد أكد (دوركين) أن الوضعية القانونيـة هـ "نمـوذج يخص نظـام القواعد

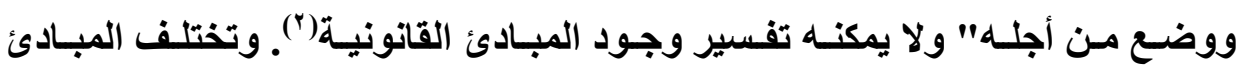

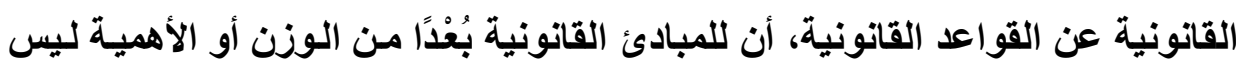

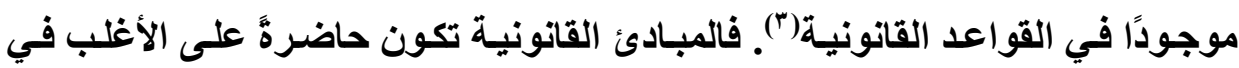

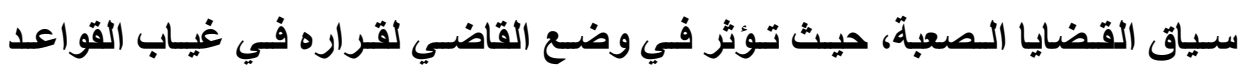

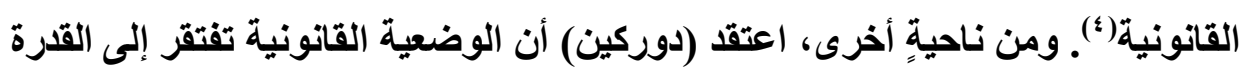

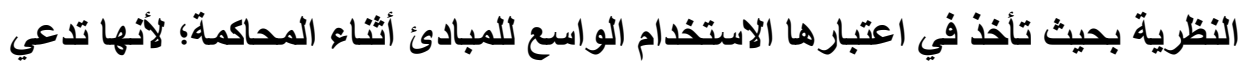

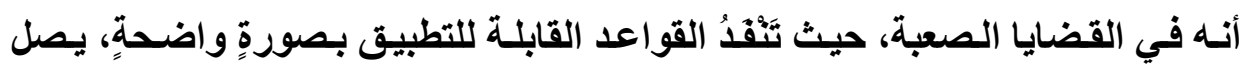

(1) Scotte SHAPIRO, "The Hart-DWORKIN" Debate: A Short Guide for the perplexed", in Arthur RIPSTEIN, ed., Ronald DWORKIN, Cambridge, Cambridge University Press, 2007, p. 55.

(2) Ronald M. DWORKIN, "The Model of Rules I", op.cit., p. 22.

(3) Ibid., p. 24- 26.

(4) See, ibid., p. 22- 24. 
القضاة فيمـا وراء القـانون إلى المعـيير غير القانونيـة في ممارستهم لحريـة التقدير القوية('). ومع ذلك وفَّا (لدوركين)، لا يتمتع القضاة أبدًا بحرية التقدير القويـة. وحتى

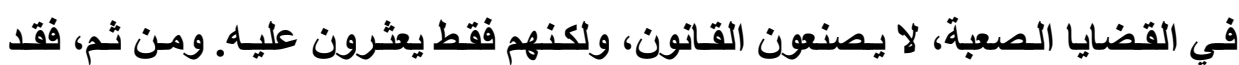
استتنج أن هذه المبادئ يجب أن تكون جزعًا من القانون.

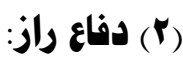

تتوفر ردودُ متنوعة على رفض (دوركين) لنظريـة المصدادر. أولاً: يؤكد (راز) على أنه بصرف النظر عن مبـادئ (دوركين)، فهي ذات مصادر اجتماعية. فبحسب نظرية المصادر، يُوجد القانون عندما ثُوجد مؤسساتُّ قضائية تقوم بـالاعتراف بـوافعَ معينةٍ وإنفاذها؛ لأنها تعتقد في صحتها أو شرعيتها القانونية، حيث إنها قد استقرت

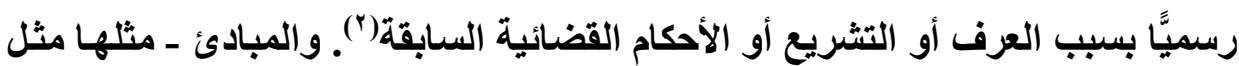
القواعد- يمكن أن تُصبح ملزمـة قانونَا عن طريق ترسيخ المحساكم لها. ورغم ذلك، فالمبادئ- بعكس القواعد- لا يمكن ترسيخها عن طريق حكم واحد بحيث تصبح سـابقة. ولكنها بدلاً من ذلك تتظور مثل العرف وتصبح ملزمة قانونًا فقط في حالة تمتعها بـعم رسمي في عدد من الأحكام القضائية("). وطبقًا لذلك، يصل استخدام المبادئ في سلسلةٍ

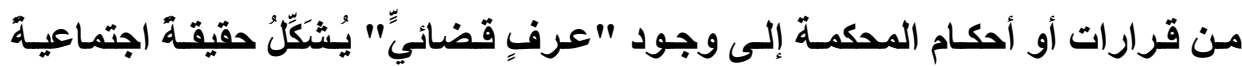
ملائمة من وجهة نظر نظرية المصادر( (؛).

(1) See, ibid., p. 31- 34.

(2) Joseph RAZ, "The Concept of a legal system, an Introduction to the theory of legal system", op.cit., p. 214.

(3) Joseph RAZ, "Legal Principles and the Limits of Law", The Yale Law Journal, no. 91, 1982, p. 823.

(4) See, ibid., p. 848. 
وهناك ردٌّ آخَرُ على رفض (دوركين)، يتصل بوجود الثُغرات في القانون كنتيجة لحدد النظرية الاجتماعية. في الواقع، لا يمكن للحقائق الاجتماعيـة أن تنتقيَ القواعد التي تقوم بتسوية كلّّ مسألة لاحقة محتملة مقدمًا. وهذا هو السبب في كون القانون يحتوي بالضرورة على العديد من التعارضات والثغرات التي يجب على القضاة ملؤها

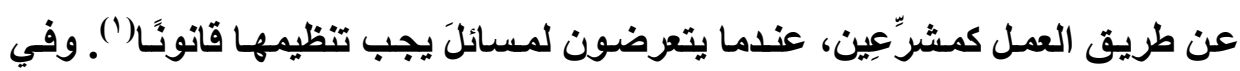

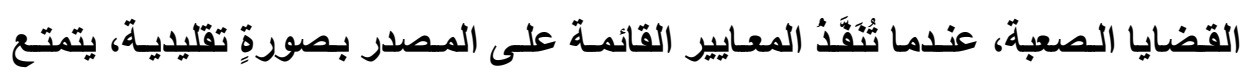
القضاة بحرية التقدير القوية التي تتضمن التزامَّا قانونيَّا بتطبيق معاييزَ غير قانونية

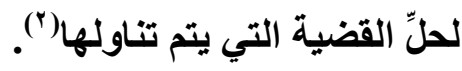

ومسن ثُم، فـانِ الالتـزام القـانوني بتطبيـق المعسايِير دون مسصادرَ اجتماعيـةٍ لا يتعارض مـع نظريـة المصادر؛ نظرًا لأن هذه المعايير غيرُ قانونيـة في سِيَِّها، وأنها تكون قابلة للنفاد فقط في ظل القانون. ب- سنَُّ القانون القضائي الدولي ونظرية المسادر: (1) التعقيد على المستوى الدولي:

في سياق سنَِّّ القانون القضائي الدولي، التساؤل الذي يدق هو: مـا إذا كانت

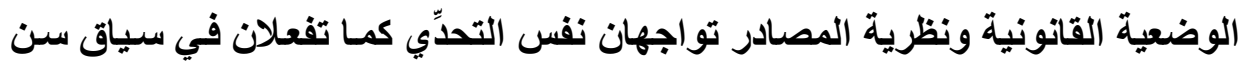

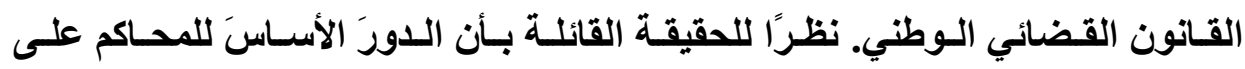
المستوى الدولي يظل كما هو عليه على المستوى الوطني. ومن ثم، تقتضي الممارسـة

(1) Scatt J. SHAPIRO, "Legality", Cambridge, Harvard University Press, 2011, p. 250.

(2) Joseph RAZ, "Legal Principles and The Limits of Law", op.cit. p. 848. 
القضائية الدولية، شـأنها شـأن الممارسـة القضائية الوطنية، خَلقَ القواعد القانونيـة

$$
\text { وتطويرها، فينبغي، إدا، أن تكون الإجابة بالإيجاب. }
$$

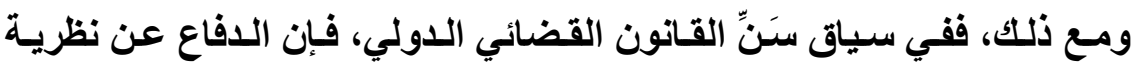

المصادر الخاصة بالوضعية القانونية قد اتضح أنـه أكثرُ تعقيدًا، ومن ثُّ فبان الانتقال

البسيط للحجـج الوطنيـة إلى المستوى الـولي قـد يبـدو مـضلاً. ويعود التعقيـ إلى

خصوصية مصادر القانون الدولي القابلة للتطبيق، وإلى وظيفة المحاكم الدولية المثبتة

$$
\text { لصحة القانون(') - (') }
$$

باختصار، فِإن مـصادر القـانون الـدولي- شـأنها شـأن مسصادر القـانون بصفةٍ

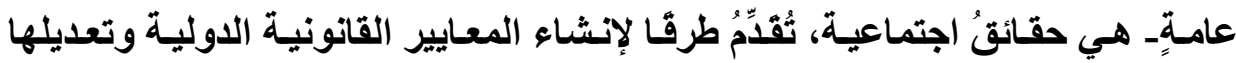

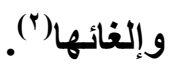

وفي الوقت الذي تُشَكَّلُ فيه كلّ من الاثِّفاقيات الدولية والعرف الدولي والمبادئ

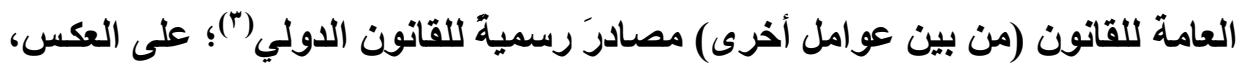

لا ثُمَتِّلُ الأحكام القضائية مصادرَ رسمية للقانون الدولي، ولكنها وسائلُ مساعدةُ لتحديد

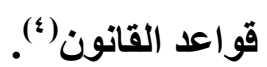

(1) See Samantha BESSON, "Theorizing the Sources of International Law", in Samantha BESSON, John-TASIOULAS., eds., "The Philosophy of International Law", op.cit., p. 169.

(2) See Samantha BESSON, "Legal Philosophical Issues of International Adjudication", op.cit., p. 257.

(3) See, Article 38.1.a-c of the ICJ Statute.

(4) Article 38.1. $d$ of the JCJ Statute. 
ويمكنتا أن نقول: إن الأخيرة ليست مصادر للقانون، ولهذا الأمر ليست مصادر

لحقوق والتزامات الدول المتقاضية. ومن ثم، تثكل الأحكام القضائية مصادر مساعدة

للمبادئ العامة والقانون الدولي العرفي (1).

ومع ذلك، ثُكَّلُّ الأحكام القضائية المصادر الرسمية للقانون الاولي في حالاتٍ

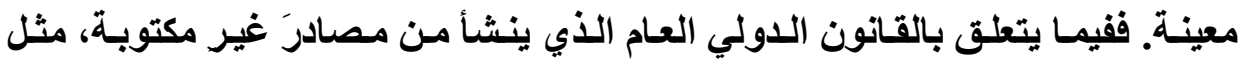

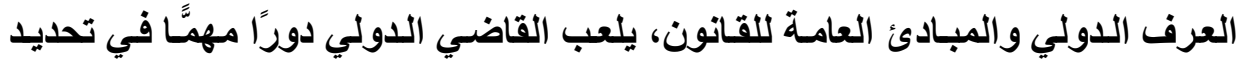

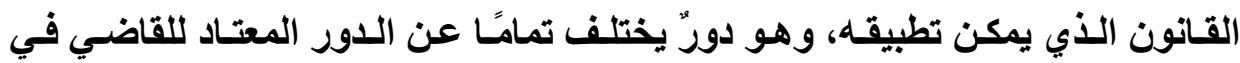

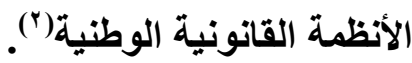

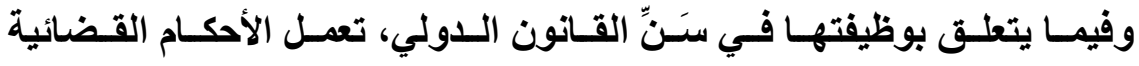

بطريقتين: أولاً: تعمل كمصادرَ مساعدةٍ لتحديد قو اعد القـانون الدولي. ثانيًا: تكمل الأحكام القضائية المصادر الرسمية للقانون بتحديد قواعد القانون الدولي"("). ومع ذلك، فإن العملية الملتبسة الخاصة بالأحكام القضائية تثير التساؤل حول كيفية إدراك إثبات التبات

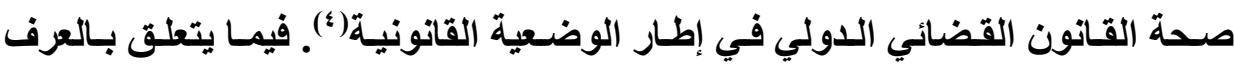
الدولي والمبادئ العامة للقانون، فإن أداء وظيفة الأحكام القضائية قد يؤديّي إلى شكلِ

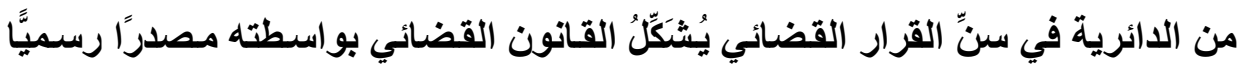
ومساعدًا في نفس الوقت. في الواقع، يبدو من الصعب أن نميز بين الأحكام القضائية

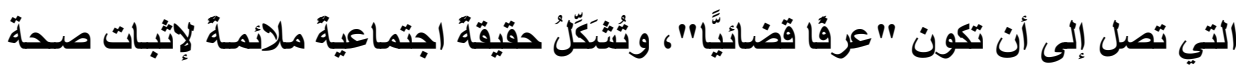

(1) Samantha BESSON, "Issues", op.cit., p. 258.

(2) Mohamed SHAHABUDDEEN, "Precedent in the World Court", Cambridge, Cambridge University Press, 1997, p. 76.

(3) Ibid., p. 78.

(4) Samantha BESSON, "Issues", op.cit., p. 260. 
القانون القضائي الاولي، والأحكام القضائية التي ثُمَتَّلُ مصادرَ وسيطة للقانون الدولي

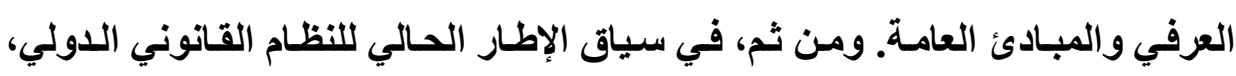
تُثَكَّلُ قاعدة التحقّ من صحة القانون التي تلعبها المحاكم الدولية فيما يتعلق بالقانون

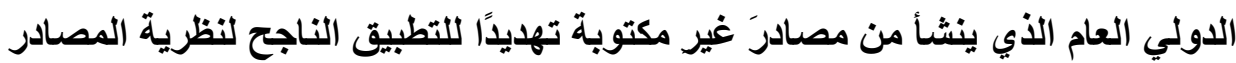
في سياق سنّ القانون القضائي الدولي" (')

(ז) (ألا يوجد هخرج؟ ثُعَدُ المعالجة البحثية للتساؤل حول مدى إمكانية تطبيق نظريـة المصادر في

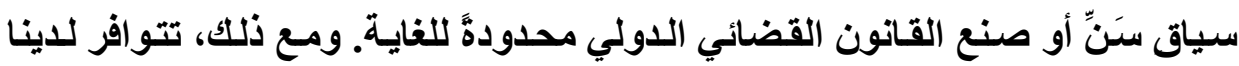
حلولٌ ممكنة مختلفة.

تتعلق المجموعة الأولى من الحلول المكنة بتفسير/ إعـادة تفسير المـادة (^^) من النظام الأساسي لمحكمة العدل الدولية، وبصورةٍ أوسعَ بمدى ملاعمدة هذه المسادة

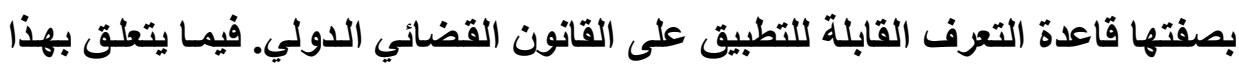

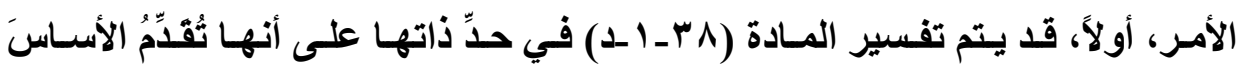

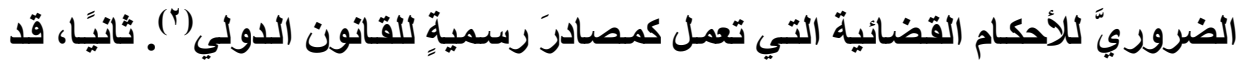

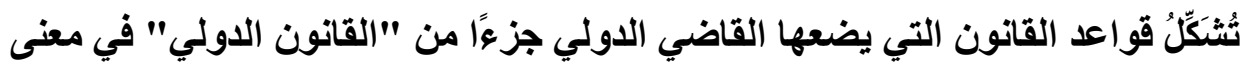

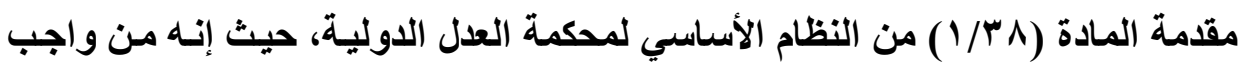
المحكمة أن تقرر أنه "وفقًا للقانون الدولي تنثأ مجموعة أخرى من الحلول المتصوَّرة من الححاولات النظرية لتصحيح نقاط الضعف في تحديد القواعد القانونية الدولية التي

(1) See, ibid.

(2) Mohamed SHAHABUDDEEN, "Precedent in the World Court", op.cit., p. 80. 
تنشأ من مصادر غير مكتوبـة". فيمـا يتعلق بهذا الأمر، وبـالنظر إلى القـانون الدولي العرفي(')، يكون أحد المقترحات هو الاستمرار في تنظيم العرف الدولي(). ثانيًا، يمكن التأسيس لعمليات سن القانون العرفي الدولي بشكلِ أكبر(").

فيما يتعلق بالمجموعة الأولى من الطلول الممكنة للغز إمكانيـة تطبيق نظريـة

المصادر على القانون القضائي الدولي، يبدو أنَّ كِلا الاقتراحَيْن يصعب التوفيق بينهمـا

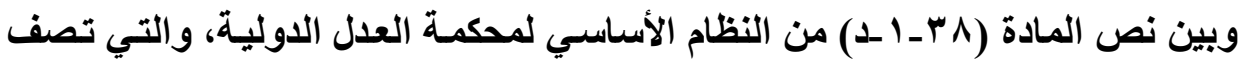
الأحكام القضائية على أنها "وسـائل مسـاعدة لتحديد قواعد القـانون". لكي يصبح المقترح الأول واقعيَّا، يجب أن تتم قراعة عبارة: "تحديد قواعد القانون" على أنها

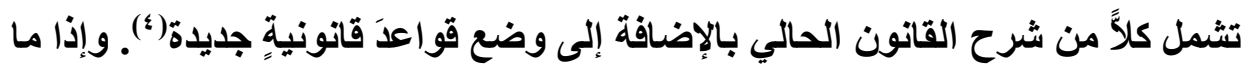
تم قبول هذه القراعة للمادة المذكورة، فقد توفر أساسًا للقانون القضائي الدولي، الذي

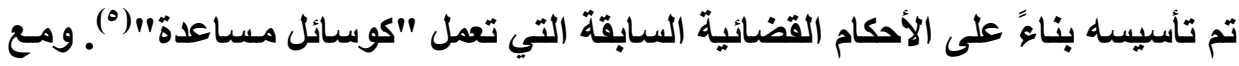

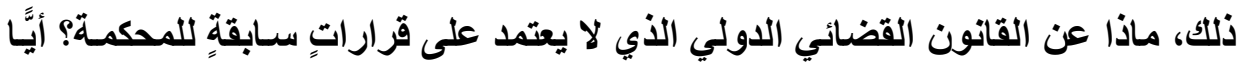

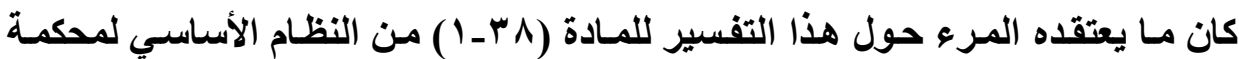
العدل الدولية، فإنه يبدو من الصعب تكييفُ الأحكام القضائية التي تعمل كمصادرَ رسميةٍ للقانون الدولي في فقرةٍ فرعيةٍ تشير بوضوح إلى الأحكام القضائية على أنها وسـائلُ

(1) Jean D'ASPREMONT, "Formalism and the Sources of International Law: A Theory of the Ascertainment of legal Rules", Oxford, Oxford University Press, 2011, p. 162.

(2) Ibid., p. 165.

(3) Ibid., p. 167.

(4) Mohamed SHAHABUDDEEN, "Precedent in the World Court", op.cit., p. 81.

(5) See, ibid. 


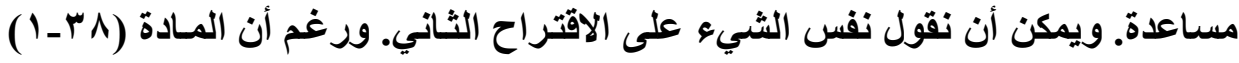
السالف ذكرها، لا ثُقدِّمُ قائمة شاملة للمصادر الرسمية للقانون الدولي، تستبعد الفقرة الفرعية (د) الأحكام القضائية(')

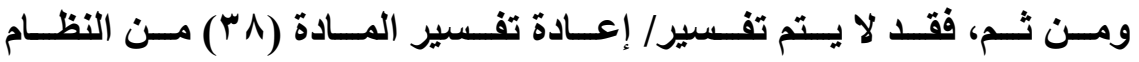

الأساسي لمحكمة العدل الدولية، بحيث تقوم بحلِّ لغز إمكاتية تطبيق نظريـة المصادر على القـانون القضائي اللدولي. إضـافة إلى ذلك، لا يمكن استخدام المصادر الأخرى

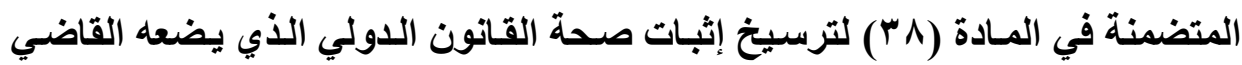
كذلك)(י)

وتهـف المجموعة الثانيـة من الحلول الممكنة لحلِّ لغز إمكانيـة تطبيق نظريـة

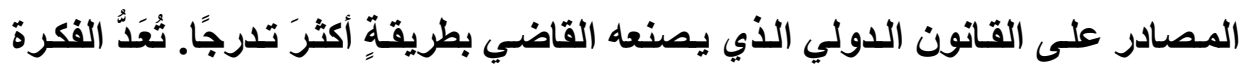
الرئيسة المشتركة بين كِلا المقترَحَيْن هي التقليل التدريجي من أهمية المحاكم الدولية في وضع أو سن القانون الدولي العام من خلال توفير آليات بديلة. وهذا سوف يُخَقِفُ من مشكلة تحديد أسـاس إثبات صحة القانون القضائي في إطار الوضعية القانونية. لتحقيق هذا الهـف، قد يـوفر المقترح الأولـ الذي يـافع عن تنظيم العرف الدولي

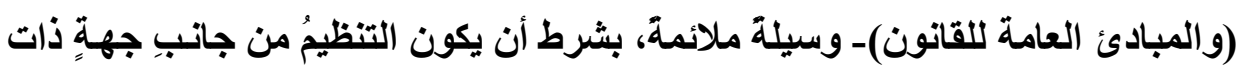
شخصيةٍ قانونية. ومع ذلك، قد لا يمكن تطبيق هذا الحل من الناحية العملية؛ لأنه قد يصعب، أحيانَا، التمييز بين التنظيم ووضع القانون(").

(1) Ibid., p. 80- 81.

(2) Samantha BESSON, "Issues", op.cit., p. 277.

(3) Jean D'ASPREMDNT, "Formalism and the Sources of International Law: A Theory of the Ascertainment of Legal Rules", op.cit., p. 168.

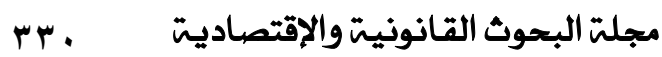


على العكس، فالمقترح الثاني ـ الذي يدافع عن المزيد من التأسيس لعلميات وضع القانون "العرفي" الدولي- قد أثبت أنـه أكثرُ فعالية في تخفيض مقدار القانون الدولي العام الأي تضعه المحاكم. فقد تتم الإشـارة إلى التأسيس لعمليـات وضـع القـانون

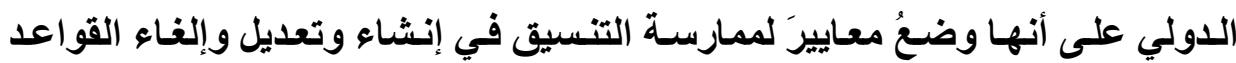
القانونية الدولية، ومن ثم تكون مثل توفير القواعد القانونية. ومن الأمثلة على ذلك، مؤتمر فيينا لقانون المعاهدات لعام 999 19، حيث قام بوضع معاييرَ للممارسة التنسيقية

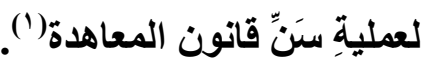
وهكذا، قد يساعد (المزيد من) وضع معايير ممارسـة التنسيق في عمليات سن أو صناعة القواعد الدولية على تكوين المنتديات متعددة الجواتب التي تتولى وضع

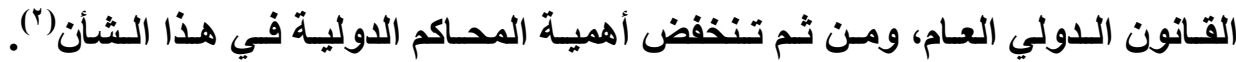
وبالتالي، قد يخفض (المزيد من) التأسيس لعمليات وضع القانون الدولي من صعوبة إمكانية تطبيق نظرية المصادر في سياق وضع القانون القضائي الدولي. ومـع ذلك، لا يقدم هذا المقترح حلاً نهائَّا.

(1) Samantha BESSON, "Theorizing The Sources of International Law", op.cit., p. 173- 174.

(2) Samantha BESSON, "Issues", op.cit., p. 169. 


\section{الفصل الثاني \\ القاضي في القانون الأوروبي}

\section{المبحث الأول \\ المشاركة في الاتِّاد الأوروبي \\ والتسوية القضائية للمنازعات}

ما تأثثير المشاركة في الاتِّحاد الأوربي على التسوية القضائية للمنازعات؟

هذا الجزء من الدراسة سوف يكون مُكرَّسًَا للإجابـة عن هذا التساؤل. فبعد أن

تصبح الدولـة عضوًا بالاتِّــاد الأوربي، هل تتغير بالنسبة لهـا احتمـالاتُ أو إمكانـاتُ اللجـوء إلى الوسـائل العاديـة للتسوية القضائية للمنازعـات والمعروفـة في القـانون

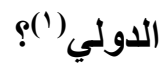

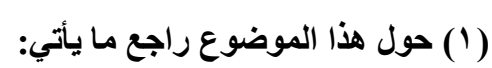

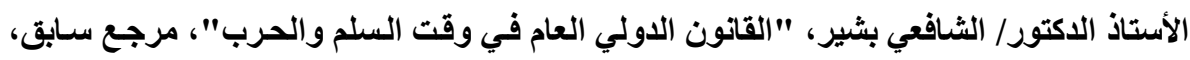

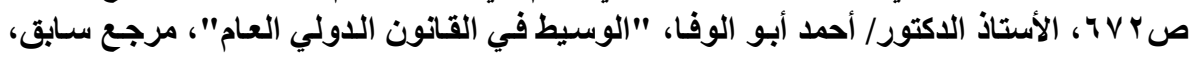

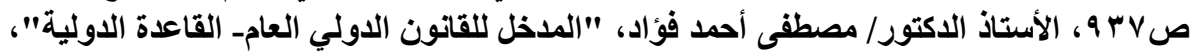

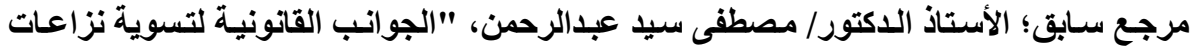

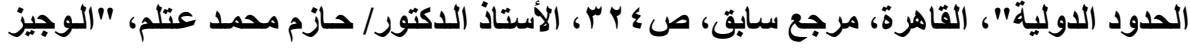

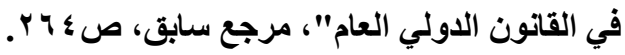

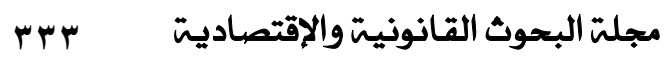


تتطلب الإجابة عن التساؤل السابق ذكره، بطبيعة الحال، بحثُ ما إذا كان النزاع

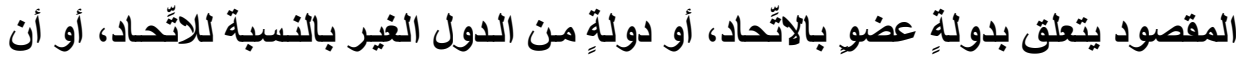

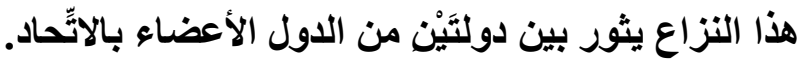
قد يبدو هذا التساؤل محدودَ الفائدة. على الرغم من أنسه يُشَكَّلُ صعوبة تقنية أو فنية أساسنًا، فهو يثير في الواقع مسألة جوهرية أو مسألكة موضوعية؛ ألا وهي معرفة:

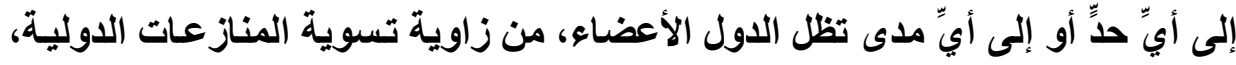

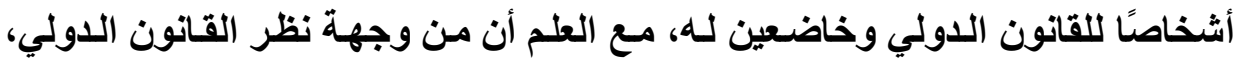
تعمل سيادة الدول في إطار تسوية المنازعات تحت ستار قاعدة من الحرية'(') ويثير تأثير الانضمام إلى الآّّاد الأوربي بشأن تنوع أو تباين إجراءات التسوية

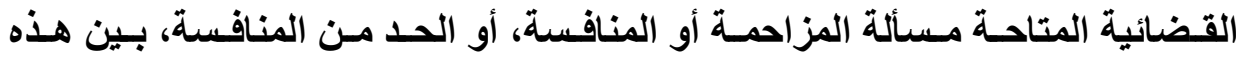

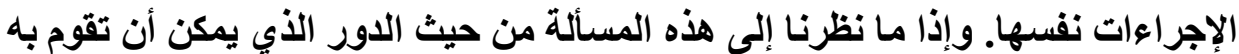

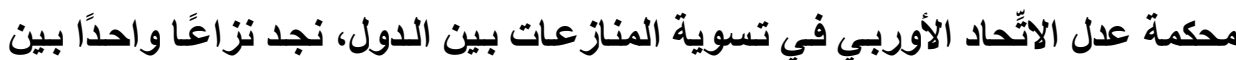

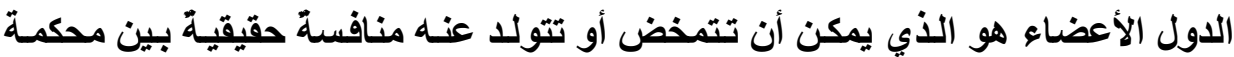
لكسمبورج والمحاكم الدولية الأخرى. مع الأخذ في الاعتبار، عدم تمتع محكمة عدل الآتّاد الأوروبي بائة ولاية أو اختصاص إزاء الاول الألير. 1 ا المنازعات بين دولة عضو ودولة هن الدول الغير: تسمح ببيان هذا النوع من المنازعات، قضية بلجيكا ضد سويسرا والمثارة أمسام

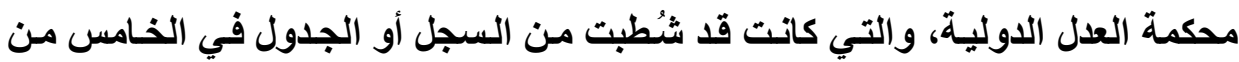

(1) Voir l'article 33 de la Charte des Nations Unies. 
أبريل من عام 1 ـ ـ (')، بناءً على طلب بلجيكا الذي تم تقديمسه في الحسادي والعشرين

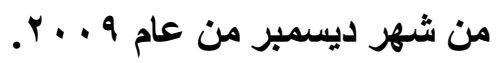

وتجدر الإشارة إلى أنه بعد إفلاس (سـابينا) والنزاعات القضائية التي كاتت قد

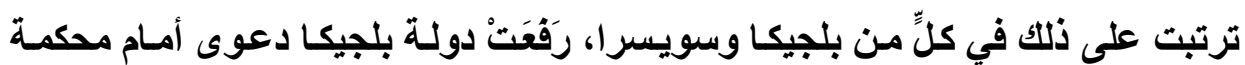

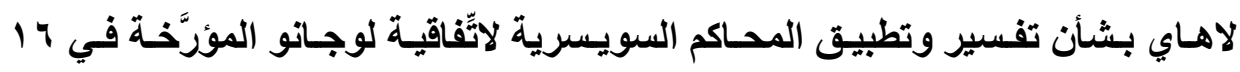

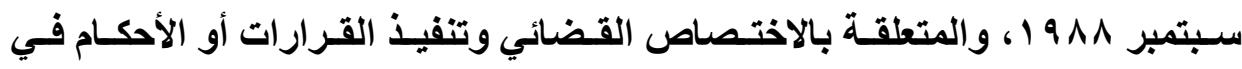
المسائل المدنية والتجارية. وبموجب هذا الصك أو هذه الوثيقة، كان قد تم التوسع في نطاق أحكام اتِّقاقية بروكسل لعام 19 ا 1، لتشمل أعضاء الرابطة الأوروبية للتجارة الحرة. وفي Y Y ديسمبر عـام . . . . ، اعتمد المجلس لائحة بروكسل ا ، والتي، مـع

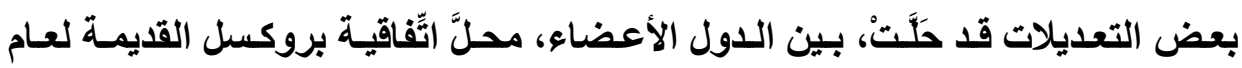
^ 9 ام. وقد استتبع هذا التجديد القانوني- لاتحـة الجماعة التي حلت محل الاتِّاقية

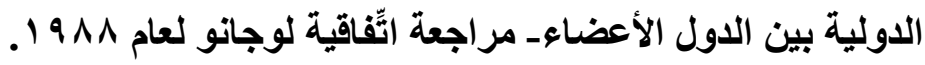
وفي الاتِّــاد الأوروبـي تثور مسألة معرفـة: مـا إذا كـان إبرام اتِّاقيـة لوجـانو

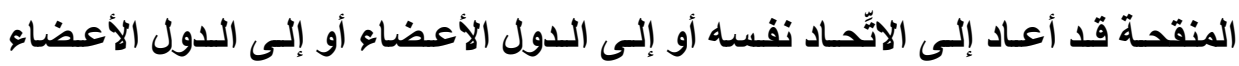

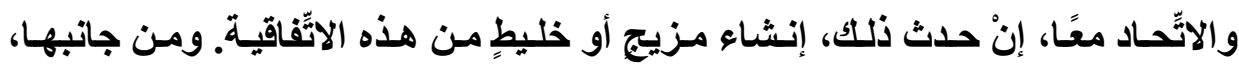
أعلنت محكمة عدل الاتِّــاد الأوروبـي أن اتِّاقيـة لوجـانو الجديدة تتعلق بالاختصاص

(1) CIJ, Compétence Judiciaire et exécution des décisions en matière Civile et Commerciale (Belgique c. Suisse), Ordonnance du 5 avril 2011. 
الخارجي الخالص للاتِّاد ('). وأن هذا الأخير قد أقدم على إبرام اتِّقاقية لوجانو بدون

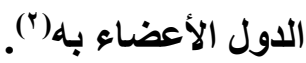

ويترتب على اتِفاقية لوجانو الجديدة والتي أبرمت من جانب الاتِّحاد الأوروبي

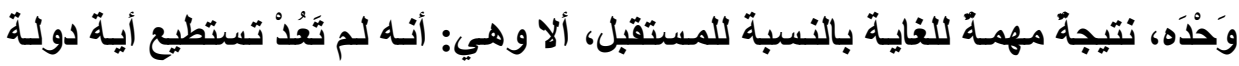

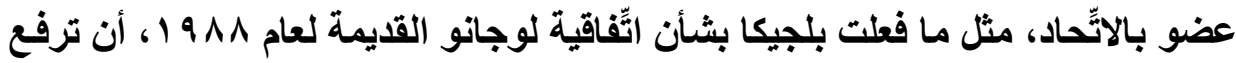

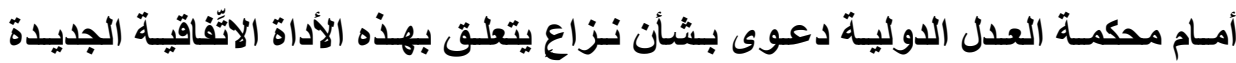

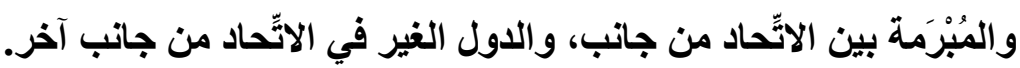

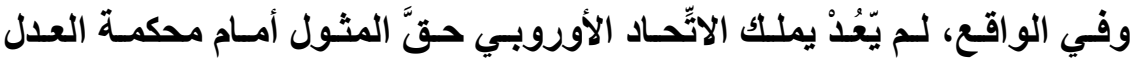

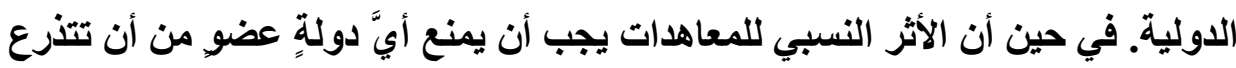
أو أن تدفع، في النظام القانوني الدولي، بانتهاك وثيقة أو صك هي ليست الئ رسميًّا طرفا

ويَحْرُمُ تنامي اختصاصات الاتِّاد الأوروبي، شيئًا فشينًا، الدول الأعضاء من

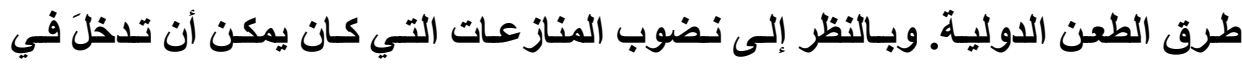
اختصاص محكمة العدل الدولية، حتى عندما تكون الدول الغير أطرافا فيها، لتحولها

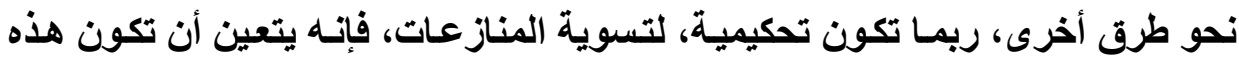

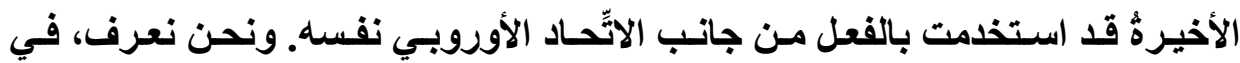

(1) CJCE, 7 février 2006, Avis 1/03, Rec. 2006, p. I- 01145.

(2) Décision du Conseil du 27 novembre $2008(2009 / 430 / C E)$ relative à la conclusion de la convention concernant la compétence Judiciaire, la reconnaissance et l'exécution des décisions en matière civile et commerciale, signée à Lugano le 30 octobre 2007, JOL 147 du 10.6. 2009, p. 1. (et texte de la convention, p. 5). 
الحقيقة، أن "اختصاص الاتّحاد بشأن العلاقّات الدولية، وأهليته في إبرام المعاهدات الدولية يتضمن بالضرورة الخضوع لقرارات أو أحكام قضاء أو محكمة منشأة أو معينة بموجب هذه الاتِّفاقيات، فيما يتعلق بتفسير أو تطبيق أحكامها"('). ونحن نعرف أيضًا، أنـه يمكن للاتِّـاد، في حالـة الضرورة، أن يُقتع شـركاءَه

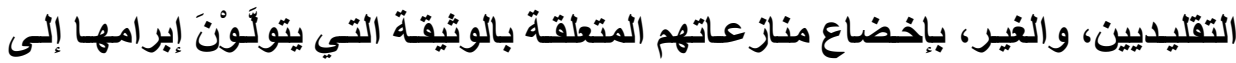
محكمة عدل الاتِّاد الأوروبي نفسها، بمنحها كذلك اختصاصاتٍ قضائية جديدة، شريطة ألا يؤثر ذلكت على وظيفـة المحكمة المنصوص عليهـا في معاهدات الاتِّــاد الأوروبـي

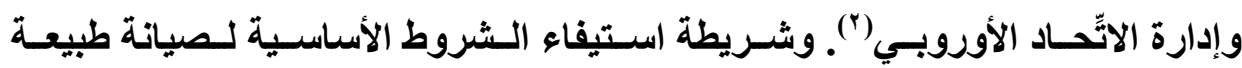
اختصاصات المحكمة، وألا ينال ذلكك من استقلال النظام القانوني للاتِّحاد (זّ). على هذا النحو، يتــافس الاتِّحاد الأوروبـي نفسه، إذا صـحَّ القول، مـع محكمـة العدل الدولية، وكذا مـع الطرق الأخرى للتسوية الدولية المتاحة للدول. ويسمح هذا الموقف، على نحو ملموس جدًا، بقياس ما تعنيه السيادة، بالنسبة للاول الأعضاء، في

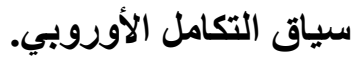

وبعيدًا عن هذه المناقشات، والتي لا جدوى من ورائها في هذا المقام، يجب أن

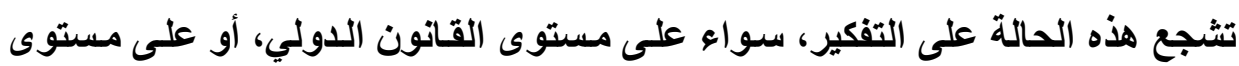

(1) CJUE, 8 mars 2011, Avis 1/09 (Juridiction du brevet européen et du brevet communautaire), Rec. 2011, p. I-1137, Point 74, se référant à l'Avis 1/91 du 14 décembre 1991, Rec. 1991, p. I- 6079, Points 40 et 70.

(2) Ibid., Point 75, se referent "Par analogie" à l'Avis 1/92 du 10 avril 1992, Rec. 1992, p. I-2821, Point 32.

(3) Ibid., Point 76, Yenvoyant à l'Avis 1/oo du 18 avril 2002, Rec. 2002, p. I3493, Point 21, 23 et 26. 
قانون الاتّّاد، في الطرق التي يجب أن تسمح للاول الأعضاء نفسها بأن تلجأ إلى

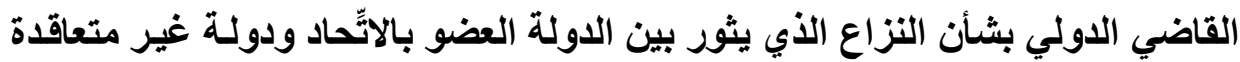

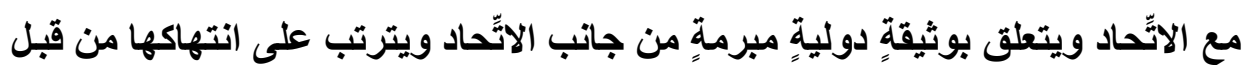
الغير إلحاقُ الضرر بإحدى الدول الأعضاء.

ودون الإثـارة إلى الافتراض الثقيل جدًا بشأن مراجعة ميثاث الأمم المتحدة

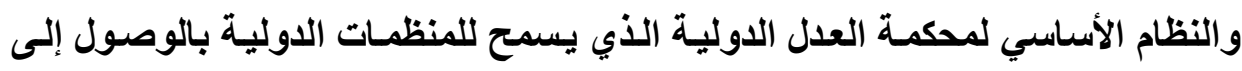
إجراءات المنازعات الدولية، يمكن للمرء أن يتصور، بلاًا من شرط التحكيم، تضمين

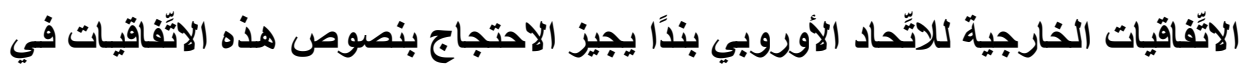

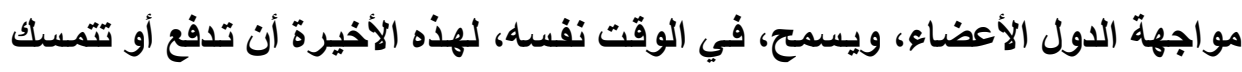

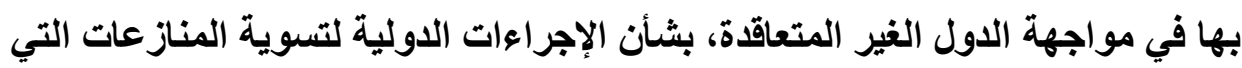

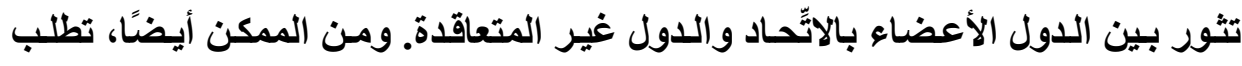

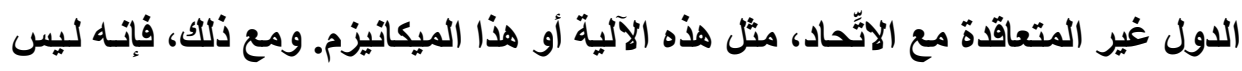

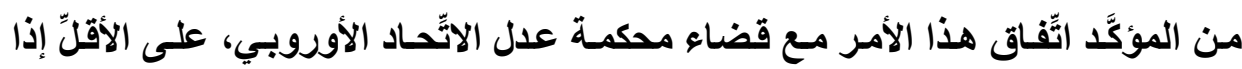

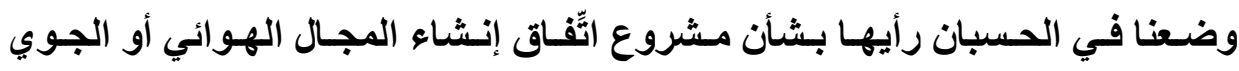

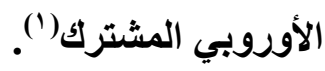

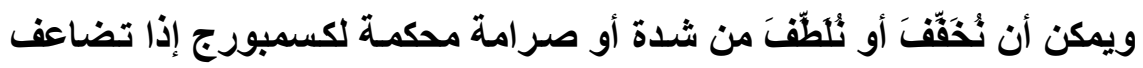
هذا النوع من الثروط الآثّاقية وسبق، في صدر الاتّّاد، إجراء داخلي للتعاون الوثيق

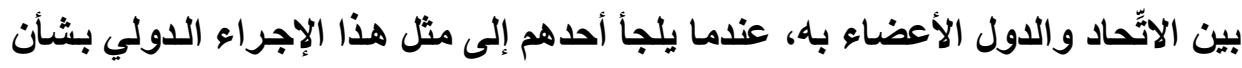

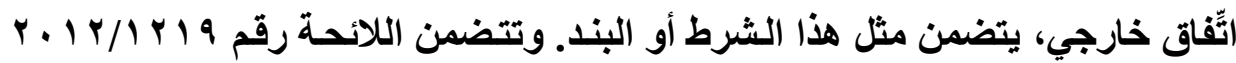

(1) CJCE, 18 avril 2002, Avis 1/00, Rec. 2002, p. I- 03493, Point 17. 
المؤرَّخة في r ا ديسمبر r ا ـ ب هذا المعنى (')، بخصوص معاهدات الاستثمار الثنائية المبرمة من جاتب الدول الأعضاء والدول الغير، والتي تخضع منذ معاهدة لشبونة(؟) للاختصاص الحصري للاتّّاد. وتتضمن هذه الاثّفاقيات غالبًا شروط تسوية المنازعات التـي تثـور بـين المستثمرين والدولـة المتعاقدة لـيس فقط، ولكن أيضًا بـين الـدول

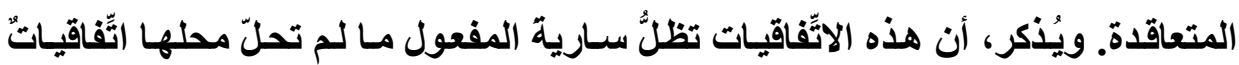
أخرى بشأن نفس الموضوع، يتم إبرامها بواسطة الاتِّحاد مع نفس الدول الغير.

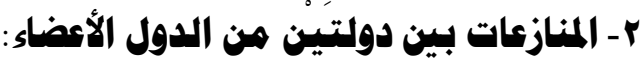

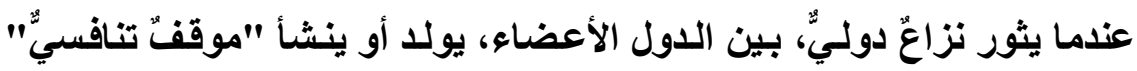
حقيقيٌّ بين طرق الطعن العادية في القانون الاولي ومحكمة عدل الاتِّاد الأوروبي. ولا ينشـأ هذا الوضع التنافسي من حيث المبدأ، إلا باجتمـاع شـرطيْن معًا: مـن جانب، يجب أن يوجد بين الدول الأعضاء الأطراف في النزاع أسـاسُ اختصاص أو ولاية لصالح محكمة العدل الدولية أو إجراءُ تسوية آخر (التحكيم على سبيل المثال)، ومن جانبِ آخَرَ؛ يجب أن يتعلق النزاع، على الأقِلِّ لأحد الأطراف، بتفسير أو تطبيق قواعدَ خاصةٍ بقانون الاتِّحاد الأوروبي.

وفيما يتعلق بهذيْنِ الشرطيْن، التساؤل الأي يدق هو: ما إذا كان يمكن اقترانههـا معًا من الناحية الواقعية، أو إذا كان وجود الشرط الثاني لا يزيل الشرط الأول.

(1) Règlement (UE) no. 1219/2012 du Parlement Européen et du Conseil du 12 décembre 2012 établissant des dispositions transitoires pour les accords bilatéraux d'investissement conclus entre des Etats membres et des pays tiers, JOL 351 du 2012. 2012, p. 40.

(2) Article 207 TFUE. 
في الحقيقة، يُعدُّ وجود الشرط الأول ضروريَّا للغاية. فإذاذا لم يتوافر، لا يمكن أن توجد محكمة العدل الدولية أو أيٌٌ قاضِ آخر أو محكم دولي في موقفٍٍ تنافسي، هذا مـا لم يكن مختصنَّا. وإذا ما تركنا تلك المواقف الافتراضية المشار إليها في الفقرة الخامسة من المادة (^^) من النظام الأساسي لمحكمة العلل الدولية، أو حتى تلك المواقف التي يخضع فيها النزاع بين الدول الأعضاء للتسوية بالتراضي، يمكنتا أن نسجل أن (1')

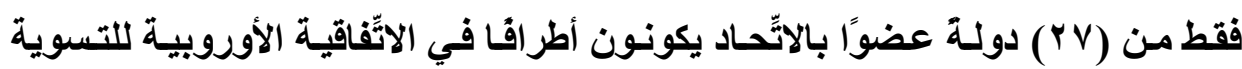

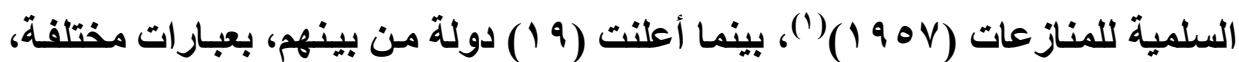
قبول الولاية الإلزامية لمحكمة العدل الدولية بـالمعنى الوارد بـالفقرة الثانيـة من المسادة

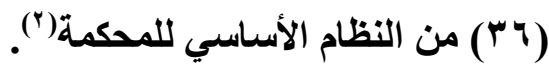
بطبيعة الحال، تلتزم الدول الأعضاء في الاتِّاد بالعديد من الوثائق أو الصكوك

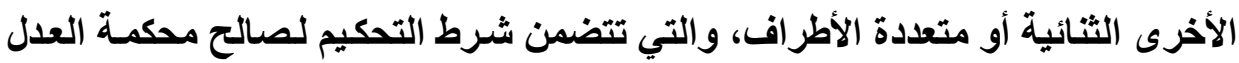

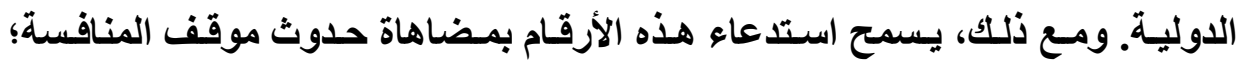

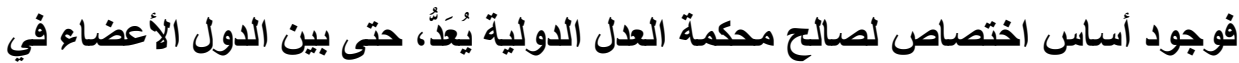

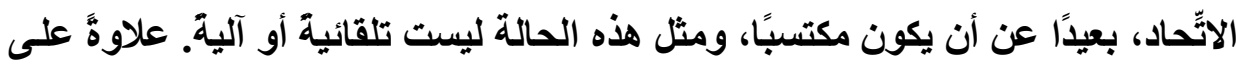

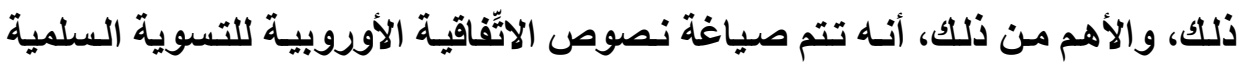
للمنازعـات، وكذا نصوص أغلبية إعلانـات قبول الاختصاص الإلزامي لمحكمة العدل الدولية أو الثروط التحكيمية لصالحها أو لصالح الآليات الأخرى التحكيمية أو القضائية الصائية

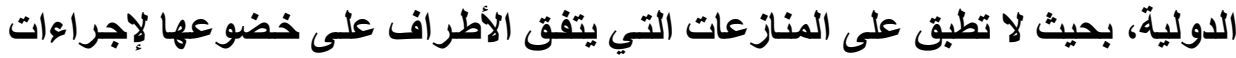

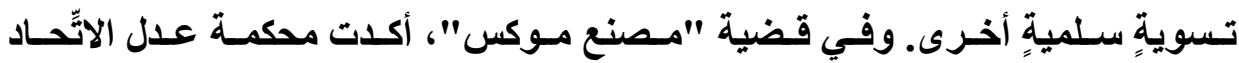

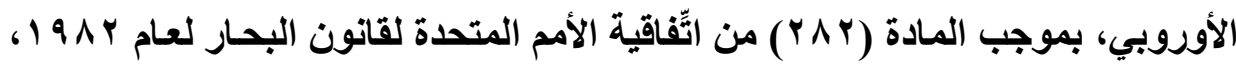

(1) http://conventions.coe.int/Treaty/commun/ChercheSig.asp?NT=0 $23 \& C M=8 \& D F=07 / 12 /-2010 \& C L=F R E>$.

(2) http://www.ici-cij.org/Jurisdiction/index.php?p1=5\&-p2=1\&p3=3> 
أن: "نظام تسوية المنازعات التي تتضمنه معاهدة الجماعة الأوروبية، يفوق، من حيث

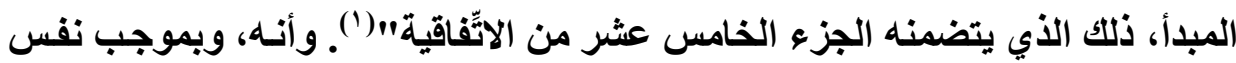

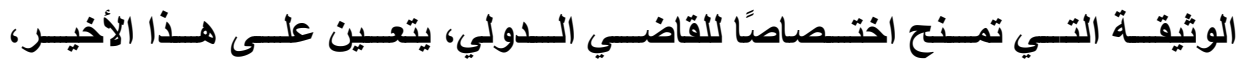

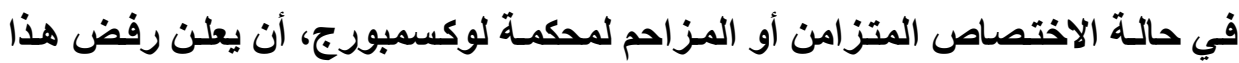

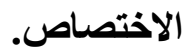

ويجب أن نعرف بالتحديـ مـا هو نظـام تسوية المنازعـات الـوارد في معاهدة الجماعة الأوروبية؟ هو: النظام الذي يشكل، لأغراض هذه الاستثناعات قبول اختصاص

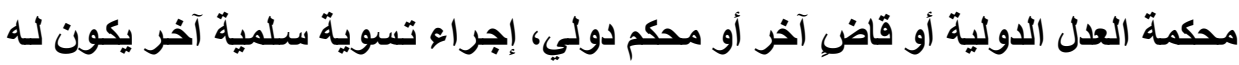

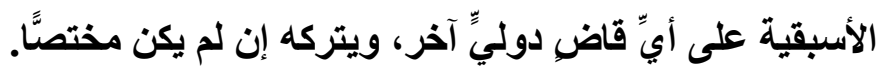

القول الفصل، أن الإجراء سالف الأكر والأي يُشَكِّلُ إجراء تسوية المنازعات بين الدول الأعضاء لم يستخدم إلا نادرًا حتى يومنا هذا. وحتى على الرغم من أنسه قد يكون

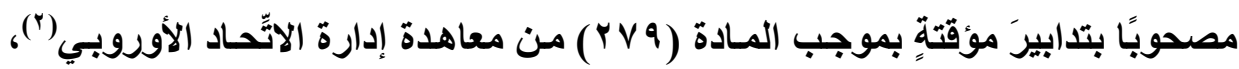

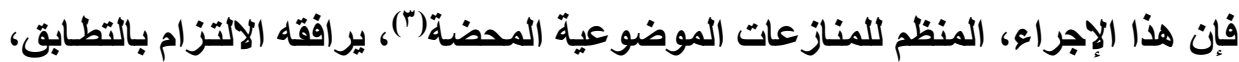

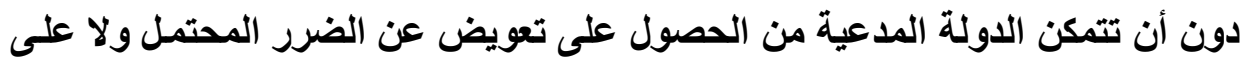

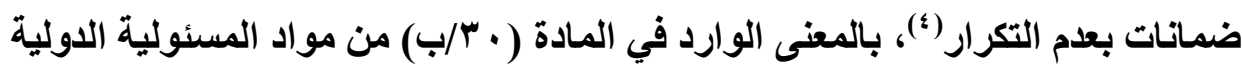

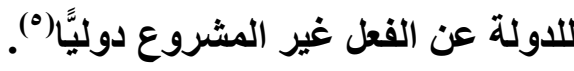

(1) CJCE, 30 mai 2006, Commission c. Irlande, C-459/03, Rec. 2006, p. I04635 , Point 125.

(2) Ibid., Point 138.

(3) Y. KERBRAT, Ph. MADDAlon, "Affaire de l'usine Mox : la CJCE rejette l'arbitrage pour le règlement des différends entre Etats membres", Revue Trimestrielle du Droit Européen, 2011, p 175.

(4) CJUE, 16 octobre 2012, Hongrie c. Slovaquie, C- 364/10.

(5) A/ 56/ 83. 
وجدير" بالذكر، أنـه يمكن رفـع طلب التعويض أو الإصـلاح أو الضمان بعدم

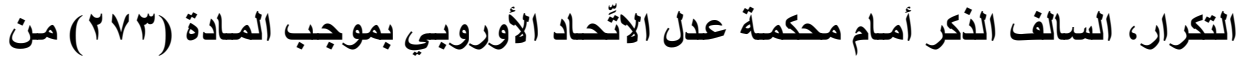

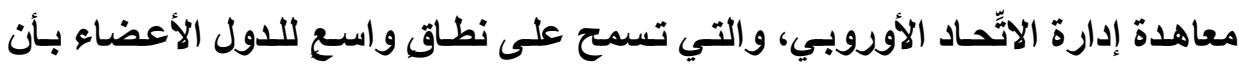

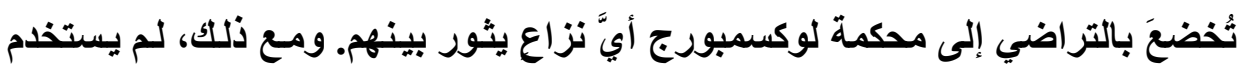

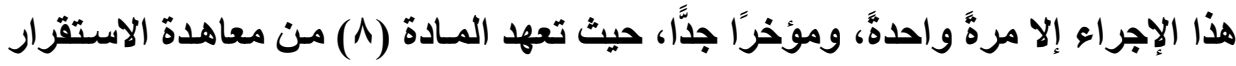

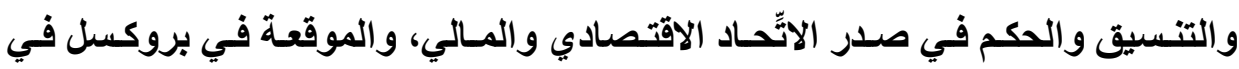

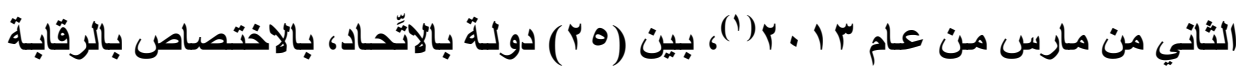

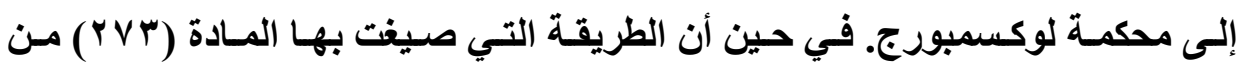

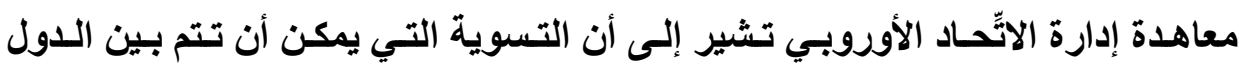

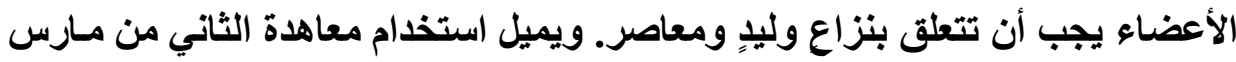

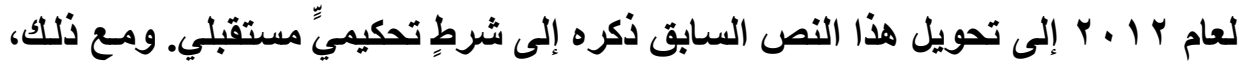

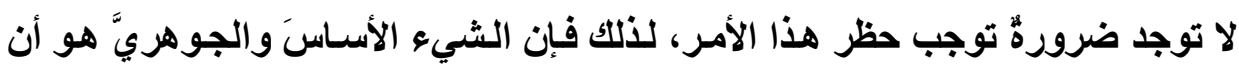
نسمح بالتوسنُع الرضائيِّ لنطاق الولاية القضائية للمحكمة. و هكذا، فِان نظام تسوية المنازعات الذي تضمنته المعاهدة سـالفة الذكر، لا يكون أيضًا كاملاً، كما لا يكون آليَّا أو تلقائيًّا. أمسا فيمـا يتعلق بالشرط الثانيـ والذي بموجبه يتعين أن تكون قو اعد قانون

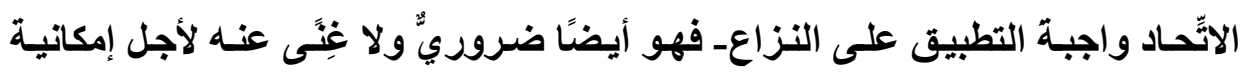

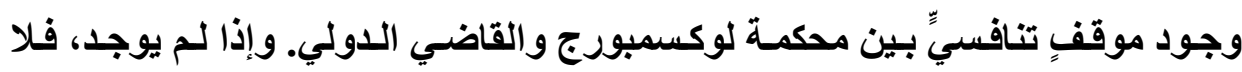

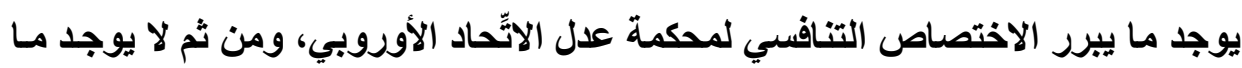

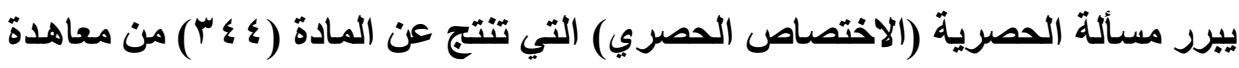

(1) http://european-Council.europa.eu/media/639232/08-tscg.fr.12.pdf

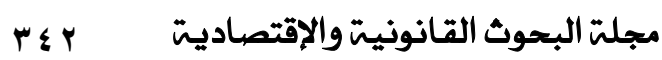


إدارة الاتَّاد الأوروبي، والتي تقترح وجود "خطر"، في الحالة التي ثُعْلِنُ فيها محكمة

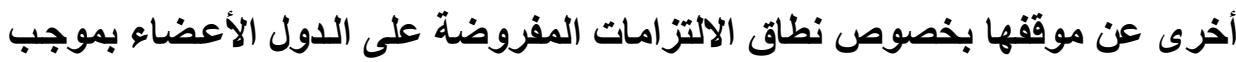

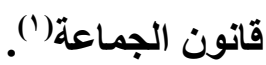

وبوسعنا، بالطبع، أن نتساعل طويلاً عن نطاق المـادة (؟ ؛ ؟) السالف الإشـارة إليها، وعن المعنى الذي أعطته إياها المحكمة في قضية موكس. وكذللك، يمكن للمرء

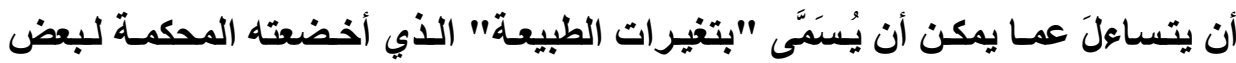
نصوص اثَّاقية الأمم المتحدة بخصوص قانون البحار، مـا دامت هذه النصوص تتعلق

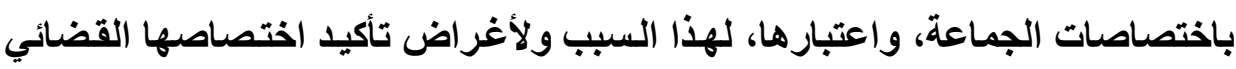

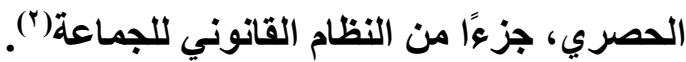

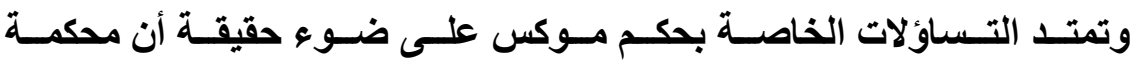

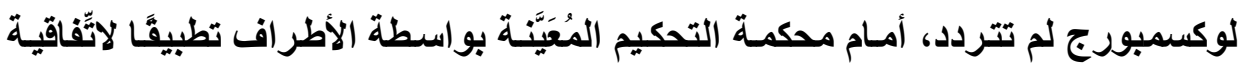

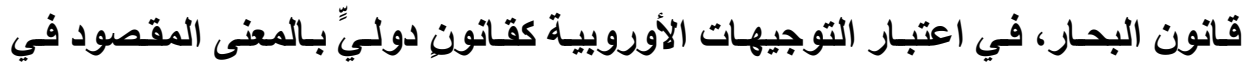

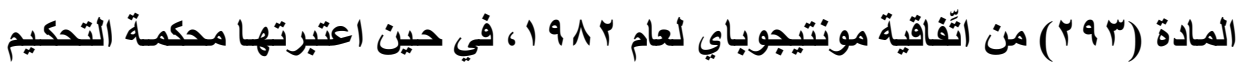

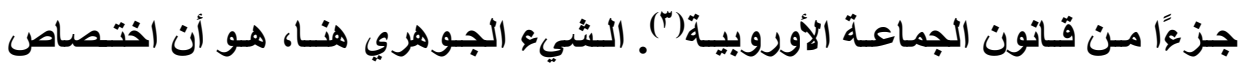

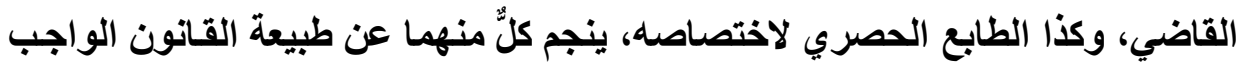
التطبيق على النزاع، حتى لو بدت هذه الطبيعة متغيرةً تبعًا للقاضسي الذي تثنور أمامسه

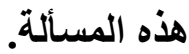

(1) CJCE, 30 mai 2006, Commission c. Irlande, C. 459/03, Rec. 2006, p. I04635, Point 177.

(2) Ibid., Point 121.

(3) Ibid., Points 149- 152. 
وتتمثل الصعوبة، مع ذلك، في معرفة مـا يغطي بشكل ملموس هذا الاختصاصن

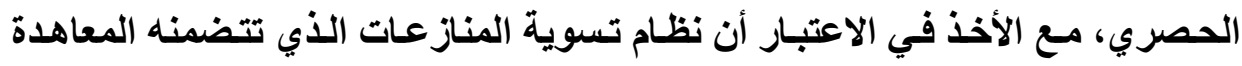
المذكورة يعدُّ بعيدًا عن أن يكون كاملاً أو آليًَا.

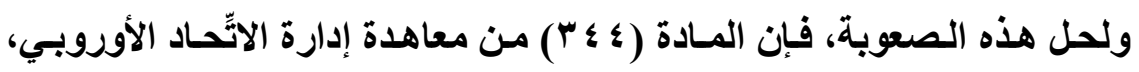
و التي لا تتعلق إلا بالمناز عات بين الدول الأعضاء مع استبعاد المنازعات التي تثور بين

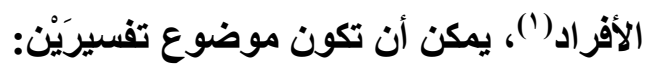
(1) أن نستنتج من هذا النص، أن إجراء تأكيد المخالفة هو الوحيد الذي يكون

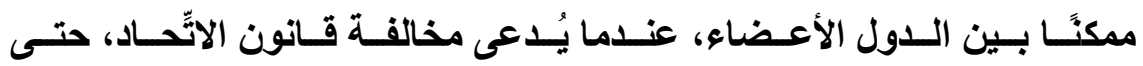

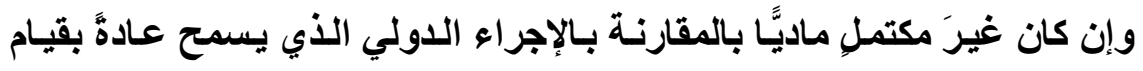

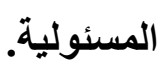

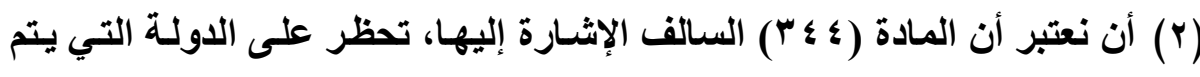

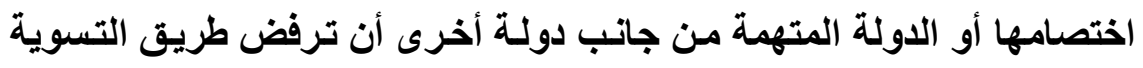

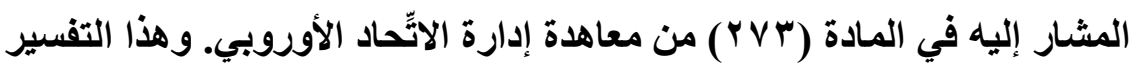

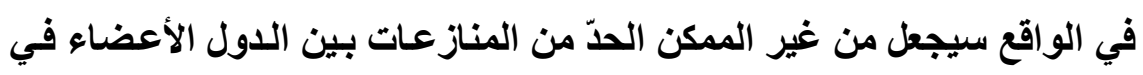

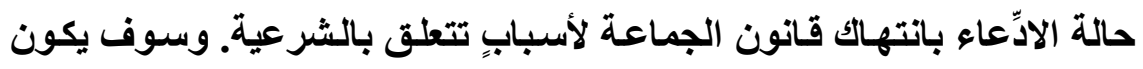

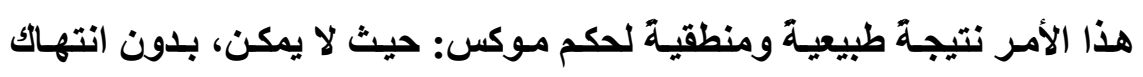

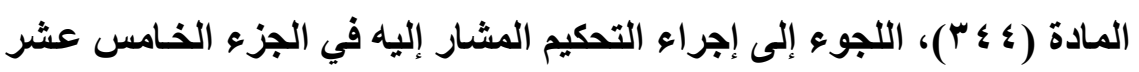

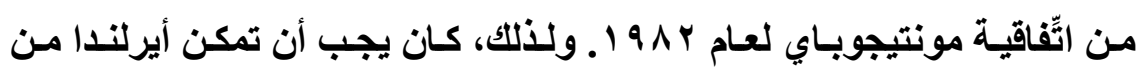

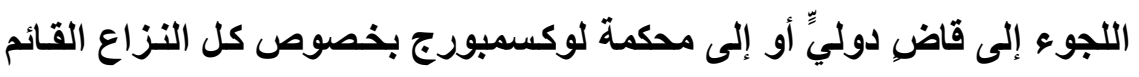
(1) CJUE, 8 Mars 2011, Avis 1/09, Rec. 2011, p. I-01137, Point 63. 
بينها مـن جهة وبين المملكة المتحدة من جهة أخرى؛ وذلكك بهدف حمايـة حقوقها أو استعادة تلك الدولة لحقوقها. وجدير" بالذكر، أنَّ أيَّ حلِّ آخر سوف يعيدنا إلى قبول أن المساهمة في الآّحـاد الأوروبي تنظوي بين الدول الأعضاء على شكل من أثنكال الرجعية أو التقهقر فيما

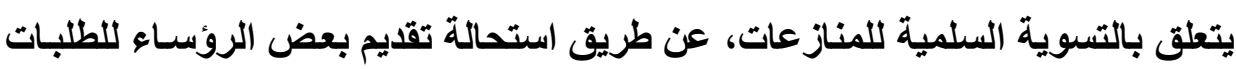

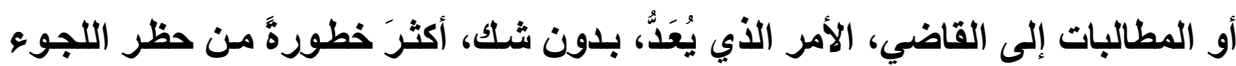

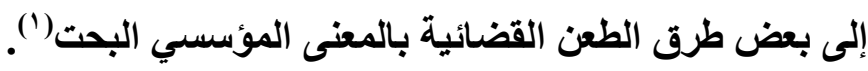
ويعيدًا عن الانتقاد الذي يمكن أن يُوَجَّة إلى حكم موكس، لا يمكن للمرء أن يدرك أثره إلا فيما يتعلق بإلغاء الموقف التنافسي القضائي؛ فعندما يتم استيفاء الثرط الثاني،

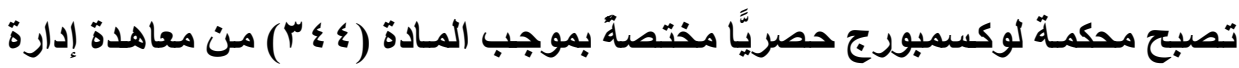
الاتّّــاد الأوروبـي. وهذه الحصرية أو هذا التفرد لا يوجد فقط في النظام القـانوني

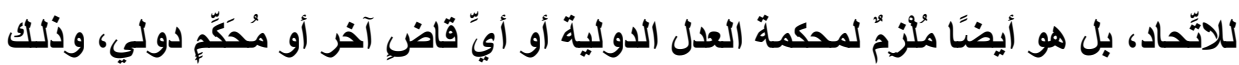
بالنظر إلى عدم تطبيق الوثائق التي تمنح الاختصاص للمحاكم الدولية حال وجود إجراءو تسويةٍ آخر مُئَقق عليه بين الأطراف المعنية. زبدة القول، لا تزال تكمن الحقيقة في أن محكمة لوكسمبورج تتنافس مع محكمة

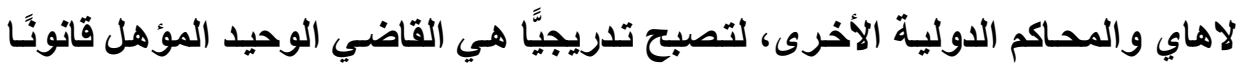

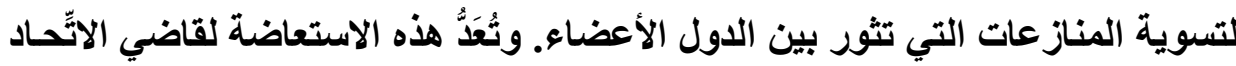

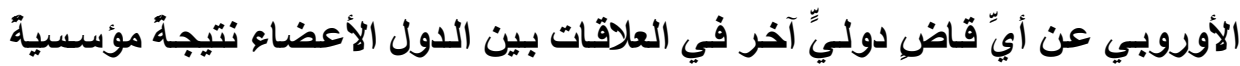

(1) Y., KERBRAT, Ph. MADDALON, "Affaire de l'Usine Mox: La CJCE rejette l'arbitrage pour le règlement des différends entre Etats membres", art. Préci., p. 177. 
د/عبد الله محمد الهوارى

العدد •r (ديسمبر r.19)

للإحلال بين الأنظمة القانونية، فحينما يتم تأسيس قانون الآّحاد الأوروبي، فإنها يَطرُدُ القانون الدولي ويحلٌ محله (').

وفي النهاية، حتى لا تفقد الدولُ الأعضاءُ في الاتَّاد الأوروبي شيئًا من الحماية القضائية، نتيجة لعملية إحلال القضاة واستبال الأنظمة القانونية، يجب أن تكون هذه الأن الأن

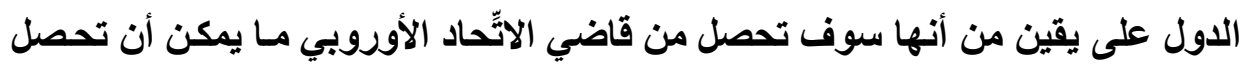
عليه من القاضي الدولي.

(1) P. D'ARGENT, "Arrêt 'Kadi': le droit Communautaire Comme droit interne", Journal de Droit Européen, 2008, p. 268.

مجلتّ البحوث القانونيت والإقتصاديت ؟ 


\section{المبمث الثاني \\ الاتِّاق أو التهاسك في هنطق القضاة الأوروبيين}

\section{تمهيد:}

نودُّ أن نستقيد من هذه الإسهامة في التفكير في مفهوم أساسِ للقانون، ألاوهو مفهوم الاتّّساق أو التماسك. ويتم دراسة هذا المفهوم أساستًا في سياق النظريـة العامـة للقانون، والتي ترمي إلى تحديد مـا هو القـانون؟ ومـع ذلك، فِانِ التماسك أو الاتِّساق الذي نهتم به هنا ليس واسعَ النطاق، وفي الوقت نفسه لا ينحصر تحديدًا في المنطق القضائي. وفي هذا الصدد، يتم تبرير التماسك أو الاتِّساق في المنطق القضائي من خلا مبدأ أمن القانون، الذي يوجد في جميع النظم القانونية. ويموجب هذا المبدأ، يجب التنبؤُ بتطبيق قاعدةٍ مـا لتمكين المتقاضـين مـن معرفـة نطـاق العقـوق والالتزامسات المفروضة عليهم. وبالتالي، فإنه من الضروريٍ أن يقوم القاضي، أثناء ممارسة مهمته المتمثلة في تفسير القواعد القانونية والعمل على احترامها، بالاستدلال أو التدليل بطرق مفهومةٍ للمتقاضين، ومن ثم، إظهار اتِّساق أو تماسكلٍٍ معين. في هذا السياق، تدليلنا، الذي لا يخلو من إثـارة بعض التحديات، أن النظريـاتِ

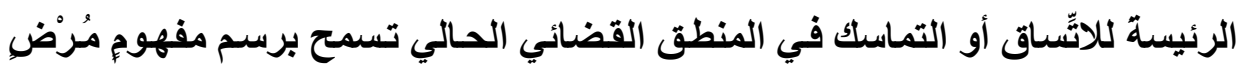
للتماسك عندما نحاول التوفيق أو التنسيق فيما بينها. علاوةً على ذلك، فإنـه يبدو لنا ـ بلا ريبٍ ـ تأثرُ منطق القاضي بالنظام القانوني الذي ينتمي إليه، ويبدو لنا أيضًا، أنه من الضروري أن نتنـاول مفهوم النظـام القـانوني، والتماسك في إطـار يحدده هذا النظـام 
ويكمن أحد التحديات الناشئة عن هذا الاقتراح في تعريف أو تحديد موضوعه. ويتطلب التدليل لـصالح الاتِّساق أو التماسـك في المنطق القضائي أن نُحَدِّدَهُ بشكلِ مُرْضِ: هل هو تماسك أو اتَّساق بَدَهِيٌ، والذي يمكن تقعيده أو إخضاعه لتحليلٍ علميٍٍ نقدي، أو هو ترابط منطقي وعقلي، ثمرة عمليةة تحليلية محددة؟ علاوةً على ذلك، مـا الغرض من الاتُّساق أو التماسك؟ وماذا نعني بمنطق القاضي؟ وتنبثق الصعوبة الثانية المتفرعة عن هذا التدليل من حصر أو تحديد التماسك أو الاتّّاق في منطق القضاة الأوروبيين، آخذين في الاعتبار أن قراراتِهم أو أحكامَهم

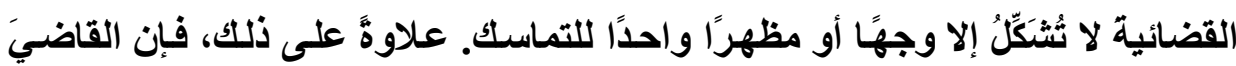
ليس هو الفاعل أو الممثل الوحيد لاتِّاذ القرارات والمعني قدمًا في هذا المنطق. ومـع ذلك، سوف نركز عليه (أي القاضس) ليس فقط لسلطته في تسوية المنازعات، ولكن

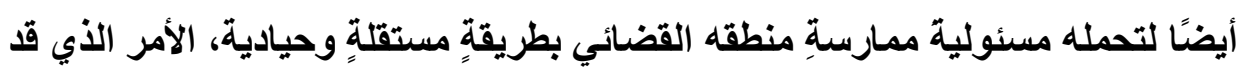

$$
\text { يكون منعدمًا في سلطات أخرى (') }
$$

ومـاز الت الرغبـة في التـليل لصالح تناستق محددٍ في الاتِّــاد الأوروبي، من

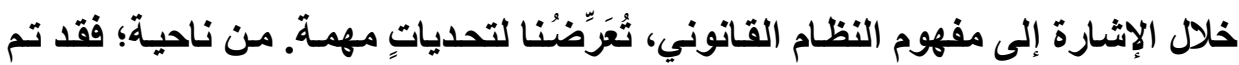
تطوير مفهوم النظام القانوني في إطار دوليٍّ، بحيث لـم يَعُدْ في الإمكان نقلُ النظريـات المختلفة التي تمَّ إعدادها بشأنه إلى نطاق الاتِّحاد الأوروبي دون إثارة تساؤلاتٍ شـائكةٍ تتعلق بخصوصية هذا الثكل القانوني.

(1) Amalia AMAYA, "Ten Theses on Coherence and Law", Working Papers Series, 21 Mai 2015, disponible sur SSRN: http://dx.doi.org/10.2139/ssrn.2064295. 
ومسن ناحيـةٍ أخرى؛ في حالـة اسـتبعاد أسسس نظريـة النظـام القـانوني للاتِّــاد

الأوروبي، ينبغي تحديد العلاقـات بين ذلك النظام والأنظمـة القانونية الداخلية للدول

الأعضاء في هذا الاتِّحاد.

إلا أنتـا لا نَدَّعِي، في سياق هذه الدراسـة، أن نُقدِّمَ نظريـة كاملـة لصالح نظـاج

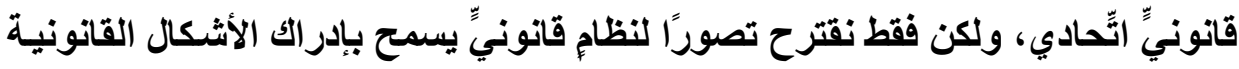

وغير القانونية على السواء. وهدفنا الوحيد، هو أن نبرهن على أنسه يمكن التدليل أو

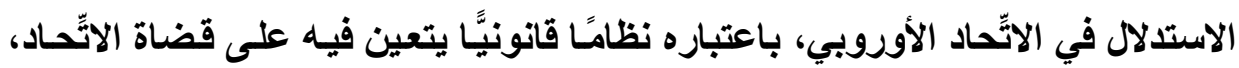

وكذا القضاهُ الوطنيون، إظهارُ الاتِّساق أو الترابط في منطقهم.

ا - المقاربات أو النُهُجُجُ المختلفة للاتِّاق أو التهماسك:

لقد اقُرحت خلال السنوات الأخيرة مقارباتُّ عديدةٌ ومختلفة للتماسك أو الاتِّساق

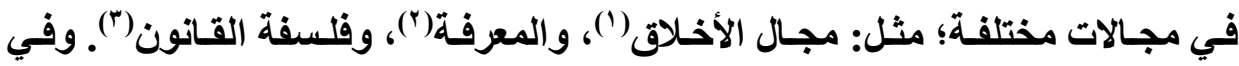

فلسفة القانون المعاصر، قد وُضعت وتطورت العديد من نظريات الاتِّساق أو التماسك

المعياري، ونظريـات تبرير البيانـات المعياريـة والقرارات أو الأحكام القضائية استنادًا

(1) Johe RAWLS, "A Theory of Justice", Cambridge, Harvard University Press, 1999; Paul THAGARD, "Ethical Coherence", Philosophical Psychology, no. 4, Vol. 11, 1998, p. 405.

(2) Laurence BONJOUR, "The Structure of Empirical Knowledge", Cambridge, Cambridge University Press, 1985; Keith LEHRER, "Theory of Knowledge", Boulder, West view Press, 2000.

(3) Neil MacCORMICK, "Coherence in Legal Justification", in Werner KRAWIETZ, "Theory of Norms", Berlin, Dunker, Humblot, 1984, p. 37; Ronald DWORKIN, "Law"s Empire", op.cit., 1986; Joseph RAZ, "The Relevance of Coherence", Boston University Law Review, no. 2, Vol. 2, 1992, p. 273. 
إلى هذه البيانات المعيارية. وترمي هذه النظريات إلى اقتراح مفهوم أوسعَ نطاقا للسبب أو العقل في القـانون، ممــا يتطلب اسـتيفاء القـرارات القضائية لمعـيير الاتِّساق أو التماسك، في الحالة التي يتمتع فيها القضاة بسُططةٍ تقديريةٍ معينة'('). وفي هذا الصدد،

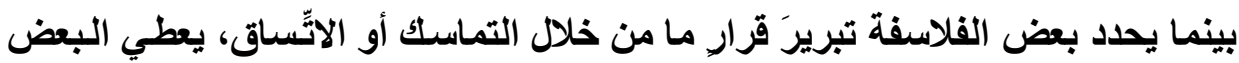
الآخر لهذا الأخير دورًا أكثرَ تواضعًا، باعتباره عنصرًا أساسنًا، ولكن ليس وحيدًا، في عملية تبرير القرار(ن)

وفي رأينا، أن نظرياتِ التماسك هذه تكون غيرَ مُرْضِيَةٍ جزئَّا، حيث لا ينبغي أن يتوقفَ فقط تبريرُ قرار قضائيٍ ما على الاتِّساق الذي يتسم به هذا الأخير مـع مجموعةٍ

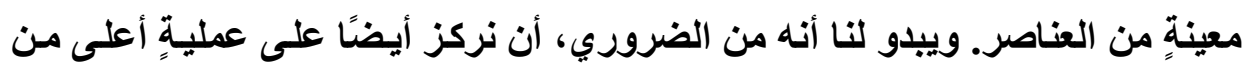
القرار حتى تكون عملية التدليل والاستدلال مُتَّقِةَّة ومتماسكة؛ لأجل تعزيز فهم وتبرير القرار القضائي الأي سيتبعه (القرار القضائي اللاحق). وقد وصفنا هذا النهج الأخير بالتماسك البََّّاء أو الخلاًّ.

(1) Amalia AMAYA, "La Cohérence en droit", disponible sur http://recursos.filosoficas. unam.mx/jrg/iifs/sitio/filosoficas/amaliaamaya.

(2) Julie DICKSON, "Interpretation and Coherence in legal reasoning", Stanford Encyclopedia of philosophy, 20 Fevrier 2015, disponible sur http://plato.stanford.edu/entries/legal-reas-interpret/\#whaconcoh.

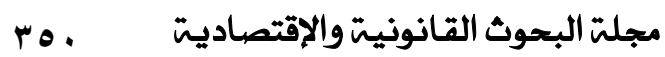


أ - التهاسك المعرفي:

لإثبات موققتـا بالنسبة لنموذج التماسك المعرفي، سوف نقدِّم ثُلاثَ مقاربـات:

نظرية التماسك المعياري لماكورميك(')، ونموذج التوازن لبيتزنيك(')، ونظرية الاتِّساق

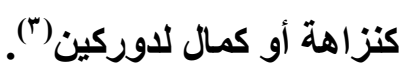

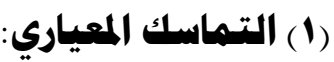

يُمَيِّزُ ماكورميك بين الاتّّاق أو التماسك المعياري المتعلق بتبرير الاستتناجات

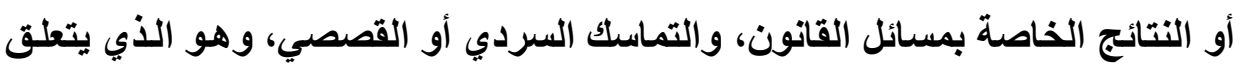

(1) Neil MAcCORMICK, "Argumentation and Interpretation in Law", Ratio Juris, no.1, vol.6, 1997; Neil MAcCORMICK, "Legal reasoning and Legal Theory", Oxford, Clarendon Press, 1998; Neil MAcCORMICK, "Rhetoric and the Rule of Law: A Theory of Legal Reasoning", Oxford, Oxford, University Press, 2005.

(2) Aleksander PECZENIK, "Certainty or Coherence?", in W.KRAWIETZ, "The Reasonable as Rational? On Legal Argumentation and Justification", Berlin, Duncker, 2000, p. 157; A. PECZENIK, "Coherence, Truth, and Rightness in The Law", in P. NERHOT, "Law, Interpretation, and Reality", Dordrecht, Kluwer, 1999, p. 275- 309; A. PECZENIK, "Law, Morality, Coherence and Truth", Ratio Juris, no. 2, Vol. 11, 1993, p. 146- 176; A. PECZENIK, "The Passion for Reason: Some Remarks on Coherence in Law", in E. GARZON, "Normative System in Legal and Moral Theory", Berlin, Duncker and Humblot, 1997, p. 309- 322.

(3) Ronald DWORKIN, "A matter of Principle", Cambridge, Harvard University Press, 1985; R. DWORKIN, "No Right Answer?", Oxford, Clarendon Press, 1977; R. DWORKIN, "Objectivity and Truth: You'd Better Believe it", Philosophy and public Affairs, no. 2, Vol. 25, 1996, p. 87- 139. 
بتبرير النتائج الخاصة بمسائل الواقع. ويتطق التماسك المعياري بمجموعةٍ من القواعد

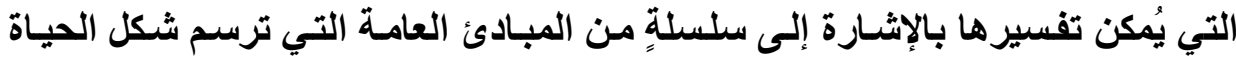

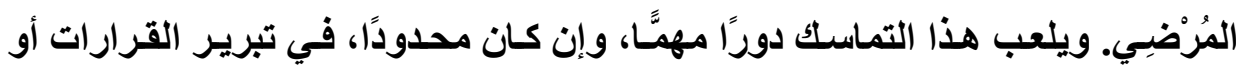
الأحكام القضائية في ظل وجود قضايا صعبة. ووفقًا له، تسمح حجج التماسك أو الترابط بتحديد مجموعةٍ من القرارات على أنها مُبَرَّرَة، وإن كانت تعتمد في تبريرها، في نهايـة

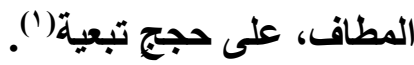

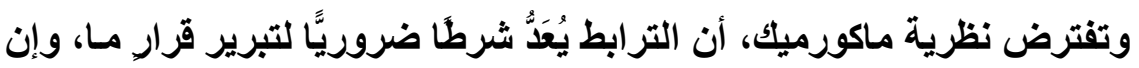
كان غيرَ كافٍ، ولكن في كل الأحوال، يُشكل إسهامة مهمة في تحقيق العدالة. ويتطلب

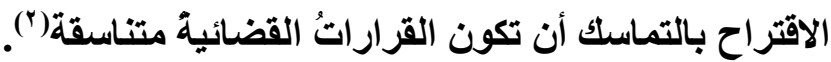

\section{(ז) التماسك الناتج عن التوازن أو الاعتدال:}

يقترح بيتزنيك نظرية التّليل القانوني التي تمنح الاتّساق أو الترابط دورًا أوسعَ

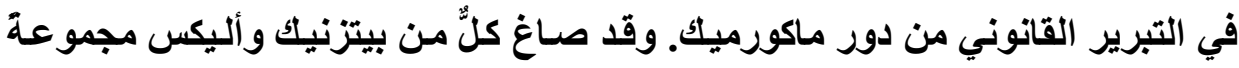

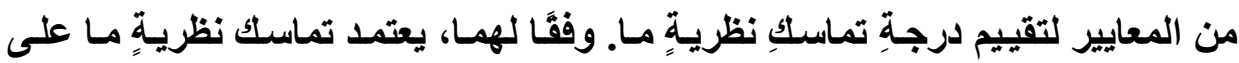
المعايير التي تحدد خصائصَ هيكل دعم النظريـة، وكذا المعاييرُ المتعلقةُ بالمفـاهيم

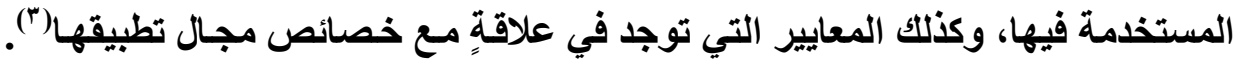

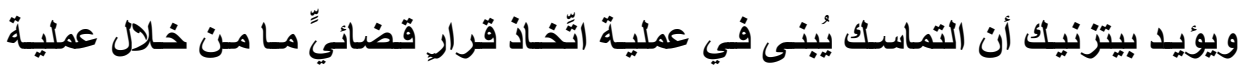
التوازن. ويُعدُ التبرير القانوني نتيجة لتماسك جميع الأسباب ذات الصيّلة، والتي تشمل فئل

(1) Amalia AMAYA, op.cit.

(2) Ibid.

(3) Robert ALEXY, A. PECZENIK, "The Concept of Coherence and its Significance for Discourse Rationality", Ratio Juris, no. 1, Vol. 8, 1995, p. $130-147$. 


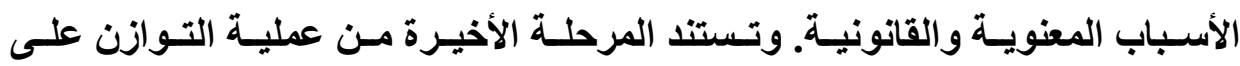

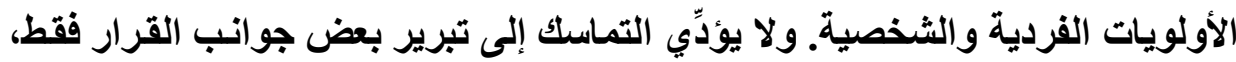

$$
\text { ولكنه يؤدي إلى تبرير كل جوانبه('). }
$$

وعلى عكس ماكورميك، لا تلعب الاعتباراتُ الذاتيـة، في اقتراح بيتزنيك، دورًا

إلا في الحالات التي يوجد فيها قراران متطابقان مع مجموعةٍ من الأسباب القانونية

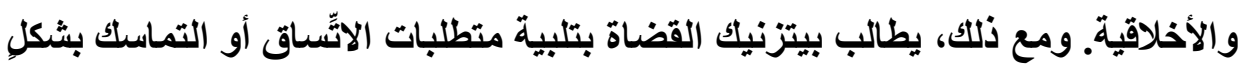
أكثرَ صرامة من تلك التي يفرضها ماكورميك. رغم ذلك، وبـالنظر إلى اعتمـاد المرحلة

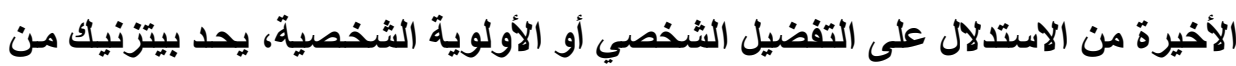

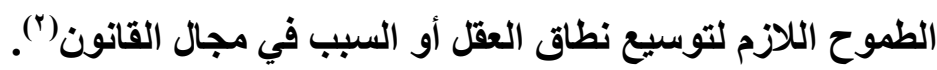

\section{(ז) التهماسك بوصفه نزاهة أو كمالاً:}

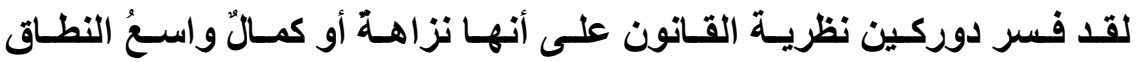

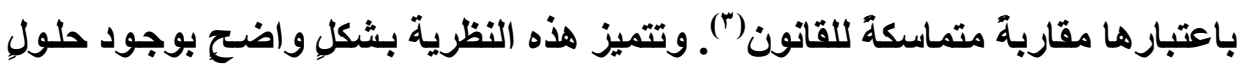

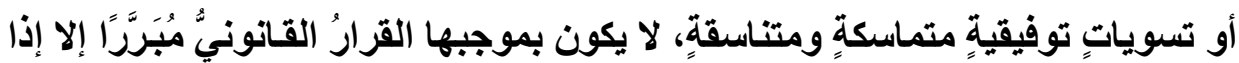

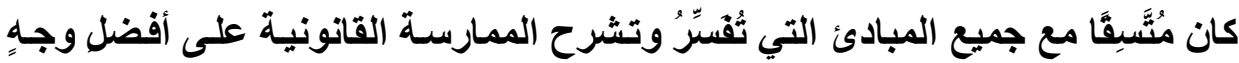

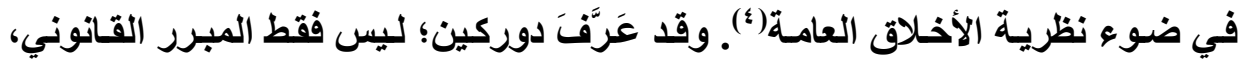

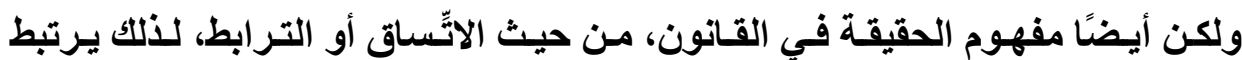

(1) Amalia AMAYA, op.cit.

(2) Ibid.

(3) Susan HURLEY, "Natural Reason, Personality and Polity", Oxford, Oxford University Press, 1999, p. 173.

(4) Andrei MARMOR, "Interpretation and Legal Theory", $2^{\text {ème }}$ éd:, Oxford, Hart Publishing, 2005, p. 129. 
نهجهمـا ارتباطسا وثيقًا بنظرية الحقيقة كتماسك. ووفقَا لهذه الأخيرة، يكون الاقتراح

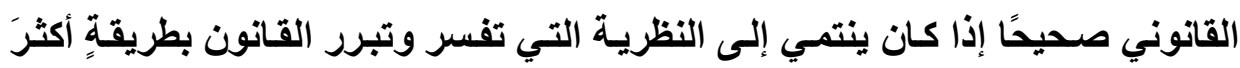

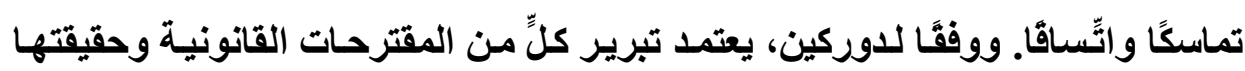
على تناسقهما مع مجموعةٍ من المعتقات التفسيرية التي تتتاسب مع القانون والأخلاق

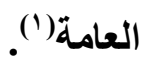

ووفقًا للنظريات السابقة، يبدو أن بيتزنيك وماكورميك قد أرادا الحدَّ من إعطاء

وظيفةٍ واسعةٍ للسبب أو العقل في القانون، في حين يبدو - دوركين- في المقابل، مُرَطا

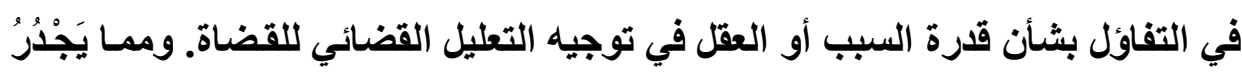

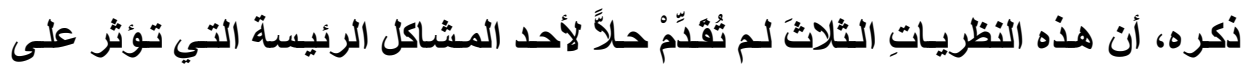

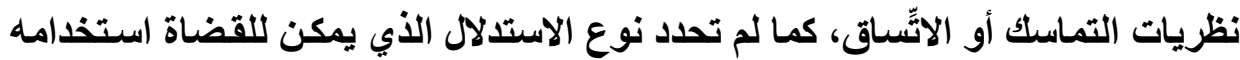

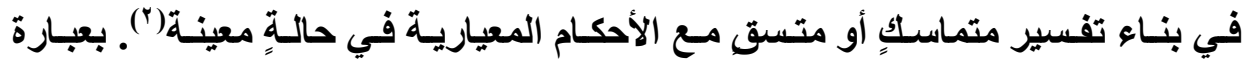

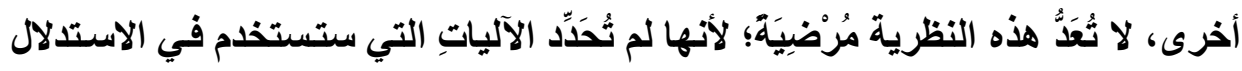

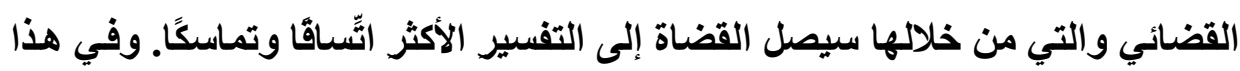

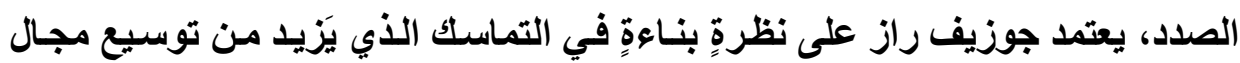
السبب أو العقل في تبرير القرارات أو الأحكام القضائية("). ب- الاتسّاق أو التهماسك البنَّاء (الخَلَّقَ): يرفض جوزيف راز نظريـات التماسك المعرفي. ووفقَا لـه، لا يمكن أن تعتمد

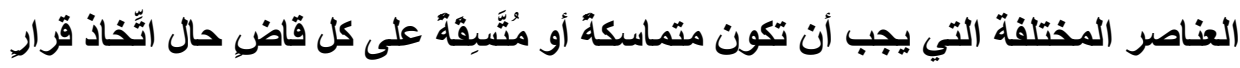

(1) Amalia AMAYA, op.cit.

(2) Ibid.

(3) Joseph RAZ, "The Relevance of Coherence", op.cit., p. 322. 
مـا. ويجب أن تكون هذه العناصرُ متمـاثلـة أو متطابقة بالنسبة لجميع القضاة، بحيث يمكن أن يؤديَ الاتِّساق المطبق عليهم إلى نظاجٍ قانونيٍٍ واحد، بغضِّ النظر عن عدد

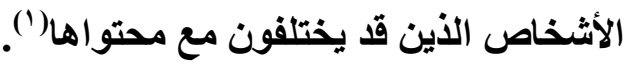

ويستتتج راز مـن هـذه الحجـة، أنـهـ يجب أن يـوفر اختبـار التماسـك العناصـر العقلانية التي تسمح للقضاة بتصور القانون كنظاج يدير سير الشئون في الدولة. وعلى الرغم من أن هذا الأخير لا يصف محتوى مثل هذا الاختبار، يبدو لنـا أن اقتراحه يكون وثيقَ الصِّةَة، دون ضرورةِ رفض النظريات المعرفيـة. وفي الواقع، يبدو أن اختبارَ الاتّّاق أو التماسك في المنطق القضائي يكون أساستًا من أجل التوصل إلى

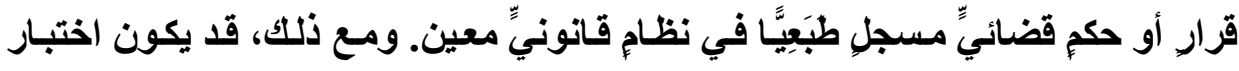

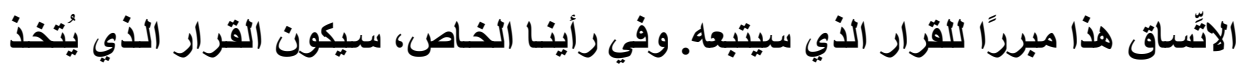

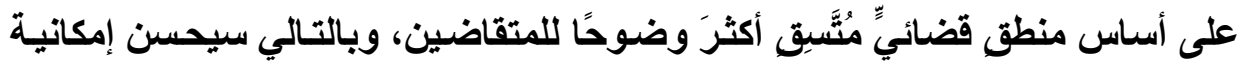

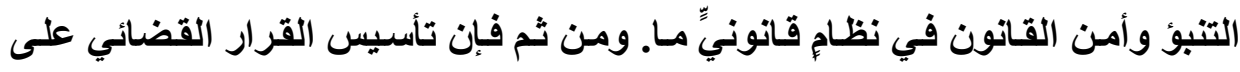
عمليةٍ عقلانيةٍ مدروسة، سوف يعطي وظيفة واسعة للسبب أو العقل في نظاجٍ قانونيٍ

\section{r- التـماسك أو الاتِّساق في المنطق القضائي:}

كما أشرنـا سابقَّا، يَكْمُنُ الدافع الرئيس للتماسك أو الاتِّساق في المنطق القضائي في توسـيع مجـال العقل أو السبب خـارج الحـدود التـي تفرضـها المقاربـات الرسـية للتفسير. ويبرر هذا الهدف في المقام الأول بأسبابِ تتعلق بالتنبؤ بـأمن القانون، حيث يجب على القضاة الأوروبيين تقدير القواعد التي ليس لها معنى موجودٌ مسبقَا، وهذا (1) Ibid. 
يأتي من النشاط التفسيري. من هنا، فبان المنطق الذي سوف يتبعه القاضسي سيكون محددًا ويستحق بعض التـأملات قبـل أن نعكف على دراسـة نمـوذج ملمسوس لمنطق قضائيٍٍ متماسكٍِ ومتسق.

\section{أ - المنطق القضائي المتماسك}

\section{(1) هفهوم المنطق القضائي.}

يقتضي إبرازُ مفهوم المنطق القضائي تحديدَه وتعريقه بشكلٍ واضح. وفي رأينا، يمكن أن يكون المنطق القضائي محددًا باعتبـاره نشاطَا عقليَّا، يعرض القاضسي مـن خلاله الحجة أو يُقيم نتيجة حجة معينة. ولا يتشكل السبب إلأ في نطاق هذا النشاط. وبالنسبة لبعض الفلاسفة، سيكون التدليل الطامح إلى اقتراح منطق قضائيٍٍ متماسكٍٍ

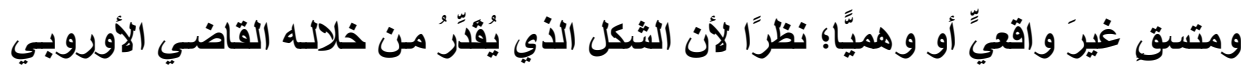

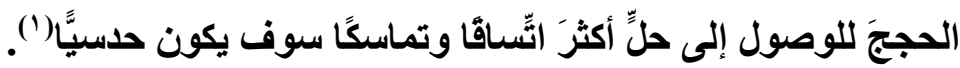
في مواجهة ذلك، نحن نتفق على أنه في مجال القانون، لا بدَّ أن تستند القرارات الصادرة من جانب القضاة الأوروبيين على عمليةٍ مدروسةٍ وعقلانيـة، ولا تكون نتيجة

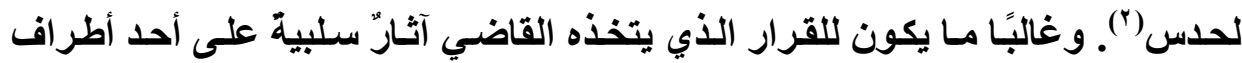

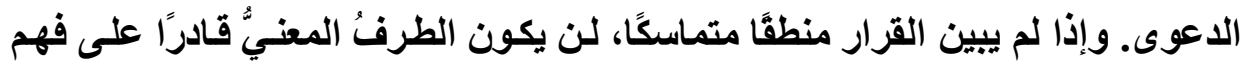

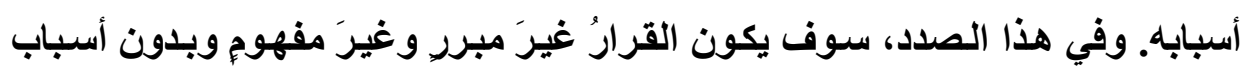
وجيهة، مما يقتضي رفضه.

(1) H. PUTNAM, "Reason, Truth and History", Cambridge, Cambridge University Press, 1985, p. 132- 133.

(2) A. AMAYA, "Ten Theses on Coherence and Law", op.cit., p. 7. 
وجدير بالذكر، أنـه يجب على القاضـي أن يضعَ، بنـاءُ على منطقـه، مبـادئَ أو

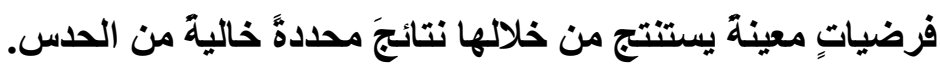

(ז) هوضوع المنطق القضائي:

يبدو لنا أن النهج الذي تقترحه الأستاذة (أماليا أمايا) يكون ذا أهميةٍ خاصةٍ فيما يتعلق بحصر استخدام التماسك أو الاتّّاق في المنطق أو الاستدلال القضائي (').ويستند

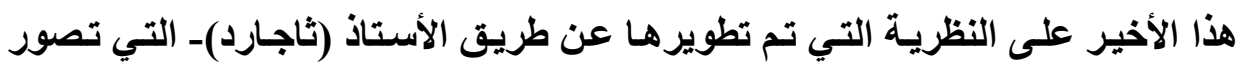

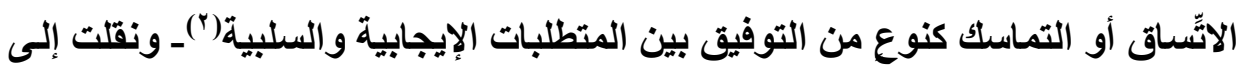
المجال القانوني لتبرير محتوى القرارات أو الأحكام القضائية. ويمكن أن نصف الاتِّساق أو التماسك - وفقَّا للأستاذة (أمايا)- بأنه استدلالّ نحو

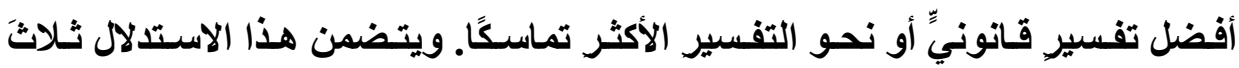
مراحل: (1) تحديد الأحكام أو القواعد المعياريـة ذات الصِّلة والافتراضـات التفسيرية المختلفة، (r) مراجعة وتنقية القرارات التي يمكن أن تتخذ بناءً على هذه الافتراضـات، (r) تقييم ومقارنـة هذه البدائل لاختيـار البديل الذي يمكن اعتبـاره مبررًا. وتسمح الخطوة الأولى، للقضاة الأوربيين، بتحديد مختلف الفرضيات المعقولة، وبالتالي تجاهل تلك التي تتناقض صراحة مع المبادئ العامة أو الأحكام القانونية. وفي المرحلة الثانية، يتم فحص كل الفرضيات المختلفة، حيثما كان ذلك مناسبًا، وفقَا لآلياتٍ محددة.

(1) A. AMAYA, "Inference to the Best Legal Explanation", in $\mathbf{H}$. KAPTEIN, A. BRAKKEN, "Legal Evidence and Proof: Statistics, Stories, Logic", Ashgate, Aldershot, 2018 p. 135; A. AMAYA, "Legal Justification by Optimal coherence", Ratio Juris, no. 6, Vol. 27, 2014, p. 304.

(2) Paul THAgARD, "Coherence in Thought and Action", Cambridge, MIT Press, 2000, p. 94. 
وأخيرًا، تسمح لنـا المرحلـة الثالثة بمقارنـة البـائل المختلفـة مـن أجل اختيـار البديل الذي يمكن اعتباره مبررًا('). ولكن من وجهة نظر ملموسـةٍة، السؤال الذي يدةق هو: ما العناصر التي يجب على القاضي أخذها في الحسبان في نهاية هذه المراحل من الاستدلال القضائي?

بثكلٍ عامٍّ، من الناحية النظرية، يعتقد المنظرون أن أساس العناصر التي ينبغي أخـذها فـي الحسبان فـي المنطـق القـضائي يـشمل بالارجـة الأولـى دســاتير الـدول

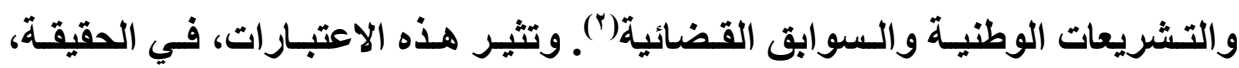
ملاحظتَيْن من جانبنا:

أولاً: وقبلَ كلّ شيء، تم تطوير هذا الأساس أو هذه القاعدة في النظريـات التي تؤسس على سياق دولةٍ مـا، وهذا الأخير هو الذي ينبفي إعـادة النظر فيه من منظور أوسعَ للوصول إلى هذه العناصر.

ثانيًا: تعتمد هذه النظريات على مفهوم قانونٍ خاصِّ بها، ولا يمكنتاـ مع ذلكــ التعرُّنُ له في سياق هذه الدراسة(").

وفي هذا الصدد، نعتقد أنسه ينبغي أن نضع معاييرَ موضوعية لتحديد عناصر القانون الذي يجب أخذه في الحسبان. وعلى الرغم من أن هذه المعايير يجب أن تكون موضعَ تحقيق شامل، تُشَكِّلُ هذه الأخيرة، وكذا القرارات الصادرة تطبيقَّا لها، أساسنًا

(1) A. AMAYA, "Ten theses on Coherence and Law", op.cit., p. 9.

(2) K. KRESS, "Coherence", in D. PATTARSON, "A Companion to Philosophy of law and legal Theory", 2ème éd., Chichester, WileyBlackwell, 2013, p. 521.

(3) N. MacCORMICK, "Coherence in Legal Justification", op.cit., p. 41. 
جوهريَّا للمنطق أو الاستدلال القضائي. وكما أعلن الأستاذ (راز)(')، يبدو من المهم أن نحصر القراراتِ والقواعدَ التي يجب مراعاتها في المجال القانوني المقصود، ومن ثم لا نعبأ بعموم القانون الموجود أو القائم في النظام القانوني المفروض أو المحدد. ويشير الاستدلال، على مستوى النظام القانوني، مشكلتَيْن أساسيتَيْن: أولاًا: أنه يميل إلى جعل القانون مثاليًّا أو أنه ينسب الكمال للقانون. ثانيًا: أن الاتّّساق مهمة صعبة، ومن ثم قد لا يمكن بلوغه عمليَّا، وذلك بـالنظر إلى

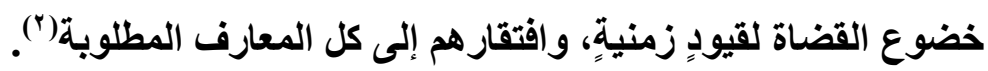
وفي استدلاله، يتعين على القاضي الأوروبي أن يبحثُ عن التماسك أو الاتِّساق داخل العناصر ذات الصيّة في مجال القـانون المعني. مـع الأخذ في الاعتبـار، أن تحديد هذا المجال، وكذا تحديد القواعد الواردة فيه، ليس بالمهمـة السهلة. ومن ثم، قد لا تتحقق إلا في نظاج قانونيٍٍ محدد. ويسمح التحقق أو التعريف بالنظام القانوني الذي باتي تنتمي إليه هذه القواعد بتحديد المجال المعني أو المقصود، ومن ثم توجيه منطق أو او أو استدلال القاضي نحو الوصول إلى قرار سيكون الأكثرَ تماسكًا أو تتاسقًا مع هذا المجال. بـ آليات الاستدلال القضائي المتشق أو المتماسك: يقوم المنطق أو الاستدلال القضائي المتماسك أو المتسق على مرحلتَّْن: أولاً،

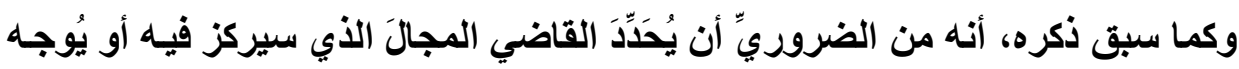
إليه منظقه أو استدلاله. وعلى الرغم من الصعوبات التي يثيرها هذا التحديد، ستساعد

(1) J. RAZ, "The Relevance of Coherence", op.cit., p. 310.

(2) B. BAUM Leven Book, "The Role of Coherence in Legal Reasoning", Law and Philosophy, no. 13, Vol. 13, 1994, p. 355- 374. 
هذه العمليـة في تحديد العناصر التي يتعين تقييمها في عمليـات الاستـلال اللاحقة. وبمجرد تحديد هذه العناصر، يمكن للقاضي الاتتقالُ إلى المرحلة الثانية؛ أي تطبيق

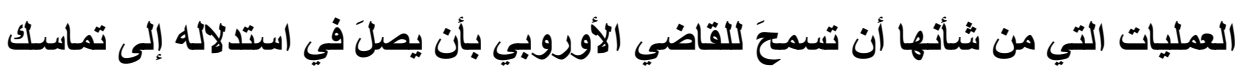
الاعتبارات التي تعزز بروز قراره والتي يمكن أن تكون مقبولة لدى المتقاضين ('). ويجب تطبيق العمليات الثلاث التي وضعتها الأستاذة (أمايـا)()، على مجموعةٍ من العناصر لجعلها متماسكة. وهي تشمل، على التوالي، الطرح، والإضـافة، وإعـادة التفسير. ويشمل الطرح استبعاد بعض فرضياتٍ أو عناصر معينـة إلى الحد الذي يجعل من الممكن تعزيز الآخرين. وهذا الإجراء يجعل من الممكن اختيار الفرضية التفسيرية التـي مسن شـأنها دعم الأحكـام القانونيـة ذات الصِّلة، والتـي تستبعد في الوقت نفسله السوابق القضائية غير الملائمة وغير المتناسقة. وتعني الإضـافة، إضـافة فرضيات أو عناصر جديدة تسمح على سبيل المثال بإثبات فرضيةٍ معينةٍة بـالرجوع إلى المبدأ العام الذي يطبق على كل مجـال مـن مجـالات القـانون المعنيـة، وإزالـة التعـارض المحتمـل وقوعه في نهايـة المطاف بين الفرضية المقترحة وبعض السوابق القضائية. وأخيرًا إعـادة التفسير، والتي ترمسي إلى تجنب فرضية أو عنصر معين واستبداله بـآخرين. وهكذا، يمكنتا إعادة تفسير حالة أو سـابقة قضائية غير مُتَّسقةٍة مـع بعض الفرضيات التفسيرية في ضوء معيارِ جدياٍ لجعلها أكثرَ تماسكًا أو أكثرَ اتِّساقًا.

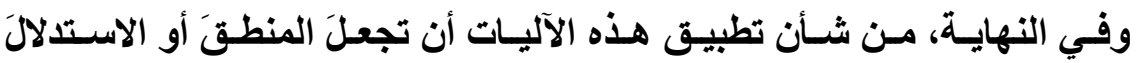
القضائيَّ متماسـكًا أو متسقًا، حيث يستجيب لمختلف القيـود والمتطلبـات الإيجابيـة والسلبية، ومن ثم يبرر للمتقاضين حجج القرار الذي سوف يصدره القاضي.

(1) A. AMAYA, "Ten Theses on Coherence and Law", op.cit., p. 9.

(2) Ibid., PP. 7- 10. 


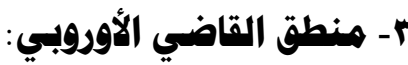

كما ذكرنا آنقا، يفهم اقتراحنا بشأن المنطق أو الاستدلال القضائي المتماسك في

الإطار الذي يُشَكَّلُ نظامًا قانونيَّا معينًا. ويلعب هذا الأخير، في الواقعَ، دورًا أساستًا، لا سيما في تحديد مجـال القانون الذي يجب أن تكون فيه العناصر المختلفة متماسكة، فضلاً عن هذه العناصر المختلفة ذاتها. ودون أن نَدَّعِيَ تقديمَ نظريـةٍ كاملـةٍ للأنظمـة القانونية، تأكد لاينا أن الإثارة إلى مفهوم النظام القانوني تكون ـ عادةً ـ كاثفة؛ لأن هذا الأخير غالبًا ما يستخدم، سواء من جاتب مؤسسات الاتِّحاد الأوروبي أو من جانب الدولة الأعضاء به، لفهم الظواهر القانونيـة المحيطة ووظيفتها في صدر كل منهاب('). وبالتـالي، فـإن مفهوم النظـام القـاتوني ليس مجرد أداة نظريـة، فقد وجد بالفعل في خطابات وأفكار مختلف الجهات الفاعلة القانونية، عندما أرادوا فهم العالم الاجتمـاعي والسياسي الذي يحيط بهم() ولكن، السؤال الأي يدق هو: هل يكفي أن يدعي كيانٌ ما،

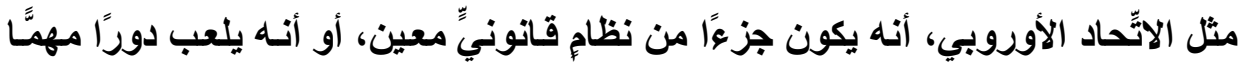
في تأسيس وجود مثثل هذا النظام؟ وستأتي الإجابة عن هذا التساؤل في سياق العناصر

\section{أ - النظام القانوني الاتِّمادي:}

منذ بايات البناء الأوروبي، أكدت محكمة عدل الاتِّاد الأوروبي في سلسلةٍ من

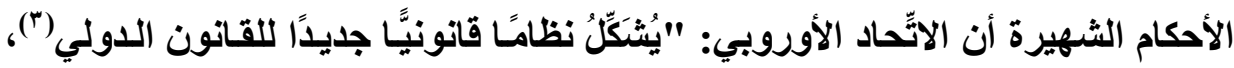

(1) J. DICKSON, "Towards a Theory of European Union Legal System", in J. DICKSON, P. ELEFTHERIADIS, "Philosophical Foundation of European Union Law", Oxford, Oxford University Press, 2008, p. 25.

(2) Ibid.

(3) Arrêt de la CJCE du 5 février 1963, NV Algemene Transport- en $=$ 
وأنه عبارة عن نظام قانوني حقيقي"('). علاوة على ذلتك، أنها قد استخدمت مفهوم النظام القـانوني لوصف الاتِّـاد الأوروبي والدول الأعضاء من خلال شرح وتفسير: "نقل الدول من نظامها القانوني الداخلي لصالح النظام القانوني للجماعة، للحقوق والالتزامـات بمـا يتفق مـع أحكـام المعاهدة"|("). غير أن المحكمـة أعلنـت مـؤخرًا أن:

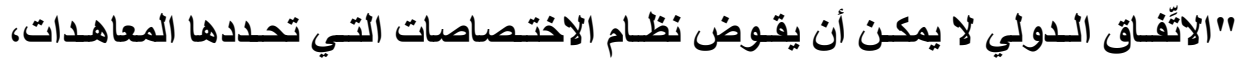

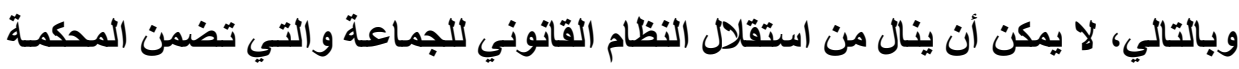
احترامهه"("). وأن: "رقابة المحكمة على صحة أيِّ فعل للجماعة فيما يتعلق بـالحقوق الأسساسية يجب أن تعتبر تعبيرًا في مجتمع القانون عن ضمانةٍ دستوريةٍ مستمدةٍ من

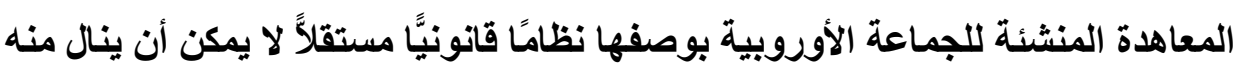

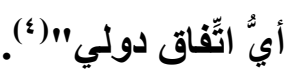

وفي سياق اجتهادها القضائي، شرعت محكمة عدل الاتِّحاد الأوروبي في تحويل

المصطحات من مفهوم Ordre Juridique إلى مفهوم Système Juridique.

Expeditie Onderneming van Gend \& Loos C/ Administration fiscale néerlandaise, aff. 26/62, Rec. 1963, p. 3, Para. 23.

(1) Arrêt de la CJCE du 15 Juillet 1964, Flamino Costa C/ ENEL, affaire 6/64, Rec. 1964, p. 1151, 1158 ; CJCE, arrêt du 19 novembre, 1991, Andrea Francovich, Danila Bonifaci et autres C/ République Italienne, C-6/90 et 9/90, Rec. 1991, p. I- 5357.

(2) Voir l'arrêt Flaminio Costa C/ENEL, p. 1160.

(3) Voir l'arrêt de la CJCE du 3 septembre 2008, Yassin Abdullah Kadi et Al Barakaat International Foundation C/Conseil de l'Union Européenne, affaire Jointes C-402/05 p et 415/ 05p, Rec. 2008, p. I- 6351, Para. 282.

(4) Voir l'arrêt Kadi, Para. 316. 


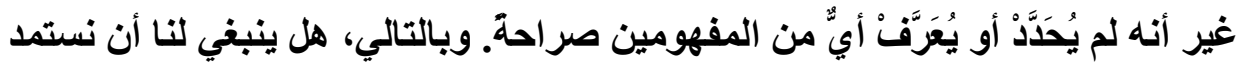
من هذا الغياب لتعريف محدد، مرادفا لمفهومي Ordre et système Juridique، أو أن هذا التحويل يعني تعديلاً للمفهوم الأساسي الذي أشارت إليه محكمة عدل الآّحاد الأوروبي؟ ييدو من الراجح أن هذا التحول يرجع أساسًا إلى الاختلافات اللغويـة التي

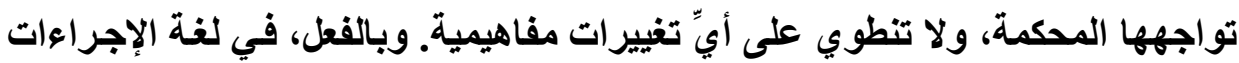

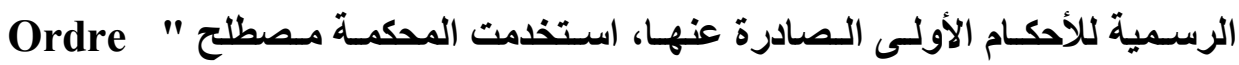
Juridique

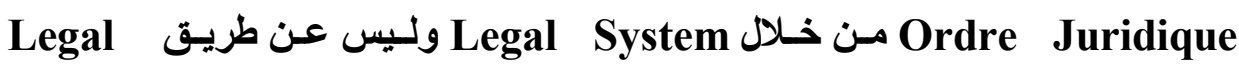
Order مع التاكيد على السوابق القضائية السابقة للمحكمة. ومن هنا، وفي هذه الأحكام، لم تكتفِ محكمة عدل الآّّاد الأوروبي بأن الآّّحساد الأوروبي يشكل بالتبادل un ordre ou un système Juridique، حيث تُستخدم

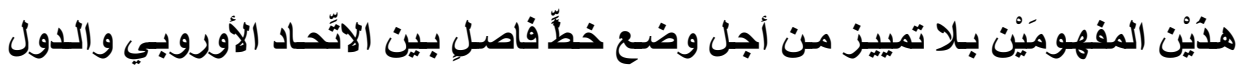

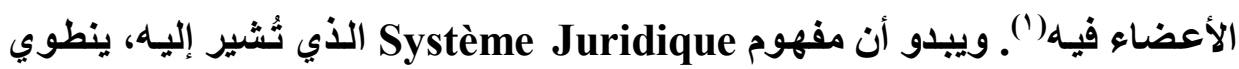

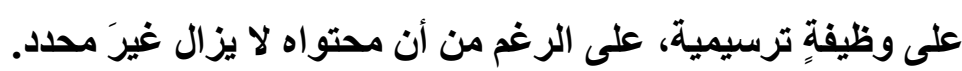

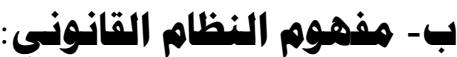

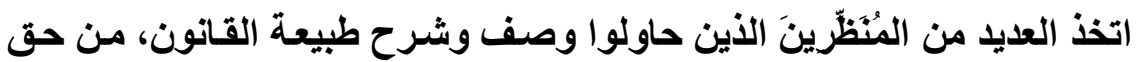
الدول ذات السيادة أساسًا للتفكير في تطور نظرياتهم الخاصة بطيعة القانون في سياق التقان

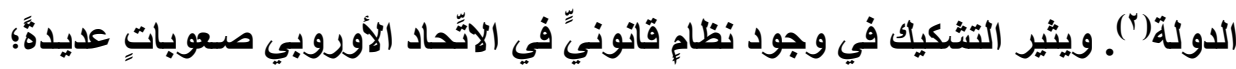

(1) J. DICKSON, "Towards \& Theory of European Union Legal System", op.cit., p. 27.

(2) H. KELSEN, "Pure Theory of Law", 2ème éd., University of California Press, 1976, p. 193- 207.

مجلت البحوث القانونيت والإقتصاديت ب بr 
نظرًا لأنه ليس بدولة. ويعتقد بعض المُنظّرِين، أنه من الضروريٍ أن نتخلى عن مفهوم

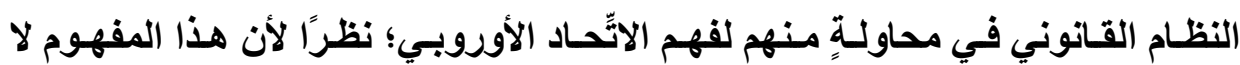
يحتوي على الموارد التوضيحية اللازمة لأن تعكس خصوصيات هذا النموذج القانوني

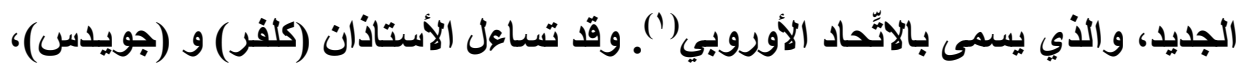
بالتالي: لماذا يتعين على المرء أن يترقبَ نظريةً متطورةًَ في نطاق الدولة ذاتِ الات السيادة،

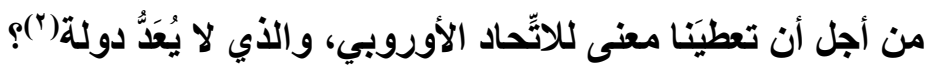

\section{(1) الخصائص المميزة للنظام القانوني:}

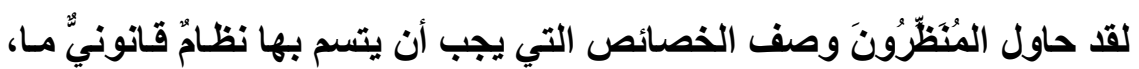

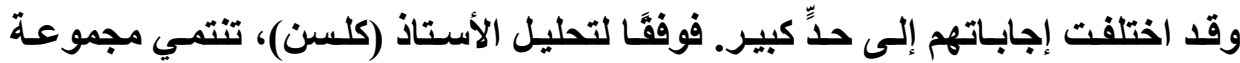

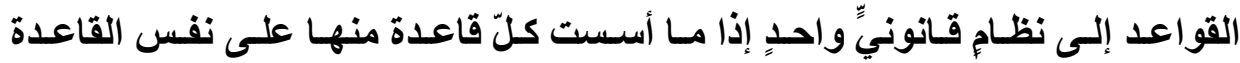
الأولية("). ومع ذلك، يعاني تحليل الأستاذ (كلسن) من العديد من نقاط الضعف، والتي تم تسليط الضوء عليها من جاتب بعض المُنظّرينَ في العقود الأخيرة. ومن بين نقاط

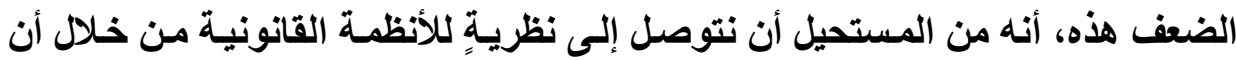

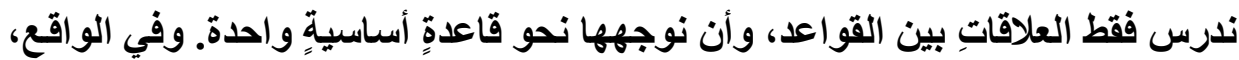
ينبخي أن نأخذ في الحسبان العواملَ الأخرى للواقع؛ مثل: موقف المؤسسات الخلاقة أو

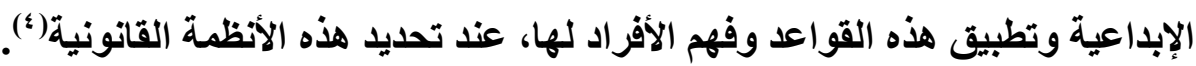

(1) K. CULVER, M. GUIDICE, "Legality's Borders: An Essays in General Jurisprudence", New York, Oxford University Press, 2010, P. xvi.

(2) K. CULVER et M. GUIDICE, "Not a system but an Order: An interinstitutional View of the European Union Law", op.cit., p. 55.

(3) H. KELSEN, "Pure Theory of law", op.cit., p. 193.

(4) J. FINNIS, "Revolutions and Continuity of Law: Oxford Essays in Jurisprudence", Oxford, Clarendon Press, 1980, p. 205. 
وقد لوحظ تباين الخصائص التي ينبغي أن يكتسيَ بها نظامٌ قانونيٌ مسا وفقًا

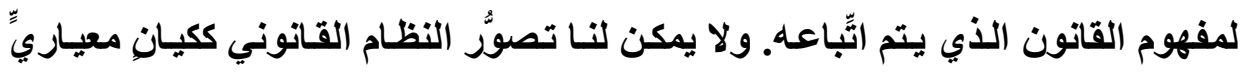
مكتفِ ذاتيًا، حيث لا يمكن أن نتعرض أو نتصدى لِهُويَّة هذا النظام بعيدًا عن التنظيمـات

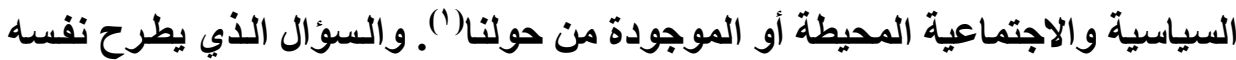

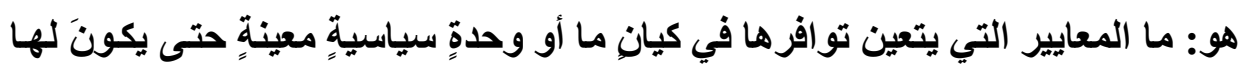

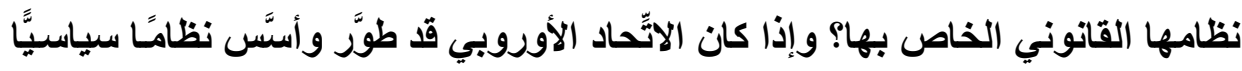

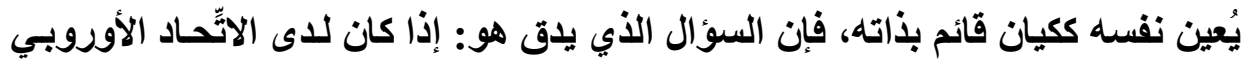

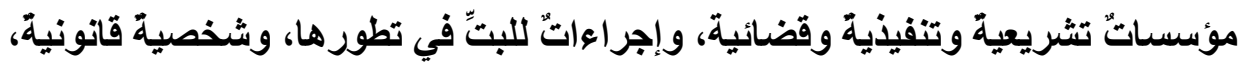

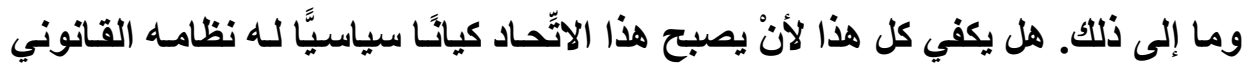

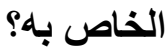

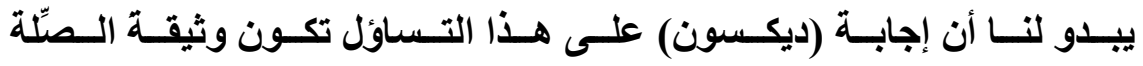

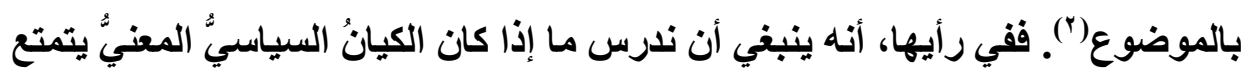

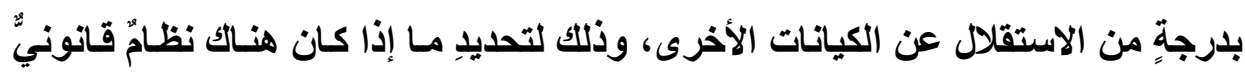

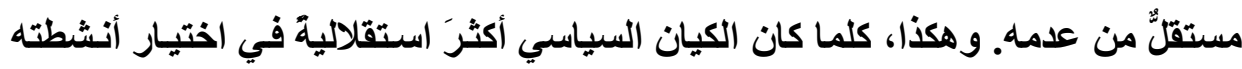

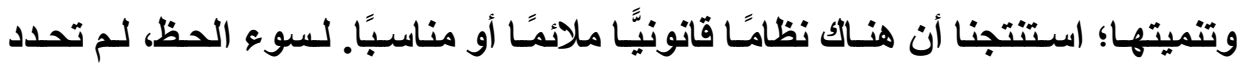

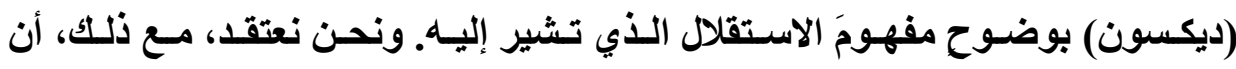

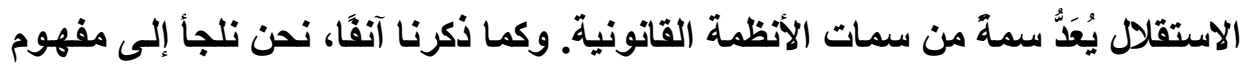

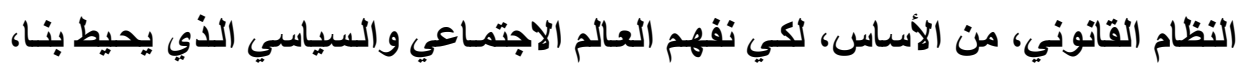

(1) J. DICKSON, "Towards a Theory of European Union Legal System", op.cit., p. 54.

(2) Ibid. 
وعلى الأخص موقفنا في هذا العـالم('). وبالتـالي، تساعدنا الإشـارة إلى مفهوم النظام القانوني في وضع خطوطٍ فاصلةٍ تُميز الأشكال القانونية الأخرى التي تحيط بنا، وتسلط الضوء على استقلال كلِّ نظام قانونيٍٍ مقارنة بالأشكال القانونية الأخرى.

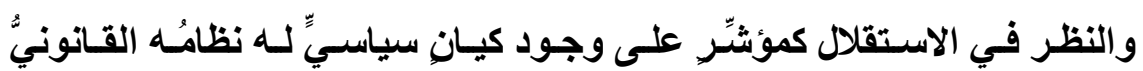

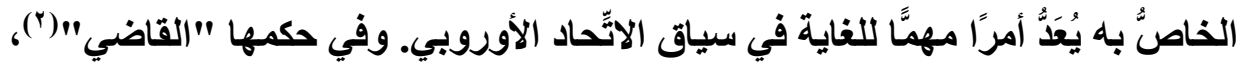

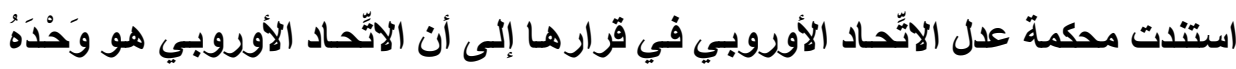
الذي يقرر صلاحية نظامه القانوني، بلدعوى أن هذا الاتِّـاد لايـه نظامٌ قانونيٌّ مستقلّ. ومن ثم، تثوافر فيه السِّماتُ الرئيسةُ للنظام القانوني، كما هو الحال بالنسبة للاول ذات

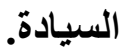

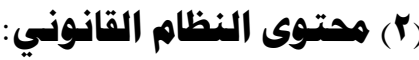

الواقع أن الممارسة الرَّاميَّة إلى تعيين نوع القواعد الناتجة بواسطة مؤسسات

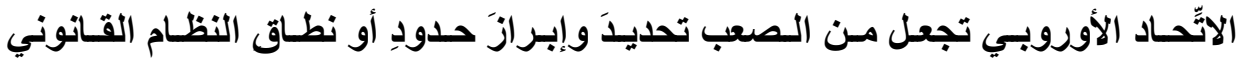

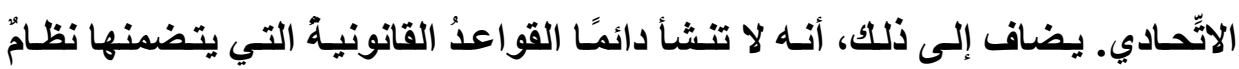
قانونيٌٌ معينٌ عن طريق الأجهزة التثريعية.

(1) Ibid.

(2) L'arrêt de la CJCE du 3septembre 2008, Yassin Kadi et Al Barakaat International Foundation C/Conseil de l'Union européenne, aff. Jointes C-402/05P et 415/ 05 P, Rec. 2008, p. I- 6351, Para. 282. 
وفيما يتعلق بالاتّحساد الأوروبي، فإنها يُعترف؛ ليس فقط بالقو اعد التي أنشأها

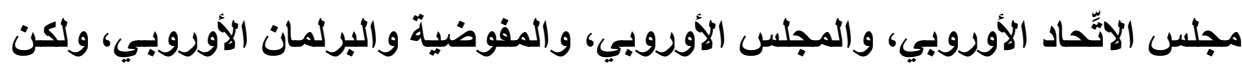

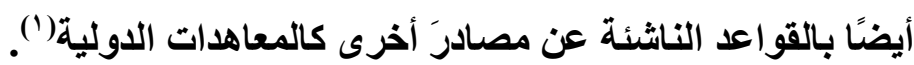

وجلير" بالذكر، أنه يجب علينـا ألا نركز على الكيانات الخالقة للقانون بقدر مـا

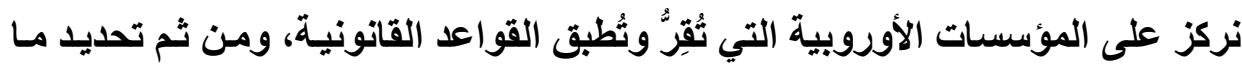

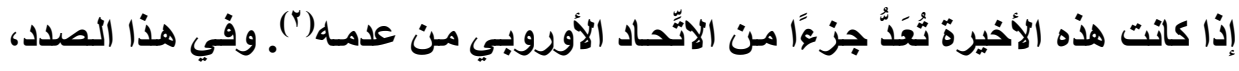

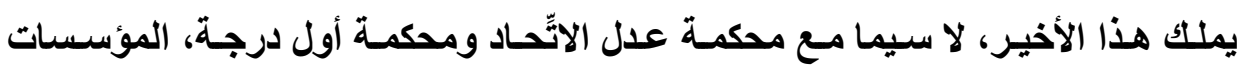

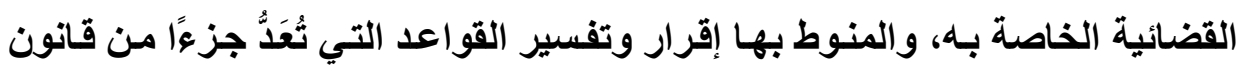
الآّّاد الأوروبي. ومع ذلك، ليست السلطات القضائية هي الوحيدة المنوط بها النها إنجاز هذه المهمة، حيث يلعب القضاهُ الوطنيون للادول الأعضاء في الآّّحاد الأوروبي دورًا

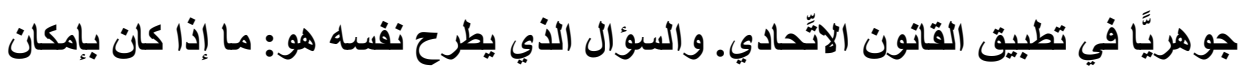

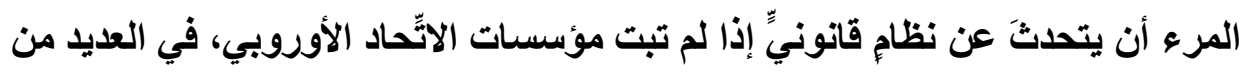

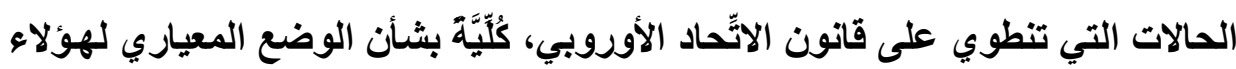

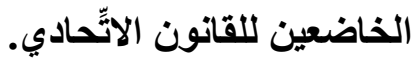

يثير هذا الموضوع، العديد من التساؤلات حول دور ووظيفة المحاكم الوطنية

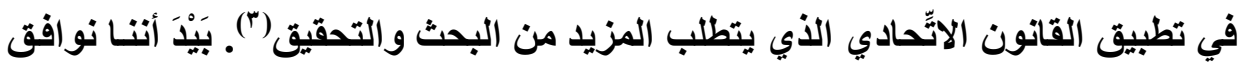
أنه عندما يشير موققّ ما مسألة قانونية يتعين أن تكون مقررةً بواسطة محكمةِ وطنية،

(1) L'arrêt de la CJCE du 30 avril 1974, R. et v. Haegeman c. Belgique, aff. 181/73, Rec. 1974, p. 449.

(2) J. DICKSON, "Towards a Theory of European Union Legal System", op.cit., p. 42.

(3) Ibid. 
تعمل هذه الأخيرة، في نهاية المطاف، كمحمةٍ تابعةٍة للاتِّحاد الأوروبي، ومن ثم يمكن اعتبارها جزعًا من النظام القانوني للاتِّحاد (').

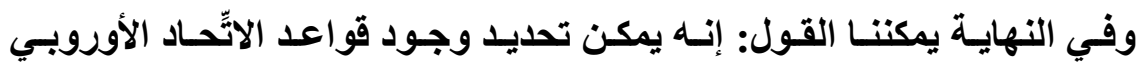
وتحديـ محتواهـا مـن خـلال مبدأ إسـناد الاختصاصات(؟). يضاف إلى ذلك، أنـه يمكن التمسك بصلاحية محكمة عدل الاتِّـاد الأوروبي في مراجعة هذه القواعد(")، وتصديد آثار ها والتمييز بين الأنظمة القانونية للاول والاتِّحاد الأوروبي (؛).

(1) N. BARBER, "Legal Pluralism and the European Union", European Law Journal, no. 5, Vol. 14, 2008, p. 306.

(2) L'art. 5 al. 1 et 2 TUE.

(3) L'art. 263 TFUE.

(4) J. DICKSON, op.cit., p. 45. 


\section{المبحث الثالث \\ القيود الأوروبية بخصوص القاضي السويسري}

شهدت العلاقات الاقتصادية بين الاتِّـاد الأوروبي وسويسرا نموًَا ملحوظـا منذ

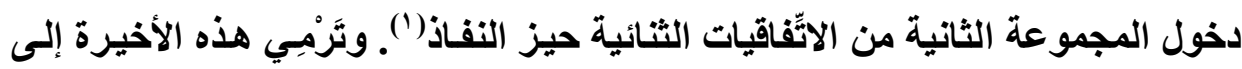
التغلُبِ على العيوب الناجمـة عن المشـاركة الجزئيـة لسويسر ا في السوق الاخليـة للاتِّحاد الأوروبي. وغالبًا ما يتمُ تحليل اختيار المسار الثنائي من جانب الفقهـه القانوني ومحلي العلوم السياسية كتعبير عن إرادة الشعب السويسري بعدم الدخول في طريق الانضمام أو المشاركة. وبالإضـافة إلى المزايـا التي ستحصل عليها مؤسسيَّا، لاسيما المشاركة في عمليـة صنع القرار، سيترتب على الانضمام، أيضًا، الخضوعُ للنظـام القضائي الاتِّحادي. فضلاً عن الامتياز التفسيري الذي سيؤول إلى محكمـة عدل الاتِّحـاد

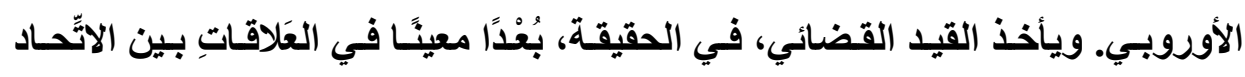
الأوروبـي وسويسسرا بسـبب الطبيعـة الثابتـة أو السـاكنة للاتِّفاقيـات التـي لا تـستبعد تفسيرها الديناميكي أو الفعال.

ومـع ذلك، فإنـه لا يكفي عدم الانتمـاء أو عدم الانتسـاب إلى الاتِّــاد الأوروبي

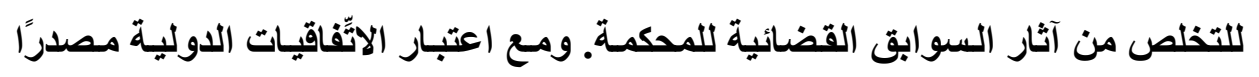

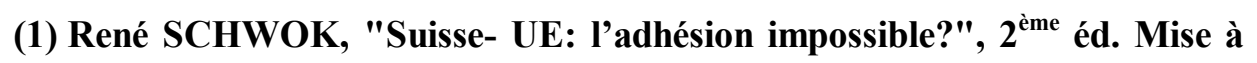
Jour, Lausanne, Press Polytechniques et Universitaire Romandes, 2010. 
لشرعية الاتِّحاد (')، قبلتنْ محكمة عدل الاتِّحاد الأوروبي منذ فترةٍ طويلةٍة تفسيرَها، مـع مراعاة أهداف الاتِّفاق(") ولذلك فمن المحتمل فهم هذا الواقع من خـلال أن المـوقعين

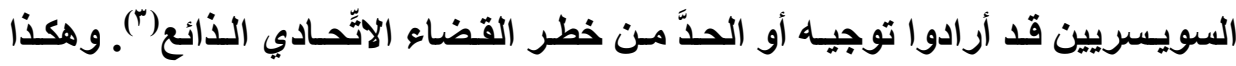
يتضمن الاتِّقاق المتعلق بحرية تنقل الأشخاص حكمًا يحدد العلاقة بين قرارات المحكمة الاتِّحاديـة الفيلرالية وأحكام القضاء الأوروبي السـابقة على توقيعه عندما يُحتمل أن

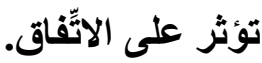

ومع ذلك، لم يُشْن هذا الحكمُ الدفاعيٌّ القاضسيَ السويسريَّ عن استخدام أسـاليب

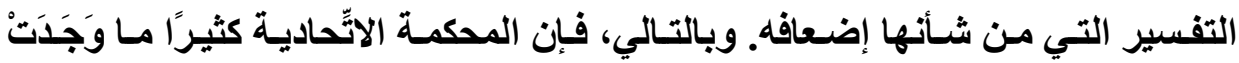
نفسها مرخصًا لها، مؤيدةً تفسيرًا مقتبسًا من طرق محكمة عدل الاتِّاد الأوروبي، بـأن

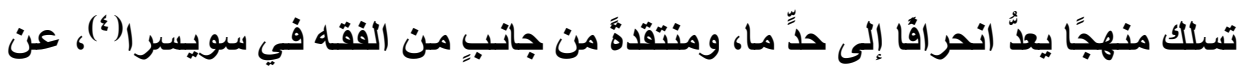
الاتِّفاقيات المذكورة. وفي الواقع، إذا وضعنا جانبًا الاتِّفاق المتعلق بالنقل الجوي، يتميز

(1) CJCE, 30 avril 1974, Haegeman, aff. 181/73, Rec. 1974, p. 449, pt 5.

(2) La Jurisprudence de la Cour s'est développée dans le champ des accords d'association c'est- à- dire des conventions à la portée Transitoire, dans l'attente d'une adhésion Ultérieure.

(3) Caroline EGGLI, "Entre Cohérence et efficacité: la Suisse dans les négociations bilatérales avec l'Union Européenne", Suisse Political Science Review, no. 4, Vol. 10, 2004, p. 5.

(4) A. EPINEY, "How Does European Union Law Influence Suisse Law and Policies?", in S. NAHRATH, F. VARONE, "Rediscovering Public Law and Public Administration in Comparative policy Analysis: a Tribute to Peter Knoepfel", Berne, 2009, p. 179; M. RANDALL, "The Europeanization of Fundamental Rights Protection in Switzerland: Two Steps Forward, One Step Back", in H. SNIJDERS, "Content and Meaning of National Law in The Context of Transnational Law", Munich, 2009, p. 53. 


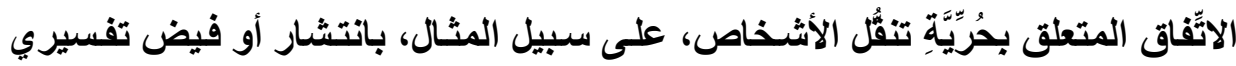
يميل إلى جعله أقربَ إلى التطور الإبداعي المميز لقضاء محكمة عدل الاتِّحاد الأوروبي. وجديرٌ بالذكر، أن القوة الملزمة التي تميز أيَّ اتِّفاقية تغيب عن الحوار أو تبادل

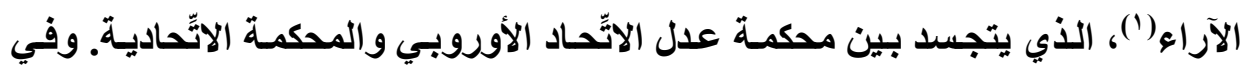
الواقع، وعلى أيـة حسال، نلاحظ شكلاً من أشكال احترام القاضسي السويسري للقاضسي (r) (الاتِّحادي

\section{ا - نهص الطريقة أو المذهج:}

أدى التفسير المحلي للقيود الضمنية من جانب القاضسي الأوروبي إلى تحرير المحكمة الاتِّحادية السويسرية لنفسها من المتطلبـات الصارمة للمـادة (7 1 ) من اتِّفاق حريـة تنقل الأشخاص، والسماح لنفسها بـأن تجلب؛ ليس فقط أسـاليب، ولكن أيضًا مفاهيم من قانون الاتِّحاد الأوروبي. أ - همكمة عدل عليا في هملكتها:

منذ البداية، حددت محكمة عدل الاتِّحاد الأوروبي نظامَ تفسير ثنائيِّ أو متفرع ثنائًَا بين أحكام معاهدات السوق الداخلية والاتِّفاقيات الدوليـة التي ترمي إلى إنشاء

(1) C. BAUDENBACHER, "Swiss Economic Law Facing the Challenges of International and European Law", Revue de droit Suisse, Vol. II, 2012, p. 419; M. RANDALL, "Le dialogue entre le Juge Suisse et le Juge européen", in F. BELLANGER, J. WERRA, "Genève au confluent du droit interne et du droit international" Mélanges offerts par la Faculté de droit de l'Université de Genève à la Société Suisse des Juristes à l'occasion du Congrès 2012, Genève, 2012, p. 19- 59.

(2) A. GARAPON, J. ALlARD, F. GROS, "Les Vertus du Juge", Dalloz, 2008, p. 95. 
أنظمةٍ مماثلة. فقد وضعت في عام ب 191 الخطوات الأولى من اجتهاداتها القضائية

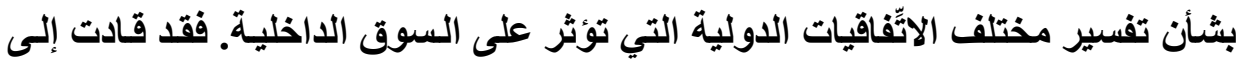

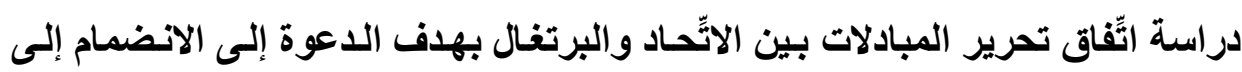

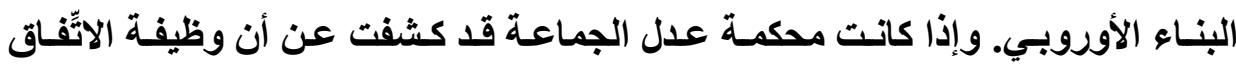

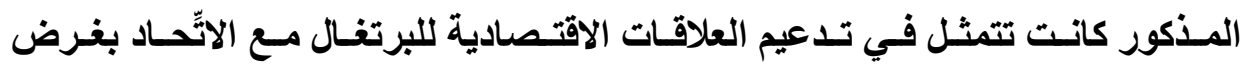

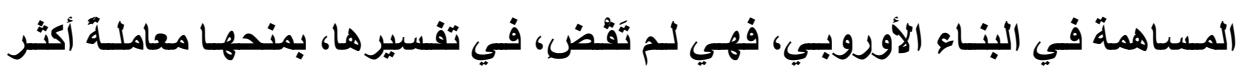
تفضيلاً.

واستنادًا إلى القواعد التقليدية لتفسير المعاهدات الدولية كتلك المستمدة من

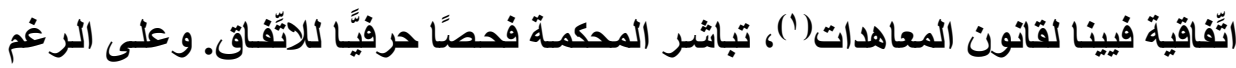

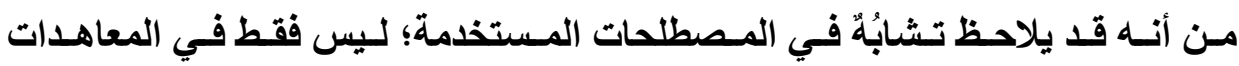

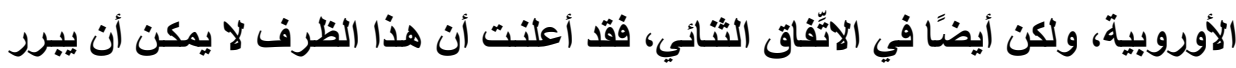

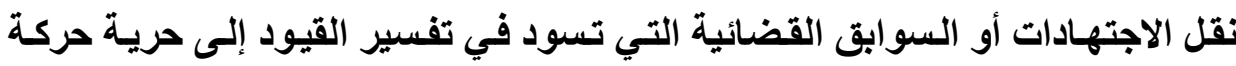

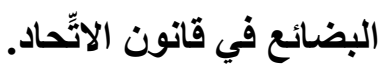

ومع حكم (بوليدور) (†)، وضعت محكمة عدل الاتَّاد للمرة الأولى مبدأ لا يمكن

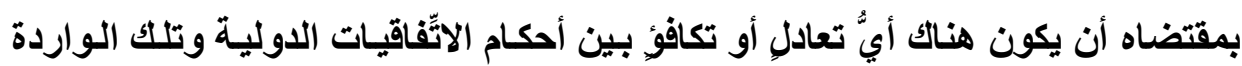
في معاهدات الآتّاد؛ وذلك لعدم وجود أهدافٍ مشتركةٍ بين النظامين. وأعلنت المحكمة

(1) بخصوص تفسير المعاهدات الدولية،، راجع بصفةٍ عامـة: أ.د/ علي صـادق أبو أبو هيف، "القانون

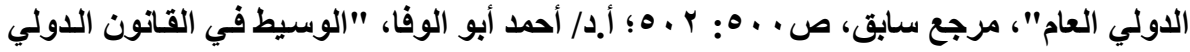

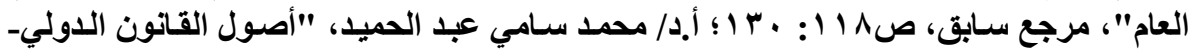

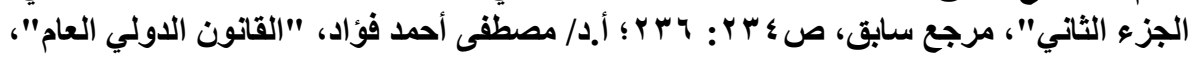

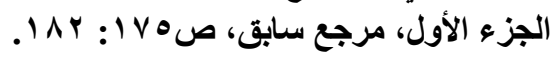

(2) CJCE, 9 février 1982, Polydore et RSO Records, aff. 270/80, Rec. 1982, p. 331 . 
ذاتها أيضًا، أنه لن يفضيَ تثابُهُ المصطلحات إلى تفسير متعادلٍ أو متساو؛ وذلك لأن الدراسـة يجب أن تأخذ في الاعتبـار أيضًا الاعتبـاراتِ السياسية التـي تتصدر اعتمـاد المعاهدات الأوروبية، والتي لا تلخل، بحكم الواقع، في الاتِّاقيات الدولية. وفي الواقـع، ومـن وجهة نظر المحكمة، يجب أن تؤخذ في الاعتبـار أهداف

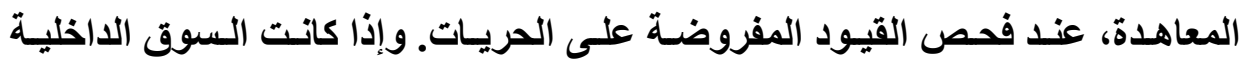
ترفض فرضَ قيودٍ معينة، فقد تكون هذه الأخيرة مقبولـة تمامًا في سياق اتِّفاق ثـائيٍٍ مثُل الاتِّفاق قيد الاراسة.

ولم تخرج محكمة عدل الاتِّحاد عن هذه الطريقة عندما تصدت لتفسير اتِّاقية الضمان الاجتماعي بين سويسرا وإيطاليا(') فمقدمة الطالب (الطالبة)، وهي مواطنة

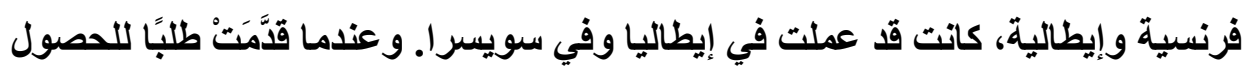
على معاش الشيخوخة في إيطاليا، طلبت من السلطات الإيطالية أن تأخذ في الاعتبار فتراتِ التأمين التي تَمَّتْ في سويسرا. رفضت هذه الأخيرة بدعوى أنها ليست من رعايا تلك الدولة. وعندما أحيل إليها الطلب، قضت محكمة عدل الاتِّحاد بأن هذا الرفضَ يكون مخالقًا للمادة (r Y ) من المعاهدة المنشئة للجماعة الأوروبية. وقضت أيضًا بـأن الدول

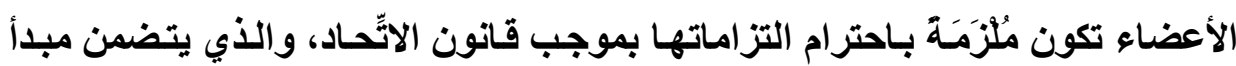
المساواة في المعاملة، عندما تنفذ الاتِّاقيات الدولية. يبـدو أن نهـج القاضــي الأوروبـي يرمسي إلـى احتـرام صــلاحيات أو سـلطات المترجمين أو المفسرين الحقيقيين في النظام القانوني للاول الغير مـع التأكيد على إنى دوره كحارس على تكامل نظامه القـانوني. وتُعزز المحكمة نهجها عندما يتعين عليها

(1) CJCE, 15 Janvier 2002, Elide Gottardo Contre Istituto nazionale della previdenza sociale (INPS), aff. 55/00, Rec. 2002, p. I-413. 


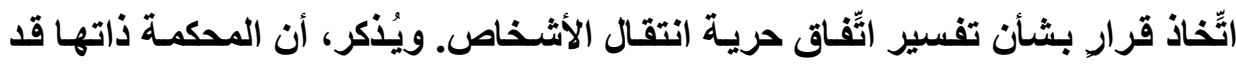

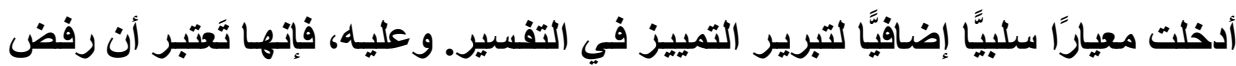

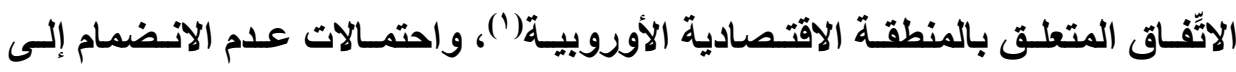

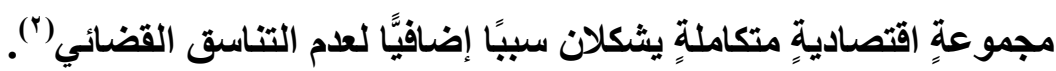

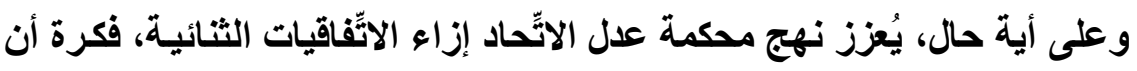

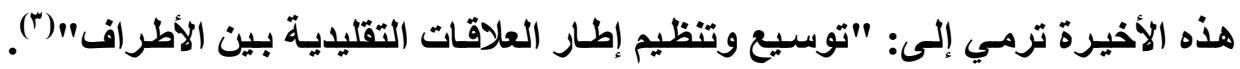

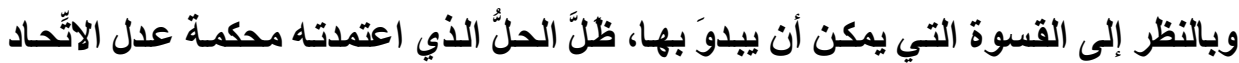

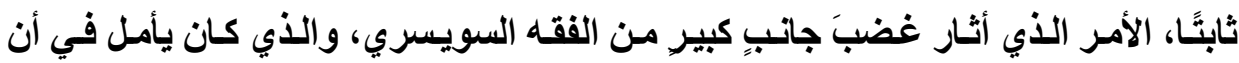

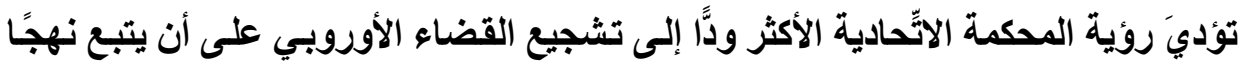
أكثرَ انفتاحًا إزاء النظام القانوني السويسري.

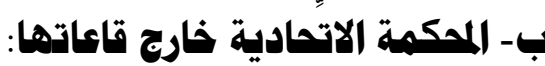

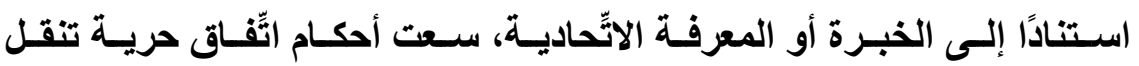

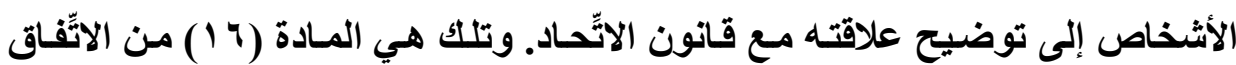
المذكور، والتي أسست قاعدة التنسيق التي توجه المحاكم السويسرية في تفسير اتِّقاق

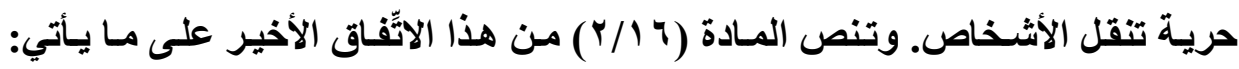

(1) JO 1994, L1, p. 3.

(2) CJUE, 12 novembre 2009, Grimme, C-351/08, Rec. 2009, P. I- 10777 ; CJUE, 11 février 2010, Fokus Invest, C-541/08, Rec. 2010, p. I- 1025 ; CJUE, 15 Juillet 2010, Hengartner et Gasser, C- 70/09, Rec. 2010, P. I7229.

(3) C. KADDOUS, "L'influence du droit communautaire dans la Jurisprudence du Tribunal fédéral Suisse", in le droit à la mesure de l'homme. Mélanges en l'honneur de Philippe Léger, 2013, p. 407. 
"بقدر مـا ينطوي تطبيق هذا الاتَّفاق على مفاهيم قانون الاتّّاد، تؤخذ في الحسبان

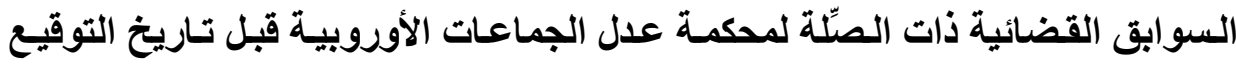

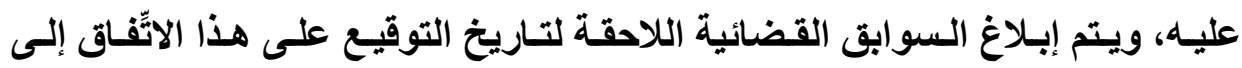
سويسر ا. وبغية ضمان حسن سير الآتّفاق، ويناءً على طلب أحد الأطر افت المتعاقدة،

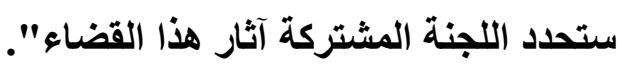

ومن الناحيـة النظريـة، وفي ضوء هذا النص، لا يمكن للمحكمة الآتّاديـة أن تأخذ في الحسبان السوابق القضائية اللاحقة لمحكمة العدل. علاوةُ على ذلك، لا يَتَبر

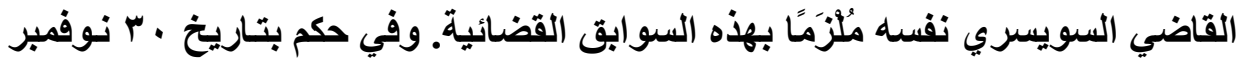

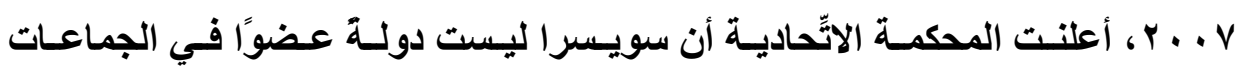

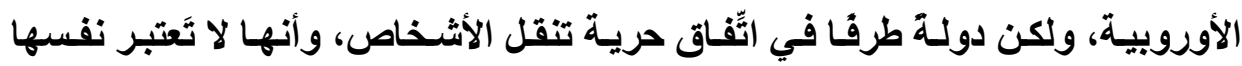

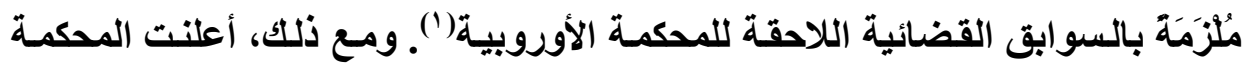

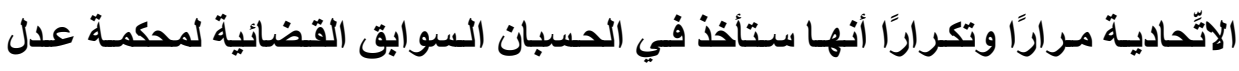

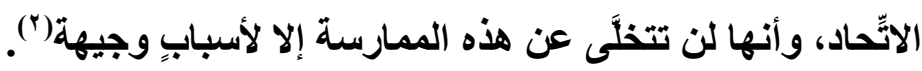
وعلى الرغم من هذا القياس الدائر، أفصحت المحكمة الاتِّادية، في سلسلةٍ من

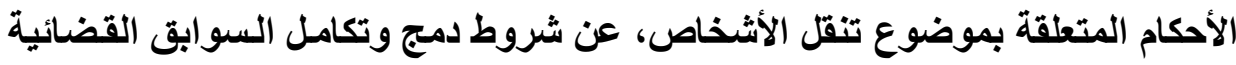

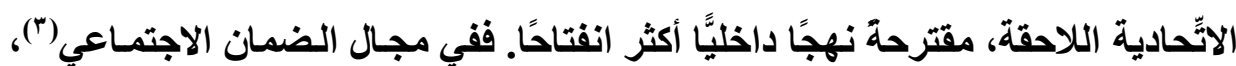

(1) ATF 134 II 10.

(2) ATF 137 III 226, C.2.2.

(3) F. WERRO, "La Jurisprudence de la CJUE en matière de responsabilité du fait des produits et son impact sur l'application de l'article 208 al. 2 Co", in S. FUHRER, C. CHAPPUIS, "Droit de la Responsabilité Civile et des assurances", Berne, Stampfli, 2014, p. 471. 
تفرض الصفة الأوروبيـة نفسها أو هـي الأهــ؛ وذلك نظرًا لأن القاضـيَ السويسريَّ يستخدم مفاهيم قانون الاتّّاد مثل مبدأ الأثر النافع، ويستخدم أسـاليب التفسير الخاصـة

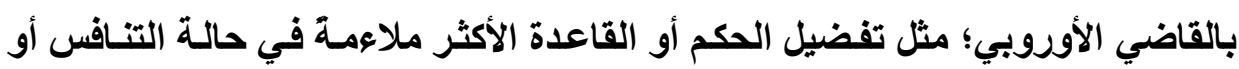
التنازع بين القواعد.

وجدير" بالذكر، أن المحكمة الاتِّحادية الفيدرالية، كانت قد أعلنت من جانبها، أن الأخذ بالسوابق القضائية اللاحقة يكون ملائمًا عندما يكون الحكم الجديد مجردَ توضيح لـكم سابق. وقد حددت أيضًا المحكمة الاتِّحادية مفهومها للتكيف أو التوافق الذاتي للقانون السويسري مع القانون الأوروبي. وأعلنت أنـه في الحـالات التي يُستمد فيها القانون الوطني السويسري جزئيَّا من القانون الأوروبي، يجب أن تؤخذ في الاعتبـار أسـاليبُ تفسير هذا القانون إلى الحدّ الذي يسمح بـه القانون الوطني. وعندما تسمح متطلبـات هذا الأخير بإعادة أخذ القانون الأوروبي، يجب على القاضي السويسري أن يأخذ في لئي الاعتبار السوابقَ القضائية اللاحقة لمحكمة عدل الاتِّحاد (').

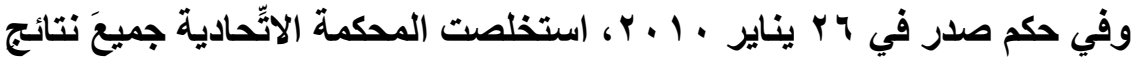

قرارها المؤسس برفض التفسير الوارد في رسـالة المجلس الاتِّحادي بشأن القوانين الضريبية التي تحدد اختلاف المعاملة بين العمـال المقيمين وغير المقيمين(؟). وقدَّرت المحكمـة ذاتهـا، أن إضـفاء الشرعية على هـذه المعاملـة غيـر العادلـة وذات الأصـل

(1) B. KAHIL-WOLFF, "L'application et l'interprétation de l'ALCP: Le cas de la sécurité Sociale", in Astrid EPINEY, B. METZ; R. MOSTERS, "L' Accord sur la libre circulation des Personnes SuisseUE", Zurich, Schulthess, 2013, p. 79 et s.

(2) ATF 136 II 241. 
السياسي، يتناقض مع السوابق القضائية لمحكمة عدل الآّّاد الأوروبي والتي تحظر

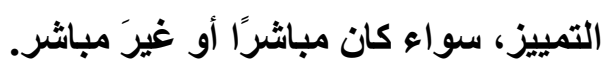

ولا ينبغي إهمالُ نطاق هذا الحكم؛ لأنها يوضح احترام المحكمة الاتِّادية إزاء المؤسسة الأوروبية. وفي الواقع، فإنه حتى في الحالات التي يكون فيها تطبيقُ اتَّاق

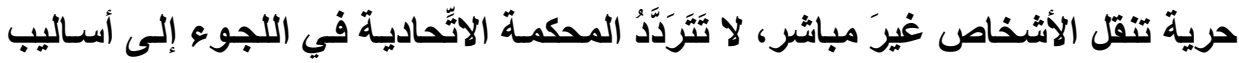
محكمة عدل الاتّحاد لتفسير الآثّاقات الثنائية التي أخذت على عاتقها توضيح أحكامها.

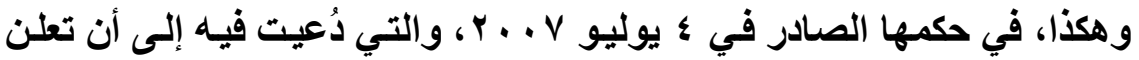

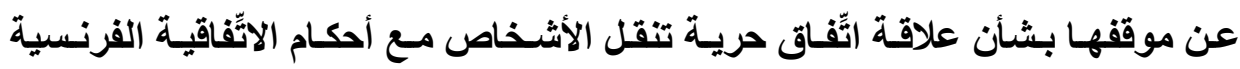
السويسرية بخصوص الضمان الاجتمـاعي، لم تتردد المحكمة الفيدرالية في تطبيق السوابق القضائية لمحكمة عدل الآّحاد في مسألة تنازع القواعد. وخلصت إلى أنسه من

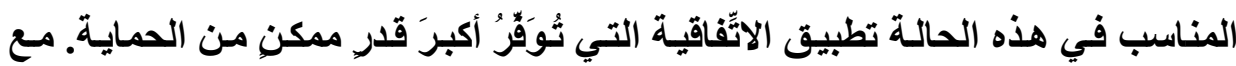
مراعاة الثروط التي وضعتها محكمة عدل الآّحاد الأوروبي في هذا الصداد.

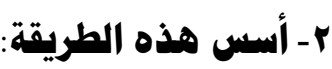

إذا اعتبر الفقـه(1) أن التفسير الموحد والمتجـانس لمفـاهيم القـانون الأوروبي

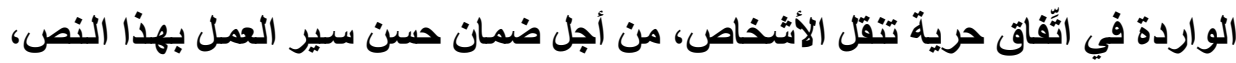

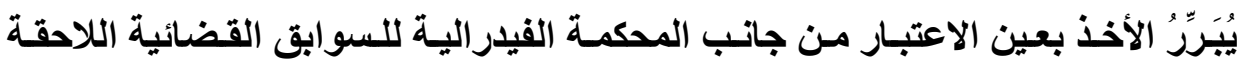
لمحكمة عدل الاتَّاد، فإنه لا يمنع من أن يثير هذا النهج سلسلة من التساؤلات، لا سيما من ناحية شرعيته. وعلى النقيض من القاضي الآّّادي الذي أسس استبعاد سويسرا

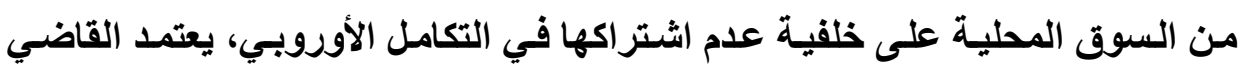

(1) C. KADDOUS, "L'influence du droit Communautaire dans la Jurisprudence du Tribunal fédéral Suisse", op.cit., p. 415. 


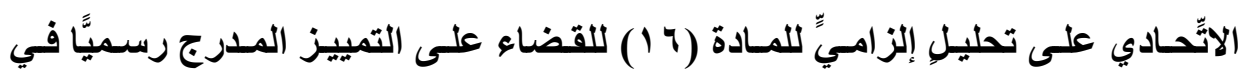

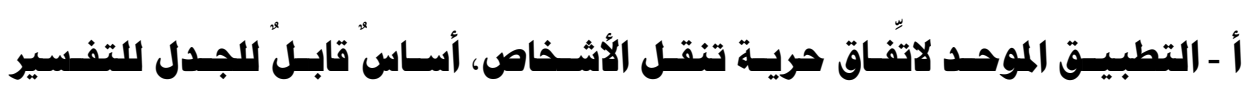

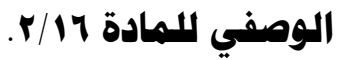

ينتج التوسع المكتسب الاتِّادي لتفسير اثِّفق حرية تنقل الأشخاص عن نهج أو مقاربة إلزامية للمادة (7 (1). وترى المحكمة الاتِّادية أن الفهم المتجانس لحرية التتقل تكون لله الأسبقية على التمبيز الذي يوجد في نظام السوق الداخلي من ناحيـة، وذلك

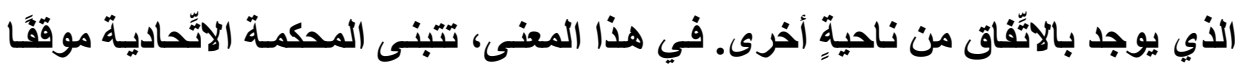

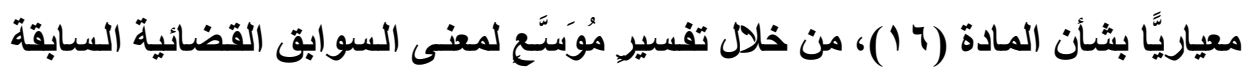
من جهة، وتحريم التمييز الذي ورد النص عليه بخصوص المعاملة التي يليق أن تمنح للسوابق القضائية اللاحقة من جهةٍ أخرى. وإذا مـا تمسكنا بـالالتزام بإعـادة أخذ السوابق القضائية السابقة، ينتج هدف مواعمة القانون السويسري مع القانون الأوروبي عن نهج غائيٍّ، أو يرتكز على شرط

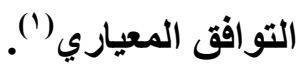
والسؤال الأي يثار الآن هو: هل ينبغي على المحاكم السويسرية أن نَّبَّعَ تفسير

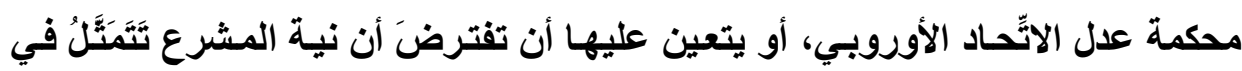
تقديم إجاباتٍ محليةٍ أو داخلية؟

(1) M. AMSTUTZ, "Le droit Privé Suisse face au droit Communautaire européen. Questions actuelles en droit de la Responsabilité civile et en droit des contrats", Berne, 2011, p. 105. 
تتوقف الإجابة عن هذا التساؤل، على التصور الذي يوجد لدى المرءع بشأن

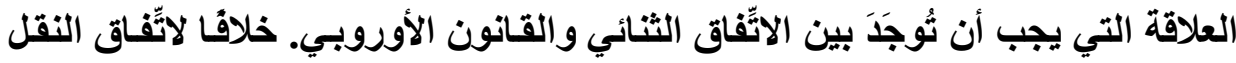
الجوي، الذي يتطلب تفسيرًا يتطابق مع السوابق القضائية للمكمة بشأن مفاهيم قانون الاتِّحاد المتضمنة في تطبيقه، يفرض اتِّاق حرية تنقل الأشخاص أن نأخذ في الحسبان السوابق القضائية للمحكمة(') وتنعكس حرية التفسير الممنوحة للقاضي السويسري في الموقف المنقسم للفقه

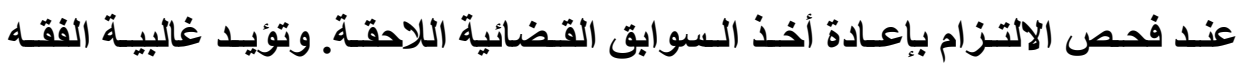
السويسري انحسار القيود الداخلية المفروضـة على القاضسي السويسري عندما يكون بصدد نظر قضيةٍة تتعلق بالثئون الأوروبية. ومن الواضح، أن النهجَ الاستدلاليَّ يؤدي

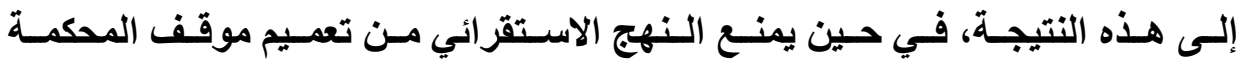

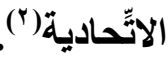

ب- هنهجيسة المككمسة الاتِّاديسة: أسساس أو تقيـيسد للمريسة التفسيرية للقاضـي السويسري؟

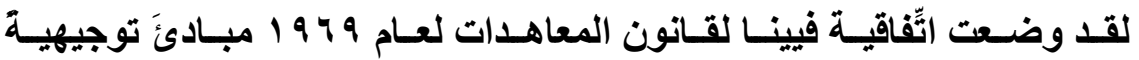

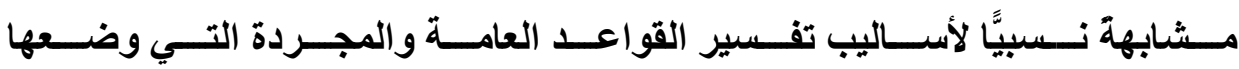
القضاء الفيدرالي (r).

(1) F. MAIANI, "La Saga-Metock, ou des inconvénients du pragmatisme helvétique dans la gestion des rapports entre droit européen, droit bilatéral et droit interne", Revue de droit suisse, Vol. I, 2011, p. 35.

(2) P. PICHONnAZ, "Le Centenaire du Code des obligations. Un Code Hors du Code", Revue de droit Suisse, Vol. II, 2011, p. 117.

(3) ATF 135 V 339, C.5.3. 
وإخلاصنًا لهذه المنهجيـة، استخدمت المحكمة الفيدراليـة تقنية جدلية نسبية،

وأعلنت أنها لم تمنح أفضلية أو امتيازًا في دراستها لأيّ عنصر من عناصر التفسير.

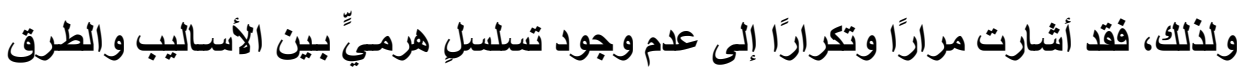

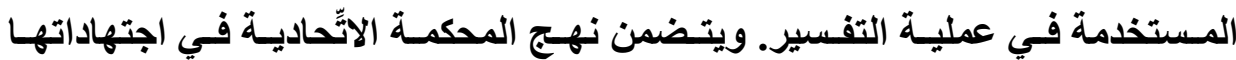

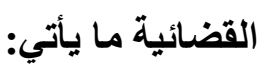

"يفسر القانون أولاً وقبلَ كلّ شيء وفقًا لرسالته (التفسير الحرفي أو النحوي)، وإذا كان النص القانوني غيرَ واضح تمامًَا، أو إذا كانت هنـالك عدةُ تفسيراتٍ ممكنة،

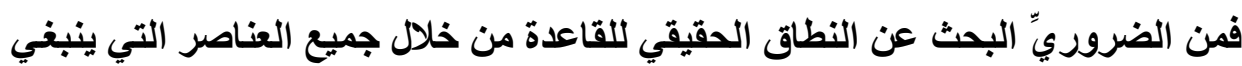

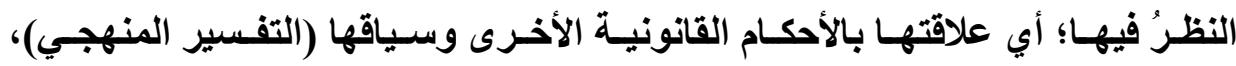

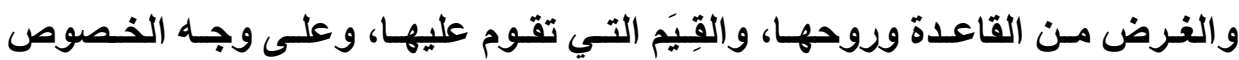
المصلحة التحَحْيَّة (التفسير الغائي). ويجب أن يقومَ التفسيرُ أيضًا على إرادة المشرع كما تبرز من الأعمال التحضيرية (التفسير الواقعي)"(') ويبدو أن المحكمة العليا قد أجْرَتْْ ما يُسَسَّى بوزن المصالح. ويمنع هذا الموقف،

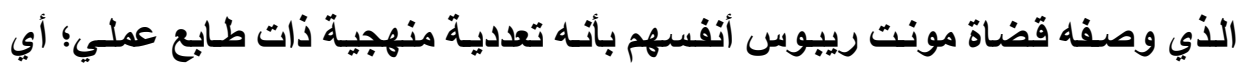
تفكير نظري عالمي بثأن تبرير تفضيل تفسير على آخر ("). وقد تعرضت المحكمة الفيدر الية نفسُها للعديد من الانتقادات المنهجية، حيثر يرى الأستاذ (فرانسوا أوست) (') أن التفسير قد يمتزج مـع حلِّ المتناقضات وسـدِّ

(1) ATF 135V 249 C.4.1 p. 252, ATF 135 II 78, C.2.2 p. 81.

(2) F. WERRO, "La Jurisprudence et le droit comparé. La Propagation des Concepts Juridiques", in Perméabilité des ordres Juridiques. Rapports Présentés à l'occasion du colloque anniversaire de l'institut suisse de droit comparé, Zurich, Schulthess, 1992.

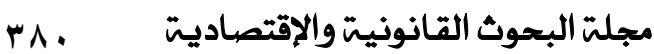


الثفرات، وإذا لزم الأمر، يمكن أن يقودَ البحثُ المزعوم عن النطاق الحقيقي لقاعدةٍ مـا،

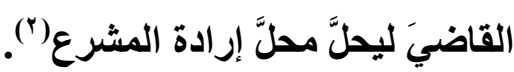
وجديرٌ بالذكر، أن الانتقاداتِ التي وُجِّهَتْْ للمحمة الفيدرالية كان لها صدُى لاى محكمة عدل الاتِّحاد الأوروبي، لا سيما عندما كاتت بصدد تطوير عقيدتها الاستورية. ففي حكمها (فان جيند ولوس)، استتدت محكمة العدل على مبدأ الأثر المباشر، وهي بصدد ممارسة نشاطها التفسيري، ممـا دفعها إلى تفضيل الأسلوب الغائي على هلى الأسلوب الحرفي. وعلى الرغم من أنها كانت قد توصلت إلى التخلص من التمسك بنص المادة r I السابقة من معاهدة الجماعة الاقتصادية الأوروبية، فإنها لم تفعل ذلك إلا بعد هل

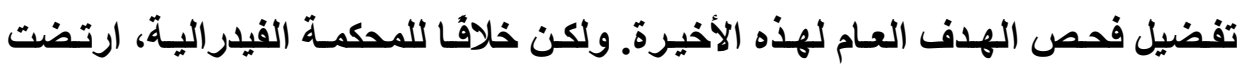

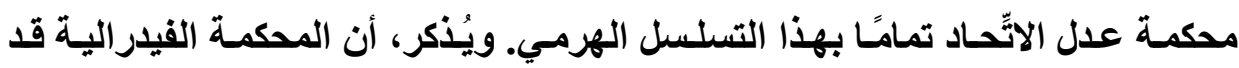

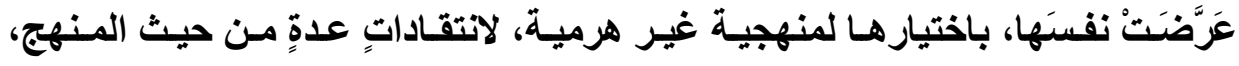
ولكنها كاتت تهرب من كلّ أوجه النقد التي ثُوَجَّهُ لها من ناحية مشروعية قرارها. ومع ذلك، تعرَّض النموذجُ التعدديٌّ للعديد من سهام النقد، وذلك عندما يستخدم لغرض تطبيق قاعدةٍ تتعلق بـالقيود الخارجيـة عبر الوطنيـة. فِإذا كـان صـحيحًا، أن النظرية الديمقراطية تتطلب من القاضي تطبيق القانون فقط، فمن الواضـح أن اللجوء إلى مبادئ المنتدى الأوروبي يكون محلًا للتساؤل. ومن خلال اعتبار نفسها ملتزمـة بالقضاء اللاحق على دخول اتِّفق حرية تنقل الأثـخاص حيز النفـاذ، تمـارس المحكمة

(1) F. OST, "Dire le droit, faire Justice", Bruxelles, Bruylant, 2014, p. 84.

(2) S. VOGENAUER, "Le pluralisme Pragmatique du Tribunal fédéral : Une méthode sans méthode ?", Pratique Juridique Actuelle, no. 4, 2010, p. 417. 
د/عبد الله محمد الهوارى

العدد •r (ديسمبر r.19)

القيدراليـة دور القاضـي الأوروبـي، متحررةًَ في الوقـت نفسه مسن متطلبـات القـانون الدولي، ومفسرةً للقيود الناتجة عن القانون الأوروبي.

ويغرض تبرير تفسير ها لأحكام ونصوص اتِّفق حرية تنقل الأشخاص، اعتبرت

المحكمة الفيدرالية نفسنها داعيةَ للتطبيق المُوحٍَّْ لهذا الاتِّفاق، رافضة هكذا، كلَّ استبعادٍ

للسوابق القضائية لمحكمة عدل الاتِّاد دون سببِ وجيه(').

وجدير" بالذكر، أنه يُنظرُ إلى السوابث القضائية لمحكمة عدل الاتِّحاد من جانب

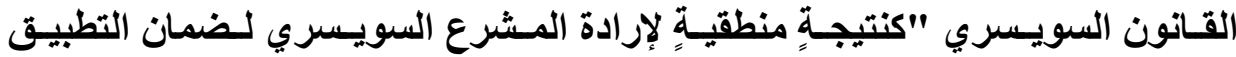

الموحد للنصوص"؛ أي المتطابق مـع ذلك الذي يسود في الدول الأعضاء الخاضعة لسلطة محكمة عدل الجماعات الأوروبية)(؟)

وفي النهاية، يبقى أن نقول: إنها يتعين على القاضسي السويسري، وهو بصدد

تفسير قاعدةٍ ما، أن يأخذ في اعتباره عددًا من العوامل التي قد تكون خارجة عن نظامه

القانوني، ولكن على الرغم من ذلك تؤثر في النظام الذي يدور فيه.

(1) ATF 136 II 5 C.3.6.1; ATF 136 II 65 C. 3.1.

(2) B. STAUDER, "L'influence de la Jurisprudence de la CJCE sur le droit des contrats", in F. WERRO ; T. PROBST, "Le droit privé suisse face au droit communautaire européen. Questions actuelles en droit de la responsabilité civile et en droit des contrats", Berne, 2014, p. 80. 


\title{
المبحث الرابع \\ بين التعددية القانونية الأوروبية واستخدام السابقة عبر الوطنية في الفصل في هنازعات القانون الخاص الأوروبي
}

\begin{abstract}
تمهيد:

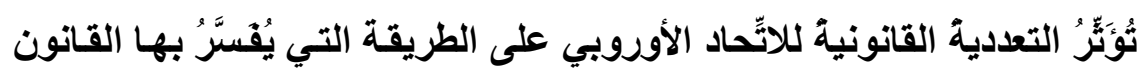

من جانب المحاكم('). وتُشير هذه الحجة؛؛ ليس فقط لطرق التفسير لكي يتم تبتّيّها بواسطة محكمة عدل الاتِّحاد الأوروبي، ولكن أيضًا للمسألة العامـة التي تتعلق بكيفيـة تفسير المحاكم الوطنية للقانون في مثل هذا السيّياق الخـاصِّ بالتعدديـة القانونية. ومن ون ثم، فقد تمَّ اقتراح القانون المقارن كطريقةٍ مثاليةٍٍ أو كنموذج للاستخدام.

وتتجاوز هذه الفكرة، في الواقع؛ ليس فقط القانون الدستوري الأوروبي، ولكن

أيضًا القانون الخاص الأوروبي. ففي مجال هذا الأخير، والذي يرتبط بطبيعته بالقانون

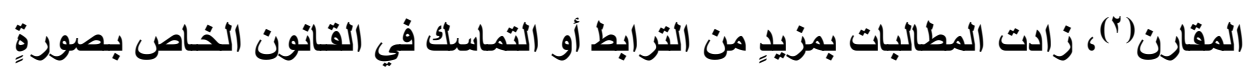

(1) M. MADURO, "Interpreting European Law: Judicial Adjudication in a context of constitutional pluralism", European Journal of Legal Studies, no2, vol.1, 2009, p.21.

(2) C. FLSESNER, "Introduction: Key Features of European Union Private Law", in, C. FLESNER, ed., "The Cambridge Companion to European Private Law", Cambridge, Cambridge University Press, 2013, p.19. 
تدريجيةٍة إلى قبولي واسع المدى بالقانون المقارن، وبصورةٍ أكثرَ دقةَ بالسابقة عبر الوطنية كطريقةٍ للتفسير في المجال القضائي أو في مجال الفصل في المنازعات.

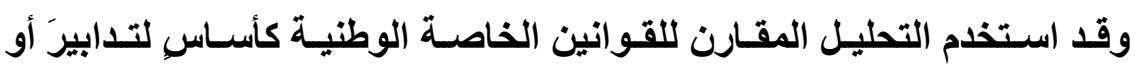

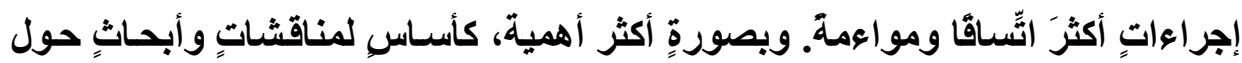

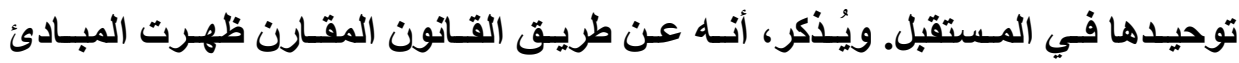
المشتركة وزاد الاعتقاد بتقارب القوانين الخاصة للاول الأعضاء المختلفة'(').

وفي الوقت الراهن، تم نقل استخدام القانون المقارن إلى المجال القضائي أو

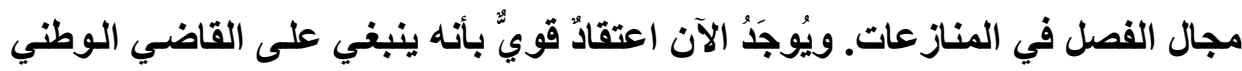

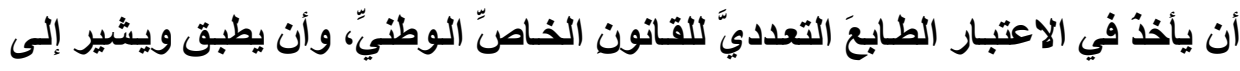

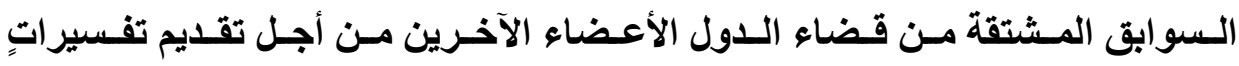

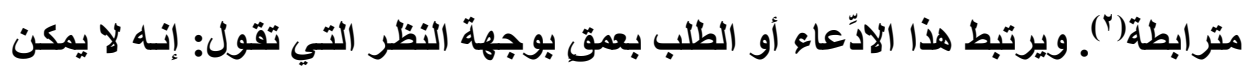

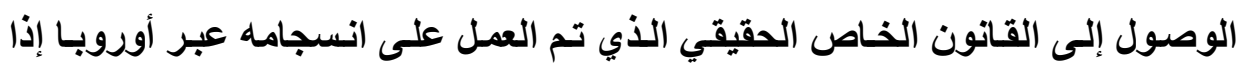

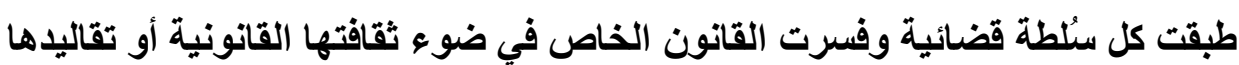

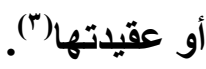

(1) B, MARKESINIS, "The Gradual convergence: foreign ideas, foreign influences, and English law on the eve of the $21^{\text {st }}$ century", Oxford, Oxford University Press, 1998, p.31.

(2) E. HONDIUS, "The Precedent and The law", Electronic Journal of Comparative Law, no3, vol. 21, 2009, p.82.

(3) Ibid. 
وعلى أيـة حال، تظهر أمامنـا أكثرُ من مشكلةٍ في هذا الشأن(') فمن ناحيةٍة

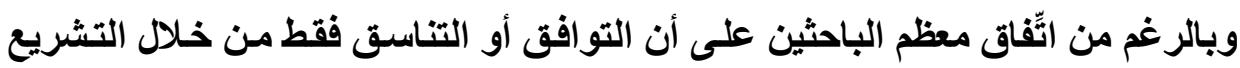

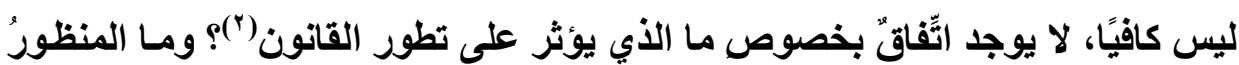

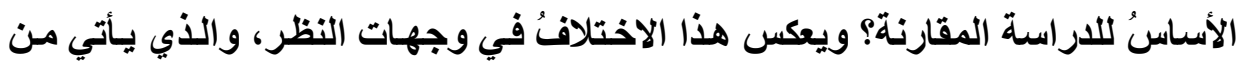

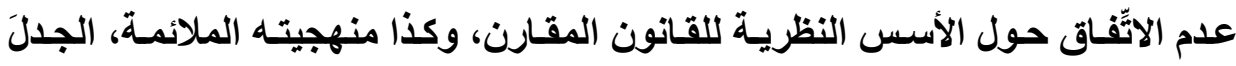
الأوسعَ بشأن إمكانية استخدام القانون المقارن بصورةٍ محضةٍ كطريقةٍ لاراسة القانون

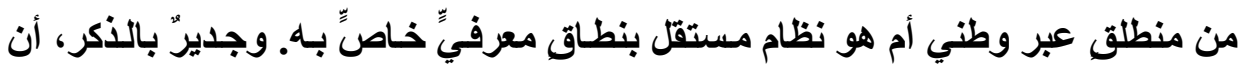

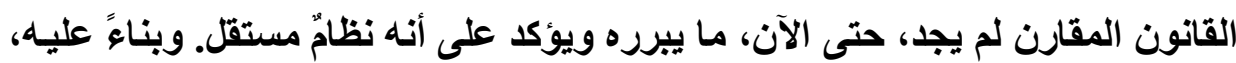

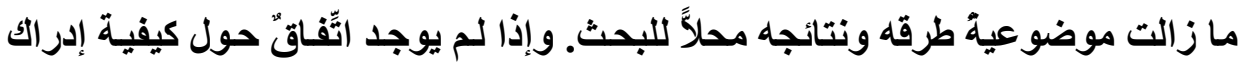
وتطبيق القانون المقارن، سوف يقوم كل قاض وطنيٍ بتفسيره من منطلق عقيدته، الأمر الذي ينتهي بنا إلى وجود تبايناتٍ في القانون.

ومن ناحيةٍ أخرى، فِان القول باستخدام القانون المقارن، وبصورةٍ أكثرَ دقة

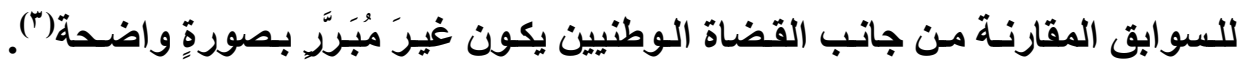
وبصورةً أكثرَ دقةَ، يُير استخدام السابقة عبر الوطنية في الفصل في المنازعات مسائلَ

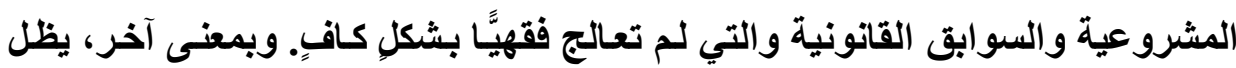

(1) S. BANAKAS, "The Contribution of Comparative Law to the Harmonization of European Private Law", in A. HARDING, "Comparative Law in the $21^{\text {st }}$ Century", London, The Hague, New York, Kluwer Academic, 2007, p.179.

(2) Including Culture, history, Society etc.

(3) J. GORDLEY, "Comparative Legal Research: its function in the Development of Harmonized Law", The American Journal of Comparative Law, no4, vol. 43, 1998, p.555. 
الدور الجوهري الذي يمكن أن تلعبه السابقة الأجنبية في تشكيل القرارات أو الأحكام

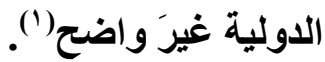

إجمـالاً، تهـف الإشــارة المشتركة إلى السوابق الأجنبيـة إلى اتُّساق وتقـارب

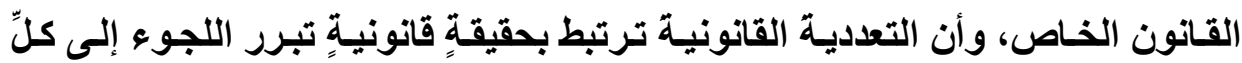
ممارسـةٍة أو تطبيق عملـي. وإذا كـان يقع على عـاتق القاضـي الـوطني التزامٌ بتطبيق مصادر القانون في نظامه، قد لا تتوافق السوابق الأجنبية، من حيث المبدأ، مع مصادر

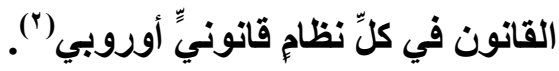

وتتعلق التعدديـة القانونيـة، في الواقع، بتعدديـة مصادر القـانون، وكـا غيـاب

التدرج فيما بينها. ويتم الدفع بهذا المصطلح غالبًا في القانون الخاص الأوروبي، ولكن دون التعرُّ لتعريفه وتحديده بشكلٍ واضـح ومتر ابط. وتأخذ معظم المناقشات في القانون الخاص الأوروبي الطبيعة التعدية للقانون الخـاص كأمر مُستَّلِ بـه، ولكن دون أن تُحَدَِّ عناصرَهُ الأساسية بشكلِ واضح. السؤال الذي يطرح نفسه، في النهايـة، مساذا يعني أن القانون الخـاص الأوروبي تعدديٌٌ وكيف يُنشئ على عاتق القاضي الوطني التزامًا باللجوء إلى السوابق القضائية من أجل تطبيقه بصورةٍ مترابطة؟

(1) P. LEGRAND, "European Legal Systems are not Converging", International and comparative Law Quarterly, no1, vol.45, 1996, p.52.

(2) J. DICKSON, "Directives in EU Legal Systems: Whose Norms are They Anyway?", European Law Journal, no2, vol. 17, 2013, P.190. 


\section{أ- هيكل القانون الخاص الأوروبي}

توجد، في الحقيقة، تعريفـاتُّ متنوعـة عن ماهيـة القـانون الخـاص الأوروبـي القائم. ففي معظم الحالات، يُستخدم المصطلح لكي يغطيَ مجالاً واسعًا من الدراسـة التي لوني تتضمن كلاً من التشريع الأوروبي والسوابق القضائية بشأن القوانين الخاصـة الوطنيـة

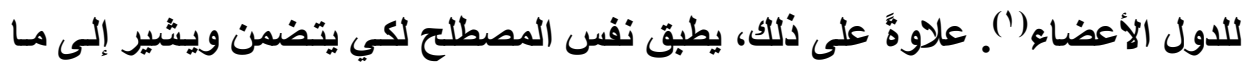
هو المشترك بين الأنظمة القانونية الوطنية (فضلاً عن قواعد القانون الدولي الخاص)، وبذلك يَجُْ هذا المصطلح نفسنه مرتبطا بشدةٍ بالقانون المقارن(َ).

وقد أجرت سلسلة من المجموعات الاراسية واللجان مشروعاتِ وأبحائَا ترمي إلى دراسة والكثف عمَّا هو المشترك في كلٍِ من الأنظمـة القانونية والقانون الخـاص الأوروبي القائم، وتوصلت إلى وجود اختلافٍ كبير بين القانون الخاص الأوروبي القائم والقانون المشتق من التحليل المقارن للقوانين الوطنية(").

ويشير القانون الخاص بمعناه التقليديٍ إلى مجالات القانون التي تُنَّمُ العَلاقِاتِ بين الأفراد (أشخاص طبيعية ومعنوية). وتتمثل المجالات الأساسية للقانون الخاص في التقليد الأوروبي في: قانون الأشخاص (متضمنًا قانون الأسرة)، وقانون الالتزامـات

(1) R. MICHAELS, "Private law Beyond The Stat? Europeanization, Globalization, Privatization", The American Journal of Comparative Law, no4, vol. 56, 2008, p.843.

(2) C. MAK, "Hedgehogs in Luxembourg? A Dworkinian Reading of the CJEU, Case Low on Principles of private law and some Doubts of the Fox", European Review of Private Law, no4, vol.22, 2014, p.323.

(3) R. MICHAELS, "Private law Beyond The Stat? Europeanization, Globalization, Privatization", op. cit., p.845. . 
(متضمنَّا الالتزامات العقدية وغير العقدية)، وقانون الملكية (متضمنَّا قانون الميراث). وتمتد هذه المجالات أيضًا إلى أجزاء من القانون التجاري (')

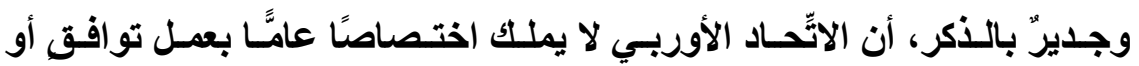

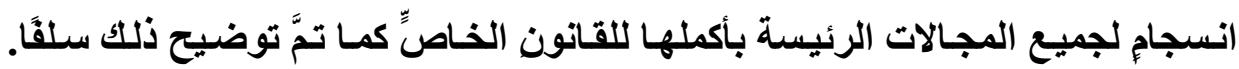
وعلى أية حال، تتضمن الأعمـال القانونية المتنوعة التي قد تصدر في مجالات وضع السياسـات التـي ترمسي إلسى العمـل السليم للسوق الواحد أحكامًَا بشأن قـانون العقود وقـانون المسئولية التقصيرية وقـانون الملكيـة. ويمكن فهـم أثر هذه الأحكـام على الممارسة القانونية للقانون الخاص على المستوى الوطني؛ ليس فقط من خلال التعاون مع القانون العام للاتّّاد الأوربي وتفاعلاته مـع القـانون الوطني، ولكن أيضًا بالتعاون مع السوابق القضائية لمحكمة عدل الاتِّحاد الأوربي.

ويَردُ القانون الخـاص الأوربي بصورةٍ أساسيةٍة في التوجيهات أو التعليمـات، والتي يجب أن يُقسَّرَ القانون الوطني في ضوئهابَ). وفي النهاية، يضع الاتِّحاد الأوربي الأهدافَ الأساسية والسياسـاتِ العامة ويطلبُ من الدول الأعضاء تنفيذها بالطريقة التي

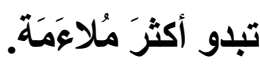

(1) A. JOHNSTON, "European Private Law by directives: approache and challenges", in T. FLESNER, ed., "The Cambridge Companion to European Private Law", op. cit., p.85.

(2) ECJ, 13 November 1990, Marleasing SA v. La Commercial International de Alimentation SA, C-106/89, ECR1990, P. I-4135. 


\section{ب- الفصل في المنازعات المتعلقة بالقانون الخاص الأوروبي:}

يُقْصَدُ بالفصل في المنازعـات بشكل عـامٍ أمران؛ أولاً: مهمـة المحساكم، وثثاتيًا:

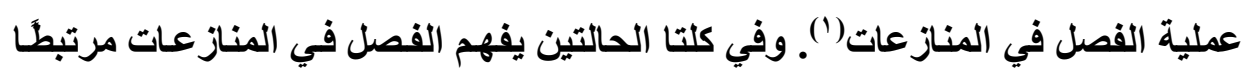
بمؤسسة المحاكم وسئطتها في الفصل في المنازعات وإصدار الأحكام. وبصورةٍ نظريـةٍ

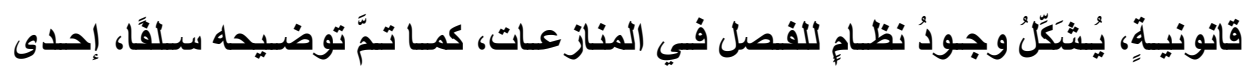

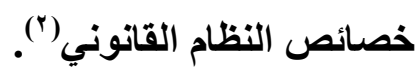

وفي مجـال القـانون الخـاص الأوروبـي، يُقسم الفـصل في المنازعـات كمهــة وكإجراء بين محكمة عدل الاتِّحاد الأوربي من جهة، والمحاكم الوطنية من جهةٍ أخرى. وكما ذكر بالفعل، تتحدد سلطة محكمة عدل الاتِّاد الأوربي بقر ما تكون مختصة فقط في تقديم تفسير سلطويٍٍ ومستقلٍِّ للقانون الأوروبـي. والمحسكم الوطنية هي تلك التي

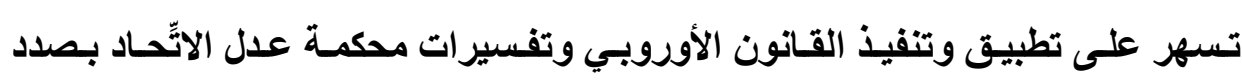
القضايا المعروضة أمامها.

r - التعددية القانمنية:

في هذا الجزء من الاراسة، سوف نلجأ إلى المناقشات بشأن التعدديـة القانونية الكلاسيكية، وبشأن التعدية القانونية للقانون الاستوري الأوروبي؛ من أجل توضيح استخدام المصطلح في القانون الخاص الأوروبي.

(1) Samantha BESSON, "Legal Philosophical Issues of International Adjudication-About The amour impossible between International Law and Adjudication", op. cit., p.132 et s.

(2) Ibid. 


\section{أ- التعددية القانونية الكلاسيكية}

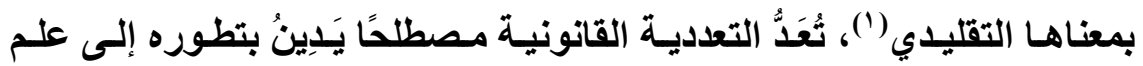

الاجتماع القانوني، وكذا علم الأنثرويولوجيا القانونية، ويرمي إلى وصف المواقف التي

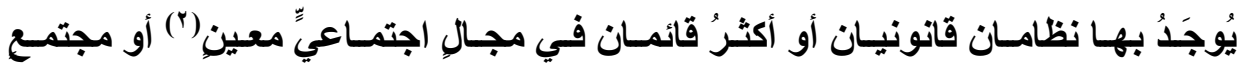

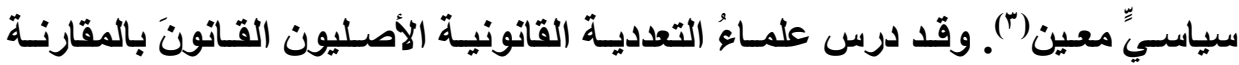

بالأيديولوجيا السائدة عن المركزية القانونية، وبصورةٍ أساسيةٍة الفكرة التي اعترفت بالقانون في مجال اجتماعيٍ معين، على أنه فقط القانون المشتق من الدولة والذي يُدار

$$
\text { بواسطتها (4). }
$$

وعلى أيـة حـال، لا يمكن للمركزيـة القانونيـة أن تحكمَ الواقِعَ القـانونيَّ المبِيعَ

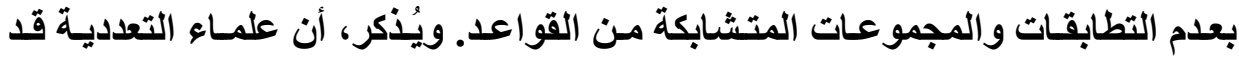

رفضوا أيَّ مفهوم للتعدديـة القانونيـة دلَّ على اعتـراف الدولـة بالأنظمـة المعياريـة

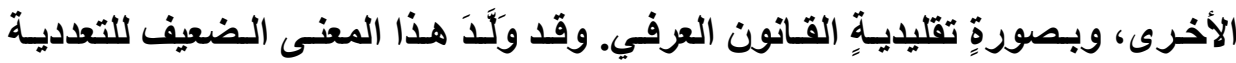
القانونية شكلاً هرميَّا من الأنظمة المعيارية المفروضة من جاتب الدولة، وبالتالي فهي غيرٌ متوافقةٍ مع مركزية هذه الأخيرة(ه).

(1) S.E. MERRY, "Legal Pluralism", Law and Society Review, no5, Vol. 22, 1988, p. 872.

(2) J. GRIFFITHS, "What is Legal pluralism", Journal of Legal Pluralism, no24, 1986, p. 1-55.

(3) G. LATAS, "Harmonic Law: The case Against Legal pluralism" in J. DICKSON, "Philosophical foundation of European Union Law", op. cit., p. 77-108.

(4) J.GRIFFITHS, "What is Legal pluralism", op. cit., p.29.

(5) Ibid. 
وقد تم تعريـف مفهوم النظام القـانوني في سبياق التعدديـة القانونيـة التقليديـة على أنها يتضمن؛ ليس فقط نظـام المحـاكم التي تديرها الدولـة، ولكن أيضًا الأنظمـة

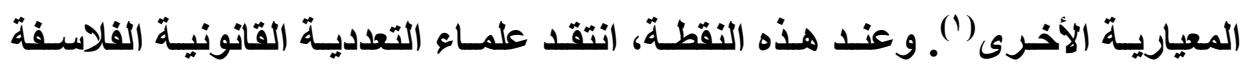
القانونيين بسبب تبنّي مفهوم ضيق للنظام القانوني لا يستطيع تقديرَ أهميةِ الأنظمـة

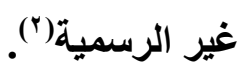
وجدير" بالملاحظة، أن التعددية القانونية الكلاسيكية قد تمكنت من إبراز وتفسير النظام الاجتماعي في المجتمعات في أوقات الاستعمار وما بعد الاستعمار، حيث تعايشت فيها أنواعٌ مختلفة من الأنظمة المعيارية مع القانون المفروض على الأوروبيين. وعلى

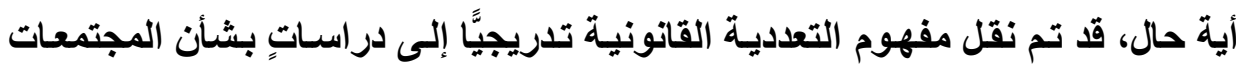
الحديثة، ومؤخرًا إلى دراسـاتٍ بشأن مجتمعـات الدول الأعضاء التـي تخضع لقـانون الاتِّحاد الأوربي (َّ). وكمـا سـوف نبين لا يُستخدم هذا المفهوم بنفس المعنى في مجـال القانون الأوروبي.

وفي سياق القانون الاستوري الأوروبي، يتمتع مفهوم التعدية القانونية بأهميةٍ

خاصةٍ لاى المُنظرِينَ القانونيين ذوي التقليد التحليلي والراغبين في إزاحة الستار عن

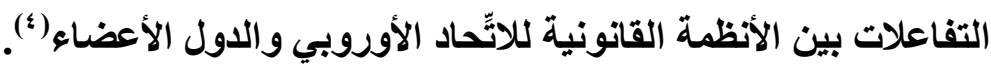

(1) G. LETAS, "Harmonic Law: The case Against Legal Pluralism", op. cit., p.870.

(2) J. GRIFFITHS, "What is Legal pluralism", 1999, p.29 et s.

(3) Ibid.

(4) G. LETAS, "Harmonic Law: The case Against Legal Pluralism", op. cit., p.872. 


\section{ب- البدل الخاص بالتعددية القانونية في القانون الدستوري الأوروبي:}

تُشير التعدديـة القانونيـة في سـياق الاتِّــاد الأوروبـي كمـا هـو الحسال بالنسبة

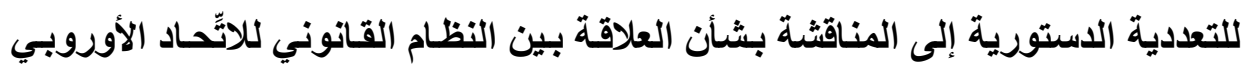
والأنظمة القانونية الوطنية. والأمر الأكثر أهمية بالنسبة للباحثين القانونيين ليس فقط

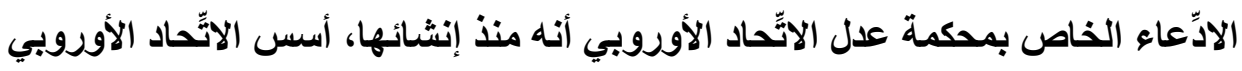
نظامًا قانونيًّا مستقلًا يعلو على الأنظمة القانونية الوطنية، ولكن أيضًا حقيقة أنه بإمكان

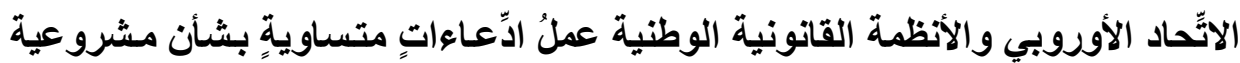
القواعد الأوروبية في الأنظمـة القانونية الوطنية. وأنه بـالأكثر، حول أي” نظاجم قانونيٍ

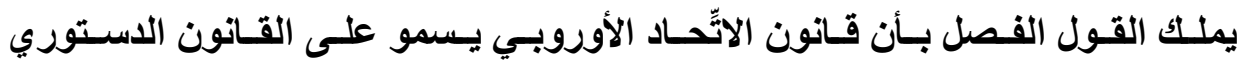
(الوطني (')

وتثير التعددية الدستورية إلى نموذج نظريٍ في فهم التفاعلات بين القانون

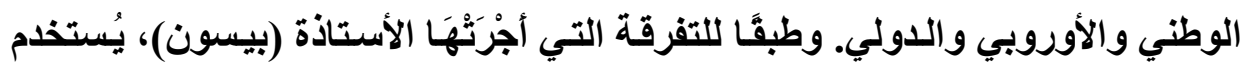
مصطلح التعددية في هذه الحالة في القانون الدولي على أنـه نمـوذجّ مضادُّ للوحدويسة، فهو يميل إلى التمكن من تعددية القواعد، والمصادر أو الأنظمة داخل القانون الدولي (الداخلي) بقر ما تكون تعددية الأنظمة القانونية خارج القانون الدولي (الخـارجي)(؟). وبهذا المعنى، فهي ثُشير إلى الجدل حول مشروعية القانون الدستوري الأوروبي في

(1) M. GIUDICE, "Not a system but an Order- An Inter-institutional view of European Union Law", in J. DICKSON, "Philosophical Foundations of European Union Law", op. cit., p. 54-76.

(2) Samantha BESSON, "How international is the European Legal order? Retracing Tuori's Steps in the exploration of European legal pluralism", No Foundations: An Interdisciplinary Journal of Law and Justice, no5, 2008, p.50-70. 
الأنظمة القانونية الوطنية. وفي كل الأحوال، يُستخدم هذا المصطلح أيضًا لكي يصف

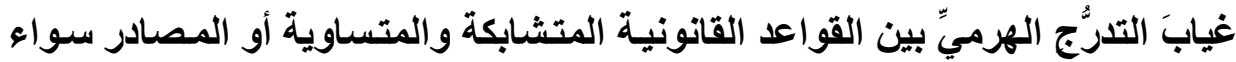
في نفس النظام القانوني أو بين الأنظمة القانونية (') (1) التعددية الدستورية كرد فِعل لنظرية وحدة القانون: أولـى محساو لات رسـ نظريـة مـن أجل إبراز وتفسير التفــاعلات بين الآّّــاد

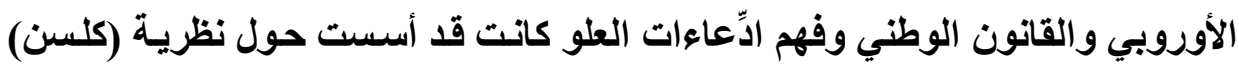
الخاصة بوحدة القانون ووجهة النظر التي تقول: إن الأنظـة القانونية الوطنية تُشكَّلُ

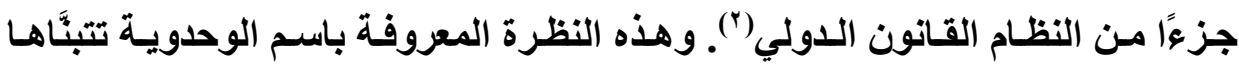

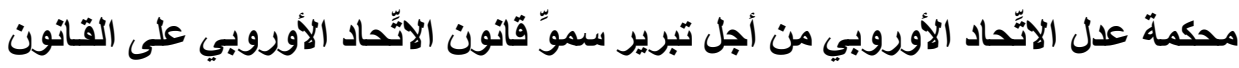

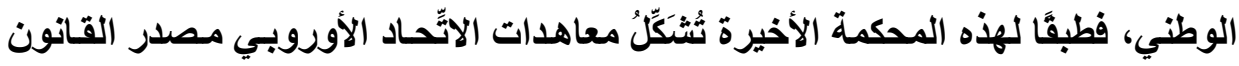

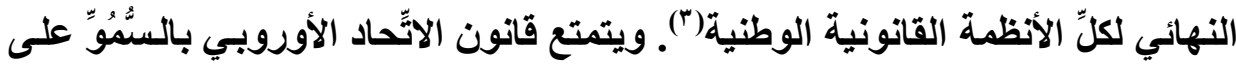

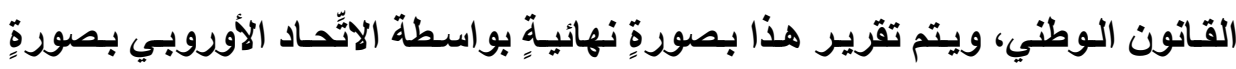
مستقلةٍ عن القانون الوطني. وطبقًا للأستاذ (ريتثموند) يتعين أن نفهم وحدة القانون

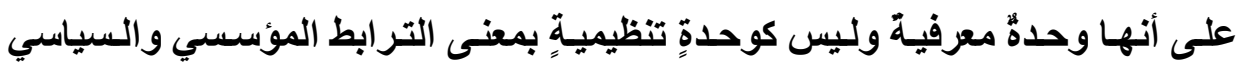

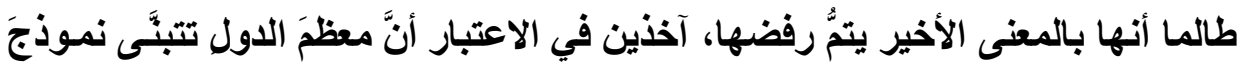
الثنائية) (4)

(1) Ibid.

(2) P.ELEFTHERIADIS, "Pluralism and Integrity", University of Oxford legal Research Paper Series, no 43, 2009. p.181.

(3) Ibid.

(4) C. RICHMOND, "Preserving the Identity Crisis: Autonomy, System and Sovereignty in European Law", Law and Philosophy, no. 4, Vol. 16, 1997, p. 377- 420. 


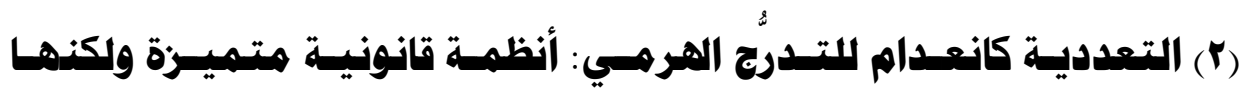

\section{متفاعلة:}

(أ ) أنظمة قانونية هتميزة ولكنها متفاعلة:

طبقَّا للأستاذة (ديكسون)، يُمكن فهم الاتِّحـاد الأوروبـي في أحسن صورةٍ من

خلال عدسات مفهوم النظام القانوني الذي يحتاج إلى إعادة دراسـةٍ طبقَّا لذلك من أجل استيعاب التحديات التي تفرضها الكيانات السياسية غير التابعة للاولة. ومن أجل قبول ادِّعاء محكمة عدل الاتِّـاد الأوروبي بـأن قانون الاتِّــاد الأوروبي يُمَتِّلُ نظامًا قانونيَّا

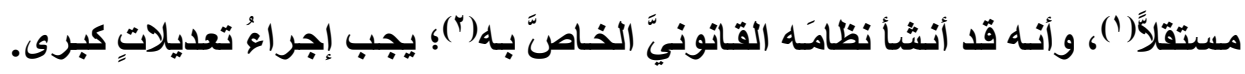

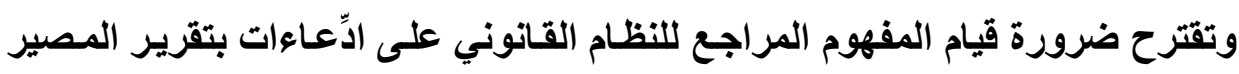
المعياري (") كمعيار بالنسبة لوجود الأنظمة القانونية.

وأخيـرًا ولـيس آخـرًا، فوفقَـا (لايكسون)، يمكن فهـم العلاقــات بـين الأنظمـة

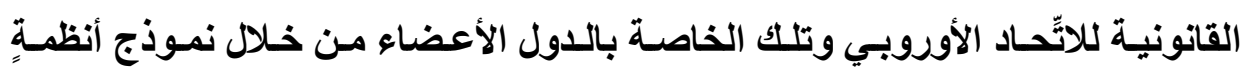
قانونيةٍ متميزةٍ ولكنها متفاعلة مـع بعضها البعض، بعد تعديلاتٍ ضروريةٍ في مفهوم النظام القانوني من أجل استيعاب وجهة النظر التي تقول: إنه يمكن للكياتـات السياسية

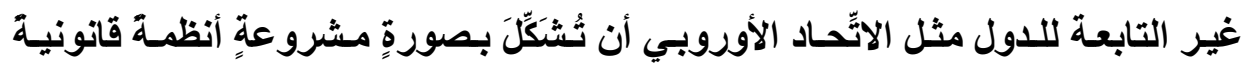
مستقلة. وتتجه أيضًا على اقتراح نموذج متغير بالنسبة للتفاعلات بين الاتِّحاد الأوروبي والأنظمة القانونية الوطنية بخصوص تطبيق قانون الاتّّاد الأوروبي.

(1) ECJ, 5 February 1963, Van Gend en loos, 26/ 62, ECR 1963, p. 1.

(2) ECJ, 15 July 1964, Costa v. ENEL, 6/64, ECR 1964, p. 585.

(3) J. DICKSON, "Towards a Theory of European Union Legal Systems", op.cit., p. 25- 53. 


\section{(ب) قانون الاتحاد الأوروبي كتفاعل بين المؤسسات:}

خلافًا لوجهة نظر (ديكسون)، قدَّمَ بعضُ المُنظّرينَ القـانونيين الحجة والدليلَ على أن مفهوم النظام القانوني لا يُعَدُّ أداةَ مفيدةَ لفهم قانون الاتِّحاد الأوروبي وتفاعلاته مع القانون الوطني (') ويساند الأستاذان (كولفر وجيوديس) مقولة أن نتظر للقانون

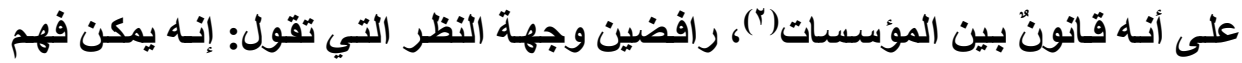
قانون الاتّّحاد الأوروبي وتفاعلاته مع قوانين الدول الأعضاء من منطلق مفهوم النظام القانوني. وبدلاً من ذلك، فإنهما يركزان على التفـاعلات بين المؤسسات كمتحكمة في التوتر والترابط(") ويؤكدان، أنه على الرغم من أن مفهوم النظام القـانوني قد شُيَِِّ حول نموذج قانون الدولة، فإن هذا لا يعنـي أنـه لا يمكن أن يفسر الأنـواع الأخرى من الظواهر (ء).

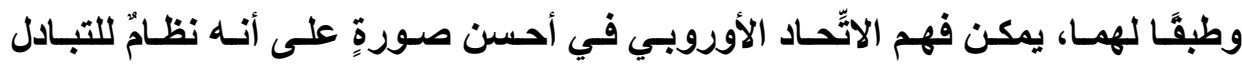
والتفاعل وترجمة للقواعد القانونية التي تنفذها مؤسسات الدول الأعضاء.

\section{(ج) تعددية القانون الخاص الأوروبي:}

يتعين علينـا أنْ نتوقـعَ أنَّ مناقشُاتِ القانون الخـاص الأوروبـي بشأن التعدديـة القانونية تُشتلهم من خلال الكتابات في مجال القـانون الاستوري الأوروبي. ومـع ذلك، فإن البحث في القانون الخاص الأوروبي قد تطور نسبيًّا بصرف النظر عن المناقشات

(1) K. CULVER; M.GIUDICE, "Not a system but an Order- An Interinstitutional view of European Union Law", op.cit., p. 77.

(2) Ibid.

(3) Ibid.

(4) Ibid. 
المشـار إليهـا ســلقًا، وأصبع يُنظر إليـه كأحـد فروع الدراسـات القانونيـة الاجتماعيـة والدراسات القانونية المقارنة'(')

وقد تَمَّتْن صياغة التعدديـة القانونيـة في مجـال القـانون الخـاص الأوروبي طبقَا

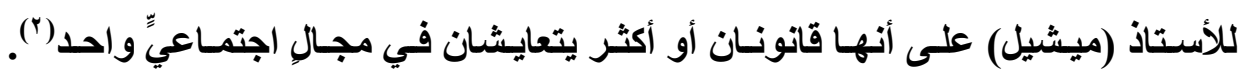
وسـوف نركز على إشـارتَيْن صريحتَيْن بالنسبة للتعدديـة القانونيـة في مجـال القـانون الخاص الأوروبي، ونحاول أن نظهر استخدامهما للمصطلح، وكذا فائدته في المناقشة حول مستقبل التوافق أو التناسـق واستخدام القـانون المقـارن كجزعِ مـن الالتزامـات القضائية المفروضة على القضاة.

في مقال حديث، حاول الأستاذ (هيسيلنك) أن يتتاول مسألة التعددية في القانون الخاص الأوروبي. ويُّكر، أنه كان قد رَكَّزَ اهتمامه على تعريف التفـاعلات بين الأنظمـة

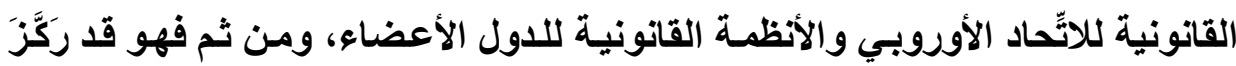

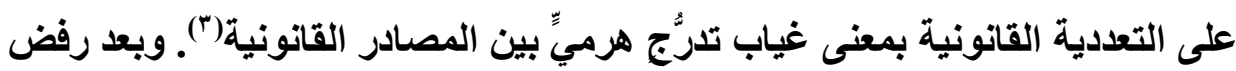
إمكانية فهم التفاعلات بين القانون الخاص الأوروبي والوطني من خلال عدسـات الفقهـ

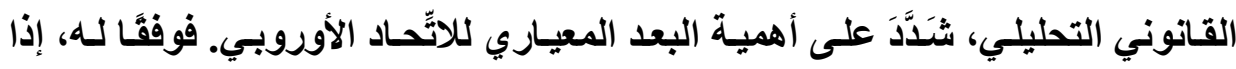

(1) J. DICKSON, "Methodology in Jurisprudence: A Critical Survey", Legal Theory, no. 3, Vol. 10, 2014, p. 117.

(2) R. MICHAELS, "Why We Have no Theory of European Private Law Pluralism", in L. NIGLIA, ed., "Pluralism and European Private Law", Oxford, Hart Publishing, 2013, p. 198.

(3) S. BESSON, "How international is the European Legal Order? Retracing Tuori's Steps in the exploration of Europan Legal Pluralism", op.cit., p. 73. 
أردنا أن يَكُونَ لاينا صورةٌ واضحة عن التفاعلات بين الأنظمة القانونية المختلفة، فِإنتا في حاجةٍ إلى روئةٍ معينةٍ بخصوص أهداف الاتِّحاد الأوروبي فيما يتعلق بموقع القانون الخـاص الوطني أو الأوروبـي أو العـالمي('). وفي النهايـة، يتبنى الأستـاذ (هيسيلنك) النموذجَ الوحدويَّ للأستاذ (كلسن) والأي يرى القانون بأكمله على أنسه وحدةُ واحدة.

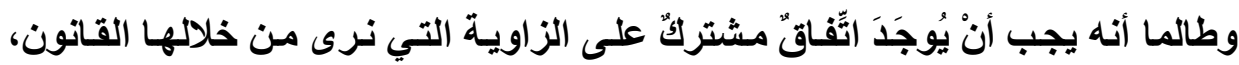
يستخدم (هيسيلتك) ثلاثَ نظرياتٍ سياسيةٍ، وهي: الوطنية والأوروبية والعالمية كحلول

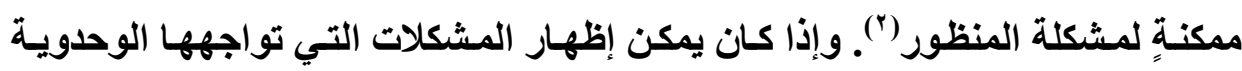
كنظريةٍ في هذا السيّاق، إلا أنَّ ما ينبغي التشديد عليه هو عدم فاعلية هذا النموذج في

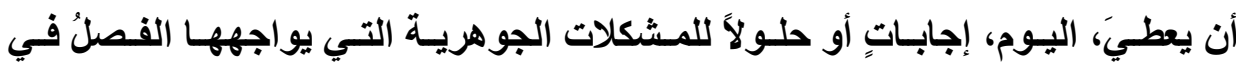

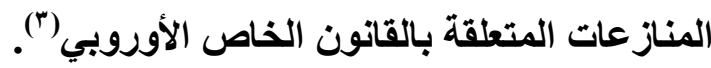
• القانون على أنه سوق:

أخيـرًا ولـيس آخـرًا، فـإن حسـاب أو تقـدير الأسـتاذ (سـميتس) عـن التعدديـة

القانونية، هو مثالرٌ آخرُ للكتابات الحديثة بثأن هذه المسألة. فهو يبدأ بوصف تعدديـة مصادر القانون الخاص بصرف النظر عن أنواع القانون الوطني والأوروبي والدولي

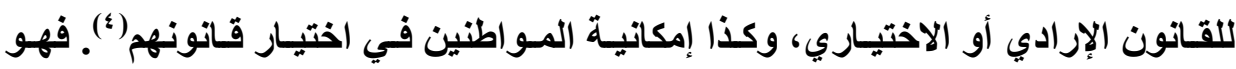

(1) M. HESSELINK, "How Many Systems of Private Law are There in Europe? On plural legal sources, Multiple Identities and the Unity of Law", op.cit., p. 540.

(2) Ibid.

(3) S. BESSON, "How International is the European Legal Order? Retracing Tuori's Steps in The exploration of European Legal Pluralism", op.cit., p. 76.

(4) J. SMITS, "Plurality of Sources in European Private Law or: How to $=$ 
يقترح، آخذين كمعيات تعددية المصادر، والتي تكمن مشروعيتها خارج الدولة، فهناك

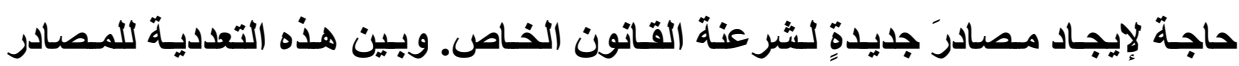
القانونيـة، فهو يأسـف على حقيقـة أن التفسير والمنهجيـة المطبقـة في الفصل فـي المنازعات ماز الت وطنية)(')

وبعيدًا عـن هذه التعدديـة للمـصادر، فهو يـدفع بعدم وجـود التـدرج القـانوني

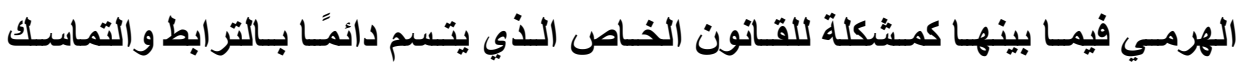
والانسجام. ثم يقترح بعض الإستراتيجيات للتعامل مـع هذا التتوع، ويختار في النهايـة نموذجًا ينظر إلى القانون على أنه كالسوق، والذي بموجبه، يمكن للأطر اف أن ثُقرِّرَ أيَّ قانون سوف يطبق على علاقاتهم (باستثناء القواعد الوجوبية)(؟). وتتمثـل المشكلات مـع هذا الحسـاب أو التقدير للتعدديـة القانونيـة في القـانون الخاص الأوروبي أولاً: في أن تعددية المصادر ومشروعيتها، وكذا عدم وجود تدرُّج

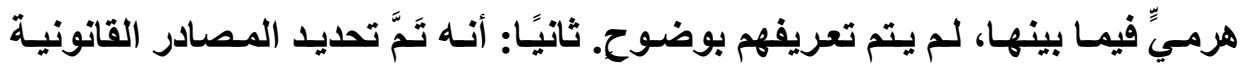
المختلفة المفترضة بصورةٍ غامضة. وبالنسبة لإمكانية الأطر اف في اختيـار قانونهم،

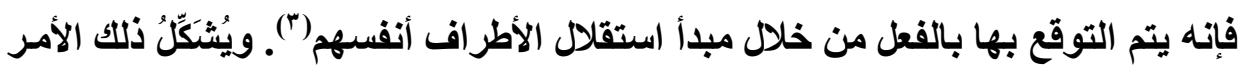
حجر زاوية القانون الخاص للاول الأعضاء. ثالثًا: وبخصوص ادِّعاء المشروعية، يبدو أن هنالك افتراضًا قائمًا حول التفاعلات بين النظام الوطني والأوروبي وكيفية أن نُصبح

live with Legal Diversity", Maastricht European Private Law Institute Working Paper, no. 14, 2011.

(1) Ibid.

(2) Ibid.

(3) R. MICHAELS, "Why We Have no Theory of European Private Law Pluralism", op.cit., p. 205. 
قواعد هذا الأخير مشروعة أو صحيحة في النظام القانوني للأول. ولم يتمّ بيـان هذا الافتراض بوضوح، ولكنه قابلٌّ للتمييز بصورةٍ غامضة. وهو هنـا يركز بصورةٍٍ أكثرَ

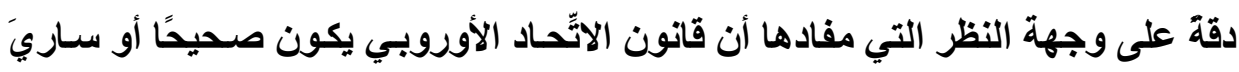

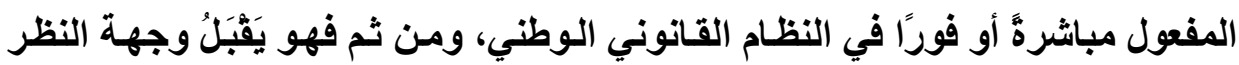
الوحدوية لمحكمة عدل الآّحاد الأوروبي. ويُقَُّمُ نظرته للقانون كسوق منهجًا معياريًا بثأن: كيف ينبغي أن يُدار القانون

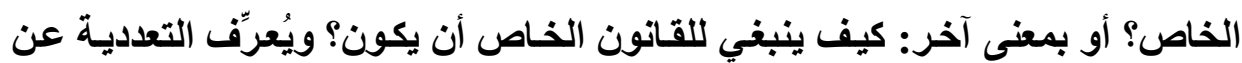
طريق تعددية الإمكانيات التي يمكن من خلالها لأشخاص القانون الخاص اختيار نظامهر

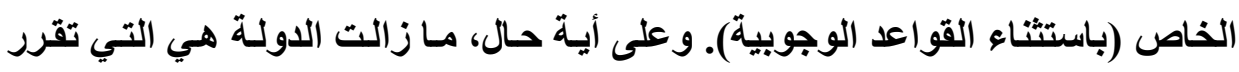

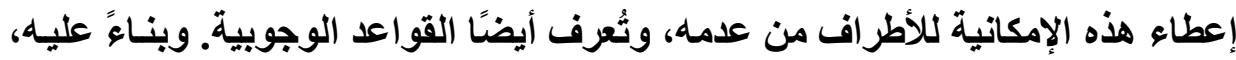
فإن هذا الحساب أو التقدير ليس ببعيدٍ عن النموذج الذي أراد أن يتجنبه، والذي يتمثل

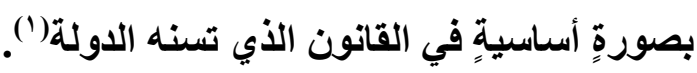

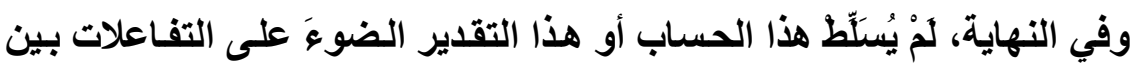
المصادر المتعددة، طالما أن التعريف بالقو اعد كأجزاء من نظام قانونِ معين لا يُعَدُّ أمراً جوهريًا.

(1) Ibid. 


\section{المبحث الخاهس \\ تأثير القانون الأوروبي بشأن الشروط التعسفية \\ في الماكم الوطنية}

منذ ما يزيد عن عشرين عامًا، اعتمد الاتِّاد الأوروبي التوجيه أو الأمر المتعلق بالثروط غير العادلة أو التعفية رقم ب / / ا ، والذي لا يزال ساريًا حتى يومنا هذ|('). ويتطلب هذا التوجيه من الدول الأعضاء العمل على وقف استخدام الثروط غير العادلة

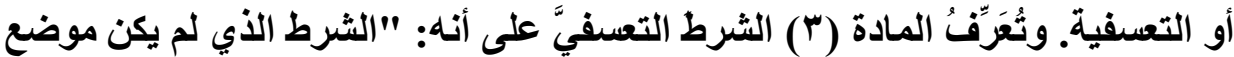
التفاوض الفردي، وخَلقَ ـ على حساب المستهلك ـ خلاً كبيرًا بين حقوق والتزامـات الأطر اف الناشئة عن عقد الاستهلاك أو الاستعمال". وجديرٌ بالداّكُر، أنَّ هذا الشرط قد أعـاد مـن جديد إلى القاضـي الـوطني، وكذا إلى قاضـي قـانون الاتِّــاد، سُـلطة ضـــان الحماية الفعالة للمستهلك من مثل هذه الثروط.

وقد درس العديد من المؤلفين تأثيرَ القانون الأوروبي بشأن الشروط التعسفية على القوانين الوطنية، وكذا تطبيق القاضي الداخلي للقانون الوطني الخاص بالشروط التعسفية. ومن ناحيةٍة أخرى، تُعَدُّ الدراسـات المتعلقة بتـأثير القـانون الأوروبي بشأن الثروط التعسفية في المحاكم الوطنية قليلة للغاية أو إلى حدٍ كبيز. ومـع ذلك، حتى لو

(1) Directive 93/13/CEE, du 5 Avril 1993.

مجلتَ البحوث القانونيت والإقتصاديت 
طبَّقَ القاضي إجراء الانتقال أو التغيير الذي يكون وطنيًا، (') يستمر القانون الأوروبي في التأثير بثكل مباشر على القانون الوضعي للادول داخل المحاكم الوطنية. و السؤال الذي يدلق هو: هل يُعَدُ القاضسي الوطني قاضيًا للقانون الأوروبي

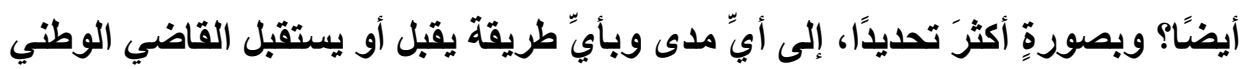

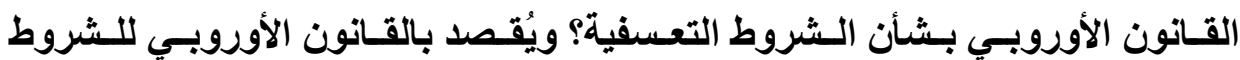

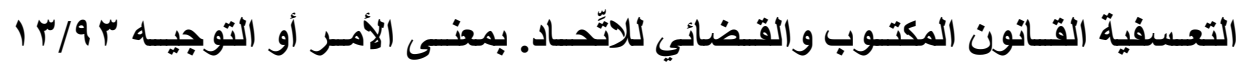
وتفسيره التدريجي بواسطة محكمة عدل الآّّاد الأوروبي.

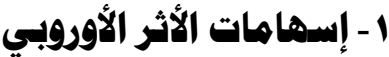

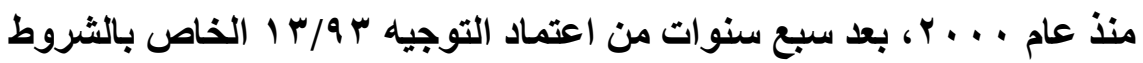

غير العادلة، لاحظت المفوضية الأوروبية تأثيرَهُ في الأنظمة القانونية الوطنية، لا سيما في المحكمة أو على القاضي: "يتزايد شعور بعض القضاة الوطنيين بالحساسية تجاه

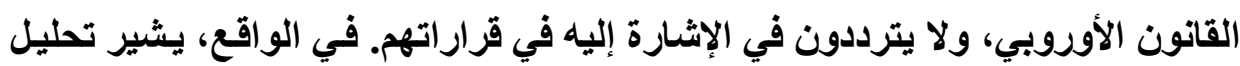

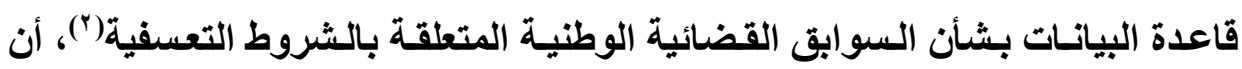

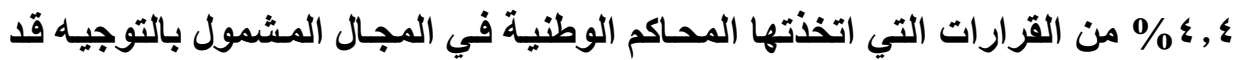
أثشار إلى هذا النص أو الأمر الأوروبي. وفي هذه المرحلة من البناء الأوروبي، يُمَتِّلُ هذا الرقمُ عددًا كبيرًا يعكس الأثرَ التدريجيَّ لقانون الجماعة في الأنظمة الوطنية"((").

(1) Article 8 de la directive 93/13.

(2) Base de données sur la jurisprudence nationale relative aux clauses abusives.

(3) COM (2000) 248, du 27 avril 2000, Rapport de la commission européenne. 
وفيمـا يتعلق بالشروط غير العادلـة، وفيمـا يتعلق بالمحكمـة أو القاضسي، تـتم

ممارسة هذا الأثر التدريجي على كلِّ من القاضي الوطني (أ)، والسوابق القضائية (ب).

\section{أ- التأثير الأوروبي على القاضي الوطني للشروط غير العادلة}

(1) إنشاء قاضٍ للاشروط غير العادلة:

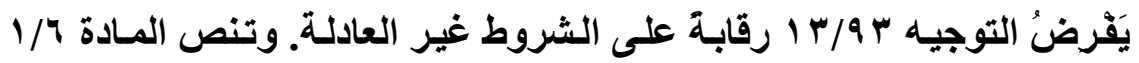

منـه على أن: "الشروط غير العادلـة ليست مُلزمَـة للمستهلكين"، بينمـا تنص المـادة

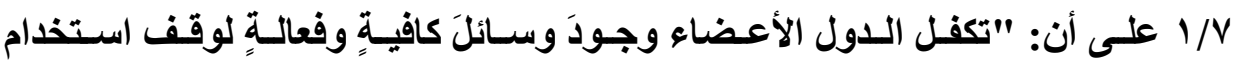

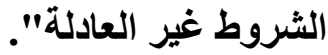

ويُترك تعريف "الوسائل" إلى حدٍ كبير للاول. على سبيل المثال، لضمان رقابة

الشروط غير العادلة، يجوز للدول أن تضع إجراءً يقوم على تلدخُل قاضِ، أو إجراءٍ إداريٍِ لا ينطوي على المحاكم. وكمـا هو مُبَيَّنٌ في تقرير المفوضية أو اللجنـة المعنية بتطبيق التوجيه ب 1 1 1، "آثرت جميع القوانين الوطنية الخيار القضائي"('). ويخضع هذا الإجراء؛ إمـا إلى المحاكم العادية (في معظم الدول الأعضاء)، أو إلى محاكمَ معينةٍ (مثلـل المحكمـة العليـا لأيرلنــا والمملكـة المتحـدة، ومحكمـة السوق في دول الـشمال

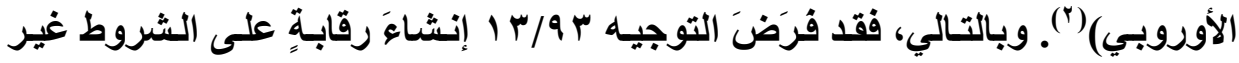
العادلة، والتي ثُرجمت في كلِّ دولة من الدول الأعضاء، من خلال إنشاء قاض مسئولي

$$
\text { عن فحص وإقرار والعقاب على الشروط التعسفية. }
$$

(1) Ibid., p. 21.

(2) Commission européenne, La directive "Clauses abusives", Cinq ans après, Évaluation et perspectives pour l'avenir, Conférence de Bruxelles, $1^{\text {er }}-3$ Juillet 1999, Luxembourg, office des publications officielles des Communautés européennes, 2000, p. 19. 
ومع ذلك، سوف يكون من الخطأ الاعتقادُ بأنَّ إنشاءَ قاض مسئولٍ عن المعاقبة

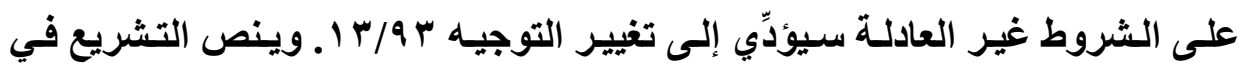
العديد من الدول بالفعل على نظاجٍ محددٍ (أو قانون عامٍ) يسمح بالعقاب على شروط التعاقد غير العادلة. وتأتي هذه الشروط، أحيانَا، تحت مسمى (الشروط غير العادية، المجحفة، غير المتوقعة، ومـا إلى ذلك)، ولكن تنظيمها أو تقعيدها قد وُجدَ من قبلُ حتى هده ولو اختلفت متطلباتها أو مقتضياتها عن شروط ومقتضيات التوجيه('). وكـان هذا هو

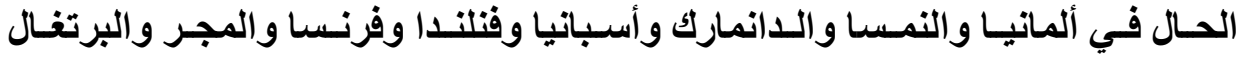
ولكسمبورج وسلوفينيا والسويد(). وعلاوةً على ذلك، حتى في الدول التي لم ثُقِرّ قانونًا ينص صراحة على تجنب أو حذف الثروط التعسفية، يمكن للقاضي مع ذلك، أنْ يُعَاقِبَ على هذه الثروط باستخدام مفـاهيمَ أكثر عموميـة؛ مثل: حسن النية، الوفـاء، الأخلاق

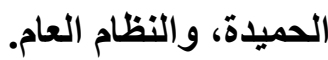

r- الزيادة في عدد القضايا أو الحالات: مـن خـلال فرض رقابـةٍ على الشروط غير العادلـة أو التعسفية، كـان للقـانون الأوروبيٍ أثُرٌ في مضاعفة عدد القضايا التي تضمنت شروطا غير عادلة، والتي تمَّ بحثُها والتعاملُ معها في المحاكم الوطنية.

وكما لاحظت ذلك المفوضية الأوروبية: "من الناحية الكمية، شهدنا زيادةً كبيرةً

في عددٍ من الدول، والحالة النموذجية هي حالة المملكة المتحدة، حيث انتقلنا من حالة

(1) Par exemple, leur champ d'application Pouvait différer de celui de la directive 93/13, les critères de définition de la clause sanctionnée pouvaient être plus ou mains proches de ceux retenus par l'Union, etc.

(2) Pour Une analyse plus détaillée, Voir: Commission européenne et Université Bielefeld, Compendium CE de droit de la consommation. 


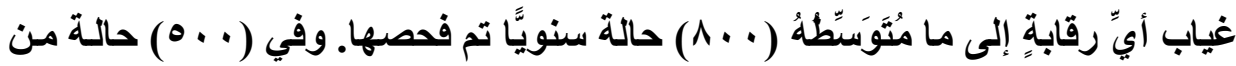

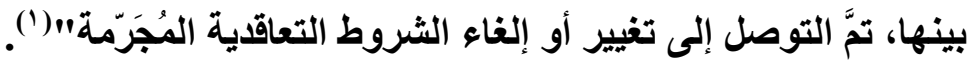

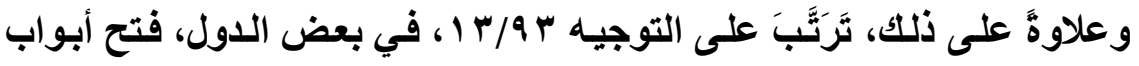
المحاكم أمسام الأثخاص أو المنظمـات التي توجد للايها مصلحة مشروعة في حمايـة

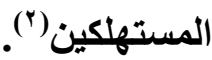

وحتى في الـول التي اعترفت بالفعل مـن قبلُ بالـاعاوى الجماعيـة لحمايـة المستهلكين، زاد عدد الدعاوى المرفوعة أمسام المحسكم، وتبدو هذه الزيادة مرتبطة

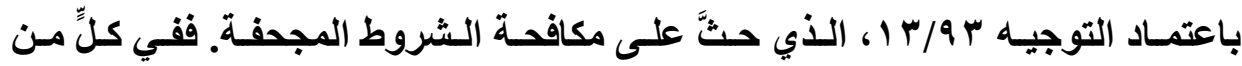
البرتغال وبلجيكا، على سبيل المثال، نثهذ زيادةً ملحوظة في الاعاوى المرفوعة أمسام المحاكم من أجل المقاومة القضائية للشروط التعفية، كما لو كان التوجيةٌ سالفُ الثّكرّ

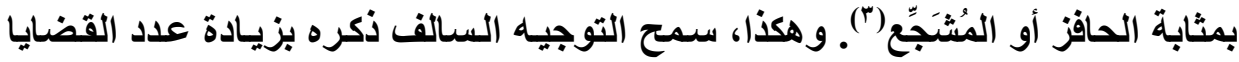

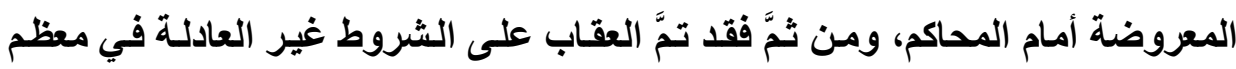

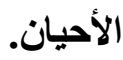

\section{(ז) زيادة صلاحيات أو سلطات القاضي:}

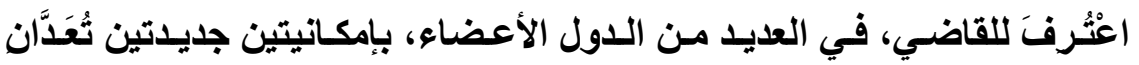

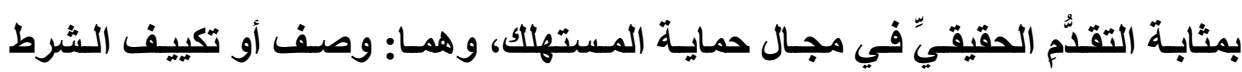
التعفي بثكل أكثرَ استقلالية على أساس تعريفه العام، وتقدير الطابع التعسفي للثرط

(1) COM (2000) 248, p. 34.

(2) Article 7.2 de la directive 93/13.

(3) COM (2000) 248, p. 35. 
(أ) الوصف الأكثر استقلالاً للشرط التعسفي أو المغالى فيه:

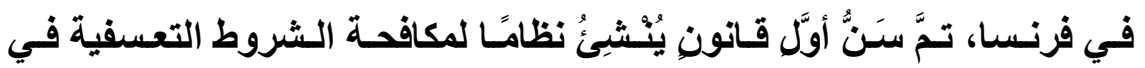

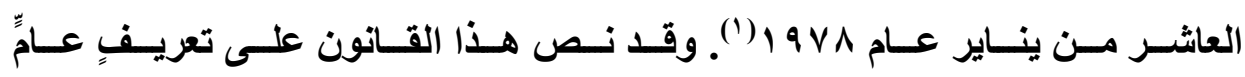

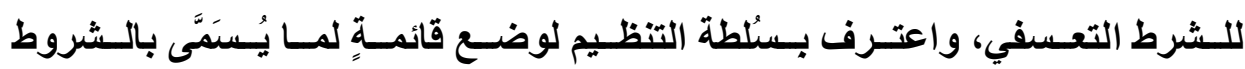

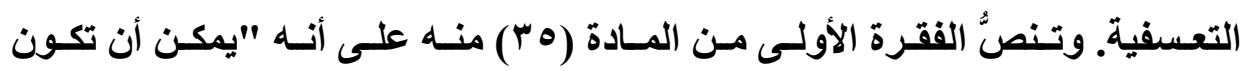

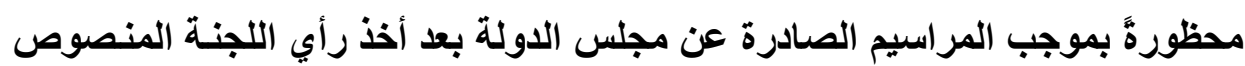

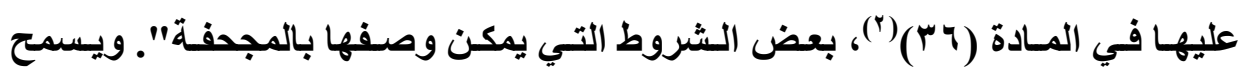
استخدام الفعل "يمكن" وليس "يكون" بحظر تلكت الشروط غير القانونيـة بوسـائلَ

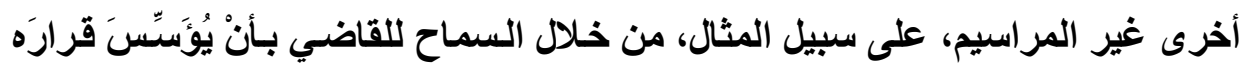

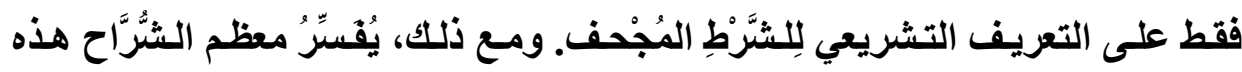
الفقرة على أنهـا تمنـع القاضـيَ مسن فرض العقـاب على الشرط المجحف في غيـاب مرسـوم، والاعتمـاد في معظم الأحيـان على الأعمـال التحضيرية للقـانون المــكور (").

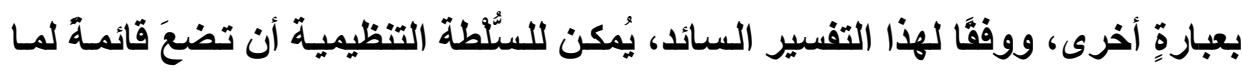

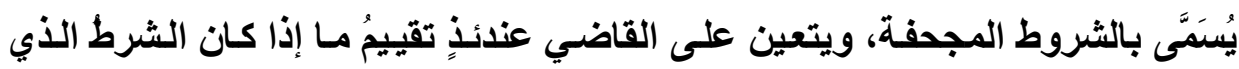

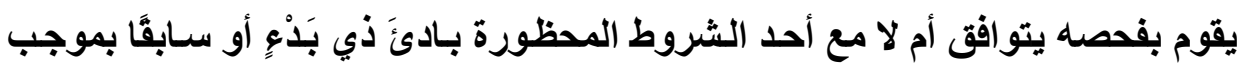

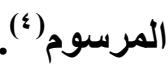

(1) Loi no 78 - 23, du 10 Janvier 1978.

(2) Il s'agit de la Commission des Clauses abusives (CCA).

(3) J. GHESTIN, "Le Pouvoir du Juge d'annuler une clause en la qualifiant d'abusive malgré l'absence d'un décret prévu par la loi du 10 Janvier 1978 sur l'information et la protection des consommateurs", Recueil Dalloz, 1990, p. 289.

(4) Ibid. 
وخلال السنوات الأولى من تطبيق المسادة (هـ)، تبين أن القضاة قد اختاروا

أيضًا هذا التفسير('). ومن هنـا، فِإن هـامش التقدير الممنوح للقاضسي بشأن وصف الشروط التعسفية قد تَقلَّصَ إلى حدٍ كبير، لدرجة أن الأستاذ (تيري) قد وصف ذلتك

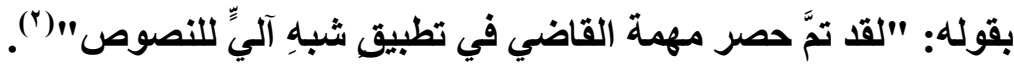

ومع ذلك، منذ نهاية عام ، 19 1 وأوائل عام • 99 19، أزاحت العديد من أحكام

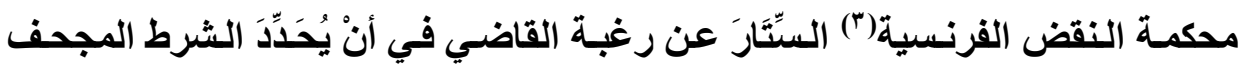

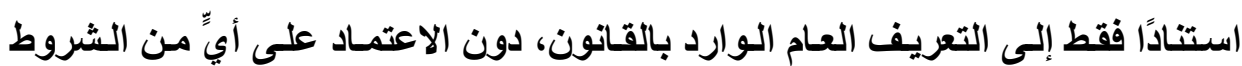

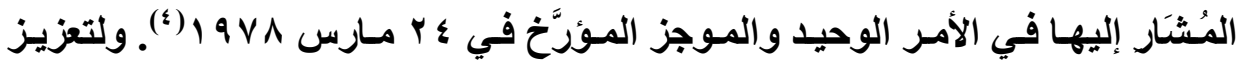

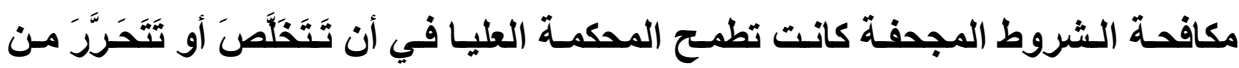
الإشارة إلى مرسوم معين في تكييفها للشرط التعسفي.

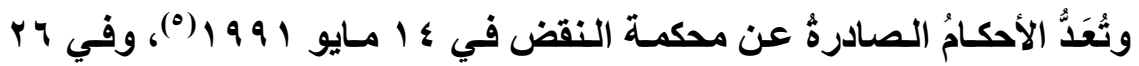

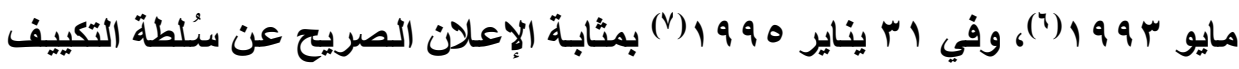

(1) A. KARIMI, "Les clauses abusives et la théorie de l'abus de droit", LGDJ, 2001, p. 559.

(2) F. TERRÉ, "Droit Civil: Les obligations", $10^{\text {ème }}$ éd., Dalloz, 2013, p. 346.

(3) Cour de Cassation Civ. 1, 16 Juillet 1987, $\mathbf{N}^{0}$ de Pourvoi 84-17331; 16 décembre 1989, no de Pourvoi 88- 16727 ; 14 mai 1991, $N^{0}$ de Pourvoi 89- 20999.

(4) Décret no 78- 464, du 24 mars 1978, Portant application du chapitre IV de la loi no 78-23 du 10 Janvier 1978 sur la protection et l'information des Consommateurs de produits et de services.

(5) Cour de Cassation, Civ. 1, 14 mai 1991, $\mathbf{N}^{0}$ de Pourvoi 89- 20999.

(6) Cour de Cassation, Civ. 1, 26 mai 1993, $\mathbf{N}^{0}$ de Pourvoi 92- 16327.

(7) Cour de Cassation, Civ. 1, 31 Janvier 1995, $\mathbf{N}^{0}$ de Pourvoi 93- 10412. 
أو الوصف الجديدة التي فاز بها القاضي. وقد تمَّ تدعيم هذا الانقلاب القضائي بشدة(')،

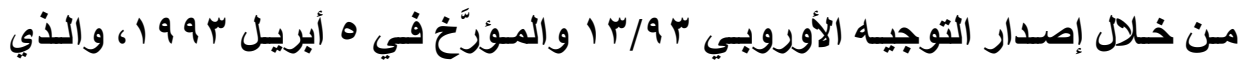

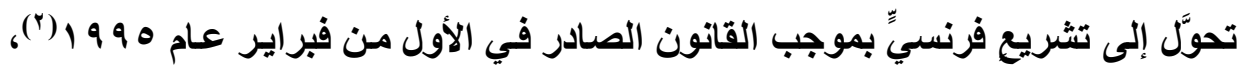

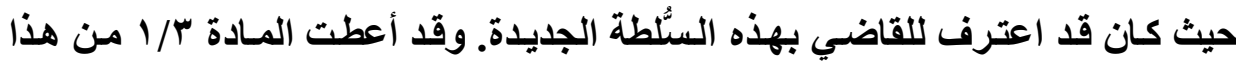
التوجيه تعريقًا عامَّا للشرطِ التعفيِّ دون أن تفرض على القاضي ضرورة الرجوع إلى لى

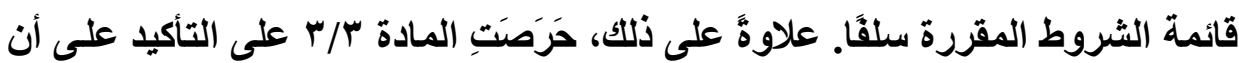
قائمة الشروط الواردة بـالمرفق ليست سوى "إرشـادية". وهكذا، يمكنتا أن نقابلَ أو نقارنَ أحكامَ محكمة النقض المتعلقة بالتطبيق المباشر للتعريف العام للشرط التعسفي

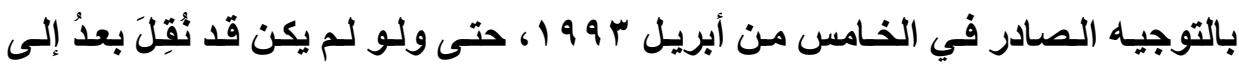

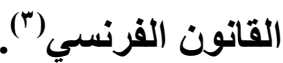
مثـال آخر، يكشف عن التأثثير الذي يمارسـه القانون الأوروبـي على سـلطات القاضـي في وصف الشروط غير العادلة يتعلق ببلجيكا. فكما هو الحسال في فرنسـا، استفاد القاضـي البلجيكي مـن التوجيـه ب 9/ ا في جعل سـلطته في وصف الشرط المجحف أكثر استقلالاً. حيث أثشارت محكمة التجارة بنامور، في حكم صسادر في الثامن

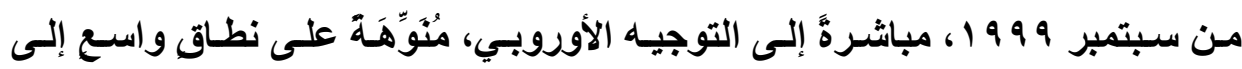
الأدبيات القانونية المتعلقة بهذا النص(؛) وقد سمح هذا الأمر للقاضي في بلجيكا بـأن

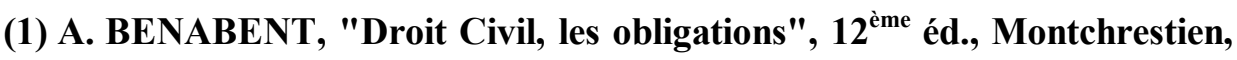
2015, p. 173.

(2) Loi no 95- 96, du 1er février 1995, Concernant les clauses abusives.

(3) A. KARIMI, "Les Clauses abusives et la Théorie de l'abus de droit", op.cit., p. 560.

(4) A. KARIMI, "Les Clauses abusives et la Théorie de l'abus de droit", op.cit., p. 561. 
يُبرِرِ سُّطته الجديدة في تكييف الشرط غير القـانوني مؤسستًا ذلك فقط على التعريف العام. ومن هنا، لم يُشِرْ القاضي البلجيكي إلى القائمة المقررة سلقًا للشروط المجحفة، وذلك خلاقا للتفسير التقليدي للقانون البلجيكي. ويدون تفسير مطابق للتوجيه، سوف

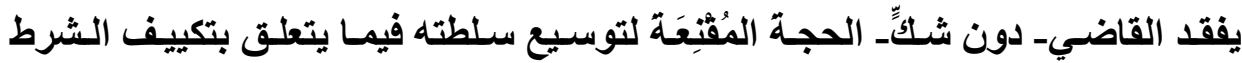

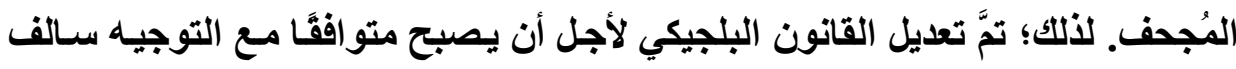

ومن اللافت للنظر، أنه في حالة بلجيكا، كما هو الحال في حالة فرنسا، فقد تمَّ

إضفاء الطابع الأوروبي على القانون الوطنيِّ لأول مرةٍ في محكمة القاضـي، قبل نقله إلى النَّصِّ التشريعي.

\section{(ب) التقدير الوظيفي أو الآلي للطابع التعسفي:}

ثمـة تأثير آخر للقانون الأوروبي بشأن الشروط غير العادلة على سُـطات أو صلاحيات القاضي، وذلك فيما يتعلق بالرقابة الآلية أو الوظيفية على تلك الشروط. في

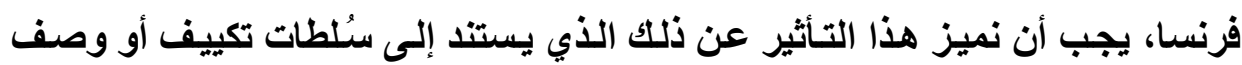
الثروط؛ لأنه لا يُمارس لتعزيز عمل محكمة النقض، ولكن يذهب على خلاف السوابق القضائية لهذه الأخيرة. وحقيقة أنه يمكن للقاضي أن يثير آليَّا أو من تلقاء نفسه الطابع

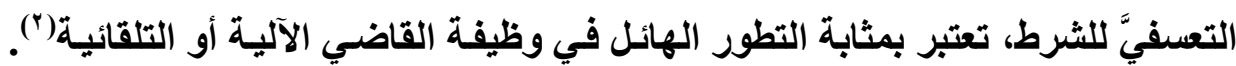

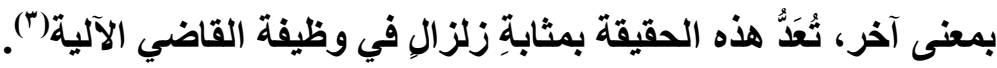

(1) Ibid.

(2) E. BAZIN, "De l'office du juge en droit de la consommation", Disponible sur : http://magat.francois.free.fr/SOCIAL.html.

(3) Ibid. 


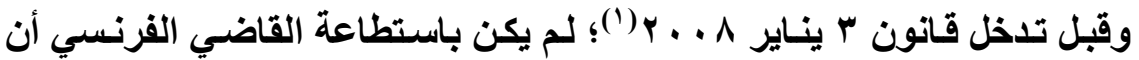

يُقيم آليَّا، ومن تلقاء نفسه، الطابعَ التعسفيَّ للشرط. وعلى الرغم من انتقادات الفقهـ ومقاومة جاتبٍ لا بأس به من قضاة الموضوع، كان موقف المحكمة العليا حازمًا: "منذ

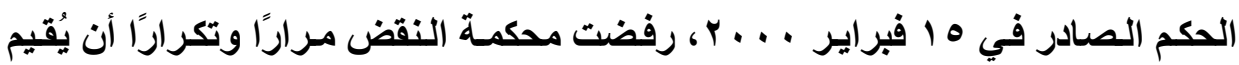
قاضي الموضوع آليَّا أو من تلقـاء نفسه جميعَ أحكام تقنين الاستهلاك" (؟). وقضت بتعارض المبدأ الذي يتعين بموجبه على القاضسي أن يحكم فيمـا يطلبه الأطر اف وليس فقط بخصوص هذا الأمر، والنظام العام للحماية، وكذا حياد القاضي مع الرقابة الآلية أو الوظيفية على الثروط التعسفية.

على العكس من ذلك، في أحكام أوسيانو (") وموستاز اكلارو( ())، قضت محكمـة

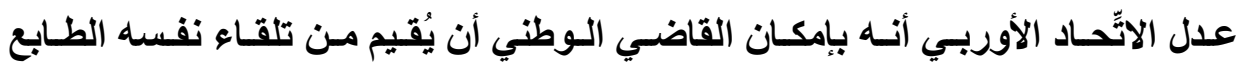
التعسفي للشرط(ْ). وقد استقبل القضاة الفرنسيون(")، الذين كـانوا قد اعترضوا على الـي قضاء محكمة النقض، برضـاعِ كاملِ هذه الوظيفة الجديدة للقاضسي والتي فُرضت عن طريق القانون الأوروبي لا سيما محكمة عدل الاتّّاد. ويسمح هذا الفحص التلقائي أو

(1) Loi no 2008-3, du 3 janvier 2008, pour le développement de la concurrence au service des consommateurs.

(2) E. BAZIN, "De l'office du juge en droit de la consommation", op. cit.

(3) CJCE, 27 Juin 2000, Oceano Grupo Editorial SA c/Muricano Quintero, C-240/98 à C-244/98, Rec. 2000, p. I-04941.

(4) CJCE, 26 octobre 2006, Elisa Maria Mostaza Claro C/Centro Movil Milenium SL, C-168/05, Rec. 2006, P.I-10421.

(5) Ibid., Point 38.

(6) E. RIGAL, "Le Juge et les clauses abusives", colloque : La commission des clauses abusives en action, 20 mars 2009. Disponible sur http://www.clauses-abusives. 
الآلي، في الواقع، بتوفير حمايةٍ أكثرَ فعالية للمستهلكين الذين يجهلون تضمين عقودهم

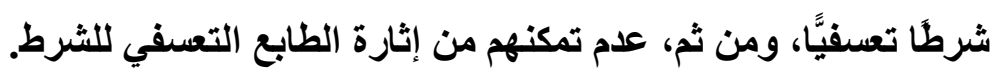

ويبدو لنا أن قضاء محكمة عدل الآَّاد الأوربي يكون أساسًا من ناحيتين؛ ليس

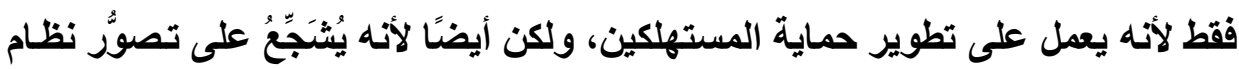
الثروط التعسفية كجزءٍ من النظام العام. وفي الواقع، يتعين على القاضي حينما يفحص

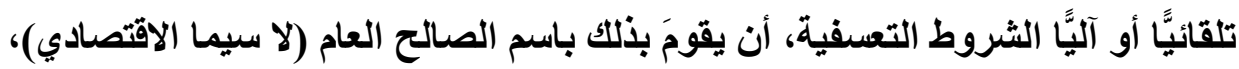

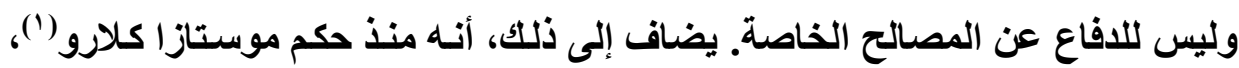

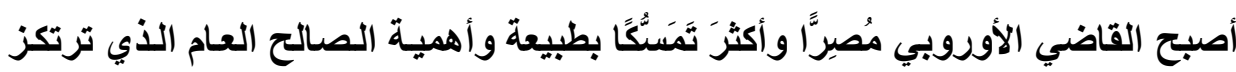

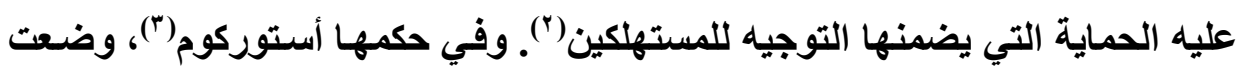

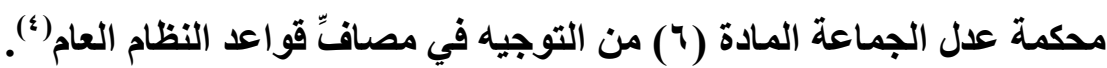

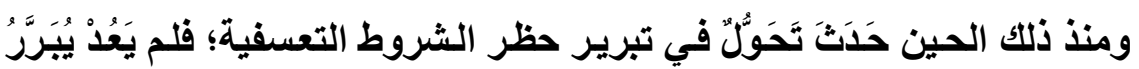
حظر ها فقط من منطلق حماية مصالح الفرد المتعاقد، ولكن أيضًا من منطلق مصالح

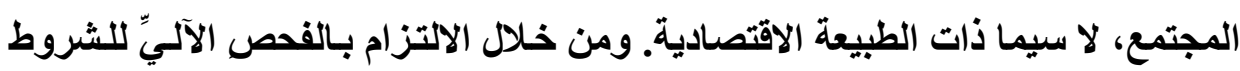
التعفية، يدافع القاضي الأوروبي عن الصالح العام عن طريق حظر الشرط التعاقدي،

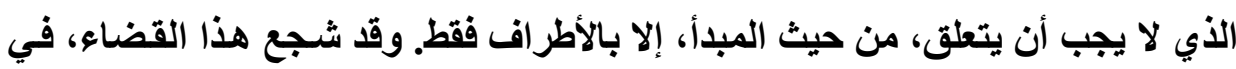
الحقيقة، على تصور العقد؛ ليس فقط كشأن من شئون الأطراف، ولكن أيضًا كـأداةٍ

(1) CJCE, 26 Octobre 2006, Elisa Maria Mostaza Clara c/centro Movil Milenium SL, C-168/05, Rec. 2006, P. I.10421.

(2) Ibid.

(3) CJUE, 6 Octobre 2009/ Asturcom télécommunications SL c/Cristina Rodriguez Nogueira, C-40/08, Rec. 2009, P.I-9579.

(4) Ibid., Point 52. 
لخدمـة النمـوذج الاجتمــاعي الاقتصـادي. ومـع ذلـك، يمكن أن يحتفظ نظــام الشروط التعسفية بنزعته نحو حماية المصالح الخاصة، وذلك في الحدود حيث تقبل محكمة عدل الاتِّاد، كما في حكم بانون(')، أن المستهلك، بعد التتبيه عليه من جاتب القاضي، يمكن أن يعدل عن التأكيد على الطـابع التعسفي لشرطِ مـا، كمـا في حالـة تغليب المـصلة الفردية على المصلحة العامة.

ومع ذلك، لم ثُقبل السوابق القضائية الأوربية المتعلقة بواجب القاضي بأن يُقيم آليَّا من تلقاء نفسه الطابعَ التعسفيَّ للشرط بشكلِ فوريٍّ وإجماعي في القضاء الوطني. وجدير" بالملاحظة، أن بعض الدول مثل جمهورية التشيك، ولاتفيا، وهولندا، وروماتيا، تفترض صلاحية الثروط غير القانونية أو التعسفية ما لم يُيرْ المستهلكُ مسألة الطابع التعسفي. وهذا المَنْعَى يتنـاقض، في الحقيقة، مـع المبـادئ التي أعلنتها محكمـة عدل الاتِّاد، والتي أشرنا إليها سلقًا.

وهكذا، يكون تأثير السوابق القضائية الأوروبيـة المتعلقة بـالفحص التلقائي أو

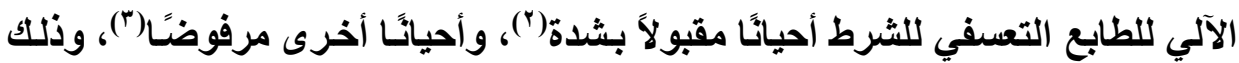
وفقَا للاول ووفةًا للقضاة أنفسهم. ومن ثم، يبقى أثُرُ الأحكام الأوروبية في المحاكم الوطنية ضعيقًا. ومع ذلك؛ وفقَّا لمبدأ الأسبقية"(؛)، يجب على القضاة احترامه.

(1) CJUE, 4 Juin 2009, Pannon GSM ZrT. c/Erzsebet Sustikne Gyorfi, C243/08, Rec. 2009, P.I-047/3, Point 33.

(2) Cour de cassation, civi.1, 16 mars 2009, $\mathrm{N}^{0}$ de Pourvoi 5-20176 ; Cour de cassation, civ. 1, 30 mai 2012, No de Pourvoi 11- 12242.

(3) Cour de cassation, civi.1, 16 mars 2004, $\mathrm{N}^{0}$ de Pourvoi 99-17955 et 9917957.

(4) CJCE, 15 Juillet 1964, Flamino Costa C/E.N.E.L., 6/64, Rec. 1964, P.1141. 
وفي النهاية، لا ينحصر أثرُ القـانون الأوروبي بثأن الثروط التعسفية على فئل

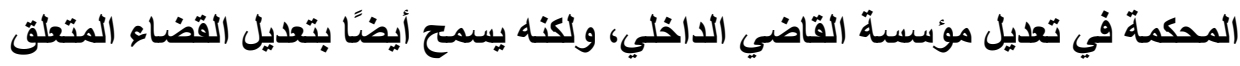
بمضمون نظام الثروط التعسفية ذاته.

\section{ب- التأثير الأوروبي على القضاء الوطني بشأن الشروط غير القانونية} (1) التأثير غير المباشر والتأثير المباشر

لقد تَّمّ تعديل القضاء الوطني، في المقام الأول؛ بسبب اعتمـاد النظام الجديد

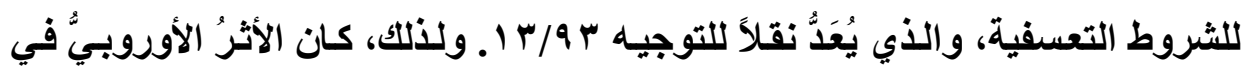
القضاء الوطني غيرَ مباشر أساسًا، فقد مَرَّ باعتمساد تدبير وطنيّ للتحويل أو النقل.

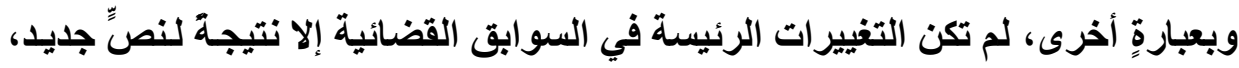
وليس نتيجة لأثر أوروبيّ مباثر . وسيكون تحليل هذه التعديلات بمثابة تقييم لأثر

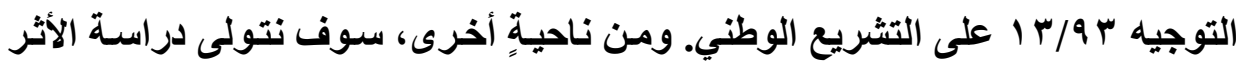

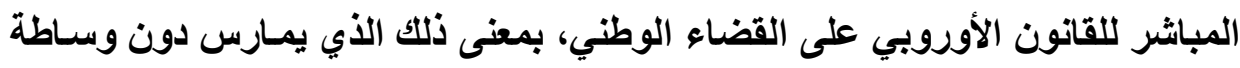

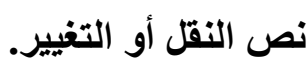
أحيانًا، يعترض المشرع الوطني على إضفاء الطابع الأوروبي على القانون

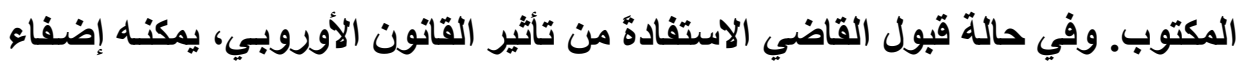

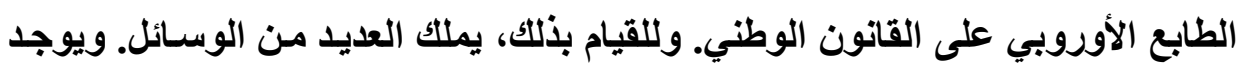
من بين هذه الوسائل "الأثر المباشر " للتوجيه، وتفسير القانون الوطني طبقًا للتوجيه

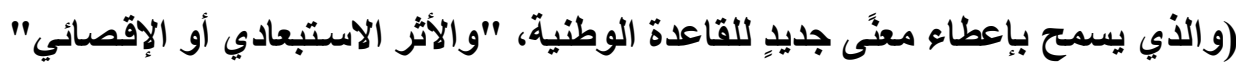
للتوجيه (و الذي يستبعد تطبيق بعض القوانين الوطنية). كذلك يمكن للقاضي الوطني

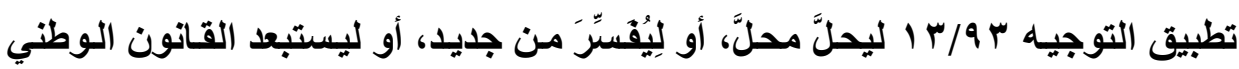

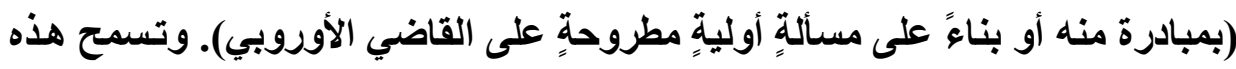


الآثار، لا سيما الإحلال والتفسير، بفرض نظام حمايـة أوروبيةٍة، وكذا تعديل (أو تحديد أو استكمال) المحتوى الأساسي للنظام الوطني.

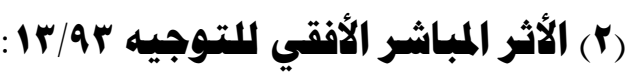

لقد أظهر القاضي الأسباني جرأَّ كبيرةَ في إضفاء الطابع الأوروبي على القانون الوطني. وفي حكمها الصادر في الثامن من نوفمبر 999 19، اعترفت المحكمة العليـا

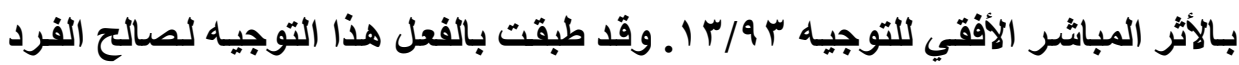
(المستهلك) ضدَّ فردٍ آخر (المهني أو الحرفي). وهذا قد سمح لها بتطبيق نظـام حمايـةٍ للمستهلك لم يكن موجودًا بعدُ في النصوص الوطنيـة. ومع ذلتك، يبدو أنها قد رجعت بخصوص هذا القرار بصفةٍ خاصدة في أحكامها الصادرة في اس يناير وس ا نوفمبر 1991 اـ إلا أن هذه القضية قد كشفت عن مدى قدرة القاضي الوطني في إخفاء عجز أو فثل المشرِع الذي لم يَقْمْ بنقل التوجيه، وكذا ضمان تأثير القانون الأوروبي في النظام القانوني الوطني. وعندما يتصرف القاضسي الوطني على هذا النحو، فغالبَّا مـا يكون مدفوعًا بوجود مصلحةٍ معروفةٍة بشكلِ واضـح؛ فهو يأمسل، على سبيل المثال، أنْ يُوَقِرَ للمستهلكِ حماية أكثرَ من تلك المنصوص عليها بالتشريعات الوطنية.

(r/ar/ar التفهيز وفقا للتوجيه

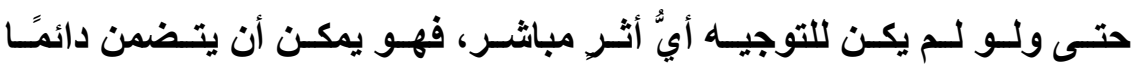

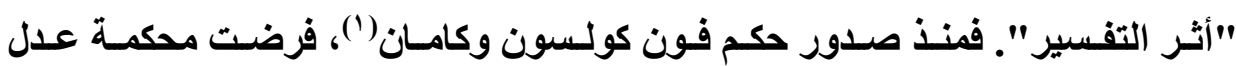
الاتِّـاد الأوروبي على المحساكم المختلفة تفسير القـانون الوطني على ضوء الغرض

(1) CJCE, 10 Avril 1984, Sabine von colson et Elisabeth Kamann c/Land Nordrhein-Westfalen, 14/83, Rec. 1984, p.1981. 


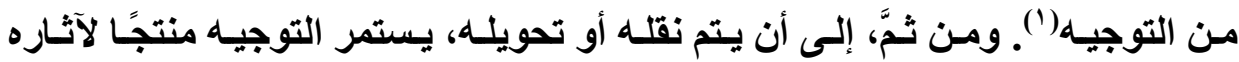

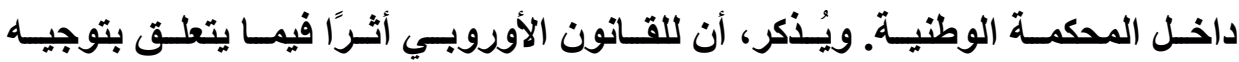

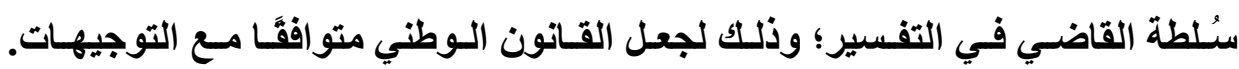

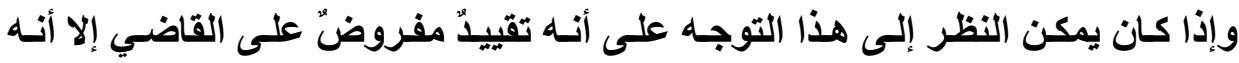
يخلق لصالح هذا الأخير فرصدة في أن يختار تفسيرًا جديدًا، وأحيانَا جريئًا، للقانون

$$
\text { الوطني. }
$$

وجدير" بالملاحظة، أنه أَجْريَت العديد من التفسيرات المتطابقة أو المتوافقة في

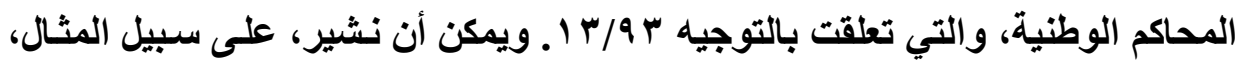
إلى حكم صادر عن المحكمة العادية في تورين في السابع من يوليو 999 19 ـوفي هذهي القضية، طلبت جمعية المستهلكين من القاضي أن يصف الشروط غير العادلة بمجرد توصياتٍ تمَّ عملها من جانب المهنيين بغرض استخدامها مستقبلاً. ويُذكر ، أن القانون

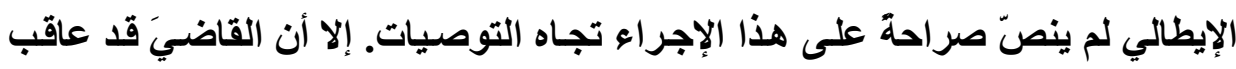

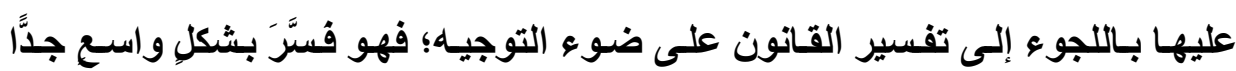
مفهوم "استخدام" الثروط، ليشمل ذلك مجرد التوصية بها. وجدير" بالذكر، أنسه يمكن

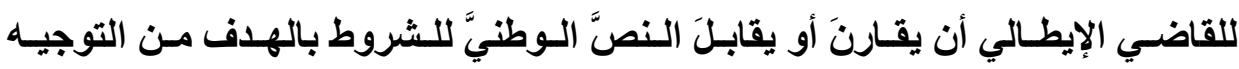

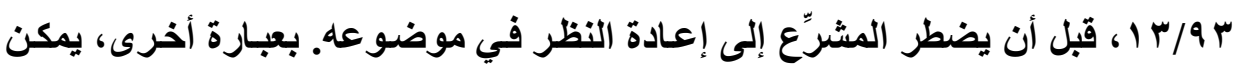

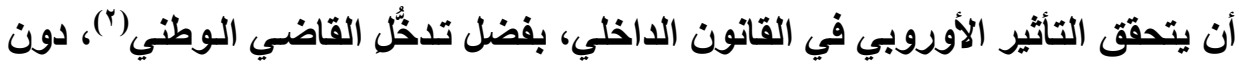
انتظار التصحيح التشريعي في هذا الصدد.

(1) Ibid., Point 26.

(2) CJCE, 24 Janvier 2002, Commission C/Italie, C-372/99, Rec. 2002, P.I00819. 
وكـان مفهوم المستهللك، أيضًا، موضـعَ تفسيراتٍ متسقة. في حكم صسادر عـام

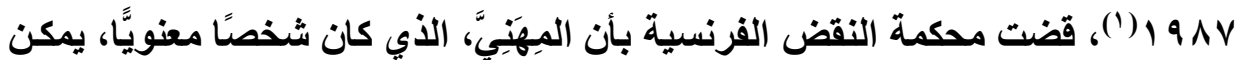

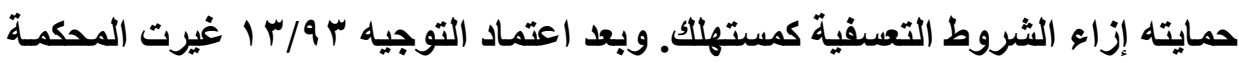
العليـا اتِّجـاه قضائها، الأمر الذي يمكن تفسيرُهُ كمؤشِّرِ على مراعـاة التوجيه سـالف

من الآن فصاعدًا، لم يَعْدُ في الإمكان تكييف أو وصف المتعاقد كمستهلك، عندما يكون العقد مرتبطا مباشرةً بنشاطه المهني (). ويبدو أن السوابق القضائية قد اعتبرت

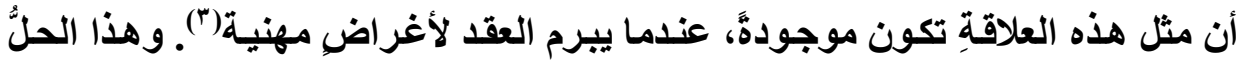
الجديد، يجعل المفهوم الفرنسي للمستهلك أقربَ إلى ذلك الذي تـمّ تحديده صراحة في المادة (ץ) من التوجيه سالف الذكر : الشخص الذي يعمل لأغر اضِ لا تُشَكَّلُ جزعًا من نشاطه المهني.

وإذا كانت محكمة النقض الفرنسية تستشهر بالقـانون الأوروبي بحذر شـدياٍ، أجيز لقضاة الموضوع استخدام هذه الإشـارة الأوروبية. ففي حكمها الصادر في 1 أس سبتمبر 991 1، أعلنت محكمة استئناف ليون صراحة أنها قد فسرت عبـارة "غير المهنيـة أو المستهلك" الـواردة فـي القـانون الفرنسي، على ضـوي أحكـام التوجيـه المعني (؛)

(1) Cour de cassation, civ. 1, 28 avril 1987, $\mathbf{N}^{0}$ de Pourvoi 85-13674.

(2) Cour de cassation, civ. 1, 24 janvier 1995, $\mathbf{N}^{0}$ de Pourvoi 92-18227.

(3) F. TERRE, "Droit Civil : Les obligations", op. cit., p.338.

(4) Cour d'appel de Lyon, $3^{\text {eme }}$ chambre, 18 Septembre 1998, RG Cour 97/01293, affaire 502. 


\section{(1) الحوار بين القاضي الوطني والقاضي الأوروبي: بداية صعبة}

تستند آلية المسألة الأولية أو الفرعية أساسًا على حسن نيةِ أو حسن تصرفِ

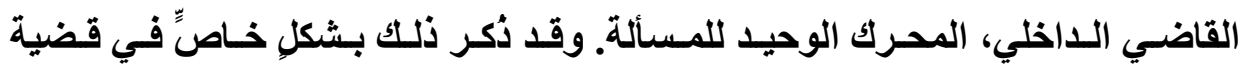
بينزوجي ليزينج(')، والمتعلقة بنظام الشروط التعسفية: تستتد المسألة الأولية على الحوار بين القضاة، والذي تتوقف إثارتـه بالكامل على تقييم المحكمة الوطنيـة لمدى أهميةِ المسألةِِ وضرورتها. وبخصوص الثروط التعسفية أو غير العادلة، تَرَدََّّ القضاة الوطنيون للغاية خلال السنوات الخمس الأولى من تطبيق التوجيه ب ب/ ا 1 بشأن طرح المسائل الأولية. وقد فضل القضاة، خلال هذه الفترة، الامتناع أو السكوت بغرض تجنب الإجابات الأوروبية التقييدية، والتي من شـأنها أن تحدَّ من سلطتهم في التفسير. وقد ترتب على هـا الامتــاع، الحدُّ مـن تـأثير القـانون الأوروبـي في الأنظمـة القانونيـة الاخلية(؟). وقد كثف تقرير المفوضية الصادر في عام . . . ب أن:

"على الرغم مـن زيـادة وعي القضاة الوطنيين بالقـانون الأوروبـي، فِإن أثرَ

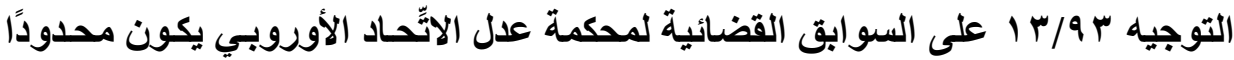

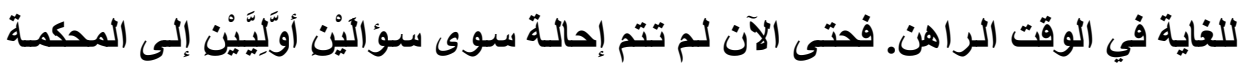
الأوروبية. وما زالت الفرص متاحةة أمسام المحاكم الوطنية لإحالة المسائل الأولية إلى الى

(1) CJUE, 9 Novembre 2010, VB Penzugyi Lizing Zrt. c/Ference de Schneider, C-137/08, Rec. 2010, p.I-10847.

(2) CJCE, 12 Fevrier 2008, Willy Kempter KG c/Hauptzollamt HamburgJonas, C-2/06, Rec. 2008, P.I- 411, point 42. 
محكمـة عدل الاتِّــاد، ومـن المفيــ جـدًا أن تـتمكن هذه الأخيرة، خـلال إجاباتها، مـن توضيح نطاق بعض أحكام التوجيه"(').

ويمكن توضيح ذلك بالإشـارة إلى السوابق القضائية لبعض المحاكم الألماتية،

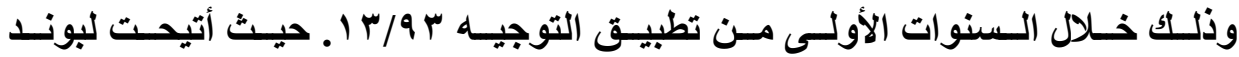
سجريشتشوف العديد من الفرص للمناقشة حول تطبيق المـادة (^) من القـانون بشأن شـروط عقود الانـضمام، والمـادة (\&/Y) مـن التوجيـه سـالف الذكر، وذلكك دون طرح المسائل الأولية، بشأن تفسير المادة الأوروبية، على القاضسي الأوروبي. وفي تقريرهـا المؤرَّخ في VV أبريل . . . . ب بشأن تطبيق التوجيه سـالف الذكر، انتقدت المفوضية

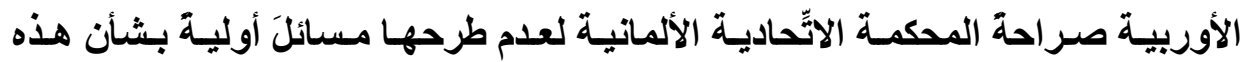

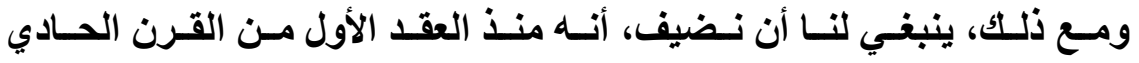
والعشرين، تُوجد زيادةٌ واضحة جدَّا في الأسئلة أو المسائل الأولية المقدَّمة إلى محكمة عدل الاتِّحاد بخصوص الشروط التعسفية أو غير العادلة. ولم تَعُدْ تتردد المحاكم في التي طرح مسائلَ أوليةٍ بشأن نقاطِ شبيهِةٍ بتلك التي سَبَقَ للمحكمة تناولُها.

(r) (r) (التفسير غير المطابق لم يثبت القاضي الوطني دائمًا أنها مبشرٌ قوي" للقانون الأوروبي في تفسيراته للقانون الداخلي. ومن الصعب، أن نراقب احترام مبدأ التفسير المطابق في كلّ قرارات القاضـي اللـاخلي، لا سـيما وأن هذا الأخير لا يخضع لرقابـة محكمـة نقض أوروبيـة. وجديرٌ بالذكر، أنـه يمكن للمحاكم الوطنيـة أن تترددَ في تفسير القانون الوطني على لونى (1) COM (2000) 248, p.36. 


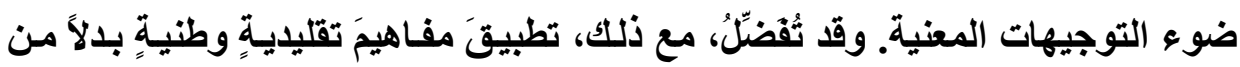
المفاهيم التي تُمليها مؤسسات الاتِّحاد؛ إما لأسبابٍ أيديولوجيةٍٍ أو لأسبابٍ عملية. على سبيل المثال، في المملكة المتحدة، نـدَّد روبرت برادجيت بـالتطبيق السَّيّئ

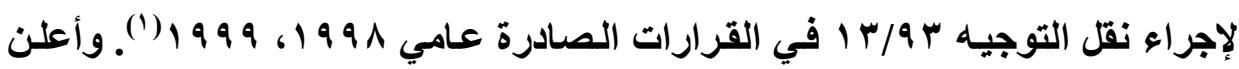
أنه لا يتفق مع الهدف الذي يسعى التوجيه إلى تحقيقه، وهو حمايـة المستهلكين: حيث لم توصف الشروط المتنازع فيها بالتعسفية، رغم أنها تبدو كذلك بشيََّّة. وقد اعترف القاضـي بـأن لغة وأسلوبَ الشرطِ المتنـازع فيهه تنتهكان روح التوجيهه والغرض منـه.

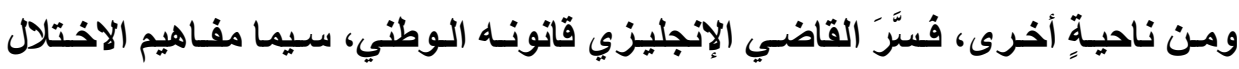
وحسن النية، دون احترام الهذف الذي يسعى التوجيه إلى تحقيقه، وهو حماية المصالح الاقتصادية للمستهلكين وليس حماية مصالح المهنيين.

وبالنظر إلى عدم وجود محكمة نقض أوروبيـة، رفض بعض القضاة الوطنيين

الحلولَ القضائية المجددة، والتي تصدر عن محكمة عدل الاتِّحاد الأوروبي (؟). ومع ذلك، لا تَتََّلَُّ حدود الأثر الأوروبي بشأن الثروط غير القانونية دائمًا عن ضـف إرادة أو سـوء نيـة القاضـي الوطني، بمعنى أن التوجيه نفسه قد يتضمن حدَّه

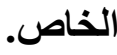

(1) Tunbridge Wells County Court, 4 November 1998, Gosling v. BurrardLucas, Current law, January, 197, Worthing County Court, 8 January 1999, Broadwater Manor School v Davis, Current law, May, 208.

(2) R. BRADGATE, "Experience in the United Kingdom", in la directive "Clauses abusives", cinq ans après, commission européenne, conférence de Bruxelles, 1999, Luxembourg, 2000, p.46. 


\section{ب- الحد المفروض هن خلال التوجيه ra/r}

(1) الحد الأدنى هن الموائهة

ثمة قيد آخر على تأثير القانون الأوروبي بشأن الشروط غير العادلة يتٌّ بحثه

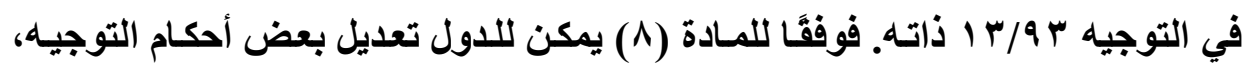
وبالتالي التخفيف من تأثيره، إذا ما استوفت شروطا معينة: أنها لا يمكن أن تعتمد إلا قواعدَ أكثرَ صرامة(')، بمعنى أكثر حماية من تلك الواردة في التوجيه، ولا يمكن إجراء التغييرات إلا في المنطقة المعنية بالتوجيه()، وأخيرًا، يجب أن تكون الأحكام الوطنية متوافقة مع المعاهدة(").

ومسن حيث الشروط غير العادلـة، يقبـل قـانون الاتِّــاد الأوروبـي حدًَا أساسيَّا لطموحه في التـأثير على الأنظمـة القانونيـة الوطنيـة. والأثر الأوروبـي هنـا، هو أقلُ مجموعةٍ من القواعد الموحدة، التي ترمي إلى تحقيق الحدِّ الأدنى من حماية المستهلك. وفي هذه اللحظة، قد يكون هذا الحدُّ ضروريًّا من وجهة نظر سياسيةِ وثقافية.

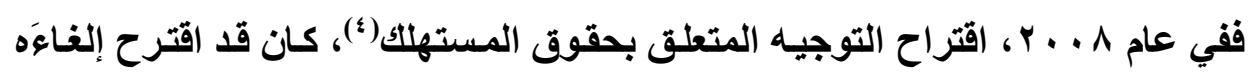

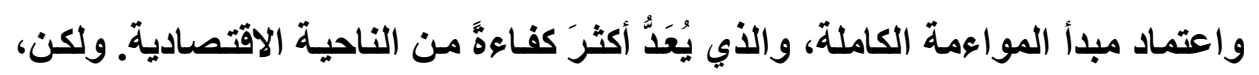
في الحقيقة، قد تمَّ التخلّي عن هذه المحاولة قريبًا، في أعقـاب العديـ من الاحتجاجـات،

(1) Article 8 de la directive 93/13/CEE.

(2) Ibid.

(3) Ibid.

(4) COM (2008) 614, du 8 octobre 2008, Proposition de directive relative aux droits des consommateurs. 
سيما من جانب الدول التي كاتت تواجه خطرَ فقدان مستوى حماية المستهلك. لذا، فِان التوجيه الذي تمَّ اعتمادُه يعمل في النهاية على صيانة مبأ الحد الأدنى من المواعمة. (r) الهد الأدنى هن المواء همة همابل التفهير المطابق

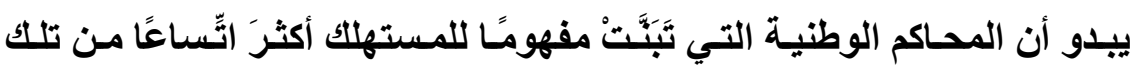
الواردة في التوجيه، تطبق مبأ مقبولاً، ألا وهو الحدُّ الأدنى من الملاعمـة؛ فهي توفر

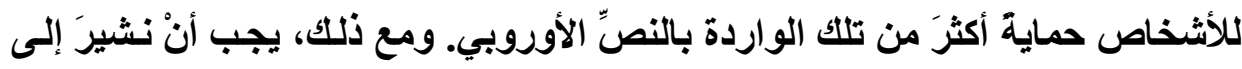

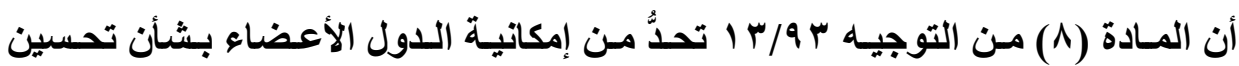
مستوى الحماية التي حَدََّها التوجيه سالف الأكر، وذلك من خلال فرض أحكاجِ وطنيـةٍ

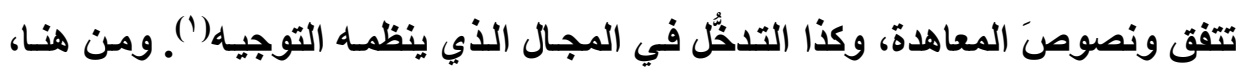
فإنه يمكنُ تجاوز مستوى الحماية الأوروبية؛؛ ليس فقط عن طريق المشرِع، ولكن أيضًا عن طريق القاضي الداخليِّ نَفسِه. وفيما يتعلق بالتوافق مع المعاهدة، يمكنتا أنْ نُفكِّرَ في احترام المـادة (ع/ب) من معاهدة الاتِّحاد الأوروبي: واجب التعاون المخلص من جانب الدول تجـاه الاتِّــاد. فقي حكم فون كولسون وكاما()، استتتجت محكمة عدل الاتِّاد من هذه المادة سالفة الذكر ،

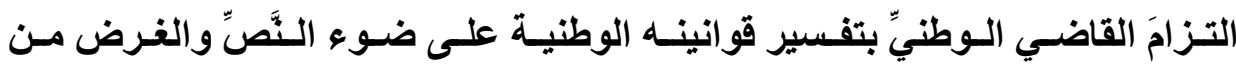
التوجيه("). والحالة هذه، يبدو لنا أن القاضيَ الذي يتبَّى مفهومًا أوسـعَ للمستهلك من ذلك الذي يُرَوِّجُ له القانون الأوروبي لا يحترم مبدأ التفسير المطابق. علاوةَ على ذلك،

(1) Article 8 de la directive 93/13.

(2) CJCE, 10 Avril 1984, Sabine von colson et Elisabeth Kamann c/Land Nordrhein-Westfalen, 14/83, Rec. 1984, p.1981.

(3) Ibid., Point 26. 
يمكن القول: إنه لا يحترم أيضًا الحدود المتعلقة بالمنطقة التي ينظمها التوجيه، والتي تتمثل في العقد المبرم بين المستهلك، الشخص الطبيعي، والمهني أو الحرفي. في فرنسـا، على سبيل المثـال، لـم يُحَدِّد المسرِّع مفـاهيم "المستهلك وغير المهني"، في القانون الأول الصادر عام \ \ 1 ، ولا في التعديلات اللاحقة. ولذلك، فقد عادت مهمة التعريف إلى القاضسي. ومـع ذلك، يبدو أن هذا الأخيرَ قد طرَحَ مبدأ الحدِّ الأدنى من الملاعمة، دون احترام الثروط الواردة بالمادة (^). ويبـدو أن القـانونَ الأوروبسَّ يزخر بالحمايـة مـن الشروط التعسفية لـصالح

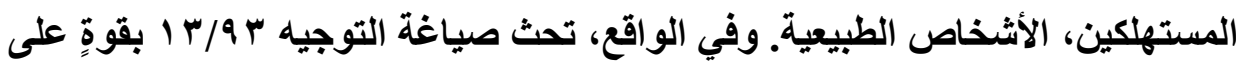
التفكير في أنه لا يمكن أن يكون المستهلك إلا شخصًا طبيعيَّا، ويُعرف المستهلك بأنها

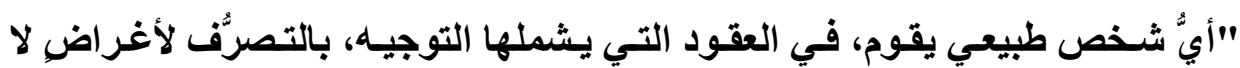
تُشَكَّلُ جزءًا من نشاطه المهني" (1). في حين أن المهنيَّ، يمكن أن يكون شخصنًا طبيعيَّا

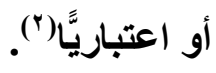

من ناحيـةٍ أخرى، أكد الحكم (كـاب)(")، على هذا التفسير الصارم لنصوص التوجيه. وفي هذا الحكم، أكد القضاء الأوروبي بوضوح تامٍ على أنه: "لا يمكن اعتبار

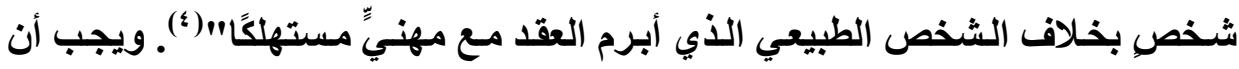

(1) Article 2.6 de la directive 93/13.

(2) Article 2.c de la directive 93/13.

(3) CJCE, 22 novembre 2001, Cape Snc c/Idealserivce Sr1 et Idealserivce MN RE Sas c/OMAI Sr1, c-541/99 et C-542/99, Rec. 2001, p. I- 09049. (4) Ibid., Point 16. 
يُقسَّرَ "مفهوم المستهلكت" كما هو محدد في المسادة (ץ/ب) من التوجيه سـالف الذكر، على أنه يشير حصريًّا إلى الأشخاص الطبيعية(').

والحالة هذه، وفي تـاريخ لاحق، منحت محكمة النقض الفرنسية في قراراتها الصادرة في الخـامس عشر مـن مـارس ه . . Y، وفي السابع والعشرين من سبتمبر

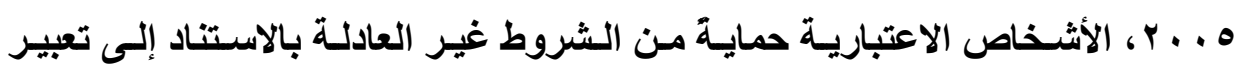
"غير المهني" الوارد في القانون الفرنسي. هذا الأمر قد قضى، في الواقع، على كلّ

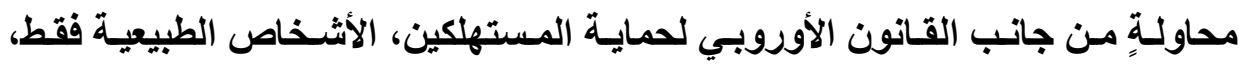

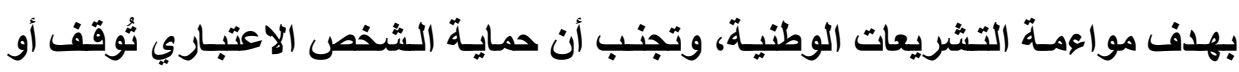
تمنح لمجرد عبور الحدود داخل أوروبا.

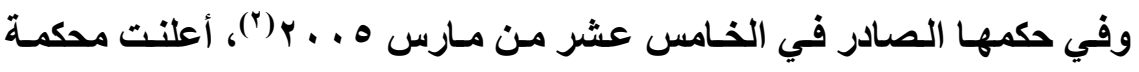

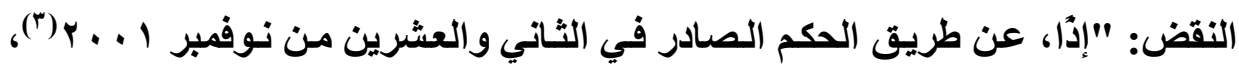
قضت محكمة عدل الجماعـات الأوروبية: "أنـه يجب تفسير مفهوم المستهلك بـالمعنى الأي يشير حصرًا إلى الأشخاص الطبيعية، فإن فكرة تمييز غير المهنيّ المستخدمة من جانب المشرِع الفرنسي، لا تستبعد الأشخاص الاعتبارية من الحماية ضد الشروط غير القانونية". ويقدر، هكذا، كلٌ من المشرِّع والقاضسي في فرنسا أن تعبير غير المهنيِّ

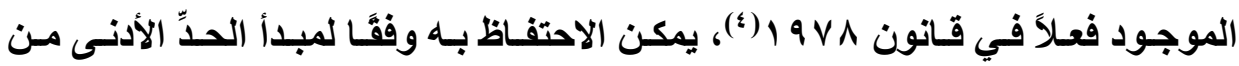
المواعمـة. ومـع ذلك، لا يشير تعبير "غير المهني"، في الواقع، إلى أيِّ شـيء آخر

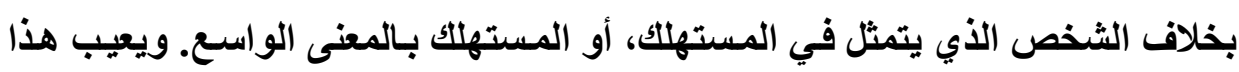

(1) Ibid., Point 17.

(2) Cour de cassation, civ.1,15 mars 2005, $\mathrm{N}^{0}$ de Pourvoi 02-13285.

(3) Arrêt Cape, CJCE.

(4) Loi no 78-23, du 10 Janvier 1978. 
المفهوم الواسـع للمستهلك القـانون الفرنسي؛ بسبب عدم احترامسه لمبـدأ التفسير

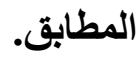

السؤال الذي يلدق هو: هل ينبغي أن يسموَ مبدأ التفسير المطابق على مبدأ

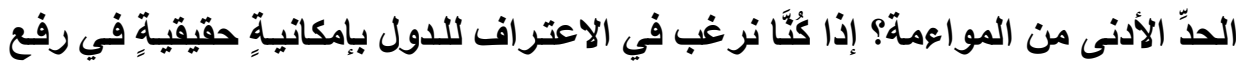
مستوى الحماية الأوروبية، يتعين أن ندرك أن مبدأ التفسير المطابق لا يطبق عندما لأنيا

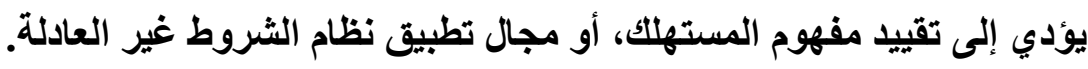
ويتضمن التسليم بمبدأ الحدً الأدنى من المواعمة قبولَ؛ ليس فقط حماية أقوى،

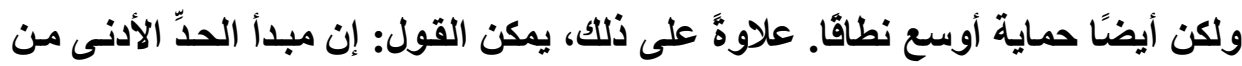

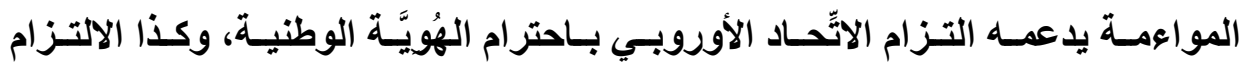

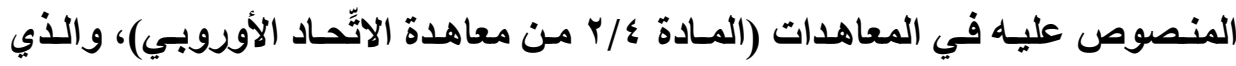

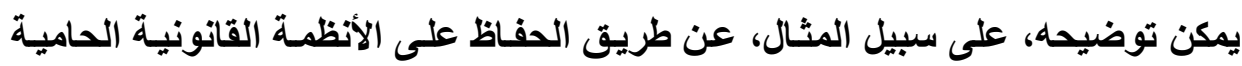

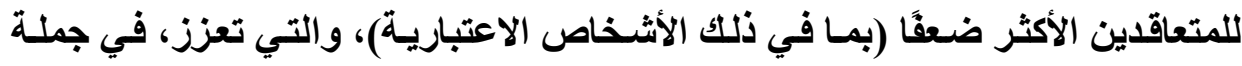

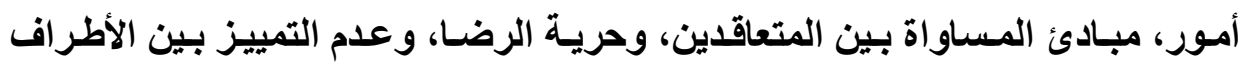

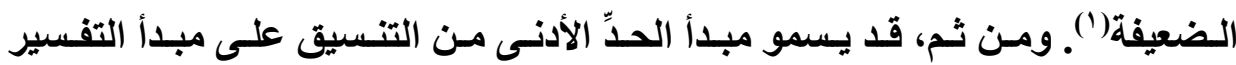

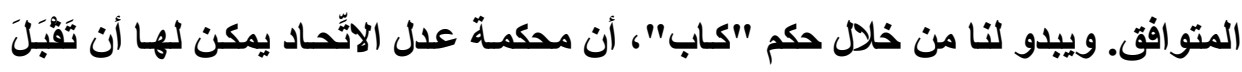

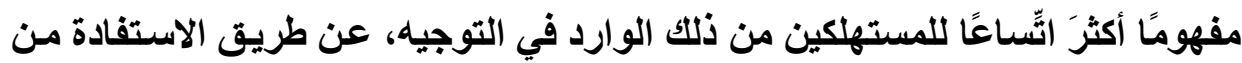
الحدًّ الأدنى للمواومة المنصوص عليه في ذلك التوجيه سالف الذكر، واحترام التعريف

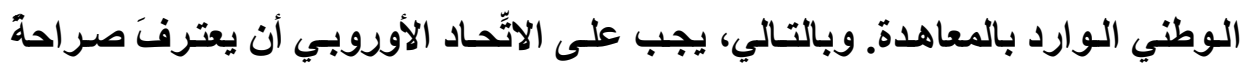

(1) A. KARIMI, "Les clauses abusives et la théorie de l'abus de droit", op. cit., p.570. 
بإمكانية الدول في توسيع نطاق الحماية إلى مجالاتٍ أخرى (أثخاص أخرى، شروط أخرى)، بخلاف تلك الواردة بالتوجيه(') و وعليه، يبدو لنا أن التأثيرَ الأوروبيَّ على القاضي الوطني يُعَدُ أمرًا مرغوبًا فيهـ للغاية، وذلك عندما يؤدّي إلى تحسين مستوى حماية المتقاضين. ولهذا السبب، يتعين الترحيب بالقضاء الأوروبي المتعلق بالفحص الآلي أو التلقائي على نحو أكثرَ إيجابية

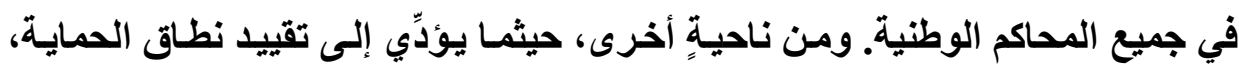

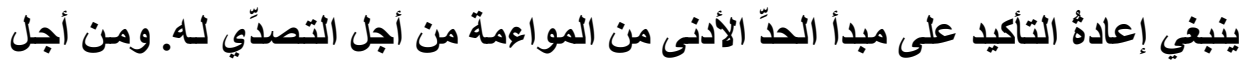

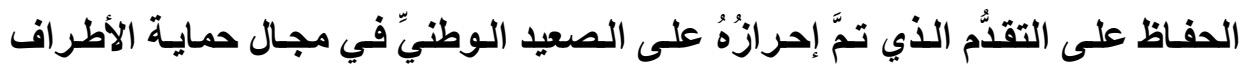
الضعيفة في العقد، أو لتعزيزه مستقبلاً، يتعين ألا يكون القاضي الوطني قاضيًا للقانون

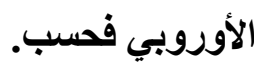

(1) Ibid. 


\section{خـاتمة}

هكذا، عالجنا موضوع القاضي في القـانون الأوروبي والدولي من خلال مبحثٍ تمهيديٍ تكلمنا فيه عن "الاعتبارات الفلسفية حول العدالة الدولية". وفصلِ أوَّلَ بعنوان

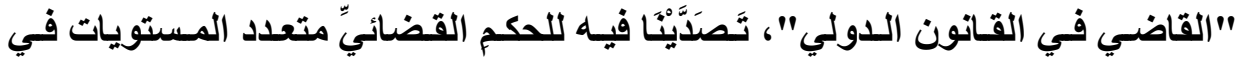
القـانون الاقتصادي الأوروبـي والدولي في مبحثٍ أولَّ، وفي المبحث الثـاني عالجنـا موضوع محكمة العدل الدوليـة في مواجهة حقِّ تقرير المصير، وفي الثالث تَصَََّينّا

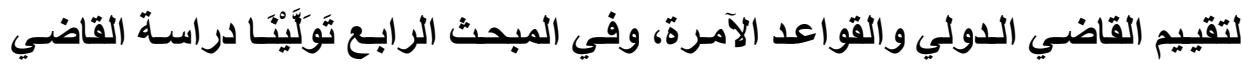
الاولي والضرورات العكرية، وفي المبحث الخامس قُمنّا باراسة موضوع القاضي في مواجهة تحدِّيات قاعات المحاكم الجنائية الدولية متعددة اللغات، وفي المبحث السادس والأخير مـن هذا الفصل عالجنـا موضـوع صـناعة القـانون القضائي الـدولي ونظريـة المصادر.

وفي الفصل الثـاني، والذذي جـاء بعنوان "القاضسي في القـانون الأوروبـي"، دَرَنْنَا المشاركة في الاتِّحاد الأوروبي والتسوية القضائية للمنازعات في مبحثٍ أوَّل،

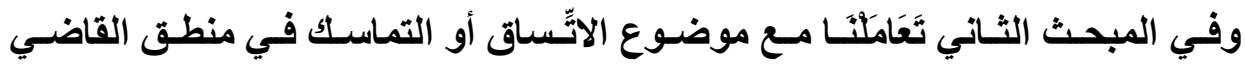

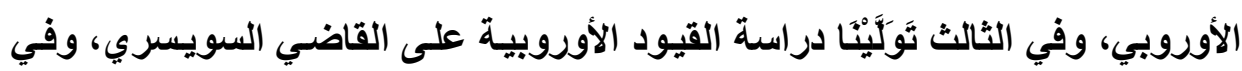

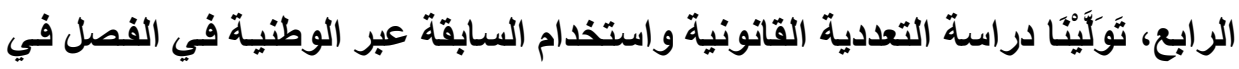
منازعات القـانون الخـاصِّ الأوروبي، وفي المبحث الخـامس والأخير من هذا الفصل، قُنَا بدراسة مدى تأثير القانون الأوروبيِّ بثأن الشروط غير القانونية أو غير العادلنة على القاضي الوطني الأوروبي. 
وبالرغم من أن موضوعَ القاضي في القانون الأوروبي والدولي هو موضوعٌ

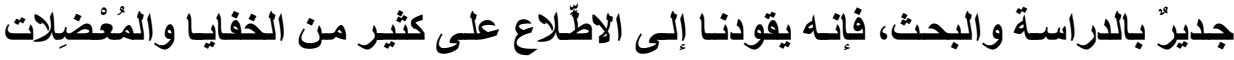

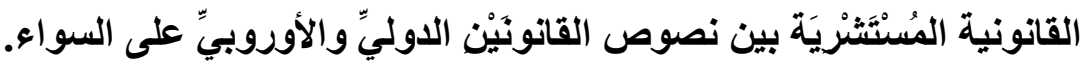
وجديرّ بالملاحظة، أنَّ قلـة الدراسـات و البحوث السابقة، أو انعدامها إذا صَحَّ القول أو التعبير حول الموضوع محلِّ البحث، جَعَلَ من عملية تجميع المعلومـات بشأنه أمرًا غاية في الصعوبة. التعير حول الموض.

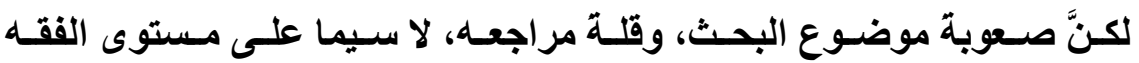
المصريٍّ والعربيّ، لا تغني مطلقًا عدم الوصول إلى أية نتائجَ قد تكون مفيدةً لمن يعتني

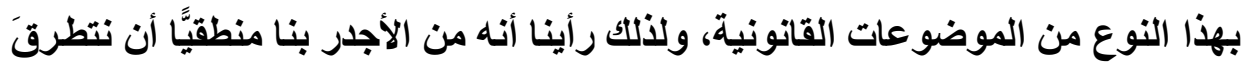
في خاتمة هذا البحث إلى إبراز أهمّ النتائج التي توصلنا إليها، وذلك على النحو الآتي:

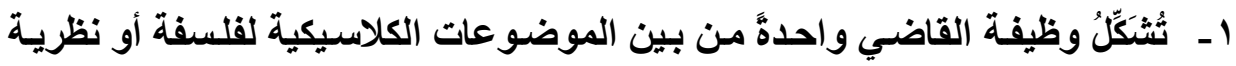

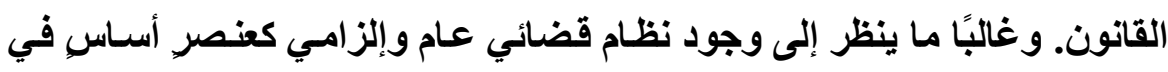

$$
\text { أيِّ نظاج قانوني. }
$$

r- يُسنهمُ القاضي الدوليُّ بالضرورة في إنثاء قو اعد القانون الدولي.

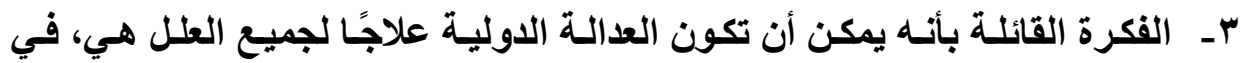

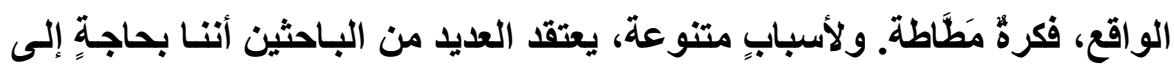

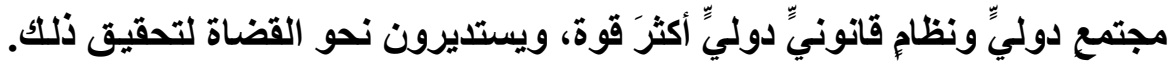

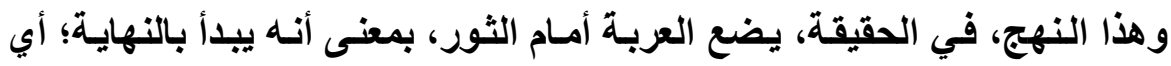

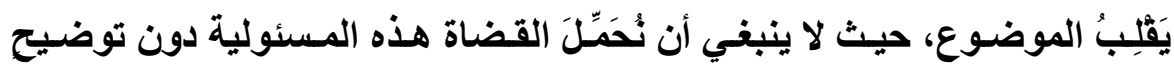

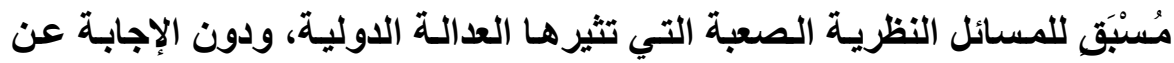

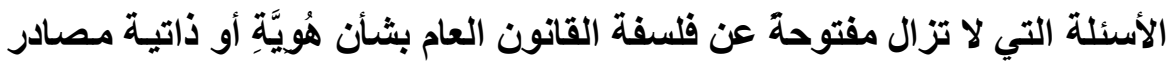


القانون الدولي ووسائل ضمان مشروعية هذا القانون، فضلاً عن ضمان أن تكونَ

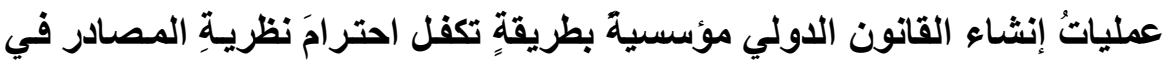
القانون الدولي والمسئولية الايمقراطية للقضاة الدوليين.

ع- - تظلُ الإشارة إلى مبدأ الضرورة العسكرية في أحكام القضاء الدولي الأخيرة قليلة

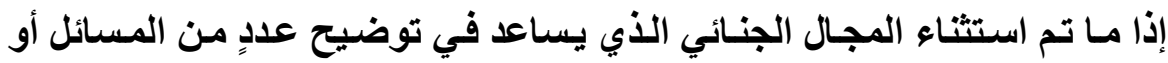

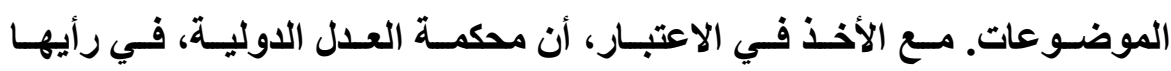
الاستشاريٍ بشأن الجدار الفاصل، قد اجتاحت حجة الضرورة العسكرية. هـ ـ أكَّد القضاء الجنائي، من ناحيته، على أنه يجبُ تقديرُ مبدأ الضرورة العكرية من

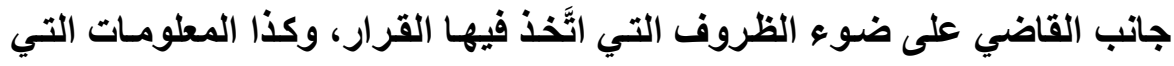

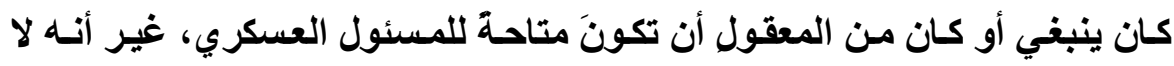

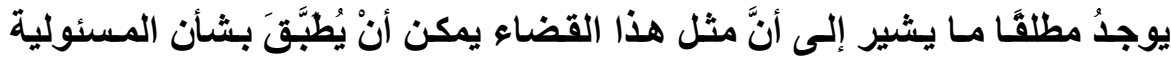

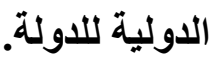

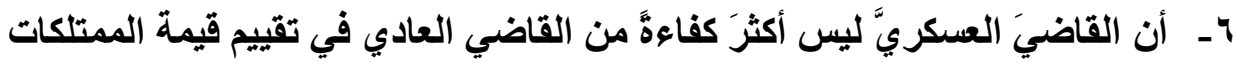

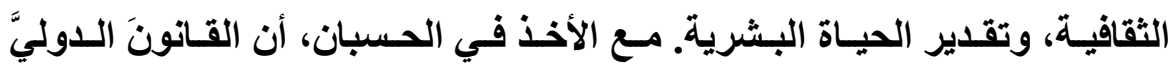

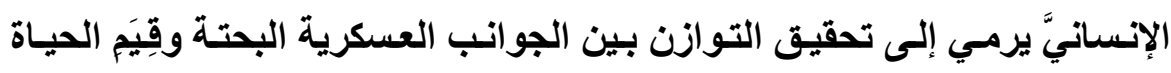

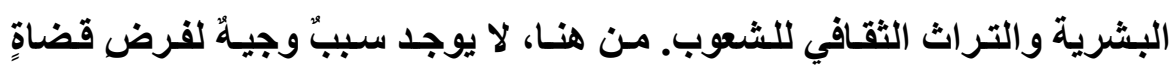
مهنيين عسكريين في الاوائر القضائية الدولية. V- - لا يُكَرِّنُ المؤيدون لمفهوم القانون طاقتهم للاعوة إلى توسيع نطاق التسوية

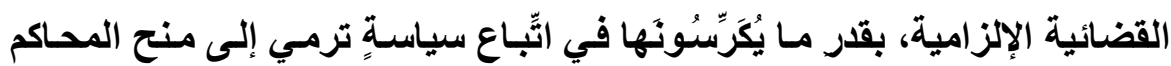

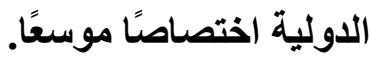

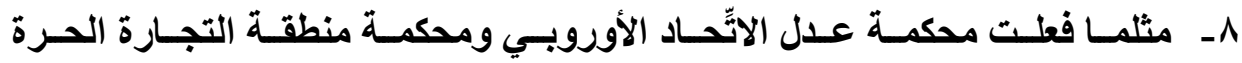


الأوروبيـة، درجـت المحكمـة الأوروبيـة لحقـوق الإنسـان علـى اسـتخدام طـرق ديناميكيـةٍ متطورةٍ في تفسير وحمايـة الحقوق الأسـاسية. وقد سـاعدت الأعداد الضخمة للثكاوى الفردية، المحاكم الثلاث في تفسير وتطوير مواثيق المعاهدات

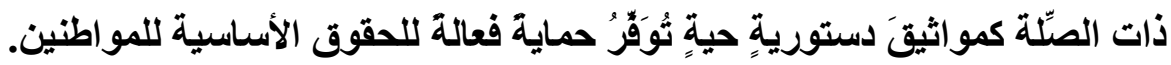
9- كلمـــاد زاد تـأثير العولمـة؛ زادت الحاجـة لمراجعـة المنــاهج القانونيـة وإصــلاح السياسات الاقتصادية والقانونية للمؤسسات ذات الحكم متعدد المستويات في سبيل تحقيق واجباتهـا القانونيـة في حمايـة حقوق الإنسـان وحق الشعوب في تقرير مصائر ها. وكلما انخفضت سيطرة البرلمانات الوطنية على عملية صناعة القانون وإصدار القواعد في المنظمات الاقتصادية الدولية؛ زادت أهمية الحماية القضائية متعددة المستويات للحقوق الاولية متعددة الجنسية وقواعد القانون عبر الوطني تحقيقًا لمصلحة المواطنين.

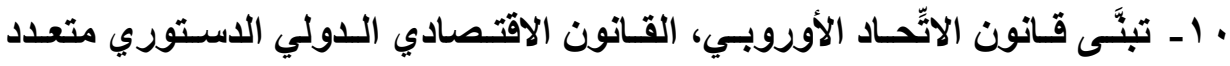
المستويات، وكذا قانون المنطقة الاقتصادية الأوروبية، وإن كان على نطاق أقلَّ الأل بهذف تنظيم الأسواق المشتركة والحقوق الأساسية للمواطنين في هذا الشأن.

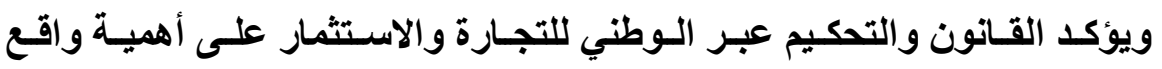
التعدديـة القانونيـة، وكذا مميزات التنسيق بين السلطات القضائية عن طريثق مبادئ وطرق تنازع القوانين.

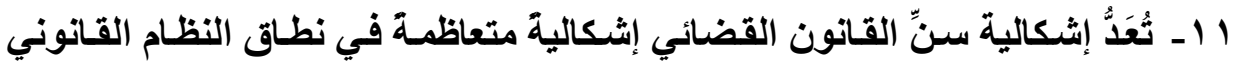
الـدولي، ويرجـع ذلـك لسبيَيْن جوهريَّنْ: الأول، هو وجود ثنغراتٍ في القـانون

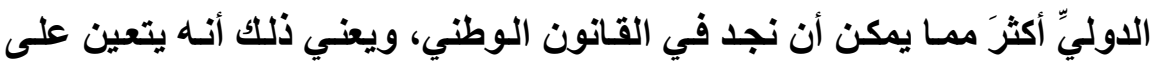
المحاكم الدولية أن تبذلز مجهودًا أكبرَ في تفسير القواعد القانونية (القليلة) التي 
توجد تحت تصرُفها بهدف إصدار حكم في قضيةٍ معينة. والسبب الثاني، هو أن

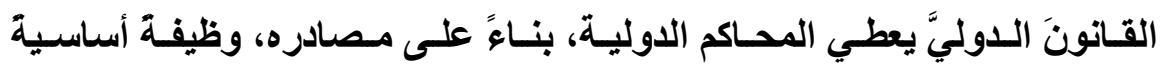
بخصوص تحديد وتفسير القواعد القانونية ذات الصيّة.

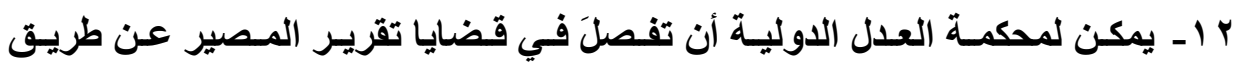

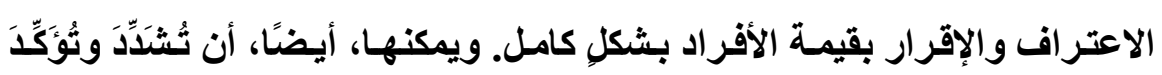
بشكل أكبرَ على أهمية احترام حقوق الإنسان الفردية.

rا ا - يجب على القضاة في قاعات المحاكم الجنائية الدولية متعددة اللغات المراجعة

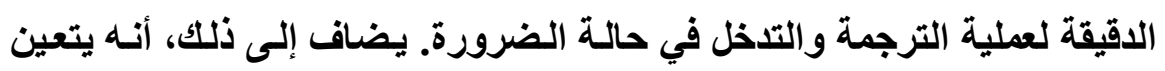

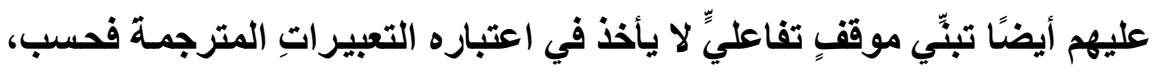

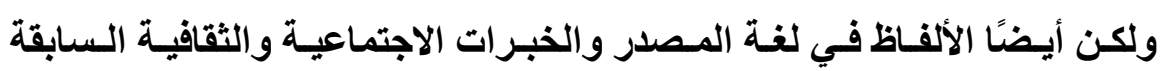

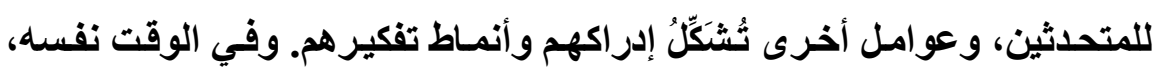

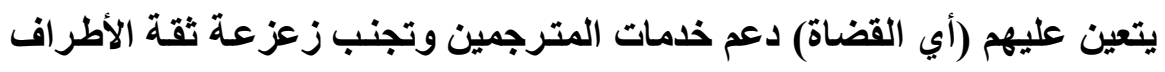

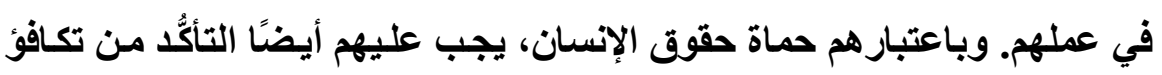

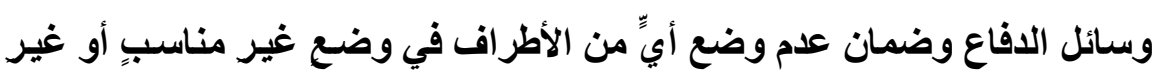
لائق عند عرض قضيته.

؛ ا ـ فيمـا يتعلق بوظيفتها في سنّْ القانون الدولي، تعمل الأحكام القضائية الدولية

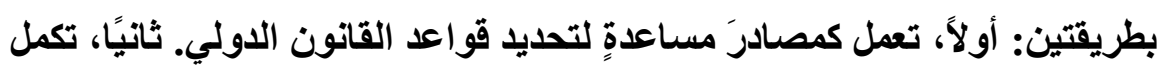
المصادر الرسمية للقانون بتحديد قواعد القانون الدولي. 1 1 ـ بينما يمكن أن ندافع عن الوضعية القانونية بنجاح في السيّاق الوطني، يكون من

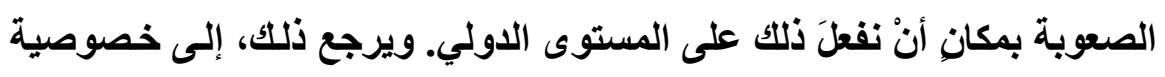

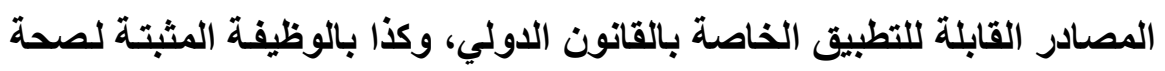

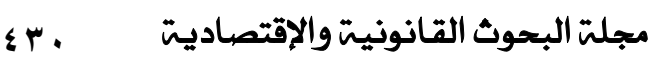


أو مشروعية القانون التي يقوم بها القاضي الدولي فيما يتعلق بالقانون الدولي

$$
\text { العام الذي ينشأ عن مصادرَ غير مكتوبة. }
$$

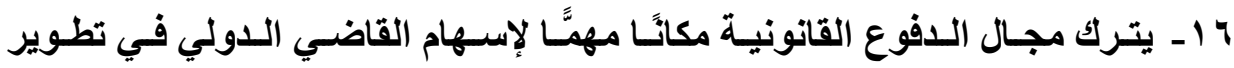

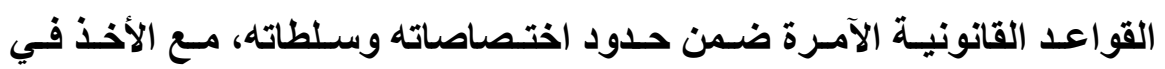

$$
\text { الاعتبار أن القاضيَ الدوليَّ ليس مشرًَِّّا. }
$$

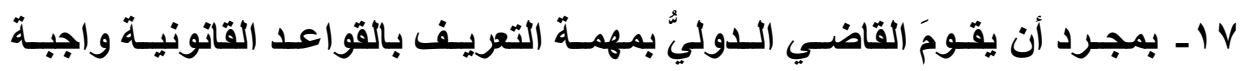

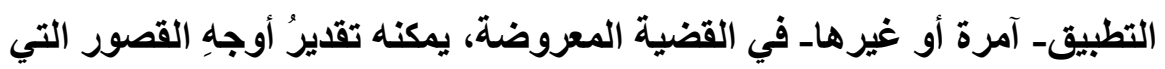

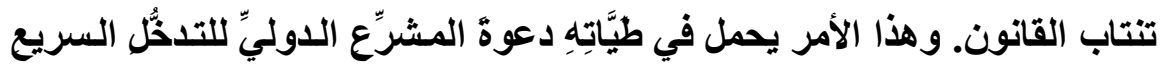
لمعالجة أوجهِ القصور هذه، بما يتفق واحتياجاتِ ومصالحَ المجتمع الاولي. 11 ــ يقسم الفصل في المنازعات كمهمة وإجراء بين محكمة عدل الآتّاد الأوروبي من

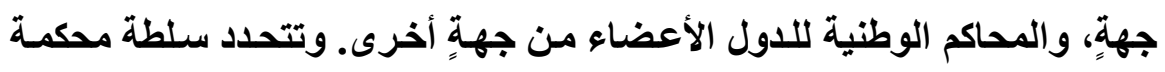

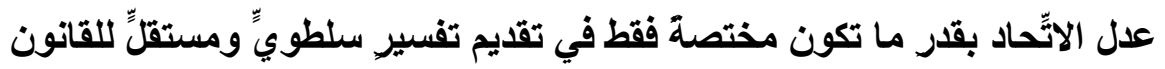
الأوروبي. 9 1 اــتبنَّى محكمة عدل الاتِّاد الأوروبي النظرة المعروفة باسم الوحدوية لتبرير سموِّ قانون الآّحاد الأوروبي على سائر القوانين الوطنية. • . - حتى لا تفقد الدول الأعضاء في الآّحاد الأوروبي شيئًا من الحماية القضائية، نتيجة عملية إحلال القضاة واستبدال الأنظمة القانونية، يجب أن تكونَ هذه الدولُ الأن

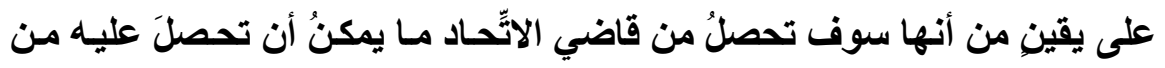

$$
\text { القاضي الدولي. }
$$

ا بـ قد لا يمكن بلوغ التماسكك أو الآّّاق في منطق القاضي الأوروبي، وذلك بالنظر

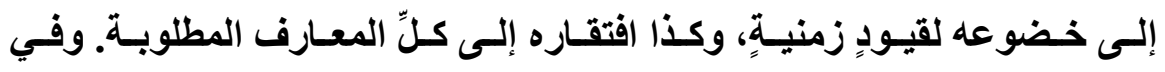


استالاله، يتعين على القاضي الأوروبي أن يبحثُ عن التماسك أو الآتّساق داخل العناصر ذات الصِّة في مجال القانون المعني. ميع الأخذ في الحسبان، أن تحديدَ

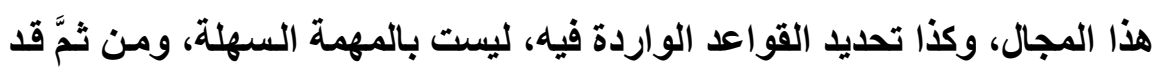

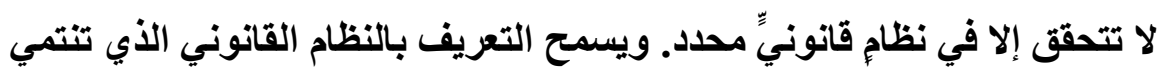
إليه هذه القواعد، تحديد المجـال المعني، ومن ثم توجيـه منطق القاضسي نحو الوصول إلى قرار سوف يكون الأكثر تناسقًا مع هذا المجال. Y Y Y - يتعين على القاضي السويسري، وهو بصدد تفسير قاعدةٍ ما، أن يأخذ في حسبانه

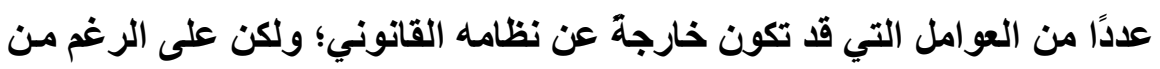
ذللك، تؤُثر في النظام الذي يدور فيه.

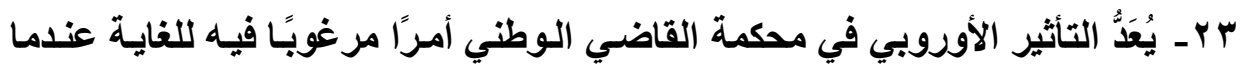

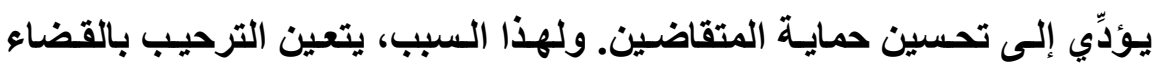

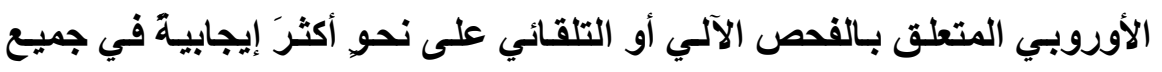

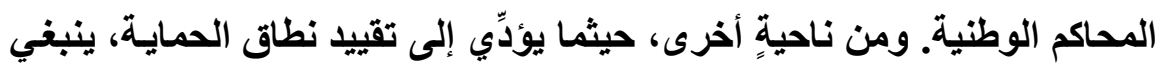

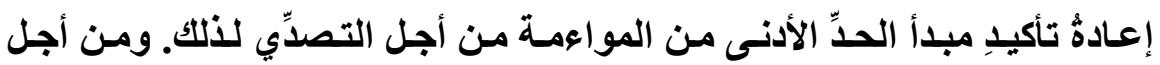

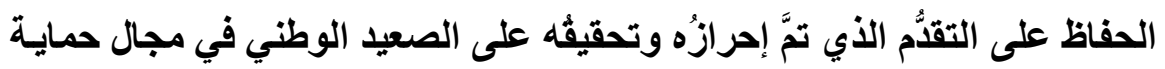

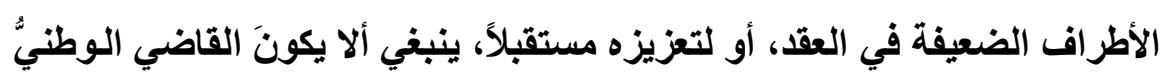
قاضيًا للقانون الأوروبيً فحسب. 


\section{قائمة الاختصارات}

1- CJCE : Cour de Justice des Communautés Européennes.

2- CJUE : Cour de Justice de l'Union Européenne.

3- CPJI : Cour Permanente de Justice Internationale.

4- EC : European Community.

5- EU : European Union.

6- ECJ : European Court of Justice.

7- ECR : European Court of Justice.

8- ECtHR : European Court of Human Rights.

9- EFTA : European Free Trade Association.

10- GA : General Assembly (UN).

11- ICJ : International Court of Justice.

12- ICC : International Criminal Court.

13- ICSID : International Center for the Settlement of Investment Disputes.

14- ICTR : International Criminal Tribunal for Rwanda.

15- ICTY : International Criminal Tribunal for the former Yugoslavia.

16- ILC : International Law Commission.

17- Rec. : Recueil.

18- aff. Affaire.

19- TUE : Traités de l’Union Européenne. 


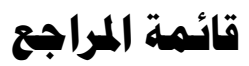

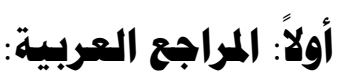

1- ـ أ.د/ أحمد أبو الوفا، "الوسيط في القانون الدولي العـام"، دار النهضة العربية،

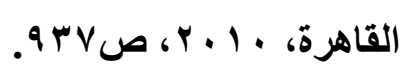

ז- ــــــ، "الوسيط في قـانون المنظمـات الدوليـة"، دار النهضة العربيـة، القـاهرة،

$$
.0 V \Lambda \sim 1991
$$

r- ــــ، "النظرية العامة للقانون الدولي الإنساني في القانون الدولي وفي الثريعة

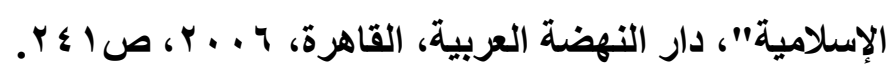

ع - أ.د/ الشافعي محمد بشير، "القـانون الدولي العـام في الستّلم والحرب"، مكتبـة

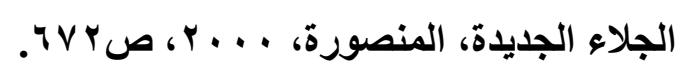

"المنظـــات الدوليـة"، مكتبـة الجـلاء الجديــة، المنـصورة، ؛ 99 1،

$$
\text { ص. n }
$$

"قانون حقوق الإسسان، مصادره وتطبيقاته الوطنية والدولية"، منشأة

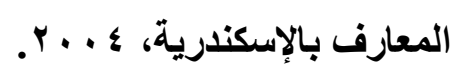

V- أ.د/ حازم محمد عتلم، "الوجيز في القانون الدولي العام"، دار النهضة العربية،

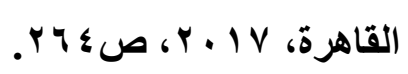

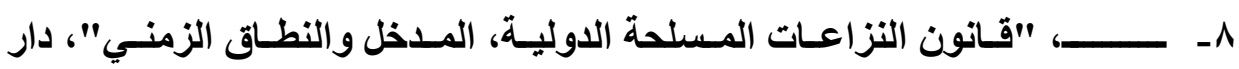

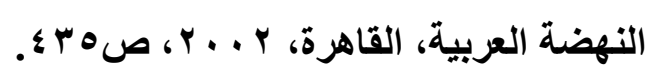


"منظمة الأمم المتحدة، دراسة تحليلية في ضوء النظرية العامـة للمنظمـات $-9$

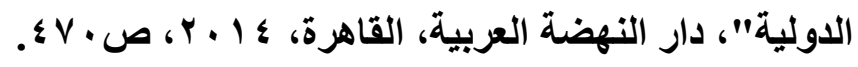

• 1 ـأ.د/ حسام أحمــ هنــاوي، "التـدخل الـدولي الإنسـاني"، دار النهضة العربيـة،

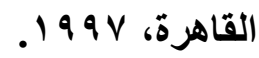

1 أـدأدسعيد سالم جويلي، "المدخل لاراسة القانون الدولي الإنساني"، دار النهضة

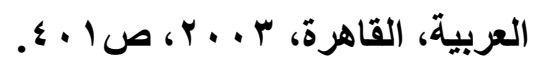

"تتفيذ القانون الدولي الإنساني"، دار النهضة العربية، القاهرة، ب . . ؟،

"المنظمات الدولية، المنظمـات الدولية العالميـة"، منظمـة الأمـم المتحدة، $-14$

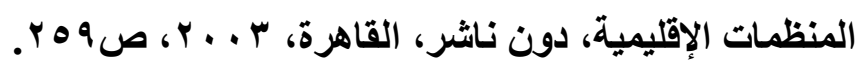

ـ ا ـأ.د/ صـلاح اللدين عـامر، "مقدمـة لاراسـة القـانون الدولي العـام"، دار النهضة

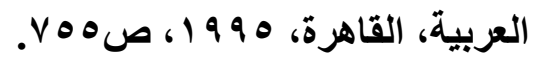

ه ــأ.د/ عبد العزيز محمـد سرحان، "القـانون الدولي العـام"، دار النهضة العربيـة،

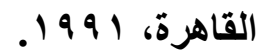

7 ا ـأ.د/ علي صادق أبو هيف، "القانون الدولي العام"، منشأة المعارف بالإسكندرية،

$$
.1990
$$

V ا ـأ.د/ محمد سامي عبد الحميد، "أصول القانون الدولي العامـ الجزء الثانيـ القاعدة

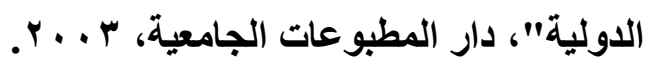

1 1 ـأ.د/ محمد سـامي عبد الحميد، وأ.د/ محمد السعيد الدقاق، وأ.د/ مصطقى سـلامة حسين، "قانون التنظيم الدولي"، منشأة المعارف بالإسكندرية، 999 و 19 ـ 
9 1 ـ أ.د/ محمد مصطفى يونس، "ملامـح التطور في القـانون الدولي الإنساني"، دار

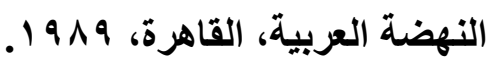

• • ـ أ.د/ محمود شريف بسيوني، "المحكمة الجنائية الدولية، نشأتها مع دراسـة لجـان

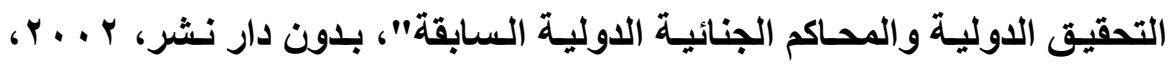
صry.

ا ـ ـأ.د/ مصطفى أحمـد فؤاد، "القـانون الـدولي العـام، الإطـار العـام للقـانون اللدولي

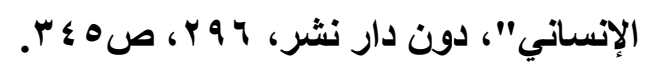

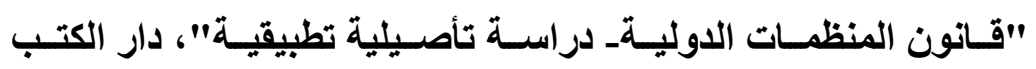
$-r r$

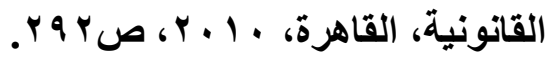
"فكرة الضرورة في القانون الدولي العام"، منشأة المعارف بالإسكندرية، $-r r$

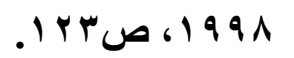

"القانون الدولي العـام- الجزء الأولـ- القاعدة الدوليـة"، دون دار نشر، $-Y \varepsilon$ . ...

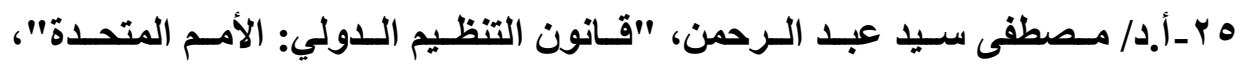

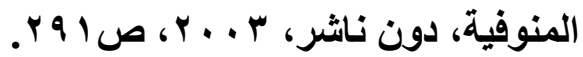

"الجوانب القانونية لتسوية نزاعـات الحدود الدولية"، دار النهضة $-r y$

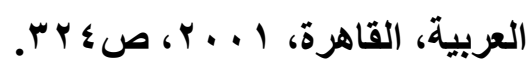




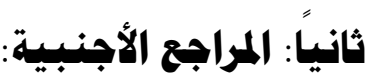

1- ABI- SAAB (G.), "Cours général de droit international public", Recueil des Cours, Vol. 207, 1987.

2- ALLARD (J.), "Les Juges dans la mondialisation", le Seuil, 2012.

3- ALTER (K.) ; ROMANO (C.) and SHANY (Y.), "Legal Philosophical of International Adjudication- Getting over the amour impossible between international Law and Adjudication", Oxford, Oxford Hand book of International Adjudication, Oxford University Press, 2017.

4- AMAYA (A.), "Legal Justification by Optimal Coherence", Ratio Juris, no. 6, Vol. 27, 2014.

$5-, \% \quad, \quad$ "Inference to the best legal explanation", in H. KAPTEIN, H.BRAKKEN, "Legal Evidence and Proof: Statistics, Stories, Logic", Ashgate, Aldershot, 2014.

6- AMSTUTZ (M.), "Le droit privé Suisse fac au droit Communautaire européen. Questions actuelles en droit de la responsabilité civile et en droit des Contrats", Berne, 2011. 
7- ANAYA (S.J.), "Indigenous Peoples in International Law", Oxford, Oxford University Press, 2013.

8- ARENDT (H.), "The Human Condition", Chicago, University of Chicago Press, 1998.

9- ASCENSIO (H.), "La notion de Juridiction internationale en question", in Société Française pour le droit international, Paris, Pedone, 2013.

10-BANAKAS, (S.) "The Contribution of Comparative Law to the Harmonization of European Private Law", in A. HARDING, "Comparative Law in the $21^{\text {st }}$ Century", London, The Hague, New York, Kluwer Academic, 2009.

11- BARBER, (N.) "Legal Pluralism and the European Union", European Law Journal, no. 5, Vol. 14, 2008.

12- . BENABENT, (A.) "Droit Civil, les obligations", $12^{\text {ème }}$ éd., Montchrestien, 2015.

13- BESSON, (S.) "General Principales in International Lawwhose principls?", in S. BESSON, "Les principes en droit européen principles en European Law", Schulthess, 2012.

14- „, " "Sovereignty International law and democracy", European Journal of International Law, no. 2,Vol. 22, 2013. 
د/عبد الله محمد الهوارى

15- ,

Dispute- Settlement and law- Enforcement-From International law without Courts to International Courts Without Law. A Reply to Anna Spain", Loyola of Los Angeles International and Comparative law Review, Vol. 34, 2012.

16- , "The Erga omnes Effect of The European Court of Human Rights Judgments", in S. BESSON, "La Cour Européenne des droits de l'homme après le protocole 14Premier bilan et Perspectives", Schulthess, 2012.

17-, "The Authority of International law- Lifting the State Veil", Sydney Law Review, no. 6, Vol. 34, 2013.

18- BIANCHI (A.), "Human Rights and The Magic of Jus Cogens", European Journal of International Law, Vol. 22, 2013.

19-BIX (B.), "Law, Language and Legal Determinacy", Oxford, Clarendon, 2007.

20- BOGDANDY (A.), "Beyond Dispute: International Judicial Institutions as law makers", German Law Journal, Vol. 12, 2011. 
د/عبد الله محمد الهوارى

العدد •V (ديسمبر 19 (Y. )

21- , „, "On the Functions of International Courts: An Appraisal in light of Their Burgeoning public Authority", A.C.I.L., 2012.

22- BOUTRUCHE (T.), "Credible Fact-Finding and Allegation of International Humanitarian Law Violations: Challenges in Theory and Practice", Journal of Conflict, Security Law, Vol. 16, 2015.

23- BOYLE (A.), "Law Making by International Courts and Tribunals", in "The Making of International Law", Oxford University Press, 2015.

24- BROWN (C.), "Article 59", in A. ZIMMERMANN, "The Statute of the International Court of Justice: A Commentary", Oxford Oxford University Press, 2012.

25-, „ "A Common Law of International Adjudication", Oxford, Oxford University Press, 2014.

26- BRUNeT (P.), "Les Principes généraux du droit et la hiérarchie des normes", in P. BRUNET et E. MILLARD, "L'architecture du droit", Mélanges en l'honneur de Michel Troper, Economica, 2015.

27-BUCHANAN (A.), "Justice, Ligitimacy and SelfDetermination : Moral Foundation for International Law", Oxford, Oxford University Press, 2014. 
د/عبد الله محمد الهوارى

العدد •V (ديسمبر 19 (Y.

28-CASELLA (S.), "La nécessité en droit international: De l'état de nécessité aux Situations de nécessité", Leiden, Boston, Martinus, Nijhoff, 2013.

29-CASSESES (A.), "Change and Stability in International Law- Making", Gruyter, 2010.

30- „, "For an Enchanced Role of Jus Cogens", in, A. CASSESES, ed., "Realizing Utopia: The Future of International Law", Oxford, Oxford University Press, 2016.

31-CHARNEY (J.), "Is International Law Threatened by Multiple International Tribunals?", Recueil des Cours, Vol. 271, 1998.

32-CHRISTOFFERSEN (J.), "Fair Balance: Proportionality, Subsidiarity and Primarity in the European Convention on Human Rights", Leiden, Nijhoff, 2016.

33-CORN (G.), "The Law of Operational Targeting: Viewing the LDAC Through an operational lens", Texas International Law Journal, Vol. 51, 2015.

34- CULVER (K.), "Legality"s Borders: An Essays in General Jurisprudence", New York, Oxford University Press, 2010. 
د/عبد الله محمد الهوارى

العدد •r (ديسمبر r.19)

35-DANILENKO (G.), "Law Making in the International Community", Dordrecht, Martinus, Nijhoff publishes, 1999.

36- D'ARGENT (P.), "Arrêt "Kadi": Le droit communautaire Comme droit interne", Journal de droit européen, 2008.

37-,, , "Les Principes généraux à la Cour Internationale de Justice", Schulthess, 2011.

38-DICKSON (J.), "Interpretation and Coherence in legal Reasoning", The Stanford Encyclopedia of philosophy, 2014.

39-,, , "Towards a Theory of European Union Legal System", in J. DICKSON, P. ELEFTHERIADIS, "Philosophical Foundation of European Union", Oxford, Oxford University Press, 2008.

40-, , , "Directives in UE Legal System: Whose Norms Are They Any Way?", European Law Journal, no. 2, Vol. 17, 2013.

41-,, , "Methodology in Jurisprudence: A critical Survey", Legal Theory, no. 3, Vol. 10, 2008.

42-DUPUY (P.M.), "Le Juge et la règle Générale", Revue Générale de Droit international public, Vol. 93, 1989. 
43- DWORKIN (R.), "Justice in Robe", Cambridge, Harvard University Press, 2013.

44- , , „ "Law's Empire", Fontana Press, 1996.

45-," " "Taking in The International Community", Dordrecht, Martinus, Nijhoff Publishers, 1999.

46- EGGLI (C.), "Entre Cohérence et efficacité : La Suisse dans les négociations bilatérales avec l'Union Européenne", Suisse Political Science Review, no. 4, Vol. 10, 2008.

47- ELEFTHERIADIS (P.), "Pluralism and Integrity", University of Oxford legal Research paper Series, no. 43, 2009.

48- EPINEY (A.), "How does European Union Law Influence Suisse Law and Policies?", in, S. NAHRATH, F.VARONE, "Rediscovering Policy Analysis: a Tribute to Peter Knoepfel", Berne, 2010.

49- FLESNER (C.), "Introduction: Key features of European Union Private Law", in, C. FLESNER, ed., "The Cambridge Companion to European Union Private Law", Cambridge, Cambridge University Press, 2013. 
50- FRANCK (T.), "Fairness in The International Legal and Institutional System: General Course on Public International Law", Recueil des Course, Vol. 240, 1993.

51- GARAPON (A.), "Les Vertus du Juge", Dalloz, 2008.

52- GARDNER (J.), "Legal Positivism", The American Journal of Jurisprudence, no. 46, 2010.

53- GERARDS (J.), "Judicial Argumentation in Fundamental Rights Cases- The Eu Courts Challenges", in, U. NEERGARD, R. NIELSEN, eds., "European legal Methodology in a Multilevel EU legal order", Copenhagen, DJOF publishing, 2012.

54-GINSBURG (T.), "Bounded Discretion in International Judicial Law- Making", Virginia Journal of International Law, Vol. 44, 2005.

55- GORDLEY (J.), "Comparative legal research: its function in the development of Harmonized Law", The American Journal of Comparative Law, no. 4, Vol. 43, 1998.

56-GOWLLAND (V.), "Judicial insights into Fundamental Values and Interests of the International Community", in S. MOLLER, eds., "The International Court of Justice: its future Role after Fifty Years", The Hague, Martinus Nijhoff, 2012. 
د/عبد الله محمد الهوارى

العدد •V (ديسمبر Y.19)

57- GREEN (L.), "Legal Positivism", Stanford Encyclopedia of Philosophy, 2013.

58- GUASTINI (R.), "Les Principes en droit en tant que source de perplexité théorique", in S. CAUDAI, "Les Principes en droit", Economica, 2012.

59- HANNESSON (O.), "Giving effect to EEA Law-Examining and Rethinking the Role and Relationship between the EFTA Court and The Icelandic National Courts in The EEA legal order", Florence, EUI, 2017.

60-HART (H.L.A.), "The Concept of Law", Oxford, Oxford University Press, 2009.

61-HAYASHI (N.), "Requirements of Military Necessity in International Humanitarian Law and International Criminal Law", Boston University International Law Journal, Vol. 30, 2012.

62- HIGGins (R.), "Problems and Process: International Law and How we use it", Oxford, Oxford University Press, 2014.

63-JACOB (M.), "Precedents: Lawmaking through international Adjudication", German Law Journal, no. 6, Vol. 16, 2014. 
د/عبد الله محمد الهوارى

العدد •V (ديسمبر r.19)

64- JENNINGS (R.), "The Judiciary International and National, and The Development of International Law", International and Comparative Law Quarterly, Vol. 45, 1996.

65- JOUNNET (E.), "La notion de Jurisprudence International en question", in Société Française Pour le Droit International, dis., "La Juridictionnalisation du droit international", Paris, Pedone, 2013.

66-KADDOUS (C.), "L'influence du droit Communautaire dans la Jurisprudence du Tribunal fédéral Suisse", in le droit à la mesure de l'Homme, Melanges en l'honneur de Philippe léger, 2013.

67- KAHIL (B.), "L'application et l'interprétation de l'ALCP : le cas de la Sécurité Sociale", in A. EPINY, R. MOSTERS, "L'accord sur la libre Circulation des Personnes SuisseUE", Zurich, Schulthess, 2013.

68- KARIMI (A.), "Les clauses abusives et la Théorie de l'abus de droit", LGDJ, 2001.

69- KARTON (J.), "Lost in Translation: International Criminal Courts and the legal Implication of Interpreted testimony", Vanderbilt Journal of transnational law, no. 1, Vol. 41, 2008. 
د/عبد الله محمد الهوارى

العدد •r (ديسمبر r.19)

70- KELSEN (H.), "The General Theory of Law and the State", Cambridge, Harvard University Press, 1995.

71- KERBRAT (Y.), "Affaire de l'Usine Mox : La CJCE rejette l'arbitrage pour le règlement des différends entre Etats membres", Revue Trimestrielle du Droit Européen, 2011.

72- KINGSBURY (B.), "International Courts : Uneven Judicialization in Global Order", in J. CRAWFORD, M. KOSKENNIEMI, "The Cambridge Companion to International law", Cambridge University Press, 2016.

73-KJAER (A.), "A Common legal language in Europe?", Oxford, Portland, 2007.

74- KLABBERS (j.), "The Right to be taken Seriously: SelfDetermination in international Law", Human Rights Quarterly, no. 1, Vol. 28, 2006.

75- KOLB (R.), "La nécessité militaire dans le droit des conflits armés- Essai de clarification Conceptuelle", in SFDI, dir., "La nécessité en droit international", colloque de Grenoble, Paris, Pedone, 2009.

76-KOSKENNIEMI (M.), "The Idealogy of international Adjudication and the 1907 Hague Conference", in Y. DAUDET, "Topicality of the 1907 Hague Conference", The Second Peace Conference, Brill Academic Publishers, 2008. 
د/عبد الله محمد الهوارى

العدد •r (ديسمبر r.19)

77-KRAMER (M.), "Where Law and Morality Meet", Oxford University Press, 2008.

78- KRESS (K.), "Coherence", in D. PATTARSON, "A Companion to Philosophy of law and legal Theory", $2^{\text {ème }}$ ed., Chichester, Wiley- Blackwell, 2013.

79- LAUTERPACHT (E.), "The Development of international law by the international Court", Cambridge University Press, 2013.

80-, , , "Aspects of the administration of international Justice", Cambridge University Press, 2013.

81-LAVRANOS (N.), "Jurisdictional Competition: Selected Cases in International and European Law", Groningen, Europa Law, 2014.

82-LEGRAND (P.), "European Legal System are not Converging", International and Comparative Law Quarterly, no 1, Vol. 45, 1996.

83-LEITER (B.), "Legal Realism, Hard Positivism and the Limits of conceptual Analysis", Oxford, Oxford University Press, 2009. 
84- LETSAS，(G.)，"Strasbourg's interpretive Ethic: Lessons for the international lawer", European Journal of International Law, no. 3, Vol. 21, 2012.

85- MAcCORMICK (N.), "Legal Reasoning and legal Theory", Oxford, Clarendon Press, 1998.

86- MADURO (M.), "Interpreting European Law: Judicial Adjudication in a context of Constitutional pluralism", European Journal of legal Studies, no. 2, Vol. 1, 2009.

87- MAIA (C.), "le Juge International au Coeur du dévoilement du droit imperatif : entre nécessité et prudence", Revue de droit international de Seience diplomatique et politique, Vol. 83, 2005.

88-MAISON (R.), "Le Juge Combattant", in Abdelwahab BIAD, P. TAVERNIER, "Le droit international humanitaire face aux défaits du XXI ${ }^{\mathrm{e}}$ Siècle", Bruxelles, Bruylant, 2016.

89- MAK (C.), "Hedgehogs in Luxembourg? Adworkinian of private law", no. 4, Vol. 22, 2014.

90-MARMOR (A.), "Interpretation legal Theory", Oxford, Hart Publishing, 2005. 
د د اعبد الله محمد الهوارى

العدد •V (ديسمبر r.19)

91-,, , "Positive Law and objective values", Oxford University Press, 2010.

92-MAULIFFE (K.), "Language and law in the EU: The Multilingual Jurisprudence of the ECJ", Oxford, Oxford University Press, 2012.

93-MICHAELS (R.), "Private Law Beyond the State? Europeanization, Globalization, Privatization", the American Journal of Comparative Law, no. 4, Vol. 56, 2008.

94- ," " "Why we Have no Theory of European Private Law Pluralism", in L. NIGLIA, ed., "Pluralism and European Private Law", Oxford, Hart Publishing, 2013.

95-NOLLKAEMPER (A.), "The Internationalized Rule of Law", Hague Journal on the Rule of law, Vol. 11, 2014.

96- NORMAND (R.), "The Legitimation of Violence: A critical History of the Law's of war", Harvard International Law Journal, Vol. 45, 2004.

97-OBRIEN (W.), "The Meaning of Military necessity in International Law", World Polity, Vol. 41, 1997.

98-OELLERS (K.), "Law Making Through Advisory Opinion?", German Law Journal, Vol. 14, 2013. 
د/عبد الله محمد الهوارى

العدد •V (ديسمبر r.19)

99- OST (F.), "Dire le droit, Faire Justice", Bruxelles, Bruylant, 2014.

100- PAULUS (A.), "International Adjudication", in S. BESSON, J. TASIOULAS, "The Philosophy of International Law", Oxford Oxford University Press, 2011.

101- PELLET (A.), "Judicial Settlement of International Disputes", in R. WOLFRUM, "Max-Planck- Encyclopedia of Public International Law", Oxford, Oxford University Press, 2016.

102- PETERSMANN (D.-U.), "Can The EU's Disregard for Strict Observance of International Law "article 3 TEU" be Constitutionally Justified?", in M. BRONCKERS, V. HAUSPIEL, R. QUIK, eds., "Liber Amicorum for J. Bourgeois", Cheltenham, Elgar, 2014.

103- $", \quad, "$ "International Economic Law in the $21^{\text {st }}$ Century. Constitutional pluralism and Multilevel Governance of interdependent public Goods", Oxford, Hart, 2016.

104- RAIC (D.), "State- Hood and the Law of SelfDetermination", The Hague, Kluwer law International, 2013. 
د/عبد الله محمد الهوارى

العدد •r (ديسمبر r.19)

105- RANDALL (M.), "Le dialogue entre le Juge Suisse et Juge européen", in, F. BELLAGER, J. WERRA, "Genève au Confluent du droit interne et du droit international", Mélanges offerts par la faculté de droit de l'Université de Genève à la Société Suisse des Juristes à l'occasion du Congrès, 2012.

106- RAZ (J.), "Incorporation by Law", Legal Theory, Vol. 15, 2013.

107- " , "The Authority of Law", Oxford University Press, 1999.

108- " " " "On The nature of Law", Archive fur Rechts, Vol. 89, 1999.

109- REGAN (D.), "International Adjudication: A Response to Paulus- Courts, Custom, Treaties, Regimes and the WTO", in S. BESSON, J. TASIOULAS, "The Philosophy of International Law", Oxford, Oxford University Press, 2011.

110- REINISCH (A.), "The Decisions on Jurisdiction in the Eastern Sugar and Eureko Investment Arbitration", in Legal Issues of European Integration, Vol. 45, 2017.

111- ROCHEL (J.), "Between Authority and Morality: Identifying two Legitimatory Rules of legal Principles", in 
د/عبد الله محمد الهوارى

العدد •V (ديسمبر r.19)

S. BESSON, P. PICHONNAZ, eds., "Principles en droit européen-principles in European Law", schulthess, 2014.

112- RUIZ-FABRI (H.), "Article 66", in O.CORTEN, P.KLEIN, eds., "The Vienne Convention on The Law of Treaties: A Commentary", Oxford, Oxford University Press, 2013.

113- SANDS (Ph.), "The Manual on International Courts and Tribunals", Oxford, Oxford University Press, 2010.

114- SASSOLI (M.), "Geneva Convention: A Commentary", Oxford, Oxford University Press, 2013.

115- SCHABAS (W.), "Unimaginable Atrocities: Justice, Politics, and Rights at the War Crimes Tribunals", Oxford, Oxford University Press, 2014.

116- SCHWOK (R.), "Suisse-UE: l'adhésion impossible?", $2^{\text {ème }}$ éd., mise à Jour, Lausanne, Press Polytechniques et Universitaire Romandes, 2010.

117- SHAHABUDDEEN (M.), "The International Criminal Tribunal for the former Yugoslavia: The Third Wang Tieya Lecture", Chinese Journal of International Law, Vol. 11, 2016. 
د/عبد الله محمد الهوارى

العدد •r (ديسمبر r.19)

118- SHANY (Y.), "Toward a general Margin of Appreciation

Doctrine in International Law", European Journal of International Law, Vol. 16, 2006.

119- SHAPIRO (S.), "Legality", Cambridge, Harvard University Press, 2012.

120- SIMMA (B.), "Mainstreaming Human Rights: The Contribution of the International Court of Justice", Journal of International Dispute Settlement, Vol. 5, 2015.

121- STAUDER (B.), "L'influence de la Jurisprudence de la CJCE sur le droit des Contrats", in F. WERRO, T. PROBST, "Le droit Privé Suisse face au droit Communautaire européen. Questions actuelles en droit de la responsabilité Civile et en droit des contrats", Berne, 2014.

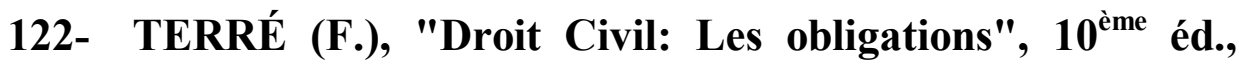
Dalloz, 2013.

123- THURER (D.), "Self-Determination", Max-Planck Encyclopedia of public International Law, 2015.

124- TIERSMA (P.), "The Oxford Hand book of Language and Law", Oxford, Oxford University Press, 2012. 
د/عبد الله محمد الهوارى

العدد •V (ديسمبر Y.19)

125- TOMUSCHAT (C.), "Human Rights and International Humanitarian Law", European Journal of International Law, Vol. 33, 2012.

126- " $, \quad, "$ "International Courts and Tribunals", in, "Max-Planck-Encyclopedia of Public International Law", Oxford University Press, 2012.

127- TREVES (T.), "Judicial Law Making in an Era of proliferation of International Courts and Tribunals: Development or Fragmentation of International Law?", Vol. 77, Berlin, Springer, 2005.

128- TZANAKO (A.), "Domestic Courts in international Law: The international Judicial Function of National Courts", Loyola of Los Angeles International and Comparative Law Review, Vol. 34, 2011.

129- VOGENAUER (S.), "Pluralisme Pragmatique du Tribunal fédéral : Une méthode sans méthode ?", Pratique Juridique Actuelle, no. 4, 2010.

130- WALDRON (J.), "The Concept and the Role of Law", Georgia Law Review, no 1, Vol. 48, 2013.

131- ״ „ "Are Sovereigns Entitled to the Benefit of the International Rule of Law?", European Journal of International Law, no. 2, Vol. 22, 2013. 
د/عبد الله محمد الهوارى

العدد •r (ديسمبر r.19)

132- WERRO (F.), "La Jurisprudence de la CJUE en matière de responsabilité du fait des produits et son impact sur l'application de l'article 28 al.2", in S. FUHRER, C. CHAPPUIS, "Droit de la responsabilité civile et des assurances", Berne, 2014.

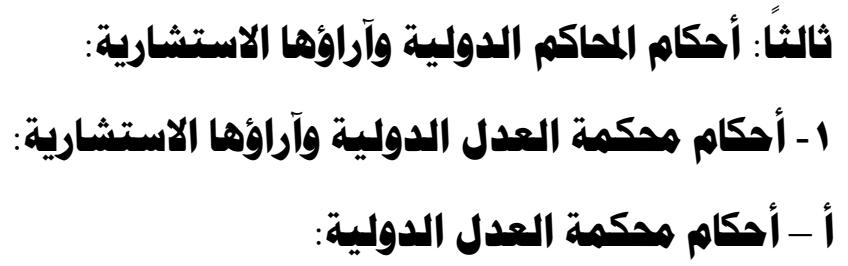

1- CIJ, 9 Avril 1949, Détroit de Corfou (Royaume-Uni de Grande-Bretagne et d'Irlande du Nord c. Albanie), arrêt, C.I.J., Recueil 1949.

2- CIJ, 20 Novembre 1950, Affaire Colombo relative au droit d'asile, arrêt, C.I.J., Recueil 1950.

3- ICJ, 13 July 1966, South West Africa (Ethiopia/South Africa, Liberia, South Africa), Judgment, I.C.J., Reports 1966.

4- ICJ, 20 February 1969, North Sea Continental Shelf, Judgment, I.C.J. Reports 1969.

5- ICJ, 25 July 1974, Fisheries Jurisdiction (United Kingdom of Great Britain and Northern Ireland/Iceland), Judgment, I.C.J. Reports 1974. 
د/عبد الله محمد الهوارى

العدد •V (ديسمبر r.19)

6- ICJ, 24 May 1980, Case concerning United States Diplomatic and Consular Staff in Tehran (United States of America/ Iran), Judgment, I.C.J. Reports 1980.

7- ICJ, 24 February 1982, Continental Shelf (Tunisia v. Libyan Arab Jamahiriya), Judgment, I.C.J. Reports 1982.

8- ICJ, 12 October 1984, Delimitation of the Maritime Boundary in the Gulf of Maine Area (Canada/ United States of America), Judgment, I.C.J. Reports 1984.

9- ICJ, 27 June 1986, Military and Paramilitary Activities in and against Nicaragua (Nicaragua/United States of America), Judgment, I.C.J. Reports 1986.

10- ICJ, 30 June 1995, East Timor (Portugal v. Australia), I.C.J Reports 1995.

11- CIJ, 11 Juin 1998, Frontière terrestre et maritime entre le Cameron et Nigeria, C.I.J. Recueil 1998.

12- CIJ, 6 Novembre 2003, plates- Formes Pétrolières (République Islamique D'Iran c. Etats Unies d'Amérique), arrêt, C.I.J. Recueil 2003.

13- CIJ, 14 Décembre 2005, Activités armées sur le territoire du Congo (République démocratique du Congo c. Ouganda), arrêt, Recueil 2005. 
د/عبد الله محمد الهوارى

العدد •V (ديسمبر r.19)

14- ICJ, 3 February 2006, Armed Activities on the Territory of the Congo (New Application: 2002) (Democratie Republic of the Congo/Rwanda), Judgment, I.C.J. Reports 2006.

15- ICJ, 26 February 2007, Application of the Convention on the Prevention and Punishment of The Crime of Genocide (Bosnia and Herzegovina/Serbia and Montenegro), Judgment 2007, I.C.J. Reports 2007.

16- CIJ, 20 Avril 2010, Usines de Pâte à papier sur le fleuve Uruguay (Argentine c. Uruguay), arrêt, C.I.J. Recueil 2010.

17- ICJ, 3 February 2012, Jurisdictional Immunities of the State (Germany/ Italy, Greece intervening), Judgment, I.C.J. Reports 2012 .

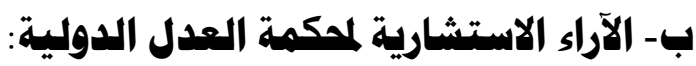

1- CIJ, 21 June 1971, Legal Consequences for States of the continued presence of South Africa in Namibia not withstanding security Council Resolution, 276, Advisory opinion, I.C.J., Reports 1971.

2- CIJ, 16 October 1975, Western Sahara, Advisory opinion, I.C.J., Reports, 1975. 
د/عبد الله محمد الهوارى

العدد •r (ديسمبر r.19)

3- CIJ, 8 Juillet 1996, Licéité de la menace ou de l'emploi d'armes nucléaires, Avis Consultatif, C.I.J., Recueil 1996.

4- CIJ, 9 July 2004, Legal Consequences of the Construction of a wall in the Occupied Palestinian Territory, Advisory Opinion, I.C.J., Reports 2004.

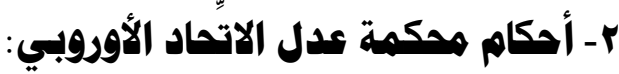

1- CJCE, arrêt du 5 Février 1963, NV Algemene Transport- en Expeditie Onderneming van Gend \& Loos C/ Administration fiscale néerlandaise, affaire 26/62, Rec. 1963, Para. 23.

2- CJCE, arrêt du 15 Juillet 1964, Flamino Costa C/ENEL, affaire 6/64, Rec. 1964.

3- CJCE, arrêt du 30 Avril 1974, R. et V. Haegeman c. Belgique, aff. 181/73, Rec. 1974.

4- CJCE, arrêt du 9 Février 1982, Polydore et RSO Records, affaire 270/80, Rec. 1982.

5- CJCE, arrêt du 10 Avril 1984, Sabine Von Colson et Elisabeth Kamann C/Land Nordrhein-westfalen, 14/83, Rec. 1984. 
د/عبد الله محمد الهوارى

العدد •r (ديسمبر r.19)

6- CJUE, arrêt du 13 Novembre 1990, Marleasing SA v la Commercial International de l'Alimentacion SA, C-106/89, ECR 1990.

7- CJCE, arrêt du 19 Novembre 1991, Andrea Francovich, Danila Bonifaci et autres C/République Italienne, C-6/90 et 9/90, Rec. 1991, P. I- 5357.

8- ECJ, arrêt du 1 June 1999, Eco Swiss China Time 1td v. Benetton, C-126/97, Rec. 1999.

9- CJCE, 27 Juin 2000, Océano Groupo Editorial SA C/Murciano Quintero, C-240/98 à C-244/98, Rec. 2000.

10- CJCE, 22 Novembre 2001, Cape Snc C/Idealservice Sr1 et Idealservice MN RE Sas C/OMAI Sr1, C-541/99 et C542/99, Rec. 2001.

11- CJCE, 24 Janvier 2002, Commission C/Italie, c-372/99, Rec. 2002, P. I-00819.

12- ECJ, 24 February 2003, Truly, C-373/00/ ECR 2003, P. I1932, Para. 35.

13- ECJ, 22 November 2005, Mangold, C-144/04, ECR 2005, p. I- 9981 ; BV erf GEZ BvR 2661/06 of 6 July 2010. 
د/عبد الله محمد الهوارى

العدد •r (ديسمبر r.19)

14- CJCE, arrêt 30 Mai 2006, Commission c. Irlande, C459/03/Rec. 2006, P. I-04635, point 125.

15- CJCE, 26 Octobre 2006, Elisa Maria Mostaza Claro C/Centro Movil Milenium SL, C-168/05, Rec. 2006, P. I10421.

16- CJCE, 12 Février 2008, Willy Kempter KG c/Hauptzollamt Hamburg-Jonas, C-2/06, Rec. 2008, P. I- 411, Point 42.

17- CJCE, arrêt du 3 Septembre 2008, Yassin Abdullah Kadi et AIBaraKaat International Foundation C/Conseil de l'Union Européenne, affaire Jointes C-402/05 P et 415/05 P, Rec. 2008, P. I- 6351, Para. 282.

18- CJUE, 4 Juin 2009, Pannon GSM zrt. c/Erzsébet Sustikné Gyorfi, C-243/08, Rec. 2009, P. I-04713, Point 33.

19- CJUE, 6 Octobre 2009, Asturcom telecomunicaciones SL c/Cristina Rodriguez Nogueira, C-40/08, Rec. 2009, P. I9579.

20- CJUE, 12 Novembre 2009, Grimme, C-3511/08, Rec. 2009, P. I- 10777.

21- CJUE, 11 Février 2010, Fokus Invest, C-541/08, Rec. 2010, p. I-1025. 
د/عبد الله محمد الهوارى

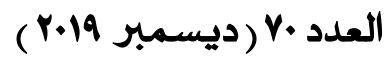

22- CJUE, 15 Juillet 2010, Hengartner et Gasser/C-70/09, Rec. 2010, P. I- 7229.

23- CJUE, 9 Novembre 2010, VB Pénzuggi Lizing zrt. c/Ferenc Schneider, C-137/08, Rec. 2010, P. I-10847.

24- CJUE, 8 Mars 2011, Avis 1/09, Rec. 2011, P. I-1137.

25- CJUE, 16 Octobre 2012, Hongrie c. Slovaquie, C-364/10.

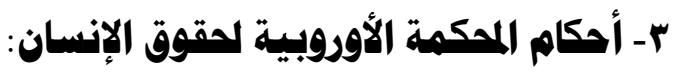

1- ECtHR, 25 April 1978, Tyrer v. United Kingdom, Judgment, appl. no. 5856/72, Series A, Vol. 26, Para. 31.

2- ECtHR, 19 December 1984, Kamasinski v. Austria, application no. 9783, Judgment, Para. 74.

3- ECtHR, 8 July 2004, VO v. France, Judgment, no. 53924/00, Reports 2004-V III.

رابعا: قرارات المنظهات والأجهرة الدوليسة (قـرارات البمهعيسة العاهـة للأهسم (المهدة):

1- GA - Resolution 1514 (XV), 1960, UN Doc A/4684.

2- GA- Resolution 2626/1970, UN Doc. A/8028, 1971.

3- GA- Resolution 61/295, 2007, UN Doc. A/Res 61/295.

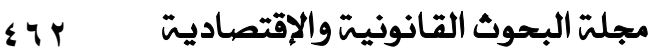




\section{خامساً: أحكام المحاكم الوطنية (أحكام همكمة النقض الفرنسية):}

1- Cour de cassation, civ. 1, 28 Avril 1987, $\mathbf{N}^{0}$ de Pourvoi 8513674.

2- Cour de cassation, civ. 1, 16 Juillet 1987, $\mathbf{N}^{0}$ de Pourvoi 8417731.

3- Cour de cassation, civ. 1, 16 Décembre 1989, $\mathbf{N}^{0}$ de pourvoi 88-16727.

4- Cour de cassation, civ. 1,14 Mai $1991, N^{0}$ de pourvoi 8920999.

5- Cour de cassation, civ. 1, 26 Mai 1993, $\mathrm{N}^{0}$ de pourvoi 9216327.

6- Cour de cassation, civ. 1, 24 Janvier 1995, $\mathbf{N}^{0}$ de pourvoi 9218227.

7- Cour de cassation, civ. 1, 31 Janvier 1995, $\mathbf{N}^{0}$ de pourvoi 9310412.

8- Cour de cassation, civ. 1, 16 Mars 2004, $\mathbf{N}^{0}$ de pourvoi 9917955 et 99-17957.

9- Cour de cassation, civ. 1, 15 Mars $2005, \mathbf{N}^{0}$ de pourvoi 0213285. 
د/عبد الله محمد الهوارى

العدد •V (ديسمبر 19.r)

10-Cour de cassation, civ. 1, 22 Janvier 2009, $\mathbf{N}^{0}$ de pourvoi 0520176.

11-Cour de cassation, civ. 1, 1 Mai 2012, $\mathbf{N}^{0}$ de pourvoi 1112242 